\title{
Studies on Self-Sorting Crystalline Mixtures, Hollow Fiber Organogels and Lumen-Loaded Gels of Nonchiral Polyurethane Model Compounds
}

by

\section{Mohammad Mostofa Kamal Khan}

\author{
A thesis submitted to the \\ Faculty of Graduate and Postdoctoral Affairs \\ In partial fulfillment of the requirements for the degree of
}

\section{Doctor of Philosophy}

Carleton University

Department of Chemistry

1125 Colonel By Drive

Ottawa, Ontario, Canada

April, 2011

(C) Copyright

Mohammad Mostofa Kamal Khan, 2011 
Library and Archives

Canada

Published Heritage

Branch

395 Wellington Street

Ottawa ON K1A ON4

Canada
Bibliothèque et

Archives Canada

Direction du

Patrimoine de l'édition

395, rue Wellington

Ottawa ON K1A ON4

Canada
Your file Votre référence
ISBN: $978-0-494-81574-8$
Our file Notre référence
ISBN: $978-0-494-81574-8$
NOTICE:

The author has granted a nonexclusive license allowing Library and Archives Canada to reproduce, publish, archive, preserve, conserve, communicate to the public by telecommunication or on the Internet, loan, distribute and sell theses worldwide, for commercial or noncommercial purposes, in microform, paper, electronic and/or any other formats.

The author retains copyright ownership and moral rights in this thesis. Neither the thesis nor substantial extracts from it may be printed or otherwise reproduced without the author's permission.
AVIS:

L'auteur a accordé une licence non exclusive permettant à la Bibliothèque et Archives Canada de reproduire, publier, archiver, sauvegarder, conserver, transmettre au public par télécommunication ou par l'Internet, prêter, distribuer et vendre des thèses partout dans le monde, à des fins commerciales ou autres, sur support microforme, papier, électronique et/ou autres formats.

L'auteur conserve la propriété du droit d'auteur et des droits moraux qui protège cette thèse. $\mathrm{Ni}$ la thèse ni des extraits substantiels de celle-ci ne doivent être imprimés ou autrement reproduits sans son autorisation.
In compliance with the Canadian Privacy Act some supporting forms may have been removed from this thesis.

While these forms may be included in the document page count, their removal does not represent any loss of content from the thesis.
Conformément à la loi canadienne sur la protection de la vie privée, quelques formulaires secondaires ont été enlevés de cette thèse.

Bien que ces formulaires aient inclus dans la pagination, il n'y aura aucun contenu manquant. 


\begin{abstract}
Hydrogen bond-mediated self-assembling biscarbamates were studied as model compounds of polyurethanes with respect to the crystallization and gelation behaviour in both solid state and solution phase respectively. Systematic investigation of effects of the structural features of biscarbamates on their crystallization and gelation morphologies was performed by varying the length of the alkyl side chains and the spacer group as well as the carbon atom parity and the type of terminal groups of the alkyl side chains. We found that change in any of these structural features results in significant variation in their crystallization and gelation morphology. Biscarbamate show odd-even effect in their thermal and crystallization Behaviours as a function of carbon atom parity in the alkyl side chains. Variation in the length of alkyl side chains as well as the spacer dictates the balance in relative contribution of hydrogen bonding and van der Waals force resulting in the change in their crystallization kinetics and subsequent morphology. Blending of these homologous molecules shows molecular selectivity and self-sorting behaviour leading to immiscibility. However, they mutually affect the thermal and morphological features. While the morphology can be tailored by changing any of the structural features mentioned above, blending thus provides extra control over the morphology of these molecules. Unlike monocarbamates, biscarbamates show a different morphology upon gelation. Biscarbamate gels show hollow tubular morphology because of the asymmetry of interactions between the molecules in three directions of fiber growth. We exploited the mechanism of such hollow gel fiber formation to fabricate metal nanoparticles or dye molecule-loaded organogel. The shape, size and the crystal growth kinetics of the dye
\end{abstract}


molecules were found to be the governing factors in fabrication of such lumen-loaded gels. Heterologous blending of a biscarbamate with a polymer also shows immiscibility and self-sorting behaviour. We utilized such immiscibility to fabricate mechanically robust composite gels comprised of an immiscible pair of a low molecular weight organogelator and a biocompatible polymer. The gelation in this case is driven by the mutual solvophobic effect. 


\section{Acknowledgements}

I feel privileged getting an opportunity to pursue my $\mathrm{PhD}$ degree under the supervision of Professor P. R. Sundararajan. I was blessed with his wisdom, teaching philosophy, and sincere guidance for the last few years. My heart-felt thanks to him for his affection and continuous support throughout my $\mathrm{PhD}$ study although I literally cannot thank him enough.

This research work was supported by the Natural Sciences and Engineering Research Council of Canada (NSERC) and the Department of Chemistry, Carleton University. I thankfully acknowledge the financial support of these funding authorities. I also thank my employer, Bangladesh Atomic Energy Commission for granting me the study leave to pursue my $\mathrm{PhD}$ degree. A significant portion of this thesis has been peerreviewed. I would like to acknowledge the insightful feedback and constructive suggestions from many of those anonymous reviewers.

My sincere thanks go to the past and present members of Professor Sundar's group namely B. Tuteja, S. Khanna, S. Saimani, M. R. Islam, E. Dahan, D. Vishnu, and A. Chan for their help and friendly discussions. I would also like to thank Jim Logan who kept the instruments running in our labs with all sorts of technical supports. Many thanks go to Peter Jones and Jianqun Wang for their kind help during SEM microscopy.

My deepest gratitude goes to my late parents who implanted in me the sense of education in my early childhood in spite of so many of their social and financial 
hardships. I would like to convey posthumously my special gratitude to my departed mother and first teacher who taught me the alphabets by helping me tracing them out with a piece of chalk on the slate right beside the wood-burning stove while she was cooking food for the whole family in a remote village of Bangladesh. My sincere gratitude goes to my brothers, sisters, and other family members who are thousand miles away from me but were always beside me with their unconditional love, inspirations and supports.

Special thanks go to my beloved little daughter, Farheen who used to welcome me to our home every evening with a big replenishing smile that helped me to forget the long, stressful and exhausting day I had behind. Finally, my heart-felt thanks go to my beloved wife Samsun Nahar. Performing the spousal responsibility for a graduate student is one of the challenging tasks someone might have. She did that task admirably by taking care of the household responsibilities, coping with my unpredictable schedules, understanding the challenges in a graduate student's life, and always supporting me in many ups and downs in pursuit of this degree. 


\section{Table of Contents}

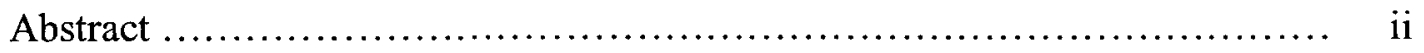

Acknowledgements ............................................. iv

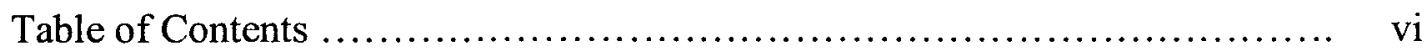

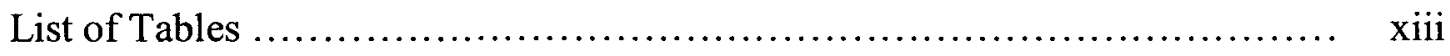

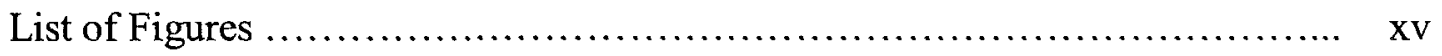

Chapter 1 Introduction .................................................. 1

1.1 Molecular Self-Assembly ............................... 2

1.2 Nature: The Grandmaster of Molecular Self-Assembly.......... 3

1.3 Molecular Self-Assembly: The Designer Toolkit .............. 5

1.4 Self-Assembling Carbamates ............................. 9

1.4.1 Applications of Carbamates ........................ 9

1.4.2 Structural Investigation on Carbamates ................ 10

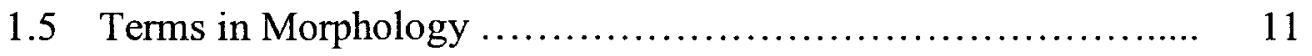

1.5.1 Birefringence ................................... 11

1.5.2 The Crystallite Size ............................. 12

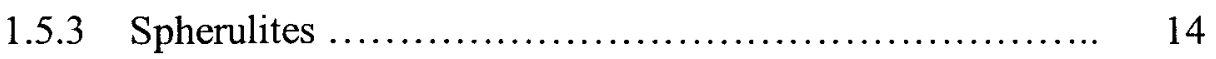

1.6 Importance of Controlling the Morphology ................. 16

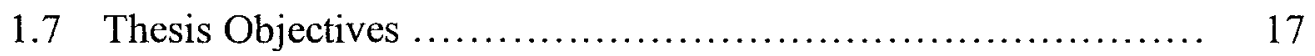

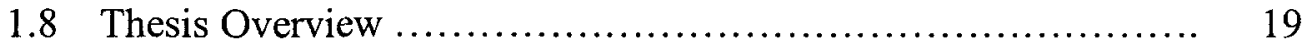

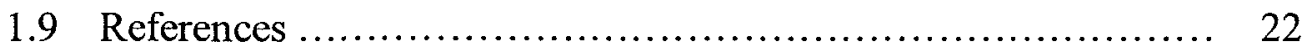




\section{Table of Contents continues}

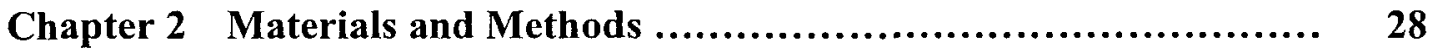

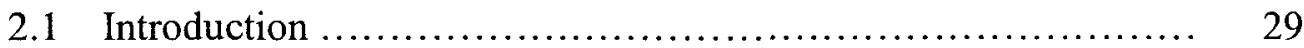

2.2 Synthesis and Characterization of the Biscarbamates .......... 29

2.2.1 FTIR Spectra of the Biscarbamates .................... 32

2.2.1 The ${ }^{1} \mathrm{H}$ NMR Spectra of the Biscarbamates ............... 34

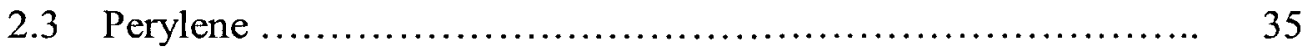

2.4 Phthalocyanine ......................................... 35

2.5 Poly $(\epsilon$-caprolactone) (PCL) ............................. 36

2.6 Preparation of the Binary Blends .......................... 37

2.7 Methods of Characterization $\ldots \ldots \ldots \ldots \ldots \ldots \ldots \ldots \ldots \ldots \ldots \ldots . \ldots \ldots$

2.7.1 Differential Scanning Calorimetry (DSC) .............. 38

2.7.2 Optical Microscopy ................................ 40

2.7.3 Scanning Electron Microscopy (SEM) ................ 42

2.7.4 X-ray Diffraction .................................. 44

2.7.5 FTIR Spectroscopy ............................. 48

2.7.6 NMR Spectroscopy .............................. 50

2.7.7 Molecular Modeling .............................. 50

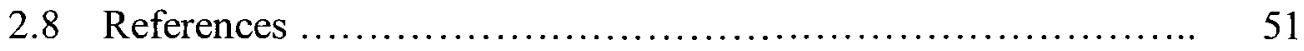


Table of Contents continues

Chapter 3 Influence of Odd-Even Carbon Atom Parity of Alkyl Side Chains on the Morphology and Crystallization Behaviour of Biscarbamates ... 53

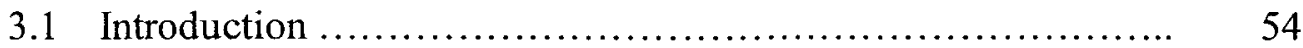

3.2 Experimental ........................................... 57

3.3 Results and Discussion ................................... 58

3.3.1 Thermal Behaviour .................................... 58

3.3.2 X-ray Diffraction and Structural Features .............. 62

3.3.3 Morphology ........................................ 68

3.3.4 Spherulite Growth Rate ............................. 73

3.3.5 Rate of Isothermal Crystallization .................... 76

3.3.6 Infrared Spectroscopy ............................. 80

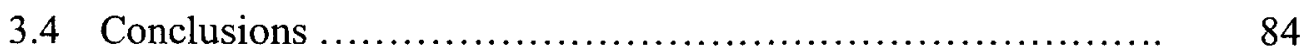

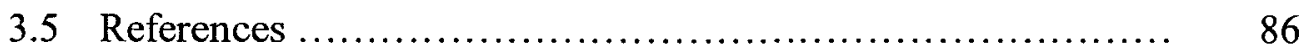

Chapter 4 Influence of Spacer Length and the Type of Terminal Groups of Alkyl Side Chains on the Morphology and Crystallization Behaviour of Biscarbamates ............................... 89

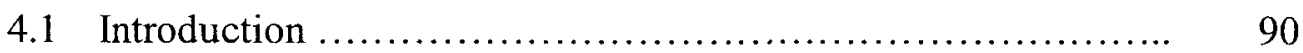

4.2 Results and Discussion ..................................... 92

4.2.1 Thermal Behaviour ..................................... 92

4.2.2 Morphology ......................................... 97 
Table of Contents continues

4.2.3 Spherulite Growth Rate ............................. 100

4.2.4 Rate of Crystallization .............................. 103

4.2.5 X-ray Diffraction and Structural Features .............. 106

4.2.6 Infrared Spectroscopy …........................... 111

4.3 Conclusions ............................................... 117

4.4 References ............................................. 118

\section{Chapter 5 Molecular Selectivity and Immiscibility during the Crystallization} of Mixtures of Biscarbamates .................................. 119

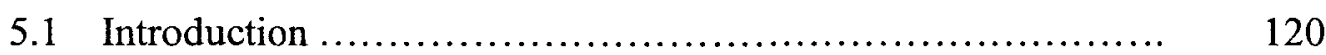

5.2 Experimental ........................................... 122

5.2.1 Preparation of the Blends ............................ 122

5.2.2 Methods .............................................. 123

5.3 Results and Discussion ...................................... 124

5.3.1 Thermal Behaviour .................................. 124

5.3.2 Effect on Spherulite Size ............................ 131

5.3.3 Spherulite Growth Rate ............................ 136

$5.3 .4 \quad$ X-ray Diffraction ................................. 143

5.3.5 IR Analysis ..................................... 147

5.4 Comparison with Hydrogen-Bonding Polymer Blends ......... 150

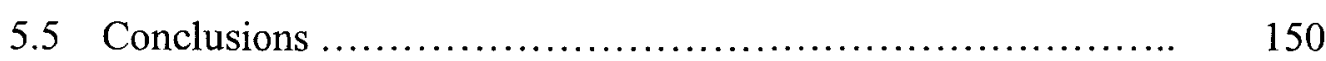

5.6 References ................................................ 153 


\section{Table of Contents continues}

Chapter 6 Influence of Double Hydrogen Bonds and Alkyl Chains

on the Gelation of Nonchiral Biscarbamates:

Sheets, Eaves Trough, Tubes and Oriented Fibers........... 155

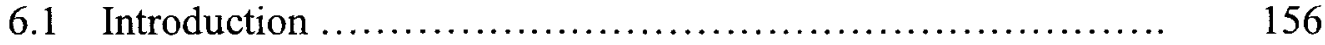

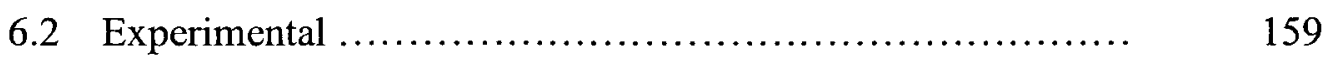

6.2.1 Preparation of the Gels and Xerogels ............... 159

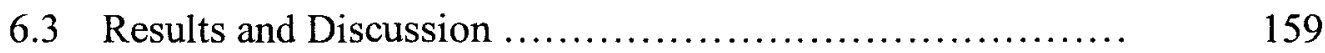

6.3.1 Morphology of the Xerogels $(0.08 \mathrm{M}) \ldots \ldots \ldots \ldots \ldots . . . \ldots$

6.3.2 Morphology of the Gels ....................... 165

6.3.3 Aging of the Gels ............................. 167

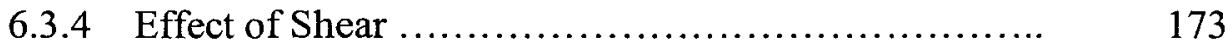

6.3.5 Cooperative Gelation with Mono and Biscarbmate Mixtures and Odd-even Biscarbamate Mixtures (Sergeant and Soldiers) $\ldots \ldots \ldots \ldots \ldots \ldots \ldots \ldots \ldots \ldots . \ldots \ldots$

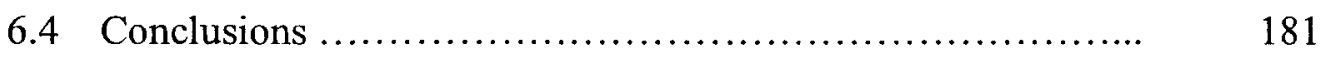

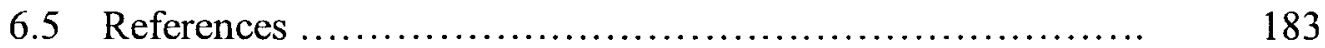

Chapter 7 Encapsulation of Dye Molecules and Nanoparticles in Hollow Organogel Fibers of a Nonchiral Biscarbamate ..... 188

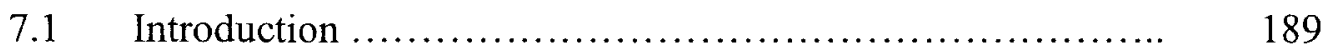

7.2 Experimental .......................................... 193 


\section{Table of Contents continues}

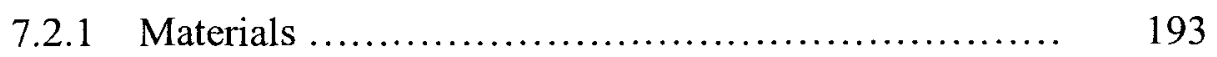

7.2.2 Preparation of the Gels ......................... 193

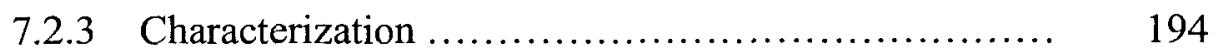

7.3 Results and Discussion ............................... 195

7.3.1 Thermal Analysis .............................. 195

7.3.2 Morphology of the Xerogels .................... 198

7.3.3 Gelation versus Crystallization Kinetics ............. 205

7.3.4 Partial Melting of the Xerogels ................... 208

7.3.5 X-ray Diffraction .............................. 211

7.3.6 Spectroscopy ............................... 214

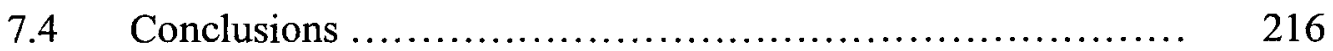

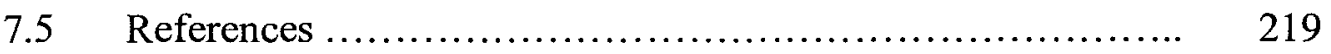

\section{Chapter 8 Immiscibility Driven Two Component Gels of}

Biscarbamates with Poly (€-Caprolactone) ................ 222

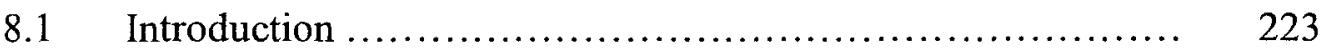

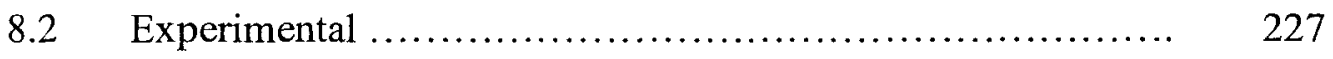

8.2.1 Materials ........................................ 227

8.2.2 Preparation of the Blends ........................ 227

8.2.3 Preparation of Gels ............................ 228

8.2.4 Characterization ............................... 228

$8.3 \quad$ Results and Discussion .................................. 229 
Table of Contents continues

8.3.1 Thermal Analysis .................................. 229

8.3.2 Morphology of the Blends ......................... 233

8.3 .3 Gelation ........................................ 242

8.3.4 Morphology of the Composite Gel .................... 245

8.3.5 Bulk Morphology of the Composite Xerogels ......... 250

8.3.6 X-ray Diffraction of the Composite Gel ............... 254

8.3.7 Infrared Spectroscopy of the Composite Gel .......... 255

$8.4 \quad$ Conclusions .............................................. 257

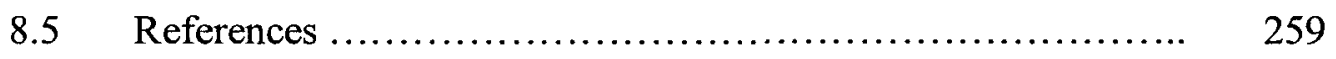

Chapter 9 Conclusions and Recommendations for Future Work ...... 264

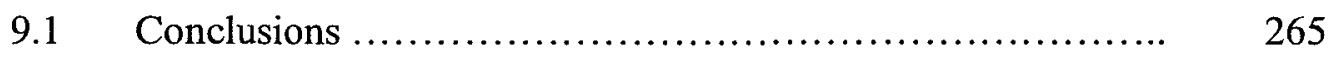

$9.2 \quad$ Recommendations for Future Work ..................... 271

Appendix A FTIR Spectra of the Biscarbamates. ......................... 273

Appendix B ${ }^{1} H$ NMR Spectra of the Biscarbamates. ....................... 282 


\section{List of Tables}

Table 2.1. Biscarbamates $\left(\mathrm{C}_{x} \mathrm{C}_{6}\right)$ synthesized from reaction of an appropriate alcohol with 1,6- diisocyanato hexane.

Table 2.2. Biscarbamates $\left(\mathrm{C}_{x} \mathrm{C}_{12}\right)$ synthesized from reaction of an appropriate alcohol with 1,12- diisocyanato dodecane. ....

Table 2.3. Stretching frequencies of the IR bands of the representative $\mathrm{C}_{12} \mathrm{C}_{6}$ biscarbamate. ..................................

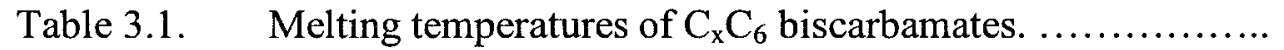

Table 3.2. Interplanar spacings, $d(\AA)$, and Intensities, $I(\%)$ of X-ray diffraction patterns of slow-cooled samples.

Table 3.3. Interplanar spacings, $d(\AA)$, and Intensities, $I(\%)$ of X-ray diffraction patterns of quenched samples.

Table 3.4. Isothermal Crystallization Data Calculated According to the Avrami Equations and Corresponding Avrami Plots...

Table 3.5. Infrared data of $\mathrm{H}$-bonded $\mathrm{N}-\mathrm{H}$, and $\mathrm{C}=\mathrm{O}$ stretching bands of biscarbamates with odd number of carbon atoms in the alkyl side chains.

Table 3.6. Infrared data of symmetric $\left(v_{\text {sym }}\right)$, and asymmetric $\left(v_{\text {asym }}\right)$ $\mathrm{C}-\mathrm{H}$ stretching bands of biscarbamates with different alkyl side chains.

Table 4.1. Comparison of the melting temperatures of the biscarbamates with different spacer groups and alkyl side chains.

Table 4.2. Avrami parameters calculated from isothermal crystallization data.

Table 4.3. Interplanar spacings, $d(\AA)$, and Intensities, $I(\%)$ of X-ray diffraction patterns of slow-cooled samples.

Table 4.4. Interplanar spacings, $d(\AA)$, and Intensities, $I(\%)$ of X-ray diffraction patterns of quenched samples. 


\section{List of Tables continues}

Table 4.5. Infrared data for $\mathrm{H}$-bonded $\mathrm{N}-\mathrm{H}$ and $\mathrm{C}=\mathrm{O}$ stretching bands of biscarbamates with different alkyl side chains.

Table 4.6. Infrared data for symmetric $\left(v_{s}\right)$, and asymmetric $\left(v_{a s}\right) \mathrm{C}-\mathrm{H}$ stretching bands of biscarbamates with different alkyl side chains.

Table 5.1. Melting Points of Mixtures of Biscarbamates.

Table 7.1. Gel-Sol transition temperatures $\left(T_{\mathrm{gel}}\right)$ of the two-component $\mathrm{C}_{12} / \mathrm{Pc}$, and $\mathrm{C}_{12} / \mathrm{Pe}$ gels.

Table 8.1. Melting temperatures and normalized heats of fusion of PCL/biscarbamate blends at different compositions.

Tabel 8.2. Elongation ratios of PCL/biscarbamate xerogels with varying concentrations of biscarbamates with different alkyl side chain lengths. 


\section{List of Figures}

Figure 1.1. (a) A marine brittlestar and its lens. (b) SEM images of the calcite microlenses of Ophiocoma wendtii after chemical cleaning to remove proteins and other organic substances. (c) Top, high-magnification SEM image of $O$. wendtii microlenses. Bottom, high-magnification SEM image of the cross-section of microlense showing the pathway of light focused by the microlens. The functional region of this lens $\left(L_{0}\right)$ closely matches the profile of a lens that compensates for spherical aberration (red lines). The light paths are shown as blue lines. (d) Structure and fiber-optical properties of spicules in the glass sponge Euplectella. Top, photomicrograph showing the basket-like cage structure and basalia spicules (arrow). Bottom, wave guiding for individual spicules upon coupling with white light. Spicules embedded in epoxide act as single-mode or few-mode waveguide (left); free-standing spicules act as multimode waveguide (right panel) [Taken from Ref. 8 of Chapter 1]. 


\section{List of Figures continues}

Figure 1.2. Structure of a monomer bearing self-complementary DAAD-ADDA patterns of hydrogen bonding sites and its directional self-assembly into a ribbon-like supramolecular polymer through an array of four hydrogen bonds [Taken from Ref. 13c of Chapter 1]

Figure 1.3. Schematic showing the hydrogen bonding in biscarbamates.

Figure 1.4. Schematic showing distinct indices of refraction in two directions.

Figure 1.5. Schematic representation of (a) crystallite size, and (b) long spacing.

Figure 1.6. Optical micrographs of biscarbamate showing spherulite growth over time during isothermal crystallization.

Figure 1.7. Optical anisotropy in spherulites.

Figure 1.8. A thin section of bulk crystallized polylactide showing Maltese cross in the birefringent spherulitic texture. The inset show the schematic of a Maltese cross.

Figure 1.9. (a) large spherulites of an opaque biscarbamate film, and

(b) very small spherulites of a transparent polycaprolactone

(PCL) film. 


\section{List of Figures continues}

Figure 1.10. Molecular structures of representative biscarbamates with different alkyl side chain and spacer length and odd versus even carbon atom parity in the alkyl side chains.

Figure 2.1. FTIR spectra of the $\mathrm{C}_{12} \mathrm{C}_{6}$ biscarbamate. ................. 33

Figure 2.2. ${ }^{1} \mathrm{H}$ NMR spectra of $\mathrm{C}_{12} \mathrm{C}_{12}$ biscarbamate.................. 34

Figure 2.3. Chemical structure of perylene. .......................... 35

Figure 2.4. Chemical structure of $1,4,8,11,15,18,22,25$-octabutoxy$29 H, 31 H$-phthalocyanine.

Figure 2.5. Chemical structure of polycaprolactone. ................... 37

Figure 2.6. DSC thermogram of polycaprolactone..................... 37

Figure 2.7. Schematic representation of a DSC cell. ................... 39

Figure 2.8. Schematic presentation of a (a) positive spherulite, (b) negative spherulite, and (c) tint $(\lambda)$ plate.

Figure 2.9. Schematic diagram of a Scanning Electron Microscope [Taken from Ref. 16 of Chapter 2].

Figure 2.10. Bragg construction illustrating the principle of diffraction where $d$ is the spacing between two atomic planes.

Figure 2.11. Schematic of the Bragg diffraction of the powder X-ray diffractometer used for the present study [from Alexander]. Here, $S_{1}, S_{2}$ and $S_{3}$ are the divergence slit, receiving slit and scatter slit respectively; $\alpha=1-4^{\circ}$. 


\section{List of Figures continues}

Figure 2.12. Schematic showing the crystalline and amorphous peak areas used for calculating percent crystallinity. .............

Figure 2.13. Schematic of full width at half-maximum (fwhm) of a particular peak.

Figure 3.1. Change of melting temperature of the biscarbamates as a function of the number of carbon atoms in the alkyl side chains.

Figure 3.2. DSC traces of biscarbamates showing phase transitions corresponding to melting and crystallization in the heating and cooling cycles respectively.

Figure 3.3. Change of heat of fusion of the biscarbamates as a function of the number of carbon atoms in the alkyl side chains. ....

Figure 3.4. Variations of the (a) molecular length $(l)$ and $d$-spacings of the highest intensity peak, and (b) crystallite size $(L)$ corresponding to the $d 3.5$ and $4.3 \AA$ reflections as a function of alkyl side chain length of the biscarbamates. ...

Figure 3.5. X-ray diffraction traces of slow-cooled samples of $\mathrm{C}_{3} \mathrm{C}_{6}$ and $\mathrm{C}_{15} \mathrm{C}_{6}$ biscarbamates.

Figure 3.6. Optical micrographs of biscarbamates with different odd number of carbon atoms in the alkyl side chains: $\left(a, a^{\prime}\right) C_{3}$, (b, b') $\mathrm{C}_{7},\left(\mathrm{c}, \mathrm{c}^{\prime}\right) \mathrm{C}_{9},\left(\mathrm{~d}, \mathrm{~d}^{\prime}\right) \mathrm{C}_{11},\left(\mathrm{e}, \mathrm{e}^{\prime}\right) \mathrm{C}_{13}$, and (f, f') biscarbamates. The first column represents the micrographs 


\section{List of Figures continues}

of quenched samples and the second column represents those of slowcooled samples.

Figure 3.7. Variation of spherulite size of $C_{x} C_{6}$ biscarbamate samples as a function of alkyl side chain length containing odd (a), and both odd and even (b) number of carbon atoms.

Figure 3.8. Optical micrographs of $\mathrm{C}_{13} \mathrm{C}_{6}$ biscarbamate captured at different time interval during isothermal spherulite growth.

Figure 3.9. (a) Growth of spherulites with time, and (b) rate of spherulite growth as a function of number of carbon atoms in the alkyl side chains.

Figure 3.10. Fractional heats of fusion of the biscarbamates as a function of time. Data for other biscarbamates in this series are omitted for clarity.

Figure 3.11. Plots of $\ln \{-\ln [1-\mathrm{X}(t)]\}$ versus $\ln t$ during isothermal crystallization of the biscarbamates. Data for other biscarbamates in this series are omitted for clarity.

Figure 3.12. Change of half crystallization time, $t_{1 / 2}$ as a function of number of carbon atoms in the alkyl side chains.

Figure 3.13. Variation of (a) asymmetric and (b) symmetric $\mathrm{CH}_{2}$ stretching vibration frequency of biscarbamates as a function of alkyl side chain length. 


\section{List of Figures continues}

Figure 4.1. DSC traces of biscarbamates showing phase transitions corresponding to melting and crystallization in the heating and cooling cycles respectively.

Figure 4.2. The variation of (a) melting temperature of biscarbamates as a function of alkyl side chain length with $\left(\mathrm{CH}_{2}\right)_{6}(----)$ and $\left(\mathrm{CH}_{2}\right)_{12}(-)$ spacers; (b) $T_{\mathrm{m}}$ as a function of the total number of $\left(\mathrm{CH}_{2}\right)$ groups in the biscarbamates and $n-$ alkanes; (c) heats of fusion. The $T_{\mathrm{m}}$ and $H_{\mathrm{f}}$ for the phenyl terminated $\mathrm{C}_{6} \mathrm{C}_{12}$ are also shown in (a) and (c).

Figure 4.3. Optical micrographs of quenched (left) and slow-cooled (right) $\mathrm{C}_{\mathrm{x}}-\mathrm{C}_{12}$ biscarbamate samples with different alkyl side chain lengths and terminal groups. ....................

Figure 4.4. Variation of spherulite size of (a) quenched, (b) slowcooled $\mathrm{C}_{\mathrm{x}}-\mathrm{C}_{12}$ biscarbamate samples as a function of alkyl side chain length and the type of terminal groups. (०) methyl terminated and $(\bullet)$ phenyl terminated biscarbamates. ........

Figure 4.5. Optical micrographs of $\mathrm{C}_{12}-\mathrm{C}_{12}$ biscarbamate showing isothermal spherulite growth with time.

Figure 4.6. Representative optical micrographs of $\mathrm{PhC}_{6}-\mathrm{C}_{12}$ showing isothermal spherulite growth over time. 


\section{List of Figures continues}

Figure 4.7. (a) Growth of spherulites with time, and (b) rate of spherulite growth as a function of number of carbon atoms in the alkyl side chains of the biscarbamates.

Figure 4.8. (a) fractional heat of fusion of the biscarbamates as a function of time; (b) the plot in terms of the Avrami equation.

Figure 4.9. Longest observed $d$-spacing and the calculated molecular length.

Figure 4.10. XRD trace of as synthesized biscarbamates: (a) $\mathrm{C}_{4}-\mathrm{C}_{12}$, (b) $\mathrm{C}_{8}-\mathrm{C}_{12}$, (c) $\mathrm{C}_{12}-\mathrm{C}_{12}$, and (d) $\mathrm{C}_{18}-\mathrm{C}_{12}$. 108

Figure 4.11. (a) XRD traces normalized to the highest intensity peak of $\mathrm{C}_{18}-\mathrm{C}_{6}$ and $\mathrm{C}_{18}-\mathrm{C}_{12}$ biscarbamates, and (b) the ratio of the peak intensity at $d=3.5 \AA$ to that of the peak with highest intensity as a function of alkyl side chain length of $\mathrm{C}_{\mathrm{x}}-\mathrm{C}_{12}$ biscarbamates.

Figure 4.12. The variation of crystallite size of the biscarbamates at $d$ 3.5 and $4.2 \AA$ as a function of alkyl side chain length.

Figure 4.13. FTIR spectra of biscarbamates in the (a) $\mathrm{CH}_{2}$ stretching, (b) $\mathrm{N}-\mathrm{H}$ stretching regions.

Figure 5.1. Heat of fusion as a function of weight percent of $\mathrm{C}_{8}$ in the mixtures of $\mathrm{C}_{8}$ and $\mathrm{C}_{12}$ 


\section{List of Figures continues}

Figure 5.2. DSC thermograms of $\mathrm{C}_{8} / \mathrm{C}_{12}$ blends (a) and (b) at a rate of $10{ }^{\circ} \mathrm{C} / \mathrm{min}$, (c) at $1{ }^{\circ} \mathrm{C} / \mathrm{min}$, and (d) $\mathrm{C}_{4} / \mathrm{C}_{18}$ blends at a rate of $10^{\circ} \mathrm{C} / \mathrm{min}$ at various compositions.

Figure 5.3. Variation of the first and second melting temperatures of (a) $\mathrm{C}_{8} / \mathrm{C}_{12}$ and (b) $\mathrm{C}_{4} / \mathrm{C}_{18}$ blends at different compositions.

Figure 5.4. Optical micrographs of biscarbamates and their blends: (a) $\mathrm{C}_{4} 100 \%$, quenched, (b) $\mathrm{C}_{4} 100 \%$, slow-cooled, (c) $\mathrm{C}_{4} / \mathrm{C}_{18}$ (50/50), quenched, (d) $\mathrm{C}_{4} / \mathrm{C}_{18}$ (50/50), slow-cooled, (e) $\mathrm{C}_{18}$ $100 \%$, quenched, and (f) $\mathrm{C}_{18} 100 \%$, slow-cooled.

Figure 5.5. Optical micrographs of $\mathrm{C}_{8}$ and $\mathrm{C}_{12}$ biscarbamates and their blends: (a) $100 \% \mathrm{C}_{8}$, quenched, (b) $100 \% \mathrm{C}_{8}$, slow-cooled, (c) $\mathrm{C}_{8} / \mathrm{C}_{12}(60 / 40)$, quenched, (d) $\mathrm{C}_{8} / \mathrm{C}_{12}(60 / 40)$, slowcooled, (e) $100 \% \mathrm{C}_{12}$, quenched, and (f) $100 \% \mathrm{C}_{12}$, slowcooled.

Figure 5.6. Optical micrographs of $\mathrm{C}_{16}$ and $\mathrm{C}_{18}$ biscarbamates and their blends: (a) $100 \% \mathrm{C}_{16}$, quenched, (b) $100 \% \mathrm{C}_{16}$, slowcooled, (c) $\mathrm{C}_{16} / \mathrm{C}_{18}$ (50/50), quenched, (d) $\mathrm{C}_{16} / \mathrm{C}_{18}$ (50/50), slow-cooled, (e) $100 \% \mathrm{C}_{18}$, quenched, and (f) $100 \% \mathrm{C}_{18}$, slow-cooled.

Figure 5.7. Spherulite size as a function of composition of (a) $\mathrm{C}_{8} / \mathrm{C}_{12}$ and (b) $\mathrm{C}_{4} / \mathrm{C}_{18}$ blends. Spherulite size distribution of $\mathrm{C}_{4} / \mathrm{C}_{18}$ (50/50) blend: (c) quenched and (d) slow-cooled. 


\section{List of Figures continues}

Figure 5.8. Optical micrographs showing spherulites of $\mathrm{C}_{8} / \mathrm{C}_{12}$ blend (50/50) at different times during isothermal crystallization.

Figure 5.9. (a) Variation of spherulite size as a function of time and (b) spherulitic growth rate for different compositions of $\mathrm{C}_{8} / \mathrm{C}_{12}$ blend.

Figure 5.10. Optical micrographs of $\mathrm{C}_{8} / \mathrm{C}_{12} 80 / 20$ blend recorded at different temperatures: (a) at below the first melting temperature, (b) at the first melting temperature $\left(95^{\circ} \mathrm{C}\right),(\mathrm{c})$ at $1{ }^{\circ} \mathrm{C}$ higher than the first melting temperature, (d) at second melting temperature $\left(99^{\circ} \mathrm{C}\right)$, (e) at $1{ }^{\circ} \mathrm{C}$ higher than the second melting temperature, and (f) at $1.8{ }^{\circ} \mathrm{C}$ higher than the second melting temperature.

Figure 5.11. Optical micrographs of $\mathrm{C}_{8} / \mathrm{C}_{12} 20 / 80$ blend recorded at different temperatures: (a) at below the first melting temperature, (b) at the first melting temperature $\left(87^{\circ} \mathrm{C}\right),(\mathrm{c})$ at $1{ }^{\circ} \mathrm{C}$ higher than the first melting temperature, (d) at second melting temperature $\left(108^{\circ} \mathrm{C}\right)$, (e) at $1^{\circ} \mathrm{C}$ higher than the second melting temperature and $(\mathrm{f})$ at $1.8{ }^{\circ} \mathrm{C}$ higher than the second melting temperature. 


\section{List of Figures continues}

Figure 5.12. X-ray diffractograms of $\mathrm{C}_{8} / \mathrm{C}_{12}$ blend (a) at different compositions, (b) of 50/50 blend at different temperatures. In part $b$, the top most curve corresponds to $70{ }^{\circ} \mathrm{C}$ and then at $5^{\circ} \mathrm{C}$ interval to downward.

Figure 5.13. Percent crystallinity of the blends at different compositions:

(a) $\mathrm{C}_{4} / \mathrm{C}_{18}$, (b) $\mathrm{C}_{8} / \mathrm{C}_{12}$, and (c) $\mathrm{C}_{16} / \mathrm{C}_{18} \ldots \ldots \ldots \ldots \ldots \ldots \ldots$

Figure 5.14. (a) fwhm, and (b) crystallite size of $d=3.8$ and $4.6 \AA$ at different compositions of $\mathrm{C}_{8} / \mathrm{C}_{12}$ blend.

Figure 5.15. FTIR spectra of $C_{8} / C_{12} 50 / 50$ blend: (a) full scale, (b) in the $\mathrm{N}-\mathrm{H}$ stretching, and (c) $\mathrm{C}=\mathrm{O}$ stretching frequency region at different temperatures.

Figure 5.16. Change in (a) $\mathrm{N}-\mathrm{H}$ and $\mathrm{C}=\mathrm{O}$ stretching frequencies, and (b) fwhm of $\mathrm{C}_{8} / \mathrm{C}_{12} 50 / 50$ blend with respect to temperature. The values in parentheses represent the peak position at the corresponding temperature.

Figure 6.1. The SEM images of quenched (left) and slow-cooled xerogels with benzonitrile (a) $\mathrm{C}_{6}$, (b) $\mathrm{C}_{8}$, and (c) $\mathrm{C}_{18} \ldots \ldots \ldots$

Figure 6.2. SEM images of the transverse section of $\mathrm{C}_{12}$ slow cooled xerogels with benzonitrile. 


\section{List of Figures continues}

Figure 6.3. SEM images of xerogels of $\mathrm{C}_{12}$ biscarbamate prepared with different organic solvents by quenching the solution: (a) benzonitrile, (b) dodecane, (c) toluene, (d) xylene, and (e) 1-octanol.

Figure 6.4. SEM images of xerogels of $\mathrm{C}_{12}$ biscarbamate prepared with different organic solvents by slowly cooling the solution:

(a) benzonitrile, (b) dodecane, (c) toluene, (d) xylene, and

(e) 1-octanol. Scale bar is $20 \mu \mathrm{m}$.

Figure 6.5. Optical micrographs of $\mathrm{C}_{12}$ gels in (a) xylene, and (b) dodecane.

Figure 6.6. SEM images (cryo condition) of quenched gels of $\mathrm{C}_{18}$ for various concentrations in benzonitrile: (a) $0.03 \mathrm{M}$, (b) 0.04 $\mathrm{M}$, (c) $0.05 \mathrm{M}$, and (d) $0.06 \mathrm{M}$.

Figure 6.7. The SEM images (cryo condition) of slow cooled gels of different $\mathrm{C}_{18}$ concentrations in benzonitrile: (a) $0.03 \mathrm{M}$, (b) $0.04 \mathrm{M}$, (c) $0.05 \mathrm{M}$, and (d) $0.06 \mathrm{M}$.

Figure 6.8. SEM images (cryo condition) of $\mathrm{C}_{8}(\mathrm{a}, \mathrm{b}, \mathrm{c})$, and $\mathrm{C}_{18}$ gels $(\mathrm{d}, \mathrm{e}, \mathrm{f}) .(\mathrm{a}, \mathrm{d}) 1^{\text {st }}$ day, (b, e) $7^{\text {th }}$ day, and $(\mathrm{c}, \mathrm{f}) 14^{\text {th }}$ day, with benzonitrile. 


\section{List of Figures continues}

Figure 6.9. SEM images of xerogels of $\mathrm{C}_{12}$ biscarbamate with different solvents prepared by slowly cooling the solution to room temperature: (a) toluene, (b) xylene, (c) dodecane, and (d) 1-octanol. The gels were dried after 3 weeks (aged) of gel formation. The arrows indicate the slits and hollow parts of the fibers.

Figure 6.10. HyperChem rendition of (energy-minimized) packing of two $\mathrm{C}_{16}$ biscarbamates along the hydrogen bonding direction. The packing in the crystal structure of $\mathrm{C}_{10}$ is similar.

Figure 6.11. SEM images of the $0.08 \mathrm{M}$ slow cooled $\mathrm{C}_{18}$ xerogels with benzonitrile after applying different levels of shear: (a) 70 , (b) 80 , (c) 100 , and (d) $110 \mathrm{rpm}$.

Figure 6.12. Optical micrographs of $\mathrm{C}_{18}$ biscarbamate organogel $(0.08$ M) prepared with benzonitrile as the solvent at different shear rates: (a) $70 \mathrm{rpm}$, (b) $80 \mathrm{rpm}$, (c) $100 \mathrm{rpm}$, and (d) $110 \mathrm{rpm}$

Figure 6.13. X-ray diffractograms of $\mathrm{C}_{18}$ biscarbamate xerogels prepared with different shear rates: (a) no shear, (b) $80 \mathrm{rpm}$, (c) $100 \mathrm{rpm}$, and (d) $110 \mathrm{rpm}$. The designation "parallel" denotes the sample orientation along the direction of the 


\section{List of Figures continues}

incident X-rays and "perpendicular" denotes the samples turned around by $90^{\circ}$ in the beam.

Figure 6.14. Optical micrographs of the $\mathrm{C}_{18}$ biscarbamate and $\mathrm{C}_{18}$ monocarbamate ( $25 \mathrm{wt} \%$ with respect to the weight of $\mathrm{C}_{18}$ biscarbamate) binary gels with benzonitrile: (a) at $25{ }^{\circ} \mathrm{C}$, (b) at $90{ }^{\circ} \mathrm{C}$. The arrows point to the molten drops of $\mathrm{C}_{18}$ monocarbamate.

Figure 6.15. SEM images of the xerogels of $C_{9}(0.08 \mathrm{M})$ and binary gels of $\mathrm{C}_{8}$ and $\mathrm{C}_{9}$ biscarbamates prepared with an equimolar concentration $(0.04 \mathrm{M})$ of each component in benzonitrile:

(a) $\mathrm{C}_{9}$ quenched, (b) $\mathrm{C}_{9}$ slow-cooled, (c) $\mathrm{C}_{8} / \mathrm{C}_{9}$ quenched, and (d) $\mathrm{C}_{8} / \mathrm{C}_{9}$ slow-cooled.

Figure 7.1. Organogels prepared from $\mathrm{C}_{12}$ biscarbamate: (a) neat $\mathrm{C}_{12}$, (b) $\mathrm{C}_{12} / 1 \% \mathrm{Pe}$ and (c) $\mathrm{C}_{12} / 1 \% \mathrm{Pc}$ gel.

Figure 7.2. $\mathrm{DSC}$ thermograms of (a) $\mathrm{C}_{12} / 2 \% \mathrm{Pe}$, and (b) $\mathrm{C}_{12} / 2 \% \mathrm{Pc}$ gels.

Figure 7.3. Optical micrographs of $\mathrm{C}_{12} / \mathrm{Pc}$ gels with different compositions and conditions: (a) 1wt\% Pc, quenched; (b) $2 w t \%$ Pc, quenched; (c) $1 \mathrm{wt} \%$ Pc, slow-cooled; (d) $2 \mathrm{wt} \%$ Pc, slow-cooled; (e) 5wt\% Pc, slow-cooled; (f) $10 \mathrm{wt} \% \mathrm{Pc}$, slow-cooled. 


\section{List of Figures continues}

Figure 7.4. Change in the width of the gel fibers as a function of the dye component loading.

Figure 7.5. $\quad C_{12}$ biscarbamate gels: (a) quenched and (b) slow-cooled samples.

Figure 7.6. SEM images of slow-cooled xerogels: (a) $\mathrm{C}_{12} / 1 \mathrm{wt} \% \mathrm{Pc}$; (b) $\mathrm{C}_{12} / 2 \mathrm{wt} \%$ Pc; (c) $\mathrm{C}_{12} / 5 \%$ Pc; (d) $\mathrm{C}_{12} / 10 \% \mathrm{Pc}$; (e) and $\mathrm{C}_{12} / 1 \% \mathrm{Pe}$. The arrow 1 in panel e indicates a well formed Pe crystal on the outer surface of the gel fiber. Arrow 2 shows the slit of a tubular fiber.

Figure 7.7. SEM images of SNP-loaded xerogel of $\mathrm{C}_{12}$ biscarbamate at different magnifications. The smooth surfaces of the fibers clearly indicate the absence of aggregation of the nanoparticles on the outer surface of the fibers. The arrows in (c) and (d) indicate pores in the SNP-filled solid fibers, which are remnants of the lumen of the hollow tubes.

Figure 7.8. Optical micrographs showing isothermal crystal growth of Pc at $63{ }^{\circ} \mathrm{C}$ in benzonitrile as a function of time. Scale bars $20 \mu \mathrm{m}$. 205

Figure 7.9. Optical micrographs showing isothermal crystal growth of Pe at $63{ }^{\circ} \mathrm{C}$ in benzonitrile as a function of time. 


\section{List of Figures continues}

Figure 7.10. Isothermal growth of Pe and Pc crystals in benzonitrile as a function of time

Figure 7.11. Optical micrographs of slow-cooled $\mathrm{C}_{12} / \mathrm{Pc}$ gel at different temperatures of (a) 25 , (b) 97 , (c) 100 , and (d) $108{ }^{\circ} \mathrm{C}$, showing the Pc crystal inside the $\mathrm{C}_{12}$ fibers of the gel. The white arrows show the Pc crystals before and after melting the fibers. The purple arrows in (d) show the coaxially aligned globular aggregates of the Pc molecules floating in the $\mathrm{C}_{12}$ melt.

Figure 7.12. Optical micrographs of slow-cooled $\mathrm{C}_{12} / \mathrm{Pe}$ gel at different temperatures of (a) 25 , (b) 97 , (c) 108 , and (d) $255^{\circ} \mathrm{C}$, showing the Pe crystal outside the $\mathrm{C}_{12}$ fibers of the gel......

Figure 7.13. Optical micrographs of SNP-loaded $\mathrm{C}_{12}$ biscarbamate gel at different temperatures of (a) 25 , (b) 115.8 , (c) $116^{\circ} \mathrm{C}$, and (d) $25^{\circ} \mathrm{C}$ after cooling.

Figure 7.14. X-ray diffraction patterns of (a) $\mathrm{C}_{12}$ biscarbamate in powder and xerogel form, and (b) $\mathrm{C}_{12}$ organogel, $\mathrm{C}_{12} / \mathrm{Pc}$ two-component organogel, and neat Pc. The $d$-spacing values are in $\AA$.

Figure 7.15. UV-visible spectra of $\mathrm{C}_{12} / \mathrm{Pc}$ gels: (a) quenched and (b) slow-cooled samples. 


\section{List of Figures continues}

Figure 7.16: UV-visible spectra of $\mathrm{C}_{12} / \mathrm{Pe}$ gels: (a) quenched and (b) slowcooled samples.

Figure 7.17. (a) FTIR spectra of $\mathrm{C}_{12}$ biscarbamate, $\mathrm{C}_{12} / \mathrm{Pc}$ organogel, neat $\mathrm{Pc}$, and benzonitrile, (b) magnified view in the region $2800-3200 \mathrm{~cm}^{-1}$

Figure 8.1. DSC thermograms of neat PCL, neat $\mathrm{C}_{12}$ and $\mathrm{PCL} / \mathrm{C}_{12}$ $50 / 50$ blend.

Figure 8.2. Normalized heat of fusion of PCL/biscarbamate binary blends: (a) $\mathrm{PCL} / \mathrm{C}_{4}$, (b) $\mathrm{PCL} / \mathrm{C}_{12}$, and (c) $\mathrm{PCL} / \mathrm{C}_{18}$. The variation of crystallinity of PCL with the concentration of the biscarbamate is also shown.

Figure 8.3. Optical micrographs of $\mathrm{PCL} / \mathrm{C}_{4}$ biscarbamate blend films cast from chloroform solution at different compositions: (a) neat PCL, (b) $1 \%$, and (c) $2 \% \mathrm{C}_{4}$ biscarbamate.

Figure 8.4. Optical micrographs of blend films cast from chloroform solutions. (a, b): PCL/C $\mathrm{C}_{12}$ biscarbamate: $99 / 1$ and $98 / 2$ (wt\%), respectively; (c, d): PCL/ $\mathrm{C}_{18}$ biscarbamate: $99 / 1$ and $98 / 2(w t \%)$, respectively. 


\section{List of Figures continues}

Figure 8.5. Optical micrographs of PCL/biscarbamate blend films cast from chloroform solutions with 5\% (wt) (left column) and $10 \%$ (right column) of biscarbamate. (a, b): $\mathrm{C}_{4}$ biscarbamate; (c, d): $\mathrm{C}_{12}$ biscarbamate, and (e, f): $\mathrm{C}_{18}$ biscarbamate.

Figure 8.6. Optical micrographs of $\mathrm{PCL} / 5 \% \mathrm{C}_{18}$ biscarbamate films at different temperatures: Heating to: (a) $25^{\circ} \mathrm{C}$, (b) $60{ }^{\circ} \mathrm{C}$, (c) $70{ }^{\circ} \mathrm{C}$, (d) $110^{\circ} \mathrm{C}$, (e) $115^{\circ} \mathrm{C}$, (f) $125^{\circ} \mathrm{C}$, and cooling to (g) $104{ }^{\circ} \mathrm{C}$, (h) $70{ }^{\circ} \mathrm{C}$, (i) $40{ }^{\circ} \mathrm{C}$, and (j) $25^{\circ} \mathrm{C}$. The channels running from top left to right in (d) - (j) are the trenches separating the domains created upon melting of the polymer at elevated temperatures. The arrows point to the crystalline aggregates of $\mathrm{C}_{18}$

Figure 8.7. Optical micrographs of (a) neat $\mathrm{C}_{12}$ at $25^{\circ} \mathrm{C}$, (b) neat PCL at $25{ }^{\circ} \mathrm{C}$, and $\mathrm{PCL} / \mathrm{C}_{12} \quad 80 / 20$ blend at different temperatures: (c) $25^{\circ} \mathrm{C}$, (d) $60^{\circ} \mathrm{C}$, (e) $110^{\circ} \mathrm{C}$ (f) $115^{\circ} \mathrm{C}$, (g) $107{ }^{\circ} \mathrm{C}$ upon cooling, and (h) $40{ }^{\circ} \mathrm{C}$ upon cooling. The white arrows indicate the droplets of the molten PCL......

Figure 8.8. Phase diagram of gelability of biscarbamates having alkyl side chains of different length at different concentrations. 


\section{List of Figures continues}

Figure 8.9. Critical gelation concentration of biscarbamates as a function of alkyl side chain length with a constant concentration $(20 \%(\mathrm{w} / \mathrm{v}))$ of PCL to gel chloroform. .......

Figure 8.10. SEM micrographs of xerogels of PCL/biscarbamate: 90/10 (wt \%) blends. (a, a') PCL/C $11 ;\left(b, b^{\prime}\right)$ PCL/C 12 ; and $\left(c, c^{\prime}\right)$ $\mathrm{PCL} / \mathrm{C}_{13}$. The left column represents the micrographs of quenched samples and the right column corresponds to the slow-cooled samples. The arrows show the eaves trough morphology of the fibers.

Figure 8.11. Optical micrographs of xerogels of PCL/biscarbamate: $85 / 15$ (wt \%) blends recorded after partially melting at 60 ${ }^{\circ} \mathrm{C}:\left(\mathrm{a}, \mathrm{a}^{\prime}\right) \mathrm{PCL} / \mathrm{C}_{11},\left(\mathrm{~b}, \mathrm{~b}^{\prime}\right) \mathrm{PCL} / \mathrm{C}_{12}$, and $\left(\mathrm{c}, \mathrm{c}^{\prime}\right) \mathrm{PCL} / \mathrm{C}_{13}$. The left column represents the micrographs of quenched samples and the right column corresponds to those of the slow-cooled samples.

Figure 8.12. Optical micrographs of PCL/C $\mathrm{C}_{11}(\mathrm{a}, \mathrm{b}, \mathrm{c})$ and $\mathrm{PCL} / \mathrm{C}_{13}(\mathrm{~d}, \mathrm{e}$, f) biscarbamate gels at different compositions of $\mathrm{C}_{11}$ and $\mathrm{C}_{13}:(\mathrm{a}, \mathrm{d}) 10 \%,(\mathrm{~b}, \mathrm{e}) 15 \%$, and $(\mathrm{c}, \mathrm{f}) 20 \%$. White arrows indicate the globular precipitates of $\mathrm{C}_{13} \ldots \ldots \ldots \ldots \ldots \ldots$ 


\section{List of Figures continues}

Figure 8.13. Optical micrographs showing the change in the fiber width as a function of alkyl side chain length at a constant (15\%) composition: (a) $\mathrm{C}_{11}$, (b) $\mathrm{C}_{12}$, and (c) $\mathrm{C}_{13}$. A graph of the variation is shown in (d).

Figure 8.14. SEM images of cross sections of PCL/15\% biscarbamate gels with different number of carbon atoms in the alkyl side chains of the biscarbamate molecules: (a) $\mathrm{C}_{11}$, (b) $\mathrm{C}_{12}$, (c) $C_{13 .}$ (d) is the magnified view of (c).

Figure 8.15. SEM images of cross sections of $\mathrm{PCL} / \mathrm{C}_{12}$ biscarbamate gels with different concentrations of $\mathrm{C}_{12}$. (a) $10 \%$, (b) $15 \%$, and (c) $20 \%$

Figure 8.16. $\mathrm{XRD}$ traces of neat $\mathrm{C}_{12}$, neat $\mathrm{PCL}$, and $\mathrm{PCL} / 15 \% \mathrm{C}_{12}$ xerogel recorded at ambient temperature. The values of $d$ spacings are in $\AA$.

Figure 8.17. ATR - FTIR spectra of neat $\mathrm{C}_{12}, \mathrm{PCL} / 15 \% \mathrm{C}_{12}$ xerogel, and neat PCL 
Chapter 1

Introduction 


\subsection{Molecular Self-Assembly}

"Molecular Self-assembly" is the most explored concept in modern chemistry and contemporary applied scientific disciplines that paved the basis of supramolecular chemistry. The term refers to the spontaneously and reversibly creating structures or patterns with a significant order out of molecules of specific design. Molecular selfassembly under thermodynamic and kinetic conditions leads to stable, structurally welldefined aggregates joined mainly by noncovalent interactions e.g., hydrogen bonding, $\pi-\pi$ interactions, van der Waals force, electrostatic interactions etc. ${ }^{1-3}$ Although these interactions themselves are rather weak, collectively they result in the formation of very stable molecular aggregates. Chemical complementarity and structural compatibility ${ }^{4}$ appear to be the key elements in molecular self-assembly leading to exquisite chemical structures. Since the power of self-assembly lies on the "molecular-scale" control over the nanostructural morphology/pattern, it is now imperative to understand the underlying key principles of molecular self-assembly to create structures of desired dimensions and functionality through this approach.

\subsection{Nature: The Grandmaster of Molecular Self-Assembly}

Molecularly self-assembled structures are ubiquitous in nature. Nature shows its mastery in building extraordinary materials and molecular machines that includes nonbiological minerals, well-ordered clays and photonic crystals and biological multifunctional macromolecular assemblies, such as hemoglobin, polymerases, ATP synthase, membrane channels, the spliceosome, the proteosome, ribosomes etc. A basic set of molecules consisting of 20 amino acids, a few nucleotides, a dozen or so lipid 
molecules and a couple of dozen sugars have evolved in nature through molecular selections and constitute the paradigm of molecular biology. ${ }^{5}$ Natural processes are capable of creating enormously diverse, self-sustaining and evolving refined structures, both of chemical and biological in nature, from these apparently simple molecules with high precision, flexibility and error correction. The most interesting and well-known biological system of this process is the formation of DNA double helix from two complementary oligonucleotides. ${ }^{6}$

The exotic functionality and superiority of biological supermolecules can be exemplified by the highly sophisticated protein assemblies of the bacterial flagellar motor. Bacteria, such as colon bacillus can swim by rotating its flagella at high speed by means of a protein motor. This motor is composed of various proteins built up through supramolecular assembly in a very sophisticated way. The flagellar motor has a diameter of $\sim 30 \mathrm{~nm}$ which can rotate at $1500 \mathrm{rpm}$. It can change its direction of rotation within one millisecond. ${ }^{7}$ Its size and functionality are far superior to those of any man-made ultrasmall machines.

Optical systems of marine organisms supersedes the delicacy of the most advanced top-down technology for fabricating a contemporary synthetic optical systems by molecular self-assembly (Figure 1.1). Fiber-optical spicules, for example, of the brittlestar Ophiocoma wendtii and the sponge Euplectella derived from the biomineralization have the dimensions of a single human hair and can act as multimode waveguides. In comparison to the contemporary synthetic optical fibers, the microfibers are much more fracture resistant because of the presence of organic ligands connecting 
the nanofibers. These spicules have high refractive indices and considerable flexibility with the capacity to act as single-mode or multi-mode waveguides. ${ }^{8}$

a

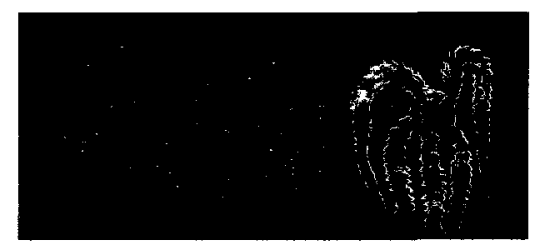

b

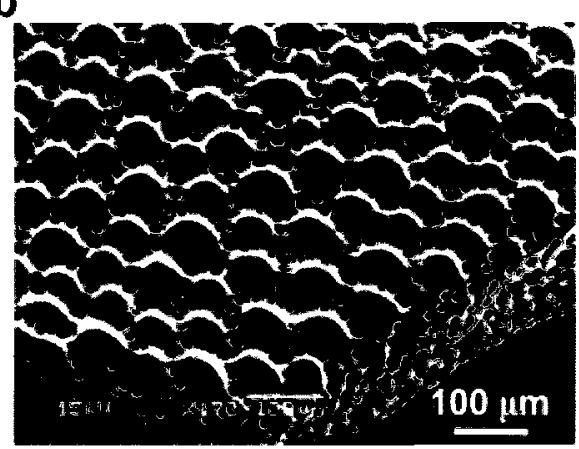

C
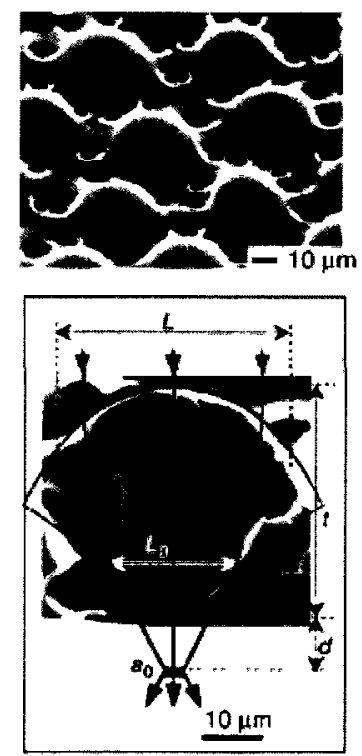

d

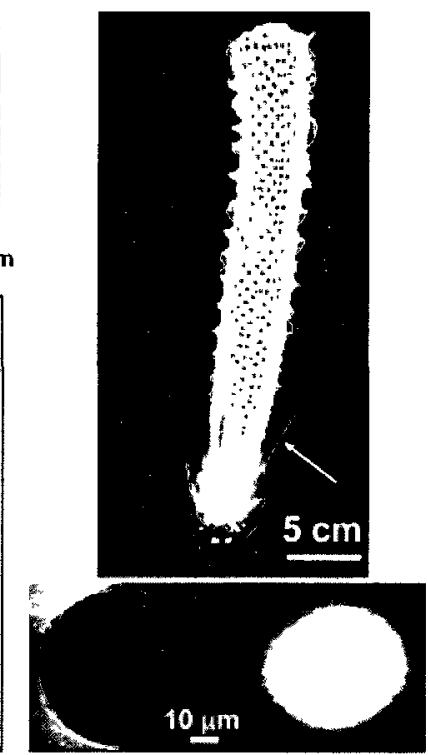

Figure 1.1. (a) A marine brittlestar and its lens. (b) SEM images of the calcite microlenses of Ophiocoma wendtii after chemical cleaning to remove proteins and other organic substances. (c) Top, high-magnification SEM image of $O$. wendtii microlenses. Bottom, high-magnification SEM image of the cross-section of microlense showing the pathway of light focused by the microlens. The functional region of this lens $\left(L_{0}\right)$ closely matches the profile of a lens that compensates for spherical aberration (red lines). The light paths are shown as blue lines. (d) Structure and fiber-optical properties of spicules in the glass sponge Euplectella. Top, photomicrograph showing the basket-like cage structure and basalia spicules (arrow). Bottom, wave guiding for individual spicules upon coupling with white light. Spicules embedded in epoxide act as single-mode or few-mode waveguide (left); free-standing spicules act as multimode waveguide (right panel). [Taken from Ref. 8].

Replication of the cell component and subsequent assembling into another cell during mitosis, paring of bases, self-splicing and self-cleaving of RNA, ribosome assembly, formation of lipid bilayer, folding of some proteins etc. constitute a set of some representative examples of molecular self-assembly in biological systems. ${ }^{9}$ Although mimicking these biological phenomena in the laboratory is an enormous challenge, the 
sophistication and success of effortless accomplishments of nature in creating biological superstructures inspire the human engineers to create new and varied structures with novel utilities.

\subsection{Molecular Self-Assembly: The Designer Toolkit}

Inspiration from nature is of particular importance for designing functional building blocks towards self-assembly. Nature-inspired molecular self-assembly has thus recently emerged as a new approach in chemical synthesis, nanotechnology, polymer science, materials science and engineering. Assembly of functional materials has long been a focus of research because of their promising applications such as in nanoelectronics, photonics, computing, environmental monitoring, medical imaging, diagnostics etc. ${ }^{10}$

Considerable advances have been made in the use of peptides, phospholipids and nucleic acids as building blocks to fabricate potential bio-based materials for a wide range of applications. ${ }^{11}$ Structural order over multiple length scales can be created in selfassembling materials by the incorporation of recognition sites and moieties of several molecular interactions including hydrophobic and hydrophilic effects, hydrogen bonding, Coulombic interactions, and van der Waals forces. ${ }^{1}$

Collier and co-workers ${ }^{12}$ have discussed multifunctional extracellular matrices based on peptide self-assembly that can regulate and be regulated by cellular processes. Base-pair structures that assemble into oligomeric units and imitate nucleic acids have been introduced by Lehn and co-workers (Figure 1.2). ${ }^{13}$ 


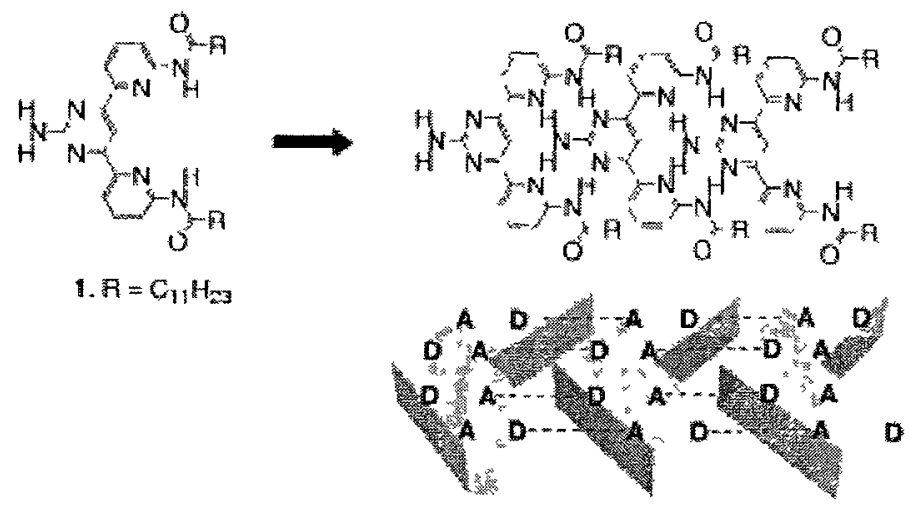

Figure 1.2. Structure of a monomer bearing self-complementary DAAD-ADDA patterns of hydrogen bonding sites and its directional self-assembly into a ribbon-like supramolecular polymer through an array of four hydrogen bonds [Taken from Ref. 13c].

Molecular ropes were produced out of matched base-pair segments that form strands of complex units. These strands resemble some of the natural fiber-forming polymers while they are held together entirely by hydrogen bonds. DNA or RNA oligonucleotide aptamers ${ }^{14}$ have recently emerged as an important class of targeting ligands that can be used in biosensing, ${ }^{15}$ drug delivery, ${ }^{16}$ diagnostic imaging ${ }^{17}$ and phototherapy. ${ }^{18}$ Specificity and affinity of such aptamer ligands are governed by the hydrogen bonding between the base-pairs leading to appropriate binding sites in the aptamer structures. Similar base-pair chemical groups have been introduced by Stadler et al. ${ }^{19}$ into elastomers to create thermally reversible networks by taking advantage of the modest thermal stability of these weak non-covalent bonds. There have been some reports on attaching liquid crystalline (LC) groups to polymer backbones by using single hydrogen bonds and the resulting structures are found to be thermally stable at the required processing temperatures. ${ }^{20}$ 
Organic conjugated molecular materials, popularly referred to as organic semiconductors, with a delocalized $\pi$-electron system have an intrinsic wide band gap. This wider band gap of these systems results in their affinity for electrons and emerged as potential materials for organic electronics. ${ }^{21}$ Self-assembly through strong $\pi$ - $\pi$ stacking in such molecules has been utilized as an effective approach to construct nanostructures of planar, rigid organic molecules leading to organic nanodevices. ${ }^{22}$ Zang et al. ${ }^{23}$ reported the enhancement of one-dimensional charge transport through intermolecular $\pi$-electron delocalization in an organic nanobelt of perylene tetracarboxylic diimide (PTCDI). The long-range $\pi$-electron delocalization enabled enhancement of electrical conductivity of such nanobelts. Molecular self-assembly through $\pi$-stacking of liquid crystals (LC) led to some exquisite structures with improved properties. ${ }^{24}$ Kato and co-workers ${ }^{25}$ have synthesized new electrochromic molecular materials combining ionic and electronic functions using liquid crystals consisting of terthiophene-based mesogens and terminal imidazolium groups that showed thermotropic smectic A phases. Nanosegregation of the $\pi$-conjugated mesogens and the ionic imidazolium moieties led to the formation of layered liquid-crystalline (LC) structures consisting of two dimensional alternating pathways for electronic charges and ionic species.

$\pi$-stacking interactions between aromatic rings have been employed by Stoddard and co-workers ${ }^{26}$ to construct catenanes which are large interlocked molecular ring structures with oligomeric properties. Such materials were found to display exceptional optical properties. Preparation of rotaxanes represents another example of supramolecular assembly leading to macromolecules in which a polymer backbone is threaded through several macro cycles and locked in place by capping the chain ends. ${ }^{27}$ Development of 
molecular devices based on rotaxanes and catenanes is a subject of current interest. ${ }^{28}$ Various polyrotaxanes have been investigated as new building blocks to construct nanostructures as well as to realize novel functions.

The self-assembly of block copolymers often lead to micelles or vesicles which can be used as nanocarriers of diagnostic and therapeutic agents. ${ }^{29}$ Dissolution of an amphiphilic block copolymer in a solvent that is only "good" for one block, leads to an attractive and a repulsive force that results in microphase separation and self-assembly of individual molecules into supramolecular structures called spherical micelles. The intended drug is either entrapped in the hydrophobic core of the micelle during its formation or covalently bound to the hydrophobic block in such formulations. ${ }^{30,31}$ The advantage of such drug delivery systems stems from the alterations of the pharmacokinetic profile of entrapped drugs, drug solubilization and/or stabilization. ${ }^{31,32}$ Chilkoti and co-workers ${ }^{33}$ have reported the fabrication of multivalent spherical micelles from stimuli responsive elastin-like polypeptides for drug targeting by thermally triggered multivalency. Micelles have been also used in anticancer drug carrier to probe into the cancer cell apoptosis. ${ }^{34}$

Molecular self-assembly has evolved as a highly promising field of contemporary research and the above mentioned examples are only a few of the immense possibilities that molecular self-assembly can offer. It has now become evident that molecular selfassembly will surely be the most important designer toolkit in the coming decades. ${ }^{4}$ 


\subsection{Self-Assembling Carbamates}

This thesis deals with the morphological investigations upon crystallization and gelation of hydrogen bond mediated self-assembling biscarbamates, which are the analogues of the hard segment of polyurethanes. The association process in biscarbamates resembles that of biological self-assembly such as protein molecules involving hydrogen bonding as shown in Figure 1.3.

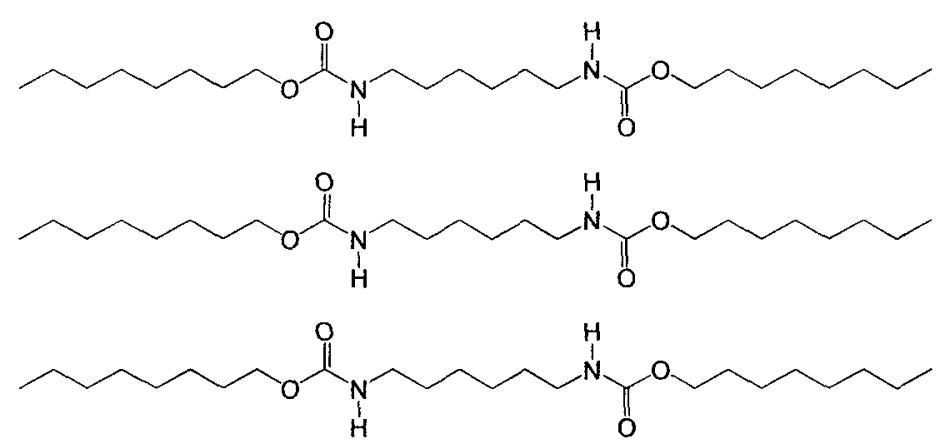

Figure 1.3. Schematic showing the hydrogen bonding in biscarbamates.

\subsubsection{Applications of Carbamates}

Scientific studies of carbamates date back to early 1900 s and continues to the contemporary time because of their potential applications as sequence-specific DNA alkylation agents, ${ }^{35}$ organic intermediates, ${ }^{36}$ photosynthetic inhibitors, ${ }^{37}$ models for alcohol prodrugs, ${ }^{38}$ efficient and nontoxic gene delivery system ${ }^{39}$ and antileukemic agents. $^{40}$ Because of their structural simılarity carbamates and biscarbamates are considered model compounds for polyurethanes and the mechanism of decomposition ${ }^{41}$ and surface adhesion ${ }^{42}$ of polyurethanes has been studied in terms of that of biscarbamates. They have been used to understand some catalytic processes and the kinetics of the reactions accompanying the polyurethane synthesis process. ${ }^{43,44}$ The structural similarities of polyurethanes and carbamates were also utilized in hydraulic 
stability and thermal resistance tests of these polymers. ${ }^{45,46}$ They can be used for increasing the abrasion resistance of polyurethane composites. ${ }^{47}$ Moreover, they have been used in improving hardness of polyurethane-based adhesives and sealants, ${ }^{48}$ adjusting the viscosity of oil and grease and as anti-inflammatory agents ${ }^{49}$ and pesticides. ${ }^{50}$ Because of their low melt viscosity of about $8-12$ centipoises, melting temperatures of $60-120^{\circ} \mathrm{C}$ and rapid crystallization upon quenching from the melt, carbamates have been considered as potential candidates as ink vehicle for ink-jet printing technologies. $^{51}$

\subsubsection{Structural Investigation on Carbamates}

Although reports on studies that deal with the structure and properties of carbamates are not abundant in the literature, there have been some attempts to reveal the structure-property relationship of this class of molecules. There was an attempt to compute the dynamic and electro-optical parameters (EOPS) of carbamates by the MINDO/3 method. ${ }^{52}$ Furer reported an extensive study on the hydrogen bonding and IR spectra of different carbamates in conjunction with quantum-chemical calculations to probe into the actual conformations present in the different phases of carbamates. ${ }^{53}$ Deetz et $a l^{54}$ used hydrogen bonding template as an effective "conformational switch" to control the syn-anti $\mathrm{C}-\mathrm{N}$ rotamer equilibrium in pyridyl carbamates. X-ray diffraction and thermal analysis were utilized to investigate the structure and properties of some short chain mono- and dicarbamates as model compounds for urethane polymers by Krol et al. ${ }^{55}$ It was found that single component carbamates developed far better crystal structures than that of mixtures of two isomers. X-ray diffraction of the mixtures of two 
isomers revealed lower intensity and wider peaks indicative of lower crystal organization and/or defective crystal structures of these compounds. Recent studies done in our group revealed the influence of single versus double hydrogen bonding motif and symmetric versus asymmetric alkyl substitution of carbamates on crystallization $^{56}$ and gelation ${ }^{57}$ morphology. It was seen that the balance between the hydrogen bonding and van der Waals forces can be optimized both by incorporating multiple hydrogen bonding motifs as well as varying the alkyl side chain length leading to the desired morphology in both the solid state and gel phase structures. This study aimed at further investigation of carbamates with respect to the variation in the length of the spacer separating the hydrogen bonding motifs as well as the effect of carbon atom parity on crystallization and gelation properties in their neat form and composites.

\subsection{Terms in morphology}

Because of the nature and context of this work, we will be referring frequently to some basic terms related to crystallization and morphology in the following chapters. These terms are briefly introduced below.

\subsubsection{Birefringence}

Birefringence is a measure of orientation in the axial directions. Many crystalline materials show optical anisotropy as birefringence which arises from the different indices of refraction associated with different crystallographic direction (Figure 1.4). Crystals that possess two distinct indices of optical refraction are called birefringent materials. 


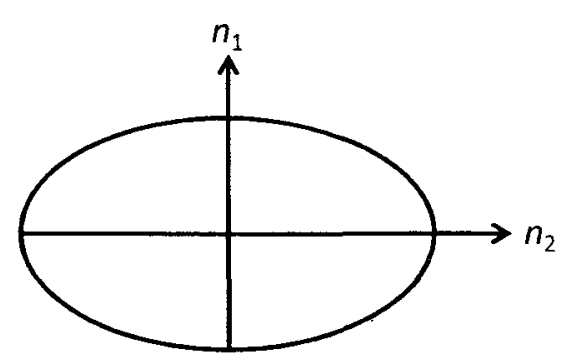

Figure1.4. Schematic showing distinct indices of refraction in two directions.

Birefringence is defined as the numerical difference of the refractive indices in an anisotropic crystal. It appears as a band of polarized colors under crossed polars.

$$
\text { Birefringence }=n_{2}-n_{1}
$$

where $n_{2}$ is the higher refractive index and $n_{1}$ is the lower refractive index in two different crystallographic directions.

\subsubsection{The Crystallite Size}

Crystallization study of crystalline or semi crystalline materials deals with two parameters very often related to growth and perfection, namely the crystallite size and the long spacing or lamellar spacing. The crystallite size is defined as the growth of a crystalline region along a specific lattice direction (Figure1.5a). These parameters can be calculated from X-ray Diffraction analysis. Although the phase identification using $\mathrm{x}$-ray diffraction relies mainly on the peak positions, the relative intensities of the peaks in a diffraction profile and the shapes of the peaks can also provide additional and often valuable information regarding the crystalline structures. The shape, particularly the full width at half maxima (fwhm) of the peak (see Chapter 2) is a measure of the amplitude of thermal oscillations of the atoms at their regular lattice sites. The well known Scherrer 
equation (discussed in chapter 2) explains peak broadening in terms of incident beam divergence which makes it possible to satisfy the Bragg condition for non-adjacent diffraction planes and calculation of the crystallite size as a function of peak width, peak position and wavelength. The larger the crystallite size, the sharper will be the x-ray reflection corresponding to that lattice direction. Directional specifications need to be mentioned in terms of the miller indices of the reflection in reporting the crystallite size. Crystallite size is usually of the order of a few hundred angstroms.

(a)

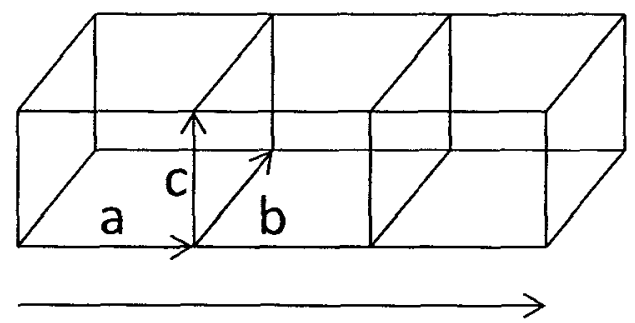

Crystal growth in this direction is given by crystallite size along a

(b)

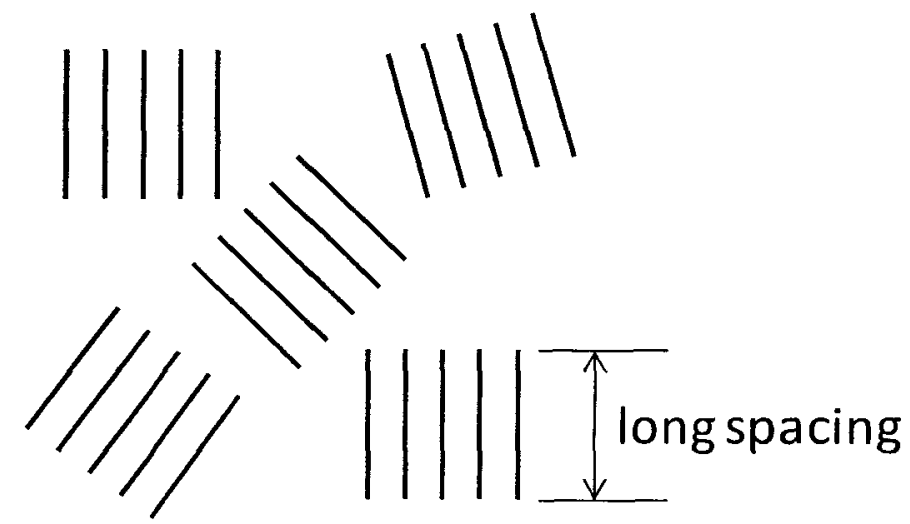

Figure 1.5. Schematic representation of (a) crystallite size, and (b) long spacing.

The long spacing is the overall size of a crystalline lamellar domain (Figure 1.5b). This can be calculated from small angle $\mathrm{x}$-ray scattering (or neutron diffraction) analysis. 
Long spacing values of crystalline materials are usually in the range of 200 to $1000 \AA$. Since this is an "average overall", no directional specifications apply.

\subsubsection{Spherulites}

As the self-defining term implies, spherulites are sphere-shaped crystalline structures formed in the bulk of a crystalline material. These are ubiquitous forms of crystalline aggregates occurring in a wide range of materials and are characterized by radial growth leading to spherical symmetry.
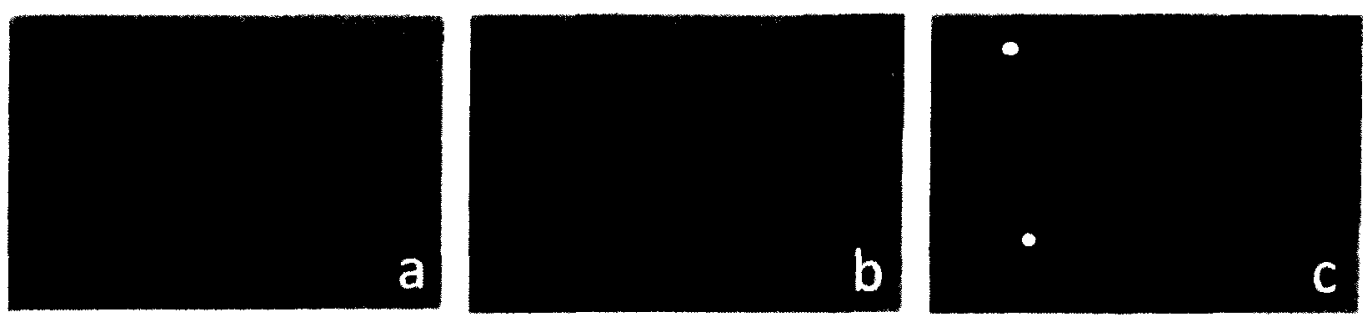

Figure 1.6. Optical micrographs of biscarbamate showing spherulite growth over time during isothermal crystallization.

The term "spherulite" may seem to be a misnomer sometimes when we look at the final shape of the crystalline aggregate referred as a spherulite. Normally the spherulites are really spherical in shape only during the initial stage of crystallization (Figure 1.6a). However, during the latter stages of crystallization, the spherulites impinge on their neighbors (Figure 1.6b) leading to deformation of the spherical shape. Boundaries between two spherulites may be straight (the imaginary line between the two white spots in Figure 1.6c) when the spherulites are nucleated almost simultaneously. However, their boundaries may appear as hyperbola if the spherulites have been nucleated at different times and hence they are different in size when impinging on each other. 
Spherulites are optically anisotropic. The anisotropy arises from the arrangement of the crystallites within the spherulites with different radial and tangential refractive indices denoted by $n_{r}$ and $n_{t}$ respectively. ${ }^{58}$ This optical anisotropy gives rise to birefringence (Figure 1.7), which is defined as

$$
\Delta n=n_{r}-n_{t}
$$

Spherulites with larger refractive index in the radial direction show positive birefringence while the spherulite having higher refractive index in the tangential direction show negative birefringence. ${ }^{59}$ Spherulites of polyethylene and polyamide are such examples showing negative and positive birefringence respectively.
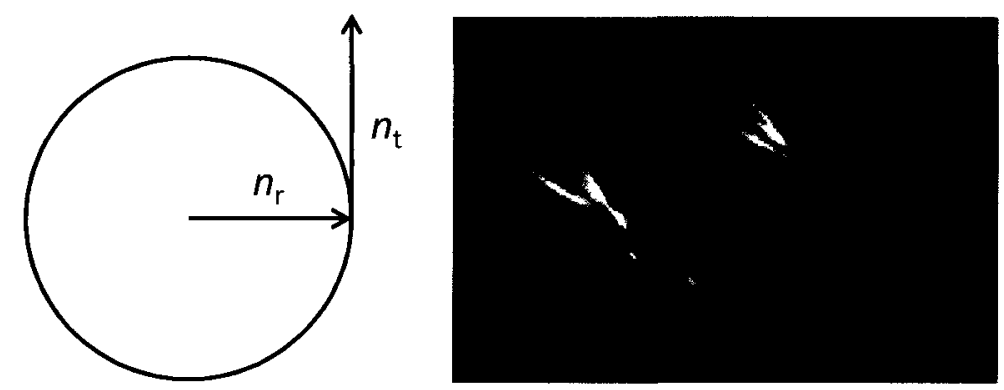

Figure 1.7. Optical anisotropy in spherulites.

When light is shed on a thin section of a sample containing spherulites between crossed polars in a polarized optical microscope, it is observed that each spherulite exhibit an extinction cross called Maltese cross. 

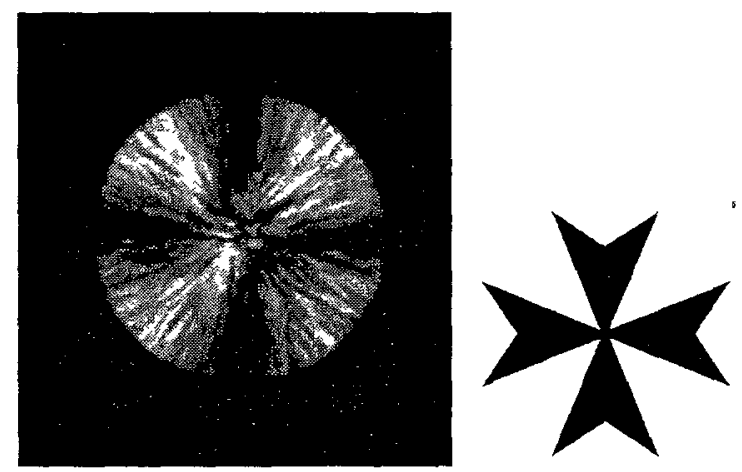

Figure 1.8. A thin section of bulk crystallized polylactide showing Maltese cross in the birefringent spherulitic texture. The inset show the schematic of a Maltese cross.

In such a Maltese cross, one arm is aligned with the vibration direction of the polarizer and the other arm is aligned with the vibration direction of the analyzer. Figure 1.8 shows the Maltese cross in the spherulites of a polylactide sample. On rotation of the specimen, the arms of the Maltese cross remain parallel to the vibration directions of the polars indicating that the section of the spherulite has circular symmetry, which could be either radial or tangential. ${ }^{59}$

\subsection{Importance of Controlling the Morphology}

The synthesis of materials and assembling them into ordered structures to render them functional and operational are crucial aspects of material science. Controlling the outward morphology of such functional materials is of paramount importance. The interplay among the structure, morphology and fabrication processes determines the physical and mechanical properties of the materials. For example, control of spherulite or crystallite size and crystallinity during crystallization of a material is very critical for its application. In this context, we can consider the case of self-assembling carbamates. As mentioned above, because of the melt viscosity of the order of $10-12$ centipoises and 
semi-crystalline nature, long chain carbamates can be used as a vehicle in ink formulation for ink-jet printers. ${ }^{51}$ High transparency and crease resistance are two important attributes for a vehicle in such applications. Crystallization with larger spherulitic morphology will hamper the transparency and crease resistance. Ideally, the average size of the spherulites upon crystallization should be of the order of the wavelength of light to impart transparency. Such small spherulites will also result in the crease resistance. The large spherulites such as in Figure 1.9a will lead to hazy and brittle prints, whereas the small spherulites shown in Figure $1.9 \mathrm{~b}$ will lead to transparent prints. Thus, control of the crystalline morphology is an important factor for such an application of a material.
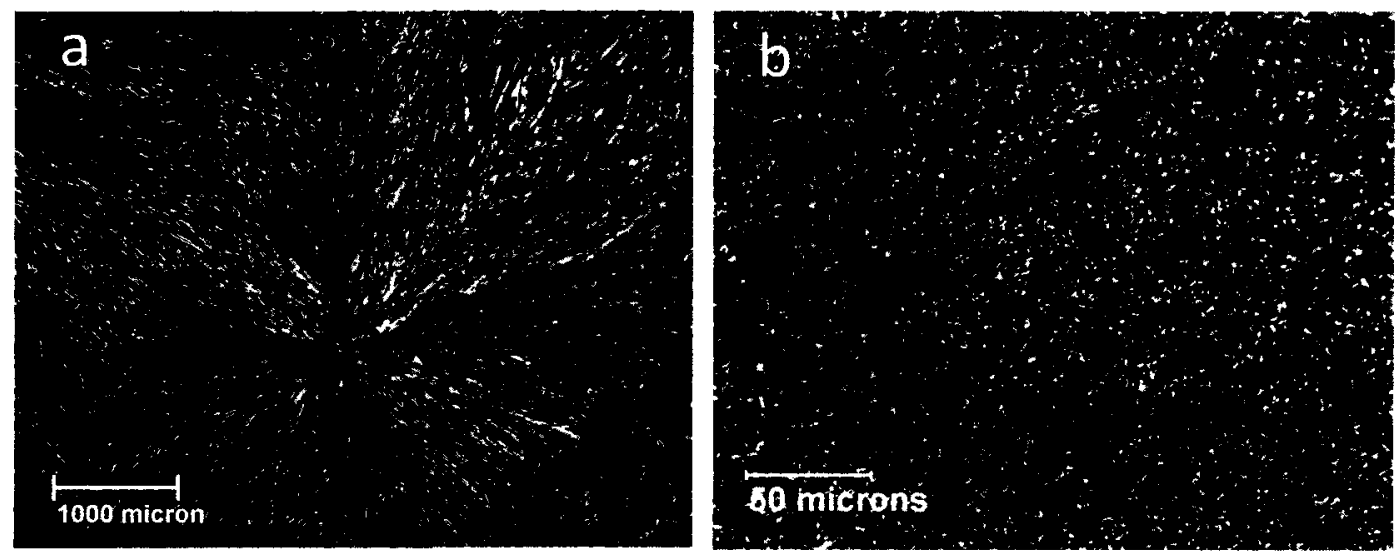

Figure 1.9. (a) large spherulites of an opaque biscarbamate film, and (b) very small spherulites of a transparent polycaprolactone (PCL) film.

\subsection{Thesis Objectives}

The exact self-assembly behavior and the resulting morphology of a given molecular system are difficult to predict and control a priori. However, it is possible to tailor these behaviors by employing a stepwise approach, i.e., by systematically varying the chemical structure (e.g. the length of the side groups and spacers) during synthesis. 
The overall objective of this thesis was to systematically investigate the role of hydrogen bonding and van der Waals forces, owing to the variation in the structural features, in controlling the morphology of self-assembling molecular systems during their crystallization in solid state and gelation in solution phase. Long chain biscarbamates were used in this study for such investigations because of their potential applications as mentioned in section 1.4.1.

The main objectives of this thesis were:

1. To synthesize a series of long chain biscarbamates (Figurer 1.10) with different alkyl side chain and spacer lengths, different terminal groups (methyl versus phenyl) of the alkyl side chains and different carbon atom parity (odd versus even) of the alkyl side chains.<smiles>CCCCCCCOC(=O)NCCCCCCNNC(=O)OCCCCCCC</smiles><smiles>CCCCCCCCOC(=O)NCCCCCCNNC(=O)OCCCCCCCC</smiles><smiles>CCCCOC(=O)NCCCCCCCCCCCCNC(=O)OCCCC</smiles><smiles>CCCCCCCCOC(=O)NCCCCCCCCCCCCNC(=O)OCCCCCCCC</smiles>

Figure 1.10. Molecular structures of representative biscarbamates with different alkyl side chain and spacer length and odd versus even carbon atom parity in the alkyl side chains. 
2. To examine the crystallization behaviour and morphology of these biscarbamates with respect to the length and carbon atom parity of the alkyl side chains.

3. To investigate the crystallization behaviour and morphology of these biscarbamates in their neat forms as a function of the variation in spacer length and type of the terminal groups of the alkyl side chains.

4. To examine the immiscibility and self-sorting behaviour of the blends of these biscarbamates as a function of alkyl side chain length.

5. To investigate the gelation behaviour leading to hollow gel fiber morphology of these biscarbamates as low molecular organogelators.

6. To fabricate dye molecule and metal nanoparticle encapsulated organogels of biscarbamates following two-component gel route.

7. To prepare mechanically robust, two-component physical gels comprised of biscarbamates and a biocompatible polymer.

\subsection{Thesis Overview}

This thesis is divided into nine chapters. In chapter 1 , we have given a general introduction to the molecular self-assembly with some discussion on the importance of self-assembling systems. Literature review of self-assembling carbamates and their applications, some basic terminologies related to crystallization and morphology, and the importance of controlling the morphology also briefly discussed in this chapter. 
Chapter 2 describes the synthesis of biscarbamates, chemical structures and physical properties of other materials used in this study, procedures used for sample preparation and different methods employed to characterize the biscarbamates and their composites.

Chapter 3 presents the results of the crystallization and morphological investigations of the biscarbamates with respect to the variation in the length and carbon atom parity of the alkyl side chains. The observed odd-even effect of these biscarbamates on the crystallization and morphology is discussed in this chapter.

Chapter 4 presents the effect of alkylene spacer length and the type of terminal groups present in the alkyl side chains on the crystallization and morphology of the biscarbamates.

Chapter 5 discusses the effect of blending of two (hydrogen bond mediated) selfassembling homologous molecules on the structure and morphology and reveals the immiscibility and self-sorting behaviour of the chemically similar biscarbamates.

Chapter 6 describes the gelation behaviour of the non-chiral biscarbamates with hollow gel fiber morphology. The mechanism of the hollow fiber formation and their oriented nature is also discussed in this chapter.

Chapter 7 discusses the encapsulation of dye molecule and metal nanoparticle into the hollow fibers of biscarbamate during their gelation. The effect of size, shape and growth 
rate of the dye crystals on their inclusion into the hollow fibers is elaborately discussed in this chapter.

Chapter 8 presents the facile formation of mechanically robust composite porous gels comprising PCL and a series of hydrogen bond mediated self-assembling biscarbamates driven by their immiscibility and self-sorting at the molecular level.

Chapter 9 presents the overall conclusion derived from this present work and recommends some ideas for future work. 


\subsection{References}

1. Whitesides, G. M.; Mathias, J. P.; Seto, C. T. Science 1991, 254, 1312.

2. Lehn, J. M. Science 1993, 260, 1762.

3. Ball, P. Nature 1994, 367, 323.

4. Zhang, S. Biotechnology Advances 2002, 20, 321.

5. Zhang, S. Nat. Biotechnol. 2003, 21, 1171.

6. Sadhasivam, S.; Yun, K. S. J. Mater. Sci. 2010, 45, 2543.

7. Ariga, K.; Kunitake, T. Supramolecular Chemistry-Fundamentals and Applications, Springer, 2006; Chap. 6.

8. (a) Aizenberg, J.; Tkachenko, A.; Weiner, S.; Addadi, L.; Hendler, G. Nature 2001, 412, 819; (b) Sundar, V. C.; Yablon, A. D.; Grazul, J. L.; Ilan, M.; Aizenberg, J. Nature 2003, 424, 899.

9. (a) Shapiro, J. A. Ann. Rev. Microbiol. 1998, 52, 81; (b) Shimoyama, N.; Sugawara, K.; Mizuguchi, T.; Hayakawa, Y.; Sano, M. Phy. Rev. Lett. 1996, 76, 3870; (c) Bonabeau, E.; Dorigo, M.; Theraulaz, G. Nature 2000, 406, 39.

10. Philp, D.; Stoddart, J. F. Angew. Chem. Int. Ed. Engl. 1996, 35, 1154.

11. (a) Schnur, J. Science 1993, 262, 1669; (b) Ghadiri, M. R.; Granja, J. R.; Buehler L. K. Nature 1994, 369, 301; (c) Bong, D. T.; Clark T. D.; Granja, J. R.; Ghadiri, M. R. Angew. Chem. Int. Ed. 2001, 40, 988; (d) Zhang, S.; Holmes, T.; Lockshin, C.; Rich, A. Proc. Natl. Acad. Sci. USA 1993, 90, 3334; (e) Holmes, T.; Delacalle, S.; Su, X.; Rich, A.; Zhang S. Proc. Natl. Acad. Sci. USA 2000, 97, 6728; (f) Aggei, A.; Bell, M.; Boden, N.; Keen, J. N.; Knowles, P. F.; McLeish T. C.; Pitkeathly, M. Nature 1997, 386, 259; (g) Aggeli, A.; Nyrkova, I. A.; Bell, M.; Harding, R.; Carrick, L.; 
McLeish, T.C.B.; Somenov, A. N. Proc. Natl. Acad. Sci USA 2001, 98, 11857; (h) Alivisatos, A. P.; Johnsson, K. P.; Peng, X.; Wilson, T. E.; Loweth, C.J.; Bruchez, Jr. M. P.; Schultz, P.G. Nature 1996, 382, 609; (i) Mirkin, C.A.; Letsinger, R. L. Mucic, R. C.; Storhoff, J. J. Nature 1996, 382, 607; (j) Winfree, E.; Liu, F.; Wenzler, L. A.; Seeman, N. C. Nature 1998, 394, 539.

12. Collier, J. H.; Rudra, J. S.; Gasiorowski, J. Z.; Jung, J. P. Chem. Soc. Rev. 2010, 39, 3413.

13. (a) Gulik-Krzywicki, T.; Fouquey, C.; Lehn, J.-M. Proc. Natl. Acad. Sci. USA. 1993, 90, 163; (b) Kotera, M.; Lehn, J.-M; Vigneron, J. -P. Tetrahedron 1995, 51, 1953; (c) Ikeda, M.; Nobori, T.; Schmutz, M.; Lehn, J.-M. Chem. Eur. J. 2005, 11, 662.

14. (a) Famulok, M.; Hartig, J. S.; Mayer, G. Chem. Rev. 2007, 107, 3715.

15. (a) Liu, J.; Cao, Z.; Lu, Y. Chem. Rev. 2009, 109, 1948; (b) Teller, C.; Shimron, S.; Willner, I. Anal. Chem. 2009, 81, 9114; (c) Shangguan, D.; Cao, Z.; Meng, L.; Mallikaratchy, P.; Sefah, K.; Wang, H.; Li, Y.; Tan, W. J. Proteome Res. 2008, 7, 2133.

16. Shieh, Y-A.; Yang, S-J.; Wei, M-F.; Shieh, M-J. ACS Nano 2010, 4, 1433.

17. Kim, D.; Jeong, Y. Y.; Jon, S. ACS Nano 2010, 4, 3689.

18. Fang, X.; Tan, W. Acc. Chem. Res. 2010, 43, 48.

19. Muller, M.; Kremer, F.; Stadler, R.; Fischer, E. W.; Seidel, U. Colloid Polym. Sci. $1995,273,38$.

20. (a) Bazuin, C. G.; Brodin, C. Macromolecules 2004, 37, 9366; (b) Sallenave, X.; Bazuin, C. G. Macromolecules 2007, 40, 5326. 
21. Hoeben, F. J. M.; Jonkheijm, P.; Meijer, E. W.; Schenning, A. P. H. J. Chem. Rev. 2005, 105, 1491.

22. Liu, H.; Xu, J.; Li, Y.; Li, Y.Acc. Chem. Res. 2010, 43, 1496.

23. Zang, L.; Che, Y.; Moore, J. S. Acc. Chem. Res. 2008, 41, 1596.

24. (a) Yasuda, T.; Ooi, H.; Morita, J.; Akama, Y.; Minoura, K.; Funahashi, M.; Shimomura, T.; Kato, T. Adv. Funct. Mater. 2009, 19, 411; (b) Han, D.; Tong, X.; Zhao, Y.; Zhao, Y. Angew. Chem. Int. Ed. 2010, 49, 9162; (c) Maeda, H.; Terashima, Y.; Haketa, Y.; Asano, A.; Honsho, Y.; Seki, S.; Shimizu, M.; Mukai, H.; Ohta, K. Chem. Commun. 2010, 46, 4559; (d) Yazaki, S.; Funahashi, M.; Kato, T. J. Am. Chem. Soc. 2008, 130, 13206.

25. Yazaki, S.; Funahashi, M.; Kagimoto, J.; Ohno, H.; Kato, T. J. Am. Chem. Soc. $2010,132,7702$.

26. Ashton, P. R. Angew. Int. Ed. Engl. 1997, 36, 735.

27. (a) Gong, C.; Gibson, H. Macromolecules 1996, 29, 7029; (b) Wenz, G. Angew. Chem. Int. Ed. Engl. 1994, 33, 803.

28. Sigler, P. B.; Xu, Z.; Rye, H. S.; Burnston, S. G.; Fenton, W. A.; Horwich, A. L.; Annu. Rev. Biochem. 1998, 67, 581.

29. Mohan, P.; Rapoport, N. Mol. Pharmaceutics 2010, 7, 1959.

30. Kataoka, K.; Harada, A.; Nagasaki, Y. Adv. Drug Deliv. Rev. 2001, 47, 113.

31. Kabanov, A. V.; Batrakova, E. V.; Alakhov, V. Y. Adv. Drug. Del. Rev. 2002, 54, 759.

32. Kown, J. S.; Okano, T. Drug Devil. Pharm. Res. 1999, 16, 597. 
33. Dreher, M. R.; Simnick, A. J.; Fischer, K.; Smith, R. J.; Patel, A.; Schmidt, M.; Chilkoti, A. J. Am. Chem. Soc. 2008, 130, 687.

34. Musacchio, T.; Toniutti, M.; Kautz, R.; Torchilin, V. P. Mol. Pharmaceutics 2009, 6, 1876.

35. Atwell, G. J.; Fan, J.-Y.; Tan, K.; Denny, W. A. J. Med. Chem. 1998, 41, 4744.

36. Martinek, T. W.; Klass, D. L. U. S. Patent 3,335,139, 1967.

37. Chueca, A.; Baron, M.; Lopez, G. J. Photosynthesis Proceedings International Congress, 5th; Akoyunoglou, G., Ed.; Balaban Int. Sci. Serv.: Philadelphia, Pennsylvania; 1981; p 555; Chem Abstr. 1981, 97, 50917.

38. Papot, S.; Bachmann, C.; Combaud, D.; Gesson, J-P. Tetrahedron, 1999, 55, 4699.

39. Xu, S.; Chen, M.; Yao, Y.; Zhang, Z.; Jin, T.; Huang, Y.; Zhu, H. J. Controlled Release 2008, 130, 64.

40. Anderson, W. K.; Mach, R. H. J. Med. Chem. 1987, 30, 2109.

41. Chambers, J.; Reese, C. B. Br. Polym. J. 1977, 9, 41.

42. Matzger, A. J.; Kim, K. Polym. Mater. Sci. Eng. 2003, 89, 825.

43. Wong, S.; Frisch, C. Ploym. Mater, Sci. Eng. 1984, 50, 480.

44. Liptova, T. E.; Bakalo, L. A.; Kzirkova, L. J. Sint. Fiz. -Khim. Polim. 1978, 23, 74.

45. Kordomenos, P. I.; Kusta, I. E.; Frisch, K. C.; Reegen, S. L. Polym. Sci. Polym. Chem. Ed. 1973, 11, 1683.

46. De Aquirre, I.; Collot, J. Bull. Soc. Chim. Belg. 1989, 98, 19.

47. Steichele, K. Belg. Patent 882, 922 (1980). Chem. Abstr. 94, 66768d. 
48. (a) Saka, K.; Noda, K. Jpn. Kokai Tokkyo Koho JP 62179 584, 1987; Chem. Abstr. 1987, 108, 39820r; (b) Tanaka, K.; Kano, Y.; Yoshida, K. Jpn. Kokai Tokkyo Koho JP 63248 894, 1988; Chem. Abstr. 1988, 110, 79137w; (c) Kinoshita, H.; Sekiya, M.; Mishima, M. Eur. Pat. EP 274 756, 1988; Chem. Abstr. 1988, 109, 233979k.

49. Rohr, W.; Franke, A.; Giertz, H.; Amann, A. Brit Patent 1,396,523, 1975.

50. D’Silva, T. D. J. U.S. Patent 4,400,389, 1983.

51. (a) Jpn. Kokai Tokyo Koho JP 58201 758, 1983; Chem Abstr. 1983, 100, 174289z; (b) Tanaka, T.; Yoshitomi, T.; Hanada Y.; Ohashi, M.; Takeda, Y. Jpn. Kokai Tokkyo Koho JP 62090 289, 1987; Chem Abstr. 1987, 107, 208963; (c) Goodbrand, B.; Boils, D.; Sundararajan, P. R.; Wong, R.; Malhotra, S. U.S. Patent 6,187,082, 2001.

52. Furer, V. L. J. Mol. Struct. 1992, 56, 43.

53. (a) Furer, V. L. J. Mol. Struct. 1998, 449, 53; (b) Furer, V. L. J. Mol. Struct. 1999, 513, 1; (c) Furer, V. L. J. Mol. Struct. 2000, 520, 117.

54. Deetz, M. J.; Jonas, M.; Malerich, J. P.; Smith, B. D. Supramoleculer Chemistry. $2002,14,487$.

55. Krol, P. Wietrzynska-Lalak, Z. Eur. Polym. J. 1995, 31, 689.

56. (a) Moniruzzaman, M.; Goodbrand, B.; Sundararajan, P. R. J. Phys. Chem. B 2003, 107, 8416; (b) Khanna, S.; Moniruzzaman, M.; Sundararajan P. R. J. Phys. Chem. $B$ 2006, 110,15251 .

57. (a) Moniruzzaman, M.; Sundararajan, P. R. Langmuir 2005, 21, 3802; (b) Khanna, S.; Khan, M. K.; Sundararajan, P. Langmuir 2009, 25, 13183.

58. Stein, R. S.; Rhodes, M. B. J. Appl. Phys. 1960, 31, 1873. 
59. Saville, B. P. in Applied Polymer Light Microscopy; Hemsley, D. A., Ed.; Elsevier Science Publisher Ltd.: New York, 1989; Chap. 4. 
Chapter 2

Materials and Methods 


\subsection{Introduction}

This chapter lists and describes the synthesis, purification and characterization procedures of the materials used in this study. The chemical structures, physical properties and general sample preparation procedures of the materials are also discussed briefly. Any special sample preparation and characterization procedure is described separately in the appropriate section of this thesis. The basic principles of the various techniques used for the characterizations of the samples are also described briefly in the following sections of this chapter.

The materials used for this present study were:

(i) Two homologous series of long-chain biscarbamates with alkyl side chains and spacer groups of different lengths.

(ii) Perylene

(iii) Phthalocyanine

(iv) Poly( $\epsilon$-caprolactone) (PCL)

(v) Blends of different biscarbamates

\subsection{Synthesis and Characterization of the Biscarbamates}

Synthesis of the biscarbamates was performed as described by Goodbrand et al. ${ }^{1}$ by reacting 1,6-diisocyanato hexane or 1,12-diisocyanato dodecane $(0.1 \mathrm{~mol})$ with appropriate alcohols $(0.2 \mathrm{~mol})$ separately in presence of a catalyst 1,4 -Diazabicyclo $[2,2,2]$ octane $(\mathrm{DABCO})$ as shown in scheme 2.1 . The reaction was carried out in toluene $(200 \mathrm{ml})$, at $85-90{ }^{\circ} \mathrm{C}$ for $6 \mathrm{~h}$ except for 1 -octadecanol $(8-9 \mathrm{~h})$. All the reagents were purchased from Sigma-Aldrich Inc., USA and were used as received. 


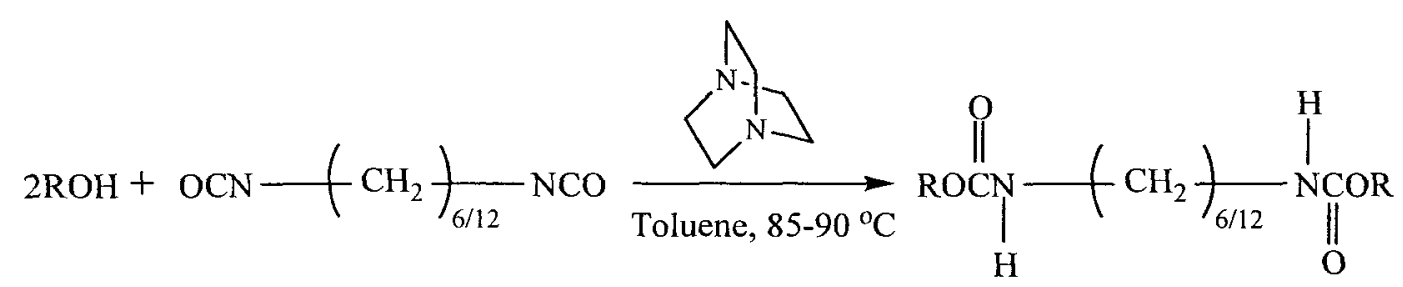

Scheme 2.1. Scheme for synthesis of the biscarbamates from respective diisocyanates and alcohols.

Products of the reactions were isolated by suction filtration. These products were purified by recrystallizing them from a solution in toluene at $60^{\circ} \mathrm{C}$. This procedure was repeated twice in order to remove any impurity or unreacted reagent (1,6-diisocyanato hexane or 1,12-diisocyanato dodecane and respective alcohols). Infrared and ${ }^{1} \mathrm{H}$ NMR spectroscopy were used to confirm the reaction products and their purity.

The names of the synthesized compounds are listed in Tables 2.1 and 2.2, and for convenience each of them has been designated as $\mathrm{C}_{x} \mathrm{C}_{6}$ and $\mathrm{C}_{x} \mathrm{C}_{12}$ where $x$ denotes the number of carbon atoms, derived from the respective alcohols, in the alkyl side chains and the numbers 6 and 12 denote the number of carbon atoms in the spacer group. These sample IDs $\left(\mathrm{C}_{x} \mathrm{C}_{6}\right.$ and $\left.\mathrm{C}_{x} \mathrm{C}_{12}\right)$ will be used to designate these compounds throughout this thesis. 
Table 2.1. Biscarbamates $\left(\mathrm{C}_{x} \mathrm{C}_{6}\right)$ synthesized from reaction of an appropriate alcohol with 1,6- diisocyanato hexane.

\begin{tabular}{llll}
\hline & & $\mathrm{C}_{x} \mathrm{C}_{6}$ Biscarbamate & \\
\hline $\mathrm{ID}$ & parent alcohol & \multicolumn{1}{c}{ molecular formula } & $T_{\mathrm{m}},{ }^{\circ} \mathrm{C}$ \\
\hline $\mathrm{C}_{3} \mathrm{C}_{6}$ & 1-propanol & $\mathrm{H}_{7} \mathrm{C}_{3} \mathrm{OOCHN}\left(\mathrm{CH}_{2}\right)_{6} \mathrm{NHCOOC}_{3} \mathrm{C}_{7}$ & 101.9 \\
$\mathrm{C}_{4} \mathrm{C}_{6}$ & 1-butanol & $\mathrm{H}_{9} \mathrm{C}_{4} \mathrm{OOCHN}\left(\mathrm{CH}_{2}\right)_{6} \mathrm{NHCOOC}_{4} \mathrm{C}_{9}$ & 91.3 \\
$\mathrm{C}_{6} \mathrm{C}_{6}$ & 1-hexanol & $\mathrm{H}_{13} \mathrm{C}_{6} \mathrm{OOCHN}\left(\mathrm{CH}_{2}\right)_{6} \mathrm{NHCOOC}_{6} \mathrm{C}_{13}$ & 97.1 \\
$\mathrm{C}_{7} \mathrm{C}_{6}$ & 1-heptanol & $\mathrm{H}_{15} \mathrm{C}_{7} \mathrm{OOCHN}\left(\mathrm{CH}_{2}\right)_{6} \mathrm{NHCOOC}_{7} \mathrm{C}_{15}$ & 108.9 \\
$\mathrm{C}_{8} \mathrm{C}_{6}$ & 1-octanol & $\mathrm{H}_{17} \mathrm{C}_{8} \mathrm{OOCHN}\left(\mathrm{CH}_{2}\right)_{6} \mathrm{NHCOOC}_{8} \mathrm{C}_{17}$ & 106.6 \\
$\mathrm{C}_{9} \mathrm{C}_{6}$ & 1-nonanol & $\mathrm{H}_{19} \mathrm{C}_{9} \mathrm{OOCHN}\left(\mathrm{CH}_{2}\right)_{6} \mathrm{NHCOOC}_{9} \mathrm{C}_{19}$ & 113.5 \\
$\mathrm{C}_{11} \mathrm{C}_{6}$ & 1-undecanol & $\mathrm{H}_{23} \mathrm{C}_{11} \mathrm{OOCHN}\left(\mathrm{CH}_{2}\right)_{6} \mathrm{NHCOOC}_{11} \mathrm{C}_{23}$ & 117.9 \\
$\mathrm{C}_{12} \mathrm{C}_{6}$ & 1-dodecanol & $\mathrm{H}_{25} \mathrm{C}_{12} \mathrm{OOCHN}\left(\mathrm{CH}_{2}\right)_{6} \mathrm{NHCOOC}_{12} \mathrm{C}_{25}$ & 114.9 \\
$\mathrm{C}_{13} \mathrm{C}_{6}$ & 1-tridecanol & $\mathrm{H}_{27} \mathrm{C}_{13} \mathrm{OOCHN}\left(\mathrm{CH}_{2}\right)_{6} \mathrm{NHCOOC}_{13} \mathrm{C}_{27}$ & 121.5 \\
$\mathrm{C}_{15} \mathrm{C}_{6}$ & 1-pentadecanol & $\mathrm{H}_{31} \mathrm{C}_{15} \mathrm{OOCHN}\left(\mathrm{CH}_{2}\right)_{6} \mathrm{NHCOOC}_{15} \mathrm{C}_{31}$ & 123.2 \\
$\mathrm{C}_{16} \mathrm{C}_{6}$ & 1-hexadecanol & $\mathrm{H}_{33} \mathrm{C}_{16} \mathrm{OOCHN}\left(\mathrm{CH}_{2}\right)_{6} \mathrm{NHCOOC}_{16} \mathrm{C}_{33}$ & 117.8 \\
$\mathrm{C}_{18} \mathrm{C}_{6}$ & 1-octadecanol & $\mathrm{H}_{37} \mathrm{C}_{18} \mathrm{OOCHN}\left(\mathrm{CH}_{2}\right)_{6} \mathrm{NHCOOC}_{18} \mathrm{C}_{37}$ & 120.4 \\
\hline
\end{tabular}


Table 2.2. Biscarbamates $\left(\mathrm{C}_{x} \mathrm{C}_{12}\right)$ synthesized from reaction of an appropriate alcohol with 1,12- diisocyanato dodecane.

$\mathrm{C}_{x} \mathrm{C}_{12}$ Biscarbamate

\begin{tabular}{lllr}
\hline ID & parent alcohol & molecular formula & $T_{\mathrm{m}},{ }^{\circ} \mathrm{C}$ \\
\hline $\mathrm{C}_{4} \mathrm{C}_{12}$ & 1-butanol & $\mathrm{H}_{9} \mathrm{C}_{4} \mathrm{OOCHN}\left(\mathrm{CH}_{2}\right)_{12} \mathrm{NHCOOC}_{4} \mathrm{C}$ & 101.3 \\
$\mathrm{PhC}_{6} \mathrm{C}_{12}$ & 6-phenyl-1-hexanol & $\mathrm{PhH}_{12} \mathrm{C}_{6} \mathrm{OOCHN}\left(\mathrm{CH}_{2}\right)_{12} \mathrm{NHCOOC}_{6} \mathrm{C}_{12} \mathrm{Ph}$ & 91.14 \\
$\mathrm{C}_{8} \mathrm{C}_{12}$ & 1-octanol & $\mathrm{H}_{17} \mathrm{C}_{8} \mathrm{OOCHN}\left(\mathrm{CH}_{2}\right)_{12} \mathrm{NHCOOC}_{8} \mathrm{C}_{17}$ & 108.1 \\
$\mathrm{C}_{12} \mathrm{C}_{12}$ & 1-dodecanol & $\mathrm{H}_{25} \mathrm{C}_{12} \mathrm{OOCHN}\left(\mathrm{CH}_{2}\right)_{12} \mathrm{NHCOOC}_{12} \mathrm{C}_{25}$ & 113.4 \\
$\mathrm{C}_{18} \mathrm{C}_{12}$ & 1-octadecanol & $\mathrm{H}_{37} \mathrm{C}_{18} \mathrm{OOCHN}\left(\mathrm{CH}_{2}\right)_{12} \mathrm{NHCOOC}_{18} \mathrm{C}_{37}$ & 117.6 \\
\hline
\end{tabular}

\subsubsection{FTIR Spectra of the Biscarbamates}

The samples were prepared for IR spectroscopy by mixing $5 \mathrm{mg}$ of the biscarbamates with dried $\mathrm{KBr}$ and were ground into fine power. The samples were coalesced into a transparent or semitransparent disk applying high pressure (ca.1470.00 $\mathrm{MPa}$ ) by means of a hydraulic press. The prepared sample was mounted in the cell, which was aligned with the infrared beam of the spectrometer. For comparison, FTIR spectra of the same set of samples were taken under ambient conditions with the same spectrophotometer in attenuated total reflectance (ATR) mode. We did not see any difference between the normal transmission mode and ATR mode. The FTIR spectra of all the biscarbamates showed a strong carbonyl stretching vibration (amide I band) at $\sim 1682 \mathrm{~cm}^{-1}$. The band due to $\mathrm{C}=\mathrm{O}$ out-of-plane vibrations was observed at $782 \mathrm{~cm}^{-1}$, which is a characteristic band as it is used as an internal standard in the IR spectra of polyurethanes. ${ }^{2}$ The amide II band, which is due to N-H bending, appears at $1537-1539$ 
$\mathrm{cm}^{-1}$ whereas $\mathrm{N}-\mathrm{H}$ stretching frequencies ${ }^{3}$ are recorded at $3317-3336 \mathrm{~cm}^{-1}$. Figure 2.1 represents the FTIR spectra of the $\mathrm{C}_{12} \mathrm{C}_{6}$ sample and the stretching frequencies of some of the bands observed in its spectrum are listed in Table 2.3.

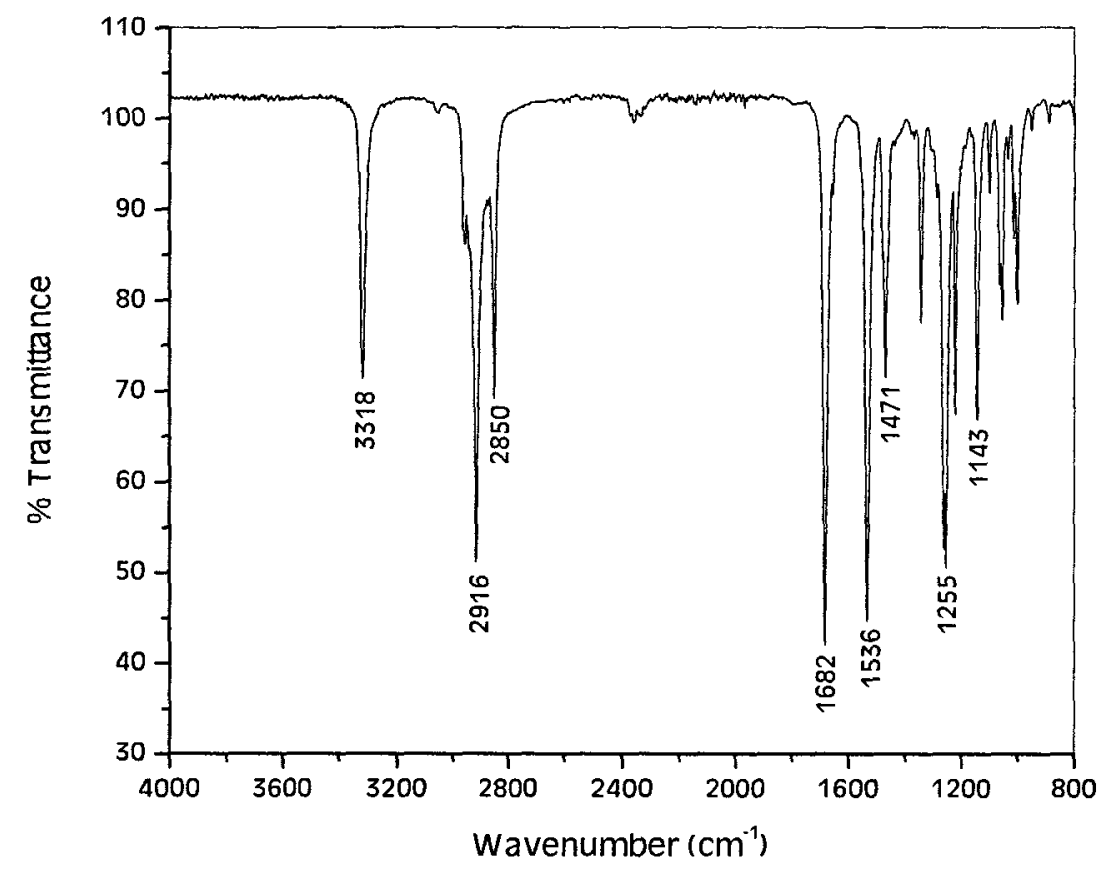

Figure 2.1. FTIR spectrum of the $\mathrm{C}_{12} \mathrm{C}_{6}$ biscarbamate.

Table 2.3 Stretching frequencies of the IR bands of the representative $\mathrm{C}_{12} \mathrm{C}_{6}$ biscarbamate.

\begin{tabular}{cl}
\hline Frequency $\left(\mathbf{c m}^{-1}\right)$ & Band Assignment \\
\hline 3318 & $\mathrm{~N}-\mathrm{H}$ stretching \\
2959 & $\mathrm{CH}_{3}$ asymmetrical stretching \\
2916 & $\mathrm{CH}_{2}$ asymmetrical stretching \\
2850 & $\mathrm{CH}_{2}$ symmetrical stretching \\
1682 & $\mathrm{C}=\mathrm{O}$ stretching vibrations \\
1536 & $\mathrm{CHN}$ gp vibration \\
1471 & $\mathrm{CH}_{3}$ bending \\
1255 & $\mathrm{C}-\mathrm{O}$ stretching \\
1143 & $\mathrm{C}-\mathrm{N}$ stretching \\
781 & $\mathrm{C}=\mathrm{O}$ out-of-plane vibration \\
718 & $\left(\mathrm{CH}_{2}\right)_{\mathrm{n}}$-in -phase rocking ${ }^{4}$ \\
\hline
\end{tabular}




\subsubsection{The ${ }^{1} \mathrm{H}$ NMR Spectra of the Biscarbamates}

The ${ }^{1} \mathrm{H}$ NMR spectra were taken in deuterated chloroform using a $300 \mathrm{MHz}$ spectrometer (Bruker). Tetramethylsilane, $\left(\mathrm{CH}_{3}\right)_{4} \mathrm{Si}$ was used for internal calibration. Figure 2.2 represents the ${ }^{1} \mathrm{H}$ NMR spectra of $\mathrm{C}_{12} \mathrm{C}_{12}$. In the ${ }^{1} \mathrm{H}$ NMR spectrum, the $\mathrm{CH}_{3}$ protons show a triplet around $\delta 0.90 \mathrm{ppm} . \mathrm{N}-\mathrm{CH}_{2}$ absorption at around $\delta 3.18 \mathrm{ppm}$ splits into a quartet by coupling with the $\mathrm{N}-\mathrm{H}$ and neighboring $\mathrm{CH}_{2}$ proton. The $\mathrm{N}-\mathrm{H}$ proton shows a broad signal around $\delta 4.63 \mathrm{ppm}$. The signal is affected by the magnetic and electric properties of ${ }^{14} \mathrm{~N}$ nucleus in such way as to make it appear as a broad signal. ${ }^{5}$ The $-\mathrm{O}-\mathrm{CH}_{2}$ protons show a triplet around $\delta 4.05 \mathrm{ppm}$. The $\mathrm{CH}_{2}-\mathrm{C}-\mathrm{O}$ - protons show a triplet at $\delta 1.6 \mathrm{ppm}$ and the $\mathrm{CH}_{2}-\mathrm{C}-\mathrm{N}$ - protons show another triplet at $\delta 1.5 \mathrm{ppm}$. The remaining $\mathrm{CH}_{2}$ protons show a multiplet around $\delta 1.27 \mathrm{ppm}$.

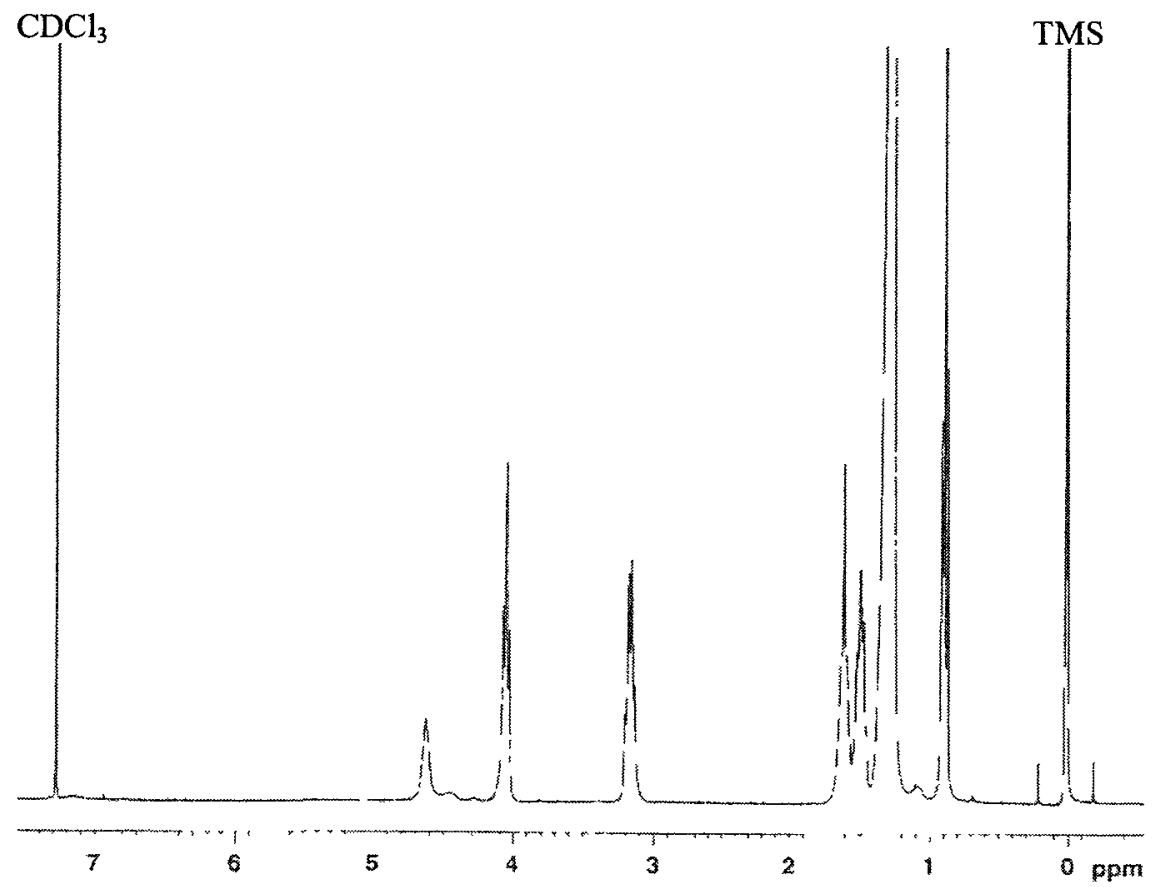

Figure 2.2. ${ }^{1} \mathrm{H}$ NMR spectra of $\mathrm{C}_{12} \mathrm{C}_{12}$ biscarbamate. 


\subsection{Perylene}

Perylene belongs to a class of polycyclic aromatic hydrocarbon dyes that have been widely utilized in many applications e.g., optoelectronics, waveguides, semiconductor devices, and organic light emitting diodes (OLEDS). ${ }^{6}$ Perylene has also been used as optical $\mathrm{NO}_{2}$ gas sensor and as the probe molecule because of its high fluorescence quantum yield. Its fluorescence intensity decay kinetics are single exponential, and its excited state fluorescence lifetime is not particularly solvent and/or temperature dependent. ${ }^{7}$ The chemical structure of perylene is shown in figure 2.3. Perylene used in this study was purchased from Sigma-Aldrich Inc. and was used as received.

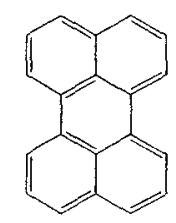

Figure 2.3. Chemical structure of perylene.

\subsection{Phthalocyanine}

Phthalocyanines $(\mathrm{Pc})$ are macrocyclic dye molecules belonging to a class of organic molecules called porphyrinoids. Pcs have a two-dimensional 18- $\pi$-electron aromatic system isoelectronic with that of porphyrins and possess unique physicochemical properties which make these macrocycles valuable building blocks in materials science. Pcs are thermally and chemically stable compounds which present an intense absorption in the red/near-infrared (NIR) region of the solar spectrum with very high extinction coefficients and fluorescence quantum yields. Facile tuning of band gaps and redox potentials of Pcs can be achieved by metal insertion into the core and /or modification at the peripheral positions. ${ }^{8}$ The phthalocyanine used in this present study is $1,4,8,11,15$, 
$18,22,25$-octabutoxy- $29 H, 31 H$-phthalocyanine which has a chemical structure as shown in the figure 2.4. Phthalocyanine was purchased from Sigma-Aldrich Inc. and was used without any further purification.

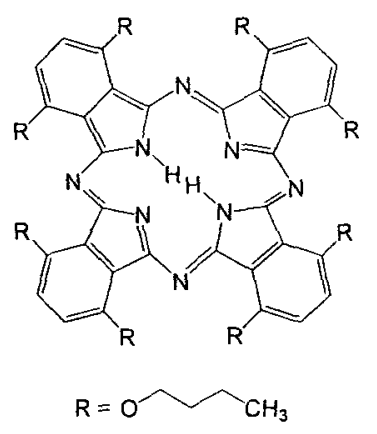

Figure 2.4. Chemical structure of $1,4,8,11,15,18,22,25$-octabutoxy-29H,31Hphthalocyanine.

\subsection{Poly(€-caprolactone) (PCL)}

Polycaprolactone is a linear, semicrystalline, synthetic aliphatic polyester (figure 2.5) and has been of immense research interest in tissue engineering ${ }^{9}$ and drug delivery systems ${ }^{10}$ owing to their excellent biocompatibility and biodegradability. PCL is one of the biomaterials used in bone repair and is regarded as a soft and hard tissue compatible material. Because of their suitable thermo-mechanical properties, PCL gives rise to polymeric composites in the form of fibers, films, or membranes with biomedical properties. Beside their applications in biomedicine, PCL and/or its composites have been explored for other applications, e.g., as biodegradable shape memory devices, micropatterning biomacromolecules on polymer surfaces, "active packaging" materials with antimicrobial properties, and stress sensing. 


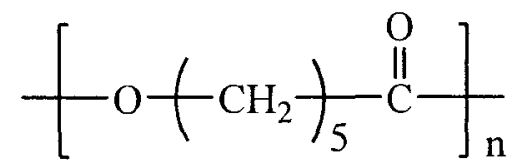

Figure 2.5. Chemical structure of polycaprolactone.

PCL used in this study was purchased from Sigma-Aldrich Inc., USA and were used as received without any further purification. The weight average molecular mass of this polymer sample was $65,000 \mathrm{~g} \mathrm{~mol}^{-1}$. The melting temperature of the PCL was recorded as $60{ }^{\circ} \mathrm{C}$ by differential scanning calorimetry. Figure 2.6 shows the DSC thermogram of PCL recorded at a heating rate of $10^{\circ} \mathrm{C} / \mathrm{min}$.

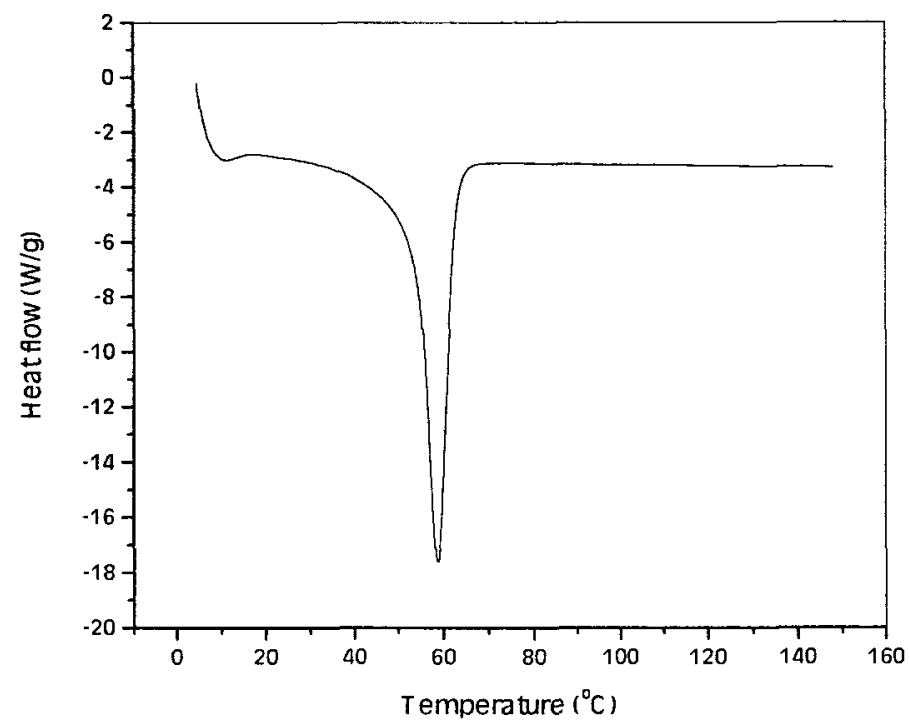

Figure 2.6. DSC thermogram of polycaprolactone.

\subsection{Preparation of the Binary Blends}

Binary blends of biscarbamates were prepared by melt mixing. Since the melt viscosity of these samples is very low, mixing via this procedure was found to be convenient. Pre-weighed mixtures of biscarbamates (total $0.5 \mathrm{~g}$ ) corresponding to the 
percent composition of the blend components were heated in a $5-\mathrm{mL}$ vial at a temperature of $20^{\circ} \mathrm{C}$ above that of the higher melting component with continuous stirring. After $1 \mathrm{~h}$, the melt was slowly cooled to room temperature. Another set of samples was prepared following the same procedure but quenching the sample from the melt.

\subsection{Methods of Characterization}

Thermal behaviour of the biscarbamates, their blends and organogels was investigated by differential scanning calorimetry (DSC). Optical microscopy (OM), Scanning Electron Microscopy (SEM), and powder X-ray Diffraction (XRD) were used to investigate the morphology of the samples. The following subsections briefly describe the basic principles of the methods and the instruments used for this study.

\subsubsection{Differential Scanning Calorimetry (DSC)}

Differential scanning calorimetry is used as a common technique for quantitative studies of thermal transitions in polymers, metals, organic materials, ceramics and composites. In DSC, the sample and an inert reference are heated, usually in an inert (e.g., nitrogen) atmosphere and thermal transitions in the sample are detected, traced and measured. Figure 2.7 represents a schematic of the DSC cell. The sample and the reference in figure 2.7 are provided with individual heaters and energy is supplied to keep the sample and reference temperatures constant. The electrical power difference between sample and reference $(\mathrm{d} \Delta \mathrm{Q} / \mathrm{dt})$ is recorded as a function of temperature. This heat flow/temperature data thus obtained provides valuable information of physical/chemical properties of the materials. For example, the crystalline melting temperature $\left(T_{\mathrm{m}}\right)$, the crystallization temperature $\left(T_{\mathrm{c}}\right)$ and the heat of fusion $\left(H_{\mathrm{f}}\right)$ of a crystalline or 
semicrystalline substance can be obtained from DSC. It is possible to determine the glass transition temperature $\left(T_{\mathrm{g}}\right)$ and the specific heat capacity $\left(C_{\mathrm{p}}\right)$ of a polymer from DSC analysis. DSC is also used in detecting polymorphic transitions of materials. ${ }^{\text {" }}$

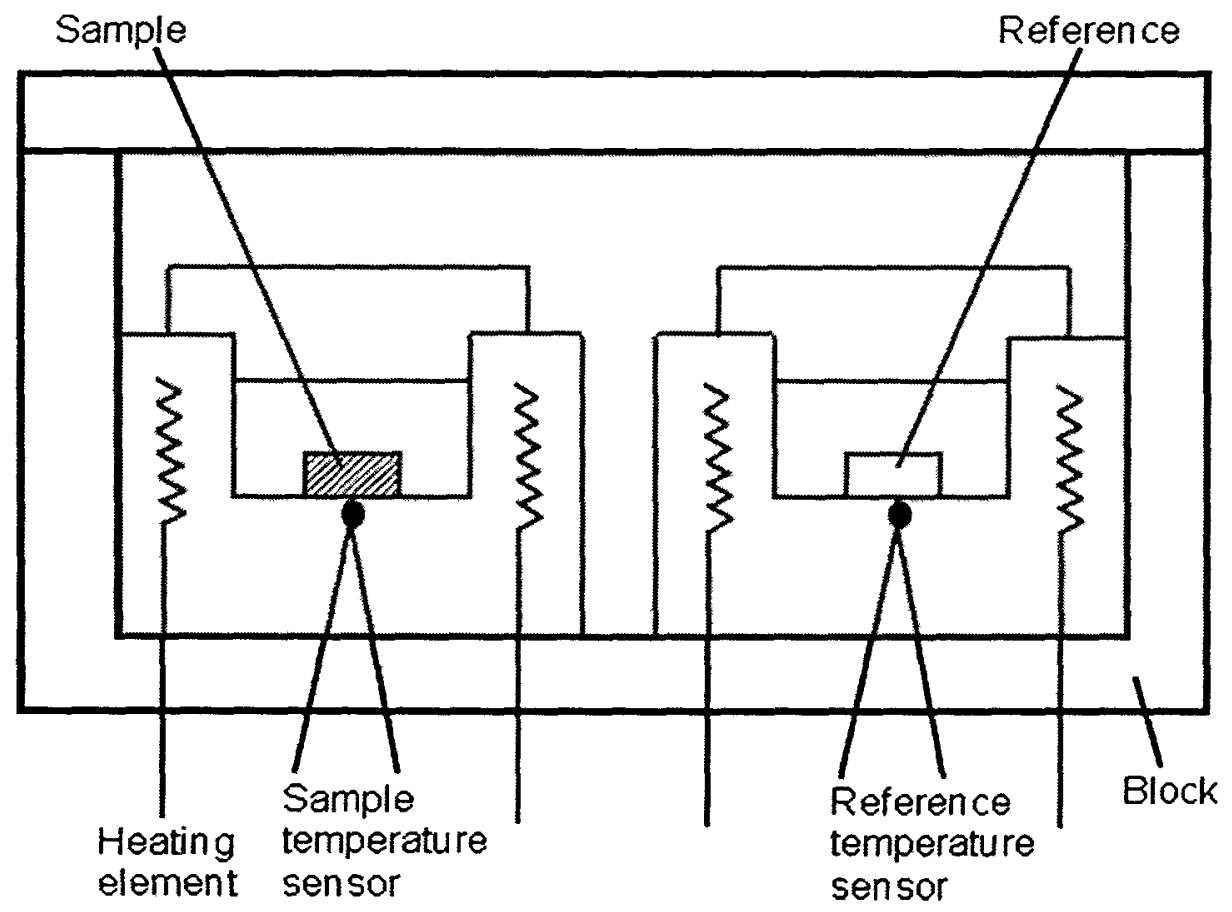

Figure 2.7. Schematic representation of a DSC cell.

In this study, thermal analysis was performed using a TA Instruments 2010 differential scanning calorimeter at a heating rate of $10{ }^{\circ} \mathrm{C} / \mathrm{min}$. A few select samples were heated at a heating rate of $1{ }^{\circ} \mathrm{C} / \mathrm{min}$. The instrument was calibrated for temperature and energy with indium and tin as certified reference materials. DSC traces were recorded with about $7-10 \mathrm{mg}$ of the biscarbamte and their blend samples, in a nitrogen atmosphere. Traces for organogel samples were recorded with about $10-15 \mathrm{mg}$ of the samples under the flow of nitrogen. The uncertainty in the measurements was $\pm 1{ }^{\circ} \mathrm{C}$ for the melting and crystallization points and $\pm 2 \mathrm{~J} / \mathrm{g}$ for the heat of fusion and crystallization. 
Isothermal crystallization kinetics was studied using the same calorimeter and the following procedure. The biscarbamate samples were heated to a temperature about $40{ }^{\circ} \mathrm{C}$ above their melting points and then allowed to cool down to a temperature $5{ }^{\circ} \mathrm{C}$ above their crystallization temperatures. The melt of the samples were then cooled to their crystallization temperature at a rate of $1{ }^{\circ} \mathrm{C} / \mathrm{min}$ and allowed to stay at isothermal condition for $30 \mathrm{~min}$. The heat of crystallization was measured at $0.6 \mathrm{~s}$ intervals and the crystallinity was determined by integrating the isothermal heat flow curve with respect to time. The fractional degree of crystallization $(\alpha)$ was calculated by the ratio of the heat of crystallization at time to the total heat of crystallization using the following equation.

$$
\alpha=\frac{\Delta H_{t}}{\Delta H_{\infty}}=\frac{\int_{0}^{t} \frac{d Q}{d t} d t}{\int_{0}^{\infty} \frac{d Q}{d t} d t}
$$

where, $\Delta H_{t}$ is the partial area between the DSC curve and the time axis at time $t$ and $\Delta H_{\infty}$ is the total area under the peak that corresponds to the total heat of crystallization.

\subsubsection{Optical Microscopy}

Optical microscopy in its simplest form is a convenient and relatively inexpensive technique to study the surface and bulk morphology of a substance. But modern microscopy is far more than merely a technique by which the details of an object which are not visible to the naked eye are rendered visible and clear with respect to magnification and resolution. It can resolve surface characteristics of the order of 2000 $\AA^{12}$ This technique is now employed not only to see more clearly the fixed and unchanging features of an object but also to probe into it to observe the behavior or other 
changes that can occur in a variety of applied conditions and circumstances. An advanced instrument thus can be equipped with a range of accessories and features - such as for various systems of illumination or technique including heating-stage, phase-contrast, interferometry, photomicrography, fluorescence, ultra-violet light, and polarizations. For example, optical microscopy now helps to determine the sing of birefringence of the spherulites when the spherulities are examined with a $\lambda$ plate. This plate adds to or subtracts from the path difference of the spherulite, depending on whether the birefringent units in the spherulite are oriented parallel to the plate or perpendicular to it. This means that one pair of quadrants of a spherulite will be raised up the scale of colors and the other will be lowered. Therefore, with spherulites showing only first order white, which is normal in a thin section, one fair will be raised to blue and the other lowered to orange. ${ }^{13}$ The housing of the $\lambda$ plate has an arrow showing the polarization direction. If the quadrants of the spherulites parallel to the arrow appears orange and the other quadrants appear blue, the spherulites are called negative spherulites and vice versa are called positive spherulites. Depending on the thickness of the sample, the colors may vary. Figure 2.8 shows the appearance of the positive and negative spherulite under optical microscope.
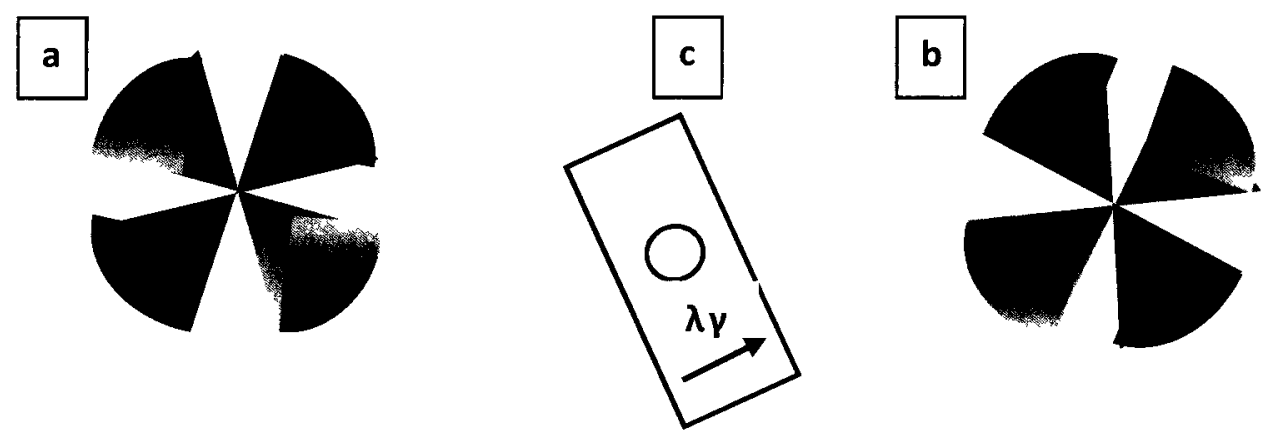

Figure 2.8. Schematic presentation of a (a) positive spherulite, (b) negative spherulite, and $(c)$ tint $(\lambda)$ plate. 
In our study, optical microscopy was used extensively to investigate into the morphology of the neat biscarbamates, their blends and organogels. In this study, the optical micrographs were recorded using a Zeiss Axioplan polarized optical microscope $(\mathrm{OM})$, equipped with a Linkam hot stage for variable temperature optical microscopy. All the optical micrographs were taken in transmission mode. Northern Eclipse (version 6.0 and 8.0) image processing software was used to record the images as well as to calculate (where it was possible) the size of the features, e.g., spherulites, pores, fibers etc. The samples for the optical microscopy of the neat biscarbamates and their blends were prepared by melting a small amount of the material on the microscope slide at a temperature $20^{\circ} \mathrm{C}$ higher than its melting point (in case of blend, $20{ }^{\circ} \mathrm{C}$ higher than the melting temperature of the higher melting component), holding it isothermally for $10 \mathrm{~min}$ to remove any morphological history and then cooling it down slowly to room temperature at the rate of $10^{\circ} \mathrm{C} / \mathrm{min}$. Another set of samples was prepared following the same procedure, but this time the samples were quenched from the melt, instead of slow cooling.

\subsubsection{Scanning Electron Microscopy (SEM)}

The need to observe, analyze, and correctly explain phenomena occurring on a micrometer or submicrometer scale is the driving force behind the development of sophisticated microscopic techniques in this era of rapidly expanding nanotechnology. The Scanning Election Microscopy is such a technique which permits the observation and characterization of heterogeneous organic and inorganic materials and surfaces on such a local scale. In SEM, the area of the sample to be examined is irradiated with a finely 
focused electron beam which is swept in a raster across the surface of the specimen. Upon irradiation, various types of signals are produced which includes secondary electrons, backscattered electrons, Auger electrons, characteristic x-rays and photons of various energies. ${ }^{14}$ In SEM, the secondary and backscattered electrons are the signals of greatest interest because of their variance as a result of differences in surface topography as the electron beam scans across the specimen surface. These scattered electrons are used to produce a signal that modulates the intensity of the electron beam in a cathoderay tube, scanning in synchronization with the microscope beam. The resulting images have great depth of fields ${ }^{11,15}$ and a remarkable three-dimensional appearance ${ }^{11}$ due to the confinement of the secondary electrons to a volume near the beam impact area of the sample and the shadow relief effect of the secondary electron contrast. SEM provides useful information on surface topology with a resolution of about $100 \AA \AA^{11,12}$ Figure 2.9 represents the schematic of a Scanning Electron Microscope.

In this study, SEM images were obtained using a JEOL JSM-6400 scanning electron microscope. Samples were prepared for SEM by mounting on carbon tape and sputter coating with $80: 20 \mathrm{Au} / \mathrm{Pd}$ alloy. The accelerating voltage of SEM was $15 \mathrm{kV}$. Scanning electron microscopy (SEM) images of some samples were obtained using a VEGAII XMU (TESCAN, Czech Republic) scanning electron microscope. Dried samples were sputter coated with 80:20 Au/Pd target using a Hummer VIII Sputtering System (Anatech Ltd., Alexandria, VA) before recording the images. SEM images were captured at an accelerating voltage ranging from 5 to $20 \mathrm{kV}$. Vega TC software were used for both the microscope manipulation and capturing the images. 


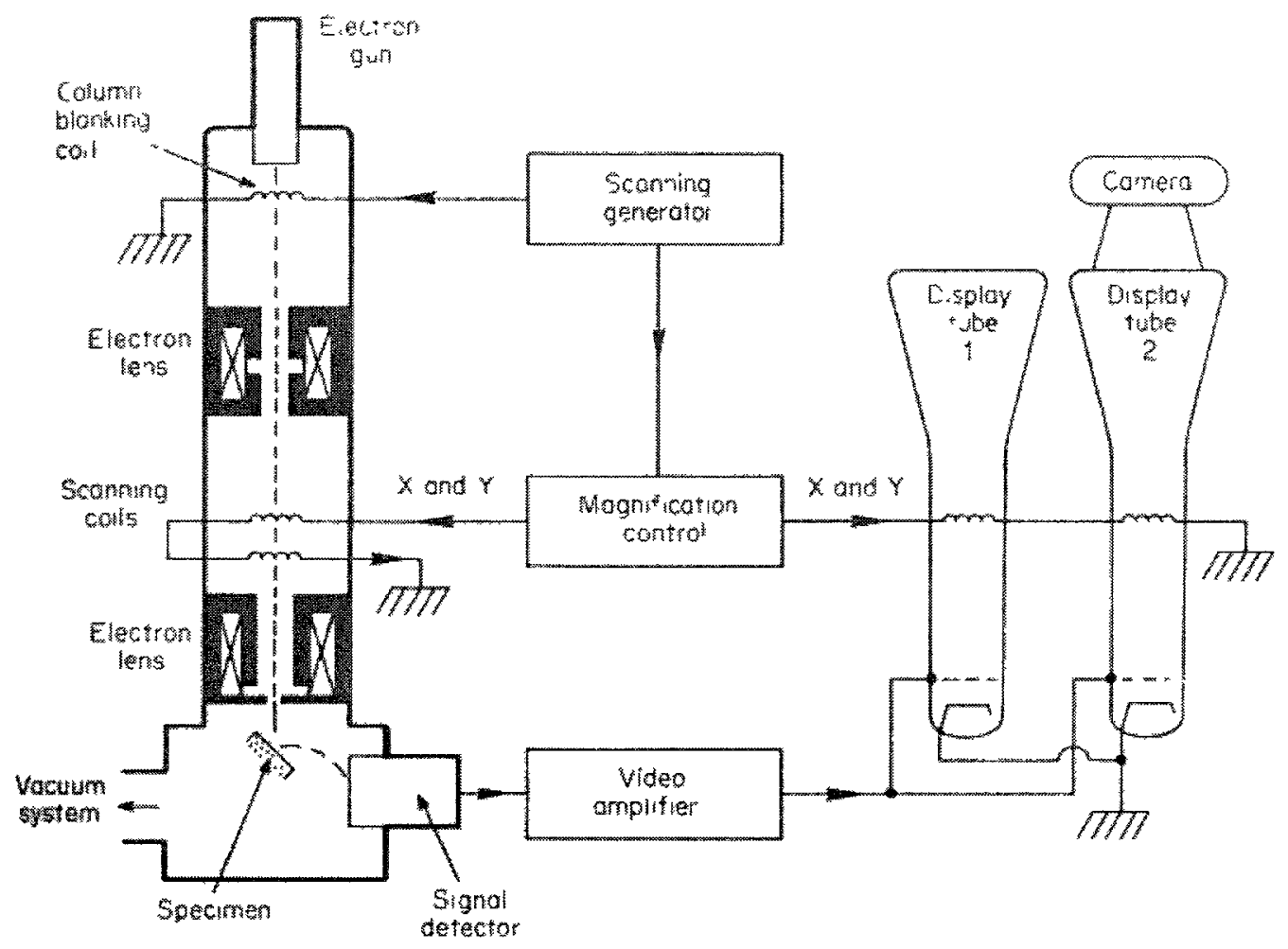

Figure 2.9. Schematic diagram of a Scanning Electron Microscope [Taken from Ref. 16].

\subsubsection{X-ray Diffraction}

The X-ay diffraction (XRD) is a powerful, non-destructive method for investigating orderly arrangement of atoms or molecules through the interaction of electromagnetic radiation to give interference effects with structures comparable in size to the wavelength of radiation. ${ }^{11}$ In XRD, the wavelengths of X-rays are such chosen that it can be comparable to interatomic distances in crystals. Most of the information about atomic positions and intramolecular distances can be obtained from x-ray diffraction measurements. Depending on the physical state of the crystalline materials, partial or complete information of the crystal structure can be obtained from XRD. It is necessary 
to obtain a single crystal of the compound to get complete information of the molecular ordering in a crystalline or semicrystalline material. In single crystal XRD, the crystal is rotated at an angle perpendicular to the incident beam so that diffraction patterns at all possible angles are recorded. However, when a single crystal is not available, powder Xray diffraction can provide valuable information regarding the interplanar distances between atomic planes ( $d$-spacing), crystallite (grain) size and crystallinity. In powder Xray diffraction, the reflections are obtained from several microcrystals present in a real sample with different orientation. This method is more convenient, but gives less information than the single crystal methods. It gives at best 20 reflections whereas single crystal can usually give $>2000$ reflections. Direct methods are available to determine the crystal structure using single crystals whereas this is not the case with the powder pattern. The basic equation of X-ray diffraction is the Bragg formula:

$$
2 d \sin \theta=n \lambda
$$

where $\lambda$ is the wavelength of X-ray radiation, $d$ is the distance between atomic planes, $\theta$ the angle of incidence of the $\mathrm{x}$-ray beam on the atomic planes and $n(1,2,3 \ldots, \mathrm{n})$ is the order of the reflection.

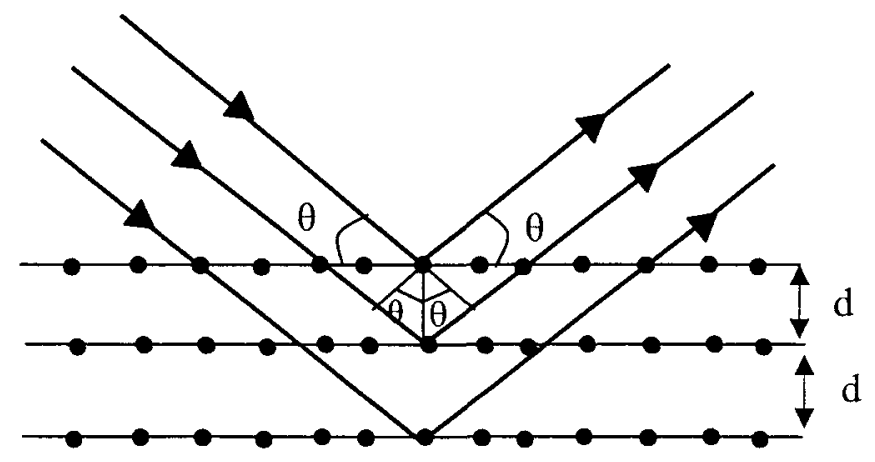

Figure 2.10. Bragg construction illustrating the principle of diffraction where $d$ is the spacing between two atomic planes. 
In real cases, higher order reflection corresponding to $n>1$ are extremely weak in intensity. Hence only those corresponding to $n=1$ are observed. Thus, the above equation reduces to

$$
2 d \sin \theta=\lambda
$$

Rearrangement of Bragg's equation gives the $d$-spacing as

$$
d=\frac{\lambda}{2 \operatorname{Sin} \theta}
$$

Equation 2.4 shows that when the distance $(d)$ between the two planes in the lattice is large, the scattering angle $(2 \theta)$ has to be small to produce a diffraction pattern. Depending on the scattering angle X-ray diffraction can be of two types. The diffractions obtained at angles smaller than $2^{\circ}(d>44 \AA)$ are called Small Angle X-ray Diffractions (SAXS). ${ }^{17}$ The diffractions obtained at all larger angles, theoretically extending up to $180^{\circ}$ are called Wide Angle X-ray Diffractions (WAXS) ${ }^{17}$ WAXS provides information about the spatial arrangement of atoms, whereas SAXS provides information about domain arrangements (e.g., long spacing). ${ }^{11}$

In our study, X-ray diffraction data were collected within the range of $2^{\circ} \leq 2 \theta \leq 0^{\circ}$ for most of the samples using a Philips automated powder diffractometer, Model PW 1710. Nickel-filterd $\mathrm{Cu} \mathrm{K}$ radiation $(\lambda=1.542 \AA)$ was used. The possible presence of texture of many samples was checked by taking additional diffractograms with samples turned in the plane of measurement by $90^{\circ}$. Figure 2.11 shows a schematic of the Bragg diffraction with this diffractometer. 


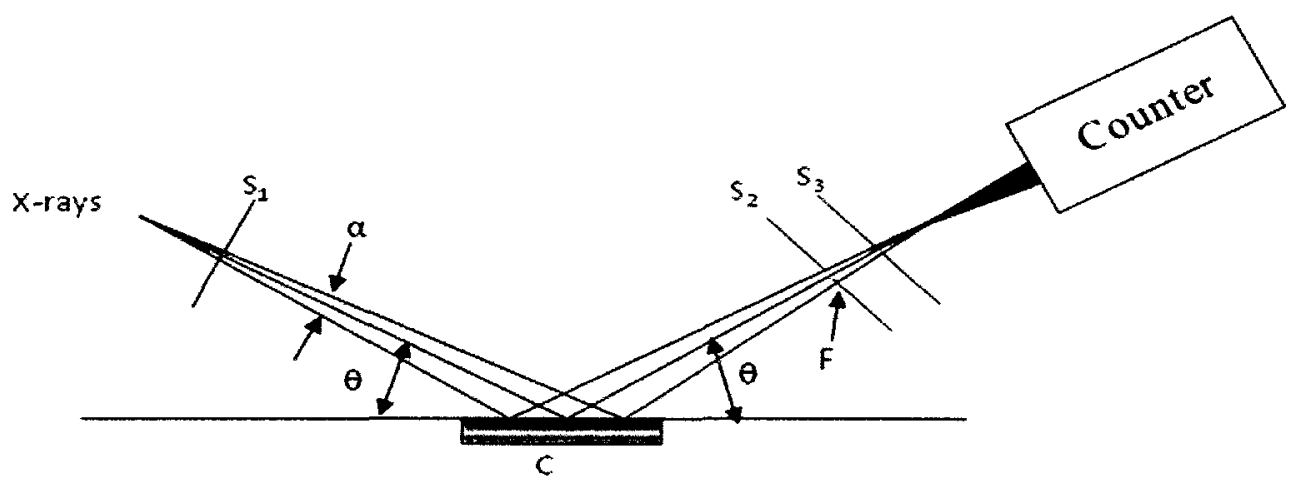

Figure 2.11. Schematic of the Bragg diffraction of the powder X-ray diffractometer used for the present study [from Alexander]. Here, $S_{1}, S_{2}$ and $S_{3}$ are the divergence slit, receiving slit and scatter slit respectively; $\alpha=1-4^{\circ}$.

The MDI Datascan 3.2 software (Materials Data Inc., Livermore, CA) was used for data collection. The results were analyzed using MDI Jade 5.0 XRD Pattern Processing software.

Percent crystallinity of the sample, $X_{\mathfrak{c}}$, was calculated using the formula

$$
X_{\mathrm{c}}=\left(I_{\mathrm{C}} / I_{\text {total }}\right) \times 100
$$

Where $I_{\mathrm{C}}$ is the crystalline area under the peak and $I_{\text {total }}$ is the total crystalline and amorphous area as shown in figure 2.12 . The reproducibility in the calculation was $\pm 2 \%$.

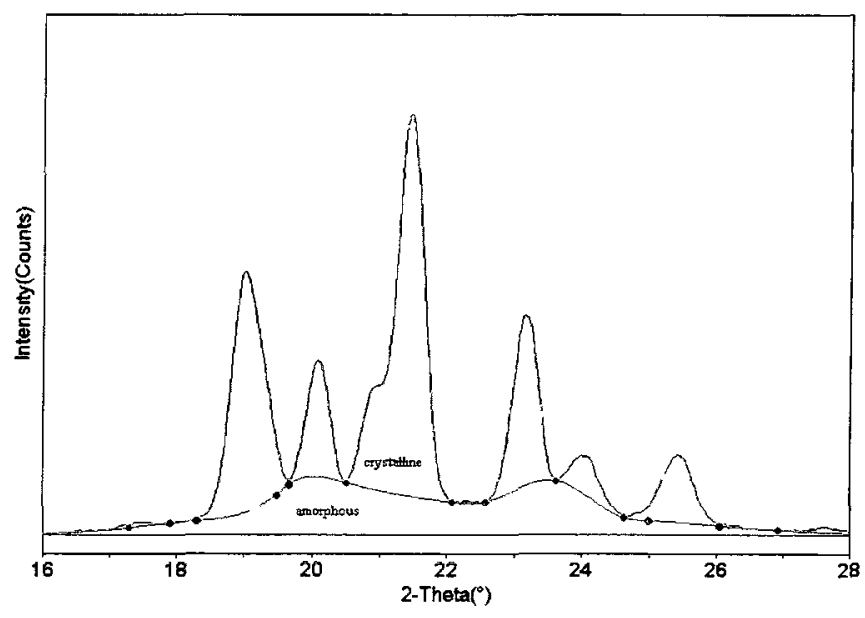

Figure 2.12. Schematic showing the crystalline and amorphous peak areas used for calculating percent crystallinity. 
The crystallite size, $L$ corresponding to a particular reflection was calculated by the Scherrer Equation. ${ }^{17}$

$$
L=K \lambda \beta \cos \theta
$$

where $\lambda$ is wavelength of the X-ray, $\theta$ is half the scattering angle, and $\beta$ is the half width of the peak on the $2 \theta$ scale in rains; $K=0.9$.

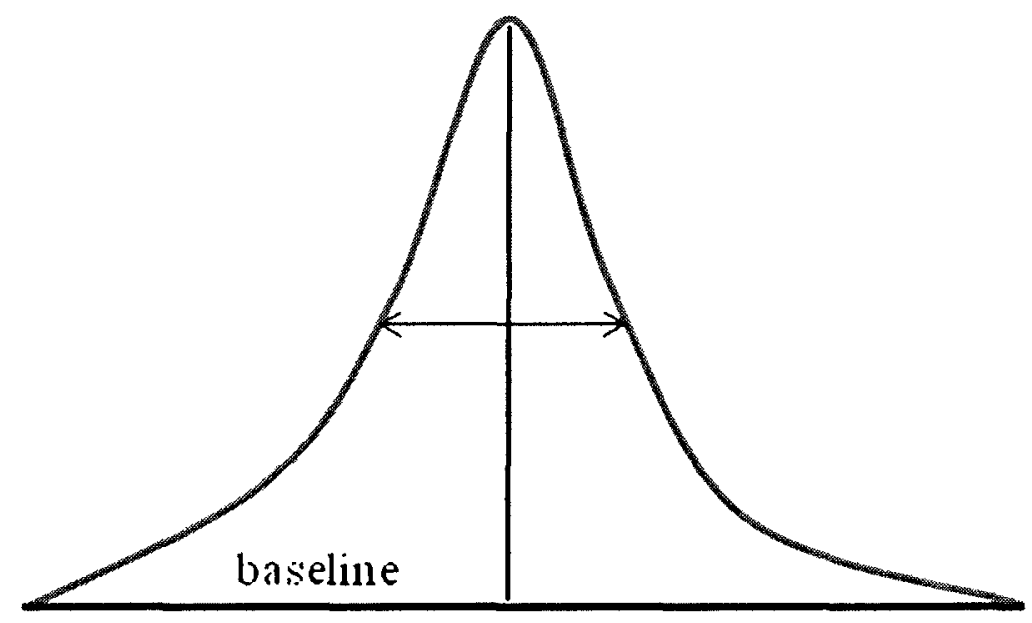

20

Figure 2.13. Schematic of full width at half-maximum (fwhm) of a particular peak.

\subsubsection{FTIR Spectroscopy}

Among various spectroscopic methods, IR spectroscopy is one of the most widely used techniques for the determination of molecular structure and for the quick identification of compounds. Beside its application in structure elucidation of chemical compounds, IR spectroscopy can also provide valuable information regarding the molecular level interactions between the components in the mixtures of chemical compounds. This technique relies on the changes in vibrational energy state of molecules caused by the irradiation of the sample with a broad-band source of radiation in the 
infrared region. To be IR active, molecules should experience a change in the dipole moment during the vibration upon irradiation. The theory of IR transitions has been discussed in details by Herzberg ${ }^{18}$ and Steinfeld. ${ }^{19}$

Applications of infrared spectroscopy in organic chemistry are almost entirely concerned with the range of $650-4000 \mathrm{~cm}^{-1}(15.4-2.5 \mu \mathrm{m})$ (the mid infrared). ${ }^{20}$ The wavenumber measured in reciprocal centimeter $\left(\mathrm{cm}^{-1}\right)$ is related to the wavelength, by the following equation:

$$
v=\frac{1}{\lambda} \quad(\text { with } \lambda \text { in } \mathrm{cm})
$$

The region of frequencies lower than $650 \mathrm{~cm}^{-1}$ refers to the far infrared, and that of frequencies higher than $4000 \mathrm{~cm}^{-1}$ is called the near infrared. The regions from $4000-$ $1400 \mathrm{~cm}^{-1}$ gives information about the functional groups present in the molecular structure of a specific compound. The regions from $600-1400 \mathrm{~cm}^{-1}$ is called the fingerprint region because of its uniqueness in the pattern of absorption in this region to any particular compound. ${ }^{21}$ The bands in this fingerprint region have thus been used with great utility to assign the aromatic ring substitution patterns of organic compounds. ${ }^{22}$

In our study, FTIR spectroscopic measurements were carried out at ambient conditions using a Varian 1000 Scimitar Series spectrophotometer. The FTIR spectra were recorded using a transparent $\mathrm{KBr}$ pellet with a background correction using the identical sample holder. Spectra of some select samples were taken under ambient conditions with the same spectrophotometer in attenuated total reflectance (ATR) mode. 
The FTIR spectra were recorded with MIRacle ${ }^{\mathrm{TM}}$ single reflection ATR accessories from Pike Technologies (Madison, WI) with a background correction using the identical sample holder. The data were processed using the Varian Resolution (version 4.0.5.009) software.

\subsubsection{NMR Spectroscopy}

${ }^{1} \mathrm{H}$ NMR spectra of biscarbamates were recorded in $\mathrm{CDCl}_{3}$ with TMS as internal standard on a Bruker-300 spectrophotometer at ambient temperature.

\subsubsection{Molecular Modeling}

Simple molecular Modeling was performed using HyperChem (from Hypercube Inc.) (version 6.01) and Spartan ES software. Geometry optimization of the molecular structures was done using the MM+ force field. 


\subsection{References}

1. Goodbrand, B.; Boils, D.; Sundararajan, P. R.; Wong, R. U. S. Patent 6,414,051, 2002.

2. Furer, V. L. J. Mol. Struct. 2000, 520, 117.

3. Socrates, G. Infrared characteristics group frequencies, Wiley-Interscience: New York, 1980; Chap. 10.

4. Nin-Vien, D.; Colthup, N.B.; Fateley, W. G.; Grasselli, J. G. The Handbook of Infrared and Raman Characteristic Frequencies of Organic Molecules, Academic Press Inc.: Boston, 1991; p 14.

5. Kalsi, P. Spectroscopy of Organic Compounds, $4^{\text {th }}$ ed.; New Age International Ltd.: New Delhi, 2000; p 255.

6. Zhang, X. H.; Liu, M. W.; Wong, O. Y.; Lee, C. S.; Kwong, H. L.; Lee, S. T.; Wu, S. K. Chem. Phys. Lett. 2003, 369, 478.

7. Lakowicz, J. R. Principles of Fluorescence Spectroscopy; Plenum Press: New York, 1983.

8. Bottari, G.; Diaz, D. D.; Torres, T. J. Porphyrins Phthalocyanines 2006, 10, 1083.

9. (a) Seyednejad, H.; Vermonden, T.; Fedorovich, N. E.; van Eijk, R.; van Steenbergen, M. J.; Dhert, W. J. A.; van Nostrum, C. F.; Hennink, W. E. Biomacromolecules 2009, 10, 3048; (b) Mattanavee, W.; Suwantong, O.; Puthong, S.; Bunaprasert, T.; Hoven, V. P.; Supaphol, P. ACS Appl. Mater. Interfaces 2009, 5, 1076; (c) Zapata, P.; Su, J.; Garcia, A. J.; Meredith, J. C. Biomacromolecules 2007, 8,1907 .

10. (a) Chen, A-L.; Ni, H-C.; Wang, L-F.; Chen, J-S. Biomacromolecules 2008, 9, 2447;

(b) Kim, B-S.; Park, S. W.; Hammond, P. T. ACS Nano 2008, 2, 386. 
11. Billmeyer, F. W. Textbook of Polymer Science, $3^{\text {rd }}$ ed; Wiley-Interscience: New York, 1984; Chap. 9.

12. Stevens, M. P. Polymer Chemistry an Introduction, $3^{\text {rd }}$ ed.; Oxford University Press: New York, 1999; Chap. 5.

13. Saville, B. P. in Applied Polymer Light Microscopy; Hemsley, D. A., Ed.; Elsevier Science Publishers Ltd.: New York, 1989; Chap. 4.

14. Goldstein, J. I.; Newbury, D. E.; Echlin, P.; Joy, D. C.; Fiori, C.; Lifshin, E. Scanning Electron Microscopy and X-Ray Microanalysis, Plenum Press, New York, 1981; Chap. 1.

15. Curson, A. D. in Applied Polymer Light Microscopy; Hemsley, D. A.; Ed. Elsevier Science Publishers Ltd.: New York, 1989; Chap. 1.

16. Wells, O. C. Scanning Electron Microscopy, McGraw-Hill, Inc., 1974; Chap. 1.

17. Alexander, L. E. X-Ray Diffraction Methods in Polymer Science, WileyInterscience: New York, 1969.

18. Herzberg, G. Molecular Spectra and Molecular Structure, $2^{\text {nd }}$ ed.; van Nostrand Reinhold Company: New York, 1950.

19. Steinfeld, J. I. Molecules and Radiation, An Introduction to Molecular Spectroscopy; The MIT Press: Cambridge, 1985.

20. Kemp, W. Organic Spectroscopy, $3^{\text {rd }}$ ed.; Macmillan Education Ltd.: London, 1991.

21. Kalsi, P. S. Spectroscopy of Organic Compounds, $4^{\text {th }}$ ed.; New Age International Ltd.: New Delhi, 2000; p 60.

22. Pavia, D. L.; Lampman, G. M.; Kris, G. S. Introduction to spectroscopy, $3^{\text {rd }}$ ed.; Harcourt College Publisher, 2001; p. 41. 
Chapter 3

Influence of Odd-Even Carbon Atom Parity of Alkyl Side Chains on the Morphology and Crystallization Behaviour of Biscarbamates 


\subsection{Introduction}

Molecular self-assembly mediated by non-covalent interactions such as hydrogen bonding, dispersion forces, $\pi-\pi$ interactions etc. has long been studied and emerged as a powerful tool for creating supramolecular architectures of desired dimension and functionality. "This toolbox offers a "bottom-up" and in fact the only practical approach for producing a variety of structures at multiple length scales. ${ }^{2}$ Among various noncovalent interactions leading to molecular self-assembly, hydrogen-bond mediated selfassembly has been extensively studied in recent years and employed to create specific secondary structures with oligomers, ${ }^{3}$ molecular strands employed in specific modes of intermolecular aggregates, ${ }^{4}$ etc. The effectiveness of hydrogen-bonding in such molecular self-assembly depends largely on the design of tailored recognition elements in the form of hydrogen-bond donor-acceptor arrays. ${ }^{5}$ It was seen that extended supramolecular assembly requires selectivity, self-complimentarity and orthogonality of recognition events which can be achieved by incorporation of multiple hydrogen-bond donoracceptor moieties in the molecules. While appropriate design of molecules with hydrogen bonding moieties leads to molecular self-assembly, morphology of the structures created by such assembly was found to be dependent on the secondary noncovalent interactions such as van der Waals forces. ${ }^{6,7}$ In many cases the length and carbon atom parity in the alkyl spacer or side chains play an important role in such secondary interactions leading to "odd-even" effect on the molecular packing, morphology and subsequent physical properties. 
The "odd-even" effect of the carbon number parity of methylene groups in aliphatic chains is a well-known and extensively studied phenomenon. ${ }^{8}$ This effect has been observed in the solid state, ${ }^{9}$ solution phases, ${ }^{10}$ and solid/liquid interfaces ${ }^{11}$ and has been mainly attributed to packing differences in the crystal structure ${ }^{12}$ between chains having an odd or even number of carbon atoms. The most known class of compounds that display such an odd-even effect is liquid crystals ${ }^{13}$ although other classes of compounds e.g., polyurethanes, ${ }^{14}$ n-alkanes, ${ }^{15}$ carboxylic acids, ${ }^{16}$ alcohols, ${ }^{17}$ bifunctional hydroxycarboxylic acids ${ }^{18}$ etc. also show odd-even effect as a function of carbon atom parity. In the overwhelming majority of the literature, this effect is discussed with respect to the carbon atom parity in the spacer groups. ${ }^{19}$ However, there are some reports where this effect is discussed as a function of the carbon atom parity in the alkyl side chains. ${ }^{20}$ In most of the cases the odd-even effect is manifested in the phase transition temperatures $^{13 b}$ and optical properties ${ }^{13 c}$ of such compounds. In this chapter we discuss the significant differences in crystallization and morphological behaviour of a class of self-assembling molecules namely biscarbamates as a function of the carbon atom parity in the alkyl side chains symmetrically attached to the hydrogen bonding moieties (scheme $3.1)$.

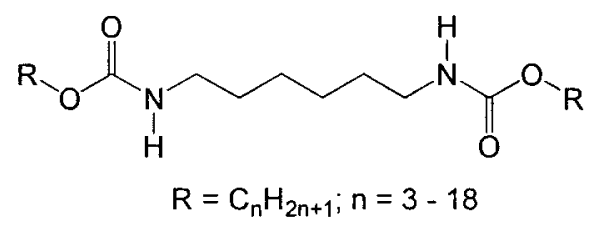

Scheme 3.1

We have been studying the influence of side chain length as well as single versus double hydrogen-bond motifs on the morphology and miscibility behaviour upon 
crystallization, blending and gelation of a class of hydrogen-bond mediated selfassembling system of carbamates ${ }^{6}$ and biscarbamates $^{7}$ with their conceived importance in scientific and technological applications. Scientific studies of these classes of molecules date back to early 1900 s and continues to the contemporary time because of their potential application as described in section 1.4.1.

In our previous works, we compared the morphology and thermal behaviours of Noctadecyl carbamates referred therein as mono carbamates ${ }^{6}$ and biscarbamates ${ }^{7}$ with alkyl side chains of various lengths ranging from $\mathrm{C}_{4}$ to $\mathrm{C}_{18}$ with an even carbon atom parity in the alkyl side chains of the compounds of both series. We observed a significant difference in their morphology and thermal properties which were attributed to the influence of single versus double hydrogen bonding motifs as well as asymmetric versus symmetric alkyl substitution of the molecules. In a sharp contrast to the monocarbamates, biscarbamates with an alkyl side chain length of $\mathrm{C}_{8}$ showed the maximum spherulite size, spherulite growth rate and rate of crystallization. These observations were rationalized with the relative contributions of hydrogen-bond and van der Waals forces. In another work, ${ }^{21}$ we showed that the biscarbamates show immiscibility and molecular selectivity at the molecular level upon blending. The alkyl side chains play the role in such selectivity and immiscibility of these chemically similar molecules. Moreover, a preliminary study ${ }^{7 \mathrm{~b}}$ on the gelation behaviour of these biscarbamates showed a significant difference in their gel state morphology depending on their carbon atom parity in the alkyl side chains. Based on these observations, we believed that it would be of interest to study the crystallization behaviour of these materials in solid state as a function of the 
carbon atom parity in the alkyl side chains. To this end, we synthesized a series of biscarbamates with both odd and even number of carbon atoms in the alkyl side chains and studied their morphology and crystallization behaviours with appropriate techniques. In this chapter, we discuss the morphology and thermal properties of these molecules and compare them with respect to the carbon atom parity in the alkyl side chains.

\subsection{Experimental}

Biscarbamates containing odd and even number of carbon atoms in the alkyl side chains were synthesised as described by Goodbrand et $a .^{22}$ from the appropriate diisocyanate and alcohols.

Thermal analysis was performed using a TA Instruments 2010 differential scanning calorimeter following the method described in section 2.7.1. The crystallization kinetics was studied by using the Avrami equation ${ }^{23}$ as follows:

$$
\begin{aligned}
& 1-X(t)=\exp \left(K t^{n}\right) \\
& \ln \{-\ln [1-X(t)]\}=\ln K+n \ln t
\end{aligned}
$$

where $X(t)$ is the relative crystallinity, $t$ the crystallization time, $n$ the Avrami exponent, and $K$ the crystallization rate constant. Half crystallization time $\left(t_{1 / 2}\right)$, that represents the crystallization rate, can be obtained from the following equation:

$$
t_{1 / 2}=[\ln 2 / \mathrm{k}]^{1 / n}
$$

For the kinetic study of the spherulite growth, a Linkam hot stage LTS 350 equipped with a Linkam TMS 94 thermo-controller and coupled with a Zeiss Axioplan 
polarized optical microscope was used. The samples were heated to a temperature of 20 ${ }^{\circ} \mathrm{C}$ above the melting temperature of the biscarbamate at a rate of $5{ }^{\circ} \mathrm{C} / \mathrm{min}$ and held at that temperature for about $10 \mathrm{~min}$. The samples were then cooled at a rate of $2{ }^{\circ} \mathrm{C} / \mathrm{min}$ down to a temperature of $5{ }^{\circ} \mathrm{C}$ above the crystallization temperature $\left(T_{\mathrm{c}}\right)$ and then at the rate of $0.1{ }^{\circ} \mathrm{C} / \mathrm{min}$ down to the $T_{\mathrm{c}}$. Northern Eclipse image processing software was used to capture the images at specific time intervals during the crystallization of the samples isothermally held at their $T_{\mathrm{c}}$ followed by the calculation of the spherulite size for subsequent data processing.

\subsection{Results and Discussion}

\subsubsection{Thermal Behaviour}

We denote the samples as $\mathrm{C}_{\mathrm{x}} \mathrm{C}_{6}$, where $\mathrm{x}$ corresponds to the number of carbon atoms in the alkyl side chain, and 6 refers to the $\left(\mathrm{CH}_{2}\right)_{6}$ spacer. The melting temperatures $\left(T_{\mathrm{m}}\right)$ of both odd and even biscarbamates as a function of number of carbons in the alkyl side chains are plotted in Figure 3.1. Two representative DSC traces of $\mathrm{C}_{3} \mathrm{C}_{6}$ (odd) and $\mathrm{C}_{4} \mathrm{C}_{6}$ (even) biscarbamates are shown in Figure 3.2, depicting phase transitions corresponding to their melting from solid to liquid and crystallization from melt to solid in heating and cooling cycles respectively. The appearance of sharp peaks without any other transitions prior to their both melting and crystallization implies high purity, crystalline property and the absence of any polymorphism in biscarbamates studied here. The actual values of $T_{\mathrm{m}}$ are listed in Table 3.1. It is seen from Figure 3.1 that biscarbamates of this series show odd-even oscillation of melting temperatures with higher $T_{\mathrm{m}}$ for a molecule with odd number of carbon atoms than that of the molecule 


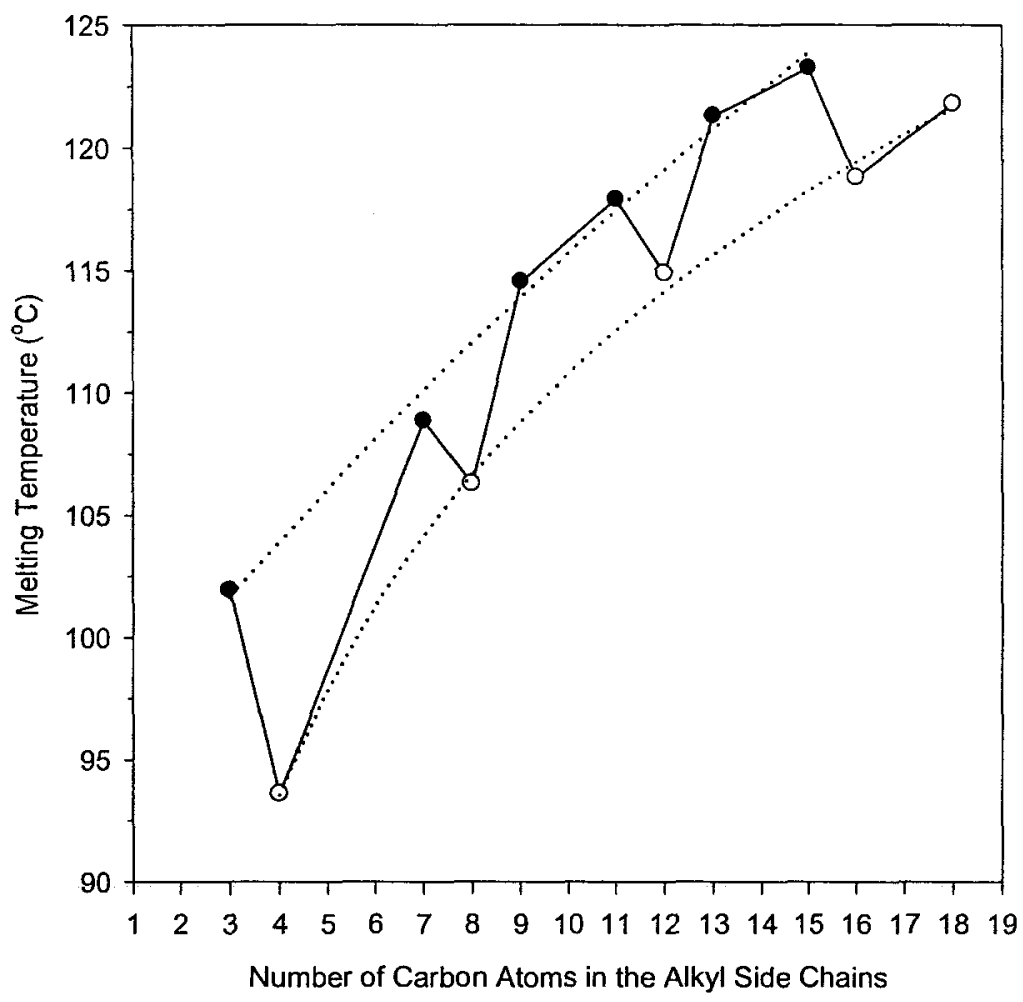

Figure 3.1. Change of melting temperature of the biscarbamates as a function of the number of carbon atoms in the alkyl side chains.

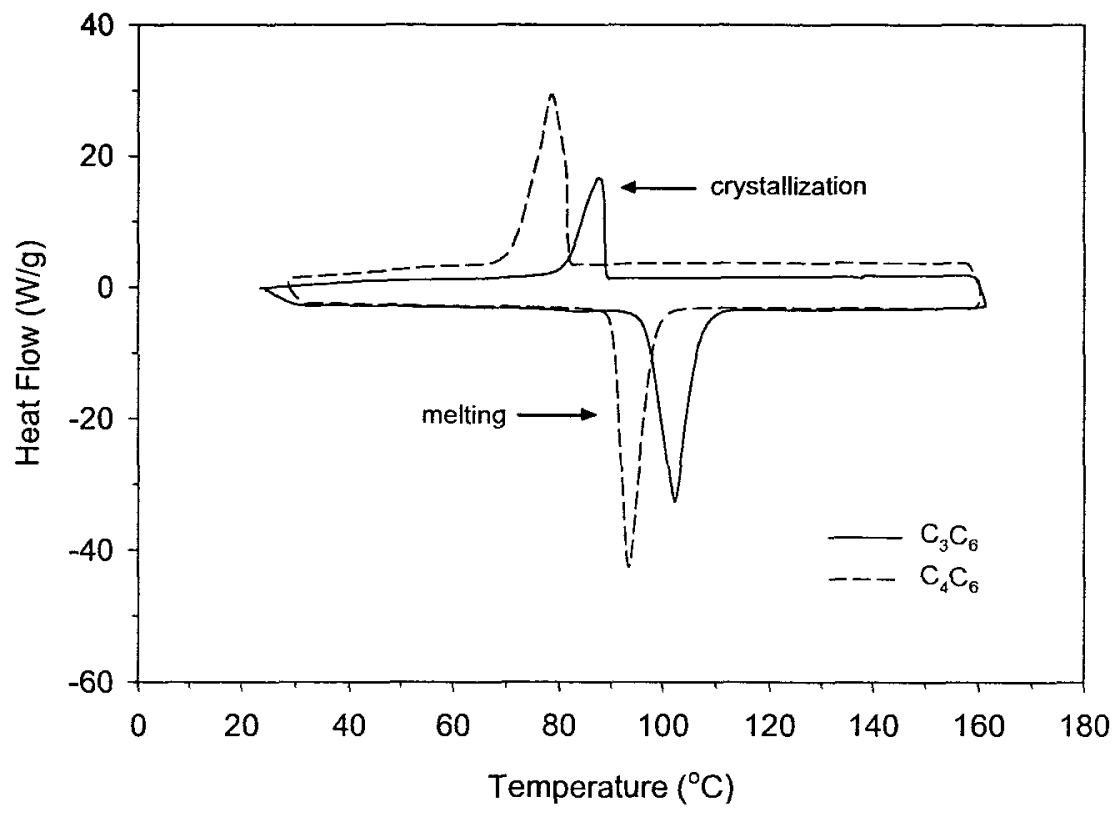

Figure 3.2. DSC traces of biscarbamates showing phase transitions corresponding to melting and crystallization in the heating and cooling cycles respectively. 
containing one carbon atom higher. The difference is more pronounced with the shorter side chains. The $T_{\mathrm{m}}$ of $\mathrm{C}_{3} \mathrm{C}_{6}$ biscarbamate is $102^{\circ} \mathrm{C}$ while that of $\mathrm{C}_{4} \mathrm{C}_{6}$ is $91.3^{\circ} \mathrm{C}$ with a difference of $\sim 11^{\circ} \mathrm{C}$. However, the difference between the melting temperatures of $\mathrm{C}_{15} \mathrm{C}_{6}$ and $\mathrm{C}_{16} \mathrm{C}_{6}$ is $4.43{ }^{\circ} \mathrm{C}$. Among this series of molecules we see the least difference in $T_{\mathrm{m}}$ between $\mathrm{C}_{7} \mathrm{C}_{6}$ and $\mathrm{C}_{8} \mathrm{C}_{6}$ which is only $2.27{ }^{\circ} \mathrm{C}$. While the odd-even effect is less pronounced with an increase in the alkyl side chain strength, the least odd-even effect in $T_{\mathrm{m}}$ is seen between $\mathrm{C}_{7} \mathrm{C}_{6}$ and $\mathrm{C}_{8} \mathrm{C}_{6}$ which show the maximum crystallization rate and spherulite size (discussed in the following sections) among the members of the biscarbamates containing odd and even number of carbon atoms.

Table 3.1. Melting temperatures of $\mathrm{C}_{\mathrm{x}} \mathrm{C}_{6}$ biscarbamates.

\begin{tabular}{lll}
\hline ID & Molecular Formula & $T_{\mathrm{m}}{ }^{\circ} \mathrm{C}$ \\
\hline $\mathrm{C}_{3} \mathrm{C}_{6}$ & $\mathrm{H}_{7} \mathrm{C}_{3} \mathrm{OOCHN}\left(\mathrm{CH}_{2}\right)_{6} \mathrm{NHCOOC}_{3} \mathrm{C}_{7}$ & 101.96 \\
$\mathrm{C}_{4} \mathrm{C}_{6}$ & $\mathrm{H}_{9} \mathrm{C}_{4} \mathrm{OOCHN}\left(\mathrm{CH}_{2}\right)_{6} \mathrm{NHCOOC}_{4} \mathrm{C}_{9}$ & 91.3 \\
$\mathrm{C}_{7} \mathrm{C}_{6}$ & $\mathrm{H}_{15} \mathrm{C}_{7} \mathrm{OOCHN}\left(\mathrm{CH}_{2}\right)_{6} \mathrm{NHCOOC}_{7} \mathrm{C}_{15}$ & 108.87 \\
$\mathrm{C}_{8} \mathrm{C}_{6}$ & $\mathrm{H}_{17} \mathrm{C}_{8} \mathrm{OOCHN}\left(\mathrm{CH}_{2}\right)_{6} \mathrm{NHCOOC}_{8} \mathrm{C}_{17}$ & 106.6 \\
$\mathrm{C}_{9} \mathrm{C}_{6}$ & $\mathrm{H}_{19} \mathrm{C}_{9} \mathrm{OOCHN}\left(\mathrm{CH}_{2}\right)_{6} \mathrm{NHCOOC}_{9} \mathrm{C}_{19}$ & 114.55 \\
$\mathrm{C}_{11} \mathrm{C}_{6}$ & $\mathrm{H}_{23} \mathrm{C}_{11} \mathrm{OOCHN}\left(\mathrm{CH}_{2}\right)_{6} \mathrm{NHCOOC}_{11} \mathrm{C}_{23}$ & 114.9 \\
$\mathrm{C}_{12} \mathrm{C}_{6}$ & $\mathrm{H}_{25} \mathrm{C}_{12} \mathrm{OOCHN}\left(\mathrm{CH}_{2}\right)_{6} \mathrm{NHCOOC}_{12} \mathrm{C}_{25}$ & 114.9 \\
$\mathrm{C}_{13} \mathrm{C}_{6}$ & $\mathrm{H}_{27} \mathrm{C}_{13} \mathrm{OOCHN}\left(\mathrm{CH}_{2}\right)_{6} \mathrm{NHCOOC}_{13} \mathrm{C}_{27}$ & 121.29 \\
$\mathrm{C}_{15} \mathrm{C}_{6}$ & $\mathrm{H}_{31} \mathrm{C}_{15} \mathrm{OOCHN}\left(\mathrm{CH}_{2}\right)_{6} \mathrm{NHCOOC}_{15} \mathrm{C}_{31}$ & 123.24 \\
$\mathrm{C}_{16} \mathrm{C}_{6}$ & $\mathrm{H}_{33} \mathrm{C}_{16} \mathrm{OOCHN}\left(\mathrm{CH}_{2}\right)_{6} \mathrm{NHCOOC}_{16} \mathrm{C}_{33}$ & 118.81 \\
$\mathrm{C}_{18} \mathrm{C}_{6}$ & $\mathrm{H}_{37} \mathrm{C}_{18} \mathrm{OOCHN}\left(\mathrm{CH}_{2}\right)_{6} \mathrm{NHCOOC}_{18} \mathrm{C}_{37}$ & 121.78 \\
\hline
\end{tabular}


The odd-even effect of carbon atom parity on thermal properties seen here is different from the trend reported for $\mathrm{n}$-alkanes. Boese et. al. ${ }^{12}$ noted that $\mathrm{n}$-alkanes having an even number of carbon atoms have higher melting temperatures than those of odd numbered alkanes. The even numbered n-alkanes are centrosymmetric, and the odd numbered ones are $\mathrm{C}_{2}$ symmetric. As shown in Scheme 3.2, in the case of hexane, the terminal methyl groups are pointing in opposite directions (anti), and those of heptanes are in the same direction (syn). This leads to differences in the packing of terminal methyl groups in the crystal structures of these molecules. The even-numbered n-alkanes have symmetrical intermolecular contacts at both ends, whereas the odd numbered ones have a longer distance of contact at one end. ${ }^{12}$ A different trend in odd-even effect is seen with the biscarbamates studied here. Biscarbamates with odd number of carbon atoms show higher melting temperatures and heat of fusion than the even numbered. By analogy to the n-alkanes shown in Scheme 3.2, we note that the terminal methyl group is disposed in a direction opposite to the ester oxygen in $\mathrm{C}_{7} \mathrm{C}_{6}$ (anti, similar to the terminal methyl groups in hexane), whereas both the ester oxygen and the terminal $\mathrm{CH}_{3}$ group are in the same direction with $\mathrm{C}_{6} \mathrm{C}_{6}(s y n$, similar to the case of heptanes in Scheme 3.2).

Such a syn disposition is also seen in the crystal structure ${ }^{32}$ of $\mathrm{C}_{10} \mathrm{C}_{6}$. Inherent differences of this nature in the molecular structure would lead to different packing modes of the odd and even series. Based on the analogy with n-alkanes, we speculate that hydrogen bonding in consonance with dispersion forces lead to a more dense packing of biscarbamates with odd numbered carbon atoms in the side chain than the even numbered biscarbamates. 
Hexane<smiles>CCCCCC</smiles>

Heptane<smiles>CCCCCCC</smiles>

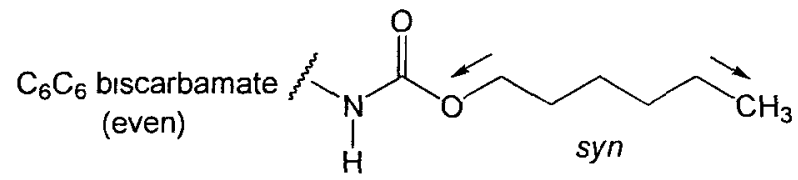<smiles>CCCCCCCOC(=O)NN(C)CCCCCC</smiles>

Scheme 3.2

Contrary to this trend, we see a less pronounced odd-even effect on the heats of fusion $(\Delta H)$ of these biscarbamates. Figure 3.3 shows that the $\Delta H$ of the series containing both odd and even number of carbon atoms increase linearly with the alkyl side chain length. We do not see any significant difference in heat of fusion of two biscarbamate containing successive odd and even number of carbon atoms in extreme lengths of alkyl side chains. However, there is a significant difference in $\Delta H$ between two biscarbamates with intermediate alkyl side chain lengths. For example, the difference in $\Delta H$ is only 1.1 and $0.6 \mathrm{~J} / \mathrm{g}$ between the $\mathrm{C}_{3} \mathrm{C}_{6} / \mathrm{C}_{4} \mathrm{C}_{6}$ and $\mathrm{C}_{15} \mathrm{C}_{6} / \mathrm{C}_{16} \mathrm{C}_{6}$ odd-even pairs respectively. On the other hand, the difference in $\Delta H$ is $10.1 \mathrm{~J} / \mathrm{g}$ between $\mathrm{C}_{11} \mathrm{C}_{6}$ and $\mathrm{C}_{12} \mathrm{C}_{6}$ biscarbamates.

\subsubsection{X-ray Diffraction and Structural Features}

The crystal structure of $\mathrm{C}_{10} \mathrm{C}_{6}$ molecule was found to be triclinic with a center of symmetry due to the symmetric attachment of alkyl side chains on both sides of the 


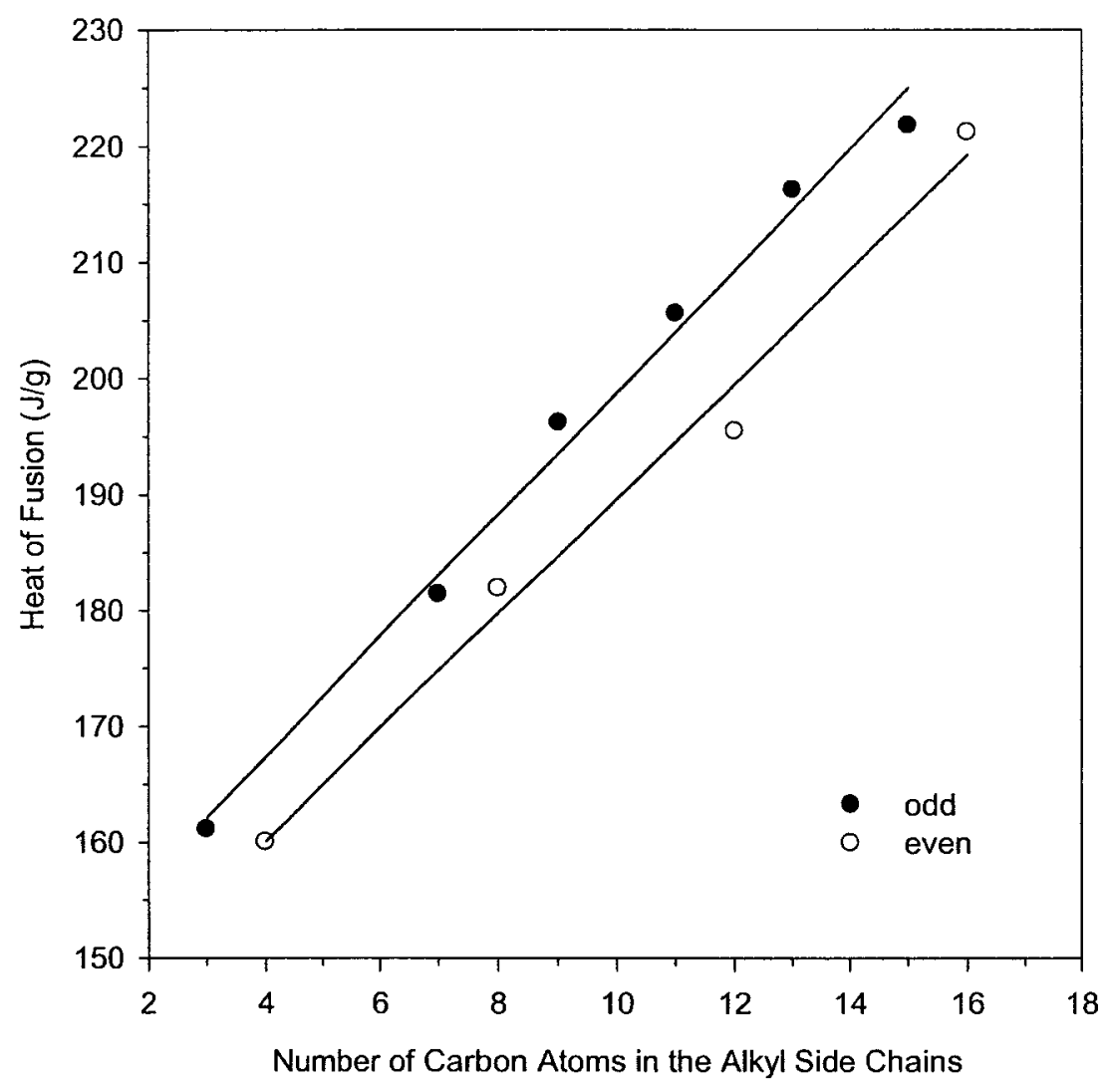

Figure 3.3. Change of heat of fusion of the biscarbamates as a function of the number of carbon atoms in the alkyl side chains.

hydrogen-bonding motifs. ${ }^{32}$ To our knowledge, crystal structures have not been reported for the other biscarbamates studied here. Based on X-ray powder diffraction data, we note a few structural features. All the biscarbamates studied here show a number of reflections in the range $18^{\circ}<2 \theta<26^{\circ}$ while the most intense one appears at $2 \theta \leq 5^{\circ}$ except for $\mathrm{C}_{3} \mathrm{C}_{6}$. The most intense reflection for $\mathrm{C}_{3} \mathrm{C}_{6}$ appears at $2 \theta=6.8^{\circ}$. The $d$-spacing and corresponding relative intensities of the reflections (normalized with respect to the most intense reflection in each case as $100 \%$ ) of quenched and slow-cooled samples are listed in Tables 3.2 and 3.3 respectively. We do not see any significant difference between the corresponding peak positions of quenched and slow-cooled samples, which 
Table 3.2. Interplanar spacings, $d(\AA)$, and Intensities, $I(\%)$ of X-ray diffraction patterns of slow-cooled samples.

\begin{tabular}{|c|c|c|c|c|c|c|c|c|c|c|c|}
\hline \multicolumn{2}{|c|}{$\mathrm{C}_{3} \mathrm{C}_{6}$} & \multicolumn{2}{|c|}{$\mathrm{C}_{7} \mathrm{C}_{6}$} & \multicolumn{2}{|c|}{$\mathrm{C}_{9} \mathrm{C}_{6}$} & \multicolumn{2}{|c|}{$\mathrm{C}_{11} \mathrm{C}_{6}$} & \multicolumn{2}{|c|}{$\mathrm{C}_{13} \mathrm{C}_{6}$} & \multicolumn{2}{|c|}{$\mathrm{C}_{15} \mathrm{C}_{6}$} \\
\hline$d$ & $I$ & $d$ & $I$ & $d$ & $I$ & $d$ & $I$ & $d$ & $I$ & $d$ & $I$ \\
\hline & & & & & & & & 21.46 & 100 & 23.22 & 100 \\
\hline \multirow[t]{2}{*}{20.64} & 24.3 & & & 19.00 & 100 & 20.23 & 100 & 18.35 & 3.3 & & \\
\hline & & 17.31 & 100 & 11.41 & 3.1 & 12.22 & 1.2 & 16.18 & 2.2 & & \\
\hline \multirow[t]{2}{*}{12.95} & 100 & 10.22 & 10.5 & & & & & & & & \\
\hline & & & & & & & & 7.62 & 5.8 & 8.32 & 5.4 \\
\hline \multirow[t]{3}{*}{7.33} & 99.1 & 7.26 & 2.1 & 6.36 & 8.2 & 6.88 & 6.8 & 6.26 & 0.6 & & \\
\hline & & 5.63 & 7.6 & & & 5.63 & 0.4 & 5.34 & 1.6 & 5.83 & 3.0 \\
\hline & & & & & & 4.77 & 1.1 & & & & \\
\hline 4.44 & 1.2 & 4.61 & 1.3 & 4.57 & 0.8 & 4.55 & 0.7 & 4.48 & 0.4 & & \\
\hline \multirow[t]{2}{*}{4.26} & 5.4 & 4.26 & 4.3 & 4.28 & 9.9 & 4.28 & 0.6 & 4.31 & 0.5 & 4.31 & 26.9 \\
\hline & & & & 4.11 & 8.1 & 4.18 & 0.8 & 4.18 & 2.0 & 4.19 & 62.7 \\
\hline \multirow[t]{4}{*}{3.95} & 24.4 & 4.06 & 1.1 & 3.89 & 15.2 & 4.00 & 0.8 & 4.02 & 0.6 & 4.04 & 7.9 \\
\hline & & 3.83 & 12.3 & 3.77 & 9.7 & 3.88 & 0.3 & 3.89 & 0.4 & 3.87 & 21.3 \\
\hline & & & & & & 3.78 & 0.6 & & & & \\
\hline & & & & & & 3.65 & 0.9 & 3.64 & 1.2 & 3.62 & 27.0 \\
\hline 3.51 & 48.7 & 3.53 & 16.6 & 3.52 & 13.5 & 3.47 & 21.8 & 3.49 & 12.6 & 3.49 & 65.8 \\
\hline 3.19 & 3.3 & 3.22 & 3.8 & 3.40 & 5.6 & 3.29 & 0.8 & & & 3.32 & 12.1 \\
\hline \multirow[t]{2}{*}{3.07} & 2.7 & & & 3.25 & 1.6 & 3.21 & 1.5 & 3.26 & 1.1 & & \\
\hline & & & & & & 2.19 & 0.4 & 2.19 & 0.3 & 2.34 & 4.4 \\
\hline
\end{tabular}


Table 3.3. Interplanar spacings, $d(\AA)$, and Intensities, $I(\%)$ of X-ray diffraction patterns of quenched samples.

\begin{tabular}{|c|c|c|c|c|c|c|c|c|c|c|c|}
\hline \multicolumn{2}{|c|}{$\mathrm{C}_{3} \mathrm{C}_{6}$} & \multicolumn{2}{|c|}{$\mathrm{C}_{7} \mathrm{C}_{6}$} & \multicolumn{2}{|c|}{$\mathrm{C}_{9} \mathrm{C}_{6}$} & \multicolumn{2}{|c|}{$\mathrm{C}_{11} \mathrm{C}_{6}$} & \multicolumn{2}{|c|}{$\mathrm{C}_{13} \mathrm{C}_{6}$} & \multicolumn{2}{|c|}{$\mathrm{C}_{15} \mathrm{C}_{6}$} \\
\hline$d$ & $I$ & $d$ & $I$ & $d$ & $I$ & $d$ & $I$ & $d$ & $I$ & $d$ & $I$ \\
\hline & & & & & & 20.08 & 100 & 21.48 & 100 & 23.26 & 100 \\
\hline & & & & 19.24 & 100 & & & 18.49 & 10.9 & & \\
\hline 18.24 & 19.7 & 17.68 & 100 & & & & & 16.33 & 8.1 & 18.06 & 24.8 \\
\hline \multirow[t]{2}{*}{12.97} & 100 & 10.30 & 8.3 & 11.46 & 2.8 & 12.26 & 1.9 & & & & \\
\hline & & & & & & & & & & 8.32 & 5.6 \\
\hline \multirow[t]{3}{*}{7.33} & 55.7 & 7.30 & 2.0 & 6.39 & 8.4 & 6.89 & 9.6 & 7.64 & 6.1 & & \\
\hline & & 5.66 & 6.6 & & & & & & & 5.83 & 3.3 \\
\hline & & & & & & & & 5.33 & 1.7 & & \\
\hline 4.44 & 6.3 & 4.62 & 1.7 & & & 4.54 & 2.1 & & & & \\
\hline \multirow[t]{2}{*}{4.26} & 15.4 & 4.27 & 18.3 & 4.28 & 19.0 & 4.33 & 10.4 & 4.31 & 7.7 & 4.31 & 27.1 \\
\hline & & & & 4.11 & 14.2 & 4.17 & 27.3 & 4.18 & 17.1 & 4.19 & 61.2 \\
\hline \multirow[t]{4}{*}{3.96} & 33.3 & 4.06 & 5.5 & 3.89 & 25.2 & 4.00 & 15.2 & 4.01 & 3.0 & 4.04 & 7.1 \\
\hline & & 3.83 & 47.9 & 3.77 & 20.9 & 3.89 & 4.9 & 3.86 & 6.4 & 3.87 & 21.6 \\
\hline & & & & & & 3.77 & 7.1 & & & & \\
\hline & & & & & & 3.65 & 10.4 & 3.64 & 11.6 & 3.62 & 26.8 \\
\hline \multirow[t]{2}{*}{3.51} & 63.5 & 3.53 & 29.3 & 3.54 & 11.0 & 3.48 & 63.5 & 3.49 & 29.4 & 3.49 & 63.2 \\
\hline & & 3.23 & 8.3 & 3.40 & 3.8 & 3.30 & 5.6 & 3.32 & 2.2 & 3.31 & 12.4 \\
\hline 3.06 & 5.1 & & & 3.27 & 1.5 & 3.21 & 2.7 & & & & \\
\hline 2.26 & 3.1 & & & 2.35 & 1.3 & 2.20 & 1.8 & 2.27 & 2.7 & 2.33 & 3.8 \\
\hline
\end{tabular}


indicates that molecular packing of these molecules is independent of sample preparation procedure (i.e., quenching or slow-cooling). It is seen from Table 3.2 that the largest $d$ spacing of individual biscarbamates increases from $12.95 \AA$ for $\mathrm{C}_{3} \mathrm{C}_{6}$ to $23.22 \AA$ for $\mathrm{C}_{18} \mathrm{C}_{12}$. Figure $3.4 \mathrm{a}$ shows the variation of the molecular length $(l)$ and $d$-spacing with the highest intensity peak. It is seen from this figure that the $d$-spacing of the highest intense peak increases linearly with the increase in the alkyl side chain length. A similar trend was found in the case of even numbered $\mathrm{C}_{\mathrm{x}} \mathrm{C}_{6}$ biscarbamates where the largest $d$-spacing increased linearly with the calculated molecular length. ${ }^{8 \mathbf{a}}$ Although this trend is similar for both odd and even biscarbamates, we see a significant difference in the values of $d$ spacings of the highest intensity peaks. The $d$-spacing values of odd biscarbamate are found to be almost half of that of the consecutive even biscarbamate (Figure 3.4a), which indicate that the packing modes are different, as could be rationalized from Scheme 2 . The peak with the largest $d$-spacing was found to be the most intense one for all the biscarbamates except $\mathrm{C}_{3} \mathrm{C}_{6}$. Tables 3.2 and 3.3 show that two reflections with $d$-spacings of $\sim 4.3 \AA$ and $3.5 \AA$ are common to all the samples studied here. These reflections were observed at $4.6 \AA$ and $3.8 \AA$ in the case of even $\mathrm{C}_{\mathrm{x}} \mathrm{C}_{6}$ biscarbamates and were assigned to the distance between the molecules in the H-bonding plane and distance between those planes, respectively. The shift of these reflections to lower $d$-spacings indicates closer packing of the molecules in that plane and between these planes.

Figure $3.4 \mathrm{~b}$ shows the variation of crystallite size of the reflections at $d=3.5$ and $4.3 \AA$ as a function of the alkyl side chain length of quenched samples. 

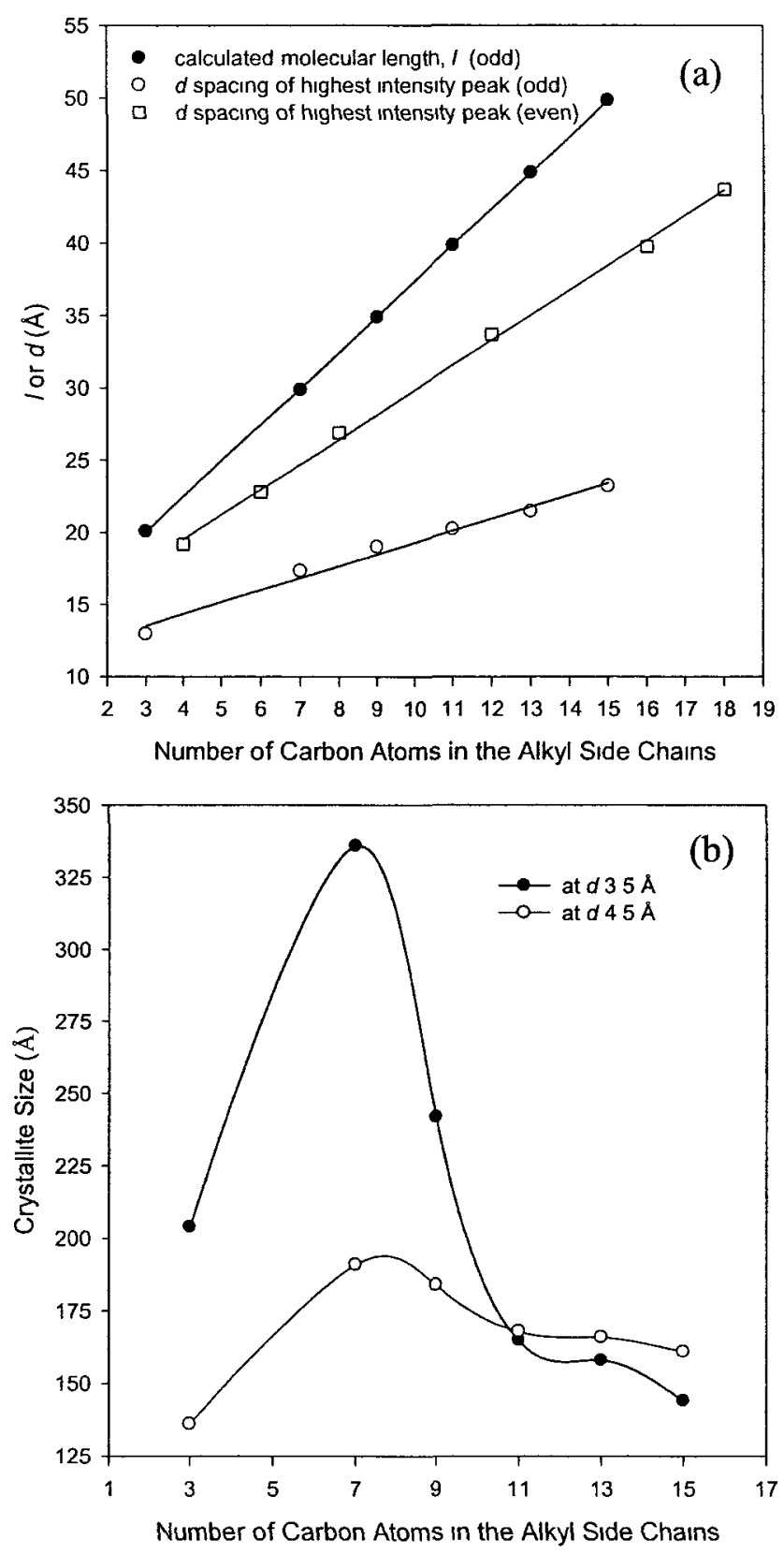

Figure 3.4. Variations of the (a) molecular length $(l)$ and $d$-spacings of the highest intensity peak, and (b) crystallite size $(L)$ corresponding to the $d 3.5$ and $4.3 \AA$ reflections as a function of alkyl side chain length of the biscarbamates.

It is seen from this figure that the crystallite size at $d=3.5 \AA$ increases sharply with the increase in alkyl chain length from $C_{3}$ to $C_{7}$ and decreases significantly with further increase. A similar trend is seen with the reflection at $d=4.3 \AA$ with less extent of 
variation in crystallite size. This observation conforms to the variation of spherulite size and rate of crystallization of these molecules (vide infra). A comparison of crystallite sizes of the corresponding reflections of both the odd and even biscarbamates reveal that odd biscarbamates show larger crystallite size than the corresponding even biscarbamate.

Another feature that is seen commonly amongst the biscarbamates with even and odd alkyl side chains as well as the longer $C_{12}$ spacer (Chapter 4 ) is that apart from the high intensity reflection with the large $d$-spacing (which we relate to the length of the molecule), most of the other reflections are weak, as seen in Figure 3.5 for $\mathrm{C}_{3} \mathrm{C}_{6}$ and $\mathrm{C}_{15} \mathrm{C}_{6}$. As will be seen later (Figure 4.10 of Chapter 4), this effect is pronounced with the longer side chains. This indicates predominant columnar stacking along one direction.

\subsubsection{Morphology}

Polarized optical microscopy was used to investigate the morphology of these biscarbamate samples prepared with two different sample preparation protocols. Figure 3.6 shows the cross polarized optical micrographs of the quenched (left) and slow-cooled (right) samples of the corresponding $\mathrm{C}_{\mathrm{x}} \mathrm{C}_{6}$ biscarbamates. All of these samples show spherulitic morphology with varying extent of optical birefringence. The $\mathrm{C}_{3} \mathrm{C}_{6}$ biscarbamate having the lowest number of carbon atoms studied in this series shows well defined spherulitic morphology for both quenched and slow-cooled samples. This is in contrast to the morphological behaviour of the corresponding $\mathrm{C}_{4} \mathrm{C}_{6}$ biscarbamate which showed no spherulitic morphology for either quenched or slow-cooled sample. 
(a)

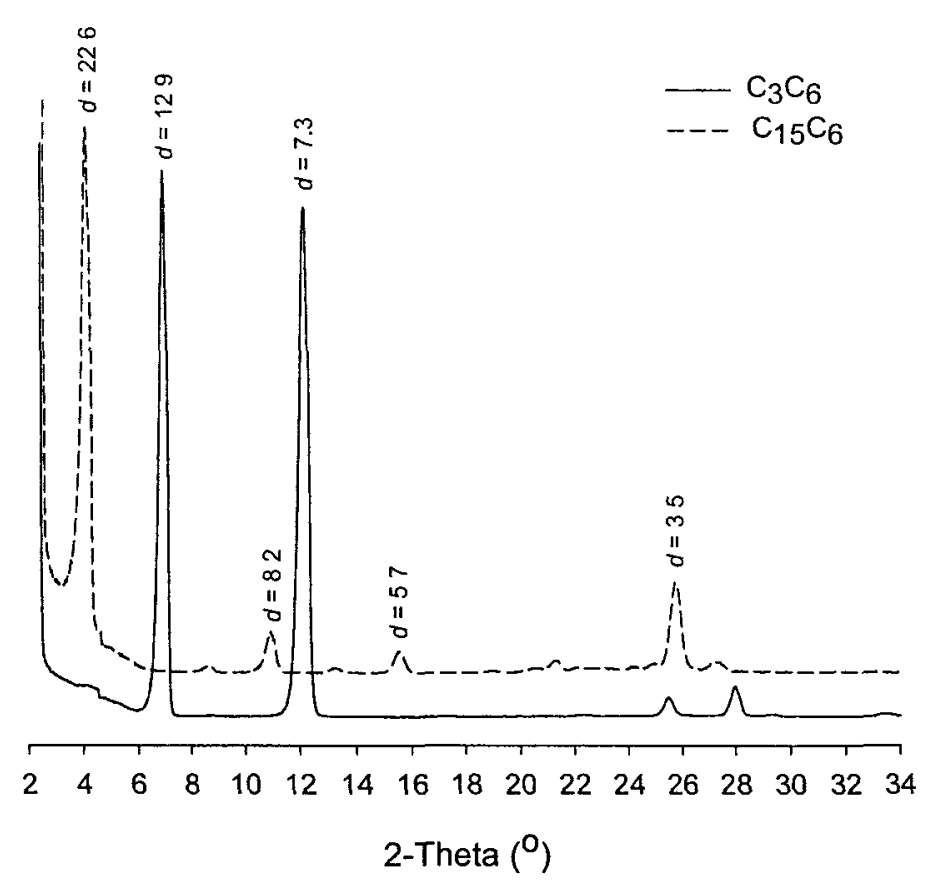

(b)

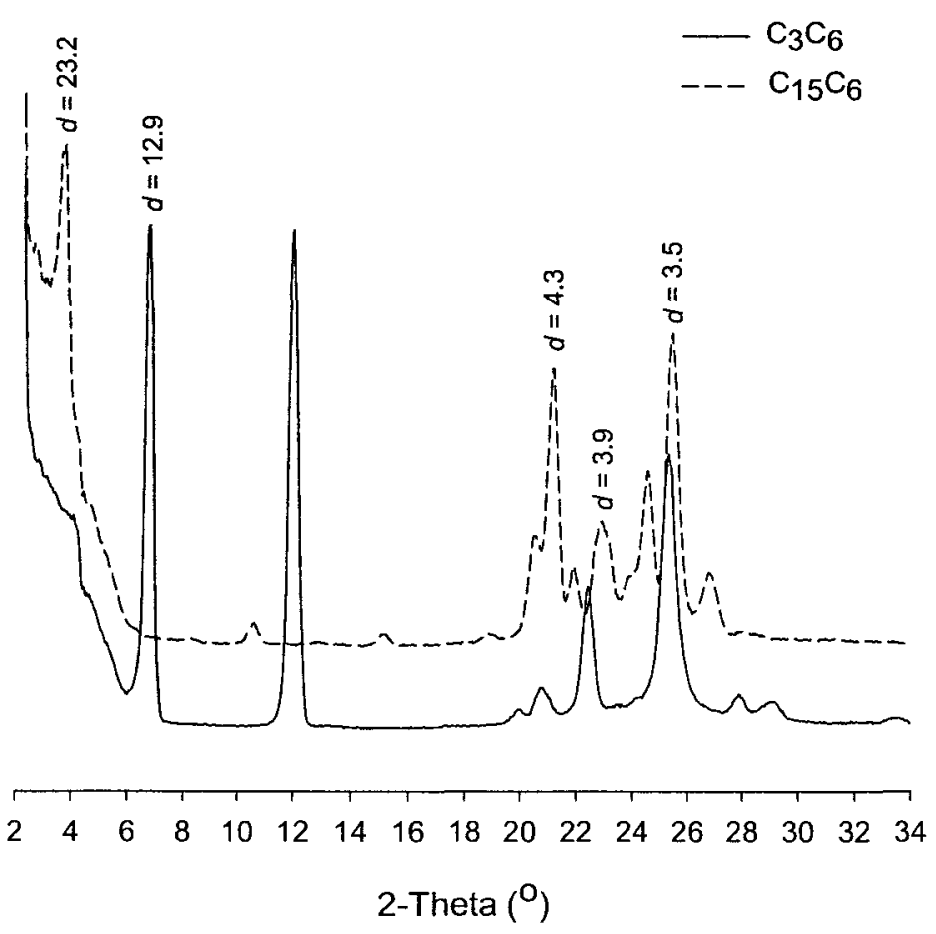

Figure 3.5. X-ray diffraction traces of (a) as synthesized, and (b) slow-cooled samples of $\mathrm{C}_{3} \mathrm{C}_{6}$ and $\mathrm{C}_{15} \mathrm{C}_{6}$ biscarbamates. $d$-spacing values are in $\AA$. 
It is seen from Figure 3.6 that the slow-cooled samples of these biscarbamates form larger spherulites than those of quenched samples upon crystallization. Figure 3.7a shows the variation of the spherulite size with respect to the alkyl side chain length for both quenched and slow-cooled samples.
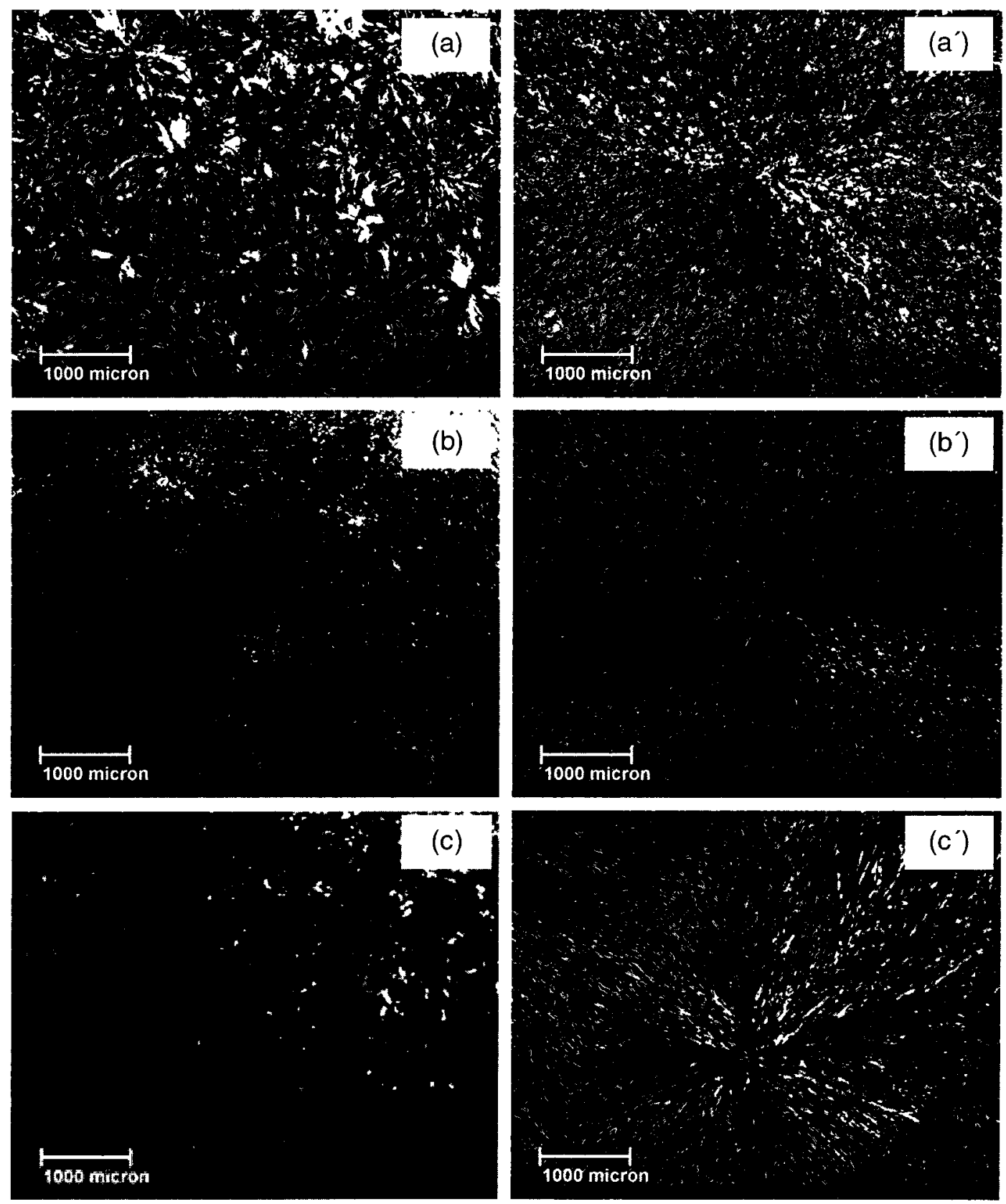

Caption on next page 

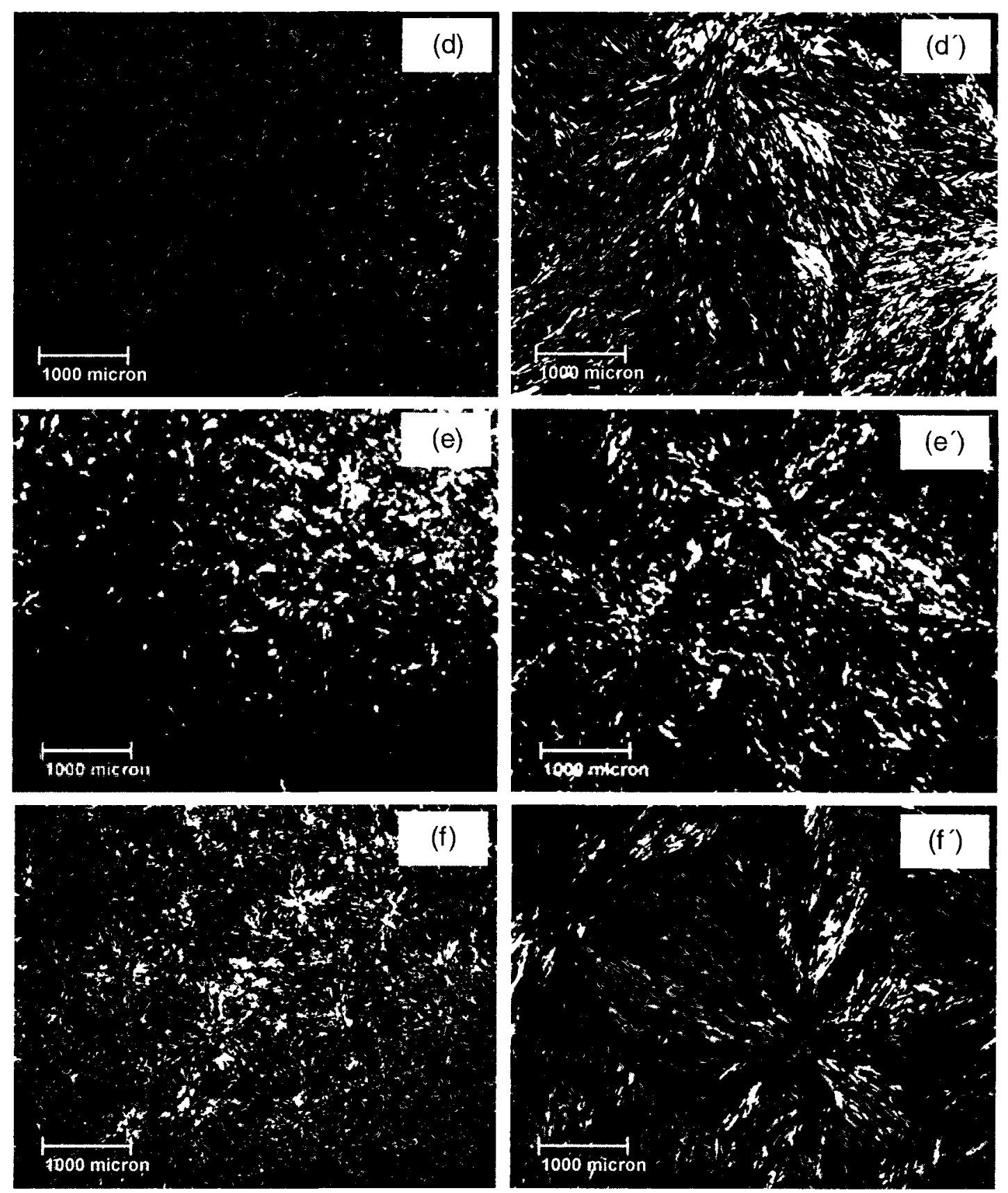

Figure 3.6. Optical micrographs of biscarbamates with different odd number of carbon atoms in the alkyl side chains: (a, a ) $\mathrm{C}_{3},\left(\mathrm{~b}, \mathrm{~b}^{\prime}\right) \mathrm{C}_{7},\left(\mathrm{c}, \mathrm{c}^{\prime}\right) \mathrm{C}_{9},\left(\mathrm{~d}, \mathrm{~d}^{\prime}\right) \mathrm{C}_{11},\left(\mathrm{e}, \mathrm{e}^{\prime}\right) \mathrm{C}_{13}$, and $\left(f, f^{\prime}\right)$ biscarbamates. The first column represents the micrographs of quenched samples and the second column represents those of slowcooled samples. 

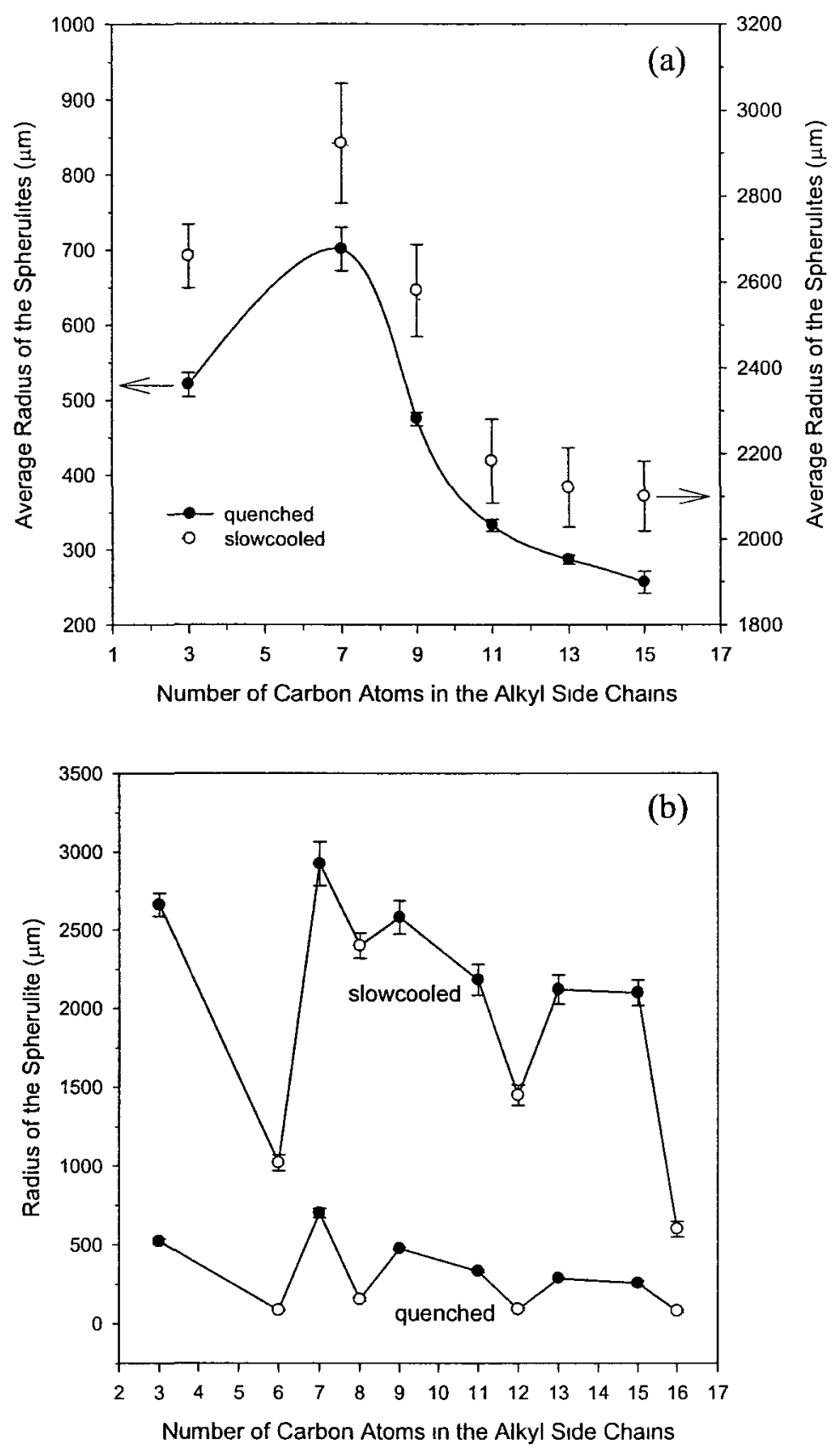

Figure 3.7. Variation of spherulite size of $\mathrm{C}_{\mathrm{x}} \mathrm{C}_{6}$ biscarbamate samples as a function of alkyl side chain length containing odd (a), and both odd and even (b) number of carbon atoms.

Spherulite size of these biscarbamates increases, like their even numbered counterparts, from $\mathrm{C}_{3} \mathrm{C}_{6}$ to $\mathrm{C}_{7} \mathrm{C}_{6}$ with an increase in the alkyl side chain length and then drastically 
decreases up to $C_{11}$ chain length, and more slowly thereafter. Fewer nucleation sites in the samples result in larger spherulites. The variation in nucleation site density and of spherulite size with respect to the alkyl side chain length can be rationalized with the relative contribution of $\mathrm{H}$-bonding and van der Waals interactions of the molecules. Increased intermolecular association is expected to contribute to increased nucleation site density and hence to reduction in the spherulite size. This rationale can be explained with infrared spectroscopy of these biscarbamates. Figure $3.7 \mathrm{~b}$ shows the change in spherulite size of biscarbamates with both odd and even number of carbon atoms. An odd-even oscillation in spherulite size is also seen in this case with a good agreement in such variation of melting temperatures and heat of fusions.

\subsubsection{Spherulite Growth Rate}

The effects of odd versus even number of carbon atoms and the length of alkyl side chains on crystallization of these molecules were further investigated with isothermal spherulite growth kinetics using hot stage microscopy as described in the experimental section. Figure 3.8 shows the micrographs of $\mathrm{C}_{13} \mathrm{C}_{6}$ recorded at different times of spherulite formation from such an experiment. Because of the very fast growth of spherulite, we could not capture the images right at the beginning of the formation of the spherulites centering at the point of nucleation. It is seen from the micrographs that spherulite grows radially with extensive sequential branching of the lamellae over time. The variation of the size of the spherulites as a function of time is shown in Figure 3.9a. It is seen that the spherulite growth is complete due to impinging of the adjacent spherulites within $10 \mathrm{~s}$ for $\mathrm{C}_{7} \mathrm{C}_{6}$ while it takes about 33 and $24 \mathrm{~s}$ for $\mathrm{C}_{3} \mathrm{C}_{6}$ and $\mathrm{C}_{15} \mathrm{C}_{6}$ 
respectively. Thus, biscarbamates with extreme alkyl side chain length show slower spherulite growth rate than that of biscarbamates with intermediate side chain length.
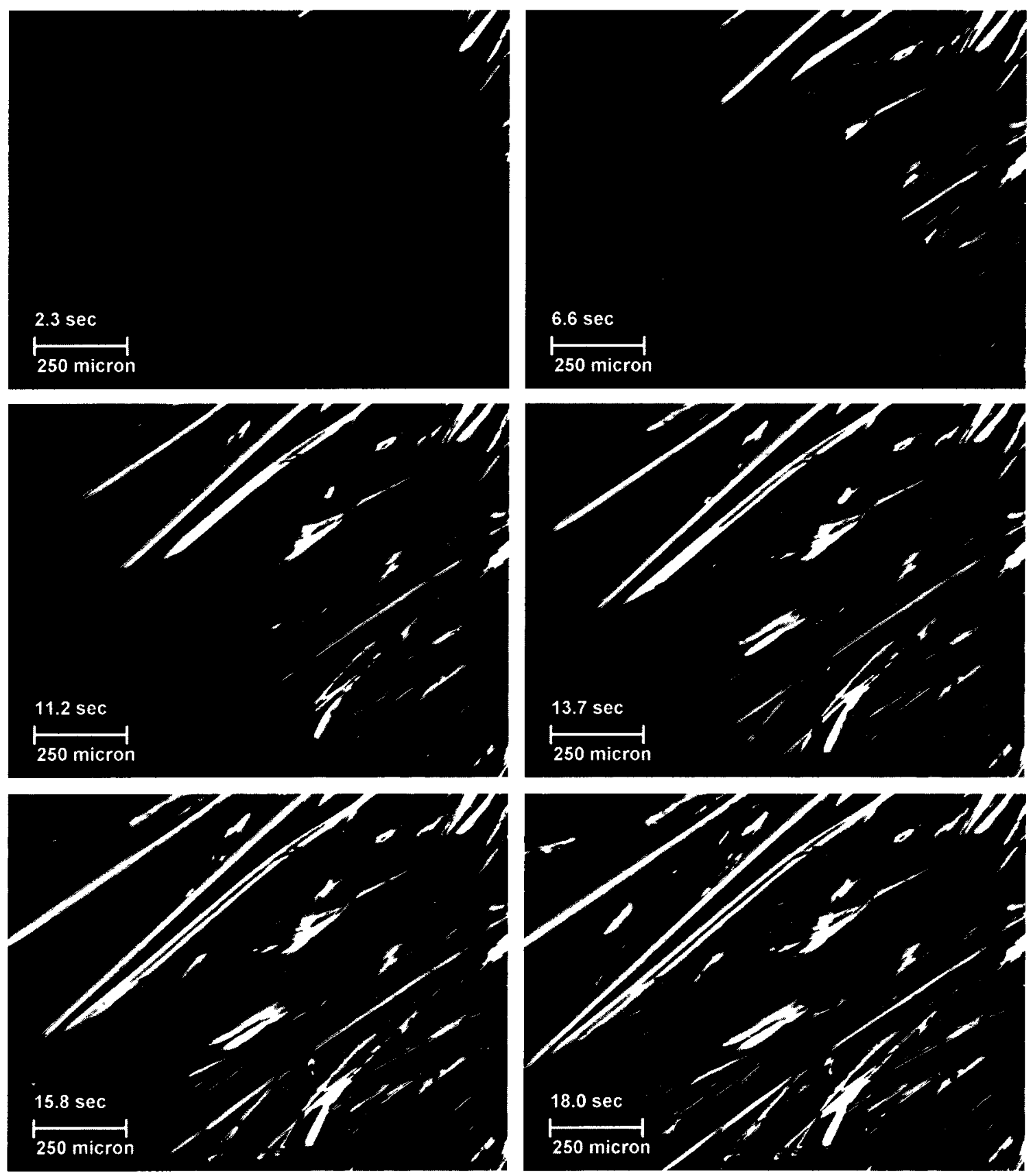

Figure 3.8. Optical micrographs of $\mathrm{C}_{13} \mathrm{C}_{6}$ biscarbamate captured at different time interval during isothermal spherulite growth. 

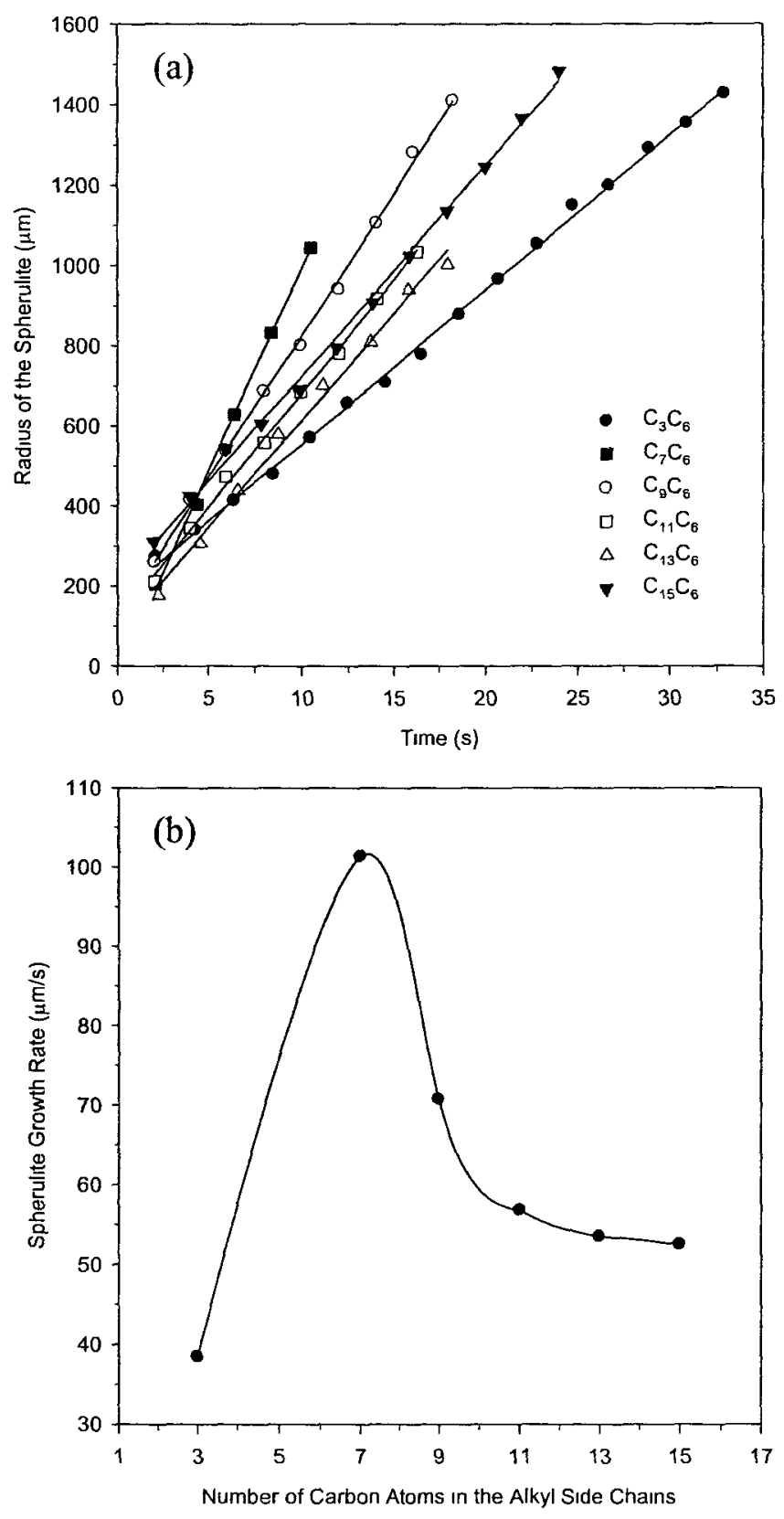

Figure 3.9. (a) Growth of spherulites with time, and (b) rate of spherulite growth as a function of number of carbon atoms in the alkyl side chains.

None of these plots extrapolate to a spherulite size of zero at $t=0 \mathrm{~s}$ indicating a very fast growth of spherulites at the beginning. Figure $3.9 \mathrm{~b}$ shows the spherulite growth rate as a function of alkyl side chain length. It increases from $\mathrm{C}_{3} \mathrm{C}_{6}$ to $\mathrm{C}_{7} \mathrm{C}_{6}$ and decreases 
significantly with the increase in the alkyl side chain length. Along this series of biscarbamates $\mathrm{C}_{7} \mathrm{C}_{6}$ shows the maximum growth rate. This observation conforms with the change in spherulite size of these molecules with respect to the alkyl side chain length. Comparison of the spherulite growth rate of biscarbamates containing odd number of carbon atoms with that of biscarbamates with even number of carbon atoms shows that odd biscarbamates have slower growth rate than the even biscarbamates up to the $C_{12}$ chain length. Beyond $\mathrm{C}_{12}$ chain length there is a trend reversal - odd biscarbamates show higher spherulitic growth rate than the corresponding even biscarbamates. For example, the spherulite growth rate of $C_{7} C_{6}$ is $100 \mu \mathrm{m} / \mathrm{s}$ while that of $C_{8} C_{6}$ is about $120 \mu \mathrm{m} / \mathrm{s}$. The similar trend is seen in the case of $\mathrm{C}_{11} \mathrm{C}_{6} / \mathrm{C}_{12} \mathrm{C}_{6}$ pair where the growth rate of $\mathrm{C}_{11} \mathrm{C}_{6}$ is $55 \mu \mathrm{m} / \mathrm{s}$ and that of $\mathrm{C}_{12} \mathrm{C}_{6}$ is about $65 \mu \mathrm{m} / \mathrm{s}$. However, the spherulite growth rate of $\mathrm{C}_{15} \mathrm{C}_{6}$ is higher $(50 \mu \mathrm{m} / \mathrm{s})$ than that of $\mathrm{C}_{16} \mathrm{C}_{6}$ biscarbamate $(\sim 30 \mu \mathrm{m} / \mathrm{s})$.

\subsubsection{Rate of Isothermal Crystallization}

Isothermal crystallization studies of the samples were performed on the DSC and analyzed using the Avrami approach to further investigate the differences in the crystallization rates between the odd and even number of carbon atoms in the alkyl side chains. Figure 3.10 shows the fractional heat of fusion $(\alpha)$ as a function of time for three representative odd-biscarbamates with extreme and intermediate alkyl side chain length namely, $\mathrm{C}_{3} \mathrm{C}_{6}, \mathrm{C}_{7} \mathrm{C}_{6}$ and $\mathrm{C}_{15} \mathrm{C}_{6}$ as well as $\mathrm{C}_{8} \mathrm{C}_{6}$. Data of the other biscarbamates studied in this series are not shown in this figure for the sake of clarity. As noted with the spherulite size and spherulite growth rate variation, we see a much slower rate of crystallization for the biscarbamates with extreme alkyl side chain length compared to those having 


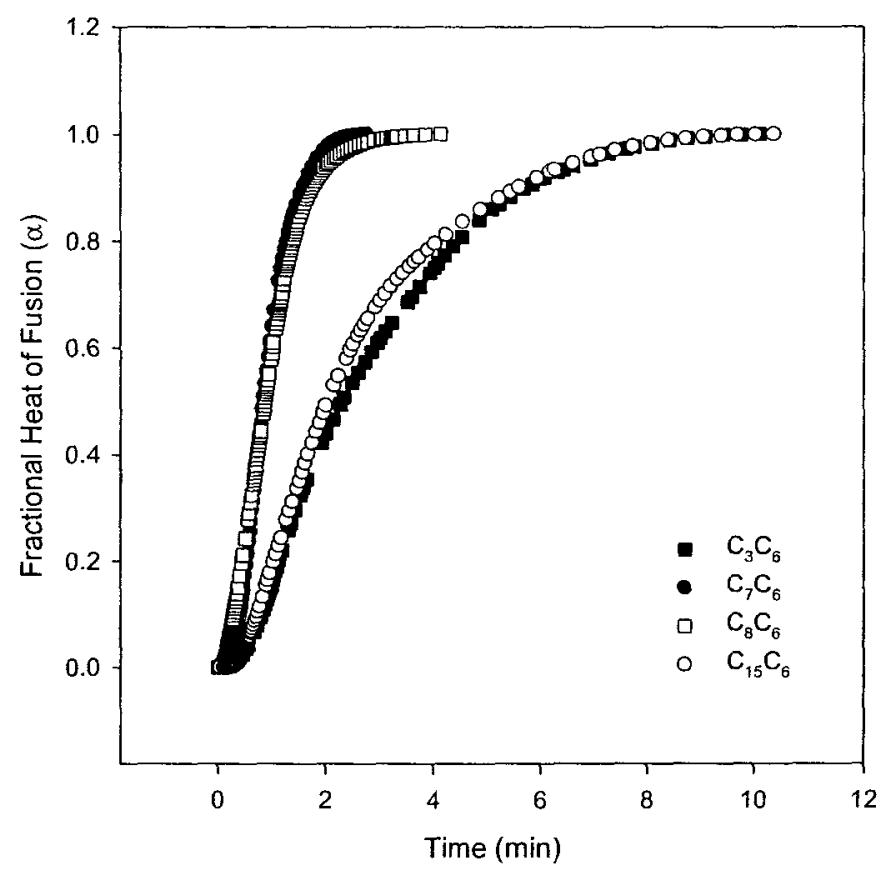

Figure 3.10. Fractional heats of fusion of the biscarbamates as a function of time. Data for other biscarbamates in this series are omitted for clarity.

intermediate side chain length. It is seen from Figure 3.10 that biscarbamate with the shortest side chain length $\left(\mathrm{C}_{3} \mathrm{C}_{6}\right)$ requires longer induction period for the commencement of crystallization while those with longer side chain length (e.g., $\mathrm{C}_{15} \mathrm{C}_{6}$ ) starts crystallization immediately after reaching the desired temperature. However, the faster rate of initial crystallization of longer chain biscarbamates slows down over time with the progress of crystallization and the initial slower crystallization rate of shorter chain length biscarbamate is overcome after certain time period during their isothermal crystallization. Along this series of biscarbamates $\mathrm{C}_{7} \mathrm{C}_{6}$ has the shortest induction time and narrowest peak time range $(1.9 \mathrm{~min})$ compared to those of the extreme chain length biscarbamates (9 min for $\mathrm{C}_{3} \mathrm{C}_{6}$ and $\mathrm{C}_{15} \mathrm{C}_{6}$ respectively) indicating the fastest crystallization rate. It is 
also seen that the rate of crystallization of $\mathrm{C}_{7} \mathrm{C}_{6}$ of the odd series and $\mathrm{C}_{8} \mathrm{C}_{6}$ show very similar growth rates.

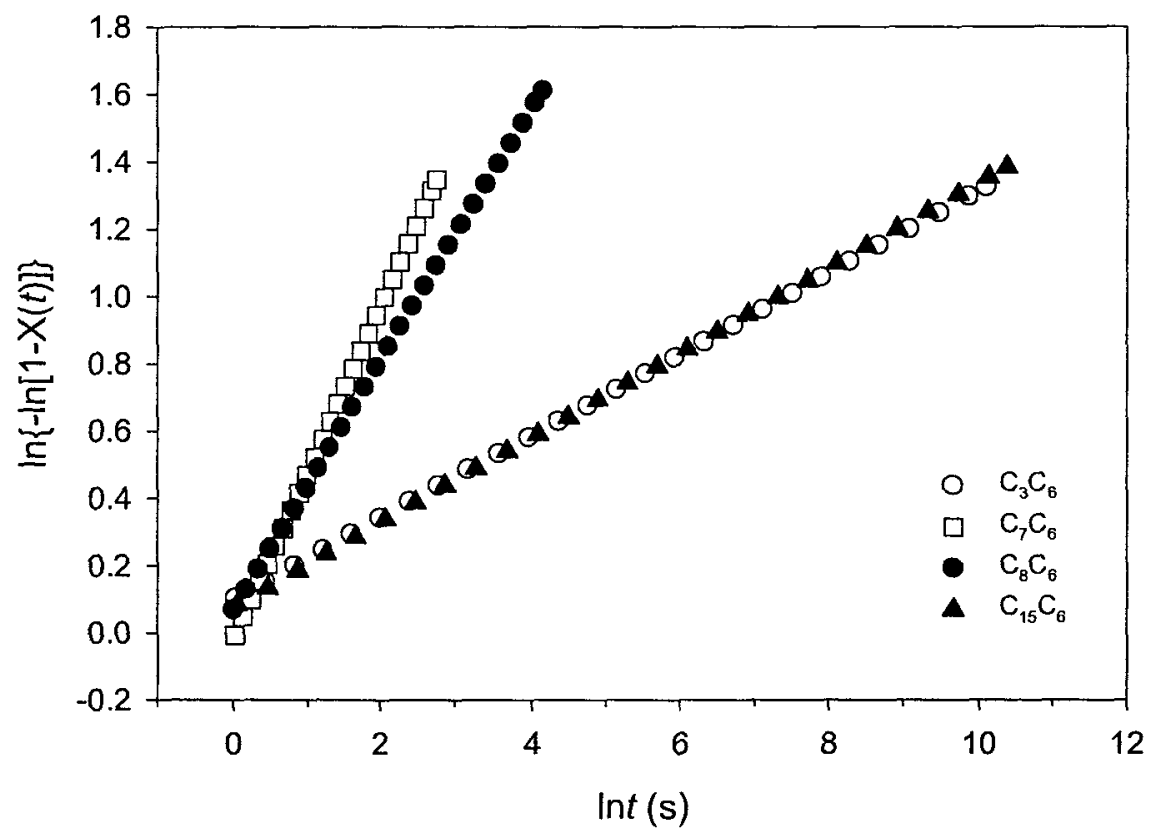

Figure 3.11. Plots of $\ln \{-\ln [1-\mathrm{X}(t)]\}$ versus $\ln t$ during isothermal crystallization of the biscarbamates. Data for other biscarbamates in this series are omitted for clarity.

Figure 3.11 shows the plots of $\ln \{-\ln [1-X(t)]\}$ versus $\ln t$ for biscarbamates crystallized isothermally at their respective crystallization temperatures with a linear relationship between these two parameters. The results derived from the Avrami equation are given in Table 3.4. It is seen that the exponent $n$ is significantly smaller than 3 , varying from 1.6 to 2.5 depending on the side chain length. A decrease of $n$ from 3 shows that the crystallization (nucleation and growth) is not truly three dimensional. This is evident from the eaves trough-like growth of the spherulites seen for $\mathrm{C}_{13} \mathrm{C}_{6}$ in Figure 3.8, which shows the smallest value of $n$. 
Table 3.4. Isothermal Crystallization Data Calculated According to the Avrami Equations and Corresponding Avrami Plots.

\begin{tabular}{lllllll}
\hline Sample & Slope $(n)$ & Intercept $(\ln K)$ & $K$ & $\ln 2 / K$ & $1 / n$ & $t_{1 / 2}(\mathrm{~s})$ \\
\hline $\mathrm{C}_{3} \mathrm{C}_{6}$ & 1.9164 & -8.740 & $1.60 \times 10^{-4}$ & 4332 & 0.5218 & 79 \\
$\mathrm{C}_{7} \mathrm{C}_{6}$ & 2.5795 & -10.241 & $3.56 \times 10^{-5}$ & 19470 & 0.3877 & 46 \\
$\mathrm{C}_{9} \mathrm{C}_{6}$ & 2.2149 & -9.280 & $9.33 \times 10^{-5}$ & 7429 & 0.4515 & 56 \\
$\mathrm{C}_{11} \mathrm{C}_{6}$ & 1.8899 & -8.073 & $3.12 \times 10^{-4}$ & 2221 & 0.5291 & 59 \\
$\mathrm{C}_{13} \mathrm{C}_{6}$ & 1.6390 & -7.353 & $6.41 \times 10^{-4}$ & 1081 & 0.6101 & 71 \\
$\mathrm{C}_{15} \mathrm{C}_{6}$ & 1.9346 & -8.861 & $1.41 \times 10^{-4}$ & 4916 & 0.5169 & 81 \\
\hline
\end{tabular}

The Avrami exponent obtained from the slope of the curves in Figure 3.11 were used to calculate the the $t_{1 / 2}$ (time required for $50 \%$ crystallization) for the respective biscarbamates according to Eq. (3.3). The variation in $t_{1 / 2}$ values as function of alkyl side chain length is shown in Figure 3.12.

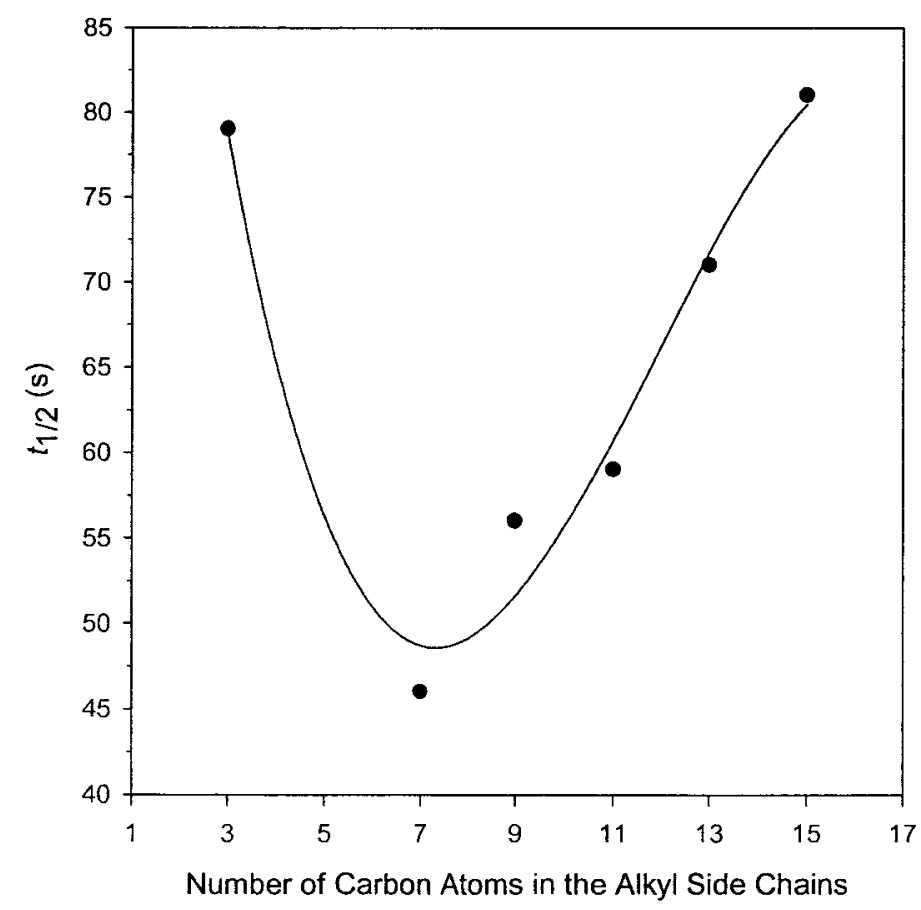

Figure 3.12. Change of half crystallization time, $t_{1 / 2}$ as a function of number of carbon atoms in the alkyl side chains. 
It is seen that $\mathrm{C}_{7} \mathrm{C}_{6}$ has the lowest $t_{1 / 2}$ value and hence the highest crystallization rate along this series while the biscarbamate with extreme side chain length have higher $t_{1 / 2}$ and consequently lower crystallization rate. This observation is in good agreement with their spherulite size and spherulitic growth kinetics. The $t_{1 / 2}$ of $\mathrm{C}_{7} \mathrm{C}_{6}$ and $\mathrm{C}_{11} \mathrm{C}_{6}$ are 46 and $59 \mathrm{~s}$ respectively while that of $\mathrm{C}_{8} \mathrm{C}_{6}$ and $\mathrm{C}_{12} \mathrm{C}_{6}$ studied earlier were only 8 and $40 \mathrm{~s}$ respectively. Comparison of the $t_{1 / 2}$ values of two biscarbamates containing successive odd and even number of carbon atoms show that biscarbamate with even number of carbon atoms show faster crystallization rate than that of the odd biscarbamate with comparable side chain length.

\subsubsection{Infrared Spectroscopy}

Infrared spectroscopy of the biscarbamate molecules containing odd number of carbon atoms in the alkyl side chains was performed with samples prepared with two different protocols i.e., by quenching and slow-cooling. There is no significant difference in the spectral profiles of the slow cooled and quenched samples which indicates that the type of intermolecular interactions of these molecules seemed to be independent of sample preparation protocol (quenching or slow-cooling) and the data presented here are of slow-cooled samples. The spectral data corresponding to $\mathrm{N}-\mathrm{H}, \mathrm{C}=\mathrm{O}$ and $\mathrm{CH}_{2}$ groups are summarized in Tables 3.5 and 3.6. Biscarbamates of this series show $\mathrm{H}$-bonded N-H stretching band at around $3319 \mathrm{~cm}^{-1}$ except for $\mathrm{C}_{3} \mathrm{C}_{6}$ which appears at $3326 \mathrm{~cm}^{-1}$. The $\mathrm{C}=\mathrm{O}$ stretching band of these molecules appears at $1682 \mathrm{~cm}^{-1}$ without any significant shift in position with respect to side chain length. Other two strong absorption bands corresponding to the symmetric and asymmetric stretching vibrations of $\mathrm{CH}_{2}$ groups were 
Table 3.5. Infrared data of $\mathrm{H}$-bonded $\mathrm{N}-\mathrm{H}$, and $\mathrm{C}=\mathrm{O}$ stretching bands of biscarbamates with odd number of carbon atoms in the alkyl side chains.

\begin{tabular}{lccccccc}
\hline & \multicolumn{3}{c}{ H-bonded N-H } & & \multicolumn{3}{c}{ H-bonded C=O } \\
\cline { 2 - 3 } $\mathrm{C}_{3} \mathrm{C}_{6}$ & 3326 & 25.8 & 26.6 & & 1681 & 43.6 & 26.4 \\
$\mathrm{C}_{7} \mathrm{C}_{6}$ & 3320 & 26.9 & 17.1 & & 1681 & 47.7 & 16.7 \\
$\mathrm{C}_{9} \mathrm{C}_{6}$ & 3320 & 25.6 & 18.9 & & 1682 & 52.4 & 21.1 \\
$\mathrm{C}_{11} \mathrm{C}_{6}$ & 3319 & 27.8 & 19.0 & & 1682 & 54.1 & 22.0 \\
$\mathrm{C}_{13} \mathrm{C}_{6}$ & 3318 & 25.9 & 19.5 & & 1682 & 57.2 & 21.4 \\
$\mathrm{C}_{15} \mathrm{C}_{6}$ & 3318 & 25.4 & 19.7 & & 1682 & 58.7 & 24.6 \\
\hline
\end{tabular}

Table 3.6. Infrared data of symmetric $\left(v_{\mathrm{sym}}\right)$, and asymmetric $\left(\mathrm{v}_{\mathrm{asym}}\right) \mathrm{C}-\mathrm{H}$ stretching bands of biscarbamates with different alkyl side chains.

\begin{tabular}{lccccc}
\hline & \multicolumn{2}{c}{ Asymmetric C-H } & & \multicolumn{2}{c}{ Symmetric C-H } \\
\cline { 2 - 3 } \cline { 5 - 5 } Frequency $\left(\mathrm{cm}^{-1}\right)$ & Intensity & & Frequency $\left(\mathrm{cm}^{-1}\right)$ & Intensity \\
\hline $\mathrm{C}_{3} \mathrm{C}_{6}$ & 2938 & 42.5 & 2858 & 28.6 \\
$\mathrm{C}_{7} \mathrm{C}_{6}$ & 2921 & 40.5 & 2856 & 27.0 \\
$\mathrm{C}_{9} \mathrm{C}_{6}$ & 2918 & 40.5 & 2853 & 27.0 \\
$\mathrm{C}_{11} \mathrm{C}_{6}$ & 2917 & 40.5 & 2851 & 27.0 \\
$\mathrm{C}_{13} \mathrm{C}_{6}$ & 2916 & 40.5 & 2851 & 27.0 \\
$\mathrm{C}_{15} \mathrm{C}_{6}$ & 2915 & 40.5 & 2850 & 27.0 \\
\hline
\end{tabular}

observed at around 2853 and $2920 \mathrm{~cm}^{-1}$ respectively. A weak band at around $2953 \mathrm{~cm}^{-1}$ and a very weak band at around $2877 \mathrm{~cm}^{-1}$ corresponding to the $\mathrm{C}-\mathrm{H}$ asymmetric and symmetric vibrations of the terminal $\mathrm{CH}_{3}$ groups are also observed. These latter weak 
bands diminish with the increased contribution of the $\mathrm{CH}_{2}$ groups as the alkyl side chain length increases. Because of the difference in their bond order, $\mathrm{N}-\mathrm{H}$ stretching mode was found to be more susceptible to the change in intermolecular interactions than that of $\mathrm{C}=\mathrm{O}$ group. A similar trend was seen with the symmetric and asymmetric $\mathrm{C}-\mathrm{H}$ vibrations where asymmetric vibrations were found to be more susceptible than the symmetric modes of vibrations. The N-H stretching band of $\mathrm{C}_{3} \mathrm{C}_{6}$ appears at $3326 \mathrm{~cm}^{-1}$ and shifts to $3318 \mathrm{~cm}^{-1}$ for $\mathrm{C}_{15} \mathrm{C}_{6}$ while that of $\mathrm{C}_{4} \mathrm{C}_{6}$ appears at $3321 \mathrm{~cm}^{-1}$ and shifts to $3316 \mathrm{~cm}^{-1}$ for $\mathrm{C}_{16} \mathrm{C}_{6}$. However, the $\mathrm{C}=\mathrm{O}$ bands appear at around $1682 \mathrm{~cm}^{-1}$ for all of these molecules of both the odd and even numbered series. It is seen from Table 3.5 that the full width at half maxima ( $\mathrm{FWHM}$ ) of the $\mathrm{H}-$ bonded $\mathrm{N}-\mathrm{H}$ and $\mathrm{C}=\mathrm{O}$ bands significantly decreases with the increase in alky side length from $C_{3}$ to $C_{7}$. Beyond $C_{7}, F W H M$ increases, although marginally, with further increase in alkyl side chain length. Such variation in the half width is indicative of molecular interactions and was attributed to the crystalline order of simple polyurethanes. ${ }^{24}$ Reduction in half width indicates increase in crystalline order. Thus the lowest half width of the H-bonded $\mathrm{N}-\mathrm{H}$ and $\mathrm{C}=\mathrm{O}$ bands of $\mathrm{C}_{7}$ indicates the highest crystalline order among the biscarbamates of this series studied here. Note that this molecule also showed the largest value of the Avrami exponent, $n$.

The variation of van der Waals interaction as a function of the alkyl side chain length was reflected in the shift of asymmetric $\left(v_{a s}\right)$ and symmetric $\left(v_{s}\right)$ absorption band positions. Figure 3.13 shows that $v_{\text {as }}$ decreases exponentially while $v_{\mathrm{s}}$ follow a sigmoidal decrease with the increase of alkyl side chain length. For $\mathrm{C}_{3}, v_{\text {as }}$ and $v_{\mathrm{s}}$ appear at 2938 and $2858 \mathrm{~cm}^{-1}$ while they shift to 2915 and $2850 \mathrm{~cm}^{-1}$ respectively for $\mathrm{C}_{15}$. 

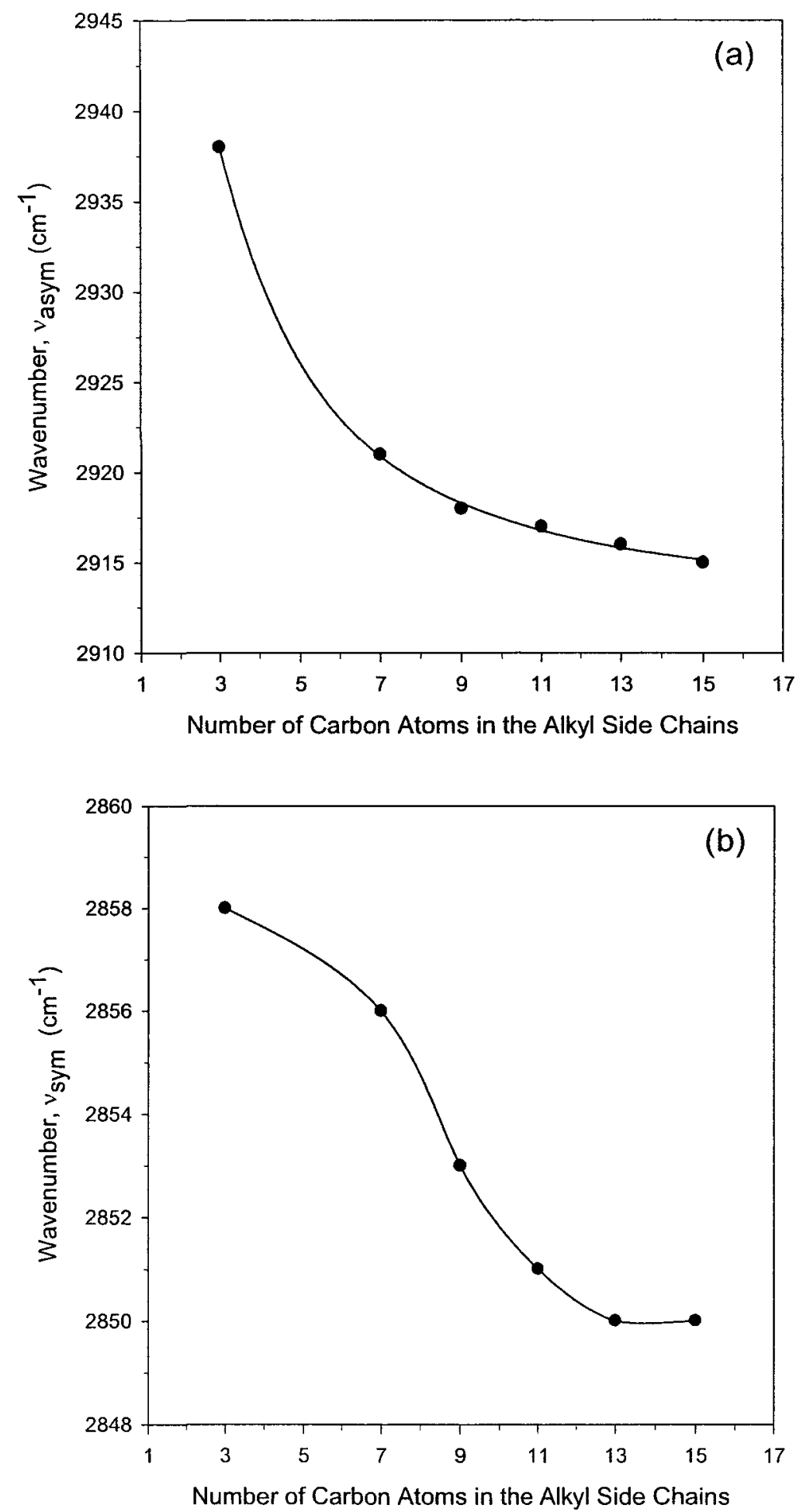

Figure 3.13. Variation of (a) asymmetric and (b) symmetric $\mathrm{CH}_{2}$ stretching vibration frequency of biscarbamates as a function of alkyl side chain length. 
The shift to lower wave number with side chain length reveals the stronger interaction and hence more organization of the alkyl groups via van der Waals forces. Between the two complementary attractive forces, hydrogen bonding dominates over the van der Waals interactions when the alkyl side chain length is short $\left(C_{3}-C_{7}\right)$. With further increase in the alkyl side chain length $\left(\mathrm{C}_{9}-\mathrm{C}_{15}\right)$ van der Waals interactions become more significant leading to enhanced packing of the alkyl side chain length. A similar trend was seen with the biscarbamate with even number of carbon atoms in the alkyl side chain length.

\subsection{Conclusions}

We discussed the crystallization behaviour and morphology of a series of homologous biscarbamate molecules with alkyl side chains of different carbon atom parity. DSC analysis showed that these molecules do not show any polymorphism and are highly crystalline in nature. The melting temperatures of $\mathrm{C}_{\mathrm{x}} \mathrm{C}_{6}$ molecules with odd versus even number of carbon atoms in the alkyl side chains show an odd-even alternation. Biscarbamates with odd number of carbon atoms show higher melting temperatures than the even numbered biscarbamates, which is in contrast to the thermal properties of $n$ alkanes. The heat of fusion shows a relatively less pronounced odd-even effect. Optical microscopy reveals that carbon atom parity in alkyl side chains influences the extent of packing of these molecules leading to spherulitic morphology. $\mathrm{C}_{4} \mathrm{C}_{6}$ biscarbamate does not show any spherulitic morphology whereas $\mathrm{C}_{3} \mathrm{C}_{6}$ forms well defined spherulites upon crystallization from the melt. It is seen that the spherulite size increases with the increase in alkyl side chain length reaching to a maximum at a certain length and then decreases 
with further increase. Hence the length of alkyl side chain, carbon atom parity in the alkyl side chains and sample preparation protocol (i.e., quenching versus slow-cooling) play an important role in the morphology of these molecules. Along this series of molecules, we have seen a maximum spherulite size, spherulite growth rate and rate of crystallization for $\mathrm{C}_{7} \mathrm{C}_{6}$ (odd series) and $\mathrm{C}_{8} \mathrm{C}_{6}$ (even series) biscarbamates. We rationalize this behaviour with relative contribution of hydrogen bonding and van der Waals forces as discerned from IR spectroscopy. Hence, we conclude that the thermal properties and the morphology of these molecules can be tailored to the desired functional level by changing the alkyl side chain length with right carbon atom parity. 


\subsection{References}

1. (a) Lehn, J.-M. Supramolecular Chemistry; VCH: Germany, 1995; (b) Supramolecular Assembly via Hydrogen Bonds II. Structure and Bonding, 111. Edited by D. M. P. Mingos (St. Edmund Hall, Oxford, UK). Springer-Verlag: Berlin, Heidelberg, New York. 2004; (c) Ikeda, M.; Nobori, T.; Schmutz, M.; Lehn, J.-M. Chem. Eur. J. 2005, 11, 662.

2. Special Issue on Supramolecular Chemistry and Self-Assembly, Service, R. F.; Szuromi, P.; Uppenbrink, J. Eds. Science 2002, 295, 2395.

3. (a) Tew, G. N., Scott, R. W., Klein, M. L.; Degrado,W. F. Acc. Chem. Res. 2010, 43, 30; (b) Horne W. S.; Gellman, S. H. Acc. Chem. Res. 2008, 41, 1399; (c) Gellman, S. H. Acc. Chem. Res. 1998, 31, 173; (d) Hill, D. J.; Mio, M. J.; Prince, R. B.; Hughes, T. S.; Moore, J. S. Chem. Rev. 2001, 101, 3893.

4. (a) Sanford, A. R.; Yamato, K.; Yang, X.; Yuan, L.; Han, Y.; Gong, B. Eur. J. Biochem. 2004, 271, 1416; (b) Yang, X.; Martinovic, S.; Smith, R. D.; Gong, B. J. Am. Chem. Soc. 2003, 125, 9932; (c) Archer, E. A.; Gong, H.; Krische, M. J. Tetrahedron 2001, 57, 1139.

5. Zimmerman, S. C.; Corbin, P. S. Struct. Bonding (Berlin) 2000, 94, 63.

6. (a) Moniruzzaman, M.; Goodbrand, B.; Sundararajan, P. R. J. Phys. Chem. B 2003, 107, 8416; (b) Moniruzzaman, M.; Sundararajan, P. R. Langmuir 2005, 21, 3802.

7. (a) Khanna, S.; Moniruzzaman, M.; Sundararajan P. R. J. Phys. Chem. B 2006, 110, 15251; (b) Khanna, S.; Khan, M. K.; Sundararajan, P. Langmuir 2009, 25, 13183.

8. Tao, F.; Bernasek, S. L. Chem. Rev. 2007, 107, 1408. 
9. (a) Badea, E.; Gatta, G. D.; D’Angelo, D.; Brunetti, B.; Rečková, Z. J. Chem. Thermodynamics 2006, 38, 1546; (b) Duer, M. J.; Roper, C. Phys. Chem. Chem. Phys. 2003, 5, 3034.

10. (a) Pistolis, G.; Andreopoulou, A. K.; Malliaris, A.; Kallitsis, J. K. J. Phys. Chem. B 2005, 109, 11538; (b) Meister, A.; Drescher, S.; Garamus, V. M.; Karlsson, G.; Graf, G.; Dobner, B.; Blume, A. Langmuir 2008, 24, 6238; (c) Stals, P. J. M.; Smulders, M. M. J.; Martín-Rapún, R.; Palmans, A. R. A.; Meijer, E. W. Chem. Eur. J. 2009, 15, 2071.

11. (a) Kikkawa, Y.; Koyama, E.; Tsuzuki, S.; Fujiwara, K.; Kanesato, M. Langmuir 2010, 26, 3376; (b) Tong, W.; Wei, Y.; Armbrust, K. W.; Zimmt, M. B. Langmuir $\mathbf{2 0 0 9}, 25,2913$.

12. Boese, R.; Weiss, H-C.; Bläser, D. Angew. Chem. Int. Ed. 1999, 38, 988.

13. (a) Šepelj, M.; Lesac, A.; Baumeister, U.; Diele, S.; Bruce, D. W.; Hameršak, Z. Chem. Mater. 2006, 18, 2050; (b) Mather, P. T.; Jeon, H. G.; Han, C. D.; Chang, S. Macromolecules 2002, 35, 1326; (c) Mizuno, M.; Hirai, A.; Matsuzawa, H.; Endo, K.; Suhara, M.; Kenmotsu, M.; Han, C. D. Macromolecules 2002, 35, 2595.

14. Fernández, C. E.; Bermúdez, M.; Munoz-Guerra, S.; León, S.; Versteegen, R. M.; Meijer, E. W. Macromolecules 2010, 43, 4161.

15. Briard, A-J.; Bouroukba, M.; Petitjean, D.; Dirand, M. J. Chem. Eng. Data 2003, 48, 1574.

16. Tao, F.; Goswami, J.; Bernasek, S. L. J. Phys. Chem. B 2006, 110, 4199.

17. Morishige, K.; Kato, T. J. Chem. Phys. 1999, 111, 7095. 
18. (a) Tao, F.; Bernasek, S. L. Langmuir 2007, 23, 3513; (b) Wintgens, D.; Yablon, D. G.; Flynn, G. W. J. Phys. Chem. B 2003, 107, 173.

19. (a) Kim, K.; Plass, K. E.; Matzger A. J. J. Am. Chem. Soc. 2005, 127, 4879; (b) Asha, S. K.; Kavita, K.; Das, P. K.; Ramakrishnan, S. Chem. Mater. 1999, 11, 3352; (c) Aoki, K.; Kudo, M.; Tamaoki, N. Org. Lett. 2004, 6, 4009.

20. (a) Goel, M.; Jayakannan, M. J. Phys. Chem. B 2010, 114, 12508; (b) Wei, Y.; Kannappan, K.; Flynn, G. W.; Zimmt, M. B. J. Am. Chem. Soc. 2004, 126, 5318.

21. Khan, M. K.; Sundararajan, P. R. J. Phys. Chem. B 2008, 112, 4223.

22. Goodbrand, B.; Boils, D.; Sundararajan, P. R.; Wong, R. U. S. Patent 6,414,051, 2002.

23. (a) Avrami, M. J. Chem. Phys. 1939, 7, 1103; (b) Avrami, M. J. Chem. Phys. 1941, $9,177$.

24. Coleman, M. M.; Lee, K. H.; Skrovanek, D. J.; Painter, P. C. Macromolecules 1986, $19,2149$. 
Chapter 4

Influence of Spacer Length and the Type of Terminal Groups of Alkyl Side Chains on the Morphology and Crystallization Behavior of Biscarbamates 


\subsection{Introduction}

While appropriate design of molecules with hydrogen bonding moieties leads to supramolcular assembly, controlling the morphology of the structures created by such assembly still remains as a challenge. Moreover, depending on the conditions of solidification, molecular self-assembly may lead to formation of single crystals, spherulites or gels of the materials. If a process, for example, allows the material to solidify with large spherulitic morphology, the resultant solid would suffer from brittleness and the lack of optical clarity. It thus becomes an important attribute to tailor both molecular structure and the process protocol to achieve the desired morphology and functionality of the materials. To this end, we have been studying the influence of side chain length as well as single versus double hydrogen-bond motifs on the morphology and miscibility behavior upon crystallization, blending and gelation of a class of hydrogen-bond mediated self-assembling system of carbamates ${ }^{1,2}$ and biscarbamates ${ }^{3,4}$ because of their various potential applications as described in Chapter 1 .

In our previous publications ${ }^{1-4}$ we studied and compared the morphology and thermal behaviour of N-octadecyl carbamates referred therein as simple or monocarbamates and biscarbamates with alkyl side chains of various lengths ranging from $\mathrm{C}_{4}$ to $\mathrm{C}_{18}$. We observed significant differences in their morphology and thermal properties which were attributed to the influence of single versus double hydrogen bonding motifs as well as asymmetric versus symmetric alkyl substitution of the molecules. The monocarbamates showed an increase in spherulite size with the alkyl side chain length. However, with biscarbamates, the maximum spherulite size and growth rate 
were observed for $\mathrm{a}_{8}$ alkyl side chain. These observations were rationalized on the basis of the relative contributions of hydrogen-bond and van der Waals forces.

Changing the alkyl spacer and side group length to modulate the ratio of hydrophobicity to hydrophilicity of a molecule is a trivial but effective technique. There has been a report that describes the effects of spacer group length on critical micelle concentration in self-organization and micelle formations of polymerizable amphiphilic organophosphorous surfactants. ${ }^{5}$ In other studies, Kawatsuki et al. ${ }^{6}$ showed that alkyl spacer length affects the photoinduced molecular reorientation and LC alignment in liquid crystalline methacrylate polymers.

In this chapter, we discuss the influence of spacer group length and the type of terminal group (i.e., methyl versus phenyl) of the alkyl side chains on the morphology and thermal behaviour of a set of biscarbamates. We synthesized a series of molecules containing a spacer group which is twice the length of that of previously studied biscarbamates and with alkyl side chains of variable length symmetrically attached to the hydrogen bonding moieties. For the purpose of this study, we designate these molecules as $\mathrm{C}_{\mathrm{x}}-\mathrm{C}_{6}$ and $\mathrm{C}_{\mathrm{x}}-\mathrm{C}_{12}$ where $\mathrm{x}$ refers to the number of carbon atoms in the alkyl side chains and numbers 6 or 12 refer to the number of $\mathrm{CH}_{2}$ units in the spacer group between the hydrogen-bonding moieties. We also synthesized a token compound with alkyl side chains terminated with phenyl groups instead of terminal methyl groups and designate it as $\mathrm{PhC}_{6}-\mathrm{C}_{12}$. The molecules studied here are shown in scheme 4.1. 
Biscarbamate:
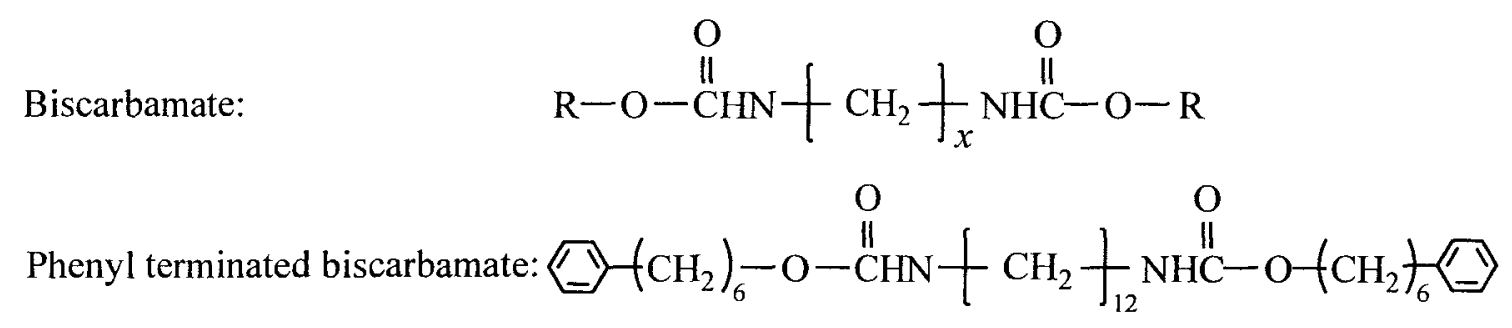

$$
\mathrm{R}=n \text { - alkyl, number of } \mathrm{C} \text { atoms ranges from } 4 \text { to } 18 ; x=6 \text { or } 12
$$

\section{Scheme 4.1}

We believe that the increase in spacer length would lead to an increase in the relative contribution of the van der Waals forces with respect to that of hydrogen bonding which remains constant in all the molecules in this series. This in turn would result in morphologies different from those observed with a $\left(\mathrm{CH}_{2}\right)_{6}$ spacer. The substitution of the terminal methyl group with a bulky phenyl group is supposed to affect the molecular organization of the molecules. In this study, we discuss the observed properties of these molecules and compare them with previously studied biscarbamates with different spacer length and alkyl terminal groups in terms of their morphology and thermal behaviour.

\subsection{Results and Discussion}

\subsubsection{Thermal Behaviour}

The biscarbamates studied here showed a single sharp transition in the DSC corresponding to their melting in the heating cycle and crystallization from melt to solid in the cooling cycle as shown in Figure 4.1. The sharp melting peak without any other transitions prior to melting indicate the purity, crystallinity and the absence of any polymorphism in these samples. 


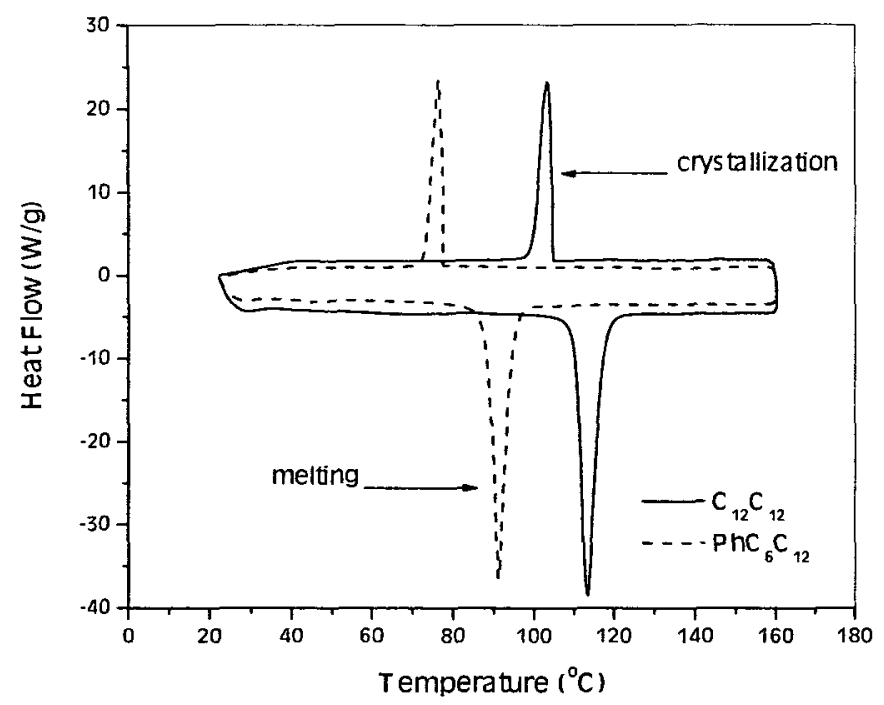

Figure 4.1. DSC traces of biscarbamates showing phase transitions corresponding to melting and crystallization in the heating and cooling cycles respectively.

The melting temperatures of these compounds are shown in Table 4.1 and Figure 4.2 along with those of another set of previously studied homologous biscarbamates with a $\left(\mathrm{CH}_{2}\right)_{6}$ spacer between the hydrogen bonding moieties. If we consider that an increase in molecular flexibility would lead to a decrease in the melting temperature, based on a comparison of the melting temperatures, we find that increasing the spacer length from $\mathrm{C}_{6}$ to $\mathrm{C}_{12}$ does not lead to an increase in flexibility of the molecules. Sandwiched between two hydrogen bonding moieties, the longer alkyl spacer enhances the van der Waals interaction and leads to higher melting temperatures. Figure $4.2 \mathrm{a}$ shows that the melting temperatures $\left(T_{\mathrm{m}}\right)$ of these biscarbamates increase with the alkyl side chain length. The effect of the alkyl chain length on the $T_{\mathrm{m}}$ is more significant with the $\mathrm{C}_{6}$ spacer than the $\mathrm{C}_{12}$. With the shorter spacer, the $T_{\mathrm{m}}$ increases by $29^{\circ} \mathrm{C}$ (from 91 to $120^{\circ} \mathrm{C}$ ) as the side chain length increases from $C_{4}$ to $C_{18}$, whereas the increase is only $16{ }^{\circ} \mathrm{C}$ with the $C_{12}$ 
spacer. In addition, with the $\left(\mathrm{CH}_{2}\right)_{6}$ spacer, an increase of $\sim 15{ }^{\circ} \mathrm{C}$ is seen between $\mathrm{C}_{4}$ and $\mathrm{C}_{8}$ side chains. However, the increase is only $7^{\circ} \mathrm{C}$ with the $\mathrm{C}_{12}$ spacer.

Table 4.1. Comparison of the melting temperatures of the biscarbamates with different spacer groups and alkyl side chains.

\begin{tabular}{|c|c|c|c|c|c|}
\hline \multicolumn{3}{|c|}{$\mathrm{C}_{\mathrm{x}} \mathrm{C}_{12}$ B1scarbamate } & \multicolumn{3}{|c|}{$\mathrm{C}_{\mathrm{x}} \mathrm{C}_{6}$ Biscarbamate $^{3}$} \\
\hline ID & molecular formula & $T_{\mathrm{m}},{ }^{\circ} \mathrm{C}$ & ID & molecular formula & $T_{\mathrm{m}},{ }^{\circ} \mathrm{C}$ \\
\hline $\mathrm{C}_{4}-\mathrm{C}_{12}$ & $\mathrm{H}_{9} \mathrm{C}_{4} \mathrm{OOCNH}\left(\mathrm{CH}_{2}\right)_{12} \mathrm{NHCOOC}_{4} \mathrm{C}_{9}$ & 1013 & $\mathrm{C}_{4}-\mathrm{C}_{6}$ & $\mathrm{H}_{9} \mathrm{C}_{4} \mathrm{OOCNH}\left(\mathrm{CH}_{2}\right)_{6} \mathrm{NHCOOC}_{4} \mathrm{C}_{9}$ & 913 \\
\hline $\mathrm{PhC}_{6}-\mathrm{C}_{12}$ & $\mathrm{PhH}_{12} \mathrm{C}_{6} \mathrm{OOCNH}\left(\mathrm{CH}_{2}\right)_{12} \mathrm{NHCOOC}_{6} \mathrm{C}_{12} \mathrm{Ph}$ & 9114 & $\mathrm{C}_{6}-\mathrm{C}_{6}$ & $\mathrm{H}_{13} \mathrm{C}_{6} \mathrm{OOCNH}\left(\mathrm{CH}_{2}\right)_{6} \mathrm{NHCOOC}_{6} \mathrm{C}_{13}$ & 971 \\
\hline $\mathrm{C}_{8}-\mathrm{C}_{12}$ & $\mathrm{H}_{17} \mathrm{C}_{8} \mathrm{OOCNH}\left(\mathrm{CH}_{2}\right)_{12} \mathrm{NHCOOC}_{8} \mathrm{C}_{17}$ & 1081 & $\mathrm{C}_{8}-\mathrm{C}_{6}$ & $\mathrm{H}_{17} \mathrm{C}_{8} \mathrm{OOCNH}\left(\mathrm{CH}_{2}\right)_{6} \mathrm{NHCOOC} \mathrm{C}_{17}$ & 1066 \\
\hline $\mathrm{C}_{12}-\mathrm{C}_{12}$ & $\mathrm{H}_{25} \mathrm{C}_{12} \mathrm{OOCNH}\left(\mathrm{CH}_{2}\right)_{12} \mathrm{NHCOOC}_{12} \mathrm{C}_{25}$ & 1134 & $\mathrm{C}_{12}-\mathrm{C}_{6}$ & $\mathrm{H}_{25} \mathrm{C}_{12} \mathrm{OOCNH}\left(\mathrm{CH}_{2}\right)_{6} \mathrm{NHCOOC}_{12} \mathrm{C}_{25}$ & 1149 \\
\hline $\mathrm{C}_{18}-\mathrm{C}_{12}$ & $\mathrm{H}_{37} \mathrm{C}_{18} \mathrm{OOCNH}\left(\mathrm{CH}_{2}\right)_{12} \mathrm{NHCOOC}_{18} \mathrm{C}_{37}$ & 1176 & $\mathrm{C}_{18}-\mathrm{C}_{6}$ & $\mathrm{H}_{37} \mathrm{C}_{18} \mathrm{OOCNH}\left(\mathrm{CH}_{2}\right)_{6} \mathrm{NHCOOC}_{18} \mathrm{C}_{37}$ & 1204 \\
\hline
\end{tabular}

Thus, the effect of the alkyl side chain becomes less pronounced with the longer spacer. In both cases, the increase in $T_{\mathrm{m}}$ becomes less significant as the side chain length increases (e.g., from $\mathrm{C}_{12}$ to $\mathrm{C}_{18}$ ). Similar decrease in increment of $T_{\mathrm{m}}$ with an increase in side chain length was also observed with aliphatic polyurethanes. ${ }^{7}$ It is also seen that with the $\mathrm{C}_{4}$ side chain, the $T_{\mathrm{m}}$ is higher by $10^{\circ} \mathrm{C}$ with the $\mathrm{C}_{12}$ spacer. With a short $\mathrm{C}_{4}$ side chain, the van der Waals interaction promoted by the longer $C_{12}$ spacer leads to an increase in $T_{\mathrm{m}}$, relative to the $\mathrm{C}_{6}$ spacer. The difference becomes less with an increase in side chain length. With both spacers, the $T_{\mathrm{m}}$ approaches that of short chain polyethylene. 

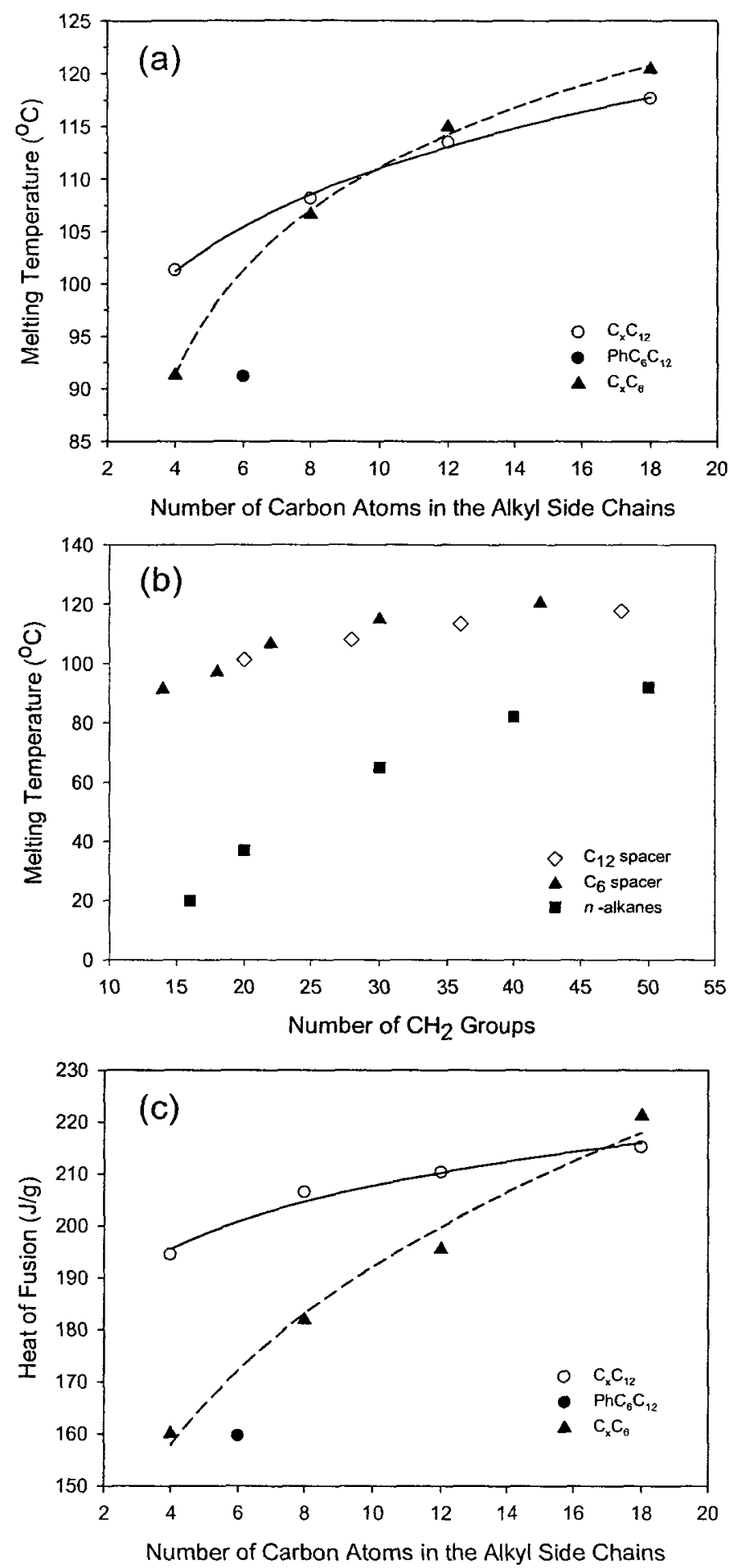

Figure 4.2. The variation of (a) melting temperature of biscarbamates as a function of alkyl side chain length with $\left(\mathrm{CH}_{2}\right)_{6}(----)$ and $\left(\mathrm{CH}_{2}\right)_{12}(-)$ spacers; (b) $T_{\mathrm{m}}$ as a function of the total number of $\left(\mathrm{CH}_{2}\right)$ groups in the biscarbamates and n-alkanes; (c) heats of fusion. The $T_{\mathrm{m}}$ and $H_{\mathrm{f}}$ for the phenyl terminated $\mathrm{C}_{6} \mathrm{C}_{12}$ are also shown in (a) and (c). 
The van der Waals and hydrogen bond interactions play a role in the variation of the $T_{\mathrm{m}}$ with the length of the spacer and the side chain. Let us consider the number of carbon atoms (not including the carbonyl carbons) in the biscarbamate molecules with $\mathrm{C}_{6}$ and $\mathrm{C}_{12}$ spacers. Figure $4.2 \mathrm{~b}$ shows a plot of the $T_{\mathrm{m}}$ versus the number of carbon atoms in the biscarbamates. It is seen that irrespective of the spacer length, $T_{\mathrm{m}}$ values fall on the same curve. (We see the difference in the variation of $T_{\mathrm{m}}$ between the two cases in Figure $4.2 \mathrm{a}$ since the alkyl side chains are placed differently). A common attribute is the contribution from the two hydrogen bond moieties. The melting temperatures of n-alkanes are also plotted in Figure 4.2b. There is difference of $71{ }^{\circ} \mathrm{C}$ in $T_{\mathrm{m}}$ between $\mathrm{C}_{4}-\mathrm{C}_{6}$ and hexadecane (both having 16 carbon atoms), which can be attributed to the presence of two hydrogen bonds in the biscarbamate. We attribute the difference in the $T_{\mathrm{m}}$ of an n-alkane and the biscarbamate (having the corresponding number of alkyl carbon atoms) to the hydrogen bond contribution. As the number of carbons in the molecule increases, the relative contribution of the hydrogen bonds decreases with respect to the van der Waals interaction. The difference in $T_{\mathrm{m}}$ is only $25{ }^{\circ} \mathrm{C}$ between $\mathrm{C}_{18}-\mathrm{C}_{12}$ and pentacontane $\left[\mathrm{CH}_{3}\left(\mathrm{CH}_{2}\right)_{48} \mathrm{CH}_{3}\right]$.

While the biscarbamates studied before had hydrogen bonding and van der Waals interactions, the purpose of introducing a phenyl termination $\left(\mathrm{PhC}_{6} \mathrm{C}_{12}\right)$ in this work was to include a third self-assembling code, namely $\pi$-stacking. Such a system with three self-assembling codes is expected to be highly stabilized, with a high $T_{\mathrm{m}}$. However, the phenyl terminated $\mathrm{PhC}_{6}-\mathrm{C}_{12}$ biscarbamate has a lower melting temperature $\left(91.3{ }^{\circ} \mathrm{C}\right)$ than that of $\mathrm{C}_{4}-\mathrm{C}_{12}$ biscarbamate $\left(101.3^{\circ} \mathrm{C}\right.$ ) (Figure 4.2). This could be due to the disruption in 
the conformational ordering of the alkyl side chains arising from the presence of bulky terminal phenyl groups, and leads to the conclusion that the terminal phenyl groups act as defects. Figure 4.2c shows the variation of heat of fusion $(\Delta H)$ as a function of alkyl side chain length. As with the $T_{\mathrm{m}}$, the $\Delta H$ is larger for the biscarbamates with the $\mathrm{C}_{12}$ spacer and $\mathrm{C}_{4}$ and $\mathrm{C}_{8}$ side chains, with a side chain length of $\mathrm{C}_{12}$ or longer, the difference in $\Delta H$ between the $C_{6}$ and $C_{12}$ spacers becomes less significant. It is also seen that the heat of fusion of $\mathrm{PhC}_{6}-\mathrm{C}_{12}$ biscarbamate is lower than that of the corresponding alkyl terminated biscarbamate by a few tens of joules per gram of the sample, indicating less order.

\subsubsection{Morphology}

Morphology of these biscarbamates was investigated with optical microscopy. Figure 4.3 shows the cross polarized optical micrographs of the quenched (left) and slowcooled (right) samples of the corresponding $C_{x}-C_{12}$ biscarbamates. All these samples exhibit spherulitic morphology, with the slow-cooled samples crystallizing with larger spherulites than the corresponding quenched samples. This is in contrast to the morphological behaviour of the corresponding $\mathrm{C}_{4}-\mathrm{C}_{6}$ biscarbamate which showed no spherulitic morphology for either quenched or slow-cooled sample. ${ }^{3}$ It indicates that the longer spacer group between two H-bonding moieties plays an important role in induction of the spherulitic morphology of this sample. Figure 4.4 shows the variation of the spherulite size with respect to the alkyl side chain length and the type of terminal group for both quenched (4.4a) and slow-cooled (4.4b) samples. The spherulites of the slow-cooled samples are larger than those of quenched samples by a factor of more than an order of magnitude. 

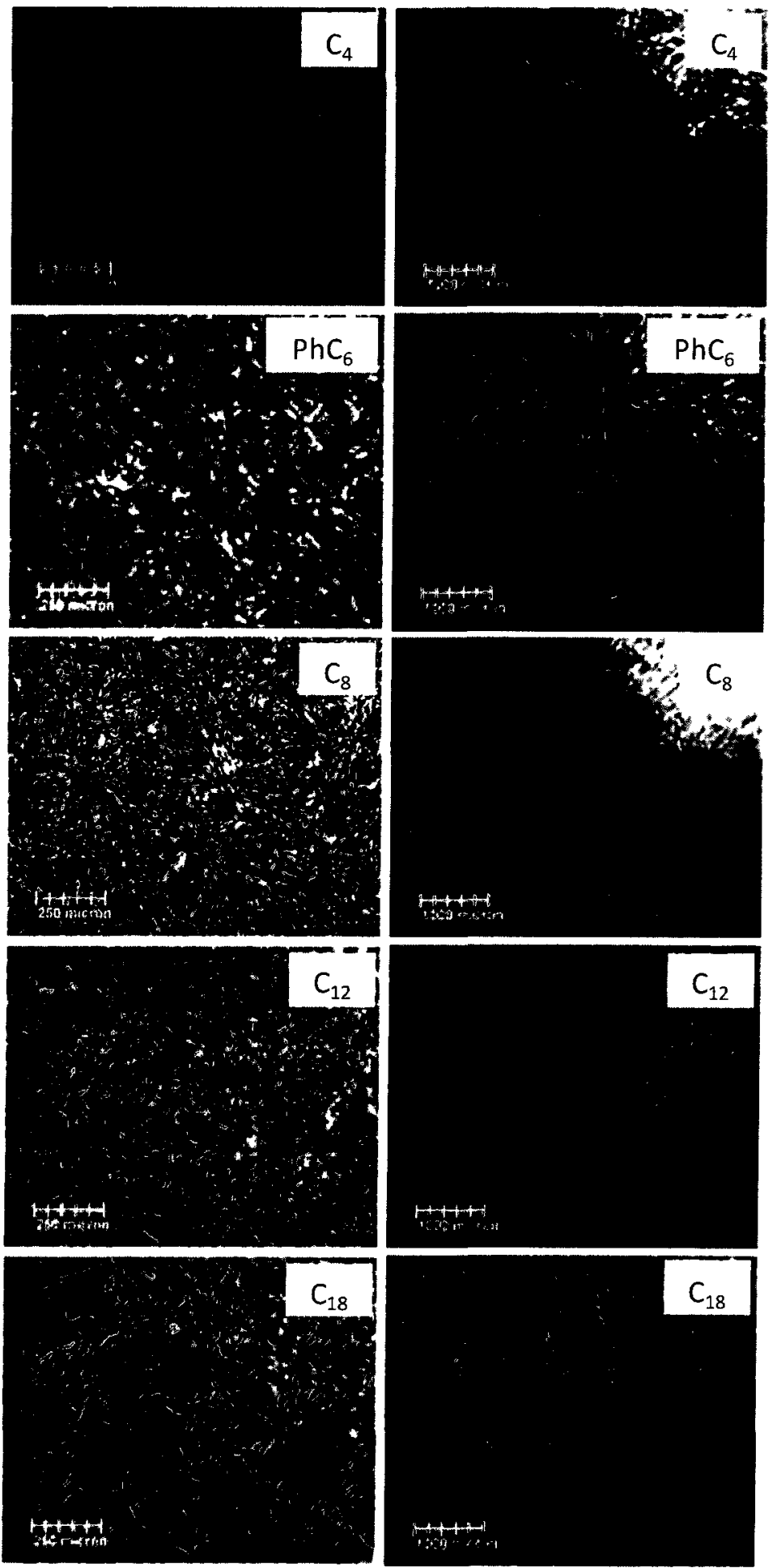

Figure 4.3. Optical micrographs of quenched (left) and slow-cooled (right) $\mathrm{C}_{\mathrm{x}}-\mathrm{C}_{12}$ biscarbamate samples with different alkyl side chain lengths and terminal groups. 

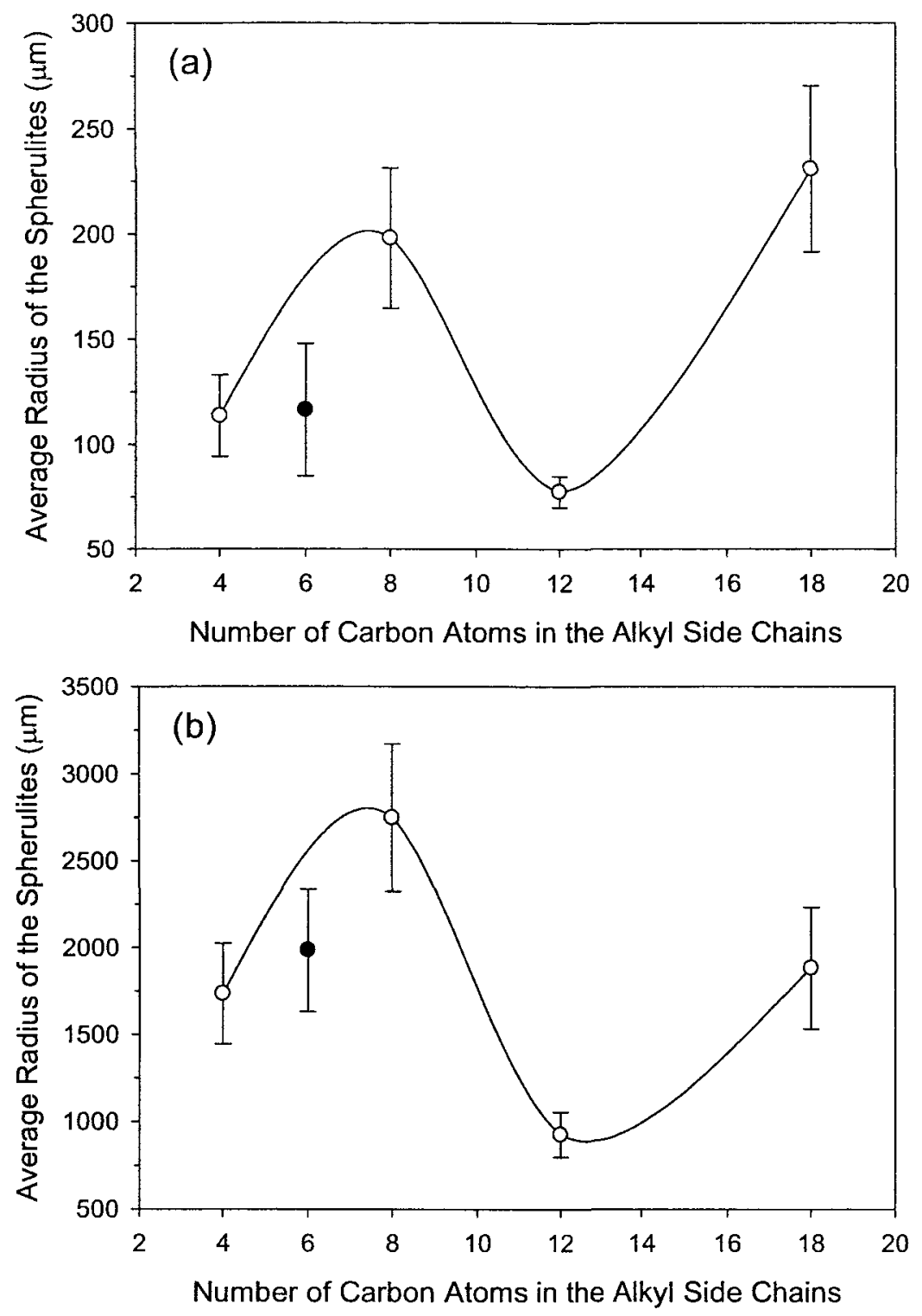

Figure 4.4. Variation of spherulite size of (a) quenched, (b) slowcooled $\mathrm{C}_{\mathrm{x}}-\mathrm{C}_{12}$ biscarbamate samples as a function of alkyl side chain length and the type of terminal groups. $(\circ)$ methyl terminated and $(\bullet)$ phenyl terminated biscarbamates.

The range of spherulite sizes is about the same with both $\mathrm{C}_{6}$ and $\mathrm{C}_{12}$ spacers, varying from 80 to $200 \mu \mathrm{m}$ for the quenched and from 500 to $2500 \mu \mathrm{m}$ in the case of slow-cooled samples, depending on the length of the alkyl side chain. ${ }^{3}$ A maximum in spherulite size is seen for $\mathrm{C}_{8}-\mathrm{C}_{12}$, similar to the case of $\mathrm{C}_{8}-\mathrm{C}_{6}$. However, with a further 
increase in side chain length, the spherulite size decreases for $\mathrm{C}_{12}-\mathrm{C}_{12}$ and a sharp increase is seen for $\mathrm{C}_{18}-\mathrm{C}_{12}$ for both quenched and slow-cooled samples. While the micrographs in Figure 4.3 show the morphology of the quenched and slow-cooled samples, the spherulitic growth is highly fibrous, consisting of twisted lamellae during isothermal growth. This is shown in Figure 4.5 for $\mathrm{C}_{12}-\mathrm{C}_{12}$. Figure 4.4 also shows that phenyl terminated $\mathrm{PhC}_{6} \mathrm{C}_{12}$ biscarbamate form smaller spherulites than expected for its corresponding methyl terminated biscarbamate. Fewer nucleation sites in the samples result in larger spherulites. The variation in nucleation site density and of spherulite size with respect to the alkyl side chain length can be rationalized with the relative contribution of $\mathrm{H}$-bonding and van der Waals interactions of the molecules. Increased intermolecular association is expected to contribute to increased nucleation site density and hence to reduction in the spherulite size. This rationale can be explained with infrared spectroscopy of these biscarbamates.

\subsubsection{Spherulite Growth Rate}

The influence of alkyl side chain and spacer group length on crystallization of these molecules was further investigated with isothermal spherulite growth using hot stage microscopy as described in the experimental section. For example, Figures 4.5 and 4.6 show the micrographs of $\mathrm{C}_{12}-\mathrm{C}_{12}$ and $\mathrm{PhC}_{6}-\mathrm{C}_{12}$ respectively, recorded at different times of spherulite formation. It is seen that the spherulite grows radially with extensive sequential branching of the lamellae. The size of the spherulites with time is shown in Figure $4.7 \mathrm{a}$ for the biscarbamates studied in this work. None of these plots extrapolate to a spherulite size of zero at $t=0 \mathrm{~s}$ indicating a very fast growth of spherulites in the beginning. 

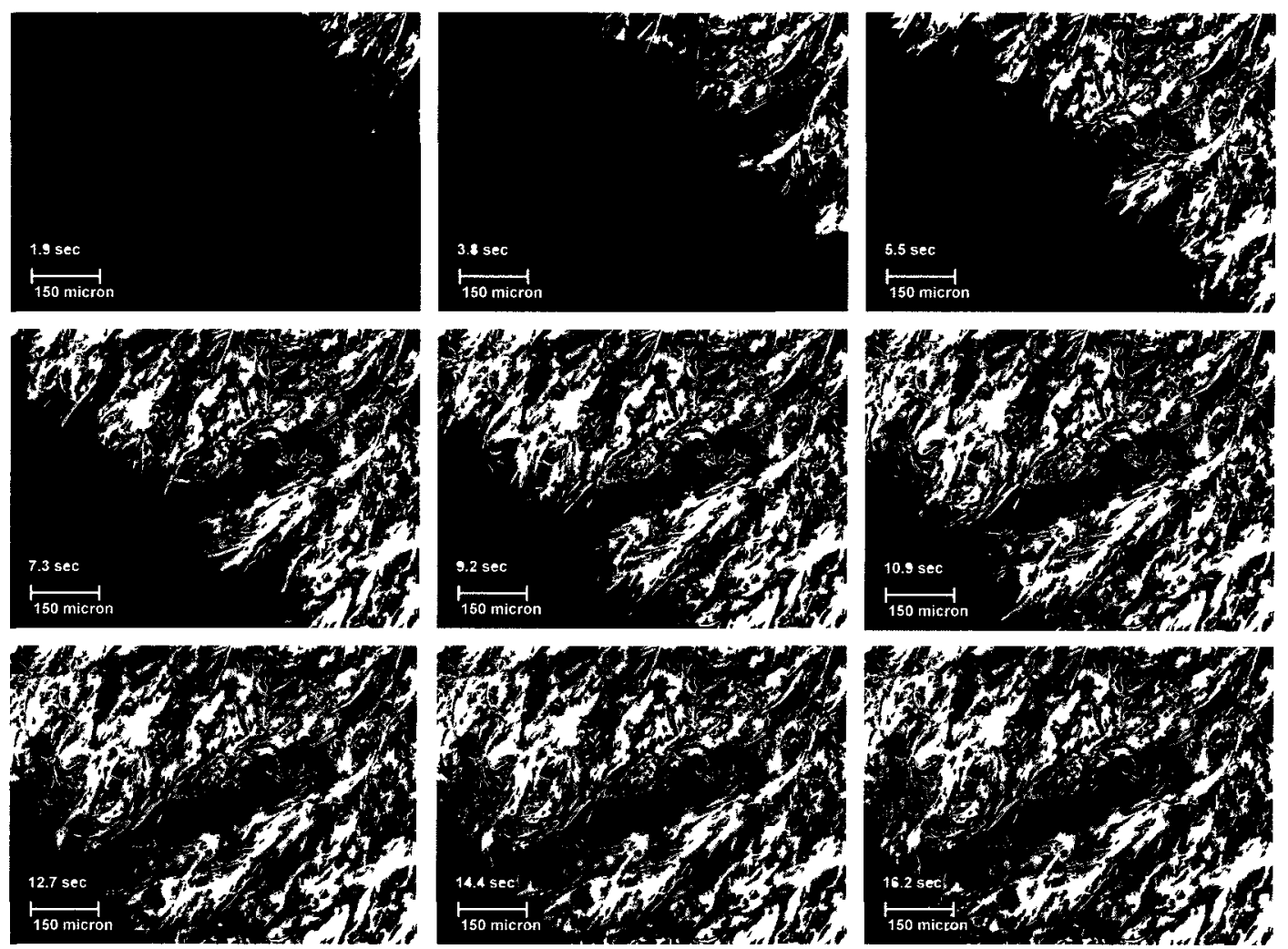

Figure 4.5. Optical micrographs of $\mathrm{C}_{12} \mathrm{C}_{12}$ biscarbamate showing isothermal spherulite growth with time.

It is seen that the spherulite growth is complete due to impinging of the adjacent spherulites within $8 \mathrm{~s}$ for $\mathrm{C}_{4}-\mathrm{C}_{12}$ and $\mathrm{C}_{8}-\mathrm{C}_{12}$ while it takes about 16 and $12 \mathrm{~s}$ for $\mathrm{C}_{12}-\mathrm{C}_{12}$ and $\mathrm{C}_{18}-\mathrm{C}_{12}$ respectively. Such completion of growth occurs faster with the $\mathrm{C}_{12}$ spacer. It was seen in our previous study that with $\mathrm{C}_{6}$ spacers, it took $20 \mathrm{~s}$ for the $\mathrm{C}_{12}$ side chain and 28 s with $\mathrm{C}_{16}$ and $\mathrm{C}_{18}$ side chains to complete the growth. ${ }^{3}$ Figure $4.7 \mathrm{~b}$ shows the spherulite growth rate as a function of alkyl side chain length. The spherulite growth rate increases from $\mathrm{C}_{4}$ to $\mathrm{C}_{8}$ with a minimum with $\mathrm{C}_{12}$. Consistent with the time to complete the growth, the rate of growth is also higher with the $C_{12}$ spacer. For example, with the $C_{8}$ alkyl side chain, the rate of spherulite growth is $160 \mu \mathrm{m} / \mathrm{s}$ with the $\mathrm{C}_{12}$ spacer (Figure 4.7b), and $115 \mu \mathrm{m} / \mathrm{s}$ with the $\mathrm{C}_{6}$ spacer. $^{3}$ The spherulite growth rate decreases 
significantly when the terminal methyl group is replaced with phenyl groups. This observation conforms with the change in spherulite size of these molecules with respect to the alkyl side chain length and the type of alkyl terminal groups.
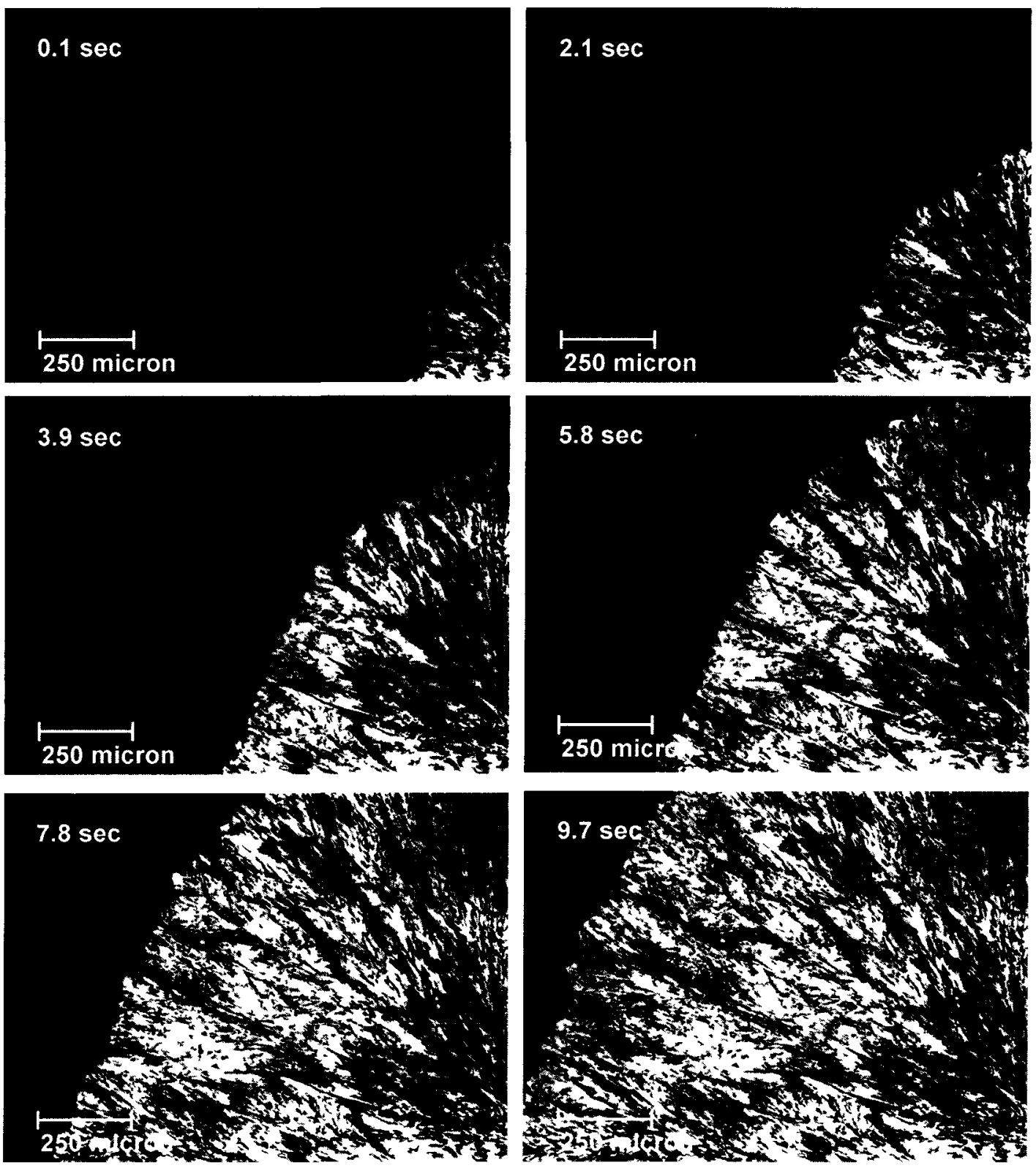

Figure 4.6. Representative optical micrographs of $\mathrm{PhC}_{6} \mathrm{C}_{12}$ showing isothermal spherulite growth over time. 

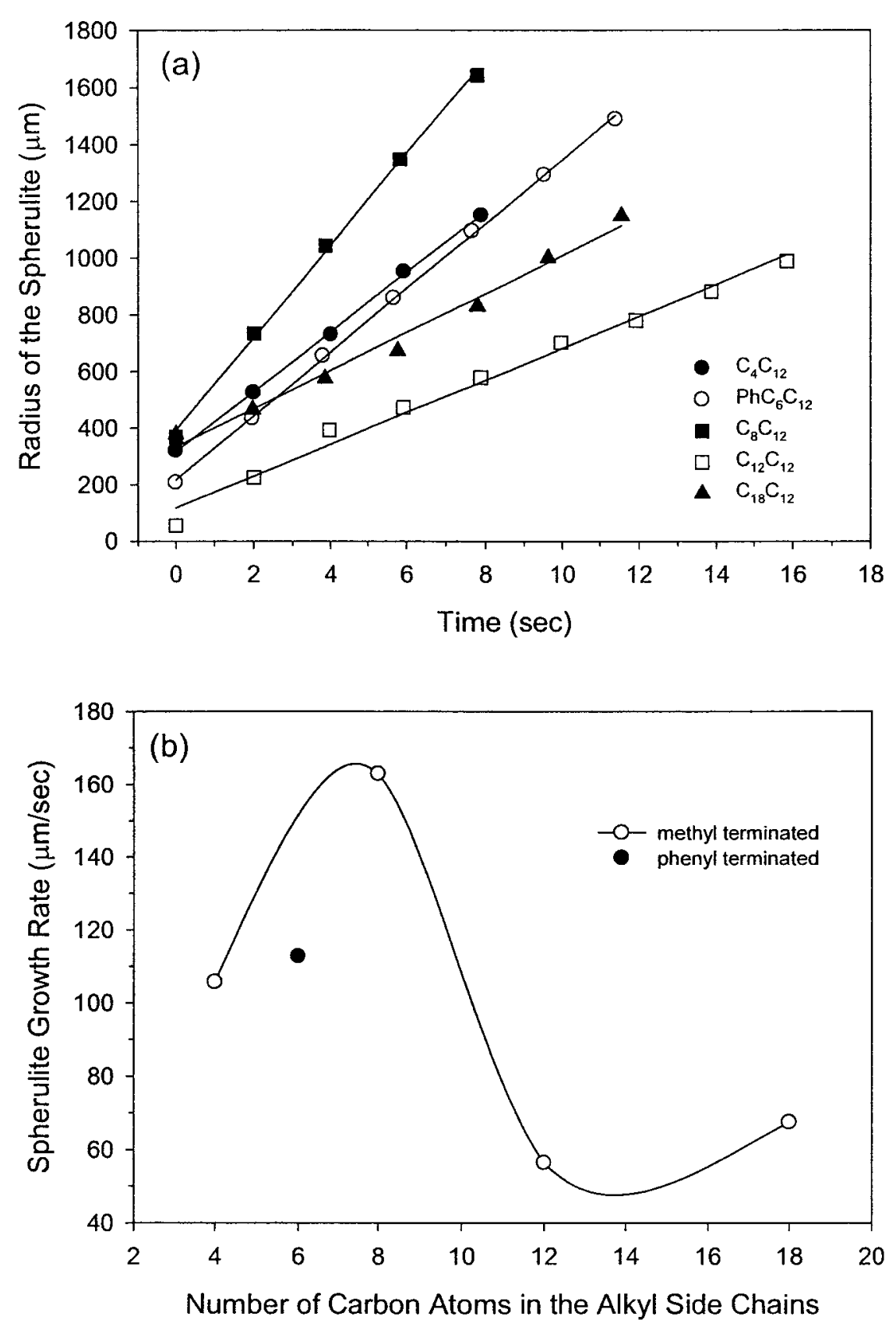

Figure 4.7. (a) Growth of spherulites with time, and (b) rate of spherulite growth as a function of number of carbon atoms in the alkyl side chains of the biscarbamates.

\subsubsection{Rate of Crystallization}

While the spherulite growth data discussed above were obtained from optical microscopy, isothermal crystallization studies were performed with the DSC as described 
in the previous chapter. The crystallization rates vary with the alkyl side chain and spacer group lengths. Figure 4.8a shows the fractional heat of fusion $(\alpha)$ as a function of time for $\mathrm{C}_{8}-\mathrm{C}_{12}, \mathrm{C}_{12}-\mathrm{C}_{12}$ and $\mathrm{C}_{18}-\mathrm{C}_{12}$ biscarbamates isothermally crystallized in the DSC. As noted with the variations in spherulite size and spherulite growth rate, a slower crystallization rate is seen for $\mathrm{C}_{12}-\mathrm{C}_{12}$ than the other two mentioned above. The $t_{1 / 2}$ (time required for $50 \%$ crystallization) values are $1.07,1.70$, and 1.09 min for $\mathrm{C}_{8}-\mathrm{C}_{12}, \mathrm{C}_{12}-\mathrm{C}_{12}$ and $\mathrm{C}_{18}-\mathrm{C}_{12}$ respectively. The differences in these values indicate that $\mathrm{C}_{12}-\mathrm{C}_{12}$ takes about double the time to crystallize than the other two. Comparison of the rate of crystallization of $\mathrm{C}_{\mathrm{x}}-\mathrm{C}_{12}$ with that of previously studied $\mathrm{C}_{\mathrm{x}}-\mathrm{C}_{6}$ biscarbamate ${ }^{3}$ shows that increase in the spacer length significantly decreases the crystallization rate of these molecules.

Figure $4.8 \mathrm{~b}$ shows a plot of the crystallization in terms of the Avrami equation for $\mathrm{C}_{8}-\mathrm{C}_{12}, \mathrm{C}_{12}-\mathrm{C}_{12}$ and $\mathrm{C}_{18}-\mathrm{C}_{12}$. The parameters are given in Table 4.2. It is seen that the plot for $\mathrm{C}_{12}-\mathrm{C}_{12}$ consists of two regions. There is a significant change in the slope after 12 seconds $(\ln t=2.5)$. The value of $n$ varies from 2.5 to 2.8 for the rest. Such values close to 3 indicate three dimensional growth of the nuclei and the non-integral values denote constant radial growth of the spherulites. For $\mathrm{C}_{12}-\mathrm{C}_{12}$, the initial value of $n$ is 3.2 , and it reduces to 1.3 after 12 seconds. The value close to 1 has been interpreted as due to nonrandom one dimensional growth. 

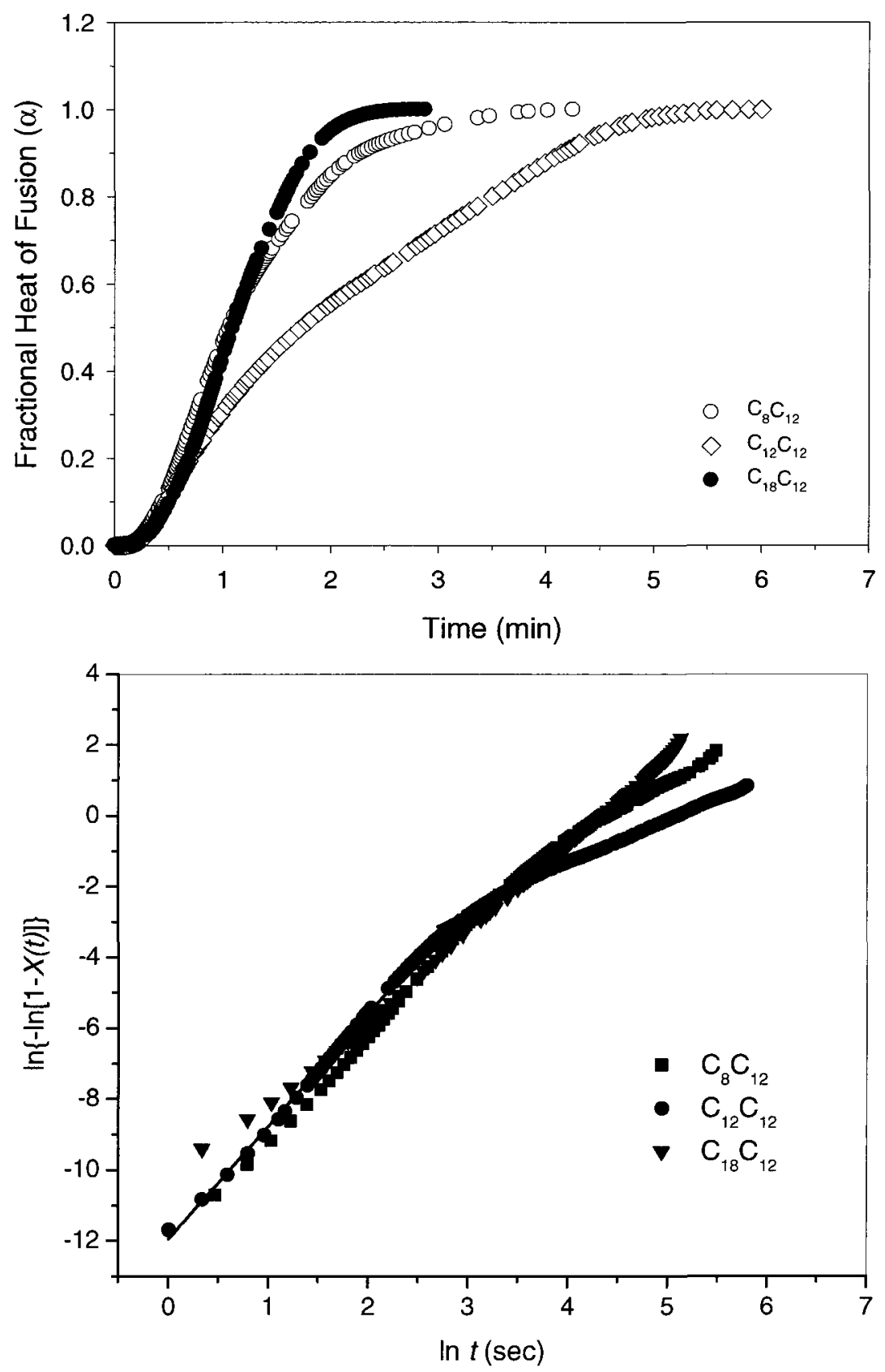

Figure 4.8. (a) Fractional heat of fusion of the biscarbamates as a function of time; (b) The plot in terms of the Avrami equation. 
Table 4.2. Avrami parameters calculated from isothermal crystallization data.

\begin{tabular}{lcc}
\hline Sample & Avrami Exponent, $n$ & $\mathrm{~K}$ \\
\hline $\mathrm{C}_{4} \mathrm{C}_{12}$ & 2.79 & $2.14 \times 10^{-6}$ \\
$\mathrm{PhC}_{6} \mathrm{C}_{12}$ & 2.46 & $3.12 \times 10^{-5}$ \\
$\mathrm{C}_{8} \mathrm{C}_{12}$ & 2.42 & $2.12 \times 10^{-5}$ \\
$\mathrm{C}_{12} \mathrm{C}_{12}{ }^{a}$ & 3.19 & $6.42 \times 10^{-6}$ \\
$\mathrm{C}_{12} \mathrm{C}_{12}{ }^{b}$ & 1.31 & $1.28 \times 10^{-3}$ \\
$\mathrm{C}_{18} \mathrm{C}_{12}$ & 2.46 & $2.29 \times 10^{-5}$ \\
\hline
\end{tabular}

${ }^{a}$ based on the first crystallization regime (data range: $\ln t$ up to $2.67(t=14.4 \mathrm{~s})$ ).

${ }^{b}$ based on the second crystallization regime (data range: $\ln t$ from 2.67 onward).

\subsubsection{X-ray Diffraction and Structural Features}

The $d$-spacings and corresponding relative intensities of the reflections of quenched and slow-cooled samples are listed in Tables 4.3 and 4.4 respectively. There is no substantial difference between the corresponding peak positions of quenched and slowcooled samples, which indicates that molecular packing mode is independent of sample preparation procedure (quenching or slow-cooling). It is seen from Table 4.3 that the largest $d$-spacing of individual biscarbamates increases from $17.28 \AA$ for $\mathrm{C}_{4}-\mathrm{C}_{12}$ to 26.72 $\AA$ for $\mathrm{C}_{18}-\mathrm{C}_{12}$. This increase is almost linear with respect to the alkyl side chain length. Figure 4.9 shows a plot of the largest $d$-spacing and the calculated molecular length as a function of alkyl side chain length. A similar trend was found in the case of $C_{x}-C_{6}$ biscarbamates where the largest $d$-spacing increased linearly with the calculated molecular length. ${ }^{3}$ Table 4.3 shows that apart from the reflection corresponding to the longest $d$-spacing, most of the other reflections are either weak or of moderate intensity. 


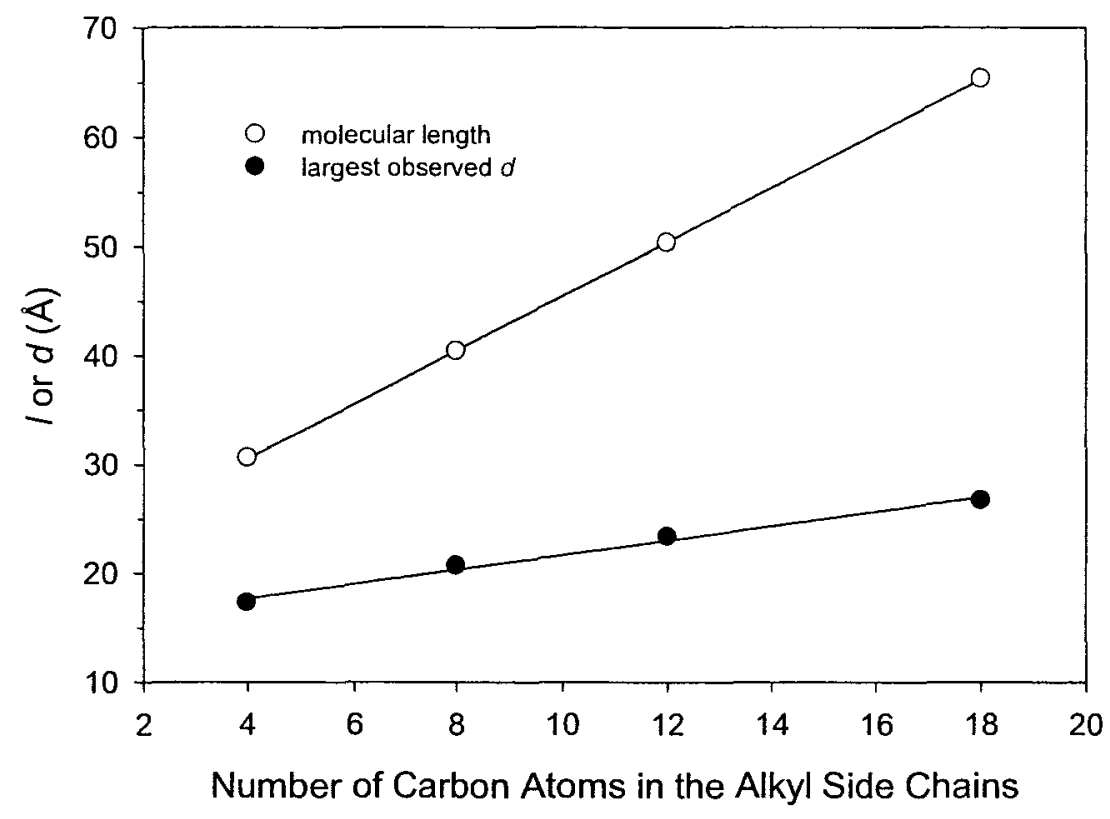

Figure 4.9. Longest observed $d$-spacing and the calculated molecular length.

As mentioned above, these are from either quenched or slow-cooled samples from the melt. We thought that it could be due to the orientation of the lamellae during the spherulitic growth. However, placing the sample in different directions in the X-ray beam did not significantly change the intensity pattern.

Figure 4.10 shows the $\mathrm{X}$-ray diffraction profiles of the as-synthesized methyl terminated biscarbamates with the $\mathrm{C}_{12}$ spacer. It is seen that except for the large $d$ spacing reflection, all the others are weak, and the reduction in intensity of these reflections becomes more significant as the alkyl side chain length increases. This is found to be the case for both $\mathrm{C}_{6}$ and $\mathrm{C}_{12}$ spacers. Figure 4.11 a compares the $\mathrm{X}$-ray diffraction traces for $\mathrm{C}_{18}-\mathrm{C}_{6}$ and $\mathrm{C}_{18}-\mathrm{C}_{12}$. In both cases, only a single reflection is of significant intensity and the others are weak. 

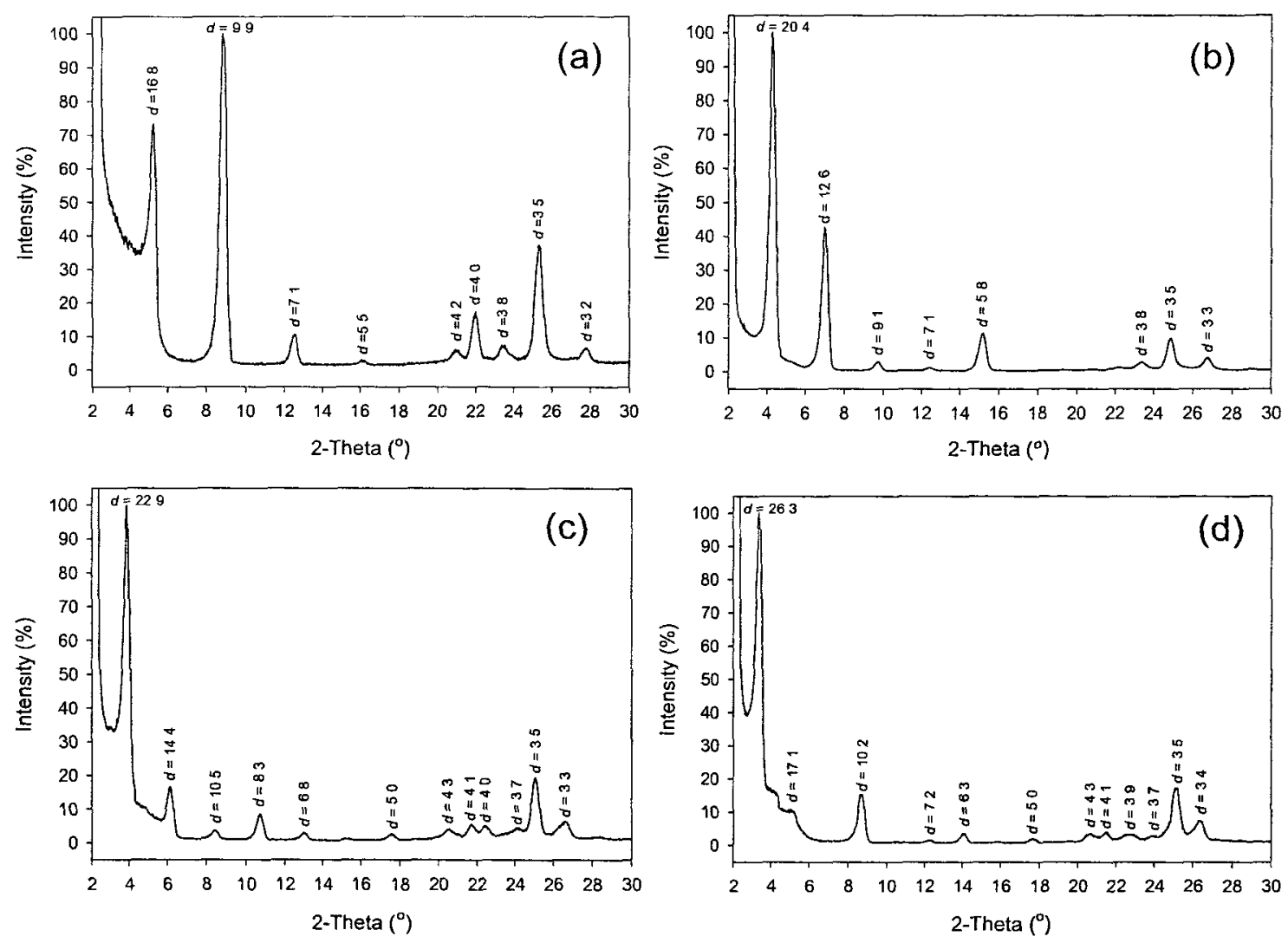

Figure 4.10. XRD trace of as synthesized biscarbamates: (a) $\mathrm{C}_{4}-\mathrm{C}_{12}$, (b) $\mathrm{C}_{8}-\mathrm{C}_{12}$, (c) $\mathrm{C}_{12^{-}}$ $\mathrm{C}_{12}$, and (d) $\mathrm{C}_{18}-\mathrm{C}_{12} . d$-spacing values are in $\AA$.

Figure $4.11 \mathrm{~b}$ shows, as an illustration, a plot of the ratio $I_{35} / I_{100}$ for the biscarbamates with $\mathrm{C}_{12}$ spacer and different alkyl chain lengths. Here, $I_{35}$ is the intensity of the reflection with $d=3.5 \AA$, and $I_{100}$ the most intense reflection in each case. The $3.5 \AA$ reflection was assigned to the distance between the hydrogen bonding planes in our previous work with the $\mathrm{C}_{6}$ spacers. $^{3}$ It is seen that the ratio becomes small with an increase in the alkyl side chain length. This shows that even with the as-synthesized sample, there is a preferential stacking of the molecule in one direction and that it becomes more significant as the length of the alkyl side chain increases. 
Table 4.3. Interplanar spacings, $d(\AA)$, and Intensities, $I(\%)$ of X-ray diffraction patterns of slow-cooled samples.

\begin{tabular}{|c|c|c|c|c|c|c|c|c|c|}
\hline \multicolumn{2}{|c|}{$\mathrm{PhC}_{6} \mathrm{C}_{12}$} & \multicolumn{2}{|c|}{$\mathrm{C}_{4} \mathrm{C}_{12}$} & \multicolumn{2}{|c|}{$\mathrm{C}_{8} \mathrm{C}_{12}$} & \multicolumn{2}{|c|}{$\mathrm{C}_{12} \mathrm{C}_{1}$} & \multicolumn{2}{|c|}{$\mathrm{C}_{18} \mathrm{C}_{12}$} \\
\hline$d$ & $I$ & $d$ & $I$ & $d$ & $I$ & $d$ & $I$ & $d$ & $I$ \\
\hline 35.45 & 41.1 & & & & & & & & \\
\hline 26.05 & 100.0 & & & 20.69 & 100.0 & 23.36 & 100.0 & 26.72 & 100.0 \\
\hline 17.82 & 25.4 & 17.29 & 70.3 & 12.62 & 42.7 & 14.84 & 18.0 & 17.02 & 17.6 \\
\hline 11.92 & 37.2 & 10.02 & 100.0 & 9.09 & 2.6 & 10.78 & 3.6 & 10.23 & 11.3 \\
\hline 8.93 & 37.9 & 7.09 & 8.1 & 7.10 & 0.9 & 8.49 & 11.3 & & \\
\hline \multirow[t]{2}{*}{7.14} & 67.7 & & & & & 6.98 & 2.2 & 6.33 & 2.0 \\
\hline & & 5.49 & 1.7 & 5.83 & 9.4 & 5.94 & 0.6 & & \\
\hline 5.06 & 12.3 & & & & & 5.17 & 2.1 & 5.05 & 0.7 \\
\hline 4.79 & 2.4 & & & & & & & & \\
\hline 4.44 & 4.2 & & & 4.60 & 0.3 & 4.58 & 0.3 & & \\
\hline 4.34 & 18.6 & & & & & & & & \\
\hline \multirow[t]{2}{*}{4.23} & 34.9 & 4.26 & 7.0 & 4.24 & 0.9 & 4.27 & 10.8 & 4.29 & 31.4 \\
\hline & & & & & & & & 4.12 & 20.9 \\
\hline \multirow[t]{2}{*}{3.95} & 30.8 & 4.02 & 50.6 & 3.99 & 2.8 & 4.01 & 15.0 & 3.95 & 13.0 \\
\hline & & 3.79 & 2.6 & 3.79 & 0.6 & & & & \\
\hline \multirow[t]{2}{*}{3.69} & 44.2 & & & 3.72 & 0.1 & 3.73 & 3.0 & 3.73 & 7.4 \\
\hline & & & & & & & & 3.65 & 8.4 \\
\hline 3.54 & 9.9 & 3.53 & 32.7 & 3.58 & 8.2 & 3.56 & 10.1 & 3.56 & 12.9 \\
\hline 3.32 & 3.1 & & & 3.33 & 2.7 & 3.37 & 7.3 & 3.41 & 15.2 \\
\hline 3.22 & 2.6 & & & 3.09 & 0.3 & 3.16 & 0.5 & 3.28 & 1.6 \\
\hline
\end{tabular}


Table 4.4. Interplanar spacings, $d(\AA)$, and Intensities, $I(\%)$ of X-ray diffraction patterns of quenched samples.

\begin{tabular}{|c|c|c|c|c|c|c|c|c|c|}
\hline \multicolumn{2}{|c|}{$\mathrm{PhC}_{6} \mathrm{C}_{12}$} & \multicolumn{2}{|c|}{$\mathrm{C}_{4} \mathrm{C}_{12}$} & \multicolumn{2}{|c|}{$\mathrm{C}_{8} \mathrm{C}_{12}$} & \multicolumn{2}{|c|}{$\mathrm{C}_{12} \mathrm{C}_{1}$} & \multicolumn{2}{|c|}{$\mathrm{C}_{18} \mathrm{C}_{12}$} \\
\hline$d$ & $I$ & $d$ & $I$ & $d$ & $I$ & $d$ & $I$ & $d$ & $I$ \\
\hline 35.45 & 41.1 & & & & & & & & \\
\hline 26.05 & 100.0 & & & 20.69 & 100.0 & 23.36 & 100.0 & 26.72 & 100.0 \\
\hline 17.82 & 25.4 & 17.29 & 70.3 & 12.62 & 42.7 & 14.84 & 18.0 & 17.02 & 17.6 \\
\hline 11.92 & 37.2 & 10.02 & 100.0 & 9.09 & 2.6 & 10.78 & 3.6 & 10.23 & 11.3 \\
\hline 8.93 & 37.9 & 7.09 & 8.1 & 7.10 & 0.9 & 8.49 & 11.3 & & \\
\hline \multirow[t]{2}{*}{7.14} & 67.7 & & & & & 6.98 & 2.2 & 6.33 & 2.0 \\
\hline & & 5.49 & 1.7 & 5.83 & 9.4 & 5.94 & 0.6 & & \\
\hline 5.06 & 12.3 & & & & & 5.17 & 2.1 & 5.05 & 0.7 \\
\hline 4.79 & 2.4 & & & & & & & & \\
\hline 4.44 & 4.2 & & & 4.60 & 0.3 & 4.58 & 0.3 & & \\
\hline 4.34 & 18.6 & & & & & & & & \\
\hline \multirow[t]{2}{*}{4.23} & 34.9 & 4.26 & 7.0 & 4.24 & 0.9 & 4.27 & 10.8 & 4.29 & 31.4 \\
\hline & & & & & & & & 4.12 & 20.9 \\
\hline \multirow[t]{2}{*}{3.95} & 30.8 & 4.02 & 50.6 & 3.99 & 2.8 & 4.01 & 15.0 & 3.95 & 13.0 \\
\hline & & 3.79 & 2.6 & 3.79 & 0.6 & & & & \\
\hline \multirow[t]{2}{*}{3.69} & 44.2 & & & 3.72 & 0.1 & 3.73 & 3.0 & 3.73 & 7.4 \\
\hline & & & & & & & & 3.65 & 8.4 \\
\hline 3.54 & 9.9 & 3.53 & 32.7 & 3.58 & 8.2 & 3.56 & 10.1 & 3.56 & 12.9 \\
\hline 3.32 & 3.1 & & & 3.33 & 2.7 & 3.37 & 7.3 & 3.41 & 15.2 \\
\hline 3.22 & 2.6 & 3.09 & 0.3 & 3.16 & 0.5 & 3.28 & 1.6 & & \\
\hline
\end{tabular}


The two reflections with $d$-spacings of $4.2 \AA$ and $3.5 \AA$ are common to all the samples studied here. In our previous work, the $4.2 \AA$ reflection was assigned to the distance between the molecules in the hydrogen bonding plane and the $3.5 \AA$ reflection, to the distance between these planes (it was actually $3.8 \AA$ in the case of biscarbamates with $\mathrm{C}_{6}$ spacer). Figure 4.12 shows the variation of crystallite size at $d=3.5$ and $4.2 \AA$ with respect to the number of alkyl side chains which conforms with the variation of spherulite size and rate of crystallization of these molecules.

\subsubsection{Infrared Spectroscopy}

Infrared spectroscopy of these molecules does not show any significant difference in the spectral profile of the slow-cooled and quenched samples, and the data presented here are of the former.

Biscarbamates of this series show $\mathrm{H}-$ bonded $\mathrm{N}-\mathrm{H}$ and $\mathrm{C}=\mathrm{O}$ bands at around 3331 and $1682 \mathrm{~cm}^{-1}$ respectively. Other two strong absorption bands corresponding to the symmetric and asymmetric stretching vibrations of $\mathrm{C}-\mathrm{H}$ bonds were observed at around 2850 and $2920 \mathrm{~cm}^{-1}$ respectively. A weak band at around $2958 \mathrm{~cm}^{-1}$ and a very weak band at around $2874 \mathrm{~cm}^{-1}$ corresponding to the $\mathrm{C}-\mathrm{H}$ asymmetric and symmetric vibrations of the terminal $\mathrm{CH}_{3}$ groups are also observed. These weak bands diminish with the increased contribution of the $\mathrm{CH}_{2}$ groups as the alkyl side chain length increases and vanish when the terminal $\mathrm{CH}_{3}$ groups are replaced by phenyl groups as shown in Figure 4.13a. Because of the difference in their bond order, the $\mathrm{N}-\mathrm{H}$ group was found to be more susceptible to change in intermolecular interactions than the $\mathrm{C}=\mathrm{O}$ group. 

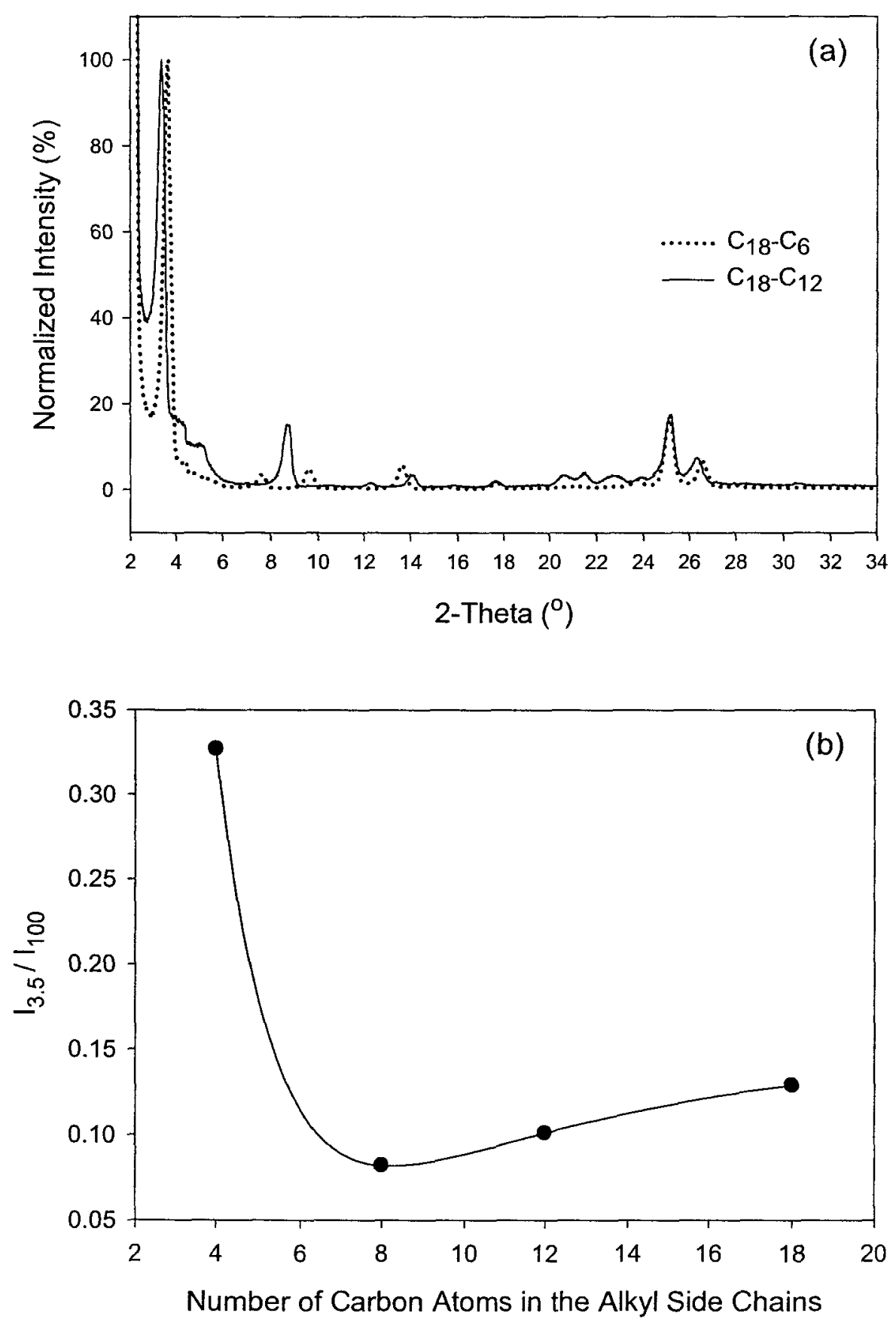

Figure 4.11. (a) XRD traces normalized to the highest intensity peak of $\mathrm{C}_{18}{ }^{-} \mathrm{C}_{6}$ and $\mathrm{C}_{18^{-}}$ $\mathrm{C}_{12}$ biscarbamates, and (b) the ratio of the peak intensity at $d=3.5 \AA$ to that of the peak with highest intensity as a function of alkyl side chain length of $\mathrm{C}_{\mathrm{x}}-\mathrm{C}_{12}$ biscarbamates. 


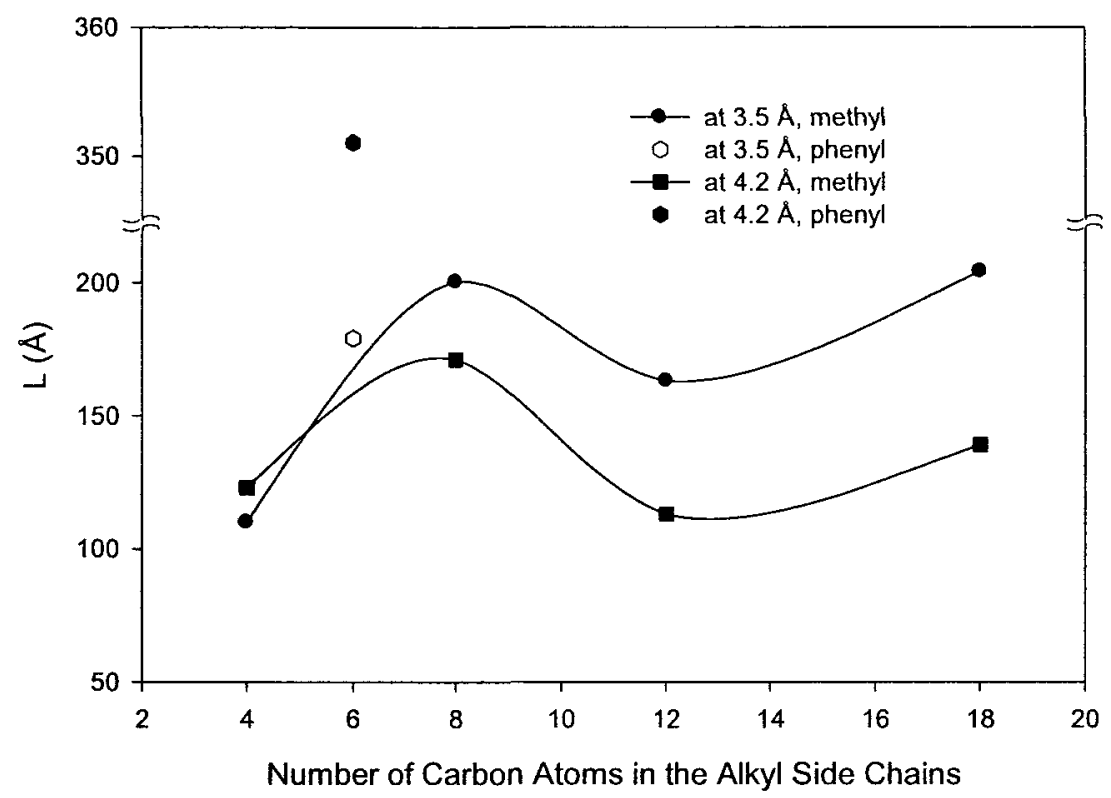

Figure 4.12. The variation of crystallite size of the biscarbamates at $d 3.5$ and $4.2 \AA$ as a function of alkyl side chain length.

Table 4.5. Infrared data for $\mathrm{H}$-bonded $\mathrm{N}-\mathrm{H}$ and $\mathrm{C}=\mathrm{O}$ stretching bands of biscarbamates with different alkyl side chains.

\begin{tabular}{lccccccc}
\hline & \multicolumn{3}{c}{ H-bonded N-H } & & \multicolumn{3}{c}{ H-bonded C=O } \\
\cline { 2 - 3 } ID & Frequency $\left(\mathrm{cm}^{-1}\right)$ & Intensity & FWHM & & Frequency $\left(\mathrm{cm}^{-1}\right)$ & Intensity & FWHM \\
\hline $\mathrm{PhC}_{6}-\mathrm{C}_{12}$ & 3336 & 23.2 & 27.1 & & 1683 & 61.9 & 20.5 \\
$\mathrm{C}_{4}-\mathrm{C}_{12}$ & 3331 & 28.9 & 30.8 & & 1682 & 65.1 & 22.1 \\
$\mathrm{C}_{8}-\mathrm{C}_{12}$ & 3330 & 26.9 & 22.9 & & 1683 & 60.0 & 20.8 \\
$\mathrm{C}_{12}-\mathrm{C}_{12}$ & 3330 & 24.9 & 23.0 & & 1684 & 57.2 & 18.7 \\
$\mathrm{C}_{18}-\mathrm{C}_{12}$ & 3328 & 20.0 & 22.5 & & 1684 & 53.8 & 18.7 \\
\hline
\end{tabular}

* Full width at half maximum 

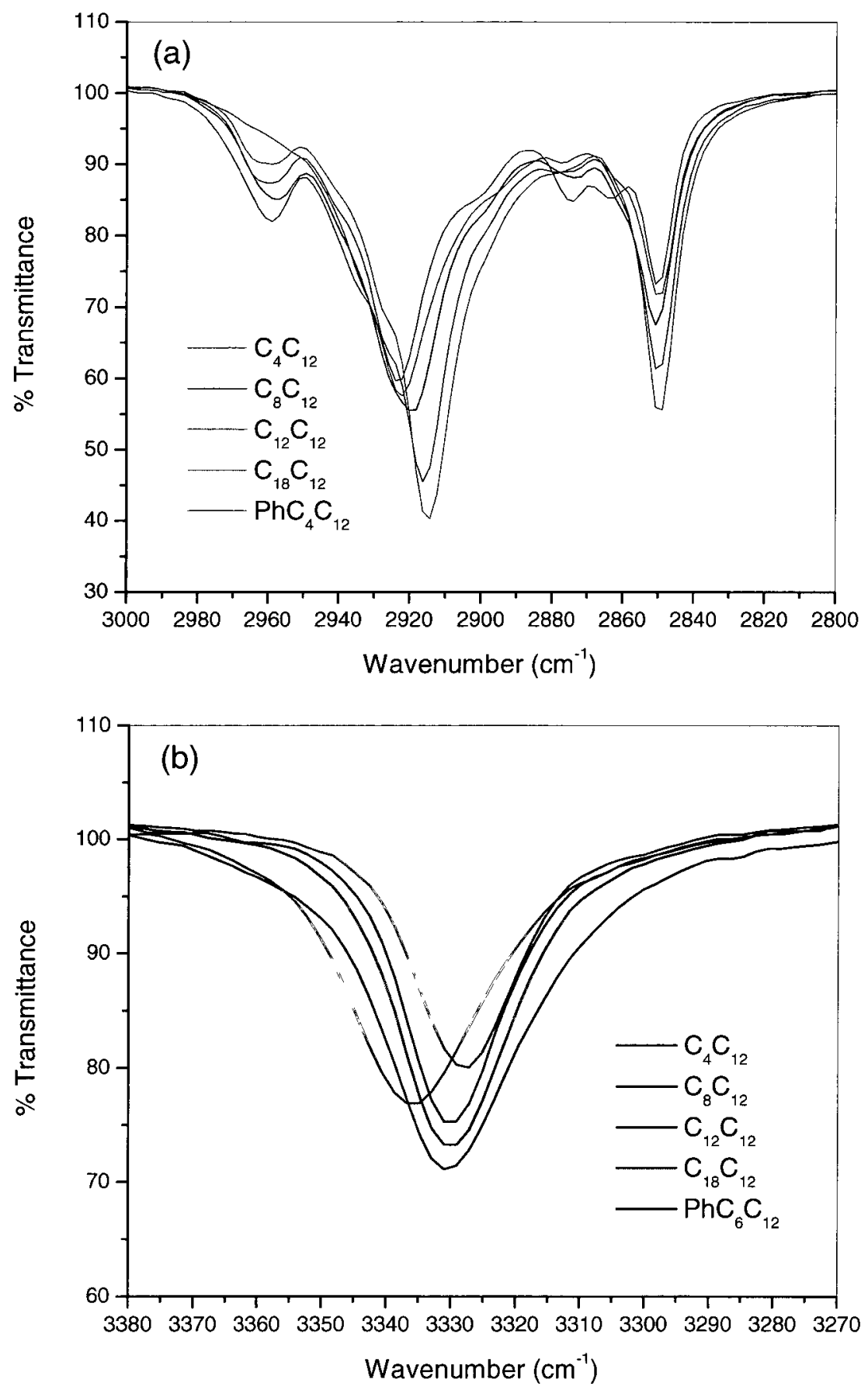

Figure 4.13. FTIR spectra of biscarbamates in the (a) $\mathrm{CH}_{2}$ stretching (b) N-H stretching regions. 
A similar trend was seen with the symmetric and asymmetric $\mathrm{C}-\mathrm{H}$ vibrations where asymmetric vibrations were found to be more susceptible than the symmetric ones due probably to the energy differences related to these modes of vibrations. This trend is found to be common among the molecules within both the $\mathrm{C}_{\mathrm{x}}-\mathrm{C}_{6}$ and $\mathrm{C}_{\mathrm{x}}-\mathrm{C}_{12}$ series and between the corresponding molecules of these two series. The $\mathrm{N}-\mathrm{H}$ band of $\mathrm{C}_{4}-\mathrm{C}_{6}$ appears at $3324 \mathrm{~cm}^{-1}$ and shifts to $3319 \mathrm{~cm}^{-1}$ for $\mathrm{C}_{18}-\mathrm{C}_{6}$ while that of $\mathrm{C}_{4}-\mathrm{C}_{12}$ appears at $3331 \mathrm{~cm}^{-1}$ and shifts to $3328 \mathrm{~cm}^{-1}$ for $\mathrm{C}_{18}-\mathrm{C}_{12}$ (Figure 4.13b). However, the $\mathrm{C}=\mathrm{O}$ bands appear at $1682 \mathrm{~cm}^{-1}$ for all of these molecules. The bands corresponding to $v_{a s}$ and $v_{\mathrm{s}}$ show a similar trend. The $v_{\text {as }}$ of $\mathrm{C}_{4} \mathrm{C}_{6}$ appears at $2935 \mathrm{~cm}^{-1}$ and shifts to $2915 \mathrm{~cm}^{-1}$ for $\mathrm{C}_{18}-\mathrm{C}_{6}$ while $v_{\text {as }}$ of $\mathrm{C}_{4}-\mathrm{C}_{12}$ appears at $2923 \mathrm{~cm}^{-1}$ and shifts to $2915 \mathrm{~cm}^{-1}$ for $\mathrm{C}_{18}-\mathrm{C}_{12}$. The difference in $v_{a s}$ between $\mathrm{C}_{4}$ and $\mathrm{C}_{18}$ molecules of both the series is more than that in $v_{\mathrm{s}}$. Table 4.5 shows that among the molecules of $\mathrm{C}_{\mathrm{x}}-\mathrm{C}_{12}$ series, the position of $\mathrm{H}$-bonded N$\mathrm{H}$ remains almost same from $\mathrm{C}_{4}-\mathrm{C}_{12}$ to $\mathrm{C}_{12}-\mathrm{C}_{12}$ and shifts slightly to a lower wave number for $\mathrm{C}_{18}{ }^{-} \mathrm{C}_{12}$. The intensity of the peak decreases from $\mathrm{C}_{4}$ to $\mathrm{C}_{12}$, but the half width also decreases from 30.8 to 22.5 wave numbers.

Table 4.6. Infrared data for symmetric $\left(v_{s}\right)$, and asymmetric $\left(v_{a s}\right) \mathrm{C}-\mathrm{H}$ stretching bands of biscarbamates with different alkyl side chains.

\begin{tabular}{lccccc}
\hline & \multicolumn{2}{c}{ Asymmetric C-H } & & \multicolumn{2}{c}{ Symmetric C-H } \\
\cline { 2 - 3 } \cline { 5 - 6 } Sample ID & Frequency $\left(\mathrm{cm}^{-1}\right)$ & Intensity & & Frequency $\left(\mathrm{cm}^{-1}\right)$ & Intensity \\
\hline $\mathrm{PhC}_{6}-\mathrm{C}_{12}$ & 2923 & 42.5 & & 2850 & 28.6 \\
$\mathrm{C}_{4}-\mathrm{C}_{12}$ & 2923 & 40.5 & & 2850 & 27.0 \\
$\mathrm{C}_{8}-\mathrm{C}_{12}$ & 2919 & 44.6 & & 2851 & 32.5 \\
$\mathrm{C}_{12}-\mathrm{C}_{12}$ & 2916 & 54.5 & & 2850 & 39.0 \\
$\mathrm{C}_{18}-\mathrm{C}_{12}$ & 2915 & 60.0 & & 2850 & 45.2 \\
\hline
\end{tabular}


On the other hand, Figure 4.13 and Table 4.6 show that the $v_{\text {as }}$ changes significantly from $\mathrm{C}_{4}-\mathrm{C}_{12}$ to $\mathrm{C}_{12}-\mathrm{C}_{12}$ indicating enhancement in van der Waals force with increased alkyl side chain length. The intensity of the $\mathrm{N}-\mathrm{H}$ band decreases while $v_{\text {as }}$ increases consistently with the increase of the alkyl side chain length indicating the relative decrease in the contribution of $\mathrm{H}$-bond compared to van der Waals forces in molecular association. Thus it is likely that there is a balance between these two forces in the $\mathrm{C}_{12}$ $\mathrm{C}_{12}$ molecule that contributes almost equally to all the three directions of crystal growth. It should be noted that these molecules assemble through both $\mathrm{H}$-bond and van der Waals forces in the H-bonding directions and with the aid of only van der Waals force in the other two directions. When the terminal groups of one of these molecules are replaced with phenyl groups, the $\mathrm{H}$-bonded $\mathrm{N}-\mathrm{H}$ and asymmetric $\mathrm{C}-\mathrm{H}$ vibration bands appear at 3336 and $2923 \mathrm{~cm}^{-1}$ respectively. The absorption frequencies of these two bands of $\mathrm{PhC}_{6}$ $\mathrm{C}_{12}$ are quite higher than that of the corresponding methyl terminated molecule. The shifts of these bands to higher wave numbers compared to the corresponding methyl terminated molecule indicate that both the H-bond and van der Waals forces are less strong in this molecule. The bulky phenyl groups seem to prevent closer packing of these molecules due to conformational mismatch instead of enhancing it through $\pi-\pi$ interactions. These observations are consistent with the lower melting temperature and smaller heat of fusion of the $\mathrm{PhC}_{6}-\mathrm{C}_{12}$ molecule compared to the methyl terminated molecules which has even fewer number of carbon atoms in the alkyl side chain. 


\subsection{Conclusions}

We studied the thermal properties and morphology of a series of homologous biscarbamate molecules with a longer spacer group than those in our previous work. DSC analysis showed that these molecules lack polymorphism and are highly crystalline in nature. While it might be expected that a longer spacer would lead to more conformational flexibility, we find that it is not the case with these molecules. With both $\mathrm{C}_{6}$ and $\mathrm{C}_{12}$ spacers, we find that the maximum in the spherulite size as well as the rate of spherulite growth occur with an alkyl side chain length of $\mathrm{C}_{8}$. The Avrami analysis of crystallization shows that the highly symmetric molecule with the $C_{12}$ spacer and $C_{12}$ side chain follows two-stage crystallization. Along this series of molecules, a minimum spherulite size, spherulite growth rate and rate of crystallization were observed for this symmetric $\mathrm{C}_{12}-\mathrm{C}_{12}$ biscarbamate. We rationalize this behaviour with relative contribution of hydrogen bonding and van der Waals forces as discerned from IR spectroscopy. When the terminal methyl group is replaced with a bulky phenyl group the melting temperature, heat of fusion and the spherulite size of the molecule decreased significantly. The phenyl terminal groups act as defects. These structural features thus provide extra knobs to tune the functional properties of these molecules. 


\subsection{References}

1. Moniruzzaman, M.; Goodbrand, B.; Sundararajan, P. R. J. Phys. Chem. B 2003, 107, 8416.

2. Moniruzzaman, M.; Sundararajan, P. R. Langmuir 2005, 21, 3802.

3. Khanna, S.; Moniruzzaman, M.; Sundararajan P. R. J. Phys. Chem. B 2006, 110, 15251.

4. Khanna, S.; Khan, M. K.; Sundararajan, P. Langmuir 2009, 25, 13183.

5. Francová, D.; Kickelbick, G. Monatsh Chem 2009, 140, 413.

6. Kawatsuki, N.; Koezuka, Y. Polymer 2009, 50, 2349.

7. McKierman, R. L.; Heintz, A. M.; Hsu, S. L.; Gido, S. P.; Penelle, J. Polym. Mater. Sci. Eng. 2001, 84, 416. 


\section{Chapter 5}

\section{Molecular Selectivity and Immiscibility during the Crystallization of Mixtures of Biscarbamates*}

*J. Phys. Chem. B 2008, 112(14), 4223. 


\subsection{Introduction}

The complementarity and specificity of hydrogen bond mediated self-assembly in biological systems has been effectively used in recent years to create supramolecular structures of various architectures. ${ }^{1-5}$ Such strategy involves design of molecules with multiple hydrogen-bonding sites, with specific donor-acceptor sequence. By the choice of complementary DAD: ADA and DAAD: ADDA pairs, linear pseudopolymer structures, and ribbonlike polymers, respectively, have been achieved. ${ }^{3}$ There is also a significant interest currently in the area of organic/inorganic hybrid materials, ${ }^{6}$ organometallics with $\mathrm{M}-\mathrm{H} \cdots$... OC type of hydrogen bonding, ${ }^{7}$ donor/acceptor complexes, etc., which involve blending/doping in order to create such hybrid systems. In designing self-assembling supramolecular structures, the side chain plays a role. Blending of two homologous self assembling small molecules, which differ only in the length of the side chain (e.g., alkyl), is expected to lead to a miscible, cocrystallized system, in which the alkyl chain of the components could intercalate. It is then of interest to investigate how the hydrogen bonding or aromatic interaction that mediates the self-assembly of the individual component would drive the final structure and morphology in the blend. We discuss here a system of homologous self-assembling small molecules, which differ only in the length of the alkyl side chain, do not show such miscibility. However, they mutually modify the crystallinity, spherulitic morphology, and spherulite growth rate.

The phenomenon of self-sorting during the association of mixtures of molecules has been studied by a number of authors..$^{8-14}$ These molecules possess self-assembling attributes such as hydrogen bonding. During aggregation in solution or crystallization, 
these molecules discriminate between self- and non-self-species, i.e., one type of molecule recognizes and interacts with its own kind. Although the possibility of interaction with the other species might exist, this is ignored. This has been termed the narcissistic self-sorting, as in enantiomeric self-recognition., ${ }^{8,11}$ Self-sorting polymers have also been described. ${ }^{12}$ These are polymers with hydrogen-bonding side chains, such as thymine and cyanuric acid based recognition units. These were shown to self-assemble with their complementary diamido pyridine and isophthalic wedge moieties. In this paper, we describe the behaviour of mixtures of homologous self-assembling molecules. These have identical hydrogen-bonding moieties and differ only in the length of the alkyl side chain. Even a small difference in the length of the alkyl chain is not tolerated during the mixing, and each type crystallizes separately.

Although there have been studies on creating supramolecular polymeric structures, small molecules bearing such hydrogen-bonding moieties have been explored for applications such as vehicles for phase-change inkjet technologies. Examples are carbamates and biscarbamates (Scheme 5.1) with alkyl side chains. ${ }^{15-17}$ These systems have a low melt viscosity of about 8-12 centipoises, which is ideal for jetting from the melt and melting temperatures $\left(T_{\mathrm{m}}\right)$ of $60-120^{\circ} \mathrm{C}$. The viscosity and $T_{\mathrm{m}}$ are varied by the choice of length of the alkyl side chains. Whereas carbamates have been known ${ }^{18}$ since the 1950s and have such diverse applications as anti-inflammatory agents, ${ }^{19}$ pesticides, ${ }^{20}$ etc., new applications are emerging in technologies such as inkjet printing. 
Simple carbamate: $\quad \mathbf{H}_{37} \mathbf{C}_{\mathbf{1 8}}-\mathbf{N H}-\stackrel{\mathbf{O}}{\|}-\mathbf{O}-\mathbf{R}$

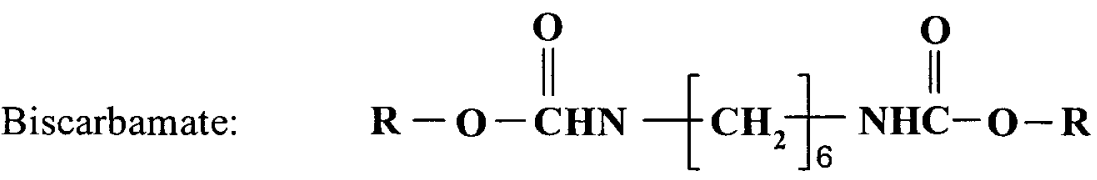

Scheme 5.1. $\mathrm{R}=\mathrm{n}$-alkyl; Number of $\mathrm{C}$ atoms ranging from 4 to 18 .

In this chapter, we discuss the effect of blending two homologous self-assembling molecules on the structure and morphology. We examine if blending two homologous self-assembling molecules, which differ only in the length of the alkyl side chain, leads to miscibility between them such that a sharing of the hydrogen-bonding scheme and mutual intercalation of alkyl chains occur. Or, do they self-sort and each of them selectively assembles with its own type? We use biscarbamates as an example, with different alkyl chain lengths. Although the central part of the molecules is the same, the difference in the side chain length causes a disruption in the packing of the molecules and changes in the melting temperature and crystallinity. In addition to a reduction in the spherulite size, the rate of growth of the spherulites is also affected. The miscibility behaviour seen here is compared with studies on hydrogen-bonded polymer mixtures. ${ }^{21-23}$

\subsection{Experimental}

\subsubsection{Preparation of the Blends}

The synthesis of biscarbamates used in this study has been described before ${ }^{15,16,24}$ and involves reacting 1,6-diisocyanatohexane with different alcohols ranging from 1butanol to 1-octadecanol. Binary blends of biscarbamates were prepared by melt mixing, 
with $80 / 20,60 / 40,50 / 50,40 / 60$, and 20/80 (wt \%) compositions. Since the melt viscosity of these samples is very low, mixing via this procedure was found to be convenient. Preweighed mixtures of biscarbamates were heated in a $5-\mathrm{mL}$ vial at a temperature of $20^{\circ} \mathrm{C}$ above that of the higher melting component with continuous stirring. After $1 \mathrm{~h}$, the melt was slowly cooled to room temperature. Three types of binary blends were prepared with $\mathrm{C}_{4} / \mathrm{C}_{18}, \mathrm{C}_{8} / \mathrm{C}_{12}$, and $\mathrm{C}_{16} / \mathrm{C}_{18}$ biscarbamates (the sample $\mathrm{C}_{x}$ refers to the biscarbamate having $x$ number of carbon atoms in the alkyl side chain derived from the alcohol). The $\mathrm{C}_{8} / \mathrm{C}_{12}$ series was used for most of the study. The other two were used to rationalize the miscibility behaviour.

\subsubsection{Methods}

The optical micrographs were recorded on a Zeiss Axioplan polarized optical microscope (OM) following the method described in Chapter 2. For the kinetic study of the spherulite growth, a Linkam hot stage LTS 350 equipped with a Linkam TMS 94 thermo-controller was used. In these studies the samples were heated to a temperature 20 ${ }^{\circ} \mathrm{C}$ above that of the higher melting component at a rate of $5{ }^{\circ} \mathrm{C} / \mathrm{min}$ and held at that temperature for about $10 \mathrm{~min}$. The samples were then cooled at a rate of $2{ }^{\circ} \mathrm{C} / \mathrm{min}$ down to a temperature of $5{ }^{\circ} \mathrm{C}$ above the crystallization temperature $\left(T_{\mathrm{c}}\right)$ and after that at the rate of $0.1{ }^{\circ} \mathrm{C} / \mathrm{min}$ down to the $T_{\mathrm{c}}$. Northern Eclipse image processing software was used to capture the images at specific time intervals during the crystallization of the samples isothermally held at their $T_{\mathrm{c}}$ followed by the calculation of the spherulite size for subsequent data processing. 
FTIR spectra of the pure biscarbamates and their blends were taken under ambient conditions with a Varian 1000 Scimitar Series spectrophotometer following the method described in Chapter 2. Spectra for select samples were recorded at different temperatures, by heating the pellet beyond the melting temperature of the sample and recording the spectra as the sample cooled and solidified.

\subsection{Results and Discussion}

\subsubsection{Thermal Behaviour}

The change of heat of fusion as a function of the composition of the binary blends prepared from $\mathrm{C}_{8}$ and $\mathrm{C}_{12}$ is shown in Figure 5.1. It is seen that the heat of fusion decreases initially with an increase in the fraction of $\mathrm{C}_{12}$ in the blend. It passes through a minimum with a weight fraction of 0.5 . It then increases significantly with the amount of $\mathrm{C}_{12}$ in the blend. A similar trend was seen with the other two sets of $\mathrm{C}_{4} / \mathrm{C}_{18}$ and $\mathrm{C}_{16} / \mathrm{C}_{18}$ blends. Such variations in heat of fusion with respect to the blend composition raises a question as to whether the components of the blends are miscible, at least at certain compositions, leading to cocrystallization with a decreased crystallinity or whether they act as mutual diluents. This was addressed by examining the DSC traces.

The components of the blends are members of a homologous series having two hydrogen-bonding moieties and symmetric alkyl side chains with a possibility of hydrogen bond either between its own type or with the other component. In all cases, the two hydrogen bonding moieties are separated by a hexyl group. The DSC thermograms of the $\mathrm{C}_{8} / \mathrm{C}_{12}$ blends at different compositions are shown in Figure 5.2. It is seen that a 
$60 / 40$ blend of $\mathrm{C}_{8} / \mathrm{C}_{12}$ shows a single peak in the DSC trace indicating the possibility that the blend components are miscible with each other. It seems, however, not to be the case if we look into the crystallization curve of this blend and melting characteristics of the blends of other compositions.

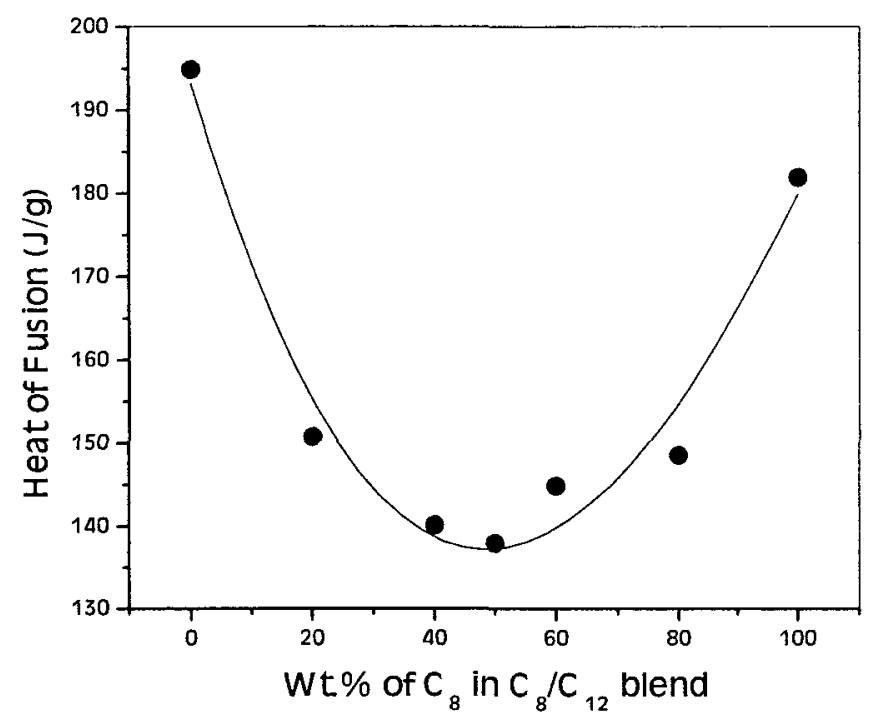

Figure 5.1. Heat of fusion as a function of weight percent of $\mathrm{C}_{8}$ in the mixtures of $\mathrm{C}_{8}$ and $\mathrm{C}_{12}$.

The melting points of the blends of biscarbamates obtained from DSC analysis are shown in Table 5.1. The difference in the $T_{\mathrm{m}}$ with a scan rate of $1{ }^{\circ} \mathrm{C} / \mathrm{min}$ was less than 1 ${ }^{\circ} \mathrm{C}$. The melting points of slow-cooled and quenched samples are not significantly different, and we discuss the slow-cooled samples here. It is seen from Table 5.1 that the melting temperature of $\mathrm{C}_{8}$ is lower than that of $\mathrm{C}_{12}$ by about $8{ }^{\circ} \mathrm{C}$. Among the various compositions of $\mathrm{C}_{8} / \mathrm{C}_{12}$ blends only $60 / 40$ composition shows a single peak in DSC (Figure 5.2a). If this single peak arises from the complete miscibility of the blend components at this particular composition, we expect the $T_{\mathrm{m}}$ of the blend to be in between 
the melting temperatures of the respective pure components. However, it is found to be less than that of the lower melting component. Moreover, the cooling curve (Figure 5.2b) shows a splitting of the peak with a temperature difference of about $6{ }^{\circ} \mathrm{C}$, which indicates a phase separation in the blend during its crystallization. The DSC trace obtained with the scan rate of $1{ }^{\circ} \mathrm{C} / \mathrm{min}$ for this blend is shown in Figure 5.2c. The inset in this figure shows a shoulder at a temperature close to the peak of the endotherm.

To rationalize again the possibility of miscibility vs mutual diluent effects, another two sets of blends were prepared and investigated with respect to their thermal behaviour. The first set comprises of $\mathrm{C}_{4}$ and $\mathrm{C}_{18}$ (Figure 5.2d) with the largest possible difference between the chain lengths of the alkyl groups and the other consists of $\mathrm{C}_{16}$ and $\mathrm{C}_{18}$ biscarbamates with the least difference in their alkyl chain length. The results obtained are also summarized in the Table 5.1. Table 5.1 shows that, for AB-type binary blends (where A refers to the biscarbamate with shorter alkyl side chain), there is a splitting of the peaks in DSC thermograms at certain compositions (Figures 5.2). The peaks correspond to two melting points where the first melting point is lower than that of the pure biscarbamate $\mathrm{A}$, and the second one was lower than that of the pure biscarbamate $\mathrm{B}$. It is seen that with the increment of fraction of $B$ in the blend the second melting point increased while the first melting point decreased, as seen from Figure 5.3 for these blends. This observation can be attributed to the possible diluent effect exerted on each other by the components present in the blend. This figure shows the effect of one component on the melting temperature of the other. 

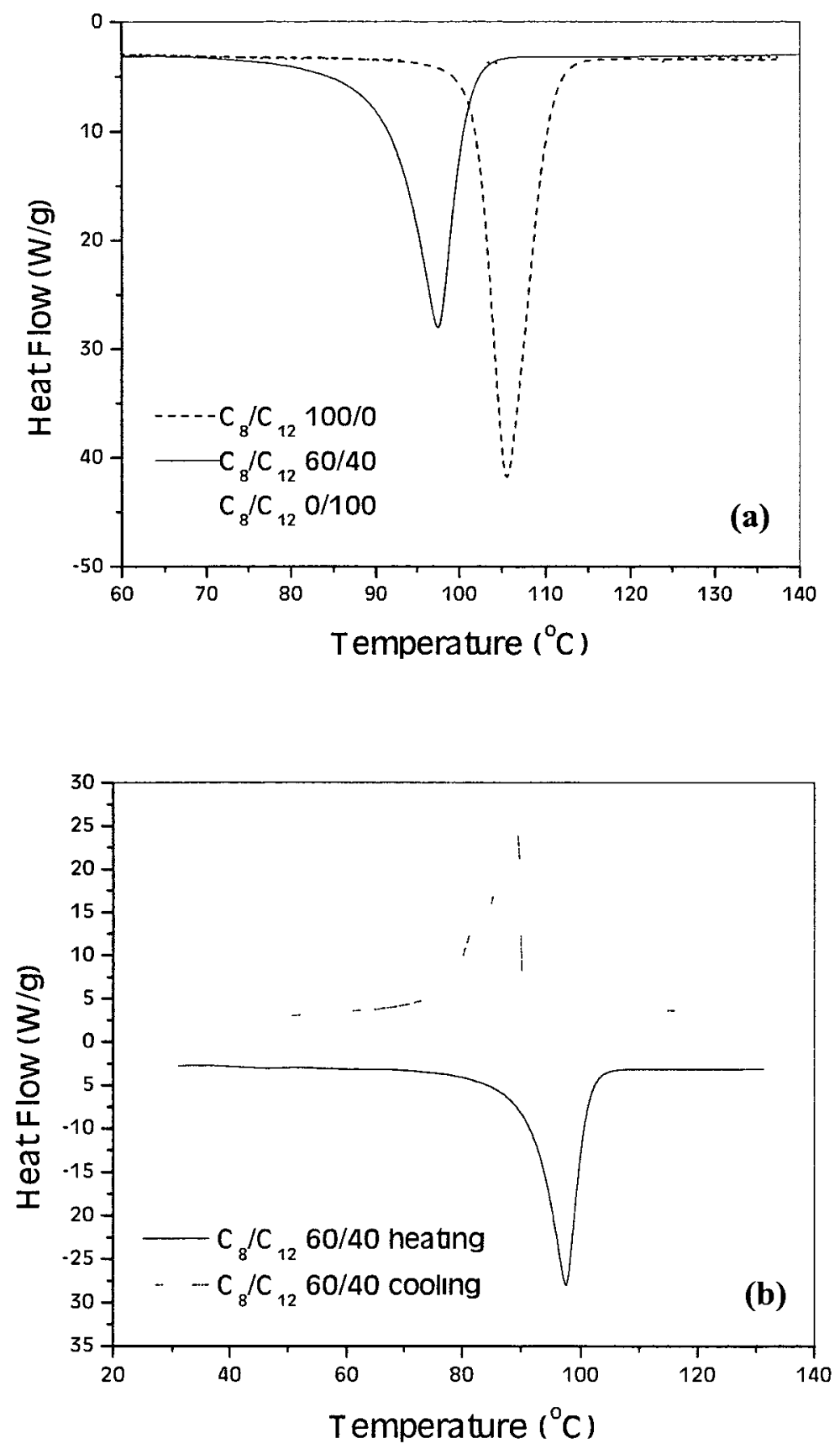

(Caption on next page) 

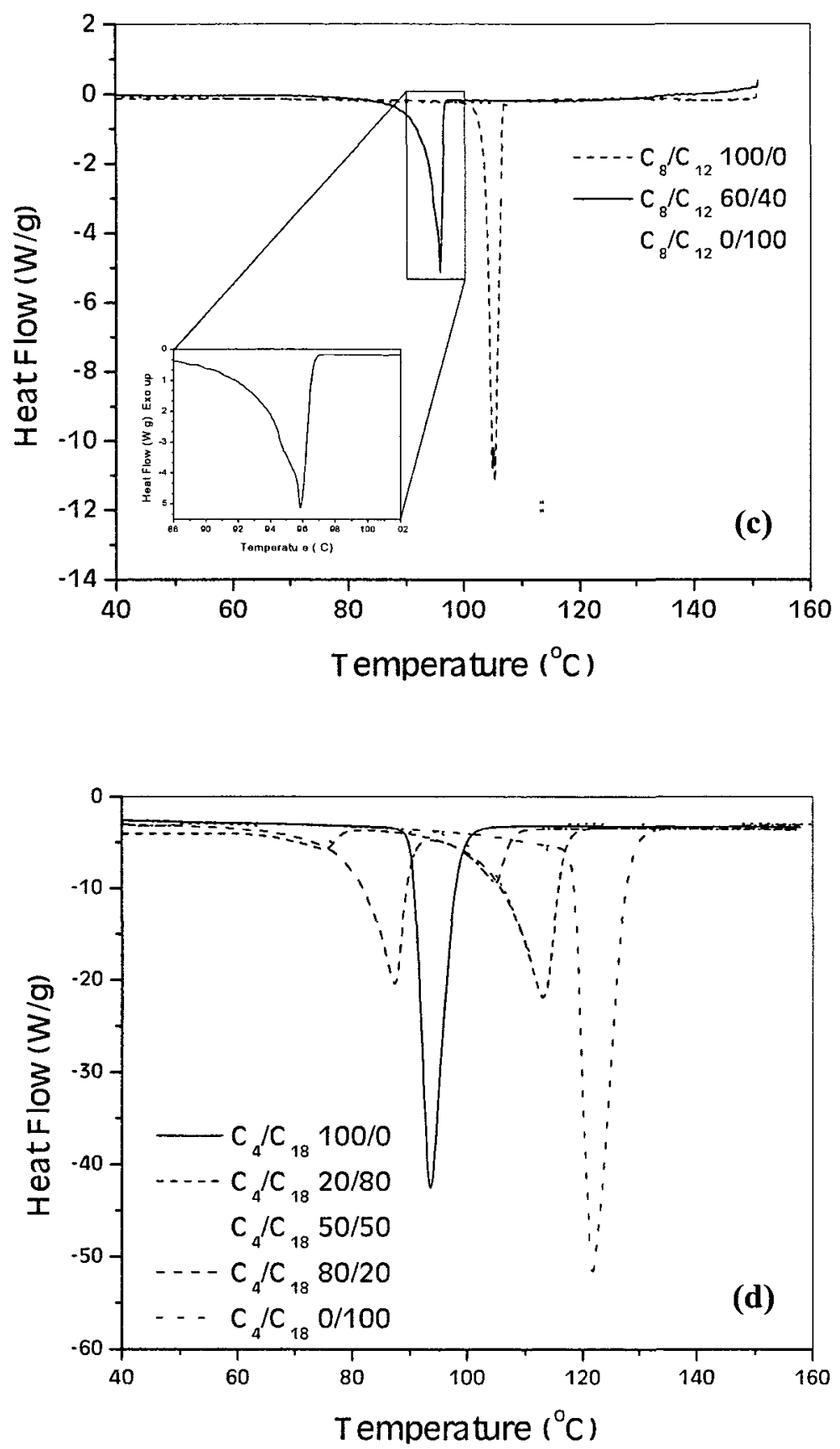

Figure 5 2. DSC thermograms of $\mathrm{C}_{8} / \mathrm{C}_{12}$ blends (a) and (b) at a rate of $10^{\circ} \mathrm{C} / \mathrm{min}$, (c) at 1 ${ }^{\circ} \mathrm{C} / \mathrm{min}$, and (d) $\mathrm{C}_{4} / \mathrm{C}_{18}$ blends at a rate of $10^{\circ} \mathrm{C} / \mathrm{min}$ at various compositions. 
Table 5.1 Melting Points of Mixtures of Biscarbamates

\begin{tabular}{|c|c|c|c|c|c|}
\hline \multicolumn{2}{|c|}{$\mathrm{C}_{4} / \mathrm{C}_{18}$ Blend } & \multicolumn{2}{|c|}{$\mathrm{C}_{8} / \mathrm{C}_{12}$ Blend } & \multicolumn{2}{|c|}{$\mathrm{C}_{16} / \mathrm{C}_{18}$ Blend } \\
\hline Sample & $T_{\mathrm{m}},{ }^{\circ} \mathrm{C}$ & Sample, & $T_{\mathrm{m}}{ }^{\circ} \mathrm{C}$ & Sample & $T_{\mathrm{m}},{ }^{\circ} \mathrm{C}$ \\
\hline $100 / 0$ & 93.6 & $100 / 0$ & 106.3 & $100 / 0$ & 118.8 \\
\hline $80 / 20$ & $87.3,104.8$ & $80 / 20$ & $97.3,100.3$ & $80 / 20$ & 115.6 \\
\hline $50 / 50$ & $81.7,109.2$ & $60 / 40$ & 96.9 & $60 / 40$ & 114.2 \\
\hline $20 / 80$ & $74.6,113.1$ & $50 / 50$ & $95.3,99.8$ & $50 / 50$ & 114.6 \\
\hline \multirow[t]{3}{*}{$0 / 100$} & 121.8 & $40 / 60$ & $93.9,103.7$ & $40 / 60$ & 115.5 \\
\hline & & $20 / 80$ & $87.3,107.6$ & $20 / 80$ & 116.9 \\
\hline & & $0 / 100$ & 114.89 & $0 / 100$ & 121.8 \\
\hline
\end{tabular}

Higher concentrations of $\mathrm{A}$ depress the melting point of $\mathrm{B}$ to such an extent that these two peaks overlap and appear as a single peak. If the difference between the melting points of the two pure components is small enough then there is such a good agreement in their mutual diluent effect that almost every composition gives a single peak in DSC thermograms. This is evident from the melting characteristics of the $\mathrm{C}_{16} / \mathrm{C}_{18}$ blends. This rationale can be validated with the melting characteristics of $\mathrm{C}_{8} / \mathrm{C}_{12}$ binary blends of $80 / 20,60 / 40$ and $50 / 50$ compositions. The $60 / 40$ composition gives a single peak in DSC trace. But an increased amount of $\mathrm{C}_{8}$ in $80 / 20$ blend depressed the melting point of $\mathrm{C}_{12}$ to such an extent that the melting peak appeared at a position lower than that of pure $C_{8}$. On the other hand, with an increased amount of $\mathrm{C}_{12}$ in the $50 / 50$ blend leads to a single peak with a shoulder at a position higher than that of $60 / 40$ single peak. This indicates that the single peak at some compositions of binary biscarbamates blends is not due to the miscibility of components but to their mutual diluent effect on each other. 

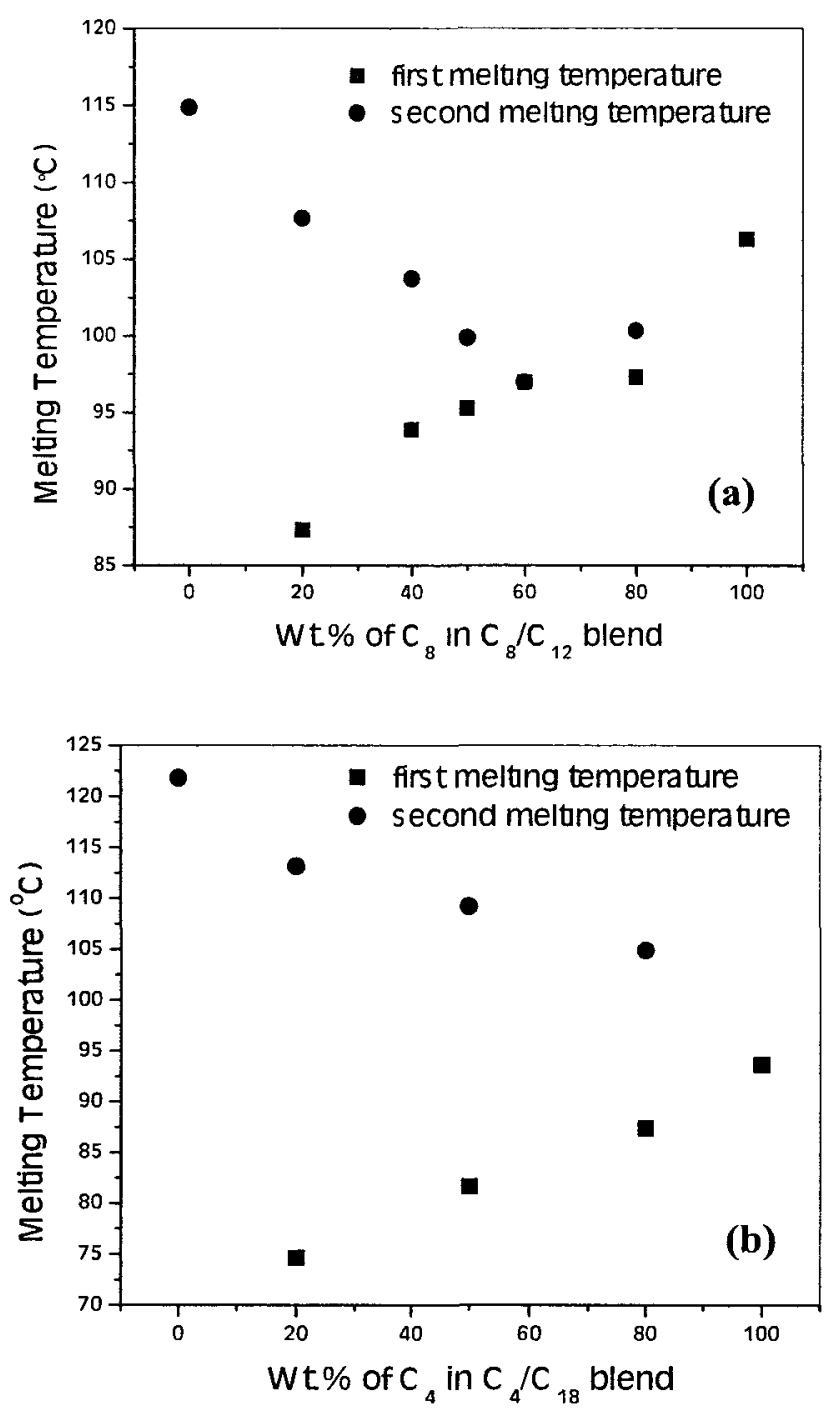

Figure 5.3. Variation of the first and second melting temperatures of (a) $\mathrm{C}_{8} / \mathrm{C}_{12}$ and (b) $\mathrm{C}_{4} / \mathrm{C}_{18}$ blends at different compositions.

Similar was the conclusion reached in the case of monocarbamates, with a single hydrogen bonding motif. ${ }^{26}$ Thus, in the case of these self-assembling molecules, selfsorting occurs through preferential association between molecules with the same alkyl chain length, although they are not chemically very different, with only a small difference in the alkyl chain length. The association hence seems to be specific. 


\subsubsection{Effect on Spherulite Size}

Optical micrographs of biscarbamates and their blends are shown in Figures 5.45.6. All the biscarbamates show spherulitic morphology with negative birefringence indicating that the long alkyl chains, symmetrically aligned on the both side of the $\mathrm{H}-$ bonding moieties, are disposed tangentially along the spherulite.
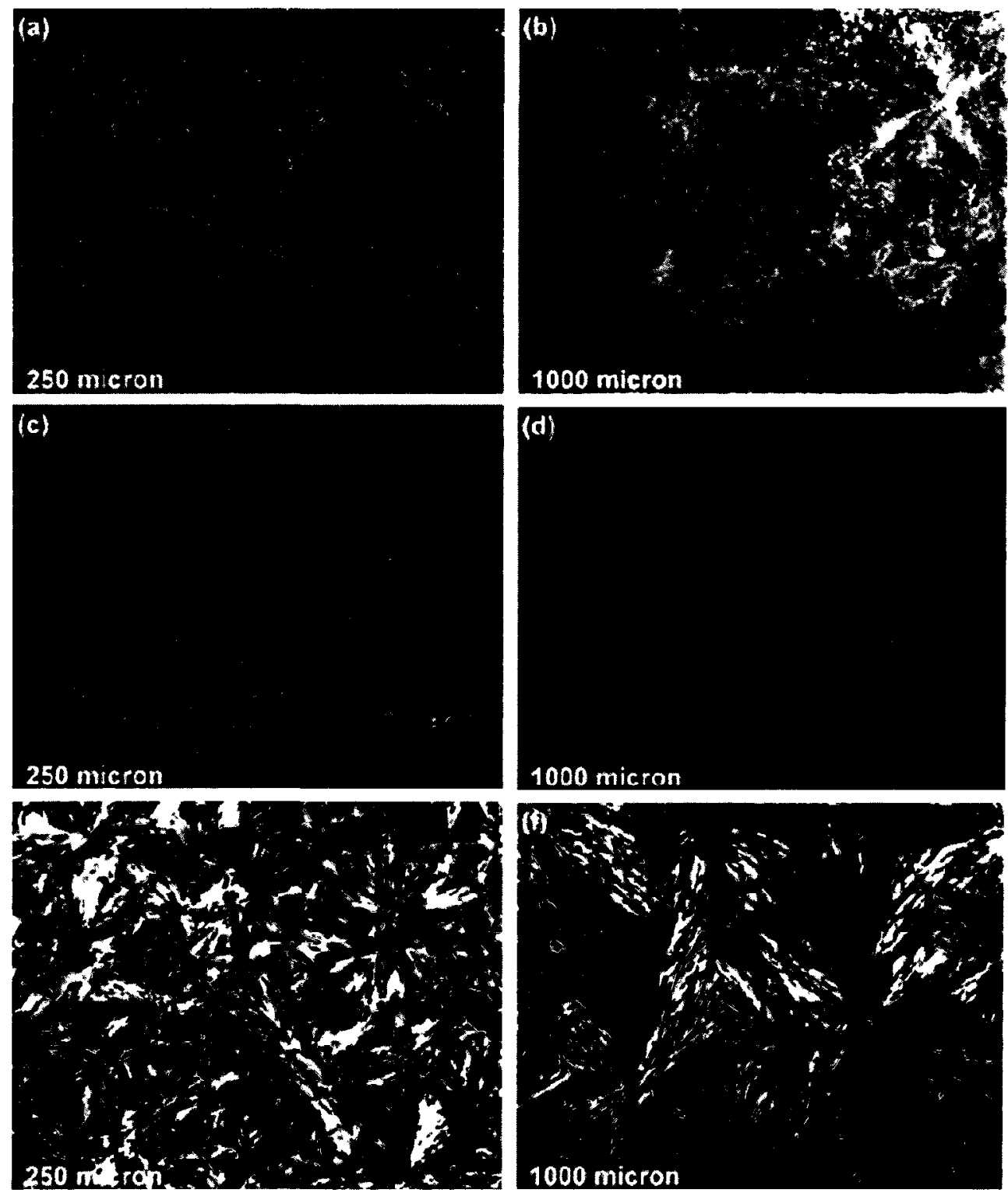

Figure 5.4. Optical micrographs of biscarbamates and their blends: (a) $\mathrm{C}_{4} 100 \%$, quenched, (b) $\mathrm{C}_{4} 100 \%$, slow-cooled, (c) $\mathrm{C}_{4} / \mathrm{C}_{18}$ (50/50), quenched, (d) $\mathrm{C}_{4} / \mathrm{C}_{18}$ (50/50), slow-cooled, (e) $\mathrm{C}_{18} 100 \%$, quenched, and (f) $\mathrm{C}_{18} 100 \%$, slow-cooled. 

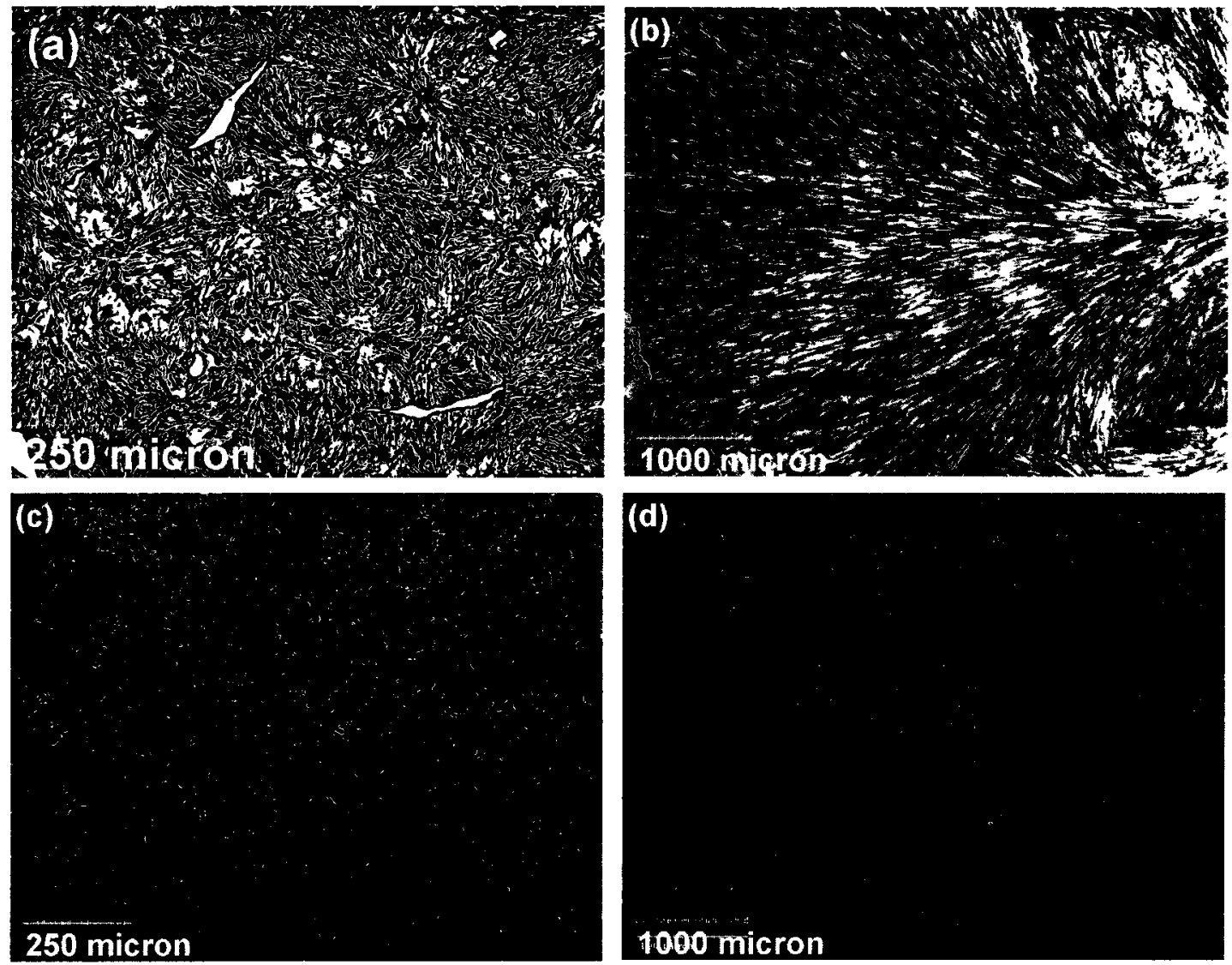

(d)

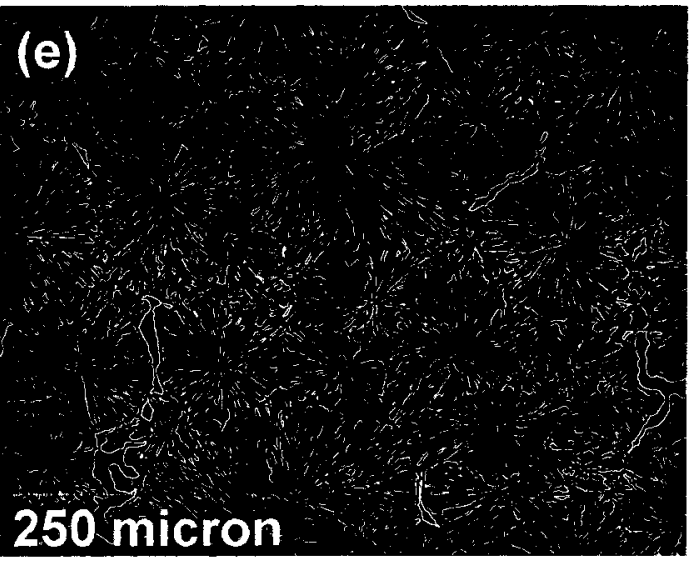

\section{0 micron}

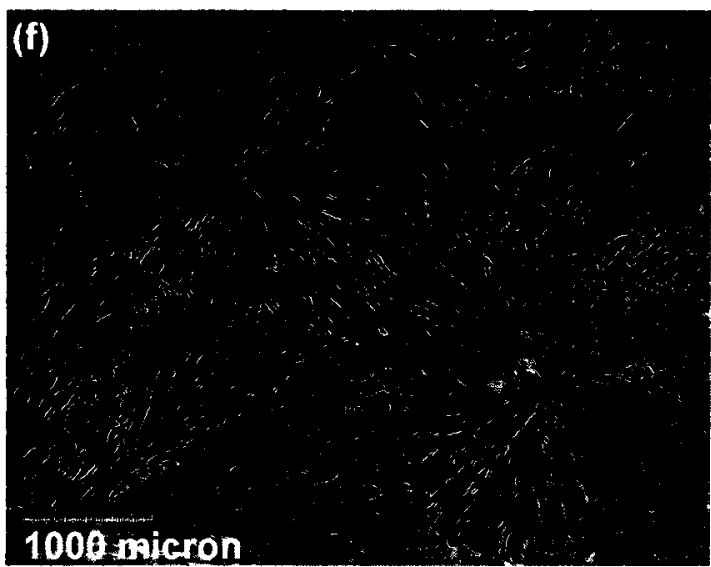

Figure 5.5. Optical micrographs of $\mathrm{C}_{8}$ and $\mathrm{C}_{12}$ biscarbamates and their blends: (a) $100 \%$ $\mathrm{C}_{8}$, quenched, (b) $100 \% \mathrm{C}_{8}$, slow-cooled, (c) $\mathrm{C}_{8} / \mathrm{C}_{12}(60 / 40)$, quenched, (d) $\mathrm{C}_{8} / \mathrm{C}_{12}$ (60/40), slow-cooled, (e) $100 \% \mathrm{C}_{12}$, quenched, and (f) $100 \% \mathrm{C}_{12}$, slow-cooled. 

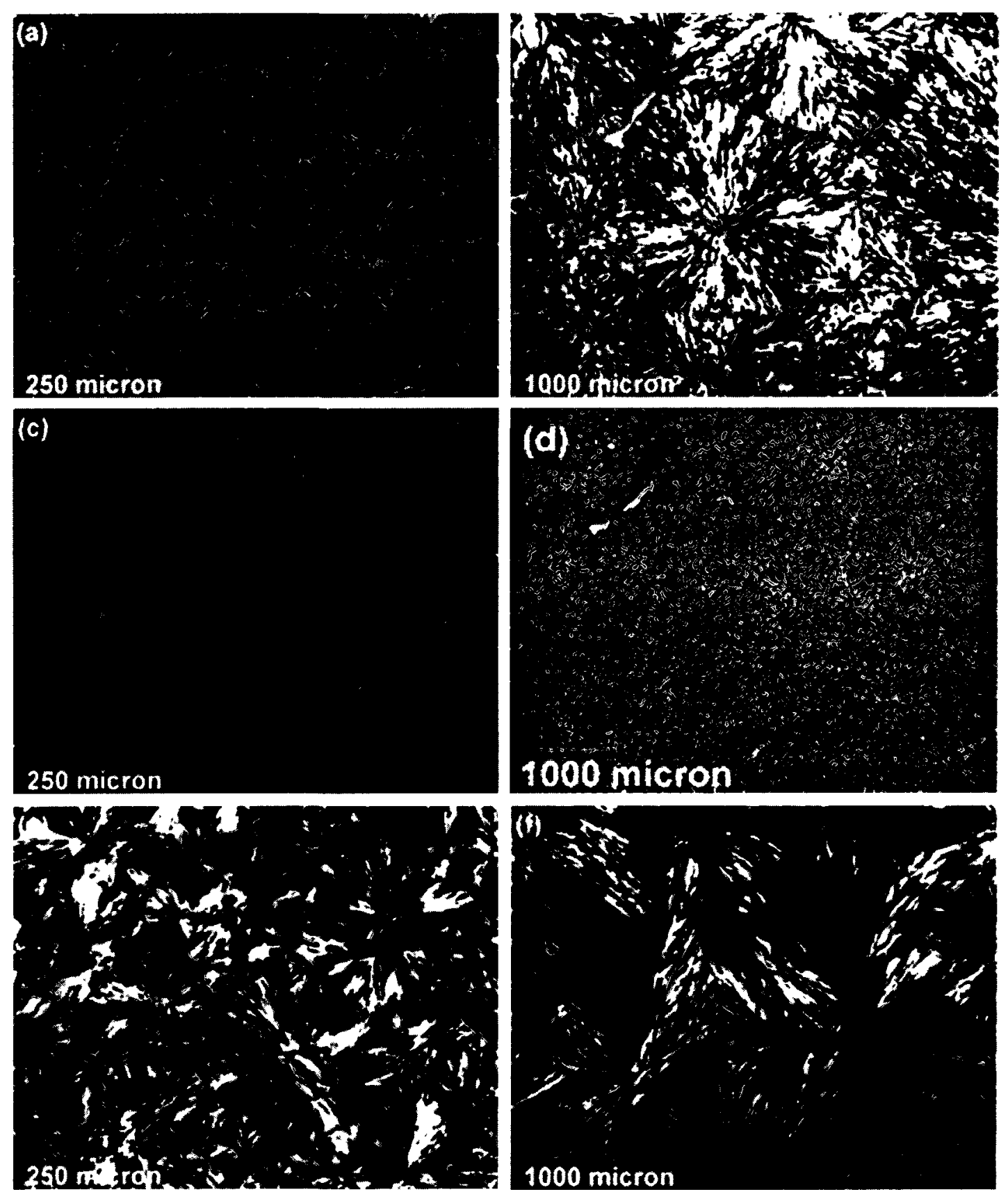

Figure 5.6. Optical micrographs of $\mathrm{C}_{16}$ and $\mathrm{C}_{18}$ biscarbamates and their blends: (a) $100 \%$ $\mathrm{C}_{16}$, quenched, (b) $100 \% \mathrm{C}_{16}$, slow-cooled, (c) $\mathrm{C}_{16} / \mathrm{C}_{18}$ (50/50), quenched, (d) $\mathrm{C}_{16} / \mathrm{C}_{18}$ (50/50), slow-cooled, (e) $100 \% \mathrm{C}_{18}$, quenched, and (f) $100 \% \mathrm{C}_{18}$, slow-cooled.

This was shown to be the case in our previous work, ${ }^{24}$ where the direction of the alkyl chain was determined by XRD. The $\mathrm{C}_{4}$ biscarbamate, both in quenched and slow-cooled 
samples, did not show significant birefringence, but the presence of spherulites can be seen. As expected, the size of spherulites of biscarbamates and their blends depend on the sample preparation protocol. Slow-cooled samples of both blends and their corresponding pure components show spherulites sizes several times larger than those of quenched samples. The spherulites corresponding to the blends are smaller than those of the individual components.

Parts $\mathrm{a}$ and $\mathrm{b}$ of Figure 5.7 show the variation in spherulite size as a function of composition of the $\mathrm{C}_{8} / \mathrm{C}_{12}$ and $\mathrm{C}_{4} / \mathrm{C}_{18}$ blends, respectively. It is seen that the spherulite size reduces significantly with the incorporation of the second component into the blends, and at 50/50 composition of $\mathrm{C}_{8} / \mathrm{C}_{12}$ blend, it shows the minimum size. A similar trend is seen in the case of $\mathrm{C}_{4} / \mathrm{C}_{18}$ blend also. In the latter, adding a small amount (e.g., 20\%) of $\mathrm{C}_{4}$ to $\mathrm{C}_{18}$ reduces the spherulite size drastically in the slow-cooled sample. In the quenched samples, the opposite effect is seen: a small amount of $\mathrm{C}_{18}$ causes a significant reduction in size. With the large variation in each of the curves for the $\mathrm{C}_{4} / \mathrm{C}_{18}$ blends (with the large difference in the alkyl chain lengths, and two melting temperatures), parts c and d of Figure 5.7 show the distribution of the spherulite size to be bimodal for the quenched and slow-cooled samples, the latter being rather broad. In the case of $\mathrm{C}_{16} / \mathrm{C}_{18}$ blends, well-defined spherulitic morphology is not seen with any of the compositions (see, e.g., parts $\mathrm{c}$ and $\mathrm{d}$ of Figure 5.6) perhaps due to their very small size, and it was practically impossible to measure the spherulite size. Thus, although there does not seem to be any mutual intercalation or cocrystallization between the components, the growing 
spherulites of one provide the nucleation sites for the other, leading to smaller spherulites.
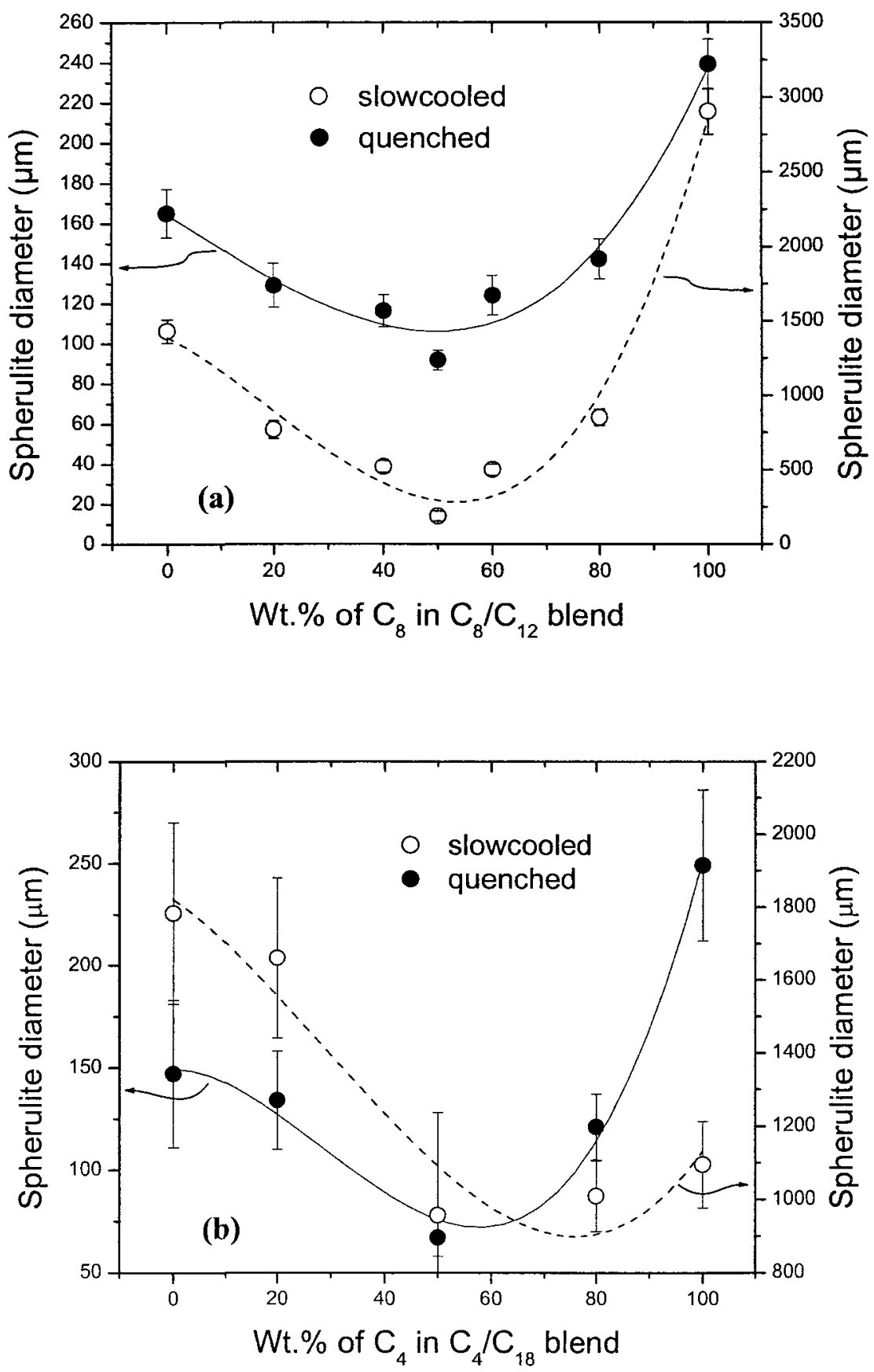

(Caption on next page) 

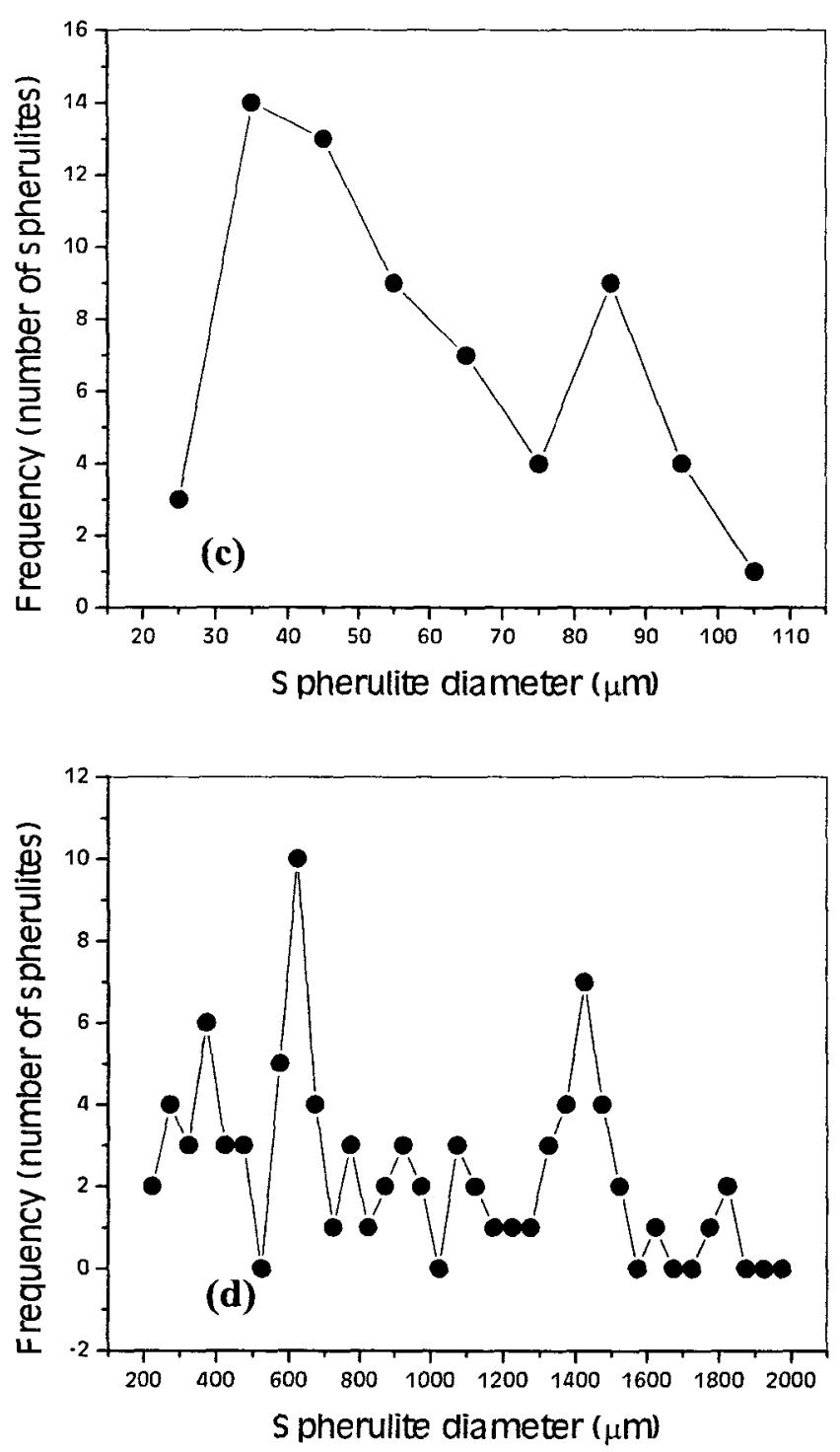

Figure 5.7. Spherulite size as a function of composition of (a) $C_{8} / C_{12}$ and (b) $C_{4} / C_{18}$ blends. Spherulite size distribution of $\mathrm{C}_{4} / \mathrm{C}_{18}$ (50/50) blend: (c) quenched and (d) slowcooled.

\subsubsection{Spherulite Growth Rate}

We have shown before ${ }^{24}$ that the growth rate of spherulites of the biscarbamates depends on the length of the alkyl side chain, exhibiting a maximum with $\mathrm{C}_{8}$. The results discussed above show that blending leads to a depression of the $T_{\mathrm{m}}$, reduction in the heat of fusion and a decrease in spherulite size. 

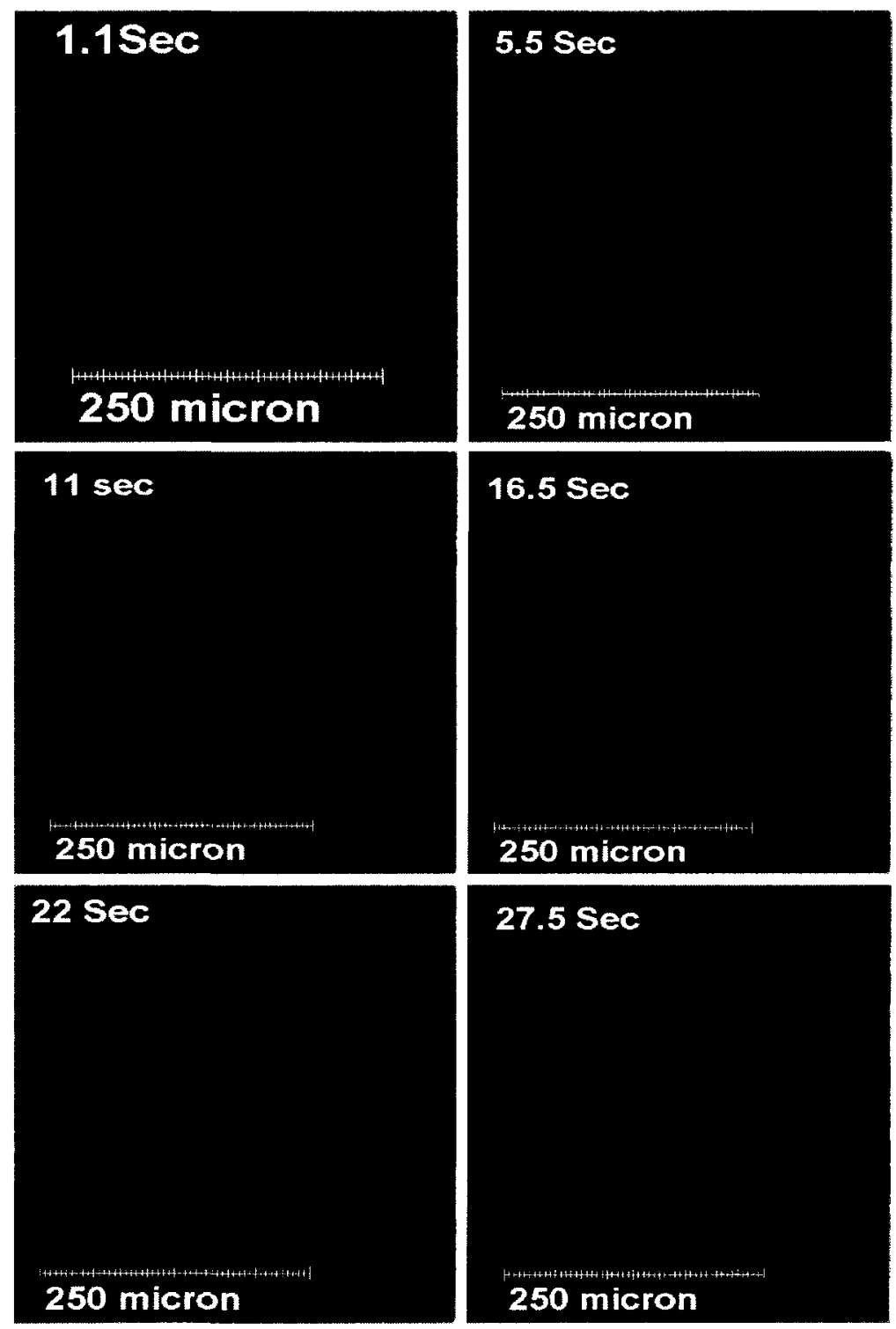

Figure 5.8. Optical micrographs showing spherulites of $\mathrm{C}_{8} / \mathrm{C}_{12}$ blend (50/50) at different times during isothermal crystallization.

It is likely that the rate of growth of the spherulites would also be affected by blending. To investigate the effect of blending on the growth rate, isothermal spherulite growth of $\mathrm{C}_{8} / \mathrm{C}_{12}$ blends was studied following the procedure described in the experimental section. Figure 5.8 shows some of the micrographs of $\mathrm{C}_{8} / \mathrm{C}_{12}: 50 / 50$ blend recorded at different times. It is seen that the spherulite grows symmetrically in this case, 

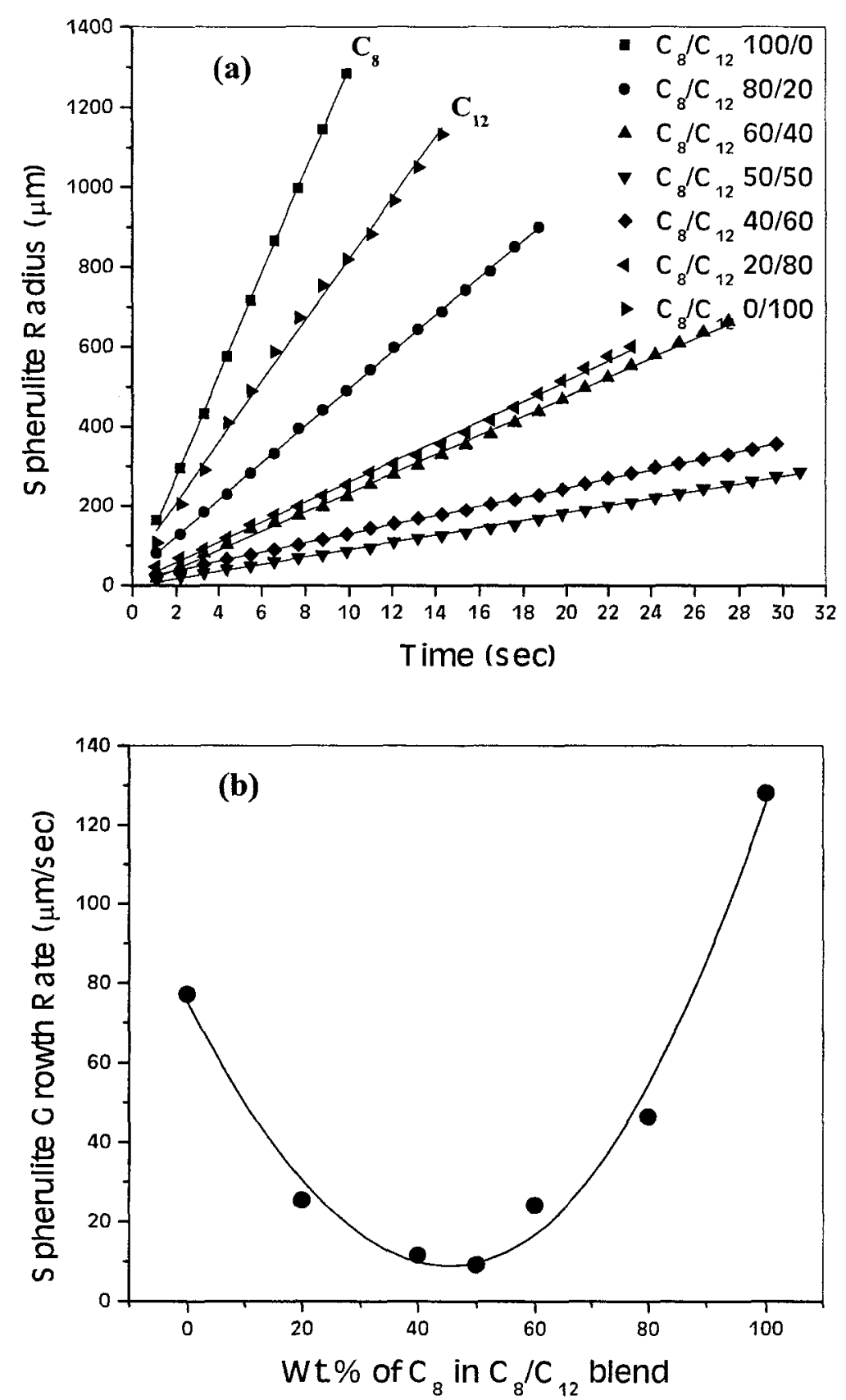

Figure 5.9. (a) Variation of spherulite size as a function of time and (b) spherulitic growth rate for different compositions of $\mathrm{C}_{8} / \mathrm{C}_{12}$ blend.

in contrast to the fan-shaped growth seen, e.g., in parts $b$ and $f$ of Figure 5.5 for the individual components. The change of spherulite size with time for $C_{8}, C_{12}$, and their blends are shown in Figure 5.9a. The growth is complete within $9 \mathrm{~s}$ for $\mathrm{C}_{8}$ (due to 
impinging with other spherulites) and within $14 \mathrm{~s}$ for $\mathrm{C}_{12}$. The growth is slower for the blends. The time for completion progressively increases with an increase in the concentration of $\mathrm{C}_{12}$, up to the 50/50 composition. For the latter it takes $31 \mathrm{~s}$ to complete the growth. With a further increase in $C_{12}$ (e.g., 20/80), the time to completion decreases again. The rate of growth is plotted in Figure $5.9 \mathrm{~b}$. With incorporation of the second component the spherulite growth reduces significantly and reaches a minimum at 50/50 composition. With rate of growth of $\mathrm{C}_{8}$ being higher than that of $\mathrm{C}_{12}$, adding the latter as a minor component to $C_{8}$ gradually reduces the growth rate. However, adding $C_{8}$ as a minor component to $\mathrm{C}_{12}$ actually increases the rate. This behaviour is similar to the change of heat of fusion and percent crystallinity of these blends.

Since the thermal studies indicate that there is no miscibility between the components, it would be of interest to examine if the spherulites corresponding to each can be identified and if each of them form distinctly from each other. To this end, the blends of $C_{8}$ and $C_{12}$, with $80 / 20$ and $20 / 80$ compositions, were heated on the hot stage, and the temperature was increased successively to (a) to the first $T_{\mathrm{m}}$ (b) $1^{\circ} \mathrm{C}$ higher than the first $T_{\mathrm{m}}$, (c) to the second $T_{\mathrm{m}}$, (d) $1{ }^{\circ} \mathrm{C}$ higher than the second $T_{\mathrm{m}}$, and (e) $1.8^{\circ} \mathrm{C}$ higher than the second $T_{\mathrm{m}}$. The heating rate was $5^{\circ} \mathrm{C} / \mathrm{min}$ up to $50^{\circ} \mathrm{C}$ and at $1^{\circ} \mathrm{C} / \mathrm{min}$ to get to the desired temperature. The sample was kept at the desired temperature for about 5 min before capturing the images. The results are shown in Figures 5.10 and 5.11 for the 80/20 and 20/80 compositions, respectively. By comparison of parts $\mathrm{c}$ and $\mathrm{d}$ of Figures 5.10, below and above the second melting temperature, the $\mathrm{C}_{8}$ has completely molten in the latter, and the parts of spherulites corresponding to $\mathrm{C}_{12}$ are seen. 


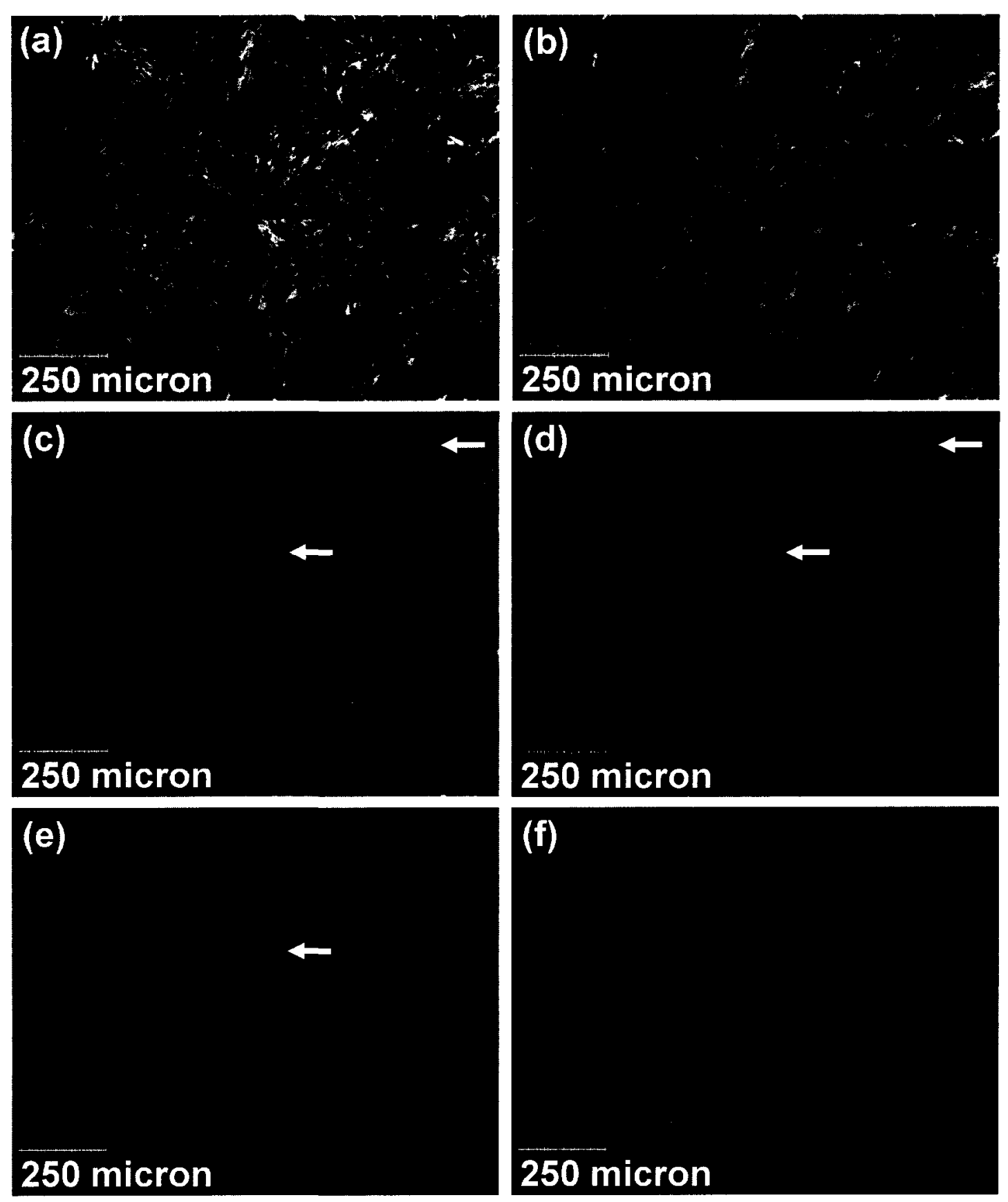

Figure 5.10. Optical micrographs of $\mathrm{C}_{8} / \mathrm{C}_{12} \quad 80 / 20$ blend recorded at different temperatures: (a) at below the first melting temperature, (b) at the first melting temperature $\left(95^{\circ} \mathrm{C}\right)$, (c) at $1{ }^{\circ} \mathrm{C}$ higher than the first melting temperature, (d) at second melting temperature $\left(99^{\circ} \mathrm{C}\right)$, (e) at $1{ }^{\circ} \mathrm{C}$ higher than the second melting temperature, and (f) at $1.8{ }^{\circ} \mathrm{C}$ higher than the second melting temperature. 


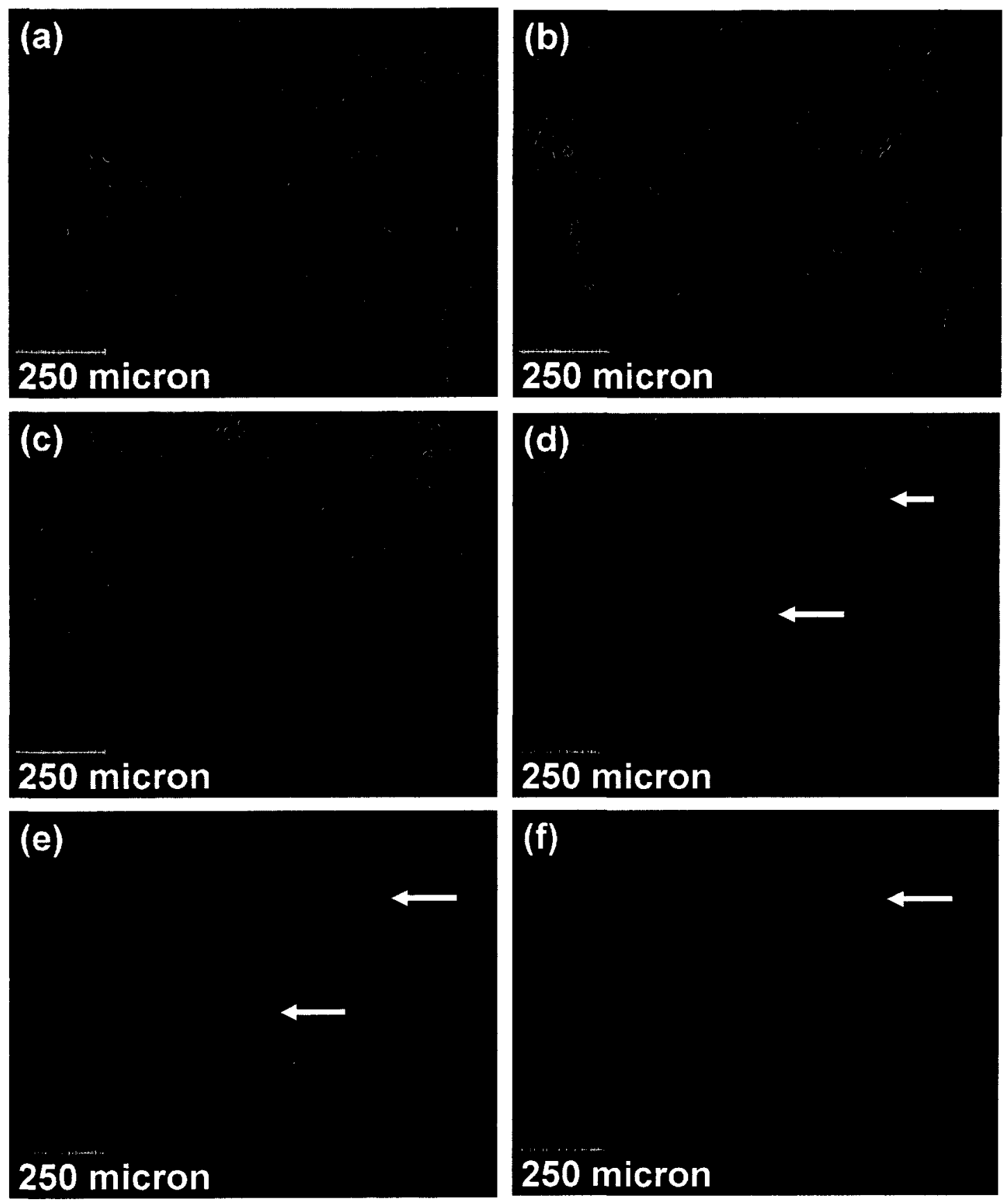

Figure 5.11. Optical micrographs of $\mathrm{C}_{8} / \mathrm{C}_{12} 20 / 80$ blend recorded at different temperatures: (a) at below the first melting temperature, (b) at the first melting temperature $\left(87^{\circ} \mathrm{C}\right)$, (c) at $1{ }^{\circ} \mathrm{C}$ higher than the first melting temperature, (d) at second melting temperature $\left(108^{\circ} \mathrm{C}\right),(\mathrm{e})$ at $1^{\circ} \mathrm{C}$ higher than the second melting temperature, and (f) at $1.8^{\circ} \mathrm{C}$ higher than the second melting temperature.

There is a further decrease in the birefringent material in Figure 5.10e. Note that the original contours of spherulites are still seen, and the arrows in these figures point to the 
fragments that were part of the spherulitic region in Figure 5.10c, which still remained in parts $d$ and e of Figure 5.10. The latter correspond to $\mathrm{C}_{12}$ in the blend. Figure 5.10f shows the isotropic structure after the melting of both components. Similar features are seen in Figure 5.11, for the $\mathrm{C}_{8} / \mathrm{C}_{12}$ with $20 / 80$ composition. The fragments that are seen in parts $\mathrm{e}$ and f of Figure 5.11 (indicated by arrows) were part of the spherulitic structure in parts a$\mathrm{d}$ of Figure 5.11 .

The above observations show that although the components of these selfassembling molecules are immiscible at the molecular level and crystallize by selfsorting, these crystalline domains profusely participate in forming the spherulitic domains. The two species do not form distinct spherulites of their own. We could identify such mixing of crystalline domains by locating the remnants of one component in the spherulitic domains of the other component after the melting of the latter, as seen from Figures 5.10 and 5.11.

\subsubsection{X-ray Diffraction}

The structural characteristics of the biscarbamates as derived from XRD were discussed before. ${ }^{24}$ Figure 5.12a shows the XRD traces of binary blends of $\mathrm{C}_{8}$ and $\mathrm{C}_{12}$ at different compositions along with those of pure components. All the blends at different compositions show the most intense reflection at $2 \theta$ less than $5^{\circ}$ and most of the reflections are in the range $18<2 \theta<26^{\circ}$ similar to the corresponding pure components. For $\mathrm{C}_{8} / \mathrm{C}_{12}: 80 / 20$ blend, there is a reduction in both the number of peaks and their relative intensities while in other compositions there is an obvious reduction in peak intensities if 
not in number of peaks. At compositions $80 / 20,60 / 40$, and 50/50, broadening of peak occurs almost in every reflection. Figure $5.12 \mathrm{~b}$ for the $\mathrm{C}_{8} / \mathrm{C}_{12}: 50 / 50$ blend shows that the XRD profile is unchanged until the melting temperature is reached. Figure 5.13 shows the percent crystallinity as a function of the composition of the $\mathrm{C}_{4} / \mathrm{C}_{18}, \mathrm{C}_{8} / \mathrm{C}_{12}$ and $\mathrm{C}_{16} / \mathrm{C}_{18}$ blends. It is seen that all of them show a minimum in crystallinity with 50/50 composition. This is in accord with the trend seen with the heat of fusion (Figure 5.1). All the biscarbamates show a common reflection with $d$-spacing of $4.6 \AA\left(2 \theta=19.3^{\circ}\right)$ and 3.8 $\AA\left(2 \theta=23 \cdot 4^{\circ}\right)$. These reflections were assigned to the distance between the molecules in the hydrogen bonding plane and the distance between these planes, respectively. ${ }^{24}$ It is seen that the relative intensities of the peaks at $d=4.6 \AA$ increases initially with the incorporation of $\mathrm{C}_{12}$ in $\mathrm{C}_{8} / \mathrm{C}_{12}$ blend and reach a maximum at 0.5 weight fraction of $\mathrm{C}_{8}$. After that it decreases significantly with the increase of weight fraction of $\mathrm{C}_{12}$. In the case of the reflection at $d=3.8 \AA$, we see an opposite trend. With incorporation of $\mathrm{C}_{12}$ the intensity of this peak decreases substantially and reaches a minimum at 0.5 weight fraction of $\mathrm{C}_{8}$ in the blend. After that it recovers to a significant extent. Figure 5.14 shows full width at half-maximum (fwhm) of reflections at $d=4.6 \AA$ and $3.8 \AA$ and the corresponding crystallite size as a function of weight fraction of $\mathrm{C}_{8}$ in $\mathrm{C}_{8} / \mathrm{C}_{12}$ blend. It is seen that for all the blends the fwhm is higher than that of the pure components. The largest fwhm (smallest crystallite size) is seen with 50/50 composition. Thus, the XRD data show that at certain compositions the blends exhibit the least crystallinity and smallest crystallite size similar to the heat of fusion and spherulite size at those compositions. This behaviour of the blend raises a question whether the reduction in the crystallinity is due to the reduction in the extent of hydrogen bonding and consequently 
less efficient self-assembling capability of molecules in the blends with respect to their corresponding pure components. This was addressed using FTIR spectroscopy.

(a)
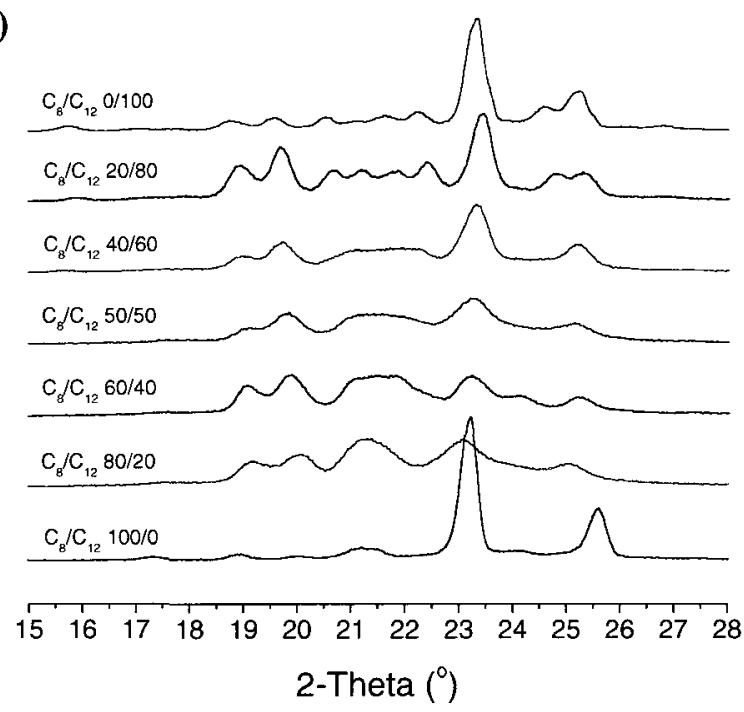

(b)

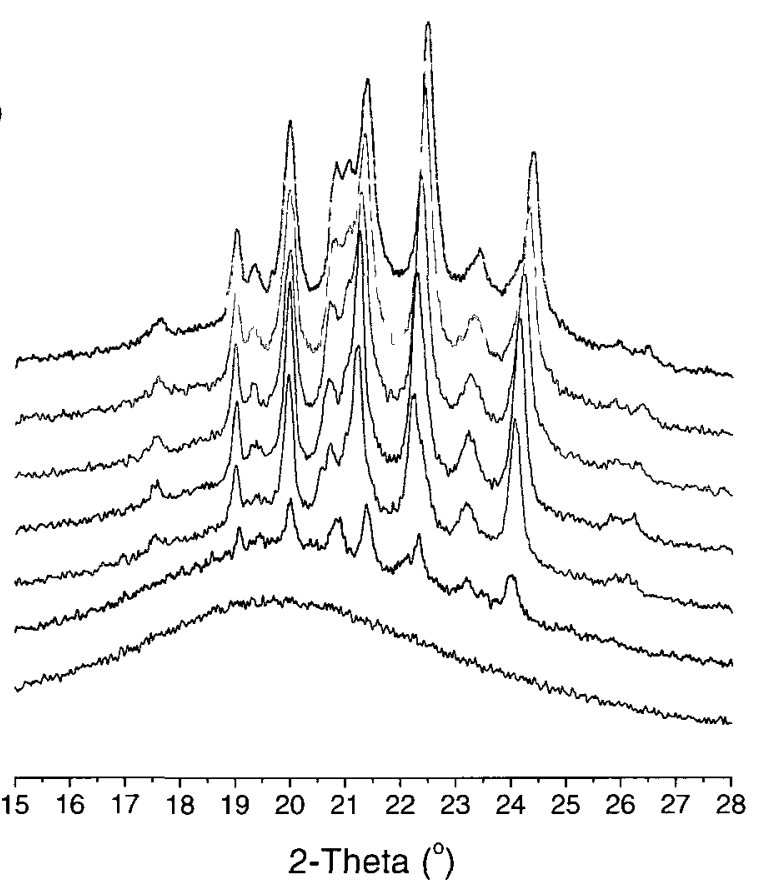

Figure 5.12. X-ray diffractograms of $\mathrm{C}_{8} / \mathrm{C}_{12}$ blend (a) at different compositions, (b) of $50 / 50$ blend at different temperatures. In part $b$, the top most curve corresponds to $70{ }^{\circ} \mathrm{C}$ and then at $5{ }^{\circ} \mathrm{C}$ interval to downward. 

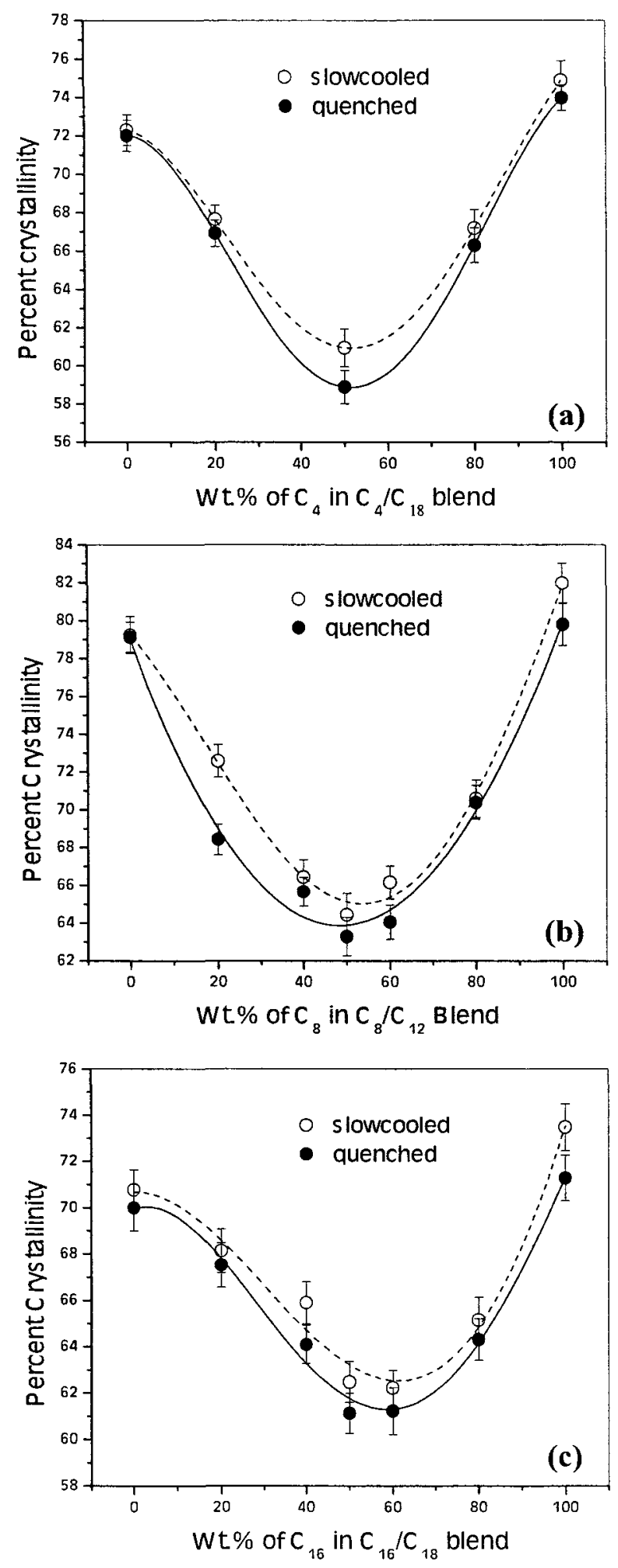

Figure 5.13. Percent crystallinity of the blends at different compositions: (a) $\mathrm{C}_{4} / \mathrm{C}_{18}$, (b) $\mathrm{C}_{8} / \mathrm{C}_{12}$, and (c) $\mathrm{C}_{16} / \mathrm{C}_{18}$. 

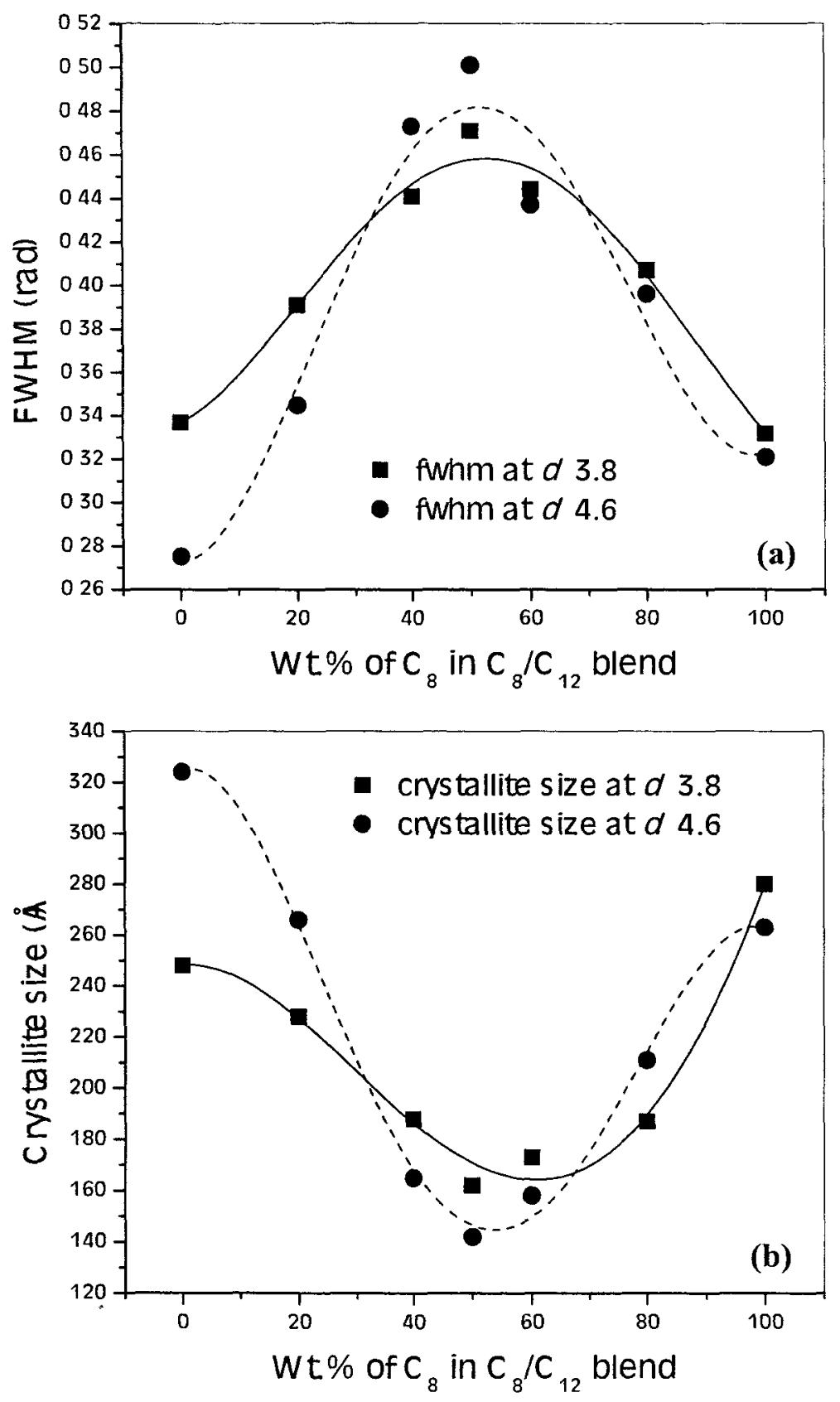

Figure 5.14. (a) fwhm, and (b) crystallite size of $d=3.8$ and $4.6 \AA$ at different compositions of $\mathrm{C}_{8} / \mathrm{C}_{12}$ blend. 


\subsubsection{IR Analysis}

The IR spectra of all the biscarbamates and their blends studied here showed (in the solid state) absorption bands at about 3321 and $1683 \mathrm{~cm}^{-1}$ corresponding to the hydrogenbonded $\mathrm{N}-\mathrm{H}$ and $\mathrm{C}=\mathrm{O}$ groups with an absence of absorption peaks corresponding to free $\mathrm{N}-\mathrm{H}$ and $\mathrm{C}=\mathrm{O}$ groups (Figure 5.15a). This shows that the extent of hydrogen bonding remains unaffected by blending any two biscarbamates. The absorption peaks were broad when the sample was in the melt state (figure $5.15 \mathrm{~b}$ and c). Figure $5.16 \mathrm{a}$ shows the change in the peak position of $\mathrm{N}-\mathrm{H}$ and $\mathrm{C}=\mathrm{O}$ groups with temperature, for $\mathrm{C}_{8} / \mathrm{C}_{12}: 50 / 50$ mixture. In the melt, there is no indication of the presence of hydrogen bond, since, e.g., the $\mathrm{C}=\mathrm{O}$ peak at $1717 \mathrm{~cm}^{-1}$ corresponds to non-hydrogen bonded carbonyl group. There is a sudden decrease in the $\mathrm{N}-\mathrm{H}$ and $\mathrm{C}=\mathrm{O}$ absorption frequencies at about $95^{\circ} \mathrm{C}$ as the sample crystallizes. There is very little change in the peak positions below this temperature. Figure $5.16 \mathrm{~b}$ shows the change in the full width at half-maximum of the $\mathrm{N}$ $\mathrm{H}$ and $\mathrm{C}=\mathrm{O}$ peaks with temperature. There is a significant decrease in peak width as the sample crystallizes. The spectral changes were similar for the individual components. In our previous study on the biscarbamates, ${ }^{24}$ the symmetric $\left(v_{\mathrm{s}}\right)$ and antisymmetric $\left(v_{\text {as }}\right)$ stretching vibrations of the $\mathrm{CH}_{2}$ groups were found to shift to lower wave numbers with an increase in the alkyl side chain length. This was attributed to enhanced packing of the alkyl chains. ${ }^{27}$ By this token, if there was miscibility, and the ordering of longer alkyl chains, e.g., in $\mathrm{C}_{18}$ was disrupted by the intercalation of $\mathrm{C}_{4}$, one should see an increase in the wave number of the $v_{\mathrm{s}}$ and $v_{\text {as }}$ vibrations. However, no change in these vibrations was noted upon blending. 

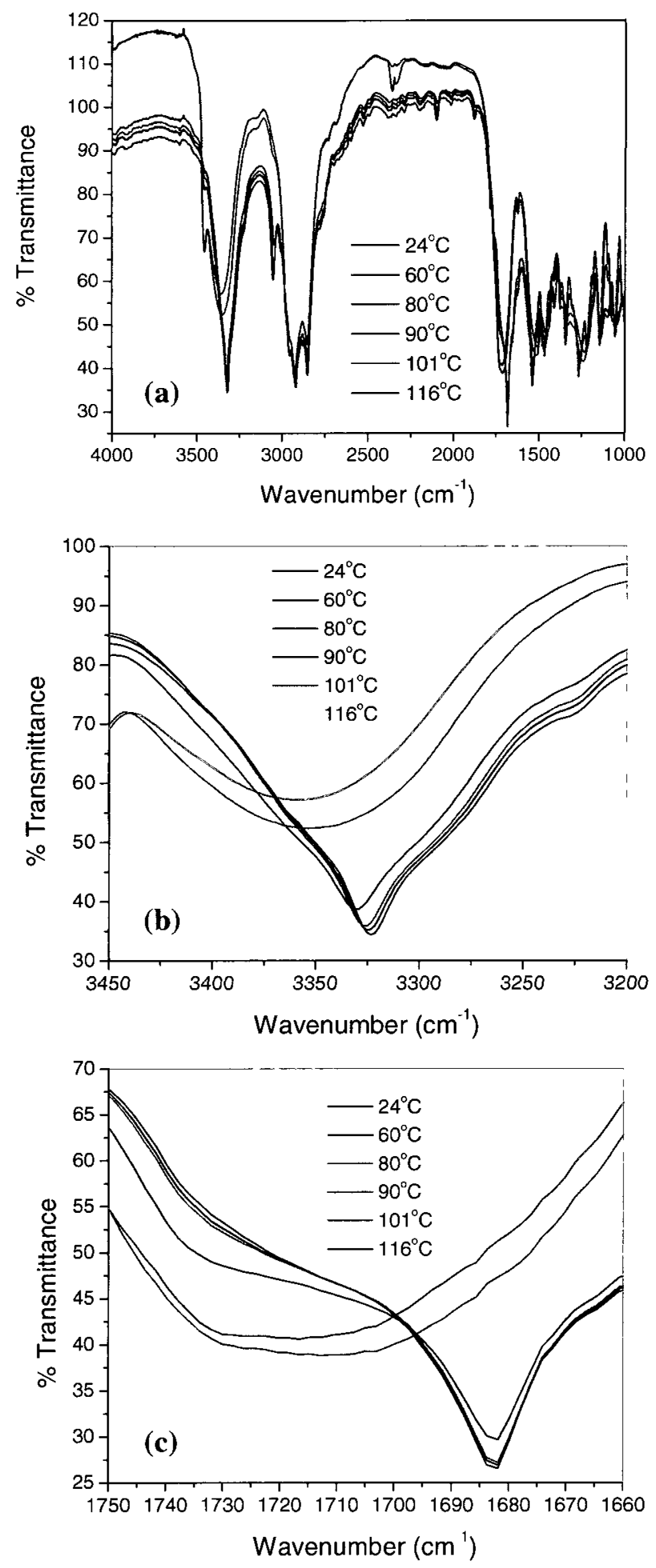

Figure 5.15. FTIR spectra of $\mathrm{C}_{8} / \mathrm{C}_{12} 50 / 50$ blend: (a) full scale, (b) in the $\mathrm{N}-\mathrm{H}$ stretching, and (c) $\mathrm{C}=\mathrm{O}$ stretching frequency region at different temperatures. 

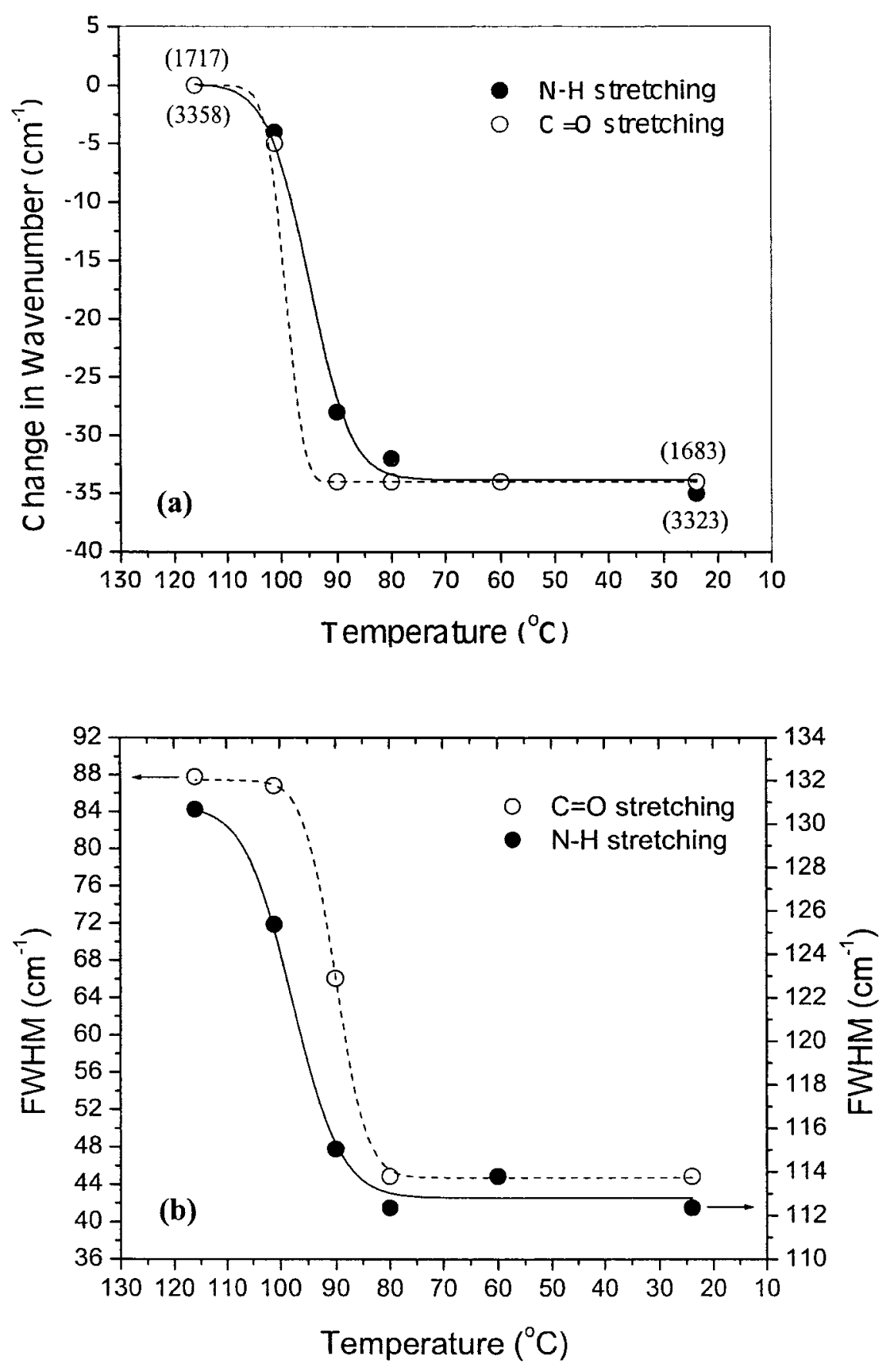

Figure 5.16. Change in (a) N-H and $\mathrm{C}=\mathrm{O}$ stretching frequencies and (b) fwhm of $\mathrm{C}_{8} / \mathrm{C}_{12}$ $50 / 50$ blend with respect to temperature. The values in parentheses represent the peak position at the corresponding temperature. 


\subsection{Comparison with Hydrogen-Bonding Polymer Blends}

The influence of hydrogen bonding on the miscibility of polymers have been investigated extensively. ${ }^{21,22}$ The bulkiness of the side group, spacer length between hydrogen bonding, the tacticity, etc., influence the miscibility. The mutual accessibility (in terms of the conformation of the chain) of the hydrogen-bonding groups to each other is the major factor. Strategic positioning of such groups has been used to enhance the miscibility in such cases. Recently Park et al. ${ }^{23}$ discussed the factors that affect the miscibility of hydrogen-bonding polymers. They concluded that a pair of polymers, each of which hydrogen bonds to itself in the pure state, is less likely to be miscible with each other. They also suggested that, if the volume fraction of the hydrogen-bonding functional group relative to the volume of the polymer repeat unit differs significantly between the two polymers, they will phase separate, even if they have identical hydrogen-bonding functional groups.

In the case of the small molecules that we discuss here, the hydrogen-bonding group is the same. The molecules differ only in the length of the alkyl side chains. The difference in the volume fraction of the hydrogen-bonding group between, e.g., $\mathrm{C}_{16}$ and $\mathrm{C}_{18}$, is not significant. Yet, these mixtures show immiscibility. Similar was the case with the simple carbamates with a single hydrogen-bonding moiety. ${ }^{26}$ Thus, the miscibility criteria for the small molecules that self-associate by themselves parallels those derived for the case of hydrogen-bonding polymer mixtures.

\subsection{Conclusions}

The results discussed above indicate that blending of two molecules used here, which are capable of hydrogen-bond mediated self-assembly lead to specific association 
between the same types and does not involve mutual intercalation at the molecular level. The melting temperatures of the blends are not intermediate between those of the lower and higher melting components, which would otherwise imply miscibility. The DSC analysis shows that the components of the blend exercise a mutual diluent effect, thereby reducing the spherulite size, crystallinity, and the heat of fusion. Isothermal crystallization studies show that the growth rates of the spherulites are also reduced upon blending, with respect to those of the individual components. In situ observations during the melting of the blends show that the spherulites of each constituent do not form separately but by mixing with each other and providing nucleating sites for each other. IR spectra show absorption peaks corresponding to only the hydrogen-bonded $\mathrm{C}=\mathrm{O}$ and $\mathrm{N}-\mathrm{H}$ groups, indicating that the extent of hydrogen bonding is not affected by blending. In addition, there is no evidence of disruption of alkyl chain packing from the IR spectra, since there was no shift of the $\mathrm{CH}_{2}$ stretching vibrations.

In the previous studies ${ }^{8-14}$ on self-sorting small molecules, specific pairing was found in crystal structures as well as in solution. In the present case, we find that, although these carbamates are self-sorting during crystallization, they exercize mutual diluent effect by affecting the spherulite size, melting temperature, spherulitic growth rate, etc. IR spectra also show that there is no hydrogen bonding between them in the melt.

We found a similar behaviour with the blends of homologous monocarbamates. Thus these types of molecules show selectivity during crystallization and form 
immiscible blends. The alkyl side chains play a role in such selectivity. The behaviour seen here with these small molecules is similar to that observed in the case of mixtures of polymers, which self-associate through hydrogen bond. 


\subsection{References}

1. Philp, D.; Stoddart, J. F. Angew. Chem. Int. Ed. 1996, 35, 1154.

2. Lawrence, D. S.; Jiang, T.; Levett, M. Chem. Rev. 1995, 95, 2229.

3. (a) Lehn, J-M. 1995, Supramolecular Chemistry, VCH, Germany; (b) Ikeda, M.; Nobori, T.; Schmutz, M.; Lehn, J-M. Chem. Eur. J. 2005, 11, 662.

4. Krische, M. J.; Lehn, J.-M. Struct. Bonding (Berlin) 2000, 94, 3

5. (a) Beijer, F. H.; Kooijman, H.; Spek, A. L.; Sijbesma, R. P.; Meijer, E. W. Angew. Chem. Int. Ed. 1998, 37, 75; (b) Lehn, J-M. Makromol. Chem. Macromol. Symp. $1993,69,1$.

6. Behrens, P.; Panz, C.; Kuehn, C.; Pillep, B. M.; Schneider, A. M. in Host-GuestSystems Based Nanoporous Crystals, Laeri, F. Ed. 2003, Wiley-VCH Germany, pp 7.

7. Braga, D.; Grepioni, F.; Desiraju, G. R. J. Organometall. Chem. 1997, 548, 33.

8. Taylor, P. N.; Anderson, H. L. J. Am. Chem. Soc. 1999, 121, 11538.

9. Wu, A.; Chakraborty, A.; Fettinger, J. C.; Flowers, R. A.; Isaacs, L. Angew. Chem. Int. Ed. 2002, 41, 4028.

10. Bilgicer, B.; Kumar, K. Tetrahedron 2002, 58, 4105.

11. Wu, A.; Isaacs, L. J. Am. Chem. Soc. 2003, 125, 4831 and references therein.

12. Burd, C.; Weck, M. Macromolecules 2005, 38, 7225.

13. He, Y.; Tian, Y.; Chen, Y.; Ribbe, A. E.; Mao, C. Chem. Commun. 2007, 165.

14. Hutin, M.; Cramer, C. J.; Gagliardi, L.; Shahi, A. R. M.; Bernardinelli, G.; Cerny, R.; Nitschke, J. R. J. Am. Chem. Soc. 2007, 129, 8774. 
15. Goodbrand, B.; Boils, D. C.; Sundararajan, P. R.; Wong, R.W.; Malhotra, S. US Patent 6,187,082, 2001.

16. Goodbrand, B.; Boils, D. C.; Sundararajan, P. R.; Wong, R.W. US Patent 6,414, 051, 2002.

17. (a) Jpn. Kokai Tokyo Koho JP 58201 758. Chem Abstr. 1983, 100, 174289z.

(b) Tanaka, T.; Yoshitomi, T.; Hanada Y.; Ohashi, M.; Takeda, Y. Jpn. Kokai Tokkyo Koho JP 6290 289, Chem Abstr. 107, $20896 \mathrm{~b}$.

18. Gaylord, N. G. J. Org. Chem. 1955, 20, 546.

19. Rohr, W.; Franke, A.; Giertz, H.; Amann, A. 1975, Brit Patent 1,396,523.

20. D'Silva, T. D. J. U. S. Patent 4,400,389, 1983.

21. Coleman, M. M.; Painter, P. C. Prog. Polym. Sci. 1995, $20,1$.

22. He, Y.; Zhu, B.; Inoue, Y. Prog. Polym. Sci. 2004, 29, 1021.

23. Park, Y.; Veytsman, B.; Coleman, M.; Painter, P. Macromolecules 2005, 38, 3703.

24. Khanna, S.; Moniruzzaman, M.; Sundararajan, P. R. J. Phys. Chem. B 2006, 110 , 15251.

25. Klug, H. P.; Alexander, L. E. X-Ray Diffraction Procedures, John Wiley \& Sons, 1954.

26. Moniruzzaman, M.; Goodbrand, B.; Sundararajan, P. R. J. Phys. Chem. B 2003, 107, 8416.

27. Suzuki, M.; Nakajima, Y.; Yumoto, M.; Kimura, M.; Shirai, H.; Hanabusa, K. Langmuir, 2003, 19, 8622. 
Chapter 6

\section{Influence of Double Hydrogen Bonds and Alkyl Chains} on the Gelation of Nonchiral Biscarbamates: Sheets, Eaves Trough, Tubes and Oriented Fibers*

* Langmuir 2009, 25(22), 13183. 


\subsection{Introduction}

Design and control of self-assembling molecules plays a vital role in developing new classes of compounds that might offer many opportunities to build systems with new types of functions and low molecular weight organic gelators (LMOGs) are examples of such compounds. Gels can be easily transformed into solution by heating them and back to gel by cooling the solution above and below their sol-gel transition temperature. ${ }^{1}$ This reversible property of the gels can be used to make matrices for applications such as controlled release of drugs, fragrance, photonic materials, catalysts, and is useful in crystal and fuel engineering. ${ }^{2-4}$ A low concentration is sufficient for gel formation, and network filaments (length up to few micrometers) are formed by well-ordered arrays of molecules.

Some of the extensively studied examples of the organogelators are certain cholesterol and anthracene derivatives, ${ }^{5}$ fatty acid derivatives, ${ }^{6,7}$ carbohydrates, ${ }^{8}$ peptide derivatives ${ }^{9}$ amino acid derivatives, ${ }^{10,11}$ porphyrins and phthalocyanines, ${ }^{12}$ n-alkanes, ${ }^{13}$ bis-urea, ${ }^{14,15}$ condensed aromatic rings, ${ }^{16}$ etc. These gelating agents of enormous structural diversity have a common trait i.e., self-assembling property. Gelator molecules self-assemble by highly specific non-covalent interactions, leading to fibrous structures, which form a three-dimensional network. Therefore, self-complementary and unidirectional intermolecular interactions can be considered a prerequisite for the gelation ability. ${ }^{1}$ The intermolecular interactions between the organogelator molecules can be hydrogen bonding, London dispersion forces, electrostatic attractions, and $\pi$ stacking. ${ }^{13,17-}$ 
In the case of many ureas, amides, amino acid derivatives and carbamates a combination of these hydrogen bonding and van der Waals forces drive gel formation. Since not all strongly hydrogen bonding molecules form gels, the van der Waals component of the interactions has strong bearing on the molecules' ability to form gels. Based on studies on ureas containing single hydrogen bonding motif and bisureas with two such sites, Feringa et $a l^{22}$ concluded that the latter is more susceptible to gelation and that increasing the length of the spacer is also effective. Here we discuss the gelation behavior of a set of model compounds for polyurethanes, namely, biscarbamates with two hydrogen bond motifs separated by an alkyl segment, and having terminal alkyl chains of lengths ranging from $\mathrm{C}_{4}$ to $\mathrm{C}_{18}$. Our previous studies on mono and biscarbamates with different alkyl chain lengths showed significant differences in the crystallization behavior. $^{23,24}$

monocarbamates:<smiles>[13CH3]CNC(=O)N[14CH3]</smiles>

biscarbamates:

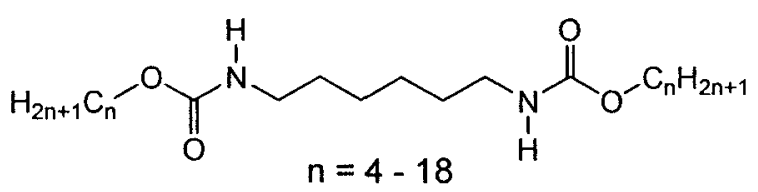

The mono carbamates contain single hydrogen bonding group and unsymmetrical substitution of alkyl chains (except $\mathrm{C}_{18}$ ) on either side. The biscabamates contain two hydrogen bonding sites separated by a $\left(\mathrm{CH}_{2}\right)_{6}$ spacer and symmetrical substitution of the alkyl chains on either side. The sample preparation technique (i.e., slow-cooled or quenched) also influences the morphological and crystallization behavior of these selfassembling biscarbamates. ${ }^{23}$ The influence of the length of the alkyl side chain on gel formation was discussed previously for the case of mono carbamates. ${ }^{17}$ 
Creation of tubular structures via molecular self assembly is an active area of research. Such structures are envisioned to serve as reaction chambers, molecular sieves and nanoscale transport media. ${ }^{25}$ Schnur $^{26}$ discussed the possible mechanisms of tube formation and the related theories. Based on a series of studies on diacetylenic lipids, ${ }^{26,27}$ molecular packing driven by chirality was identified as a requirement for such tube formation. Surfactant-like peptides ${ }^{28}$ were also found to form helical structures leading to nanotubular shapes, with bilayer formation as a precursor. Diamides with bulky aromatic esters also led to tubules during gelation. ${ }^{29}$ In addition, a two-component system with amphiphilic groups exhibited tubular shape, with an internal diameter of about $5 \mu \mathrm{m}$ although the mechanism of formation was not discussed in this case. ${ }^{30}$

While the above examples involve either chirality or amphiphilicity, in this chapter we discuss the formation of tubular ribbons during the gelation of the biscarbamates, which do not belong to either class of molecules. They initially form sheets, which then wrap into hollow tubes. Due to competing tendency between gelation and crystallization, the fibers are short, and in some cases both forms occur. In contrast, the previous work on mono carbamates showed long fibers and crystal formation was not seen generally. In an effort to obtain oriented X-ray diffraction pattern for identifying the growth direction, we were able to induce some orientation of the gel fibers by simply stirring during gelation. 


\subsection{Experimental}

The synthesis of biscarbamates of different alkyl side chain lengths was described in Chapter 2. In this chapter, we designate the biscarbamates as $C_{x}$ where $x$ denotes the number of carbon atoms in the alkyl side chains.

\subsubsection{Preparation of the Gels and Xerogels}

Similar to our previous work ${ }^{17}$ on mono carbamates, benzonitrile was used for most of the experiments. Gels were prepared in capped vials to avoid evaporation of the solvent. Weighed amounts of biscarbamates of different alkyl side chain lengths were dissolved in requisite amount of benzonitrile at a temperature ranging from $95-110^{\circ} \mathrm{C}$, resulting in clear solutions. Gels were made either by quenching the clear solution in an ice bath or by slowly cooling to room temperature by turning off the hot plate. The vials were turned upside down to check for gelation. If the samples were not visually separated and did not flow perceptibly they were considered as gels. All the gels were opaque. These gels were dried at room temperature for a few weeks and then kept under vacuum for a few days to form xerogels. A few experiments were performed with dodecane, toluene, xylene, and 1-octanol.

\subsection{Results and Discussion}

As the self assembly is governed by the number of hydrogen bonds in the molecule and the length of the alkyl side chain, there is a competition between the trend towards gelation and crystal formation. The formation of gel fibers is due to rapid two dimensional growth whereas three dimensional growth would result in crystal formation. This is reflected in the morphology of the biscarbamate gels discussed below. 


\subsubsection{Morphology of the Xerogels (0.08 M)}

The morphology of the gels of biscarbamates is distinctly different from those of mono carbamates. The SEM 1mages of quenched and slow-cooled gels (xerogels) of $\mathrm{C}_{6}$, $\mathrm{C}_{8}$ and $\mathrm{C}_{18}$ are shown in Figure 6.1.
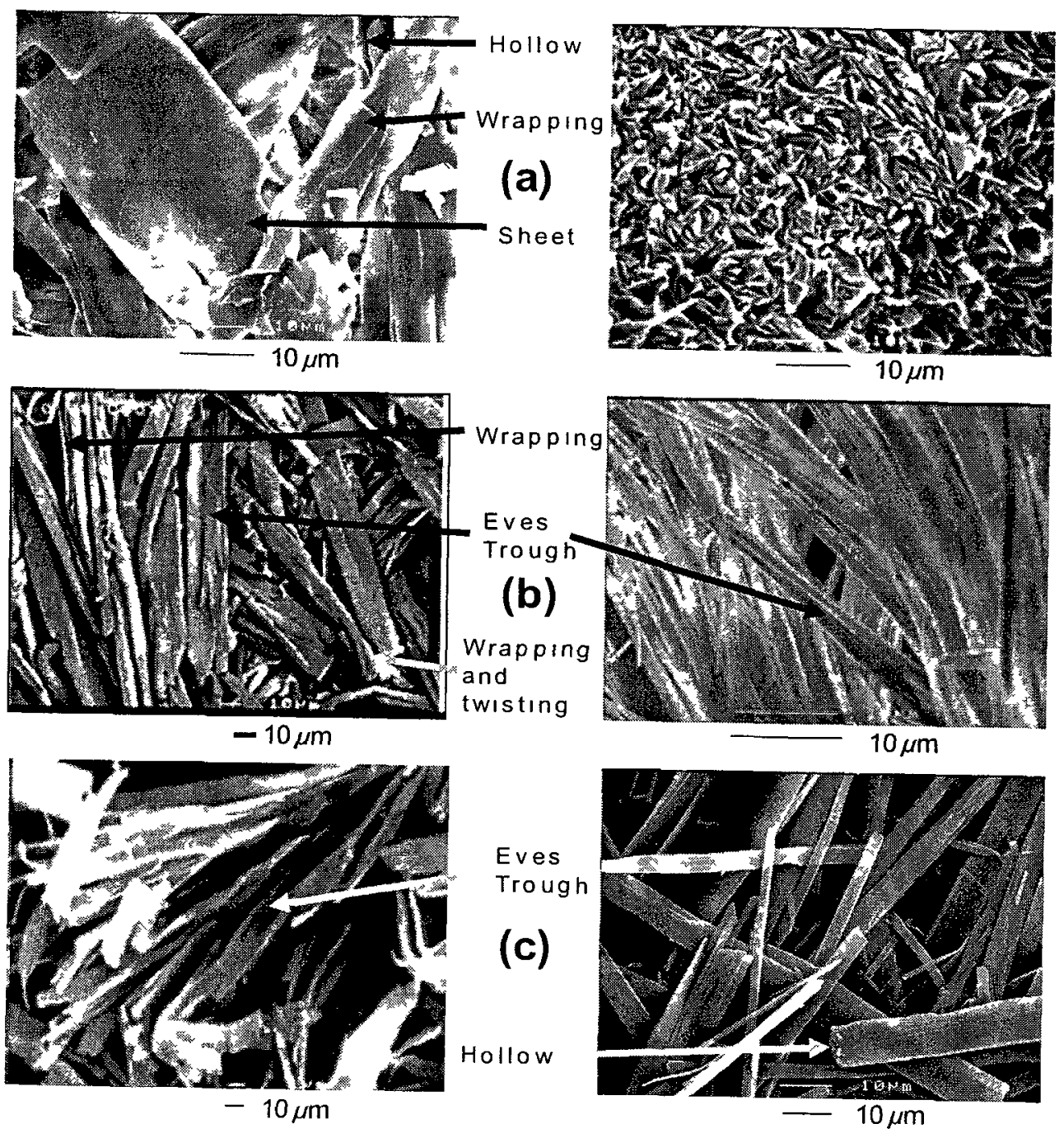

Figure 6.1. The SEM images of quenched (left) and slow-cooled xerogels with benzonitrile (a) $\mathrm{C}_{6}$, (b) $\mathrm{C}_{8}$, and (c) $\mathrm{C}_{18}$

The morphology in this case consists of shorter tapes, ribbons and hollow fibers depending on the length of the alkyl side chain and the method used for gelation (slow cooled versus quenched). Long smooth fibers that were seen with mono carbamates are 
not observed here. The xerogels of quenched $\mathrm{C}_{6}$ form irregular tape or ribbon like structures, with a semicylindrical shape (Figure 6.1a). These tapes tend to wrap, ultimately forming fibers. Wrapping of the tapes can result in the formation of hollow fibers. The population of tapes is more compared to the fibers. The fibers are not long and do not show entanglement. The slow cooled samples of $\mathrm{C}_{6}$ form densely populated petal like structures (Figure 6.1a, right). These gels did not form fibers. The $\mathrm{C}_{8}$ quenched gels exhibit a combination of semicylindrical tapes, similar to an eaves trough. Similar to the $\mathrm{C}_{6}$ samples, wrapping is common here too. While partial wrapping leads to the eaves trough morphology, near-complete wrapping results in hollow fiber formation, showing a slit (Figure 6.1b). The length of the $C_{8}$ fibers is more than that of $C_{6}$. The fibers of slow cooled $\mathrm{C}_{8}$ xerogels (Figure $6.1 \mathrm{~b}$, right) are longer than their quenched counterparts. Note that the gel fibers resemble the radiating lamellae of a spherulite. The quenched xerogels have a combination of wide and narrow fibers while the slow-cooled xerogels form relatively uniform fibers. The $\mathrm{C}_{12}$ and $\mathrm{C}_{16}$ gels also exhibited similar morphologies. Typical of fiber-forming gels, in all the cases the length of the fibers is more than their width. This indicates that the rate of growth is anisotropic, which is the result of a preferred orientation of the molecules within the sheets. The fibers of quenched $\mathrm{C}_{18}$ xerogels form a corolla like structure. This structure can result from the branching of the fibers and these branches further divide into daughter branches or there is a possibility that the fibers, which are already branched, overlap with each other and finally form a corolla-like structure (Figure $6.1 \mathrm{c}$, left). This again resembles a spherulitic lamellar morphology. The slow cooled $\mathrm{C}_{18}$ xerogels result in a very different morphology than their quenched counterparts (Figure 6.1c, right). They form very smooth fibers without 
any entanglements. Thus, biscarbamate xerogels show very different morphology than mono carbamate xerogels. The latter xerogels form long, branched, entangled and rope like fibers. ${ }^{17}$

The SEM images reveal stacking and wrapping of the sheet in the case of quenched gels which indicates the possibility that fibers obtained from the quenched as well as from the slow cooled gels could be hollow in nature. Figure 6.2 shows the SEM images of the transverse section of the slow cooled xerogel of $\mathrm{C}_{12}$ which clearly indicates that the fiber is hollow, although it is not uniform as in the case of lipids and diamides mentioned in Introduction. ${ }^{26-30}$
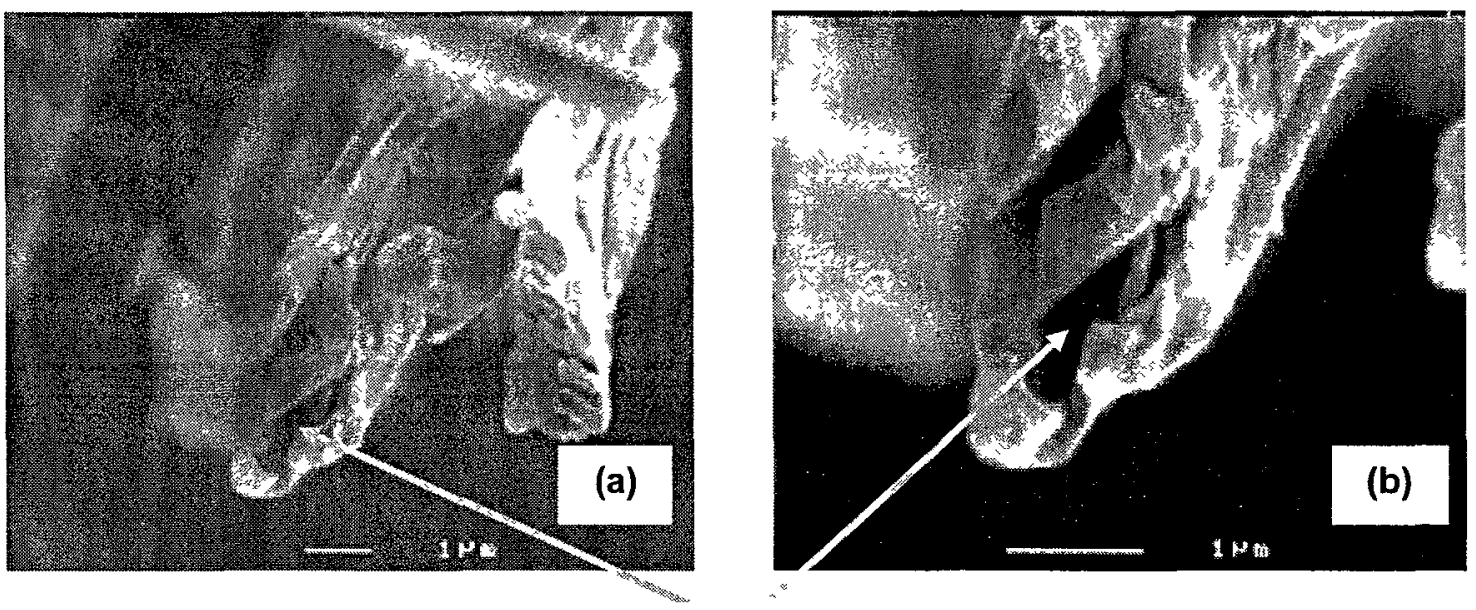

Hole

Figure 6.2. SEM images of the transverse section of $\mathrm{C}_{12}$ slow cooled xerogels with benzonitrile.

van Esch et $a l^{22}$ studied the gelation of a series of diurea compounds, with two hydrogen bonding motifs separated by a $\left(\mathrm{CH}_{2}\right)_{\mathrm{n}}$ group $(\mathrm{n}=3,6,9$, and 12$)$, in different solvents. They observed that those with $\left(\mathrm{CH}_{2}\right)_{9}$ and $\left(\mathrm{CH}_{2}\right)_{12}$ spacers gelled 1- and 2octanol, whereas $\mathrm{C}_{3}$ and $\mathrm{C}_{6}$ did not. Likewise, the latter gelled toluene and $\mathrm{p}$-xylene, 
while $\mathrm{C}_{9}$ and $\mathrm{C}_{12}$ did not. None of them gelled hexadecane. In the present case, the biscarbamates have a $\left(\mathrm{CH}_{2}\right)_{6}$ spacer between the hydrogen bonding groups.

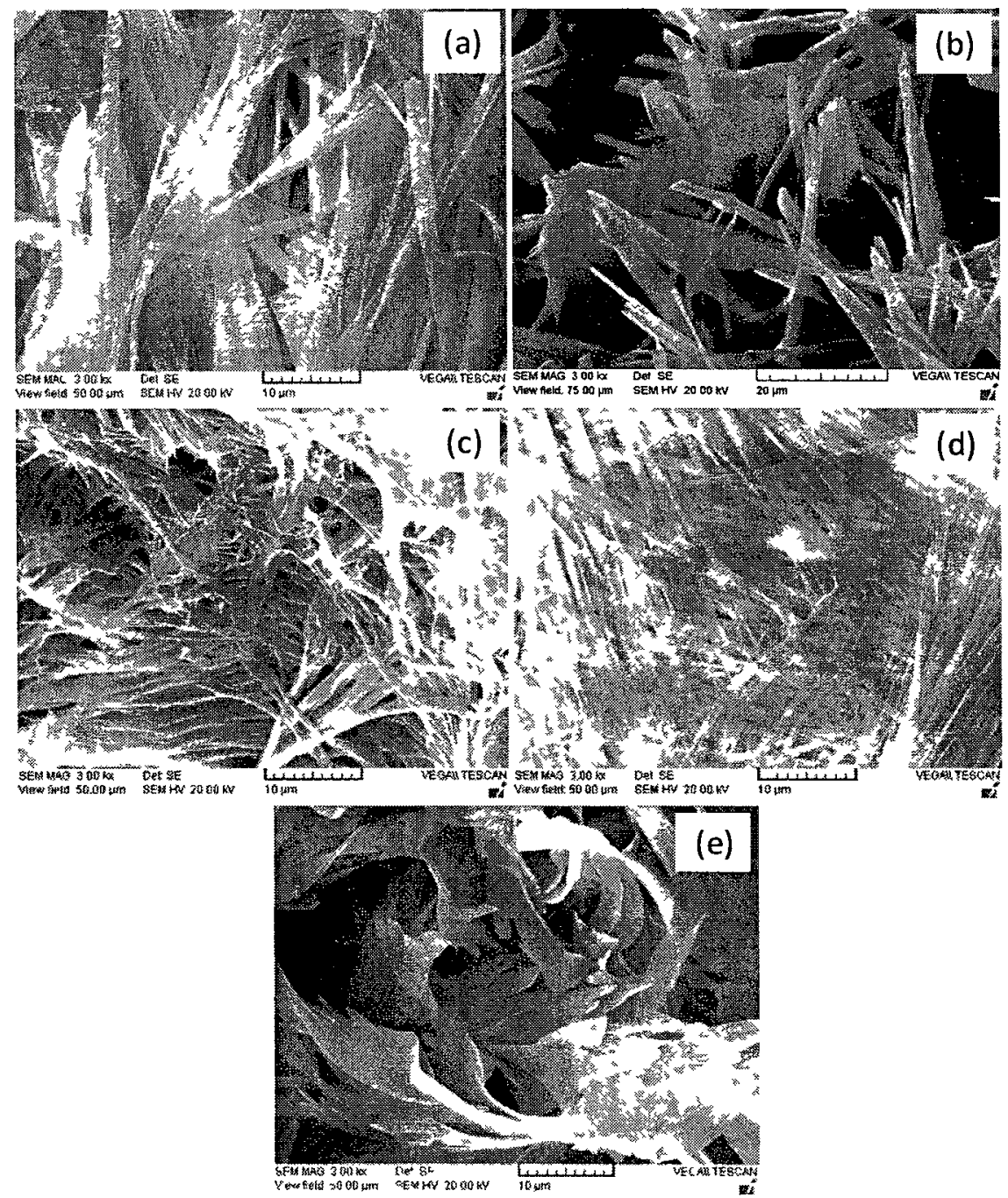

Figure 6.3. SEM images of xerogels of $\mathrm{C}_{12}$ biscarbamate prepared with different organic solvents by quenching the solution: (a) benzonitrile, (b) dodecane, (c) toluene, (d) xylene, and (e) 1-Octanol.

The side groups in our case are long alkyl chains, whereas these were only phenyl groups in the case of ref. 22. Although we did not examine the biscarbamates with different alkyl chain lengths with such solvents, it was found that $\mathrm{C}_{12}$ side chain was able to gel 1-octanol, toluene, xylene and dodecane. The morphologies of the quenched and 
slow-cooled gels are shown in Figures 6.3 and 6.4 respectively. These are similar to those prepared with benzonitrile. The gel fibers were birefringent as seen in the optical microscope (Figure 6.5). Thus the diurea and the biscarbamate compounds have a few common gellable solvents.
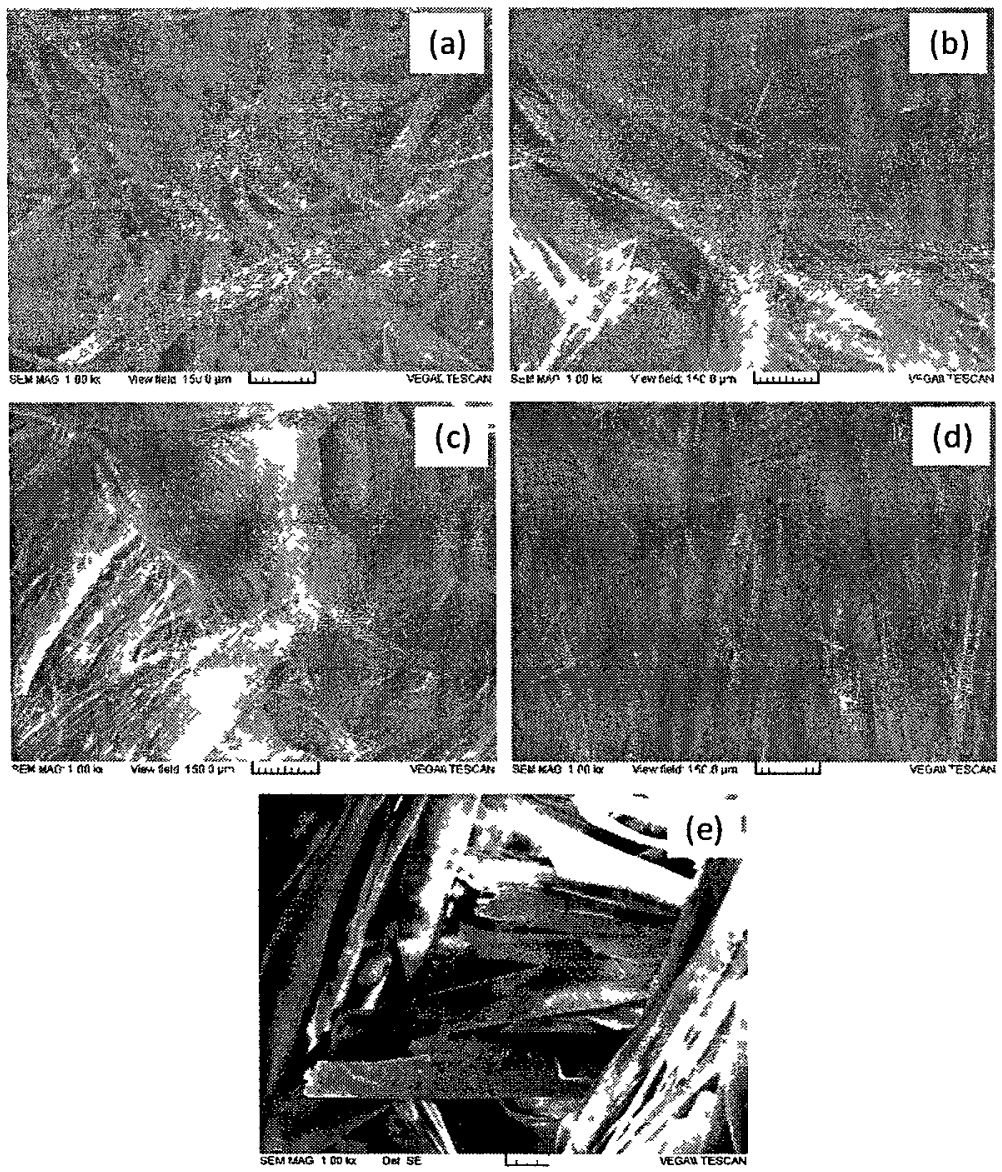

Figure 6.4. SEM images of xerogels of $\mathrm{C}_{12}$ biscarbamate prepared with different organic solvents by slowly cooling the solution: (a) benzonitrile, (b) dodecane, (c) toluene, (d) xylene, and (e) 1-Octanol. Scale bar is $20 \mu \mathrm{m}$.

During our studies on monocarbamates, we were exploring various solvents to grow single crystals, in order to determine their crystal structures. During one of those attempts, we found that with benzonitrile gelation occurred. We then began studying the gels using this solvent, for both mono and biscarbamates. With the above finding that it is 
possible for biscarbamates to gel other solvents, as in the case of diurea compounds, our future studies would examine the features of gels using such solvents, and determine the role of the type of solvent on these features.
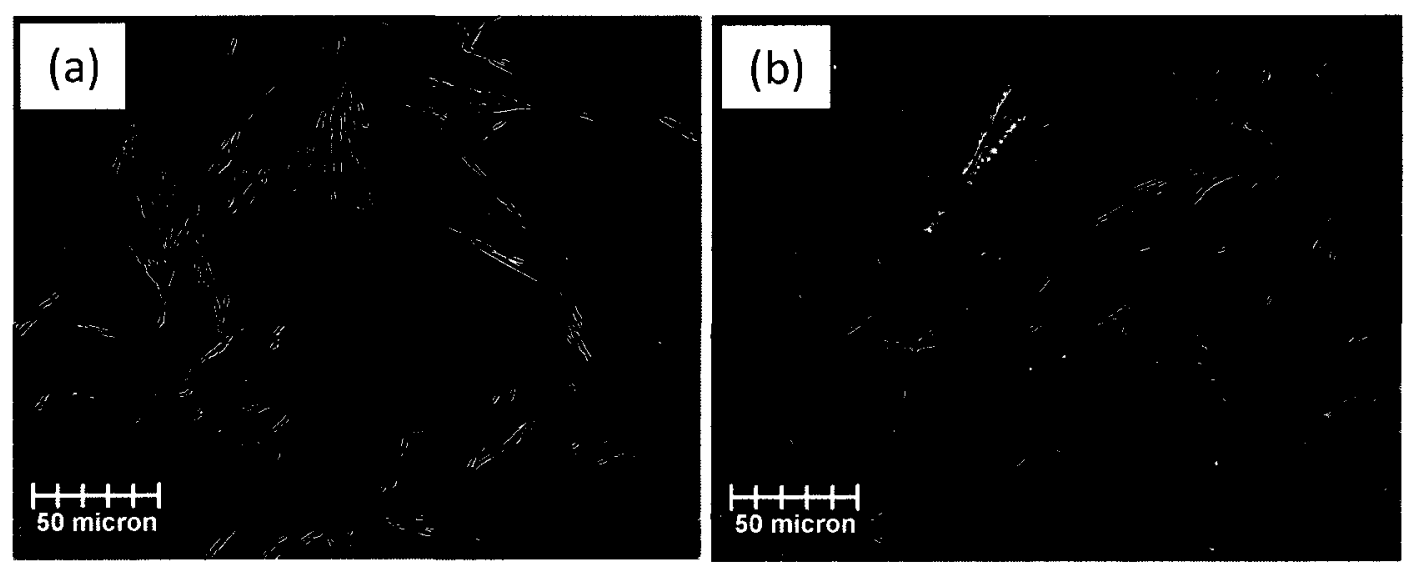

Figure 6.5. Optical micrographs of $\mathrm{C}_{12}$ gels in (a) xylene, and (b) dodecane.

\subsubsection{Morphology of the Gels}

To further examine the hollow nature of the fibers, the morphology of quenched (Figure 6.6) and slow-cooled gels (Figure 6.7) of different concentrations of $\mathrm{C}_{18}$ was studied using SEM under cryogenic conditions. The quenched gels of $0.03 \mathrm{M}$ concentration form a tape or ribbon like structure, with eaves trough morphology. Moreover, crystals were also found in between these fibers (Figure 6.6a). The slowcooled gels of the same concentrations show that the fibers are not fully formed and crystals as well as fibers are seen. The image appears as if while the fibers are part of spherulitic growth. Crystals are found to be embedded in the gel (Figure 6.7a). The quenched gels of $0.04 \mathrm{M}$ show a morphology in which the tapes are short, irregular in shape and show wrapping. The eaves trough morphology is seen as well. 
Wrapping

and twisting
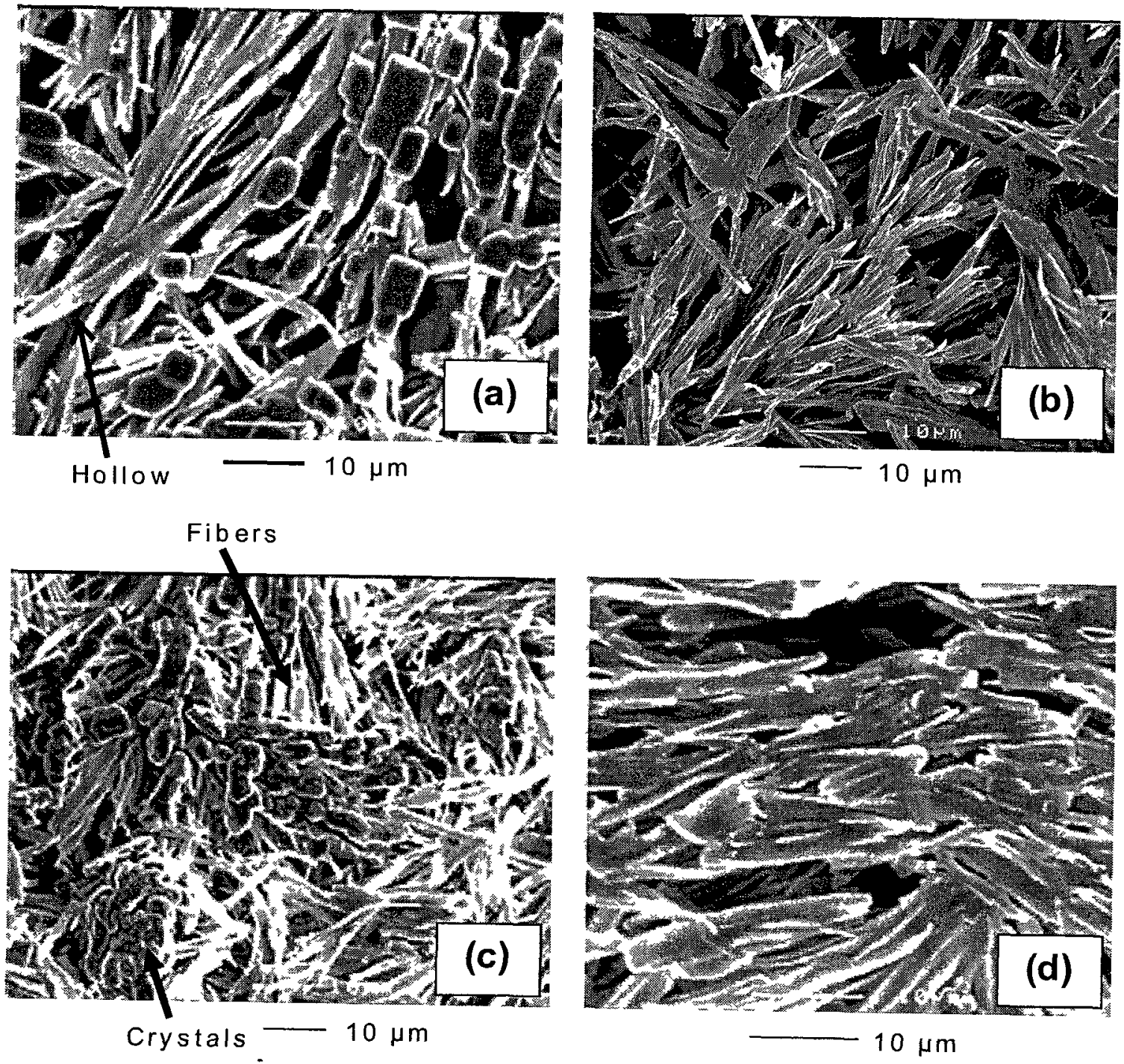

Figure 6.6. SEM images (cryo condition) of quenched gels of $\mathrm{C}_{18}$ for various concentrations in benzonitrile: (a) $0.03 \mathrm{M}$, (b) $0.04 \mathrm{M}$, (c) $0.05 \mathrm{M}$, and (d) $0.06 \mathrm{M}$.

Crystals were seen in this case also (not shown here). The slow cooled gels of $0.04 \mathrm{M}$ formed fibers and some of the fibers are bifurcated (Figure 6.7b). Such bifurcation is commonly seen with these biscarbamates. A profuse population of crystals is seen with the quenched samples of $0.05 \mathrm{M}$ gels (Figure 6.6c). 

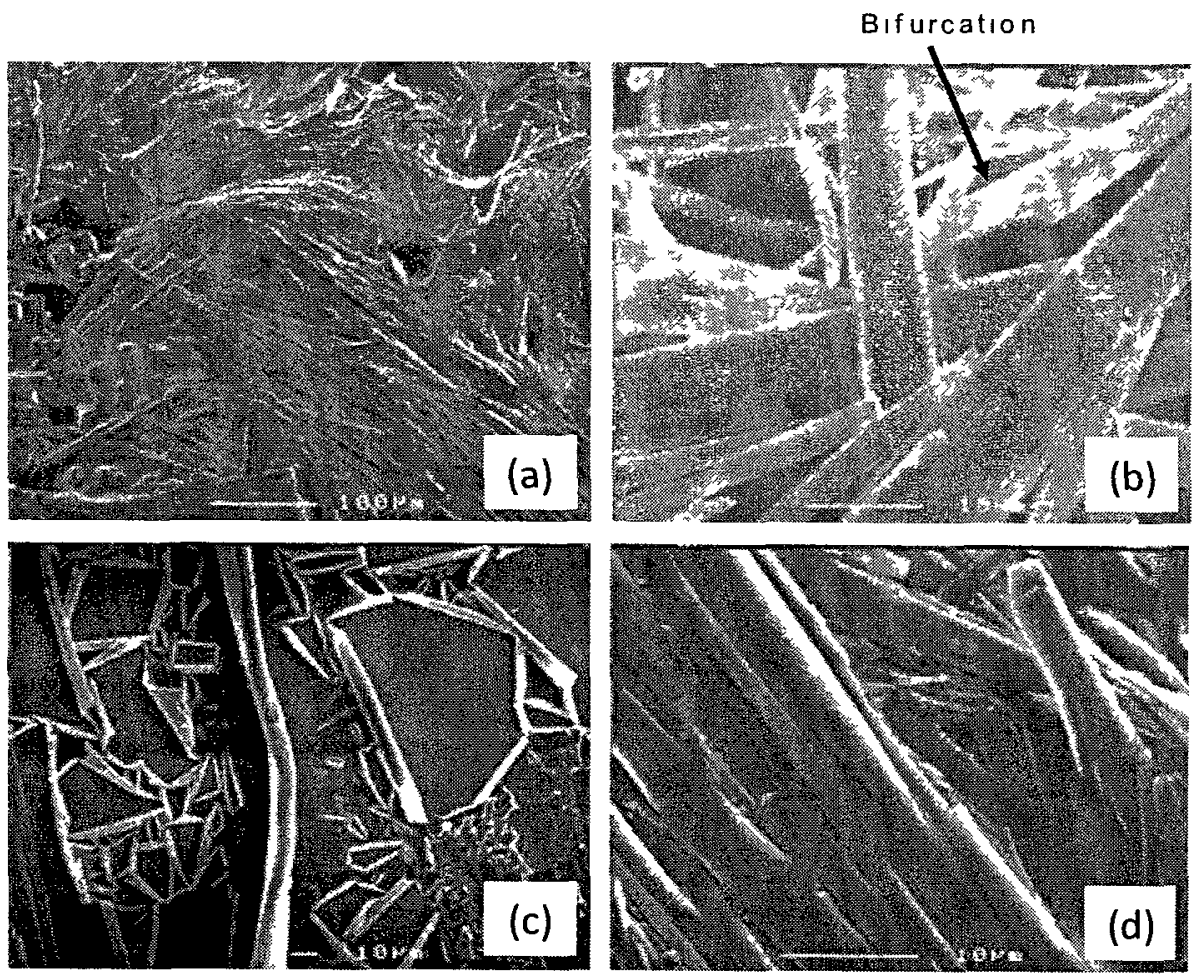

Figure 6.7. The SEM images (cryo condition) of slow cooled gels of different $\mathrm{C}_{18}$ concentrations in benzonitrile: (a) $0.03 \mathrm{M}$, (b) $0.04 \mathrm{M}$, (c) $0.05 \mathrm{M}$, and (d) $0.06 \mathrm{M}$.

The slow-cooled gels of $0.05 \mathrm{M}$ show petal like structures (Figure 6.7c) with a wrapping at the edges. This indicates that these gels first form such petal like structures and then their wrapping takes place, ultimately leading to the formation of hollow fibers. In fact, a fiber with a slit is seen in the left part of Figure $6.7 \mathrm{c}$. The quenched $0.06 \mathrm{M}$ gels, in addition to the short tapes (Figure 6.7d), also showed petal-like structures (not shown). It seems that generally, the tapes become shorter with an increase in concentration.

\subsubsection{Aging of the Gels}

The petal-like wrapping seen in Figure 6.7c cannot be attributed to shrinkage and wrinkling upon drying, as these were wet gels observed under cryo condition. To verify that these petals wrap into hollow fibers (or even partially as seen in the above images 
with a slit), aging of the $\mathrm{C}_{8}$ and $\mathrm{C}_{18}$ slow-cooled gels was studied. The gels were examined in the cryo SEM after 1, 7 and 14 days after preparation. In both the cases freshly prepared gels showed a petal-like structure (Figures 6.8a and $\mathrm{d}$ for $\mathrm{C}_{8}$ and $\mathrm{C}_{18}$, respectively) with wrapping at the edges. The micrographs recorded for both the samples a week later (Figures $6.8 \mathrm{~b}$ and e) showed that the sheets are almost completely wrapped leaving behind very thin slits. When the micrographs of the same samples were recorded another week later, these gel platelets or sheets were fully transformed into fibers (Figures $6.8 \mathrm{c}$ and $\mathrm{f}$ ). Thus the formation of the petals is the partial stage of growth. Note that the morphology seen in Figure $6.6 \mathrm{~b}$ and $\mathrm{c}$ (quenched 0.04 and $0.05 \mathrm{M} \mathrm{C}_{18}$ gels) also resemble the partially wrapped petals. Figure 6.9 shows the morphology of slow-cooled and aged gels of $\mathrm{C}_{12}$ prepared with toluene, xylene, dodecane and 1-octanol. The arrows show the wrapping, eaves trough and hollow tube formation. While in the case of lipids and diamides the tube formation ${ }^{26-30}$ is uniform and complete, the often incomplete wrapping and hollow fibers observed in this case can be attributed to the sheets that tend to wrap into tubes.

Schnur $^{26}$ reviewed the various theories proposed for tube formation in chiral systems. Of these, according to Helfrich and Prost ${ }^{31}$ an intrinsic bending force due to chirality would lead a tilted chiral bilayer to form a cylinder. Similar theory has also been advanced by Ou-Yang and $\mathrm{Liu}^{32}$ using an analogy with cholesteric liquid crystals. Both experiments and calculations show that the tubule diameter is independent of tubule length. The fundamental basis of these theories is that the interaction between molecules in the bilayer is chiral. This results from the three-dimensional chirality of the molecules. 
Schnur $^{26}$ also noted that helical twist due to chiral interaction is a precursor to tube formation.
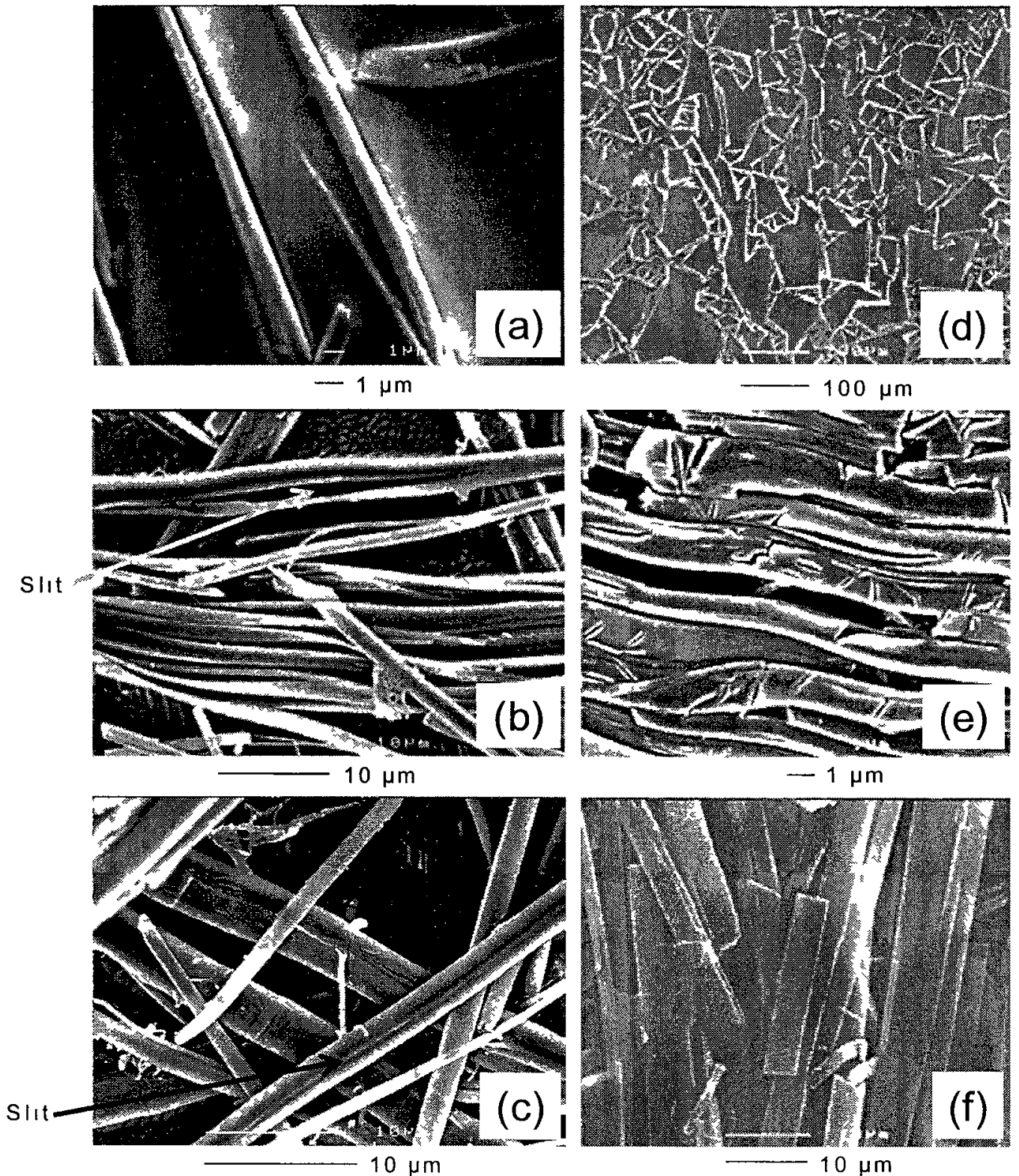

Figure 6.8. SEM images (cryo condition) of $\mathrm{C}_{8}\left(\mathrm{a}, \mathrm{b}\right.$, and $\mathrm{c}$ ), and $\mathrm{C}_{18}$ gels $(\mathrm{d}, \mathrm{e}, \mathrm{f}) .(\mathrm{a}, \mathrm{d})$ $1^{\text {st }}$ day, $(\mathrm{b}, \mathrm{e}) 7^{\text {th }}$ day, and (c, f) $14^{\text {th }}$ day, with benzonitrile. 

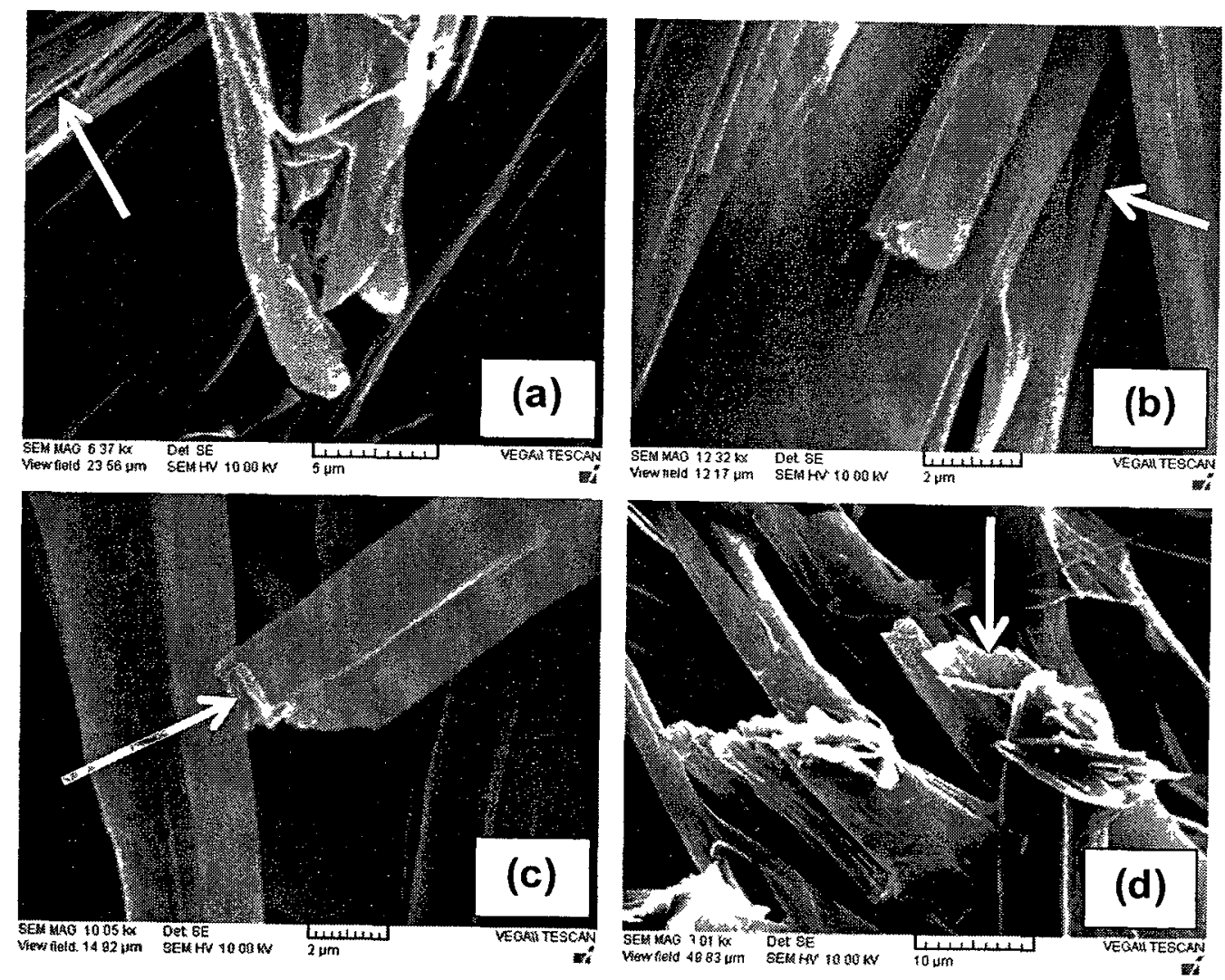

Figure 6.9. SEM images of xerogels of $\mathrm{C}_{12}$ biscarbamate with different solvents prepared by slowly cooling the solution to room temperature: (a) toluene, (b) xylene, (c) dodecane, and (d) 1-octanol. The gels were dried after 3 weeks (aged) of gel formation. The arrows indicate the slits and hollow parts of the fibers.

In the previous sections we discussed the differences in the morphology upon quenching and slow cooling, the effect of the length of the side chain on the nucleation and diffusion. We also noted the relative contributions of the hydrogen bond and van der Waals interactions. The previous study on the crystallization of these biscarbamates showed that the rates of spherulitic growth and crystallization were maximum for the $\mathrm{C}_{8}$ side chain. The reason for the wrapping and hollow tube formation has now to be traced. In the case of chiral molecules, the twist propagates in the packing of successive molecules, leading to helical structures and tubule formation. However, in the case of 
biscarbamates, there is no unidirectional twist in the molecular shape. The crystal structure of $\mathrm{C}_{10}$ is known and it is triclinic. ${ }^{33}$ The molecular packing of two molecules of $\mathrm{C}_{16}$, energy minimized with HyperChem software, is shown in Figure 6.10. Both the conformation of the individual molecule and the packing are similar in the crystal structure of $\mathrm{C}_{10}$. Such a curvature in the molecule does not lead to helical twisting. Thus, the crystalline packing itself can not account for the wrapping and tube formation.

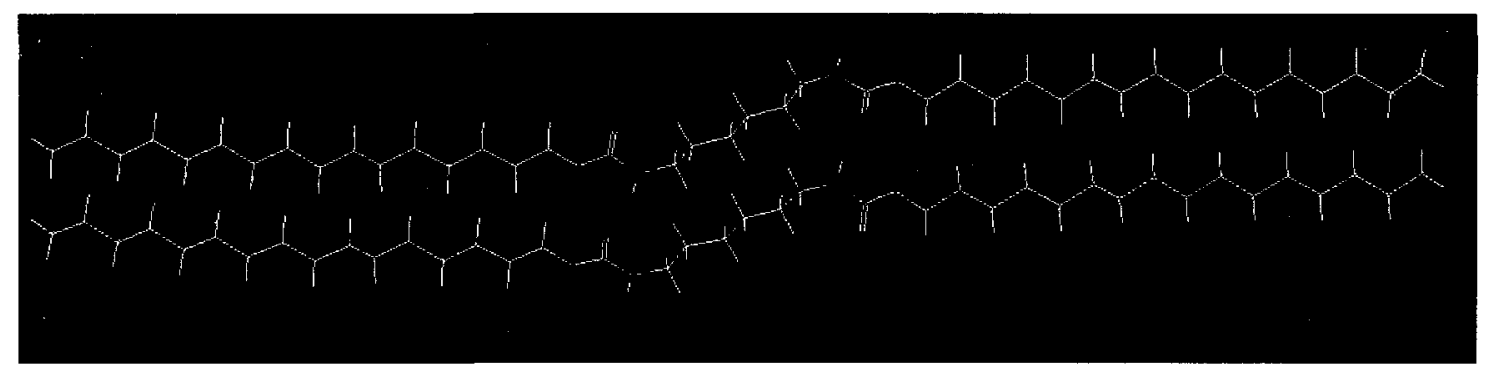

Figure 6.10. HyperChem rendition of (energy-minimized) packing of two $\mathrm{C}_{16}$ biscarbamates along the hydrogen bonding direction. The packing in the crystal structure $^{33}$ of $\mathrm{C}_{10}$ is similar.

We then offer the following as a plausible origin of tubes in this case. Helfrich and Prost $^{31}$ noted that amphiphilic mono and bilayers are not at their minimal energy when they are flat, and preference is for a bent state. In the case of biscarbamates, there is no chiral interaction. As seen in the micrographs discussed above (e.g., Figures 6.1a, 6.6b, $6.7 \mathrm{c}, 6.7 \mathrm{~d}, 6.8 \mathrm{c}$, and $6.8 \mathrm{~d}$ ) the gels of biscarbamates form sheets. We propose that when these sheets, when the gel is wet, prefer not to be flat but curl and wrap into hollow fibers. The curling and twisting occur due to the anisotropy of interactions in the sheet. In addition, as shown in Scheme 6.2, due to the long alkyl chains on either end of the molecules, van der Waals interaction between these side chains also occur along the same direction as the hydrogen bonds, i.e., along the growth direction. The interaction in the 
direction normal to the growth direction is simply the van der Waals interaction between the terminal methyl groups of the molecules. There is only the van der Waals interaction between the hydrogen bonded sheets also. Thus, both hydrogen bond and van der Waals interactions predominate along the growth direction. This could lead to significant anisotropy, and cause the twisting of the sheets, leading to hollow tubes, similar to the case of chiral molecules.

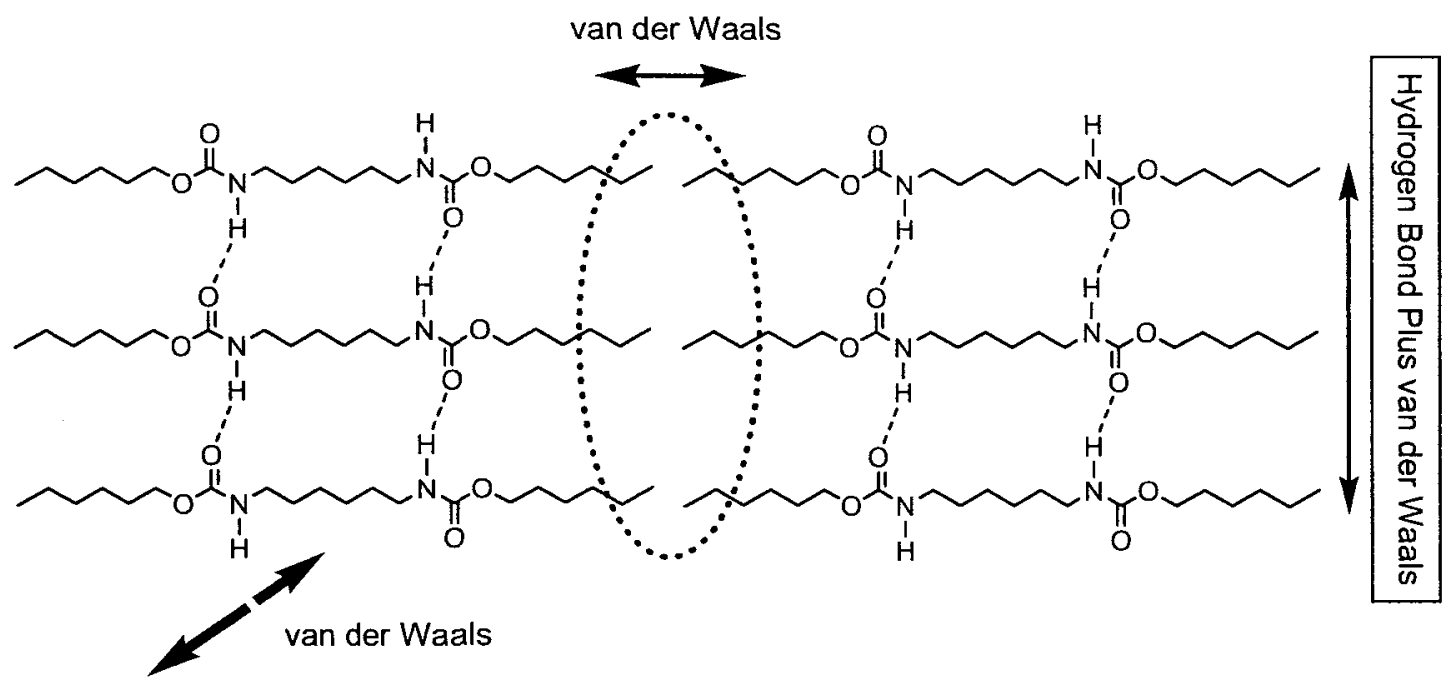

Scheme 6.2

Chappell and $\mathrm{Yager}^{34}$ also concluded such anisotropy of intermolecular interactions in the case of chiral lipids would lead to hollow tube formation. Note that the internal diameter of the tubes in the case of chiral molecules is in the nanometer scale, where as it is of the order of a few microns in the case of biscarbamate gels. SEM micrographs show crystallization (i.e., three dimensional crystal formations) along with gelation (rapid growth along the hydrogen bond direction). Such combination of events might be the cause of the formation of tapes and sheets, which are shorter than the fibers usually observed during organo gelation. 


\subsubsection{Effect of Shear}

The formation of fibers and tapes during gelation is due to higher growth rate in one dimension compared to the other two. Such faster growth is due to the formation of sheets that are facilitated by self-assembly, e.g., via hydrogen bonds. It is informative to determine the direction of these (hydrogen-bonded) sheets along the fibers of the gels. If the fibers could be aligned (oriented), X-ray diffraction could be used to characterize the direction of growth. However, the fibers in the gels are randomly intertwined and they lack the mechanical integrity for stretching (in contrast to the case of polymer gels). In the case of polymer films, rubbing is a technique used for aligning the molecules. ${ }^{35}$ Rubbing-induced molecular alignment has been studied in the case of thin polystyrene films, liquid crystals and other polymers. In order to determine the growth direction of the hydrogen bonded sheet, in our previous study on mono carbamates the gel fibers were gently stroked with fingers to impart some orientation, and a partially oriented X-ray diffraction was obtained. ${ }^{17}$

The flow induced alignment and crystallization of polymers is also a well known phenomenon. Rotational shear of polymer melts (as in a parallel plate or cone and plate rheometer) and applying longitudinal velocity gradients are known to cause alignment of the molecules. ${ }^{36}$ Such alignment and crystallization have also been observed in stirred solutions. ${ }^{37}$ In addition, orientation is also observed in the case of spin casting of solutions. Due to the centrifugal force during spinning, in-plane optical anisotropy has been observed, ${ }^{38}$ and the spinning speed could be used to control the morphology of the films in devices. ${ }^{39}$ Following these examples, an attempt was made in the present case, to 
induce such orientation in situ, by applying rotational shear during gelation by using the magnetic stirrer. This is a first attempt to induce orientation during the gelation, and we describe the trends observed with speed of stirring.
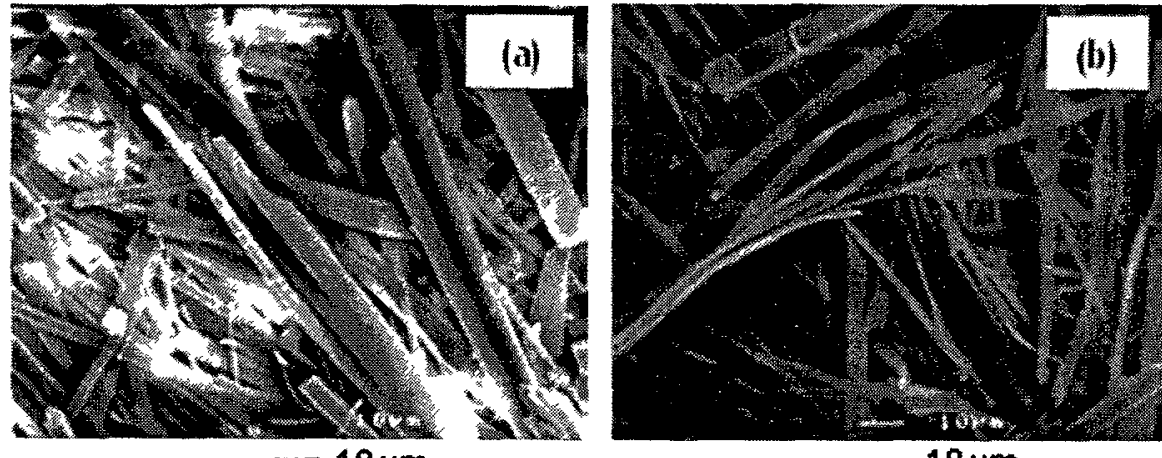

$-10 \mu \mathrm{m}$
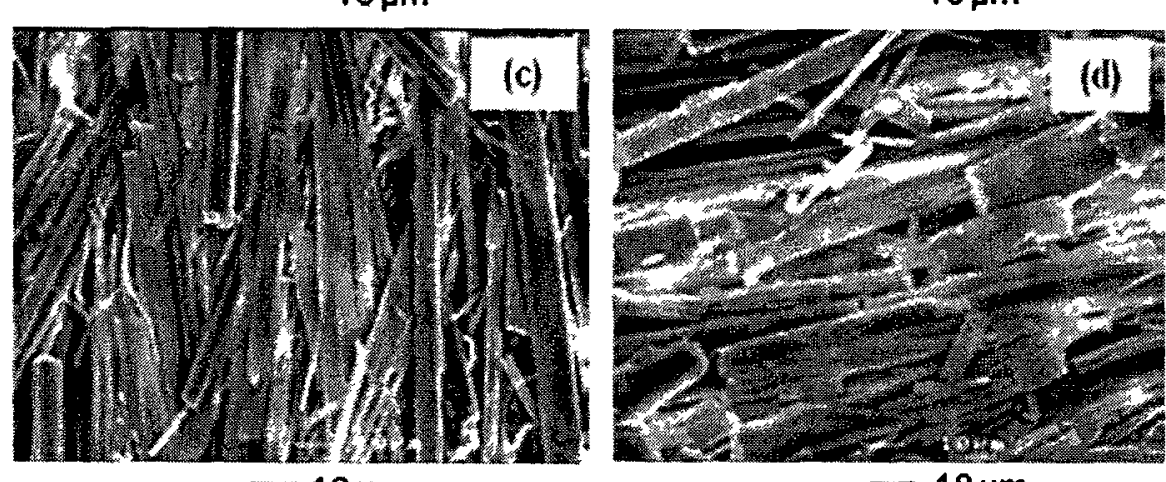

$-10 \mu \mathrm{m}$

Figure 6.11. SEM images of the $0.08 \mathrm{M}$ slow cooled $\mathrm{C}_{18}$ xerogels with benzonitrile after applying different levels of shear (a) 70, (b) 80, (c) 100, and (d) $110 \mathrm{rpm}$.

A shear was applied at different rpm speeds $(70,80,100,110)$ using the magnetic stirrer bar (size: $5 \times 2 \mathrm{~mm}$ ) during the preparation of $0.08 \mathrm{M}$ slow-cooled $\mathrm{C}_{18}$ gels, in a bottle with $2 \mathrm{~cm}$ internal diameter. The xerogels were obtained from their corresponding gels after the removal of the solvent. Note that the speeds of 70 to $110 \mathrm{rpm}$ used here are far less than the several hundred rpm usually employed for spin casting of thin films. A 
comparison of Figures 6.11 a-d shows that well-oriented fibers were only seen in the case of xerogels obtained at 100 and $110 \mathrm{rpm}$. The orientation was not limited to a small area of the sample. Figure 6.12 shows the optical micrographs of an area of approximately $1500 \mu \mathrm{m} \times 1250 \mu \mathrm{m}$ for the samples prepared with $70,80,100$ and $110 \mathrm{rpm}$. Figure $6.12 \mathrm{a}$ and $b$ do not show significant alignment of the fibers. However, by increasing the speed from 80 to 100 and $110 \mathrm{rpm}$, significant orientation is seen. Note that the centrifugal force varies (not linearly but) with the square of the velocity.
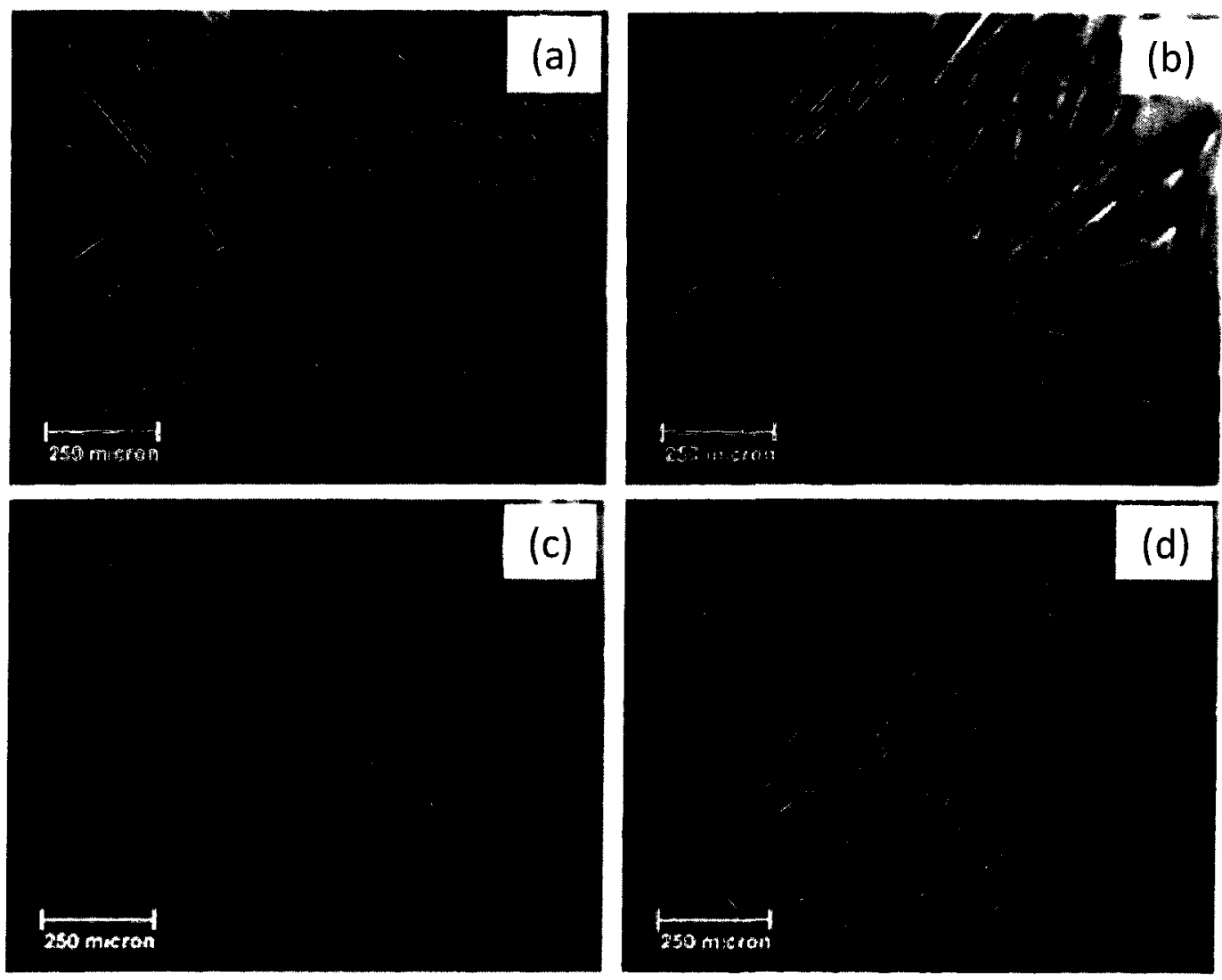

Figure 6.12. Optical micrographs of $\mathrm{C}_{18}$ biscarbamate organogel $(0.08 \mathrm{M})$ prepared with benzonitrile as the solvent at different shear rates: (a) $70 \mathrm{rpm}$, (b) $80 \mathrm{rpm}$, (c) $100 \mathrm{rpm}$, and (d) $110 \mathrm{rpm}$.

To further confirm the orientation, X-ray powder diffraction traces were recorded, with the sample aligned with the intended orientation direction parallel to the direction of 
the incident beam and then perpendicular, by turning the sample by $90^{\circ}$. In the absence of orientation, no difference would be observed in the intensities of the diffraction peaks recorded in these two directions. ${ }^{40}$ Figure 6.13 shows the diffraction traces thus recorded for the xerogels prepared with no shear, 80,100 and $110 \mathrm{rpm}$. Consider the intense diffraction peak at $2 \theta=25^{\circ}$ which corresponds to the distance between hydrogen bonded planes. ${ }^{24}$ With no shear, Figure 6.13 (a) shows that there is no difference in the intensity of this peak in the parallel $(\|)$ and perpendicular $(\perp)$ modes of recording the pattern, indicating the absence of orientation. With $80 \mathrm{rpm}$, the peak is slightly lower in intensity in the $\perp$ mode than in the $\|$ mode. This shows that there is some preferred orientation in the sample. The difference becomes more pronounced with 100 and $110 \mathrm{rpm}$, confirming significant orientation. The ratios $I_{\|} / I \perp$ for the peak are $1.02,1.3,2.63$ and 3.2 for 0,80 , 100 and $110 \mathrm{rpm}$, respectively. Significant differences in the diffraction between the $\|$ and $\perp$ modes are also seen in the region of $2 \theta=7$ to $14^{\circ}$ with $110 \mathrm{rpm}$. This is a first attempt to induce orientation during the gelation, and the general effectiveness of the method will be studied further. All the gels obtained from different shear levels showed the existence of hollow fibers. Application of a shear itself might be a route to tailor the length of the gel fibers. The shear did not affect the process of fiber formation i.e., wrapping of the sheets leading to the formation of fibers. 

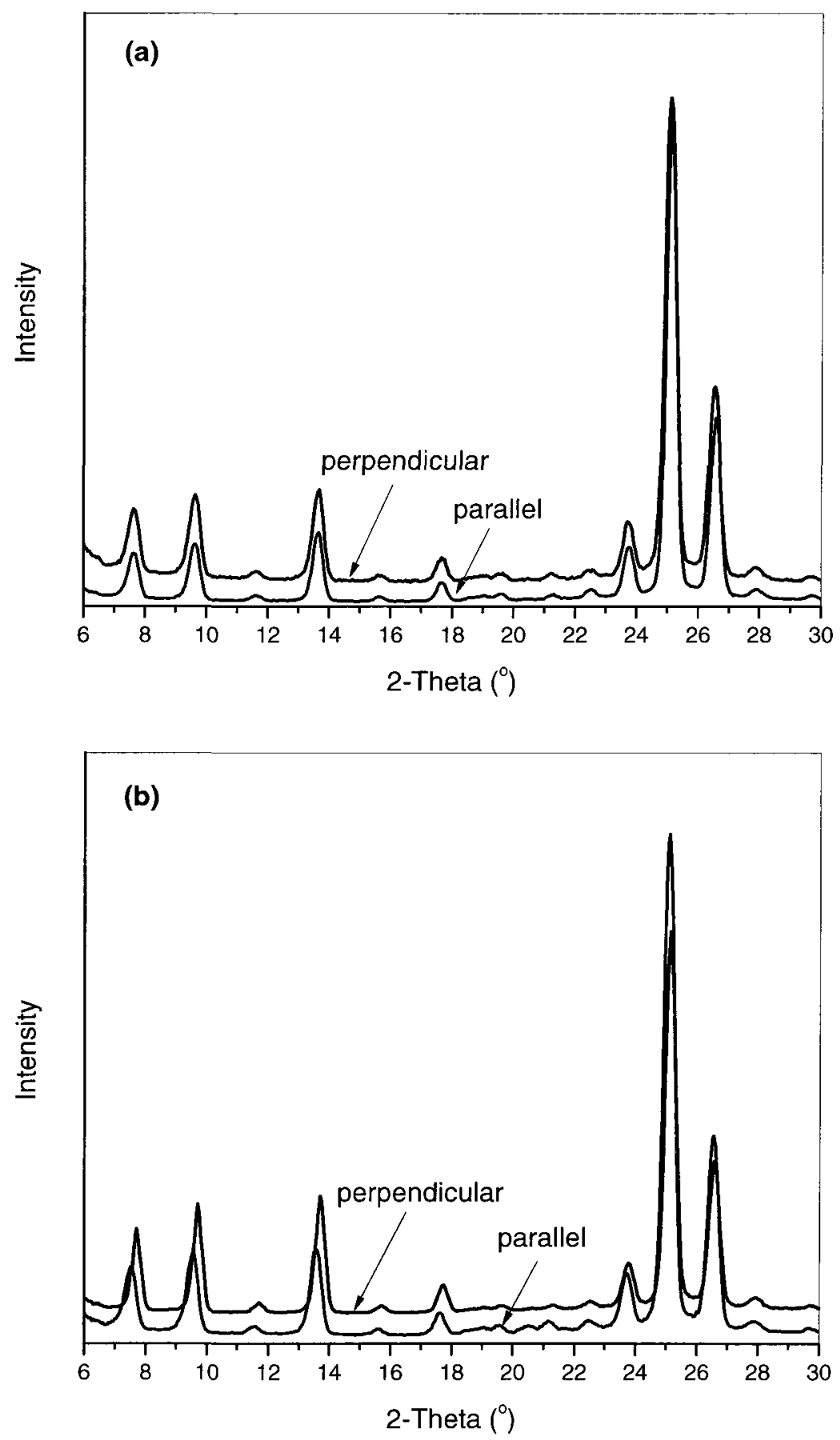

Caption on next page 

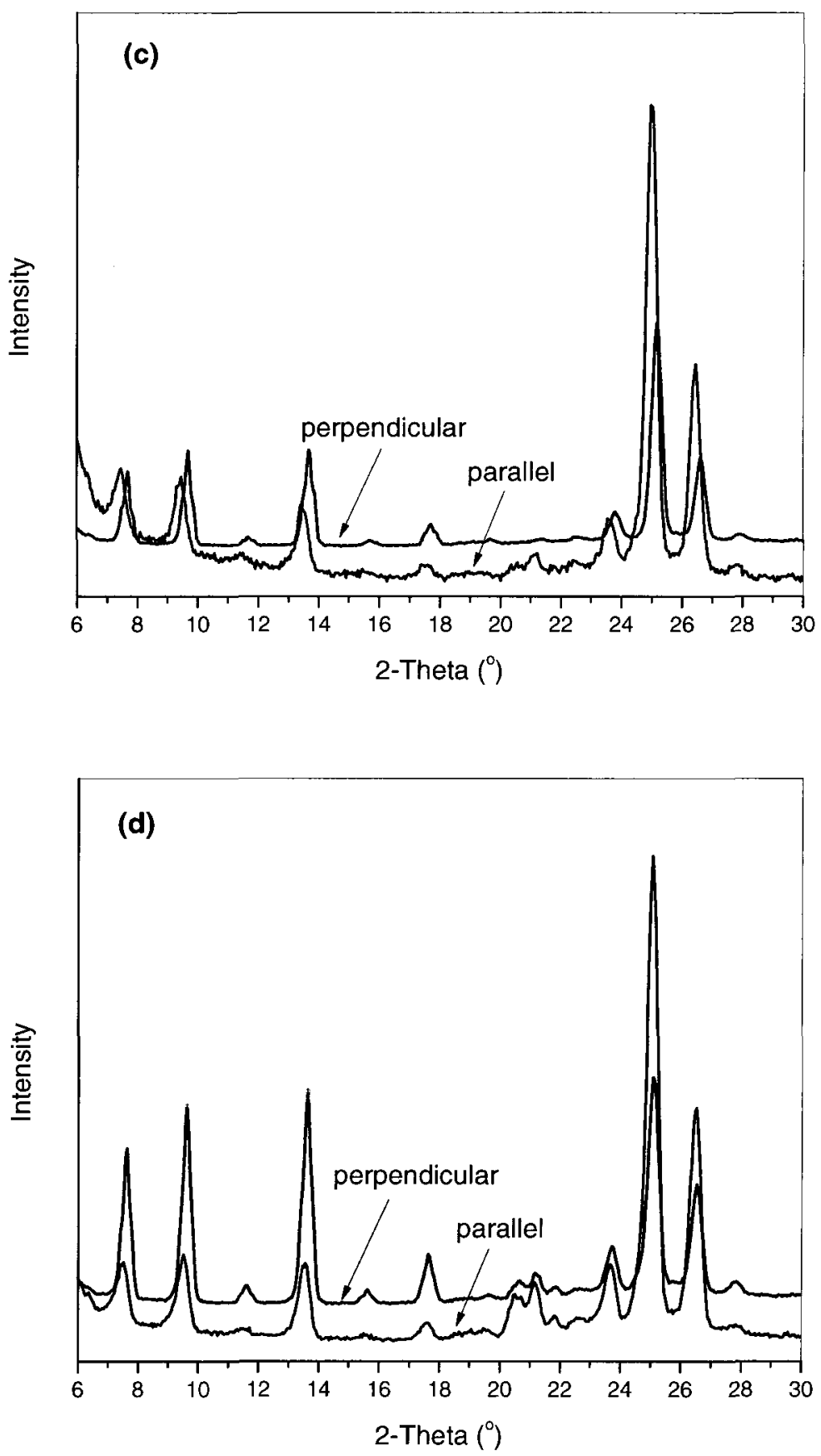

Figure 6.13. X-ray diffractograms of $\mathrm{C}_{18}$ biscarbamate xerogels prepared with different shear rates: (a) no shear, (b) $80 \mathrm{rpm}$, (c) $100 \mathrm{rpm}$, and (d) $110 \mathrm{rpm}$. The designation "parallel" denotes the sample orientation along the direction of the incident X-rays and "perpendicular" denotes the samples turned around by $90^{\circ}$ in the beam. 


\subsubsection{Cooperative Gelation with Mono and Biscarbmate Mixtures and Odd-even Biscarbamate Mixtures (Sergeant and Soldiers)}

There have been several studies ${ }^{41}$ on the principle of "Sergeants and Soldiers" i.e., amplification of chirality in self-assembling systems and that the achiral components assume the helicity of the chiral members. Our previous study on the monocarbamates showed that crystallization rather than gelation occurred with alkyl side chains of $\mathrm{C}_{16}$ and $\mathrm{C}_{18}$. In an attempt to examine if these would gel in the presence of biscarbamates of the same side chain length, gels of binary mixtures were prepared in benzonitrile.
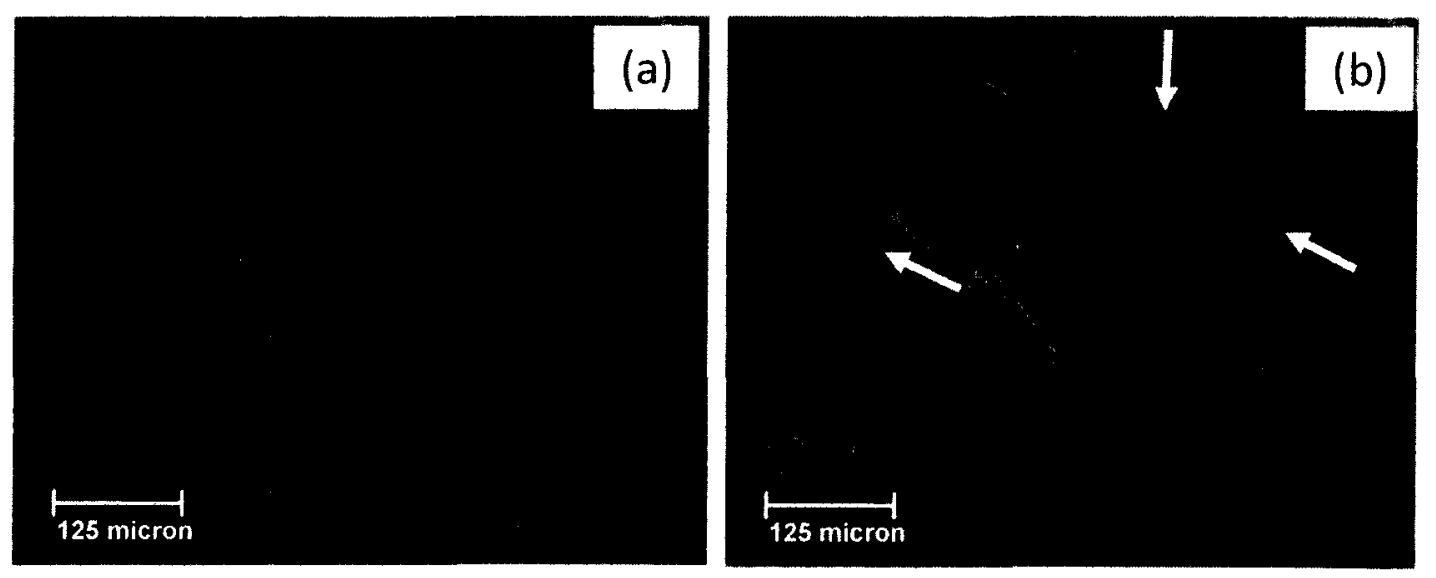

Figure 6.14. Optical micrographs of the $\mathrm{C}_{18}$ biscarbamate and $\mathrm{C}_{18}$ monocarbamate (25 wt\% with respect to the weight of $\mathrm{C}_{18}$ biscarbamate) binary gels with benzonitrile: (a) at $25^{\circ} \mathrm{C}$, (b) at $90{ }^{\circ} \mathrm{C}$. The arrows point to the molten drops of $\mathrm{C}_{18}$ monocarbamate.

We found that while the biscarbamate gelled, the mono carbamate crystallized on the gel fibers of the former (Figure 6.14a). To distinguish the two components, hot stage optical microscopy was used to selectively melt the monocarbamate which has a lower melting temperature. The $\mathrm{C}_{16}$ mono and biscarbamates melt at 83 and $117.8{ }^{\circ} \mathrm{C}$ respectively. Likewise, the melting temperatures of $\mathrm{C}_{18}$ mono and biscarbamates are 86.5 and 120.4 ${ }^{\circ} \mathrm{C}$, respectively. The optical micrographs in Figure $6.14 \mathrm{~b}$ of the binary mixture at 90 
${ }^{\circ} \mathrm{C}$ show the gel fibers of the biscarbamate and the melt droplets of the crystallized monocarbamate.

Our previous study on the crystallization (Chapter 5) of blends of biscarbamates (homologous series with $\mathrm{C}_{4}$ to $\mathrm{C}_{18}$ side chains) showed that these molecules are highly selective in their assembly and that no cocrystallization was observed even with close pairs such as $\mathrm{C}_{16}$ and $\mathrm{C}_{18}$. The same trend was observed during the crystallization of monocarbamates as well. Thus, the gelation of $\mathrm{C}_{16}$ or $\mathrm{C}_{18}$ did not influence that of the corresponding mono carbamates.
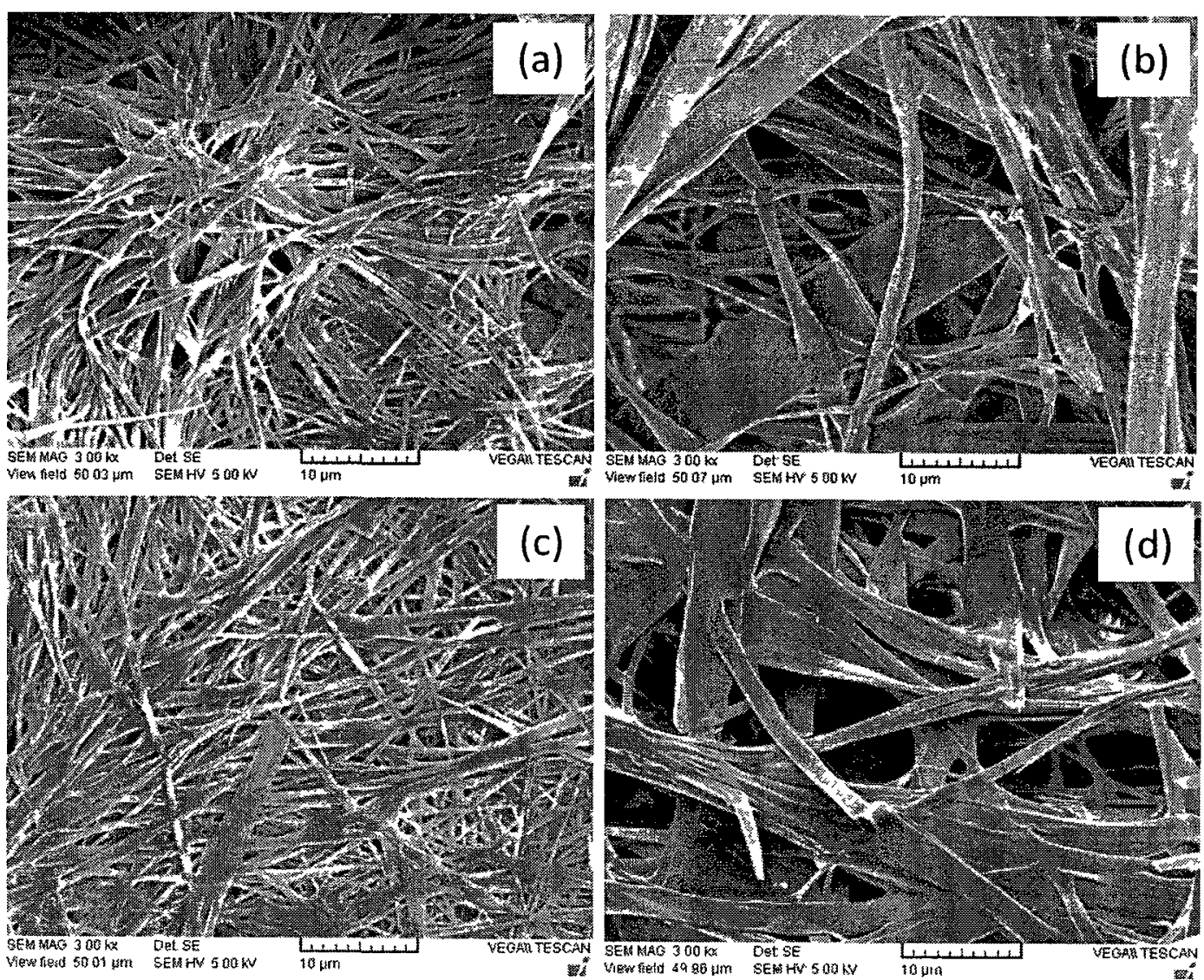

Figure 6.15. SEM images of the xerogels of $\mathrm{C}_{9}(0.08 \mathrm{M})$ and binary gels of $\mathrm{C}_{8}$ and $\mathrm{C}_{9}$ biscarbamates prepared with an equimolar concentration $(0.04 \mathrm{M})$ of each component in benzonitrile: (a) $\mathrm{C}_{9}$ quenched, (b) $\mathrm{C}_{9}$ slow cooled, (c) $\mathrm{C}_{8} / \mathrm{C}_{9}$ quenched, and (d) $\mathrm{C}_{8} / \mathrm{C}_{9}$ slow-cooled. 
In the next example, a preliminary study was performed with a biscarbamate having an odd number of $\left(\mathrm{CH}_{2}\right)$ groups in the side chain. Figures $6.15 \mathrm{a}$ and $\mathrm{b}$ show the SEM of the gels of $\mathrm{C}_{9}$ prepared with benzonitrile by quenching and slow cooling, respectively. Long fibers are seen in this case. Flat ribbons are seen as well, but the crystals that were seen with the even numbered biscarbamates are absent. Figures $6.15 \mathrm{c}$ and $\mathrm{d}$ show the micrographs for the compound gels with equimolar concentrations of $\mathrm{C}_{9}$ and $\mathrm{C}_{8}$ biscarbamates. The fibers are again long, and the short fibers or crystals are not seen. Thus, the presence of $\mathrm{C}_{9}$ biscarbamate significantly modified the gel morphology of the even numbered $\mathrm{C}_{8}$ biscarbamate. This is an example of the sergeant-soldier behavior in a non-chiral system. We will report a detailed study of this system in future.

\subsection{Conclusions}

Of the polyurethane model compounds, the gelation behavior of biscarbamates with two hydrogen bond motifs and symmetrically disposed alkyl chains is very different from that of mono carbamates with a single hydrogen bond group flanked by alkyl chains of unequal lengths. Long alkyl chains such as $\mathrm{C}_{16}$ and $\mathrm{C}_{18}$ gel the various solvents used here (benzonitrile, toluene, xylene, dodecane and 1-octanol), whereas such long side chains promoted only crystallization in the case of mono carbamates.

Hollow fibers were seen in the gelation of biscarbamates, although the system is neither chiral nor amphiphilic. We propose that due to the predominant van der Waals interaction between the long alkyl chains, in addition to the double hydrogen bonding in biscarbamates, the morphology consists of sheets and tubules, in contrast to long fibers 
seen in the case of mono carbamates and other organogelators. Due to the bending force described by Helfrich and Prost, ${ }^{31}$ the sheets and tapes wrap into tubes. Incomplete wrapping shows the eaves trough morphology. While the tubules seen in the case of chiral molecules were attributed to the twisting caused by chirality, the bending of the sheets in the present case could be rationalized on the basis of the asymmetry of the strength of the interactions: (i) a dominant force of hydrogen bonding as well as the van der Waals interaction between the long alkyl chains along the gel tape growth direction, (ii) weak interaction between essentially the terminal methyl groups in the direction normal to the gel tape growth direction, and (iii) van der Waals interaction between the sheets of hydrogen bond in the third direction.

Well-oriented fibers were formed in the gels made by simply using a magnetic stirrer on a hot plate, at 100 and $110 \mathrm{rpm}$. A preliminary study on the gelation of mixtures of biscarbamates with odd and even number of $\left(\mathrm{CH}_{2}\right)$ groups in the side chains, e.g., $\mathrm{C}_{9}$ and $\mathrm{C}_{8}$ shows that the presence of the odd member promotes long fiber formation for $\mathrm{C}_{8}$, and the crystals and short fibers that were seen with $C_{8}$ are not observed. This is perhaps the first example of the sergeant-soldier principle in a non-chiral system. 


\subsection{References}

1. Terech, P.; Weiss, R. G. Chem. Rev. 1997, 97, 3133.

2. (a) Ajaygosh, A.; George, S. J.; Praveen, V. K. Angew. Chem., Int. Ed. 2003, 42, 332; (b) Urabe, H.; Jung, J. H.; Ono, Y.; Shinkai, S.; Soai, K. Tetrahedron Lett. 2003, 44, 721; (c) Tiller, J. C. Angew. Chem., Int. Ed. 2003, 42, 3072; (d) Friggeri, A.; Feringa, B.; van Esch, J. J. Controlled Release 2004, 97, 241; (e) Roubeau, O.; Colin, A.; Schmitt, V.; Clerac, R. Angew. Chem., Int. Ed, 2004, 43, 3283; (f) Yang, Z.; Gu, H.; Fu, D.; Gao, P.; Lam, J. K.; Xu, B. Adv. Mater. 2004, 16, 1440; (g) Sugiyasu, K.; Fujita, N.; Shinkai, S. Angew. Chem., Int. Ed. 2004, 43, 1229; (h) Yao, S.; Begnin, U.; Gress, T.; Lysetska, M.; Wurthner, F. J. Am. Chem. Soc. 2004, 126, 8336; (i) Kiyonaza, S.; Sada, K.; Yoshimura, I.; Shinkai, S.; Kato, N.; Hamachi, I. Nat. Mater. 2004, 3, 58.

3. Henisch, H. K. Crystal growth in Gels Pennsylvania State University Press: University Park, PA, 1970.

4. Srivastava, S. P.; Saxena, A. K.; Tendon, R. S.; Shekhar, V. Fuel 1997, 76, 625.

5. (a) Lin, Y.-C.; Weiss, R. G. Macromolecules 1987, 20, 414; (b) Murata, K.; Aoki, M.; Nishi, T.; Ikeda, A.; Shinkai, S. J. Chem. Soc., Chem. Commun. 1991, 1715; (c) Mukkamala, R.; Weiss, R. Langmuir 1996, 12, 1474; (d) Geiger, C.; Stabescu, M.; Chen, L.; Whitten, D. G. Langmuir 1999, 15, 2241.

6. Pilpel, N. Chem. Rev. 1963, 63, 221.

7. Uzu, Y. J. Jpn. Oil Chem. Soc. 1975, 24, 261.

8. (a) Yamamoto, S. J. Soc. Chem. Ind. Jpn. 1943, 46, 279; (b) Taravel, F. R.; Pfannemueller, B. Makromol. Chem. 1990, 191, 3097; (c) Yamasaki, S.; Tsutsumi, 
H. Bull. Chem. Soc. Jpn. 1994, 67, 2053; (d) Hafkamp, R. J. H.; Feiters, M. C.; Nolte, R. J. M. J. Org. Chem. 1999, 64, 412; (e) Beginn, U.; Keinath, S.; Moller, M. Macromol. Chem. Phys. 1998, 199, 2379; (f) Yoza, K.; Amanokura, N.; Ono, Y.; Akao, T.; Shinmori, H.; Shinkai, S.; Reinhoudt, D. N. Chem.-Eur. J. 1999, 5, 2722.

9. (a) de Vries, E. J.; Kellogg, R. M. J. Chem. Soc., Chem. Commun. 1993, 238; (b) Aggeli, A.; Bell, M.; Boden, N.; Keen, J. N.; Knowles, P. F.; McLeish, T. C. B.; Pitkeathly, M.; Radford, M. Nature 1997, 386, 259.

10. Campbell, J.; Kuzma, M.; Labes, M. Mol. Cryst. Liq. Cryst. 1983, 95, 45.

11. Hanabusa, K.; Tange, J.; Taguchi, Y.; Koyama, T.; Shirai, H. J. Chem. Soc., Chem. Commun. 1993, 390.

12. (a) Terech, P.; Gebel, P.; Ramasseul, R. Langmuir 1996, 12, 4321; (b) Engelkamp, H.; Middelbeek, S.; Nolte, R. J. M. Science 1999, 284, 785.

13. Abdallah, D. J.; Weiss, R. G. Langmuir 2000, 16, 352.

14. (a) Hanabusa, K.; Shimura, K.; Hirose, K.; Yamada, M.; Shirai, H.; Chem. Lett. 1996, 885; (b) Shi, H.; Huang, Z.; Kilic, S.; Xu, J.; Enick, R. M.; Beckman, E. J.; Carr, A. J.; Melendez, R. E.; Hamilton, A. D. Science 1999, 286, 1540.

15. (a) van Esch, J.; de Feyter, S.; Kellogg, R. M.; de Schryver, F.; Feringa, B. L. Chem.-Eur. J. 1997, 3, 1238; (b) de Loos, M.; van Esch. J.; Stokroos, I.; Kellogg, R. M.; Feringa, B. L. J. Am. Chem. Soc. 1997, 119, 12675; (c) van Esch, J.; Schoonbeek, F.; de Loos, M.; Kooijman, H.; Spek, A. L.; Kellogg, R. M.; Feringa, B. L. Chem. Eur. J. 1999, 5, 937.

16. Murata, K.; Aoki, M.; Susuki, T.; Harada, T.; Kawabata, H.; Komori, T.; Ohseto, F.; Ueda, K.; Shinkai, S. J. Am. Chem. Soc. 1994, 116, 6664. 
17. Moniruzzaman, M.; Sundararajan, P. R. Langmuir, 2005, 21, 3802.

18. Sohna, J-E. S.; Fages, F. Chem Commun. 1997, 327.

19. Hanabusa, K.; Maesaka, Y.; Kimura, M.; Shirai, H. Tetrahedron Lett. 1999, 40, 2385 .

20. Kimura, T.; Yamashita, T.; Koumoto, K.; Shinkai, S. Tetrahedron Lett. 1999, 40, 6631.

21. Bhattacharya, S.; Acharya, S. N. G. Chem. Mater. 1999, 11, 3121.

22. van Esch, J.; Kellogg, R. M.; Feringa, B. L. Tetrahedron Lett. 1997, 38, 281.

23. Moniruzzaman, M.; Goodbrand, B.; Sundararajan, P. R. Phys. Chem. B, 2003, 33, 8416.

24. Khanna, S.; Moniruzzaman, M.; Sundararajan, P. R. J. Phys. Chem. B, 2006, 110, 15251.

25. (a) Han, W.; Kohler-Redlich, P.; Christina Scheu, C.; Ernst, F.; Ruhl, M.; Grobert, N.; Terrones, M.; Kroto, H. W.; Walton, D. R. M. Adv. Mater. 2000, 12, 1356; (b) Pham-Huu, C.; Keller, N.; Estournès, C.; Ehret, G.; Grenèche, J. M.; Ledoux, M. J. Phys. Chem. Chem. Phys. 2003, 5, 3716; (c) Bong, D. T.; Clark, T. D.; Granja, J. R.; Ghadiri, M. R. Angew. Chem. Int. Ed. 2001, 40, 989.

26. (a) Schnur, J. M.; Ratna, B. R.; Selinger, J. V.; Singh, A.; Jyothi, G.; Keaswaran, K. R. K. Science, 1994, 264, 945; (b) Schnur, J. M. Science, 1993, 262, 1669.

27. Frankel, D. A.; O'Brien, D. F. J. Am. Chem. Soc. 1994, 116, 10057.

28. (a) Vauthey, S.; Santoso, S.; Gong, H.; Watson, N.; Zhang, S. Proc. Natl. Acad. Sci. 2002, 99, 5355; 
(b) Valéry, C.; Paternostre, M.; Robert, B.; Gulik-Krzywicki, T.; Narayanan, T.; Dedieu, J-C.; Keller, G.; Torres, M-L.; Cherif-Cheikh, R.; Calvo, P.; Artzner, F. Proc. Natl. Acad. Sci. 2003, 100, 10258.

29. Díaz, N.; Simon, F-X.; Schmutz, M.; Rawiso, M.; Decher, G. Jestin, J.; Mésini, P. J. Angew. Chem. Int. Ed. 2005, 44, 3260.

30. Lee, H. Y.; Nam, S. R.; Hong, J-I. J. Am. Chem. Soc. 2007, 129, 1040.

31. Helfrich, W.; Prost, J. Phys. Rev. A. 1988, 38, 3065.

32. Ou-Yang, Z.-C.; Liu, J.-X. Phys. Rev. A. 1991, 43, 6826.

33. Alimova, L. L.; Atovmyan, E. G.; Filipenko, O. S. Kristallografiya, 1987, 32, 97.

34. Chappell, J. S.; Yager, P. Chem. Phys. Lipids 1991, 58, 253.

35. (a) Tsang, O. C.; Xie, F.; Tsui, O. K. C.; Yang, Z.; Zhang, J.; Shen, D. J. Polym. Sci. Part B : Polym. Phys. 2001, 39, 2906; (b) Huang, J. Y.; Li, J. S.; Chen, S.-H. Molec Cryst. Liq. Cryst. Sci. Tech, Sec. A: Molec Cryst. Liq. Cryst. 1995, 270, 77;

(c) Huang, J. Y.; Li, J. S.; Juang, Y-S.; Chen, S-H. Japanese J. Appl. Phys. Part 1 $1995,34(6 A), 3263$.

36. (a) Porter, R. S.; Johnson, J. F. J. Appl. Polym. Sci. 1963, 7, S33; (b) Mackley, M. R.; Frank, F. C.; Keller, A. J. Mater. Sci. 1975, 10, 1501.

37. (a) Pennings, A. J.; van der Mark, J. M. A. A.; Booij, H. C. Kolloid Z. Polym. 1970, 236, 99; (b) Pennings, A. J.; Pijpers, M. F. J. Macromolecules 1970, 3, 261; Mackley, M. R.; Keller, A. Phil. Transactions, Ser. A, 1975, 278, 29; (c) Zwijnenburg, A.; van Hutten, P. F.; Pennings, A. J.; Chanzy, H. D. Colloid Polym. Sci. 1978, 256, 729. 
38. (a) Law, C. W. Y.; Wong, K. S.; Yang, Z.; Horsburg, L. E.; Monkman, A. P. Appl. Phys. Lett. 2000, 76, 1416; (b) Hu, X.; Shin, K.; Rafailovich, M.; Sokolov, J.; Stein, R.; Chan, Y.; Williams, K.; Wu, W. L.; Kolb, R. High Perf. Polym. 2000, 12, 621.

39. Shi, Y.; Liu, J.; Yang, Y. Polym. Preprints, Am. Chem. Soc. 2000, 41, 802.

40. Klug, H. P.; Alexander, L. E. X-Ray Diffraction Procedures, $2^{\text {nd }}$ Edition, Wiley Interscience, N. Y. 1974, pp. 709.

41. (a) Langeveld-Voss, B. M. W.; Waterval, R. J. M.; Janssen, R. A. J.; Meijer, E. W. Macromolecules 1999, 32, 227; (b) Green, M. M.; Reidy, M. P.; Johnson, R. J.; Darling, G.; O’Leary, D. J.; Willson, G. J. Am. Chem. Soc. 1989, 111, 6452; (c) Prins, L. J.; Timmerman, P.; Reinhoudt, D. N. J. Am. Chem. Soc. 2001, 123, 10153; Smulders, M. M. J.; Schenning, A. P. H. J.; Meijer, E. W. J. Am. Chem. Soc. 2008, 130, 606; (d) Green, M. M.; Peterson, N. C.; Sato, T.; Teramoto, A.; Cook, R.; Lifson, S. Science 1995, 268, 1860. 


\title{
Chapter 7
}

\section{Encapsulation of Dye Molecules and Nanoparticles in Hollow} Organogel Fibers of a Nonchiral Biscarbamate*

\author{
* Chem. Eur. J. 2011, 17, 1184.
}




\subsection{Introduction}

Low-molecular weight organogels have emerged as an important class of organic smart materials in the last few years. Their importance lies largely in their ease of fabrication, reversibility in their gel-sol phase transition, and rapid response to a number of physicochemical stimuli, such as light, ${ }^{1}$ temperature, ${ }^{2} \mathrm{pH}^{3}{ }^{3}$ and ionic chemical species. ${ }^{3 a, 4,5}$ The facile tunability of the properties up to the optimum functional level and sufficiently quick response of these gels to various microenvironments have caused them to be considered for various potential applications, for example, sensors, chirooptical molecular switches, ${ }^{6}$ drug delivery and release, ${ }^{7}$ template synthesis, ${ }^{8}$ electrophoresis, ${ }^{9}$ and light-harvesting solar cells, ${ }^{10}$ and can be expanded to the limit of the imagination of scientists and technologists. Molecular engineering transformed the serendipitous discovery of organogels into an efficient method of making gels with presumed structure and properties. A wide spectrum of organic molecules has been discovered as lowmolecular-weight organogelators, that is, amino acid derivatives, ${ }^{11}$ benzoic acid hydrazides, ${ }^{12}$ carbazoles, ${ }^{13}$ saccharides, ${ }^{14,15}$ dendrimers, ${ }^{16}$ and carbamates. ${ }^{17,} 18$ Noncovalent interactions, such as hydrogen bonding, van der Waals interactions, $\pi-\pi$ interactions, and coordination bonding between organic molecules, have been successfully employed to fabricate self-assembled fibrilar networks. Several examples of organogelators, such as small peptides or pseudopeptides ${ }^{19}$ and urea or thiourea, ${ }^{20}$ have been previously reported in the literature and have been studied as models for hydrogenbonding-type organogelators. 
Several factors, such as solubility ${ }^{14}$ and structure of the gelator and solvent, ${ }^{21}$ were found to play important role in the gelation process. There is a recent report on the fabrication of a low-molecular-mass organogel system through synergistic multicomponent interactions, in which the presence of five components is required to form a gel. $^{22}$ Three dimensional fibrillar network of the gels can be comprised of different types of structures, for example, solid ${ }^{17}$ or hollow fibres, ${ }^{18,23}$ strands, tapes, ${ }^{3}$ depending on the type of the noncovalent interactions and the molecular geometry of the organogelators.

Hollow fibers are subjects of particular fascination and interest, with conceived applications as reactor vessels and functional delivery systems. ${ }^{24}$ Such tube formations have been observed when chirality-driven molecular packing occurs in lipids, and when bilayer formation leads to helical structures with tubular morphology. ${ }^{24}$ We described in previous chapter the tube formation in nonchiral biscarbamate gels, in which we initially observed long sheets, which then folded into eaves trough morphology and then wrapped into hollow tubes with time (while still in the wet gel state). ${ }^{18}$ This was rationalized as being due to the difference in the strength of molecular interactions along and across the sheets. The energy of interaction between the molecules along the growth direction involves both hydrogen bonding and van der Waals forces, whereas the other two directions involve only the latter. The tubular morphology in the organogels was confirmed by using cryo-SEM and this morphology was maintained in the xerogels (see Figures $1-5$ in ref. 18).

Fabrication of nanocomposites with incorporated metal nanoparticles is another active area of research. Zan and $\mathrm{Su}^{25}$ recently described a method to incorporate 
nanoparticles into polyelectrolyte multilayers through counterion exchange and in situ reduction of the precursor metal ions. In an another report, organic-inorganic hybrid type metal nanoparticle-incorporated mesoporous silica spheres have been synthesized with adsorbed zinc phthalocyanine in the channels and on the surfaces of the spheres as electrode modifiers. $^{26}$

In terms of conferring similar functional attributes to organogels, fibrous gels have been found to be particularly important as structure-directing agents in the synthesis of multiwalled metal nanotubes and nanoporous materials. ${ }^{27}$ Gels doped with a suitable dye/chromophore molecule that interact with the molecular aggregates in the gel have been found to change its color upon gel-to-sol transition and can be used as thermochromic sensors. ${ }^{28}$ Moreover, there has been an attempt to fabricate a twocomponent gel through the self-assembly of a hydrogen-bonded organogelator and entrapment of the conventional columnar discotic-shaped liquid crystalline molecule, which resulted in a thermoreversible physical gel that shows an electro-optical response. ${ }^{27,29}$

There have been some attempts to create hybrid organic-inorganic structures by loading the lumen of wood-pulp fibers with inorganic magnetic materials by using both impregnation and in situ synthesis of ferrites to fabricate magnetic papers. ${ }^{30-32} \mathrm{~A}$ similar approach to making two-component gels, in which the gel morphology consists of hollow tubes, was thought to be viable. 


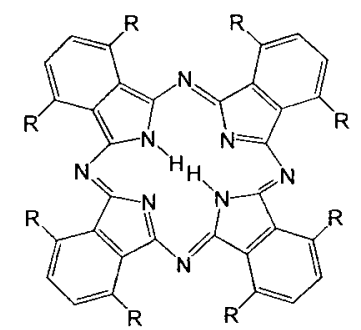

$\mathrm{R}=\mathrm{O} \mathrm{CH}_{3}$

Phthalocyanıne

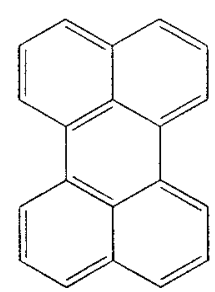

Perylene

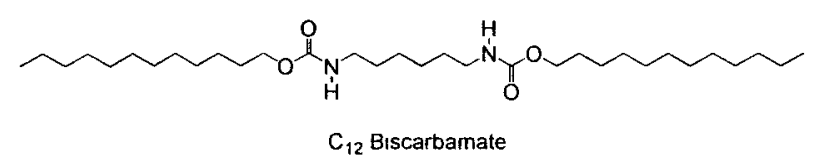

Scheme 7.1. Structure of $1,4,8,11,15,18,22,25$ octabutoxy- $29 \mathrm{H}, 31 \mathrm{H}$ phthalocyanine, perylene and $\mathrm{C}_{12}$ biscarbamate.

Herein we report a facile sol-gel method of fabricating two-component organogels that encapsulate metal nanoparticle and organic dye molecule into the hollow fibers of the gel. We used a low-molecular-weight organogelator, namely $\mathrm{C}_{12}$ biscarbamate (Scheme 7.1), which has double hydrogen-bonding moieties symmetrically attached to alkyl side chains (the subscript 12 indicates the number of carbon atoms in the alkyl side chain of the biscarbamate molecule, henceforth designated as $\mathrm{C}_{12}$ ). This work is an attempt to exploit the tube-forming mechanism to fabricate two-component physical gels of biscarbamate with poly (vinyl pyrrolidone) - functionalized silver nanoparticles (SNP), perylene dye $(\mathrm{Pe})$, and liquid-crystalline phthalocyanine $(\mathrm{Pc})$ molecules incorporated into the hollow fibers of biscarbamate organogels. We expect entrapment of particles from a mixture of gelator/nanoparticle or gelator/dye molecules in solution to occure during the wrapping of the biscarbamate sheets, leading to the particle-loaded fibers. We found that in the case of the dye molecules, the morphology of the dye crystal determines whether or not the dye is incorporated in the hollow fibers. 


\subsection{Experimental}

\subsubsection{Materials}

The $\mathrm{C}_{12}$ biscarbamate was synthesized according to the procedure described in Chapter 1 as well as in our previous papers. ${ }^{33,34}$ PVP-functionalized silver nanoparticles were synthesized by polyol synthesis method ${ }^{35}$ and was used as particle-dispersed solution in ethanol. The average size of the particles was determined to be about $50-60$ nm from atomic force microscopic (AFM) measurements. Perylene, phthalocyanine and other chemicals were purchased form Sigma-Aldrich Inc., and were used as received without any further purification.

\subsubsection{Preparation of the gels}

Pre-weighed amount of $\mathrm{C}_{12}$ biscarbamate was dissolved in $2 \mathrm{~mL}$ benzonitrile to make a $0.08 \mathrm{M}$ solution by heating it up to $90{ }^{\circ} \mathrm{C}$ in a $5-\mathrm{mL}$ scintillation vial. The solution was kept at that temperature for about $10 \mathrm{~min}$ and then slowly cooled (the hot plate was turned off). The completion of the gel formation was confirmed by vial inversion method. ${ }^{36}$ SNP-loaded $C_{12}$ gel was prepared by dissolving a pre-weighed amount (corresponding to $0.08 \mathrm{M}$ concentration of the $\mathrm{C}_{12}$ in the solution) of the $\mathrm{C}_{12}$ sample in benzonitrile and adding drop wise an equal volume of SNP/ethanol solution. The solution mixture was then slowly cooled to room temperature after stirring it for $10 \mathrm{~min}$ at $90{ }^{\circ} \mathrm{C}$. For the two-component gels with $\mathrm{C}_{12}$ and perylene or phthalocyanine, required amount of the dye, according to the percent composition, was dissolved in benzonitrile along with the $\mathrm{C}_{12}$ following the same protocol as above. Another set of gels was prepared following exactly the same procedure but quenching the hot solution using an ice bath. We chose 
$\mathrm{C}_{12}$ as a representative example for lumen loading, and benzonitrile as the solvent, because we have used it in our previous work.

\subsubsection{Characterization}

TA Instruments 2010 differential scanning calorimeter was used for thermal analysis at a heating rate of $10^{\circ} \mathrm{C}$ per min. The DSC was calibrated for temperature and energy with indium standard reference material. DSC traces were recorded in a nitrogen atmosphere with $c a .7-10 \mathrm{mg}$ of the gel samples placed carefully into an aluminum pan and capped with a lid by using a Perkin Elmer hand press.

Optical micrographs were recorded with a Zeiss Axioplan polarized optical microscope. Northern Eclipse (version 6.0) image processing software was used to capture the images and for subsequent data acquisition and processing. For the kinetic study of the isothermal crystal growth of Pc and $\mathrm{Pe}$ and the partial melting experiment with the $\mathrm{C}_{12} / \mathrm{SNP}, \mathrm{C}_{12} / \mathrm{Pc}$ and $\mathrm{C}_{12} / \mathrm{Pe}$ xerogels, a Linkam hot stage (LTS 350) equipped with a Linkam TMS 94 thermo controller was used. For the isothermal crystal growth, a temperature of $63{ }^{\circ} \mathrm{C}$ was used and the micrographs were recorded as the crystals were growing in benzonitrile. This temperature is the range in which the gelation of $\mathrm{C}_{12}$ occurs in the slow-cooled gels.

Scanning electron microscopy (SEM) images of the xerogels were obtained using a JEOL JSM-6400 scanning electron microscope. Gel samples were prepared for SEM by mounting them on carbon-tape-coated aluminum stubs and drying them in air for $c a .24 \mathrm{~h}$ 
and under vacuum for $c a .5 \mathrm{~h}$. Some samples were mounted on carbon-tape-coated brass pucks and were dried in the same way to record the images of the edges of the gel fibers at different angles. Scanning electron microscopy (SEM) images of some of the SNP loaded $\mathrm{C}_{12}$ xerogel samples were obtained using a VEGAII XMU (TESCAN, Czech Republic) scanning electron microscope. Dried samples were sputter coated with 80:20 Au/Pd target using a Hummer VIII Sputtering System (Anatech Ltd., Alexandria, VA) before recording the images. SEM images were captured at an accelerating voltage ranging from 5 to $20 \mathrm{kV}$. Vega $\mathrm{TC}$ software was used for both the microscope manipulation and capturing the images from the latter microscope.

UV-visible spectra were recorded by using a Varian Cary 3 UV-Visible spectrometer equipped with Cary WinUV Scan Application software. FTIR spectra of the pure biscarbamates and their gels were taken under ambient conditions with a Varian 1000 Scimitar Series spectrophotometer. The FTIR spectra were recorded by placing the sample on transparent $\mathrm{NaCl}$ disc, with a background correction using the identical sample holder. Varian Resolution (version 4.0.5.009) software was used for data recording and further processing.

\subsection{Results and Discussion}

\subsubsection{Thermal Analysis}

Organogels prepared from $\mathrm{C}_{12}$ biscarbamate along with $1 \mathrm{wt} \%$ of phthalocyanine $(\mathrm{Pc})$ or perylene $(\mathrm{Pe})$ loading with respect to the gelator are shown in Figure 7.1. A solution of $\mathrm{C}_{12}$ biscarbamate $(0.08 \mathrm{M})$ in benzonitrile was used to prepare the gels. The 
clear solutions of the components formed turbid gels upon cooling to the gelation temperature $\left(63{ }^{\circ} \mathrm{C}\right)$, which indicated the fibrous aggregation of the gelator molecules. Gels formed from $\mathrm{C}_{12}$ biscarbamate and $\mathrm{Pe}$ or Pc show thermo reversibility, which is observed in the differential scanning calorimetry (DSC) scans in Figure 7.2 for the $\mathrm{C}_{12} / 2 \mathrm{wt} \% \mathrm{Pe}$ and $\mathrm{C}_{12} / 2 \mathrm{wt} \% \mathrm{Pc}$ slow-cooled and quenched samples.

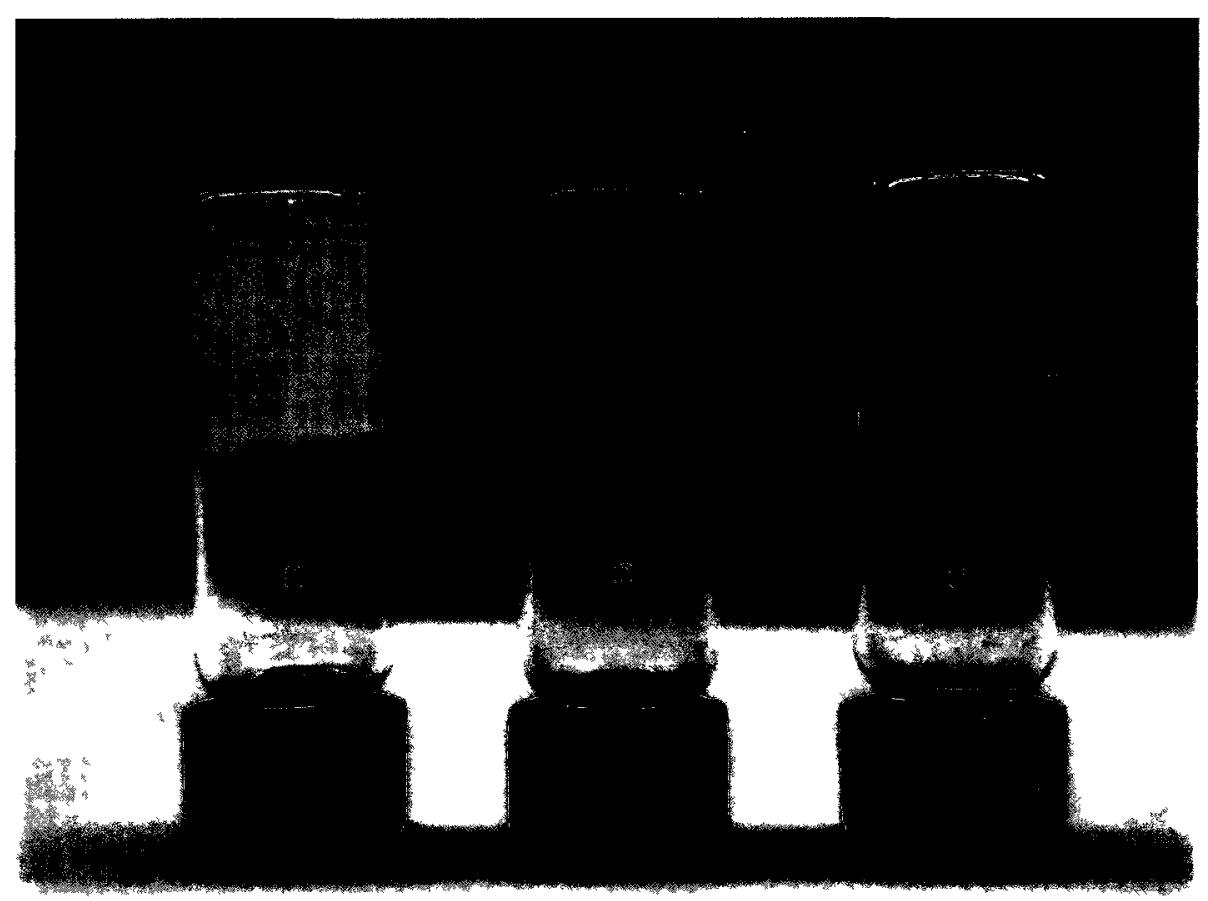

Figure 7.1. Organogels prepared from $\mathrm{C}_{12}$ biscarbamate: (a) neat $\mathrm{C}_{12}$, (b) $\mathrm{C}_{12} / 1 \%$ Pe and (c) $\mathrm{C}_{12} / 1 \%$ Pc gel.

Table 7.1 summarizes the gel-to-sol transition temperatures $\left(T_{\text {gel }}\right)$ of these two-component gels at various compositions. There was no difference in the transition temperatures between scan rates of 5 and $10{ }^{\circ} \mathrm{C} / \mathrm{min}$. The DSC results show that these two-component systems form quite stable gels with $T_{\text {gel }}$ values ranging from around $63{ }^{\circ} \mathrm{C}$ to $87{ }^{\circ} \mathrm{C}$ depending on the fabrication procedure and compositions of the components. 

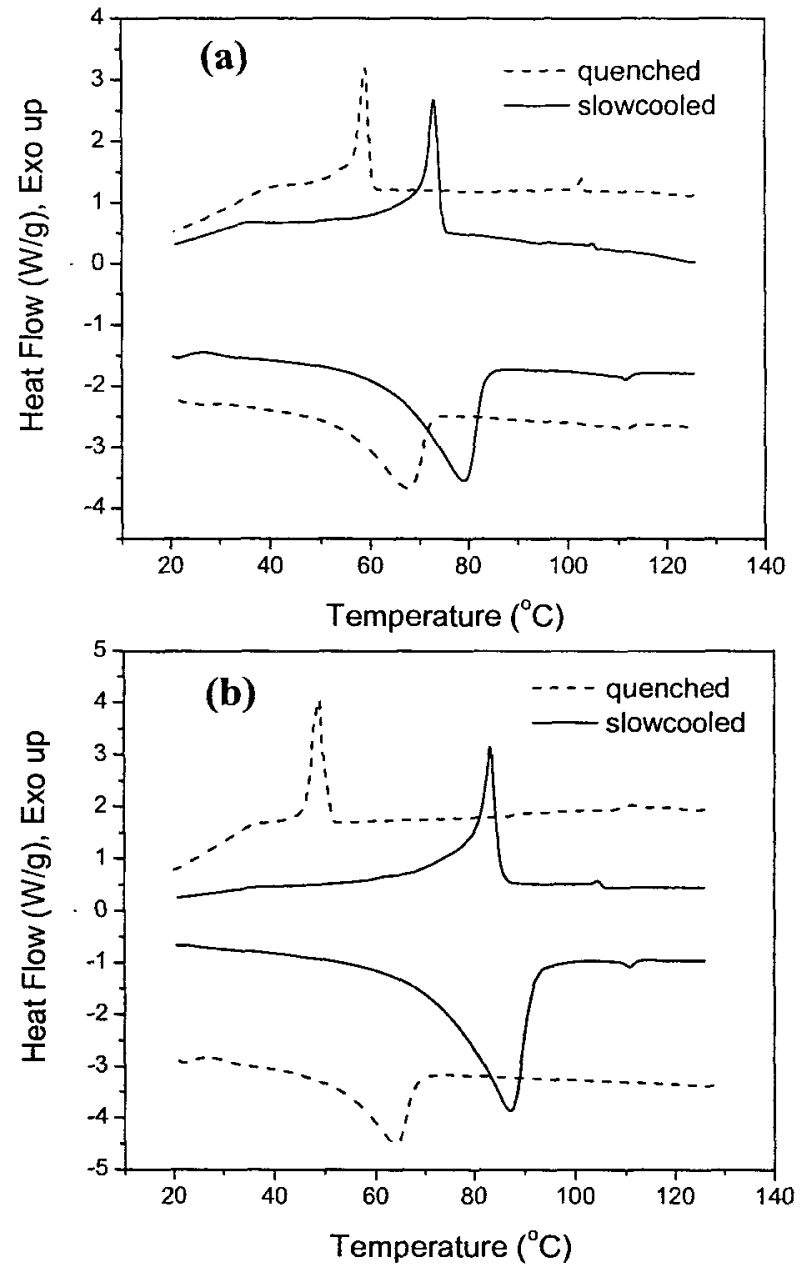

Figure 7.2. DSC thermograms of (a) $\mathrm{C}_{12} / 2 \% \mathrm{Pe}$ and (b) $\mathrm{C}_{12} / 2 \%$ Pc gels.

The $T_{\text {gel }}$ of slow-cooled samples is about $23{ }^{\circ} \mathrm{C}$ higher than that of the quenched samples in the case of $\mathrm{C}_{12} / \mathrm{Pc}$ and about $12{ }^{\circ} \mathrm{C}$ higher for $\mathrm{C}_{12} / \mathrm{Pe}$ gels, which indicates more gelation behavior in the slow-cooled samples than the quenched ones. This can be understandably attributed to better formation and entanglement of fibrils in the slowcooled samples as compared with quenched samples, in which formation and entanglement are hampered by the thermodynamic arrest of the molecules during rapid cooling. 
Table 7.1. Gel-Sol transition temperatures $\left(T_{\text {gel }}\right)$ of the two-component $\mathrm{C}_{12} / \mathrm{Pc}$ and $\mathrm{C}_{12} / \mathrm{Pe}$ gels.

\begin{tabular}{llclcc}
\hline Gel composition & \multicolumn{2}{c}{$T_{\text {gel }}\left({ }^{\circ} \mathrm{C}\right)$} & Gel composition & \multicolumn{2}{c}{$T_{\text {gel }}\left({ }^{\circ} \mathrm{C}\right)$} \\
\cline { 2 - 3 } \cline { 5 - 6 } & Slowcooled & Quenched & & Slowcooled & Quenched \\
\hline $\mathrm{C}_{12}$ & 73.3 & 62.7 & & & \\
$\mathrm{C}_{12}+1 \% \mathrm{Pc}$ & 85.2 & 62.9 & $\mathrm{C}_{12}+1 \% \mathrm{Pe}$ & 74.4 & 66.8 \\
$\mathrm{C}_{12}+2 \% \mathrm{Pc}$ & 86.8 & 63.7 & $\mathrm{C}_{12}+2 \% \mathrm{Pe}$ & 77.1 & 67.4 \\
$\mathrm{C}_{12}+5 \% \mathrm{Pc}$ & 87.2 & 64.0 & $\mathrm{C}_{12}+5 \% \mathrm{Pe}$ & 79.9 & 67.5 \\
$\mathrm{C}_{12}+10 \% \mathrm{Pc}$ & 84.8 & 63.1 & $\mathrm{C}_{12}+10 \% \mathrm{Pe}$ & 73.1 & 62.8 \\
\hline
\end{tabular}

Table 7.1 shows that the $T_{\text {gel }}$ of the both series of samples increases slightly with the incorporation of $\mathrm{Pc}$ and $\mathrm{Pe}$ and reaches maximum at $5 \mathrm{wt} \% \mathrm{Pc}$ or $\mathrm{Pe}$ with respect to $\mathrm{C}_{12}$, after which it decreases as the percentage of Pc and Pe is increased. The significantly higher $T_{\text {gel }}$ values of slow-cooled $\mathrm{C}_{12} / \mathrm{Pc}$ gels compared with $\mathrm{C}_{12} / \mathrm{Pe}$ gels indicates the enhanced contribution of $\mathrm{Pc}$ in the gelation capability of $\mathrm{C}_{12}$ and thus increased thermal stability compared with Pe in these two-component gels. We found that phthalocyanine by itself does not gel benzonitrile.

\subsubsection{Morphology of the Xerogels}

The morphology of the xerogels of $\mathrm{C}_{12}$ biscarbamate and $\mathrm{C}_{12} / \mathrm{Pc}$ and $\mathrm{C}_{12} / \mathrm{Pe}$ gels were studied by using optical (OM) and scanning electron microscopy (SEM). For OM, samples were prepared by dispersing the gel fibers in a saturated solution of the gel, placing a small amount of this solution on a microscope slide, and drying the sample in air for $24 \mathrm{~h}$ and under vacuum for $5 \mathrm{~h}$. Figure 7.3 shows the optical micrographs of the slow-cooled and quenched gels with different compositions of $\mathrm{Pc}$ and $\mathrm{C}_{12}$. It is seen that the fibers in quenched gels (Figures $7.3 \mathrm{a}$ and $\mathrm{b}$ ) are around 45 to $50 \mu \mathrm{m}$ long and about 5 
to $10 \mu \mathrm{m}$ wide. The slow-cooled gels, however, show significantly longer and wider fibers. This leads to better entanglement and thus improved solvent immobilization capability and higher thermal stability than the quenched gels. This is evident from the $T_{\text {gel }}$ values for the slow-cooled and quenched gels listed in Table 7.1. Similar differences in morphology between the quenched and slow-cooled gels were also seen in $\mathrm{C}_{12} / \mathrm{Pe}$ gels.

Figure 7.4 shows the change in fiber width as a function of the dye component loading in the gel. It is seen that with the addition of Pc in the gel, the width of the fibers increases exponentially with concentration and tends to level off between 5 and 10 wt $\%$ Pc loadings. This indicates the possibility of $\mathrm{Pc}$ being incorporated within the hollow $\mathrm{C}_{12}$ fibers. A different trend is seen with regard to the change in the fiber dimensions of $\mathrm{C}_{12} / \mathrm{Pe}$ gels. Even at $1 \mathrm{wt} \%$ Pe loading, the width of the fiber increased significantly and reached the plateau level. Further addition of Pe did not significantly change the width of the fiber. This observation raises a question as to whether or not the Pe molecules are entrapped within the $\mathrm{C}_{12}$ gel fibers. This was resolved by studying the SEM images.

Figure 7.5 shows the SEM images of neat $C_{12}$ xerogels. It is seen that $C_{12}$ molecules form thin sheets that wrap into hollow fibers, as reported previously. ${ }^{18}$ In the case of quenched gels the wrapping of the sheets are not complete (Figure 7.5a), but for slowcooled gels the sheets completed the wrapping to form hollow tubes (Figure 7.5b). 


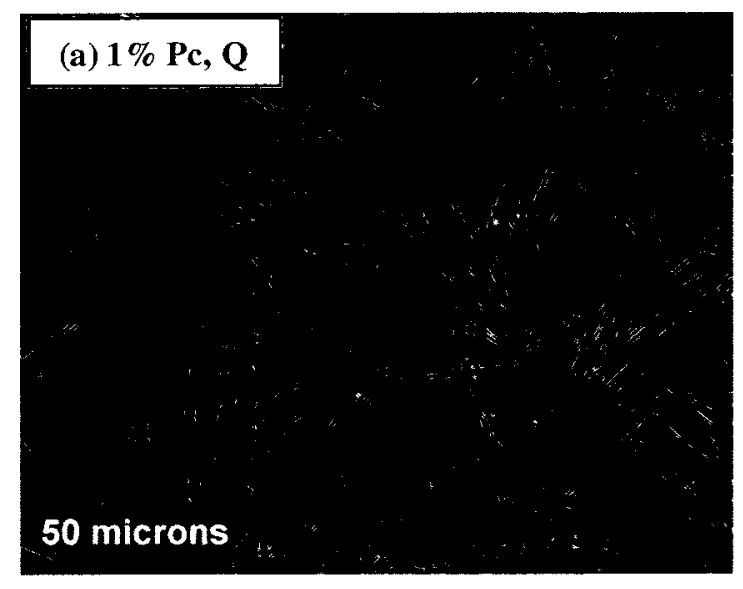

(b) $2 \% \mathrm{Pc}, \mathrm{Q}$

\section{(c) $1 \% \mathrm{Pc}, \mathrm{SC}$}

50 microns

(d) $2 \% \mathrm{Pc}, \mathrm{SC}$

50 microns

(e) $5 \% \mathrm{Pc}, \mathrm{SC}$
50 microns

\section{(f) $10 \% \mathrm{Pc}, \mathrm{SC}$}

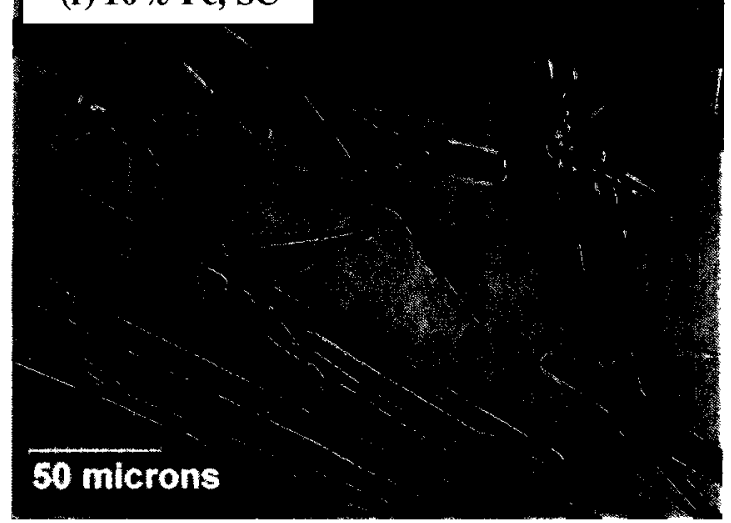

50 microns

\section{0 microns}
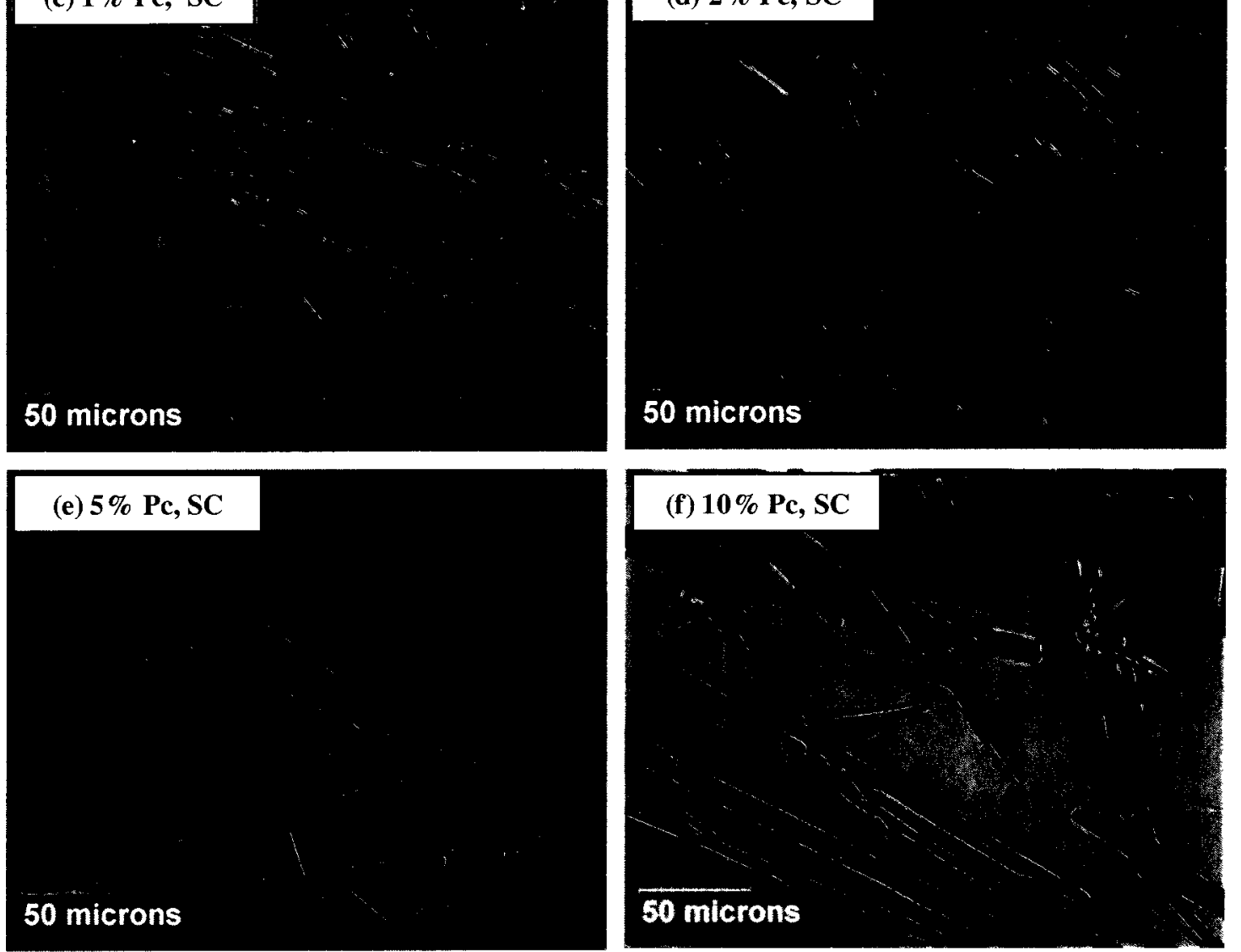

Figure 7.3. Optical micrographs of $\mathrm{C}_{12} / \mathrm{Pc}$ gels with different compositions and conditions: (a) $1 \mathrm{wt} \% \mathrm{Pc}$, quenched; (b) $2 \mathrm{wt} \%$ Pc, quenched; (c) $1 \mathrm{wt} \% \mathrm{Pc}$, slow-cooled; (d) $2 \mathrm{wt} \%$ Pc, slow-cooled; (e) $5 \mathrm{wt} \%$ Pc, slow-cooled; (f) $10 \mathrm{wt} \%$ Pc, slow-cooled. 


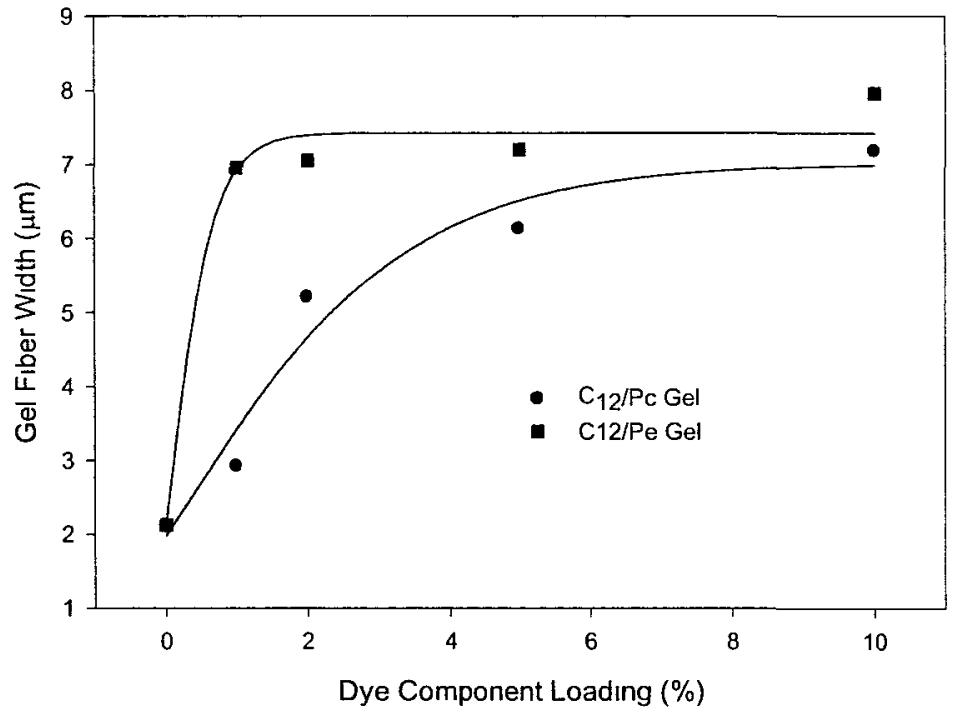

Figure 7.4. Change in the width of the gel fibers as a function of the dye component loading.
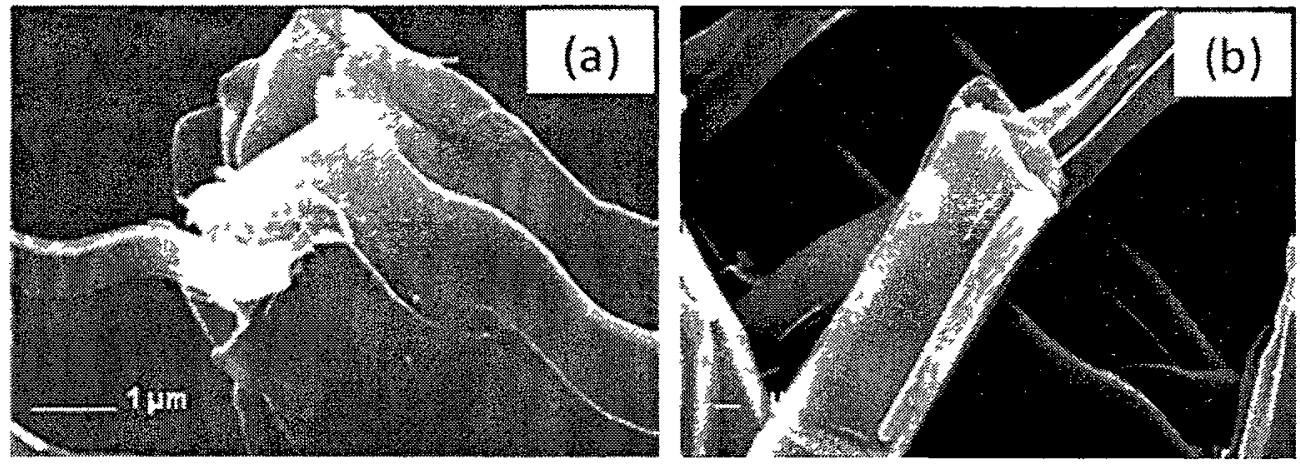

Figure 7.5. $\mathrm{C}_{12}$ biscarbamate gels: (a) quenched and (b) slow-cooled samples.

Figure 7.6 shows the morphology of the fibers in the two-component $\mathrm{C}_{12} / \mathrm{Pc}$ and $\mathrm{C}_{12} / \mathrm{Pe}$ gels. When Pc is added to $\mathrm{C}_{12}$, we see a different morphology in which most of the fibers are not hollow but filled with the second component, namely, Pc (Figure 7.6a-d). The Pc crystals deposit themselves onto the gel sheets and as the sheets wrap into tubes they become encapsulated, as shown in Scheme 7.2. 

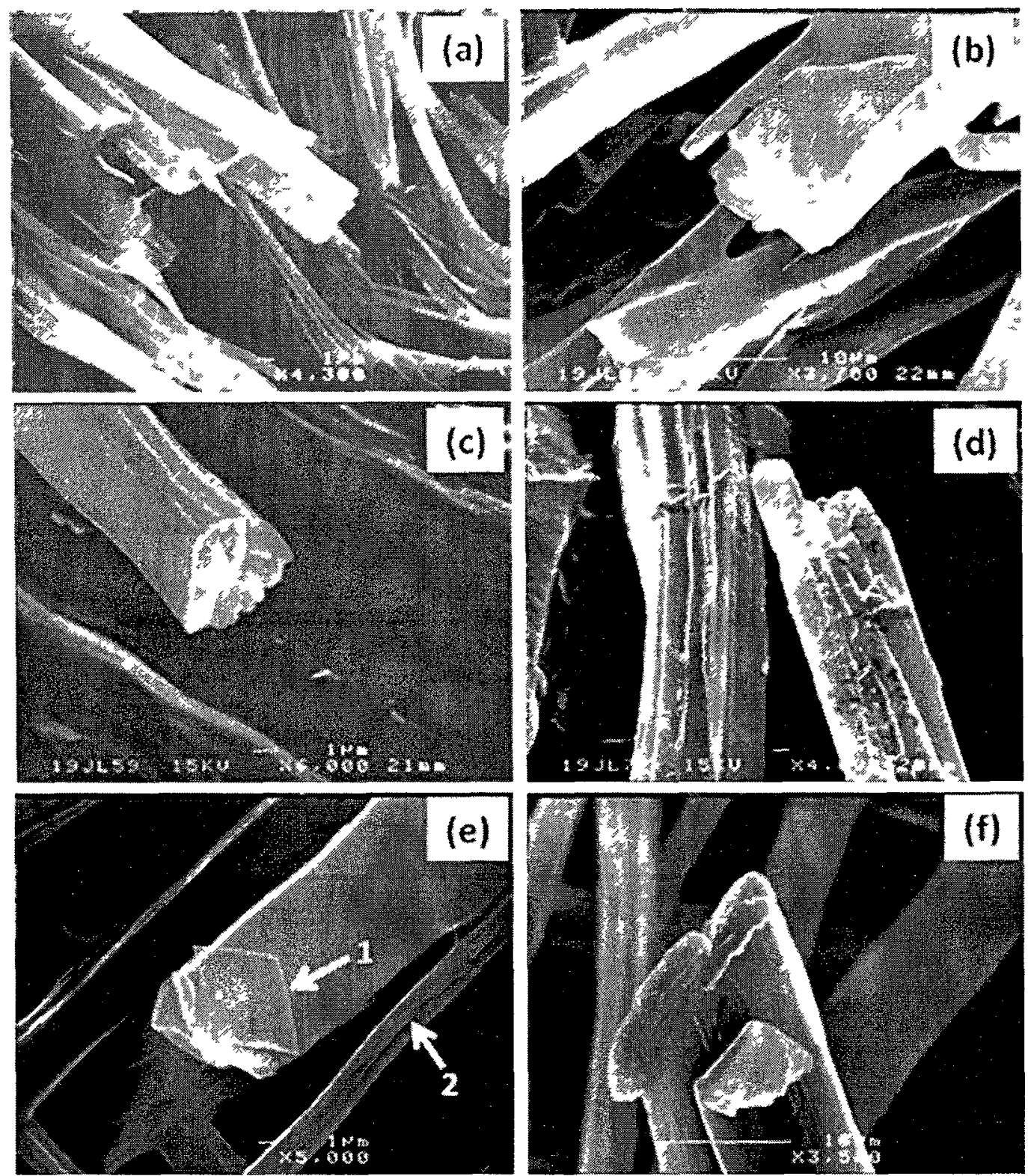

Figure 7.6. SEM images of slow-cooled xerogels: (a) $\mathrm{C}_{12} / 1 \mathrm{wt} \% \mathrm{Pc}$; (b) $\mathrm{C}_{12} / 2 \mathrm{wt} \% \mathrm{Pc}$; (c) $\mathrm{C}_{12} / 5 \% \mathrm{Pc}$, (d) $\mathrm{C}_{12} / 10 \% \mathrm{Pc}$, (e) and $\mathrm{C}_{12} / 1 \% \mathrm{Pe}$. The arrow 1 in panel e indicates a well formed Pe crystal on the outer surface of the gel fiber. Arrow 2 shows the slit of a tubular fiber. 


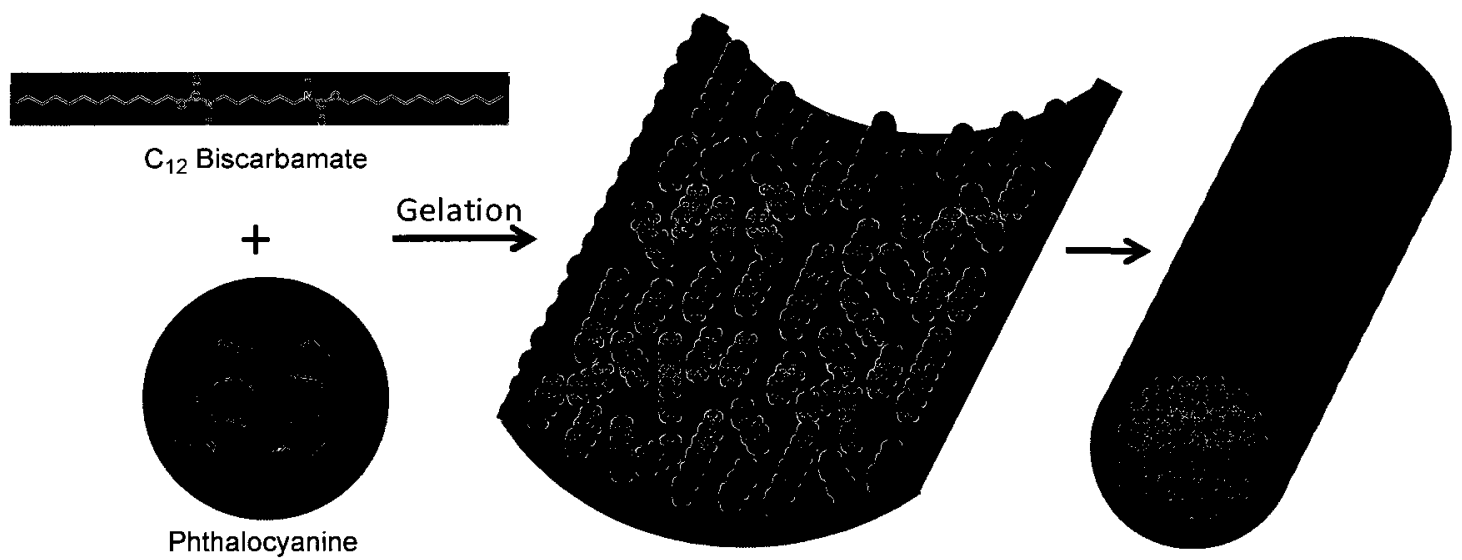

Scheme 7.2. Proposed model for the encapsulation of phthalocyanine in the hollow tubes of biscarbamate gels.

On the other hand, the $\mathrm{C}_{12} / \mathrm{Pe}$ gels show both hollow and flat fibers on addition of Pe (Figure 7.6 e). It appears that Pe molecules are not encapsulated within the fibers; rather they tend to crystallize outside the fibers (Figure 7.6e). This hinders the flat sheets of $\mathrm{C}_{12}$ (arrow1 in Figure 7.6e) from wrapping into tubes and leads to a flattened growth of the $\mathrm{C}_{12}$ fibers with the growth of the Pe crystals (see also Figure 7.6f). This might be the reason for the sudden increase in the average width of the $\mathrm{C}_{12} / \mathrm{Pe}$ gel fibers seen in Figure 7.4. The fibers without Pe crystals on the surface are hollow (arrow 2 in Figure 7.6e). This difference in morphology can be attributed to difference in the crystal-growth kinetics of $\mathrm{Pc}$ and $\mathrm{Pe}$ with respect to the gelation kinetics of $\mathrm{C}_{12}$, as discussed below.

Figure 7.7 shows SEM images of SNP-loaded slow-cooled gels of $\mathrm{C}_{12}$. It is seen that the morphology of these gel fibers is also different from that of the neat $C_{12}$ gel fibers. Most of the fibers are solid-filled with SNPs. The nanometer sized individual particles or even the aggregates of the nanoparticles cannot completely fill the micrometer-sized lumens of the tubes. 

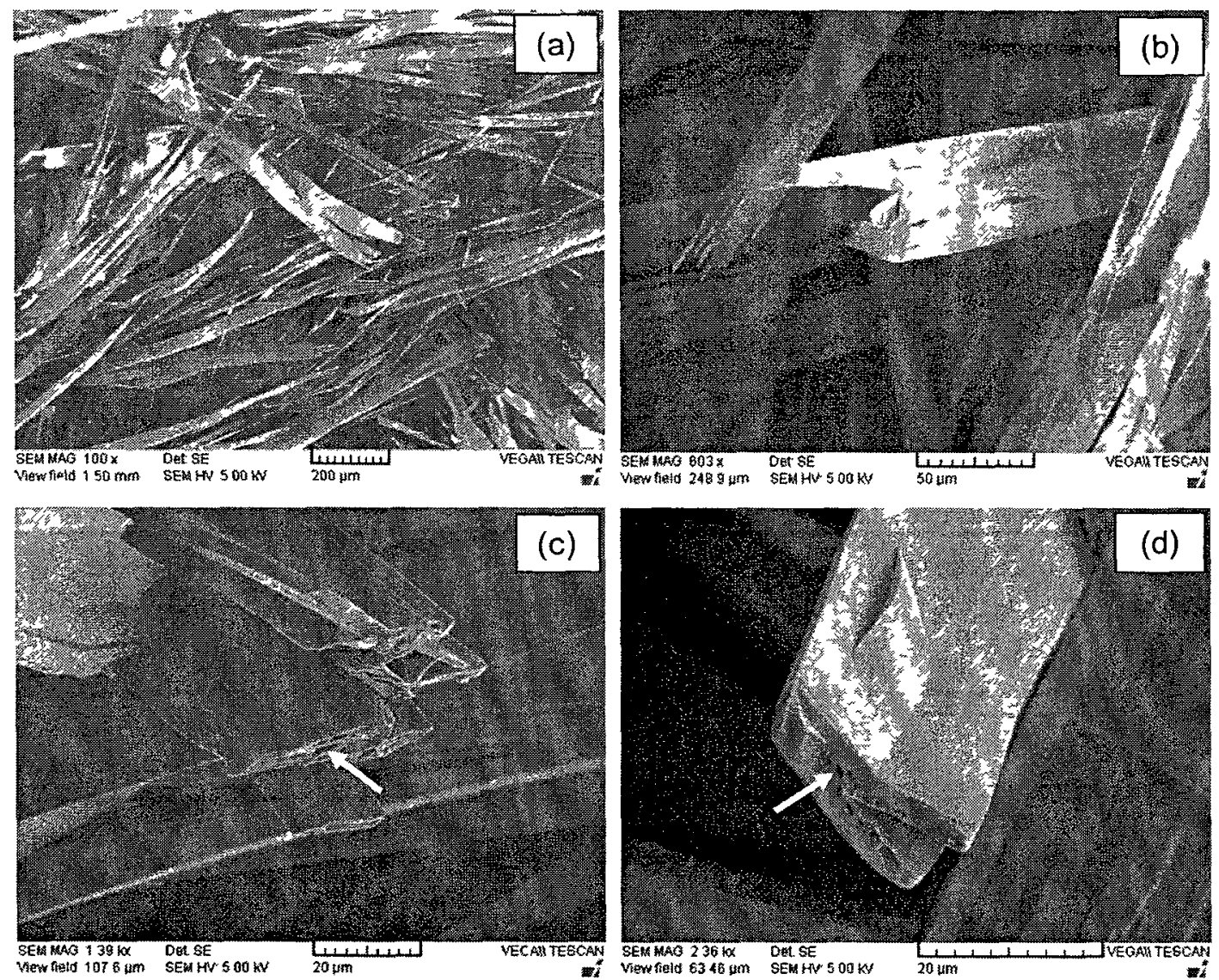

Figure 7.7. SEM images of SNP-loaded xerogel of $\mathrm{C}_{12}$ biscarbamate at different magnifications. The smooth surfaces of the fibers clearly indicate the absence of aggregation of the nanoparticles on the outer surface of the fibers. The arrows in (c) and (d) indicate pores in the SNP-filled solid fibers, which are remnants of the lumen of the hollow tubes.

Therefore, we see a few small pores, indicated by the arrows in Figures $7.7 \mathrm{c}$ and d, as remnants of the lumen of the tubes. Close study of these images reveals the smooth outer surfaces of the gel fibers and the absence of any aggregation of the nanopartıcles on the outer surfaces of the fibers. Partial melting experiments with hot-stage optical microscopy further confirmed these obsevations. 


\subsubsection{Gelation versus Crystallization Kinetics}

The SEM observations described above show that Pc was occluded in the gel fibers whereas Pe was not. This is attributed to the differences in the crystal-growth kinetics and morphology of Pc and Pe under the gelation conditions. During gelation, it was seen that complete immobilization of the solvent occurred within about $25 \mathrm{~min}$ for the neat $\mathrm{C}_{12}$ gel and for the $\mathrm{C}_{12} / \mathrm{Pc}$ or $\mathrm{C}_{12} / \mathrm{Pe}$ gels.
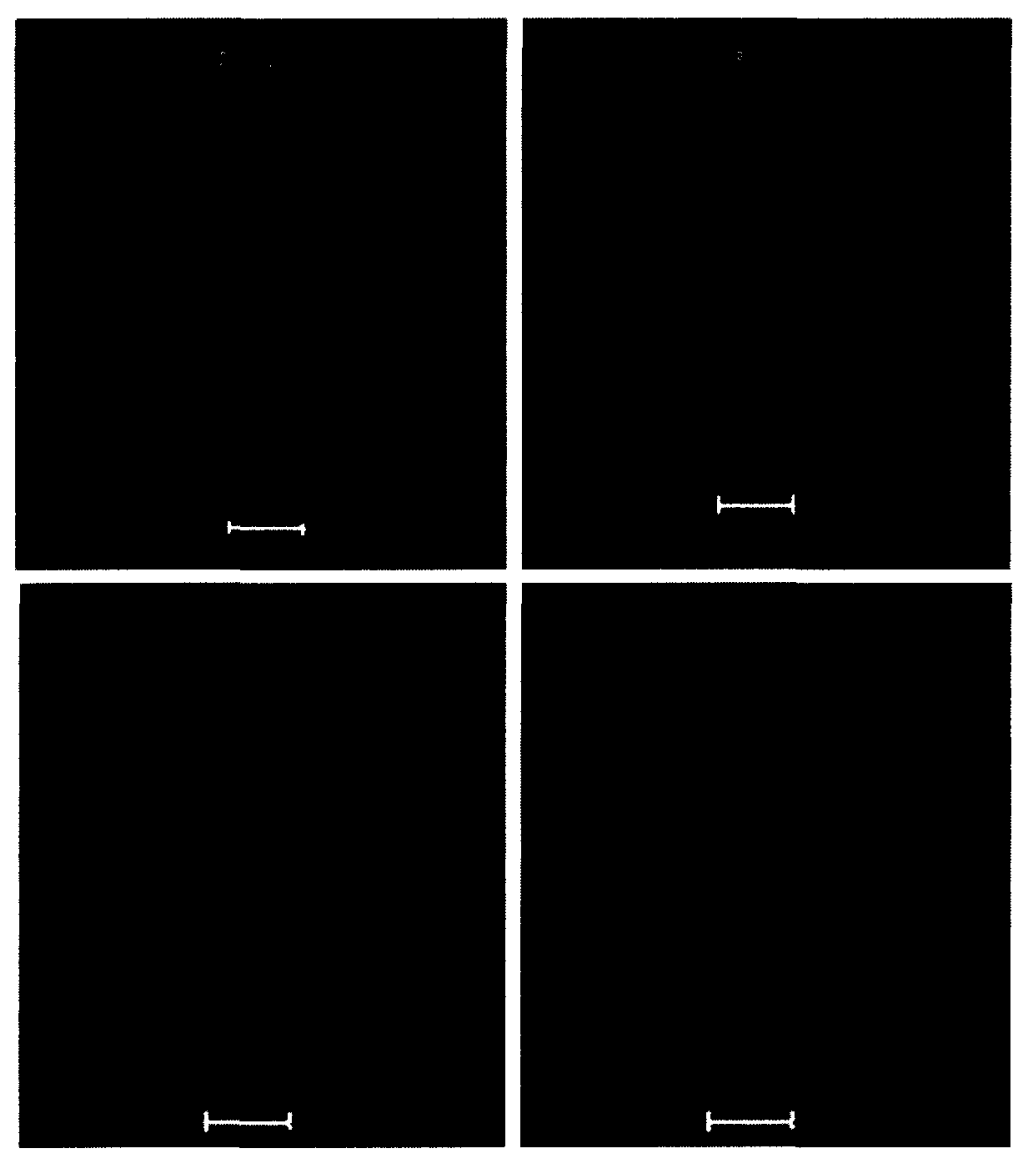

Figure 7.8. Optical micrographs showing isothermal crystal growth of $\mathrm{Pc}$ at $63{ }^{\circ} \mathrm{C}$ in benzonitrile as a function of time. Scale bars $20 \mu \mathrm{m}$.

To compare the crystallization kinetics of $\mathrm{Pc}$ and $\mathrm{Pe}$ with the gelation of these two component gels in benzonitrile, we studied the isothermal crystal-growth kinetics by using an optical microscope equipped with a hot stage. Figures 7.8 and 7.9 show the 
micrographs recorded at different times during the crystallization of $\mathrm{Pc}$ and $\mathrm{Pe}$, respectively, from corresponding sols of the same concentration used to prepare the gels.
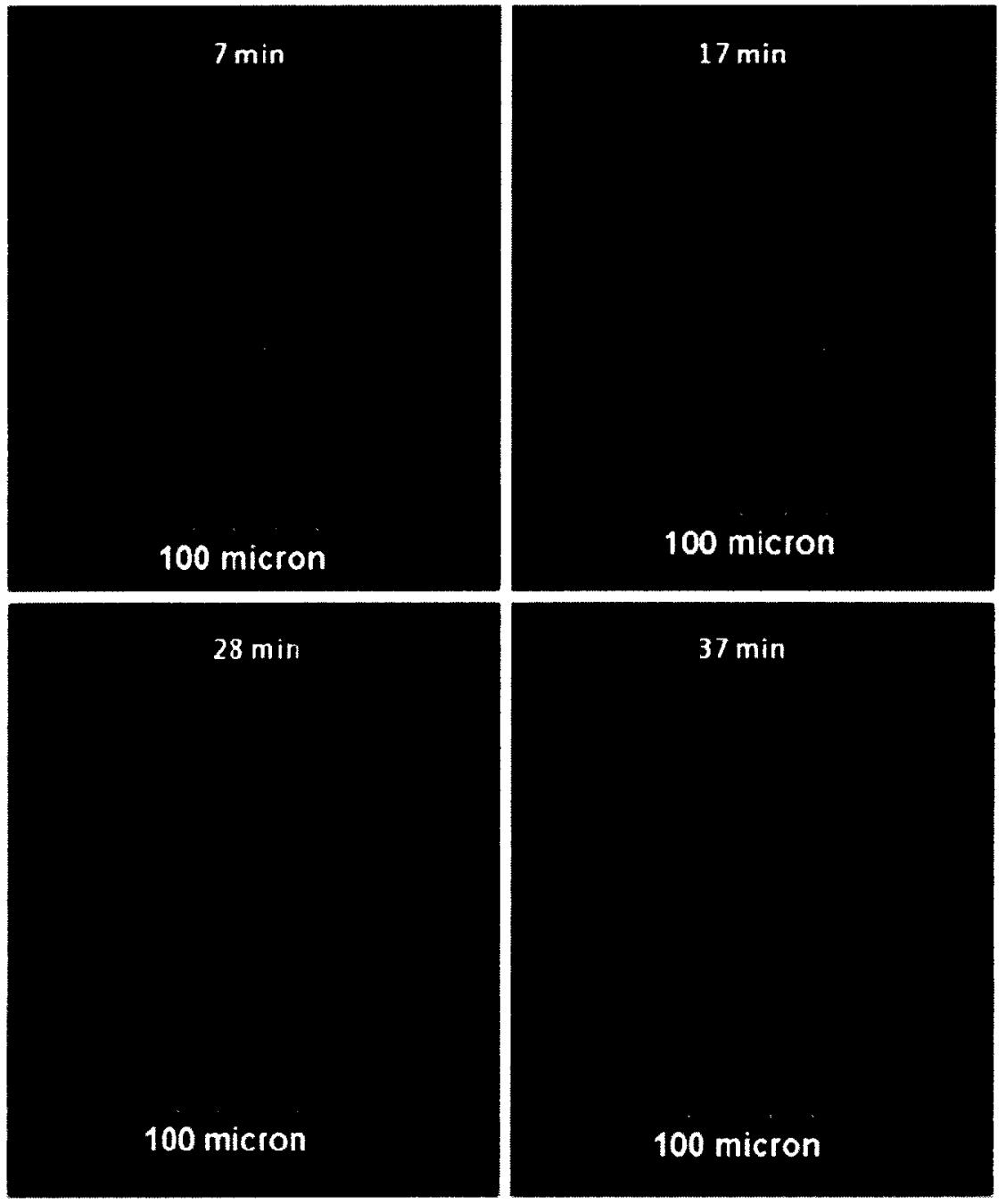

Figure 7.9. Optical micrographs showing isothermal crystal growth of $P e$ at $63{ }^{\circ} \mathrm{C}$ in benzonitrile as a function of time.

It is seen from Figure 7.8 that Pc crystallizes in needle shapes of about $35 \mu \mathrm{m}$ in length and a few micrometers in width. On the other hand, Pe forms almost square-shaped crystals with diagonal length of around $105 \mu \mathrm{m}$ (Figure 7.9). Plots of the linear (Pc) and 
diagonal $(\mathrm{Pe})$ lengths of the growing crystals with time are shown in Figure 7.10. It is seen that crystallization of both Pc and Pe initially occurs almost linearly as a function of time. It is evident that the initial growth rate of Pc crystals is comparable to that of the $\mathrm{C}_{12}$ fibers in the gel. The favorable needle-like geometry and a width of a few micrometers, which is well below the internal diameter of the $C_{12}$ fibers, leads to encapsulation of the $\mathrm{Pc}$ crystals by the hollow fibers of $\mathrm{C}_{12}$ during the gelation process. On the other hand, the initial growth rate of Pe crystals is greater than that of the $\mathrm{C}_{12}$ fiber formation. Moreover, the $\mathrm{Pe}$ crystal dimension exceeds the interior diameter of the $\mathrm{C}_{12}$ fibers within about $15 \mathrm{~min}$, which is earlier than the commencement of the formation of the gel fibers and thus rules out the possibility of the encapsulation of Pe crystals within the fibers. This argument was further confirmed by partial melting of the $\mathrm{C}_{12} / \mathrm{Pc}$ and $\mathrm{C}_{12} / \mathrm{Pe}$ xerogels.

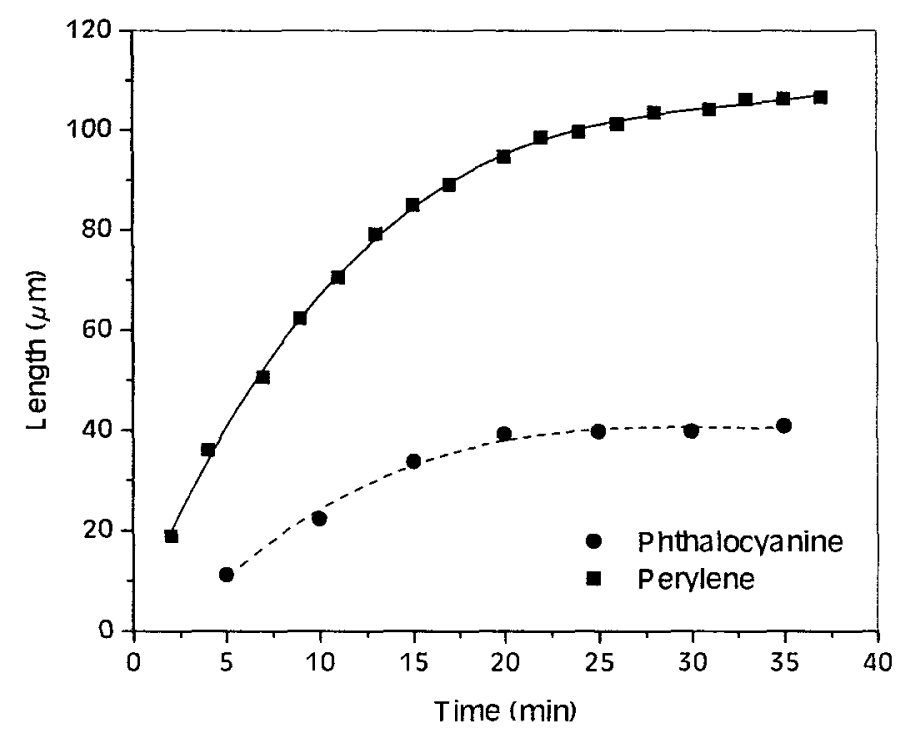

Figure 7.10. Isothermal growth of $\mathrm{Pe}$ and $\mathrm{Pc}$ crystals in benzonitrile as a function of time. 


\subsubsection{Partial Melting of the Xerogels}

Pc and Pe melt at 230 and $280^{\circ} \mathrm{C}$, respectively, whereas the melting temperature of neat $\mathrm{C}_{12}$ is only $115{ }^{\circ} \mathrm{C}$. This large difference in the melting temperatures of the components of the gels was exploited in the partial melting experiment to confirm the incorporation of the Pc and Pe molecules into the hollow tubes.
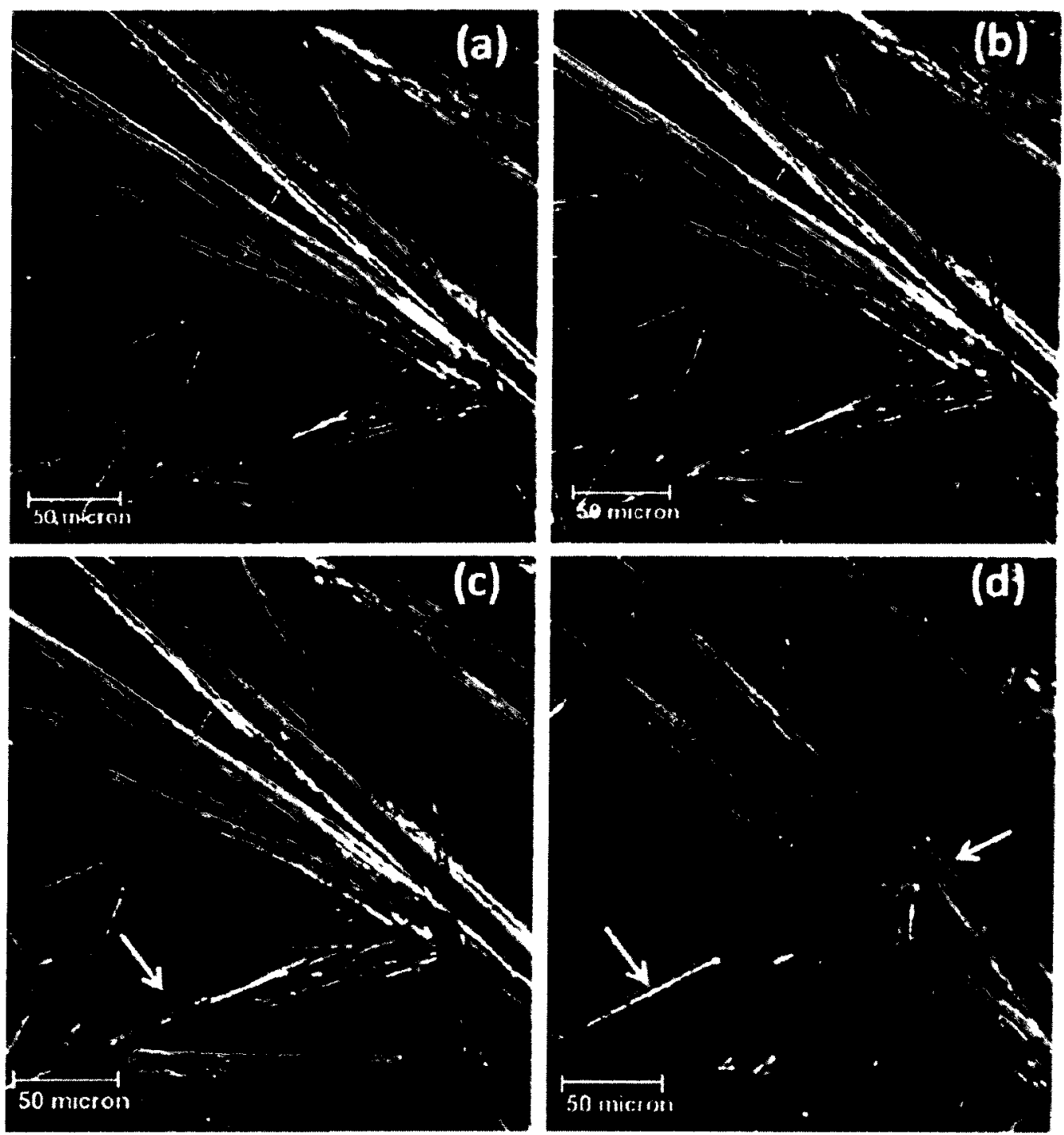

Figure 7.11. Optical micrographs of slow-cooled $\mathrm{C}_{12} / \mathrm{Pc}$ gel at different temperatures of (a) 25 , (b) 97 , (c) 100 , and (d) $108{ }^{\circ} \mathrm{C}$, showing the Pc crystal inside the $\mathrm{C}_{12}$ fibers of the gel. The white arrows show the Pc crystals before and after melting the fibers. The purple arrows in (d) show the coaxially aligned globular aggregates of the Pc molecules floating in the $\mathrm{C}_{12}$ melt. 

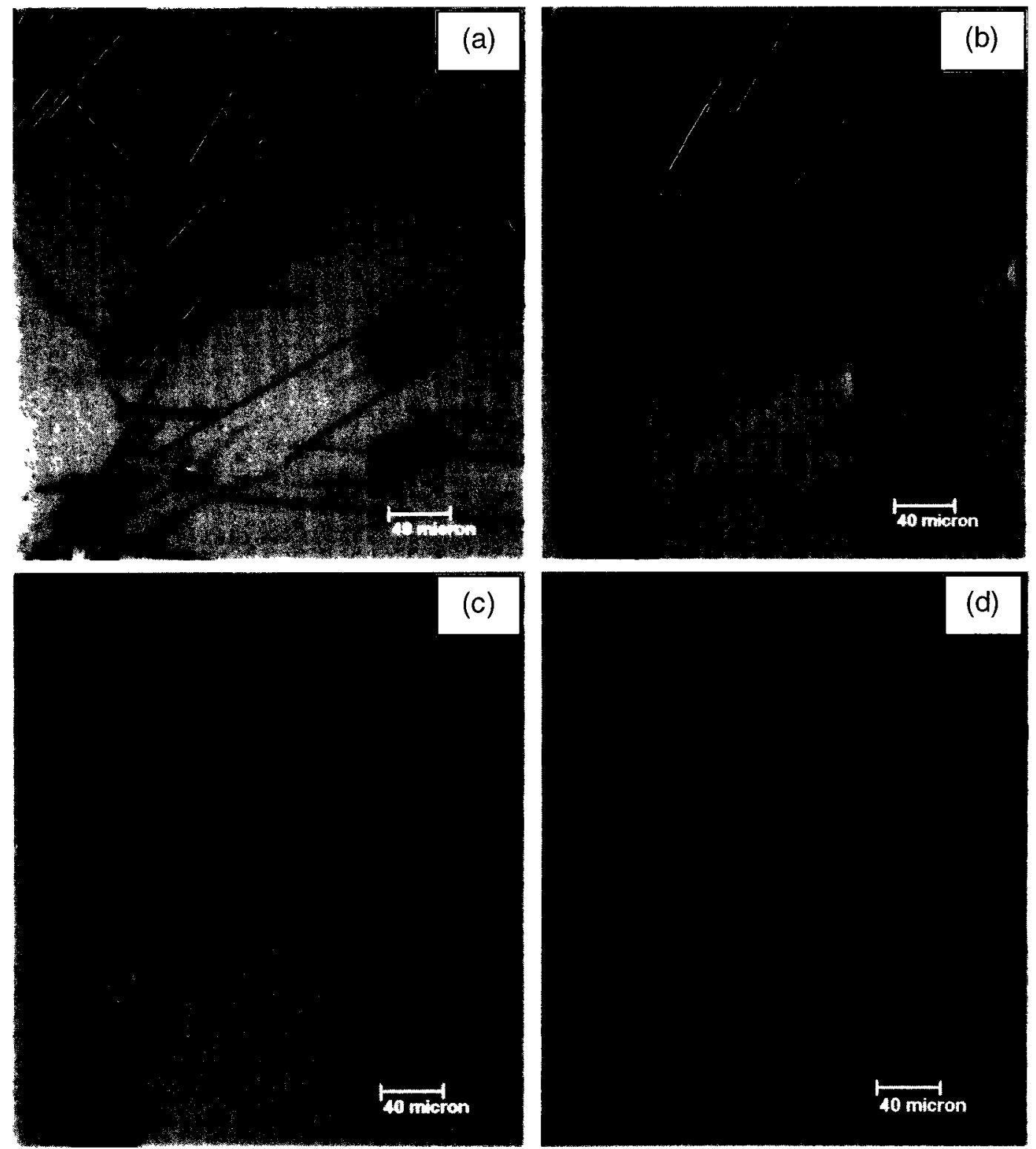

Figure 7.12. Optical micrographs of slow-cooled $\mathrm{C}_{12} / \mathrm{Pe}$ gel at different temperatures of (a) 25 , (b) 97 , (c) 108 , and (d) $255^{\circ} \mathrm{C}$, showing the Pe crystal outside the $\mathrm{C}_{12}$ fibers of the gel.

It was seen that in the xerogel the components mutually plasticize each other and thus reduce their melting temperature significantly (about 5,22 , and $30^{\circ} \mathrm{C}$ for $\mathrm{C}_{12}, \mathrm{Pc}$, and $\mathrm{Pe}$, respectively). We partially melted the xerogel at different temperatures above the melting 
temperature of the lowest melting component, $\mathrm{C}_{12}$, by using the Linkam hot stage described in the Experiment Section. Figures 7.11 and 7.12 show the micrographs recorded at different temperatures from this experiment with $\mathrm{C}_{12} / \mathrm{Pc}$ and $\mathrm{C}_{12} / \mathrm{Pe}$ gels. It is seen from Figure 7.11 that Pc forms crystals longitudinally along the axis of the gel fibers. When the $C_{12}$ fibers are completely molten, the Pc crystals are seen as remnants of the fibers that, along with the solid fibrous morphology depicted in the SEM images (Figure 7.6), clearly indicate the inclusion of Pc molecules within the hollow fibers of $\mathrm{C}_{12}$. Contrary to this observation, we see a sort of epitaxial growth of Pe crystal at the outer surface of the $C_{12}$ fibers (Figure 7.12). After melting the $C_{12}$ at a temperature above its melting point, we see the presence of the Pe crystals. This observation clearly proves that the Pe molecules are not encapsulated within the hollow fibers of $C_{12}$ in the gels but form crystals outside the fibers. Figure 7.13 shows optical micrographs from similar partial melting experiments with the SNP-loaded $C_{12}$ xerogels. Figure 7.13 a shows the smooth outer surface of a free-standing gel fiber at room temperature and clearly indicates the absence of nanoparticle aggregation on the surface. After partially melting the fiber of $\mathrm{C}_{12}$, we see a coaxial array of nanoparticles both at the edges and the centre of tubes in Figures $7.13 \mathrm{~b}$ and $c$. The nanoparticles remain exposed even after the crystallization of the melt by cooling down to the room temperature, as shown in Figure 7.13d. These observations clearly prove the inclusion of the nanoparticles into the hollow gel fibers. 

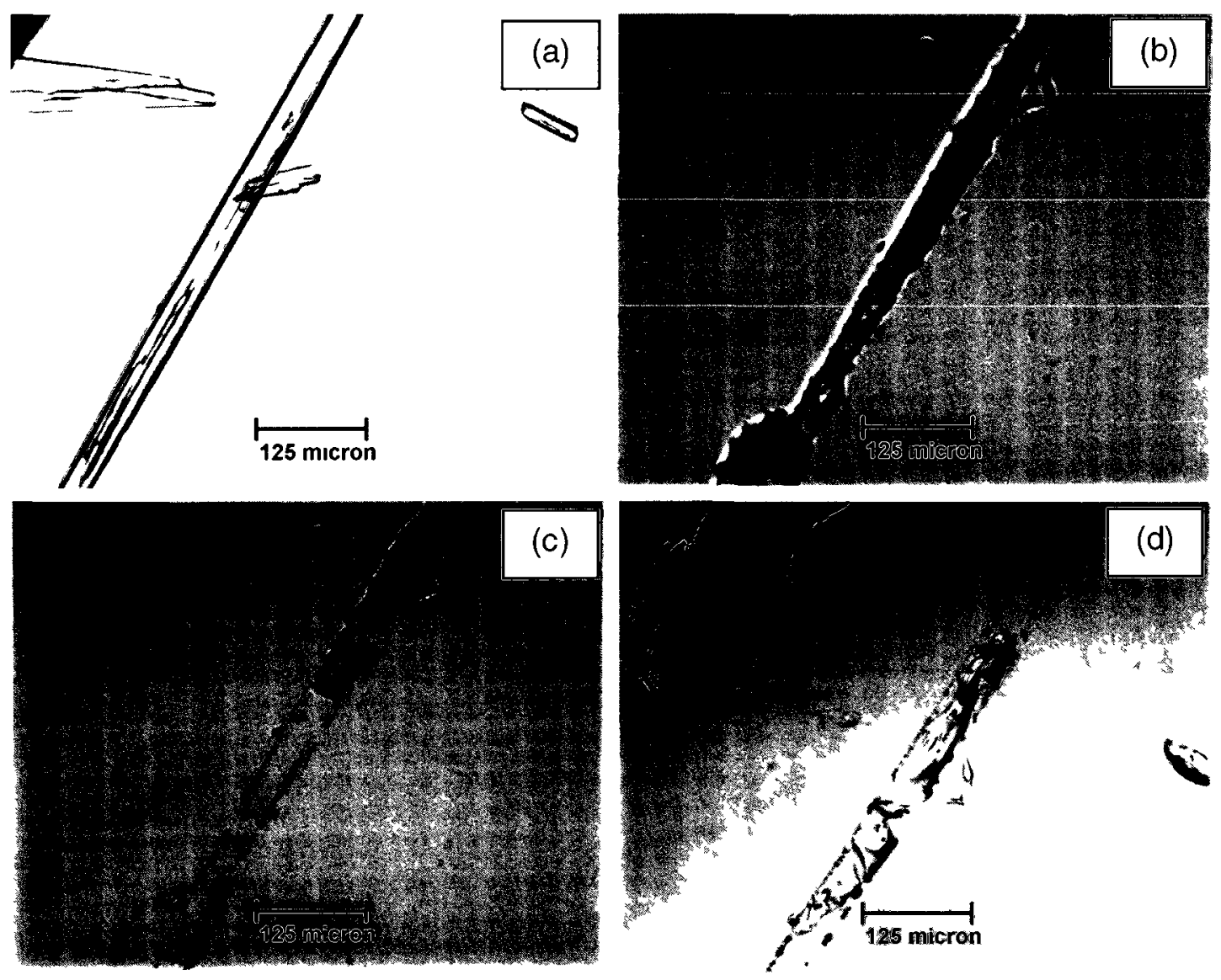

Figure 7.13. Optical micrographs of SNP-loaded $\mathrm{C}_{12}$ biscarbamate gel at different temperatures of (a) 25 , (b) 115.8 , (c) $116^{\circ} \mathrm{C}$, and (d) $25^{\circ} \mathrm{C}$ after cooling.

\subsubsection{X-ray Diffraction}

$\mathrm{X}$-ray diffraction traces of neat components and their organogels and xerogels are shown in Figure 7.14. All the gels show a series of intense reflections in the $2 \theta \sim 20$ to $25^{\circ}$ range, which indicates the layered structure of the molecules in the gel fibers. Figure 7.14a shows the XRD patterns of the $C_{12}$ biscarbamate in both its powder and xerogel forms. The peaks of $C_{12}$ biscarbamate with $d$-spacings of 4.6 and $3.8 \AA$ were assigned to the distance between the hydrogen-bonding molecules in a plane and the distance between these planes in the bulk crystals, respectively. ${ }^{34}$ 

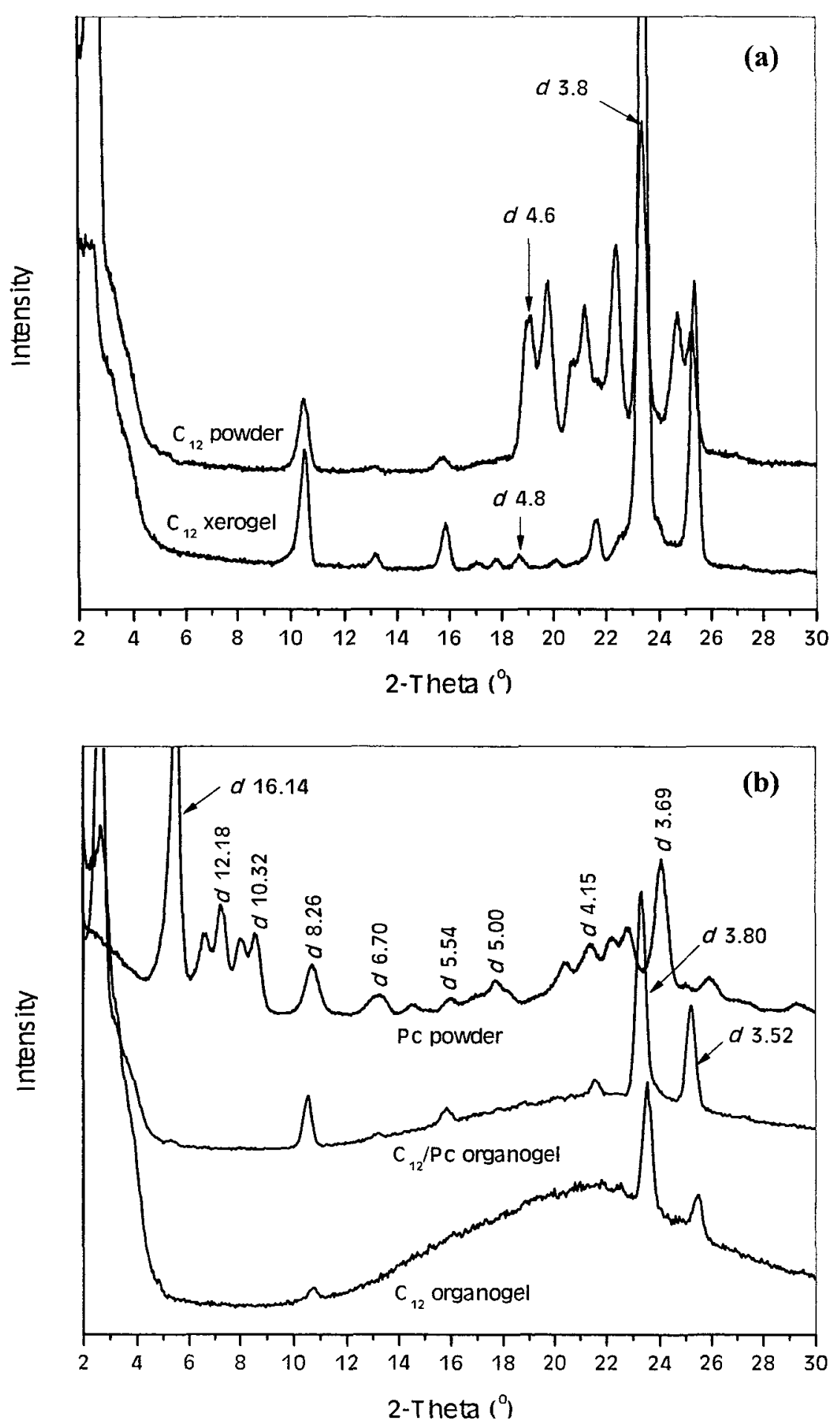

Figure 7.14. X-ray diffraction patterns of (a) $\mathrm{C}_{12}$ biscarbamate in powder and xerogel form, and (b) $\mathrm{C}_{12}$ organogel, $\mathrm{C}_{12} / \mathrm{Pc}$ two-component organogel, and neat Pc. The $d$ spacing values are in $\AA$. 
In the xerogel, the reflection at $d=3.8 \AA$ appears at the same position compared to that of the powder form. The full width at half maxima and thus the crystallite size corresponding to this reflection remains essentially the same. But the reflection at $d=4.6$ $\AA$ becomes less intense and shifted to about $4.8 \AA$. We attribute the reduction in intensity of several reflections to the wrapping of the fibers into tubes and the resultant nonuniformity in the sample exposed to the X-ray beam. This is in contrast to our previous observations with the xerogels of monocarbamates, ${ }^{17}$ in which the X-ray diffraction remained the same for the powder and xerogel forms. No wrapping was observed in that case.

XRD traces of $\mathrm{C}_{12}$ organogel (not dry), neat $\mathrm{Pc}$, and the $\mathrm{C}_{12} / 10 \mathrm{wt} \% \mathrm{Pc}$ twocomponent organogel are shown in Figure $7.14 \mathrm{~b}$. The crystal structures of both the metalfree and the $\mathrm{Cu}$ derivative of the octabutyl Pc are known. ${ }^{37,38}$ The former crystallizes in the triclinic form and the latter in the monoclinic form. In both cases, the closest face-toface packing distance is $3.57 \AA$, and the centre-to-centre distance is $8.14 \AA$. The peaks in the XRD trace for neat Pc with $d$-spacings of 3.69 and $8.26 \AA$ correspond to these distances. In the XRD pattern for the two-component gel, these peaks are present, although at 3.52 and $8.26 \AA$. The peaks at $2 \theta=21.6(d=4.15 \AA), 15.9(d=5.54 \AA)$, and $13.2(d=6.70 \AA)$ are derived from Pc and clearly indicates the presence of crystalline Pc in the $\mathrm{C}_{12} / \mathrm{Pc}$ organogel. Note that peaks corresponding to large $d$-spacings recorded for the $\mathrm{Pc}$ powder that would reflect the three-dimensional structure of $\mathrm{Pc}$, are absent in the XRD pattern for the $\mathrm{C}_{12} / \mathrm{Pc}$ gel. Thus, growth of the Pc crystals seems to be predominantly one-dimensional, similar to the growth of the gel fibers. Spectroscopic 
analysis was performed to further investigate the molecular packing through intermolecular interactions between molecules of same type versus different types in the gels.

\subsubsection{Spectroscopy}

$\mathrm{Pc}$ and Pe are intensely colored compounds with $\lambda_{\max }=773$ and $437 \mathrm{~nm}$, respectively, in benzonitrile.
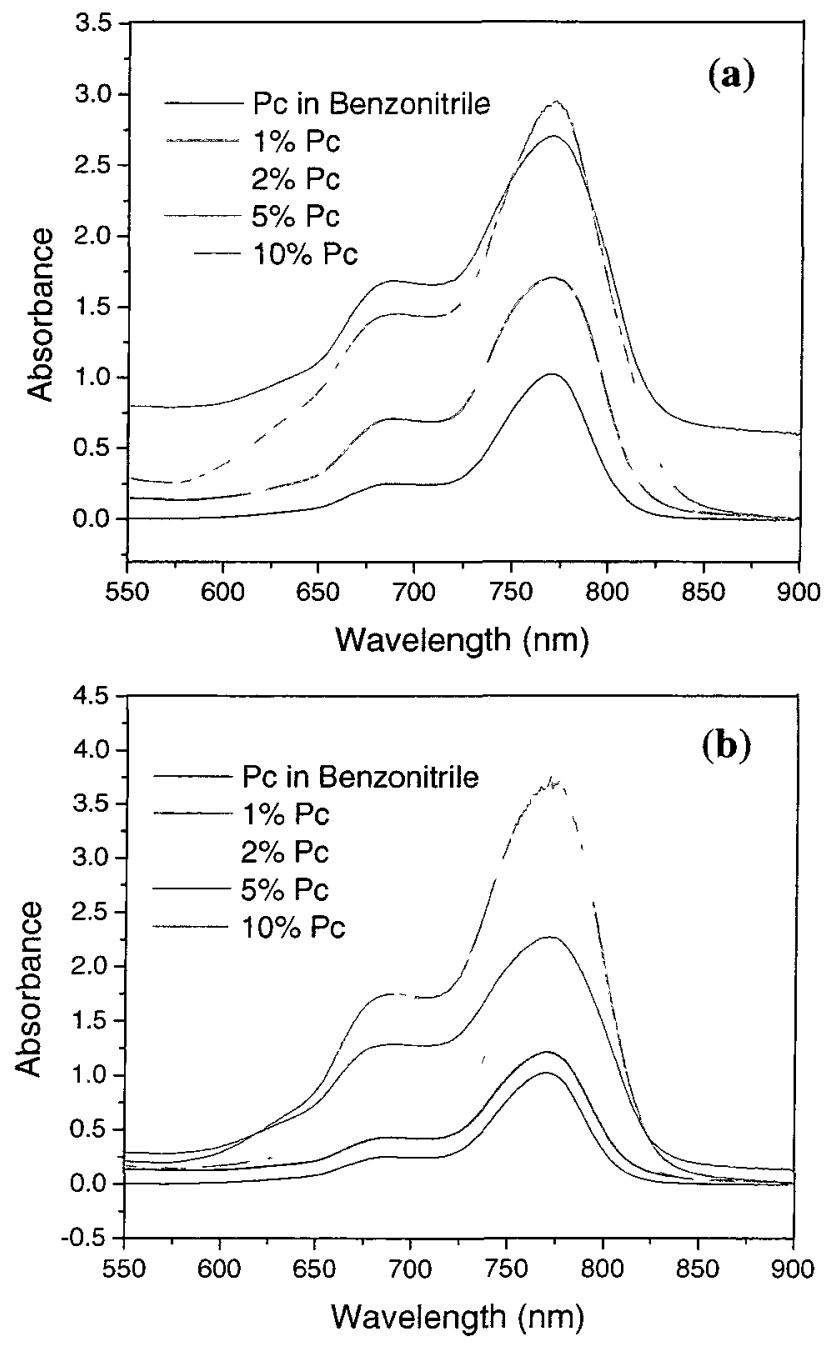

Figure 7.15. UV-visible spectra of $\mathrm{C}_{12} / \mathrm{Pc}$ gels: (a) quenched and (b) slow-cooled samples. 

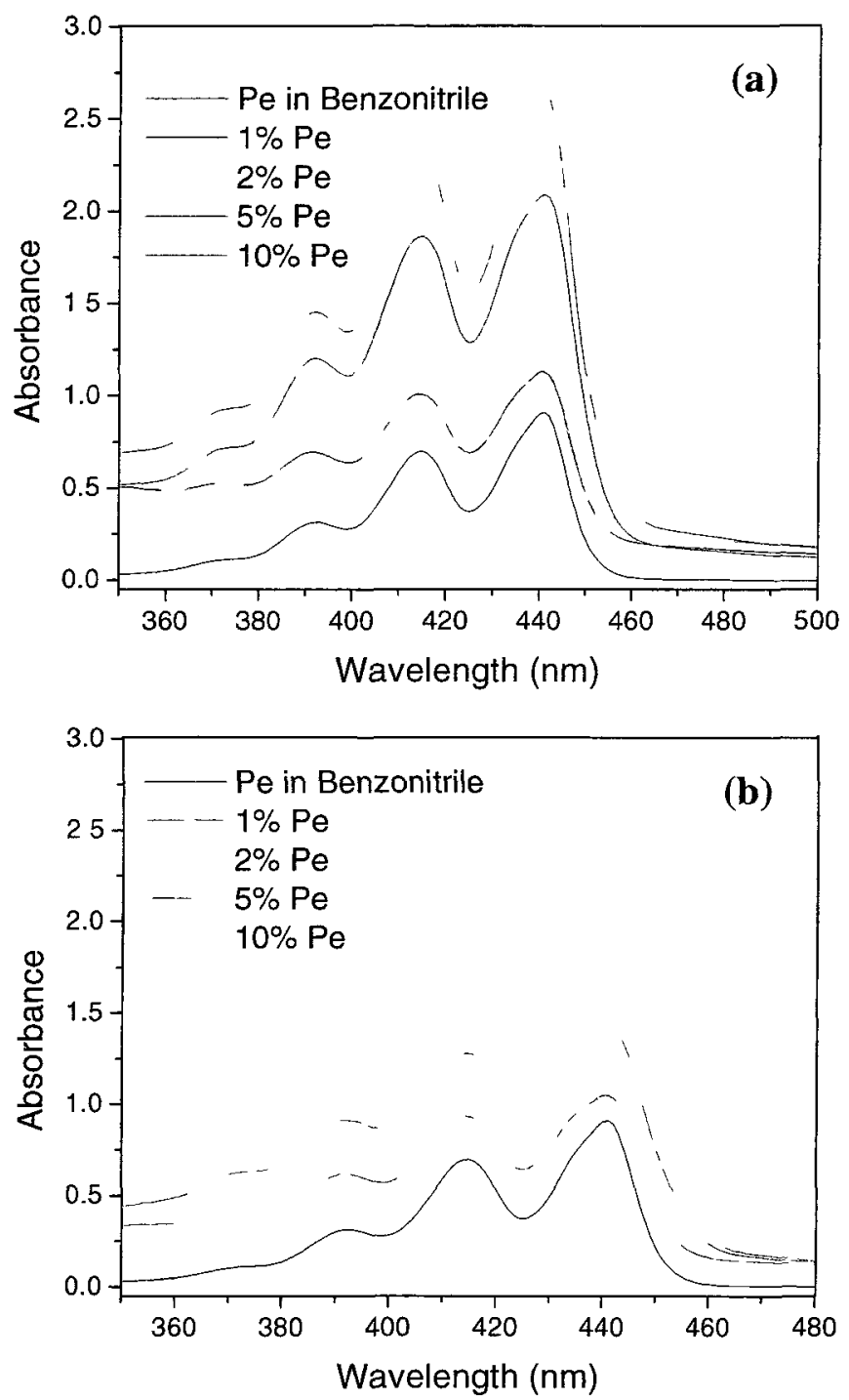

Figure 7.16: UV-visible spectra of $\mathrm{C}_{12} / \mathrm{Pe}$ gels: (a) quenched and (b) slow-cooled samples.

Figures 7.15 and 7.16 show the UV/Vis spectra of the $\mathrm{C}_{12} / \mathrm{Pc}$ and $\mathrm{C}_{12} / \mathrm{Pe}$ gels along with that of the neat $\mathrm{Pc}$ and $\mathrm{Pe}$ in benzonitrile. It is evident from the spectra that there is no shift in the absorption position of Pc in the gels compared to its absorption in the pure form. Neither the sample preparation protocol (i.e., quenching or slow cooling) nor the concentration of Pc has any influence on the absorption profile. There is simply an increase in the absorption intensity with the increase of concentration of $\mathrm{Pc}$ and $\mathrm{Pe}$ in the 
gels. This shows that the packing of the Pc molecules by themselves in benzonitrile and as a component in the gel is the same.

The modes of aggregation of $\mathrm{C}_{12}$ and $\mathrm{Pc}$ in the gel were further investigated by IR spectroscopy of the components. Figure 7.17 shows the IR spectra of $\mathrm{C}_{12}, \mathrm{Pc}$, and $\mathrm{C}_{12} / \mathrm{Pc}$ organogel. In the IR spectra of neat $\mathrm{C}_{12}$, absorption bands at $v=3320$ and $1683 \mathrm{~cm}^{-1}$ correspond to the hydrogen-bonded $\mathrm{N}-\mathrm{H}$ and $\mathrm{C}=\mathrm{O}$ groups, respectively. Appearance of the absorption bands essentially at the same frequencies and absence of free $\mathrm{N}-\mathrm{H}$ and $\mathrm{C}=\mathrm{O}$ bands in the IR spectra of the $\mathrm{C}_{12}$ gel clearly indicates the presence of the intermolecular hydrogen-bonding during their aggregation into a fibrillar structure in the gel. The presence of $\mathrm{C}_{12}$ and $\mathrm{Pc}$ in the two-component gels has no effect on either component's absorption frequencies in the IR spectra, which indicates self-sorting aggregation of the components in the gels. Therefore, this is an example of organic dye occluded two-component organogel.

\subsection{Conclusions}

Herein, we discussed a novel biscarbamate-based organogelator for benzonitrile doped with metal nanoparticles and organic dye molecules. These are examples of lumen-loaded organogel fibers. Our previous morphological studies ${ }^{18}$ showed that $\mathrm{C}_{12}$ biscarbamate gels benzonitrile at a nominal concentration of $0.08 \mathrm{M}$ with hollow fibrillar network morphology. Optical and scanning electron microscopy showed that $\mathrm{C}_{12}$ molecules form sheets that eventually wrap into hollow fibers to form the gel network. 

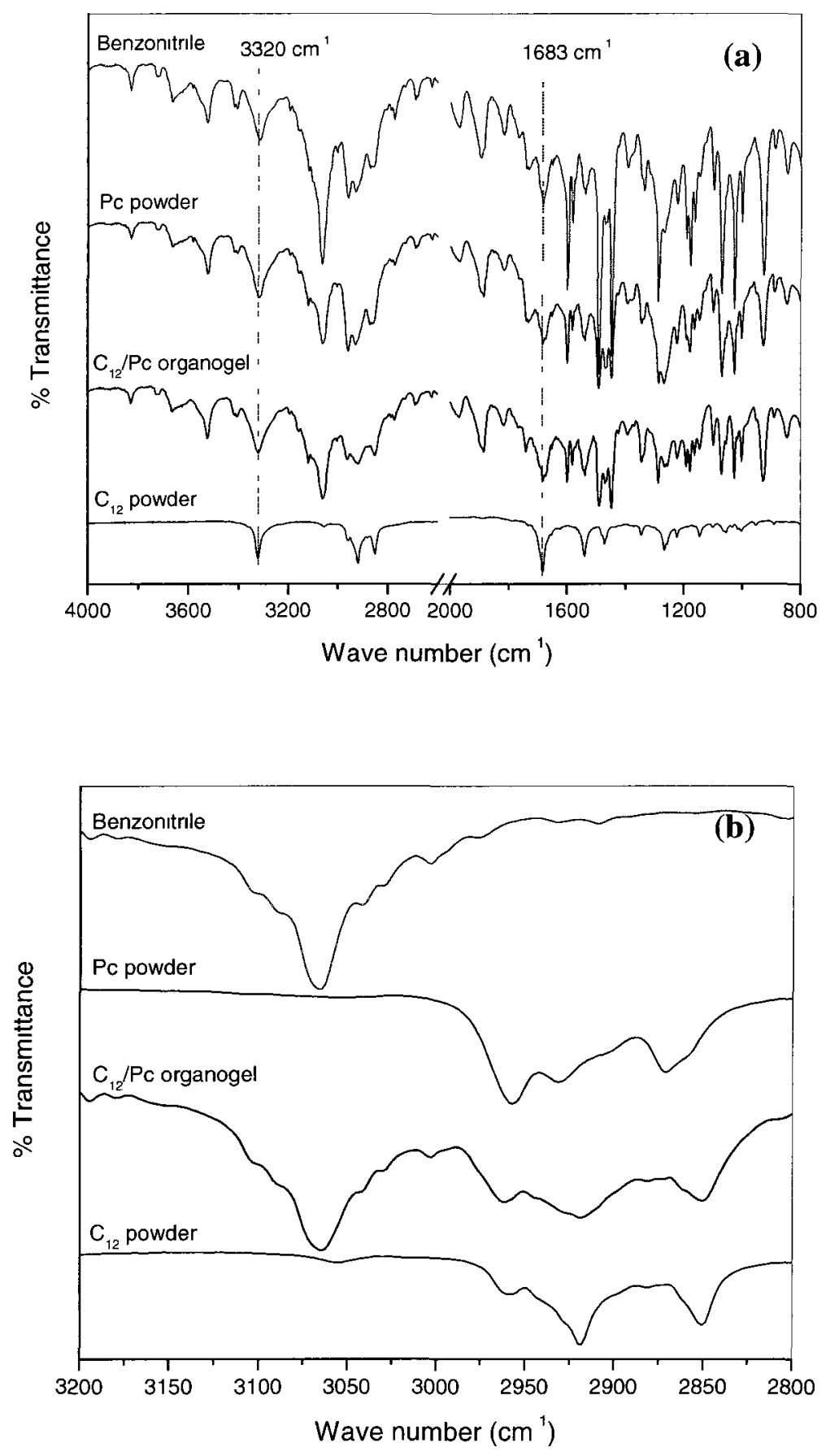

Figure 7.17. (a) FTIR spectra of $\mathrm{C}_{12}$ biscarbamate, $\mathrm{C}_{12} / \mathrm{Pc}$ organogel, neat $\mathrm{Pc}$, and benzonitrile (b) magnified view in the region $2800-3200 \mathrm{~cm}^{-1}$. 
Although chirality driven hollow tube formation is known, in the present case a nonchiral molecule forms hollow tubes, and this was previously rationalized ${ }^{18}$ as being due to the asymmetry of interactions between the molecules in the three directions. Herein, addition of PVP-coated silver nanoparticles during the gelation of $\mathrm{C}_{12}$ led to a different morphology of the gel, in which the nanoparticles deposited on the sheets and these sheets wrapped into SNP-loaded fibers. Likewise, lumen-loaded organogel fibers were prepared with Pc dye molecules with needle-like crystal growth inside the hollow fibers. Lastly, Pe molecules were found more prone to form crystals on the outer surface of the $\mathrm{C}_{12}$ fibers. This different behavior of Pc and Pe molecules is attributed to their crystal geometry and significantly different crystal-growth kinetics compared with that of $\mathrm{C}_{12}$ fiber formation in the gels. DSC analysis showed that $\mathrm{C}_{12}$ forms quite a stable gel with benzonitrile, and addition of Pc contributes more to the thermal stability of these gels than Pe. XRD and spectroscopic analysis showed that the hydrogen-bond mediated selfassembly of the $\mathrm{C}_{12}$ molecules and the packing behavior of the Pc and Pe molecules were not affected during the two-component gel formation. We find that for the dye molecule crystals to be occluded in the hollow gels, the growth rate of the crystals and the size and shape should be similar to those of the gel fibers. We have thus shown that lumen-loaded gel fibers (with nanoparticles and dye molecules) can be prepared by the two-component gel route, without any inter-molecular interaction in effect, provided that the abovementioned growth rate, shape, and size conditions are satisfied. 


\subsection{References}

1. (a) Yagai, S.; Nakajima, T.; Kishikawa, K.; Kohmoto, S.; Karatsu, T.; Kitamura, A. J. Am. Chem. Soc. 2005, 127, 11134; (b) Miljanić, S.; Frkanec, L.; Meić, Z.; Žinić, M. Langmuir 2005, 21, 2754.

2. Kawano, S.; Fujita, N.; Shinkai, S. Chem. Eur. J. 2005, $11,4735$.

3. (a) Liu, Q.; Wang, Y.; Li, W.; Wu, L. Langmuir 2007, 23, 8217; (b) Ahmed, S. A.; Sallenave, X.; Fages, F.; Mieden-Gundert, G.; Müller, W. M.; Müller, U.; Vögtle, F.; Pozzo, J-L. Langmuir 2002, 18, 7096.

4. Kim, H-J.; Lee, J-H.; Lee, M. Angew. Chem. Int. Ed. 2005, 44, 5810.

5. Wang, C.; Zhang, D.; Zhu, D. Langmuir 2007, 23, 1478.

6. de Jong, J. J. D.; Lucas, L. N.; Kellogg, R. M.; van Esch, J. H.; Feringa, B. L. Science, 2004, 304, 278.

7. (a) Vemula, P. K.; Li, J.; John, G. J. Am. Chem. Soc. 2006, 128, 8932; (b) Sato, T.; Uchida, R.; Tanigawa, H.; Uno, K.; Murakami, A. J. App. Pol. Sci., 2005, 98, 731;

(c) Vintiloiu, A.; Leroux, J. C. J. Control. Release, 2008, 125, 179.

8. (a) Ono, Y.; Nakashima, K.; Sano, M.; Hojob, J.; Shinkai, S. J. Mater. Chem., 2001, 11, 2412; (b) Llusar, M.; Monrós, G.; Roux, C.; Pozzo, J. L.; Sanchez, C. J. Mater. Chem., 2003, 13, 2505; (c) Llusar, M.; Sanchez, C. Chem. Mater. 2008, 20 , 782.

9. Mizrahi, S.; Gun, J.; Kipervaser, Z. G.; Lev, O. Anal. Chem. 2004, 76, 5399.

10. Mohmeyer, N.; Kuang, D.; Wang, P.; Schmidt, H-W.; Zakeeruddin, S. M.; Grätzel, M. J. Mater. Chem., 2006, 16, 2978. 
11. Suzuki, M.; Sato, T.; Kurose, A.; Shiraib, H.; Hanabusaa, K. Tetrahedron Letters $2005,46,2741$.

12. Tan, C.; Su, L.; Lu, R.; Xue, P.; Bao, C.; Liu, X.; Zhao, Y. J. Mol. Liq. 2006, 124, 32.

13. Su, L.; Bao, C.; Lu, R.; Chen, Y.; Xu, T.; Song, D.; Tan, C.; Shi, T.; Zhao, Y. Org. Biomol. Chem. 2006, 4, 2591.

14 Kiyonaka, S.; Sugiyasu, K.; Shinkai, S.; Hamachi, I. J. Am. Chem. Soc. 2002, 124, 10954.

15. Kiyonaka, S.; Shinkai, S.; Hamachi, I. Chem. Eur. J. 2003, 9, 976.

16. Smith, D. K. Adv. Mater. 2006, 18, 2773.

17. Moniruzzaman, M.; Sundararajan, P. R. Langmuir 2005, 21, 3802.

18. Khanna, S.; Khan, M. K.; Sundararajan, P. Langmuir 2009, 25, 13183.

19. Hanabusa, K.; Okui, K.; Karaki, K.; Koyama, T.; Shirai, H. J. Chem. Soc., Chem. Commun., 1992, 1371.

20. Gao, P.; Zhan, C.; Liu, M. Langmuir 2006, 22, 775.

21. Pham, Q. N.; Brosse, N.; Frochot, C.; Dumas, D.; Hocqueta, A.; Jamart-Gre'goire, B. New J. Chem., 2008, 32,1131.

22. Velázquez, D. G.; Díaz, D. D.; Ravelo, A. G.; Tellado, J. J. M. J. Am. Chem. Soc. 2008, 130,7967.

23. Lee, H. Y.; Nam, S. R.; Hong, J.-I. J. Am. Chem. Soc. 2007, 129, 1040.

24. (a) Han, W.; Kohler-Redlich, P.; Christina Scheu, C.; Ernst, F.; Ruhl, M.; Grobert, N.; Terrones, M.; Kroto, H. W.; Walton, D. R. M. Adv. Mater. 2000, 12, 1356; 
(b) Pham-Huu, C.; Keller, N.; Estournès, C.; Ehret, G.; Grenèche, J. M.; Ledoux, M. J. Phys. Chem. Chem. Phys. 2003, 5, 3716; (c) Bong, D. T.; Clark, T. D.; Granja, J. R.; Ghadiri, M. R. Angew. Chem., Int. Ed. 2001, 40, 989.

25. Zan, X.; Su, Z. Langmuir 2009, 25, 12355.

26. Pal, M.; Ganesan, V. Langmuir 2009, 25, 13264.

27. Kato, T. Science, 2002, 295, 2414.

28. Maitra, U.; Mukhopadhyay, S.; Sarkar, A.; Rao, P.; Indi, S. S. Angew. Chem. Int. Ed. 2001, 40, 2281.

29. Kato, T.; Hirai, Y.; Nakaso, S.; Moriyama, M. Chem. Soc. Rev. 2007, 36, 1857.

30. Zakaria, S.; Ong, B. H.; van de Ven, T. G. M. Colloids and Surfaces A: Physicochem. Eng. Aspects 2004, 251, 31.

31. Zakaria, S.; Ong, B. H.; Ahmad, S. H.; Abdullah, M.; Yamauchi, T. Mater. Chem. Phys. 2005, 89, 216.

32. Marchessaultt, R. H.; Rioux, P.; Raymond, L. Polymer, 1992, 19, 4024.

33. Goodbrand, B.; Boils, D.; Sundararajan, P. R.; Wong, R. U. S. Patent 6,414,051, 2002.

34. Khanna, S.; Moniruzzaman, M.; Sundararajan, P. R. J. Phys. Chem. B 2006, 110, 15251.

35. Wiley, B.; Sun, Y.; Xia, Y. Acc. Chem. Res. 2007, 40, 1067.

36. Mal, S.; Maiti, P.; Nandi, A. K. Macromolecules 1995, 28, 2371.

37. Wang, J-D.; Huang, J-L.; Cai, J-W.; Chen, N-S. Chinese J. Struct. Chem. 2002, 21, 617.

38. Cai, J.; Wang J.; Huang J.; Chen, N. Chinese Sci. Bull. 2002, 47, 644. 
Chapter 8

Immiscibility Driven Two Component Gels of Biscarbamates with Poly ( $\epsilon$-Caprolactone) 


\subsection{Introduction}

Exploring the potential of molecular self-assembly and organic templates to fabricate functional materials constitutes significant contemporary research interest. ${ }^{1}$ Strategic use of noncovalent interactions between molecular units leading to molecular self-assembly has been developed as a highly promising means for the construction of supramolecular architectures that have specific structures, dimensions, properties, and functions. ${ }^{2}$ Low molecular weight organogels have emerged as an important class of soft organic materials in recent years. ${ }^{3}$ Significant research effort has so far been invested in transforming the serendipitous discovery of organogels into an efficient way of making gels with predetermined structure and properties. ${ }^{4}$ Two-component gel route is one such idea which relies on the non-covalent interactions between the two complementary components with an additional level of control in the hierarchical assembly process. Even a facile change in the composition of a two-component system can induce a significant change in the morphology of the resulting gel-phase materials that underscores the usefulness of this approach. ${ }^{5}$

Since the number of synthetic polymers leading to organogels is limited, efforts have been made to covalently functionalize polymers such as poly (dimethyl siloxane), polycarbonate, poly(ethylene glycol) (PEG), poly(propylene glycol) (PPG) etc, with known organogelators, e.g., L-isoleucine and L-valine derivatives. ${ }^{6}$ The latter promote the formation of organogels of these polymers. Two-component systems of blends of a gelator and a polymer which mutually interact via hydrogen bonding e.g., blends of sorbitol and PEG or PPG or blends of a cyclodextrin and poly(acrylic acid) have also been studied. ${ }^{7}$ These systems are based on hydrogen bonding interactions between the polymer and the organogelator, or chemical functionalization. In this chapter we describe 
a two-component gel system in which the polymer and the gelator are immiscible, and neither of them gel chloroform individually.

Self-assembly of incompatible molecular components leading to phase separation comprises a powerful approach toward the fabrication of complex nano-architectures and new materials. ${ }^{8}$ Phase-separated systems leading to various architectures of different dimensions and functionalities have been developed so far based on the immiscibility of block-copolymer segments ${ }^{9}$ or fluorinated compounds with hydrocarbons. ${ }^{10}$ This toolbox has recently been extended to low molecular weight gels in liquid crystalline phases ${ }^{11}$ and surfactant micelles. ${ }^{12}$

Component-selective self-assembly, popularly known as self-sorting, of complex mixtures of building blocks have been of significant interest to fabricate materials with desired dimension, morphology, and functionality. ${ }^{13}$ Concepts of self-sorting have recently been employed to quantify the extent of molecular scale information that controls the selective self-assembly process in gel-phase materials. ${ }^{14}$

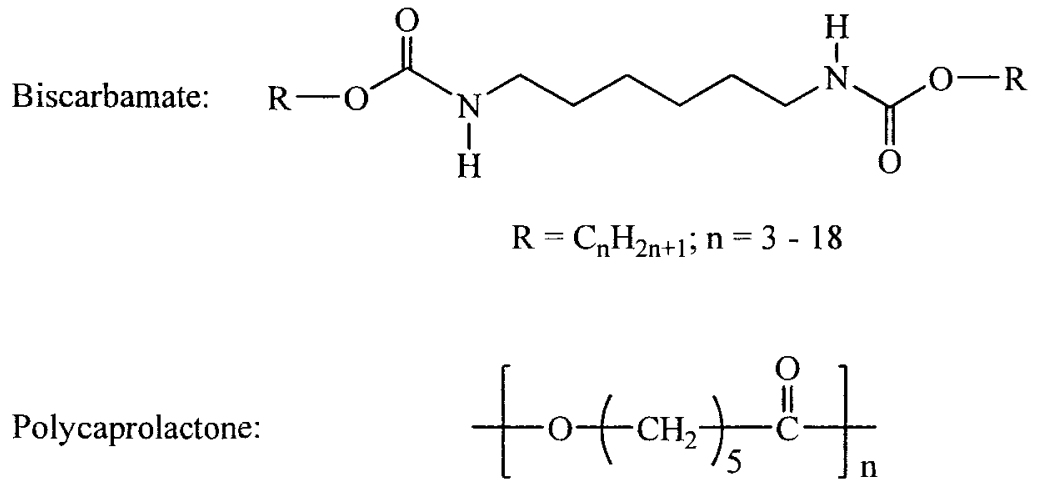

Scheme 8.1. Structures of biscarbmates and poly ( $\epsilon$-caprolactone).

In Chapter 5 we discussed the self-sorting behaviour during crystallization of a set of polyurethane (PU) model compounds. ${ }^{15}$ These are biscarbamate molecules having two 
hydrogen bonding motifs separated by an $\left(\mathrm{CH}_{2}\right)_{6}$ spacer and symmetrically attached with alkyl side chains of different length (Scheme 8.1). It was found that blends of any two of these molecules are immiscible at the molecular level in spite of their chemical similarity. Molecular recognition leading to component-selective self-assembly took place even with a small change in the alkyl side chain length. However, they mutually affect the crystallization kinetics, crystallinity and morphology of the blends. These features parallel those of hydrogen bond-mediated self-sorting in polymer blends.

Our previous studies on gelation of these biscarbamates showed that they could gel benzonitrile at a nominal concentration of $0.02 \mathrm{M}$ with hollow tubular morphology. ${ }^{16}$ Gelation accompanied by precipitation occurred in benzonitrile with some of the biscarbamates unlike the case of monocarbamates ${ }^{17}$ in the same solvent. A preliminary study ${ }^{16}$ on two-component gels based on homologous biscarbamates with odd versus even number of carbon atoms in the alkyl side chains showed enhancement of gelation with significantly different morphology following the sergeant-and-soldier principle ${ }^{18}$ and absence of precipitation of the gelator molecules (Chapter 6). Hollow tubes are observed typically when chirality-driven molecular packing occurs, for example, in lipid bilayer formation leading to helical structures with tubular morphology. ${ }^{19}$ Such hollow tube formation during gelation of biscarbamates is the first instance of a non-chiral molecule exhibiting this behavior. However, hollow biscarbamate gels are too soft to be used in any practical application. Dispersing or impregnating these in a polymer via the two-component gel route could improve their mechanical properties and these could serve as separation membranes and find use in similar applications. To this end, the 
present study explores the gelation of a series of homologous biscarbamte molecules with polycaprolactone (PCL).

Poly( $\epsilon$-caprolactone), a linear, semicrystalline, biocompatible and biodegradable ${ }^{20}$ synthetic aliphatic polyester has been of interest in tissue engineering ${ }^{21}$ and drug delivery systems $^{22}$, biodegradable shape memory devices ${ }^{23}$, micropatterning biomacromolecules on polymer surfaces ${ }^{24}$, "active packaging" materials with antimicrobial properties ${ }^{25}$, and stress sensing. ${ }^{26}$. Because of their suitable thermo-mechanical properties, PCL gives rise to polymeric composites in the form of fibers, films, or membranes with biomedical properties.

To develop biodegradable polyurethanes, incorporation of PCL as the soft segment has been reported, with a view to study the phase separation of the hard and soft segments. ${ }^{27}$ These contained aromatic or cyclohexyl based hard segments. For example, it was found that with low molecular weight of PCL $\left(M_{\mathrm{w}} \approx 800\right)$ there was compatibility between the hard and soft segments, whereas higher $M_{\mathrm{w}}$ led to phase separation. ${ }^{27 \mathrm{~d}}$ In this chapter, we discuss the phase separation during crystallization, and gelation of the two component blends, with the PU model compound (biscarbamates) and PCL. Thus, in this case, it is the blend of PCL instead of covalently linked polymer as in biodegrable polyurethanes. ${ }^{27 \mathrm{c}}$ We discuss the facile formation of composite porous gels comprising PCL and a series of hydrogen bond mediated self-assembling low molecular weight organogelators driven by their immiscibility and self-sorting at the molecular level, although these components do not gel chloroform individually. 


\subsection{Experimental}

\subsubsection{Materials}

Biscarbamates with different alkyl side chain length were synthesized from respective diisocyanate and alcohols according to the procedure described in Chapter 2 as well as in our previous papers. ${ }^{28,29}$ PCL $\left(M_{\mathrm{w}}=65,000 \mathrm{~g} \mathrm{~mol}^{-1}\right)$ was purchased from Sigma-Aldrich Inc., USA and was used as received.

\subsubsection{Preparation of the Blends}

To study the miscibility behavior of PCL/biscarbamate blends, pre-weighed amounts of PCL and the corresponding biscarbamate sample with respect to the intended compositions were dissolved in a $20-\mathrm{mL}$ scintillation vial with sufficient amount of chloroform at $60{ }^{\circ} \mathrm{C}$ with constant magnetic stirring. The solution was kept at that temperature for $10 \mathrm{~min}$ and then cooled to room temperature. The solvent was then allowed to evaporate by removing the vial cap. The blends thus prepared were dried in the fume hood for 3 days and under vacuum for $24 \mathrm{~h}$. To study the dispersion behavior of biscarbamates in the PCL matrix, films of some select biscarbamate samples at concentrations ranging from 1 to $10(\mathrm{w} / \mathrm{w}) \%$ of the biscarbamates with respect to PCL were prepared by casting the chloroform solutions on a glass surface using an electrically driven film coater. These films were dried in the fume hood for $24 \mathrm{~h}$ and under vacuum for another $24 \mathrm{~h}$. 


\subsubsection{Preparation of the Gels}

Pre-weighed amount of $\mathrm{C}_{\mathrm{x}}$ biscarbamates (the subscript $\mathrm{x}$ indicates the number of carbon atoms in the alkyl side chain of the biscarbamate molecule) and PCL were dissolved in required volume of chloroform to make solutions of varying concentrations with respect to $\mathrm{PCL}(\mathrm{w} / \mathrm{v} \%)$ by heating it up to $60{ }^{\circ} \mathrm{C}$ in a $20-\mathrm{mL}$ scintillation vial. The solution was kept at that temperature for about $10 \mathrm{~min}$ after dissolution of both components and then slowly cooled at a rate of $c a .5{ }^{\circ} \mathrm{C} / \mathrm{min}$ to the room temperature. The completion of the gel formation was confirmed by vial inversion method and was considered gel when complete immobilization of the solvent was attained. Another set of gels with some select biscarbamates samples was prepared following the same procedure but quenching the hot solution using an ice bath.

\subsubsection{Characterization}

TA Instruments 2010 differential scanning calorimeter was used for thermal analysis at a heating rate of $10{ }^{\circ} \mathrm{C}$ per min. The DSC was calibrated for temperature and energy with indium standard reference material. DSC traces were recorded in a nitrogen atmosphere with $c a .7-10 \mathrm{mg}$ of the samples in an aluminum pan and were capped with a lid by a Perkin Elmer hand press. The crystallinity of PCL was calculated using a value of $139.3 \mathrm{~J} / \mathrm{g}$ for the heat of fusion $(\Delta H)$ of $100 \%$ crystalline $\mathrm{PCL}^{28}$, using the equation ${ }^{30 \mathrm{a}, \mathrm{c}}$

$$
X_{\mathrm{c}}=\Delta H / \Delta H^{\mathrm{O}}
$$

where $X_{\mathrm{c}}$ is the weight fraction crystallinity, and $\Delta H^{\circ}$ is heat of fusion corresponding to the $100 \%$ crystalline sample. 
Small-angle light scattering in the $\mathrm{H}_{\mathrm{v}}$ mode was used to measure the average size of the PCL spherulites, using the set up and Eq. (8.2), as described by Jabarin and Stein. ${ }^{31}$

$$
\begin{aligned}
& 4 \pi(\mathrm{R} / \lambda) \sin (\theta / 2)=4 \\
& \text { with } \theta=\tan ^{-1}(\mathrm{r} / \mathrm{D})
\end{aligned}
$$

where $\mathrm{R}$ is the radius of the spherulite, $\lambda(0.6328 \mu \mathrm{m})$ is the wavelength of the laser beam, $\mathrm{r}$ is the distance from the center of the incident beam to the point of maximum intensity on the $\mathrm{H}_{\mathrm{v}}$ four-leaf clover pattern, and $\mathrm{D}$ is the distance between the sample and the recording plane.

\subsection{Results and Discussion}

We will first discuss the immiscibility as deduced from thermal analysis and morphology of the blends and then the gelation behavior.

\subsubsection{Thermal Analysis}

The miscibility behavior of PCL and biscarbamate blends was studied with differential scanning calorimetry. Figure 8.1 shows the DSC thermograms of neat PCL, neat $\mathrm{C}_{12}$, and $\mathrm{PCL} / \mathrm{C}_{12}(50 / 50)$ blend. Both the PCL and $\mathrm{C}_{12}$ show a single endothermic peak in their DSC traces corresponding to their melting temperatures $\left(T_{\mathrm{m}}\right)$ at 60 and 115.5 ${ }^{\circ} \mathrm{C}$, respectively while the $50 / 50$ blend of these components shows two distinct peaks in its DSC trace. The large difference in the melting temperatures of these two components led to well separated distinct peaks and implied the immiscibility and consequent phase separation of these components at this composition. Table 8.1 shows that the melting temperatures of PCL and the biscarbamate in the blend depends on the length of the alkyl 
side chain and the blend composition. The $T_{\mathrm{m}}$ and the heat of fusion $(\Delta H)$ recorded here for $100 \% \mathrm{PCL}$ are about the same as those reported by other authors. ${ }^{28}$

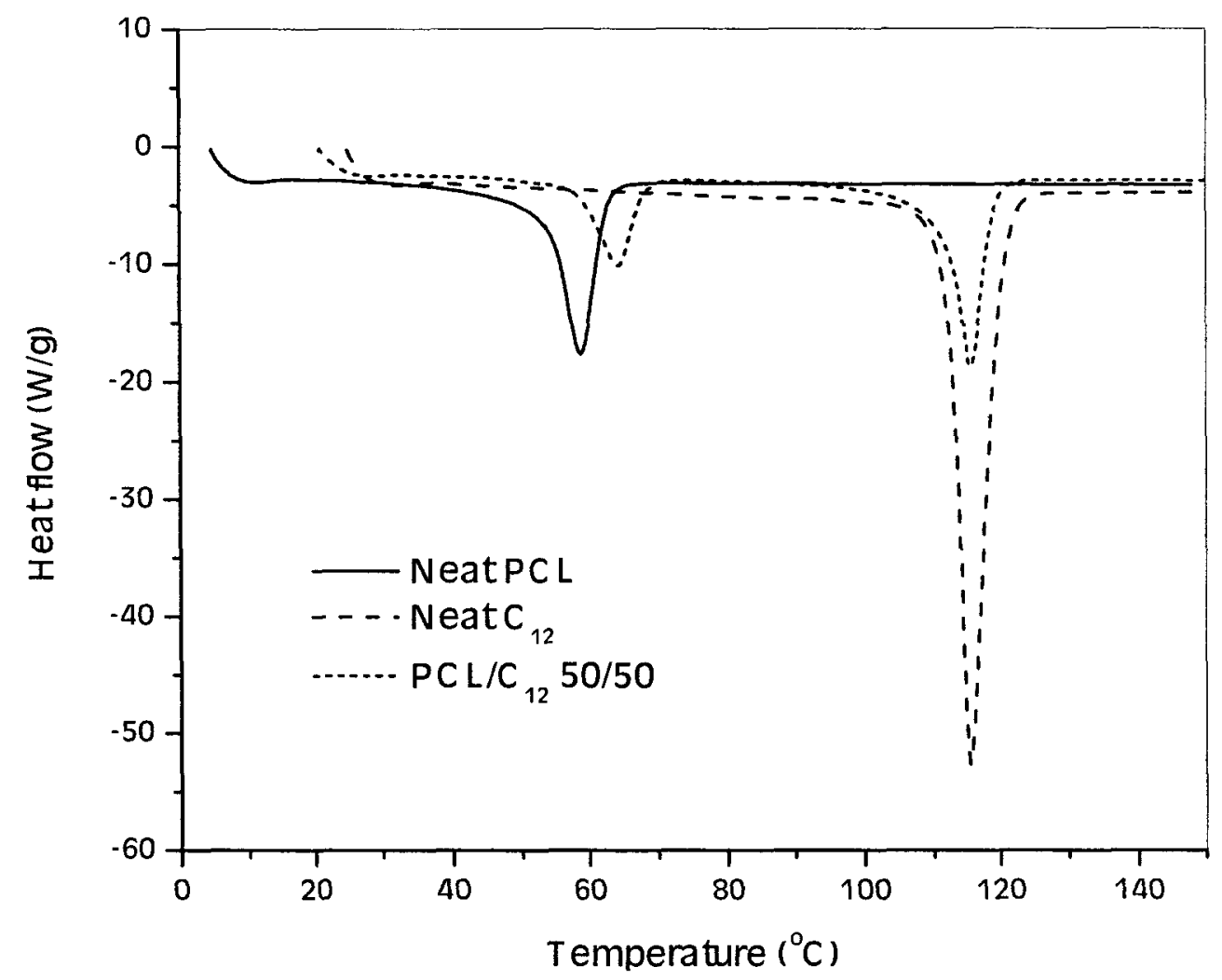

Figure 8.1. DSC thermograms of neat PCL, neat $\mathrm{C}_{12}$ and $\mathrm{PCL} / \mathrm{C}_{12}$ 50/50 blend.

The $T_{\mathrm{m}}$ of PCL slightly increases, by $4.4{ }^{\circ} \mathrm{C}$ with $20 \% \mathrm{C}_{4}$, and the increase becomes smaller with further concentration of $\mathrm{C}_{4}$. With the addition of $\mathrm{C}_{12}$, a maximum increase of $4.3^{\circ} \mathrm{C}$ is seen with $50 \%$, and the addition of $\mathrm{C}_{18}$ causes less of an increase. On the other hand, the $T_{\mathrm{m}}$ of the biscarbamate is reduced with the addition of PCL, the reduction being more significant for $\mathrm{C}_{4}$ (varying from 6.5 to $2.3^{\circ} \mathrm{C}$ as the $\mathrm{PCL}$ content of decreasing from 80 to $40 \%$ ). The $T_{\mathrm{m}}$ of $\mathrm{C}_{12}$ is reduced by $3{ }^{\circ} \mathrm{C}$ with $80 \% \mathrm{PCL}$, and no further change is seen at lower concentrations of PCL. The reduction of $T_{\mathrm{m}}$ is less pronounced for $\mathrm{C}_{18}$. It thus appears that lower concentrations of a biscarbamate serve as a nucleating agent and 
increase the $T_{\mathrm{m}}$ of PCL, while PCL itself plasticizes the biscarbamate, lowering its melting temperature.

Table 8.1. Melting temperatures and normalized heats of fusion of $\mathrm{PCL} /$ biscarbamate blends at different compositions.

\begin{tabular}{|c|c|c|c|c|c|c|}
\hline \multirow[t]{3}{*}{ Composition } & \multicolumn{6}{|c|}{ Blends $^{a}$} \\
\hline & \multicolumn{2}{|c|}{$\mathrm{PCL} / \mathrm{C}_{4}$} & \multicolumn{2}{|c|}{$\mathrm{PCL} / \mathrm{C}_{12}$} & \multicolumn{2}{|c|}{$\mathrm{PCL} / \mathrm{C}_{18}$} \\
\hline & $T_{\mathrm{m}}\left({ }^{\circ} \mathrm{C}\right)$ & $H_{\mathrm{f}}(\mathrm{J} / \mathrm{g})$ & $T_{\mathrm{m}}\left({ }^{\circ} \mathrm{C}\right)$ & $H_{\mathrm{f}}(\mathrm{J} / \mathrm{g})$ & $T_{\mathrm{m}}\left({ }^{\circ} \mathrm{C}\right)$ & $H_{\mathrm{f}}(\mathrm{J} / \mathrm{g})$ \\
\hline $100 / 0$ & 60.0 & 70.5 & 60.0 & 70.5 & 60.0 & 70.5 \\
\hline $80 / 20$ & $64.4,87.1$ & $40.5,0.8$ & $62.8,112.6$ & $39.8,7.5$ & $61.6,120.7$ & $40.7,8.3$ \\
\hline $60 / 40$ & $63.9,89.5$ & $20.6,10.3$ & $63.8,115.7$ & $20.9,30.5$ & $63.6,122.9$ & $19.3,39.8$ \\
\hline $50 / 50$ & $60.9,89.9$ & $15.4,23.1$ & $64.3,115.5$ & $17.4,36.9$ & $62.4,123.4$ & $12.0,59.1$ \\
\hline $40 / 60$ & $60.9,91.3$ & $9.6, \quad 35.2$ & $63.0,116.7$ & $8.4, \quad 65.0$ & $61.9,123.2$ & $6.0, \quad 77.3$ \\
\hline $20 / 80$ & $60.3,93.2$ & $2.8,84.4$ & $61.3,115.6$ & $2.7, \quad 100.6$ & $61.6,122.6$ & $2.1, \quad 120.6$ \\
\hline $0 / 100$ & 93.6 & 160.0 & 115.5 & 196.2 & 122.1 & 222.4 \\
\hline
\end{tabular}

$a=$ first value corresponds to PCL and second, to the respective biscarbamate.

The increase in the $T_{\mathrm{m}}$ of PCL with the addition of biscarbamate does not lead to an increase in its crystallinity, as seen from the change of heat of fusion $(\Delta H)$. Contrary to the trend in the change of melting temperatures, the heats of fusion of both components in the blend decrease significantly. Figure 8.2 shows the variation of normalized (with respect to the relative weight of each component) heat of fusion as a function of the weight percent composition of the blends. Irrespective of the alkyl chain length, the $\Delta H$ of PCL decreases from 70.5 to about $3 \mathrm{~J} / \mathrm{g}$, with an increase of the weight fraction of the biscarbamate (see Table 8.1 also). 

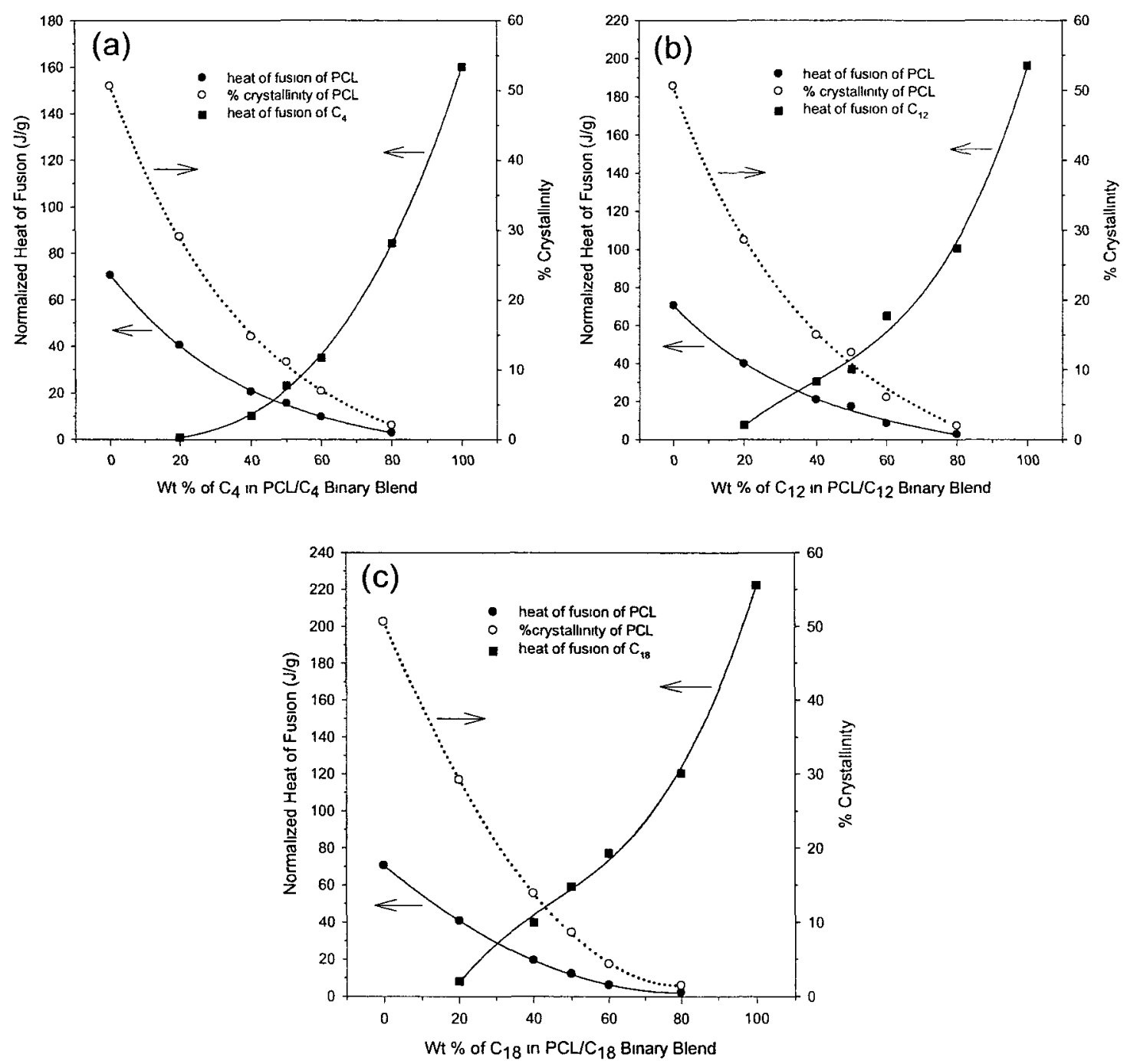

Figure 8.2. Normalized heat of fusion of PCL/biscarbamate binary blends: (a) PCL/ $\mathrm{C}_{4}$, (b) $\mathrm{PCL} / \mathrm{C}_{12}$, and (c) $\mathrm{PCL} / \mathrm{C}_{18}$. The variation of crystallinity of $\mathrm{PCL}$ with the concentration of the biscarbamate is also shown.

It is seen from this figure that the effect of PCL on the $\Delta H$ of biscarbamate is more significant. For $\mathrm{C}_{4}$, for example, the $\Delta H$ decreases from 160 to $0.8 \mathrm{~J} / \mathrm{g}$ with an increase in the weight fraction of PCL. Similar significant reduction of $\Delta H$ is seen for $\mathrm{C}_{12}$ and $\mathrm{C}_{18}$ in Figures $8.2 \mathrm{~b}$ and $\mathrm{c}$, respectively, with an increase in PCL content. This trend in change 
of heat of fusion parallels that of the homologous blends of biscarbamates and we attribute this to the mutual diluent effect of immiscible blend components on each other. ${ }^{15}$ van Bogart et $\mathrm{al}^{27 \mathrm{~d}}$ found that in the case of polyurethanes with PCL as the soft segment, there was compatibility with the hard segment with a PCL of $M_{\mathrm{w}}$ of 830 , but increasing the $M_{\mathrm{w}}$ of the PCL segment to 2000 led to microphase separation. These authors used aromatic or cyclohexyl based hard segments. In the present case of blends of PCL with biscarbamates (model compounds for aliphatic polyurethanes), such phase separation occurs, as seen from the DSC results. Since the purpose of this study is to disperse gel fibers in a polymer to make a system that would be amenable to handling, we did not use a low molecular weight $\left(M_{\mathrm{w}}\right.$ of 830$) \mathrm{PCL}$ as in the work of van Bogart et al. ${ }^{27 \mathrm{~d}}$

\subsubsection{Morphology of the Blends}

Since we wanted to disperse the biscarbamates in the PCL matrix, we studied the morphology of the blends with PCL as the major component. We chose the biscarbamates with extreme and intermediate lengths of the alkyl side chains. Figure 8.3 shows the $\mathrm{OM}$ of PCL and PCL/C 4 : 99:1 and 98:2 (wt \%) films cast from chloroform solutions. The PCL crystallizes with the well known spherulitic morphology (Figure 8.3a), with an average spherulite size of $9 \mu \mathrm{m}$ (as measured from solid state light scattering). Figures $8.3 \mathrm{~b}$ and $\mathrm{c}$ for $\mathrm{PCL} / \mathrm{C}_{4}: 99 / 1$ and $98 / 2$ (wt \%) show that the biscarbamate forms phase separated droplet domains in the PCL matrix (these are birefringent droplets, but appear black due to the thickness). That these droplets are those of $\mathrm{C}_{4}$ was confirmed by partially melting the sample above the $T_{\mathrm{m}}$ of PCL. Similar phase separated domains of biscarbamates are seen with an increase in alkyl side chain length, 
as shown in Figure 8.4 for PCL/C $\mathrm{C}_{12}$ and PCL/C 18 blends with $99 / 1$ and 98/2 (wt \%) compositions.
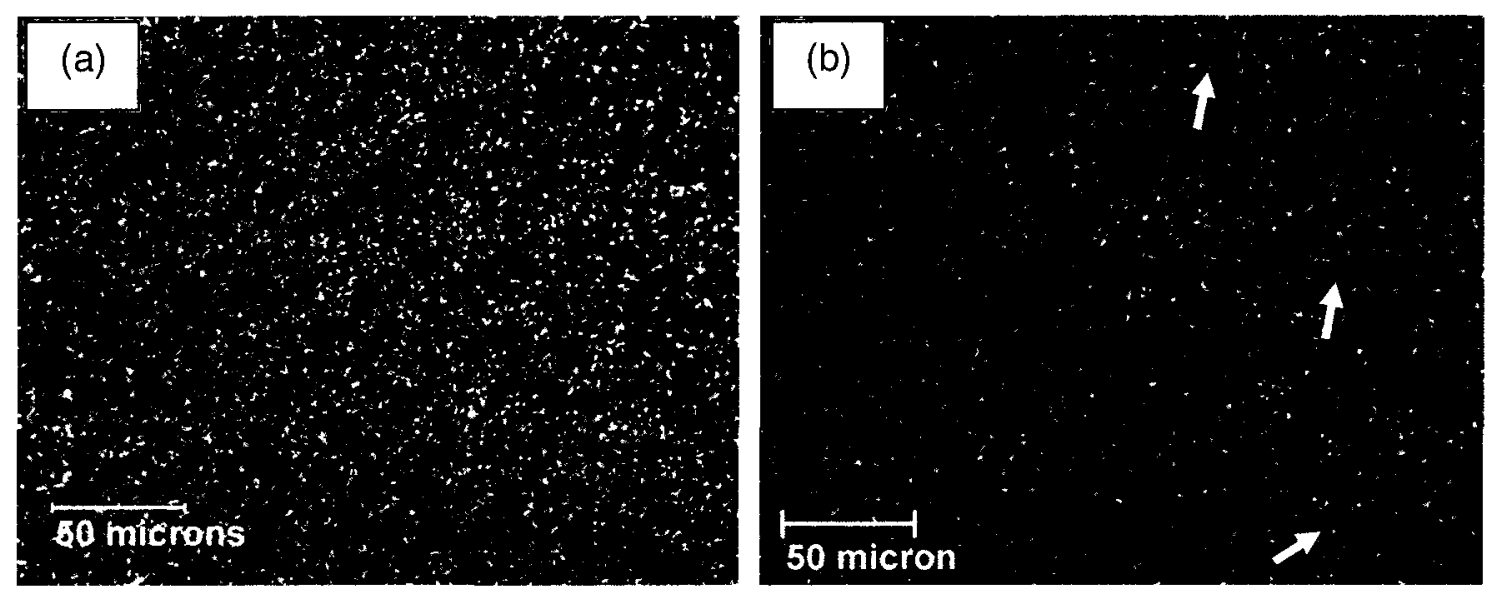

\section{(c)}

\section{0 micron}

Figure 8.3. Optical micrographs of $\mathrm{PCL} / \mathrm{C}_{4}$ biscarbamate blend films cast from chloroform solution at different compositions: (a) neat PCL (b) $1 \%$, and (c) $2 \% \mathrm{C}_{4}$ biscarbamate.

Increase in the concentration of biscarbamates leads to pronounced phase separated domains, as shown in Figure 8.5 for $\mathrm{C}_{4}, \mathrm{C}_{12}$ and $\mathrm{C}_{18}$ biscarbamates with 5 and $10 \mathrm{wt} \%$ in PCL. With PCL/C 4 : 95/5 and 90/10 (wt \%), the domains of $\mathrm{C}_{4}$ become more numerous and larger than those in Figure 8.3. As the alkyl chain length increases, the size of the PCL spherulites increases as well, as seen from Figures $8.5 \mathrm{~d}$, e and $\mathrm{f}$, and the biscarbamates form domains within the lamella of the spherulites. Although the 
biscarbamates are known to crystallize rapidly, the presence of PCL as the major component prevents the spherulite formation. The decrease in the heat of fusion of PCL with biscarbamate concentration could be attributed to the interspersion of the latter in the spherulitic domains of PCL.
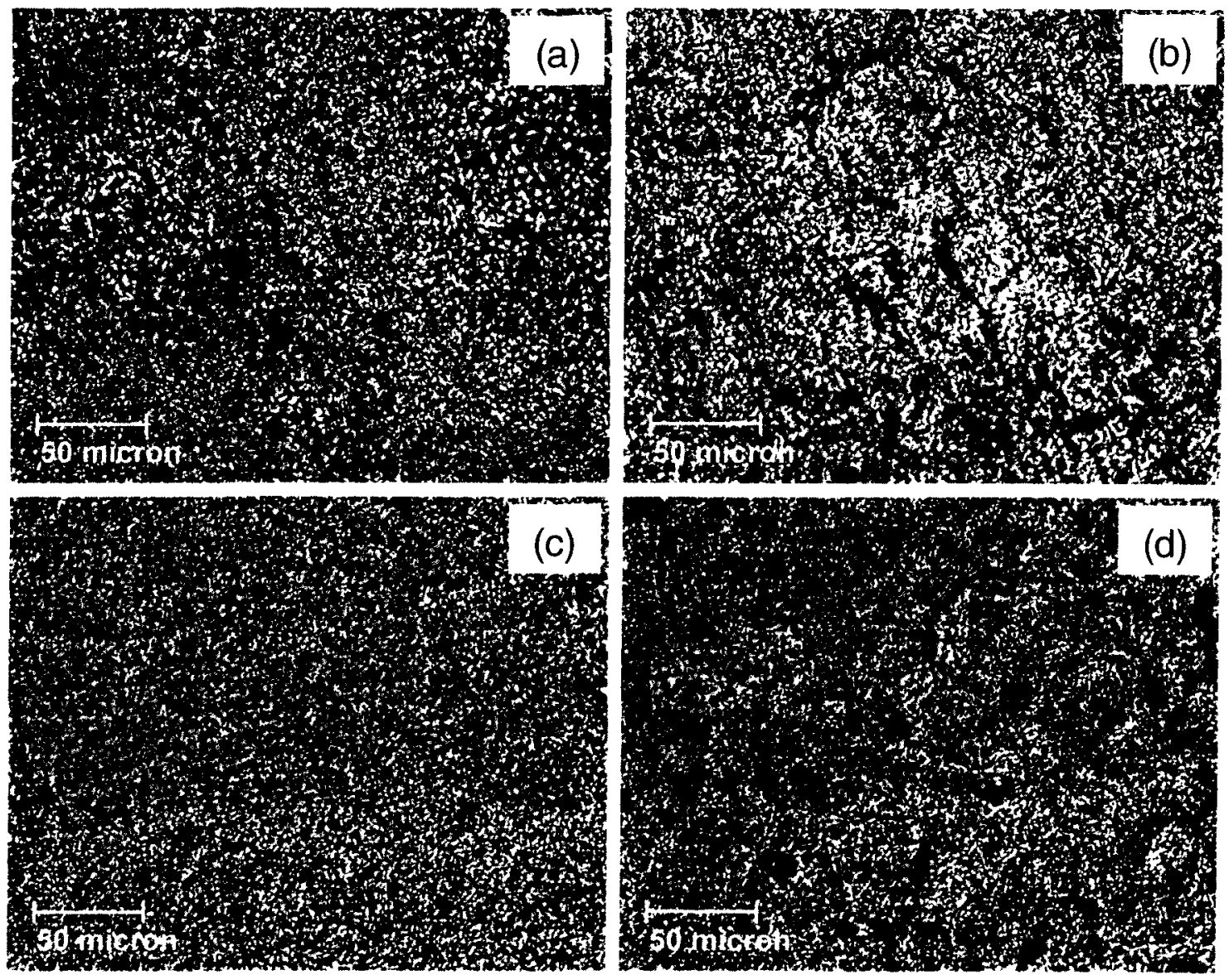

Figure 8.4. Optical micrographs of blend films cast from chloroform solutions. $(a, b)$ : PCL/ $\mathrm{C}_{12}$ biscarbamate: $99 / 1$ and $98 / 2$ (wt\%), respectively; (c, d): $\mathrm{PCL} / \mathrm{C}_{18}$ biscarbamate: 99/1 and 98/2 (wt\%), respectively.

While the partial melting experiments confirmed the statements above that biscarbamates form crystalline aggregates in the PCL matrix in the case of solvent cast films, phase inversion occurs upon cooling the molten film. This is illustrated in Figure 8.6 for the case of $\mathrm{PCL} / \mathrm{C}_{18}: 95 / 5$ (wt $\%$ ) film. At $25^{\circ} \mathrm{C}$, aggregates of $\mathrm{C}_{18}$ crystals are 
seen (Figure 8.6a) in the PCL matrix. At $110^{\circ} \mathrm{C}$ (Figures $8.6 \mathrm{~d}$ ), PCL had melted, and channels arise (seen from top left to right) due to the phase separated, molten polymer.
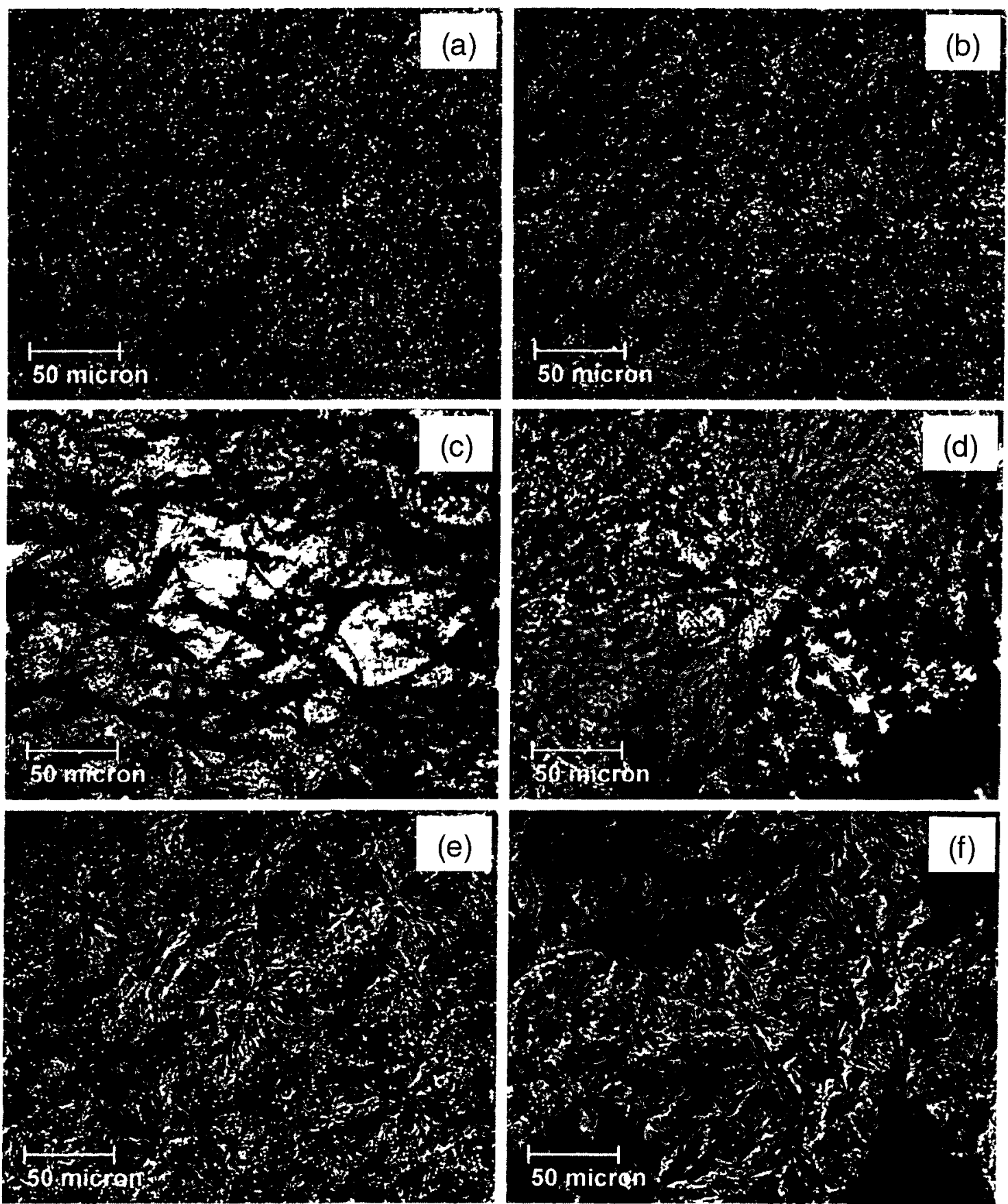

Figure 8.5. Optical micrographs of PCL/biscarbamate blend films cast from chloroform solutions with $5 \%(\mathrm{wt})$ (left column) and 10\% (right column) of biscarbamate. (a, b): $\mathrm{C}_{4}$ biscarbamate; (c, d): $\mathrm{C}_{12}$ biscarbamate, and (e, f): $\mathrm{C}_{18}$ biscarbamate. 
At $125^{\circ} \mathrm{C}, \mathrm{C}_{18}$ has also melted. Upon cooling to 104 and $70{ }^{\circ} \mathrm{C}, \mathrm{C}_{18}$ crystallizes as radiating lamellae. Upon further cooling to $40{ }^{\circ} \mathrm{C}$ PCL crystallized along the channels and also as aggregate crystals between the lamellae of $\mathrm{C}_{18}$ (Figure $8.6 \mathrm{i}$ and $\mathrm{j}$ ). Such phase inversion occurs since the crystallization temperature of $\mathrm{C}_{18}\left(111.9^{\circ} \mathrm{C}\right)$ is higher than that of PCL $\left(40.7^{\circ} \mathrm{C}\right)$.

While the above discussion relates to films cast from chloroform, we also examined the bulk morphology of the PCL/biscarbamate blends prepared by solution blending and the effect of temperature. To this end, a blend of PCL/ $\mathrm{C}_{12}: 80 / 20$ (wt \%) (not the cast film) was heated on the hot stage, and the temperature was increased successively to (1) the melting temperature of PCL, (2) the melting temperature of $\mathrm{C}_{12}$, (3) $5^{\circ} \mathrm{C}$ higher than the melting temperature of $\mathrm{C}_{12}$; and decreased successively to (1) the crystallization temperature of $\mathrm{C}_{12}$, (2) the crystallization temperature of $\mathrm{PCL}$, and (3) room temperature. The heating rate was $5{ }^{\circ} \mathrm{C} / \mathrm{min}$ up to $50{ }^{\circ} \mathrm{C}$ and then $1{ }^{\circ} \mathrm{C} / \mathrm{min}$ to get to the desired temperature on heating and cooling. The sample was kept at the desired temperature for about 5 min before recording the images. Figure $8.7 \mathrm{a}$ and $\mathrm{b}$ show the samples of $\mathrm{C}_{12}$ and PCL slowly cooled from the respective melts with spherulitic morphology. However, when they are blended together, only the biscarbamate crystallizes as spherulites while PCL crystallizes as droplets dispersed between the lamellae of $\mathrm{C}_{12}$ (Figure 8.7c). This indicates that the presence of $\mathrm{C}_{12}$ significantly impedes the crystallization and the corresponding spherulitic morphology of PCL in the blends. Selective melting at $60{ }^{\circ} \mathrm{C}$ leads to droplets of molten PCL (indicated by the arrows in Figures $8.7 \mathrm{~d}$ and e), while the spherulites of $\mathrm{C}_{12}$ remain unaffected. Increasing the temperature to $115^{\circ} \mathrm{C}$ above the $T_{\mathrm{m}}$ of $\mathrm{C}_{12}$ resulted in an isotropic melt (Figure $8.7 \mathrm{f}$ ). 

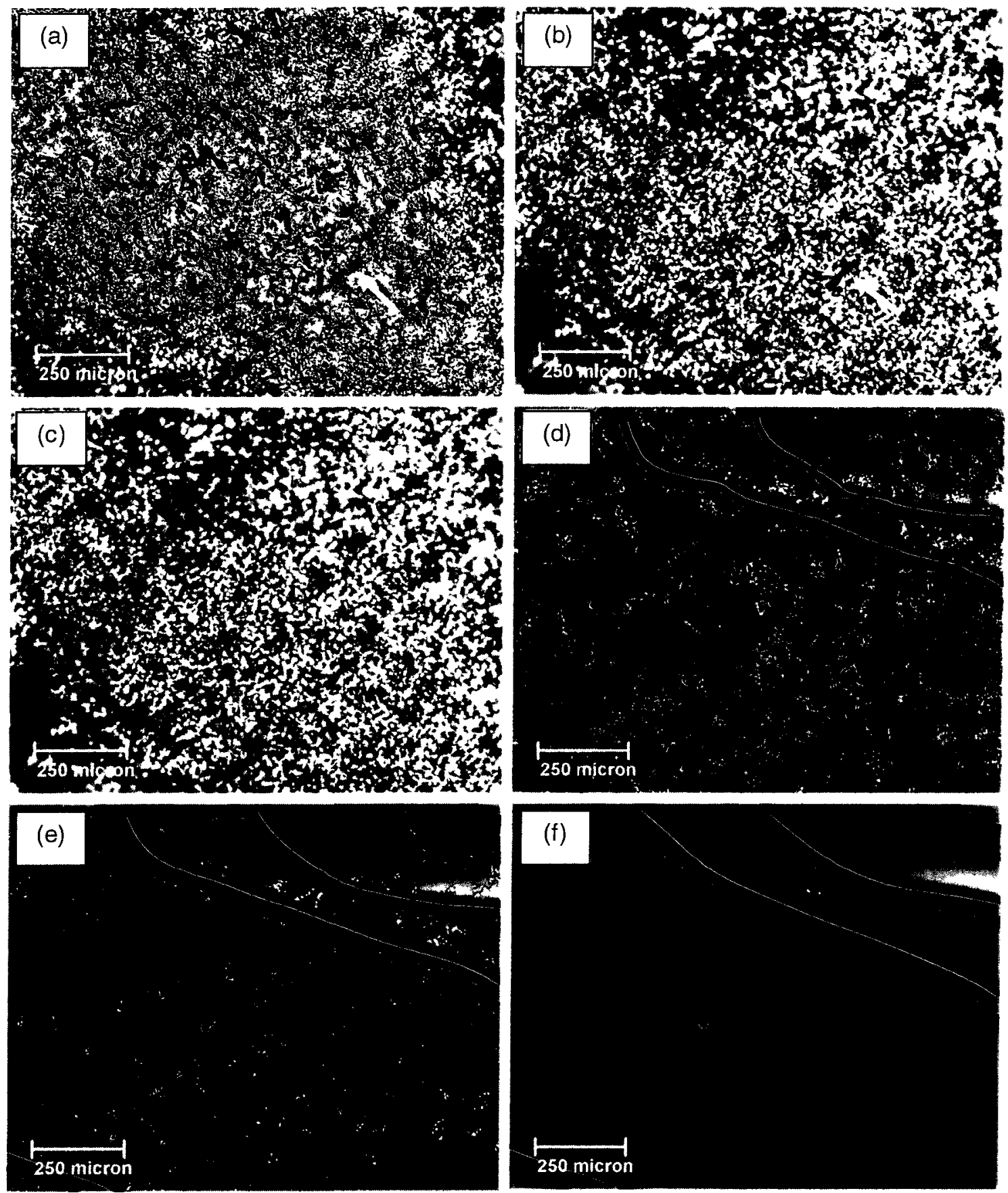

Figure 8.6 continued on next page 

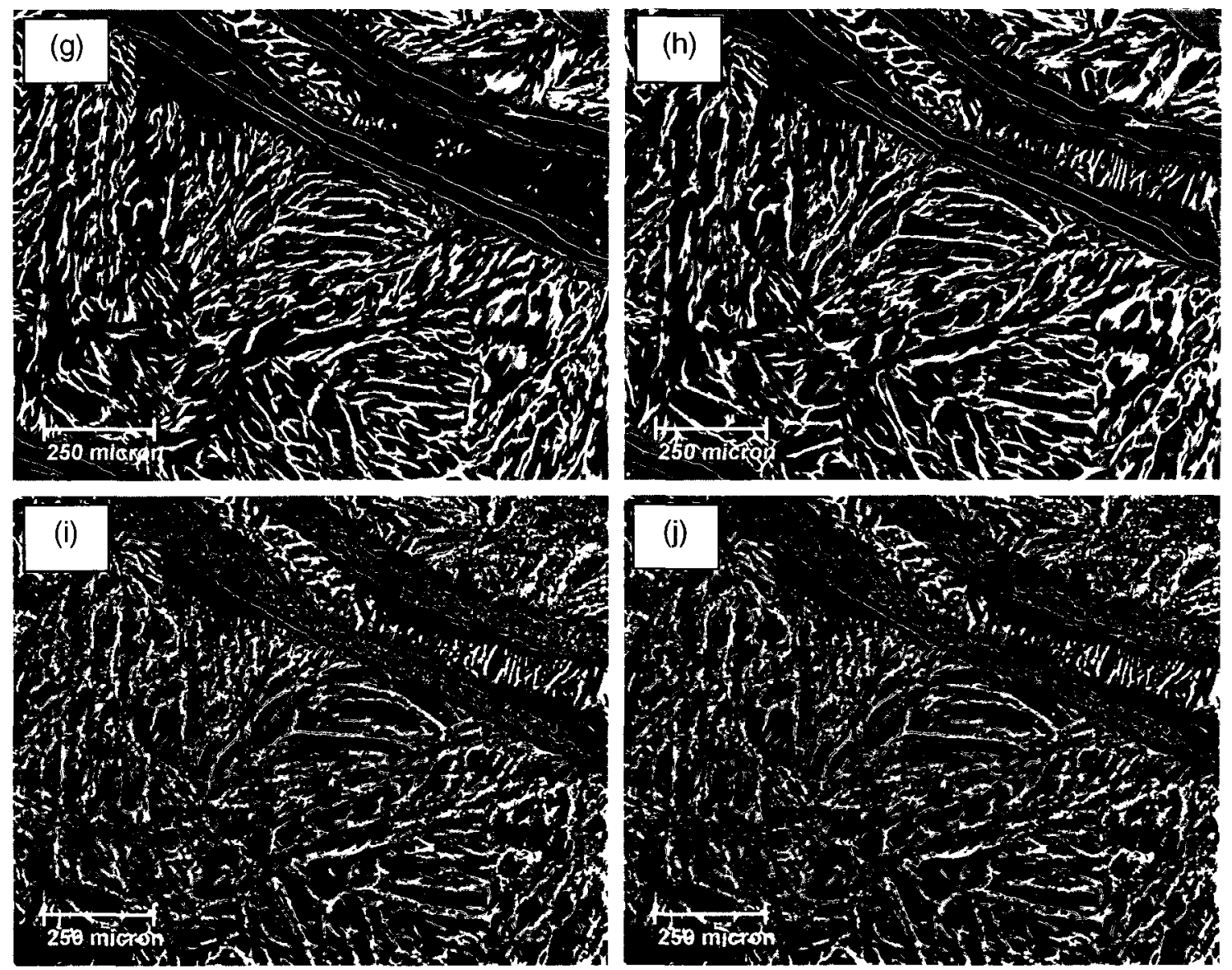

Figure 8.6. Optical micrographs of $\mathrm{PCL} / 5 \% \mathrm{C}_{18}$ biscarbamate films at different temperatures: Heating to: (a) $25^{\circ} \mathrm{C}$, (b) $60^{\circ} \mathrm{C}$, (c) $70^{\circ} \mathrm{C}$, (d) $110^{\circ} \mathrm{C}$, (e) $115^{\circ} \mathrm{C}$, (f) 125 ${ }^{\circ} \mathrm{C}$, and cooling to $(\mathrm{g}) 104{ }^{\circ} \mathrm{C}$, (h) $70{ }^{\circ} \mathrm{C}$, (i) $40{ }^{\circ} \mathrm{C}$, and (j) $25{ }^{\circ} \mathrm{C}$. The channels running from top left to right in (d) - (j) are the trenches separating the domains created upon melting of the polymer at elevated temperatures. The arrows point to the crystalline aggregates of $\mathrm{C}_{18}$.

Upon cooling to $107{ }^{\circ} \mathrm{C}$, the spherulitic morphology of $\mathrm{C}_{12}$ redevelops, and further cooling to $40{ }^{\circ} \mathrm{C}$ results in the droplet formation of PCL in the matrix of $\mathrm{C}_{12}$, although PCL is the major component in the blend (Figures $8.7 \mathrm{~g}$ and $\mathrm{h}$ ). Such droplet formation of PCL in the matrix of polyurethanes with PCL as the soft segment, in the melt-mixed 
blends of PCL and PU has been reported by Ajili et al. ${ }^{27}$ In their work, the $M_{\mathrm{n}}$ of PU was $2000 \mathrm{~g} / \mathrm{mol}$, and that of PCL was $42,500 \mathrm{~g} / \mathrm{mol}$. They rationalized droplet formation on
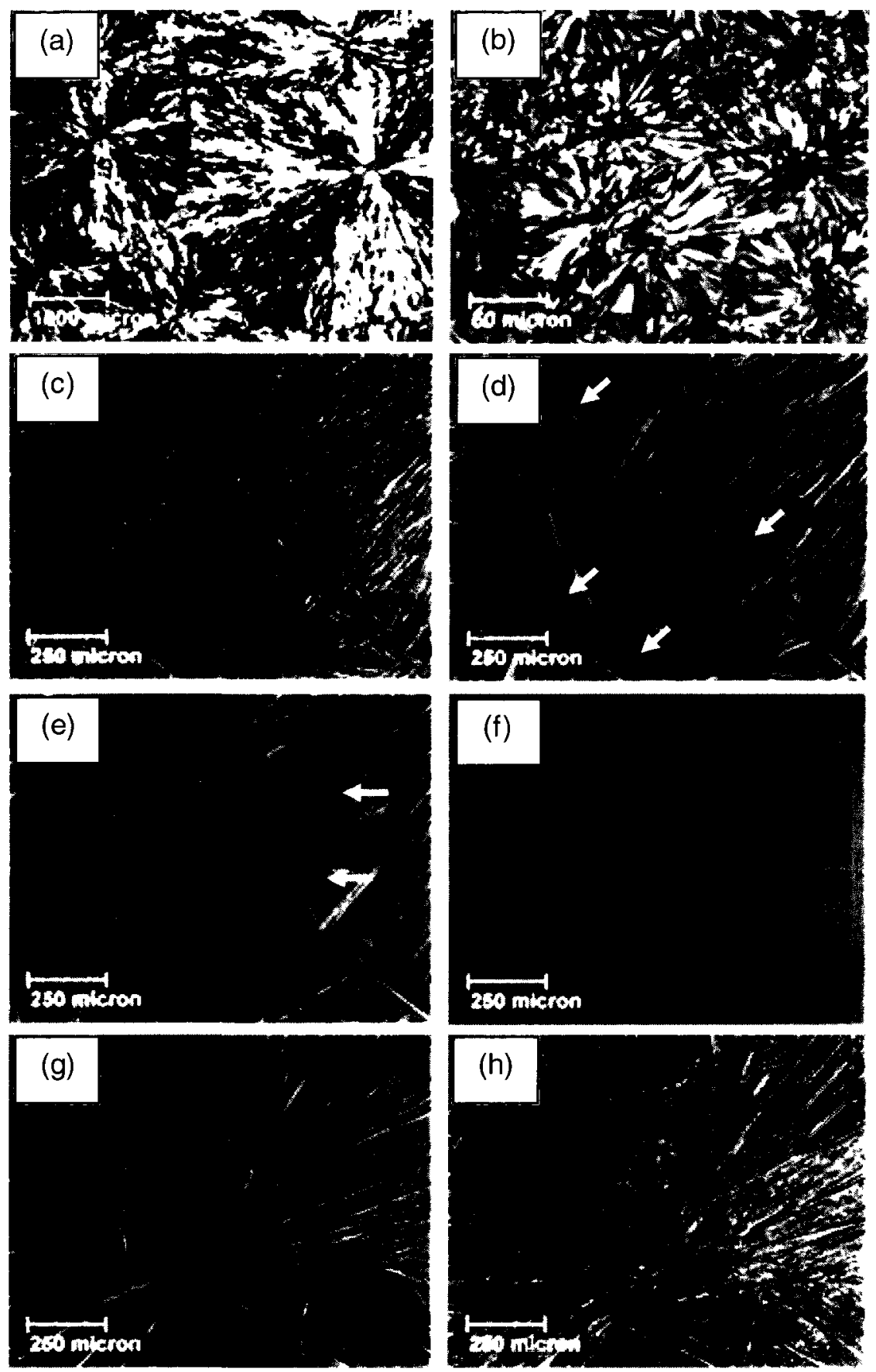

Figure 8.7. Optical micrographs of (a) neaat $\mathrm{C}_{12}$ at $25{ }^{\circ} \mathrm{C}$, (b) neat $\mathrm{PCL}$ at $25{ }^{\circ} \mathrm{C}$, and $\mathrm{PCL} / \mathrm{C}_{12} 80 / 20$ blend at different temperatures : (c) $25^{\circ} \mathrm{C}$, (d) $60{ }^{\circ} \mathrm{C}$, (e) $110{ }^{\circ} \mathrm{C}$ (f) 115 ${ }^{\circ} \mathrm{C}$, (g) $107{ }^{\circ} \mathrm{C}$ upon cooling, and (h) $40{ }^{\circ} \mathrm{C}$ upon cooling. The white arrows indicate the droplets of the molten PCL. 
the basis that due to its higher molecular weight, PCL did not fully mix with the lower molecular weight PCL diol segment of the PU, and formed micellar droplets.

The droplet formation in the present work could be attributed to the difference in the crystallization rate of the components. Goulet and Prud'homme ${ }^{32}$ reported a crystallization half time $\left(t_{1 / 2}\right)$ of $4.5 \mathrm{~min}$, for a PCL sample crystallized from the melt at $45{ }^{\circ} \mathrm{C}$. The $t_{1 / 2}$ for $\mathrm{C}_{4}$ is only a few seconds. ${ }^{29}$ Thus, while the biscarbamate forms domains in the PCL matrix in solution cast films, the opposite is seen with the asprepared blends upon crystallization from the melt. These observations show that the self-assembling component (biscarbamate) of the blend is immiscible with PCL at the molecular level and crystallizes by self-sorting. The volume filling crystallization of the biscarbamate from the melt precludes the crystallization of PCL, which has a much lower temperature. Even otherwise, a similar study on the homologous blends of the biscarbamates $^{15}$ studied here showed that these self-assembling molecules are also immiscible at the molecular level and crystallize by self-sorting although the melting and crystallization temperatures differ only by a few degrees. However, the crystalline domains of the homologous blend components of biscarbamates profusely participate in forming the spherulitic domains than forming distinct spherulites of their own. We utilized this immiscibility between PCL and the biscarbamates to fabricate composite gels using the two-component gel route. The gelation behavior and the morphology of the resulting gels are discussed in the following sections. 


\subsubsection{Gelation}

The immiscibility driven gelation of $\mathrm{PCL} /$ biscarbamate blends in $\mathrm{CHCl}_{3}$ was studied with the biscarbamates having alkyl side chains with number of $\mathrm{C}$ atoms in the side chain ranging from $\mathrm{C}_{3}$ to $\mathrm{C}_{18}$ at different compositions. The clear solutions of PCL and biscarbamate components either form semi-solid turbid mass indicating the fibrous aggregation and/or crystalline precipitation of the gelator molecules or remained as clear solution upon cooling to the gelation temperature $\left(43^{\circ} \mathrm{C}\right)$. Neither neat PCL nor neat biscarbamates gel chloroform. However, the presence of both PCL and biscarbamate lead to gelation. Figure 8.8 shows the phase diagram of the composite gel with respect to the biscarbamate concentration as a function of number of carbon atoms in alkyl side chains. We kept the PCL concentration constant at $20 \%(\mathrm{w} / \mathrm{v})$ while varying the concentration of biscarbamates with respect to that of PCL. It is seen that the gelation of biscarbamates in PCL solution is dependent on the alkyl side chain length irrespective of their relative concentration. Biscarbamates with alkyl side chain shorter than $\mathrm{C}_{11}$ remain soluble and do not form a gel (Figure 8.8a) while beyond $\mathrm{C}_{13}$ they precipitate (Figure $8.8 \mathrm{c}$ ) at ambient temperature. Only three members of the series with $C_{11}$ to $C_{13}$ side chains form gel at a relative concentration ranging from $5 \%$ to $25 \%$ (Figure $8.8 \mathrm{~b}$ ).

The critical gelation concentration (CGC) of these three biscarbamates differs significantly as shown in Figure 8.9. It is seen from this figure that the CGC for $\mathrm{C}_{11}$ is $10 \%$ which is quite high compared to the other two biscarbamates (5 and $4 \%$ for $\mathrm{C}_{12}$ and $\mathrm{C}_{13}$, respectively). This gelation behavior of biscarbamates can be attributed to the immiscibility of biscarbamates in PCL matrix which helps them self-sort and phase separate in the polymer matrix. 


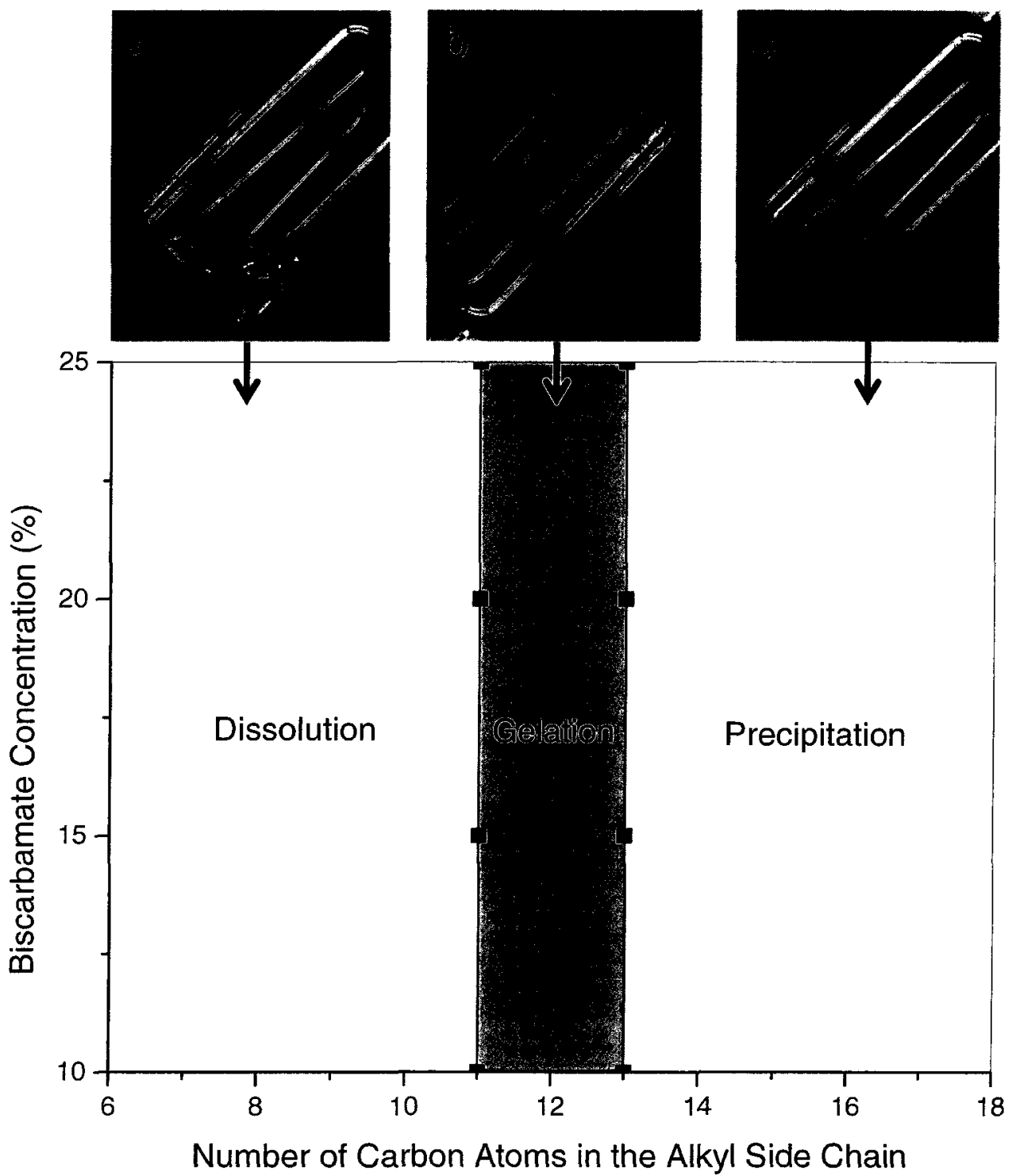

Figure 8.8. Phase diagram of gelability of biscarbamates having alkyl side chains of different lengths at different concentrations.

The varying extent of intermolecular association of biscarbamates with different alkyl side chain length plays important role in such phase separation. The increased alkyl side chain length leads to increased van der Waals interaction while the extent of hydrogen bonding remains same. Because of this, the biscarbamate molecules with optimal van der Waals to hydrogen bonding ratio leads to unidirectional aggregates of the molecules 
resulting in gel fiber formation. Biscarbamates with shorter chain length and hence smaller van der Waals force tends to be dispersed in the polymer matrix while biscarbamates with longer alkyl chains precipitates. Thus the immiscibility and gelation of biscarbamates in the presence of PCL depend on intermolecular forces between the molecules of same type and of the blendophobic components.

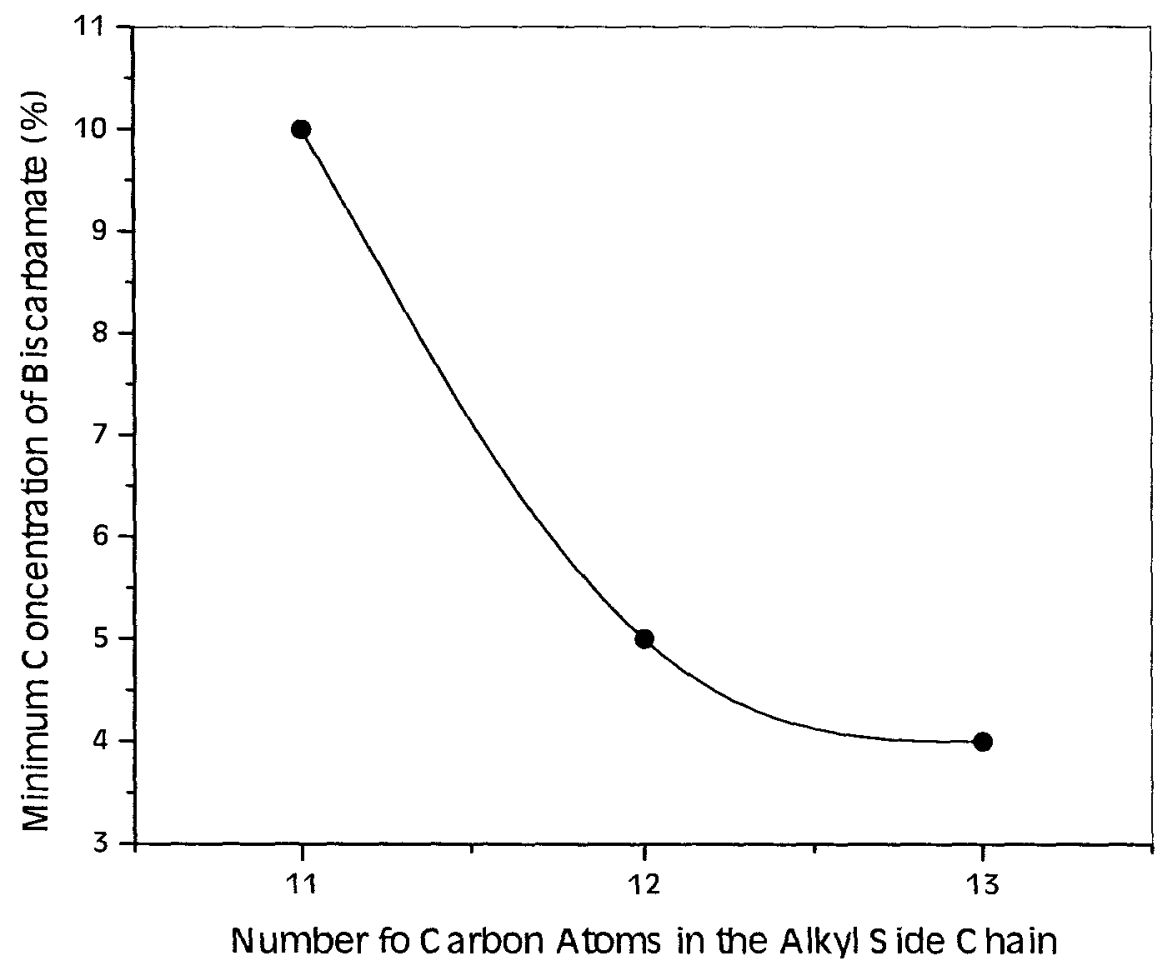

Figure 8.9. Critical gelation concentration of biscarbamates as a function of alkyl side chain length with a constant concentration $(20 \%(w / v))$ of PCL to gel chloroform. 


\subsubsection{Morphology of the Composite Gel}

The morphologies of both slow-cooled and quenched samples of PCL/biscarbamate gels were studied with electron and optical microscopy.
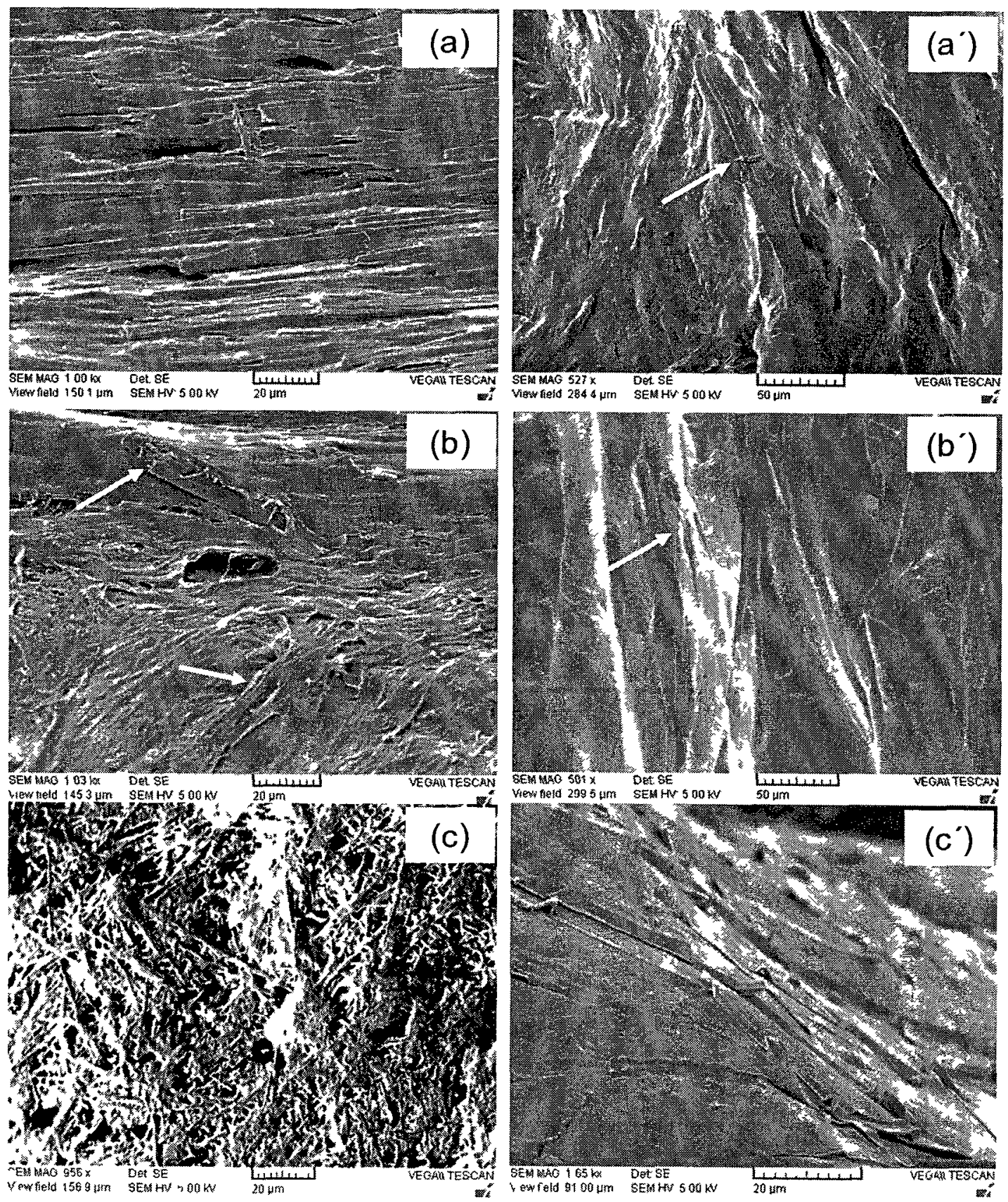

Figure 8 10. SEM micrographs of xerogels of PCL/biscarbamate: 90/10 (wt \%) blends $\left(a, a^{\prime}\right) \operatorname{PCL} / C_{11} ;\left(b, b^{\prime}\right) P C L / C_{12}$, and $\left(c, c^{\prime}\right)$ PCL/C 13 The left column represents the micrographs of quenched samples and the right column corresponds to the slow-cooled samples The arrows show the eaves trough morphology of the fibers 

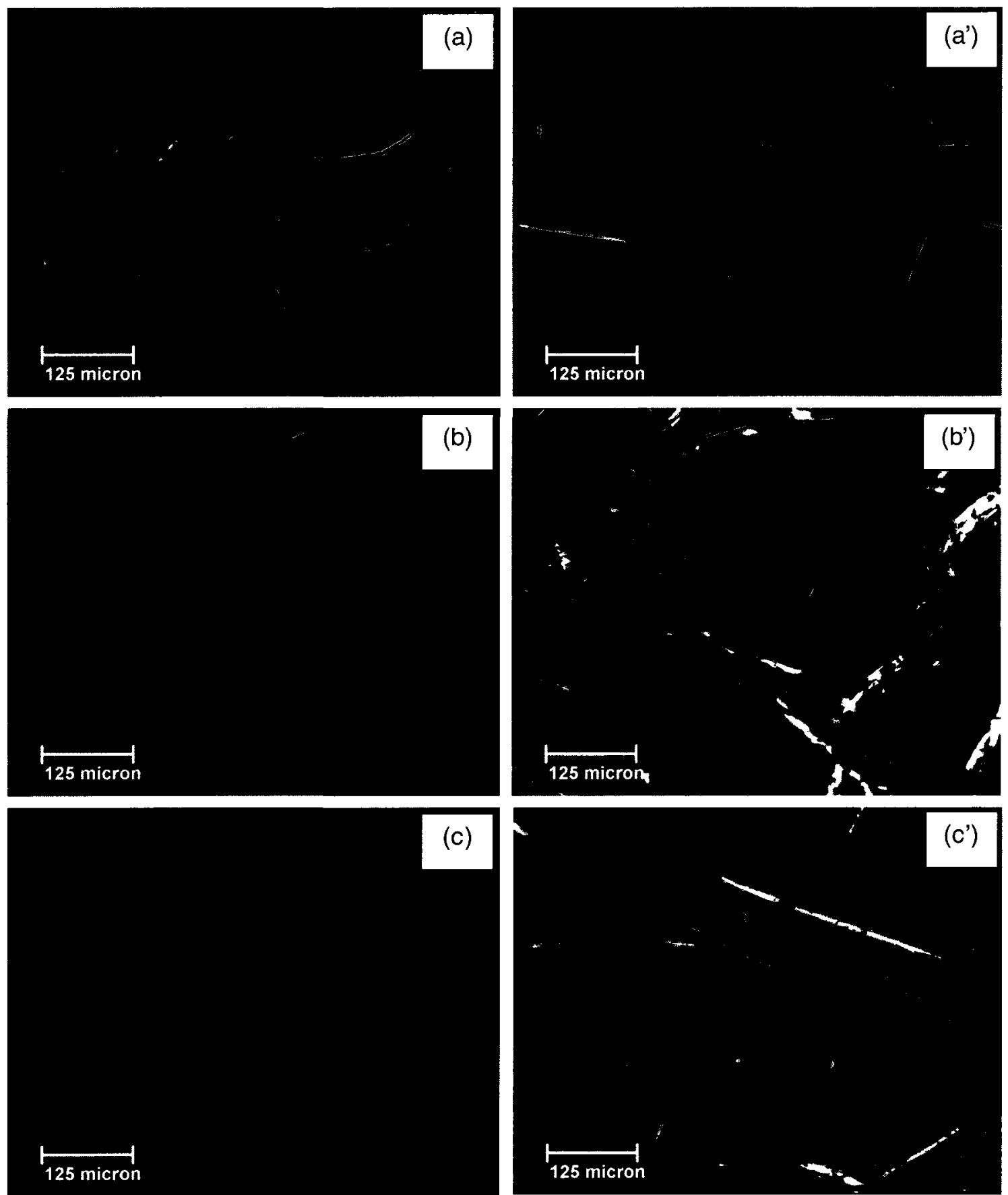

Figure 8.11. Optical micrographs of xerogels of PCL/ biscarbamate: $85 / 15$ (wt \%) blends recorded after partially melting at $60{ }^{\circ} \mathrm{C}$ : (a, a') PCL/C $11,\left(b, b^{\prime}\right)$ PCL/C 12 , and (c, c') $\mathrm{PCL} / \mathrm{C}_{13}$. The left column represents the micrographs of quenched samples and the right column corresponds to those of the slow-cooled samples. 
We discuss the xerogels as it was difficult to maintain the wet gels due to the rapid evaporation of chloroform. Figure 8.10 shows the SEM micrographs of the quenched and slow-cooled xerogels. It is seen that the PCL does not form any spherulites upon gelation, rather it serves as a coarse fibrillar polymer matrix in which the biscarbamate fibers that formed upon gelation are impregnated. The eaves trough morphology that led to hollow fibers that was seen before with biscarbamate gels ${ }^{16}$ is present here as well.

PCL melts at $\sim 60{ }^{\circ} \mathrm{C}$ while the $T_{\mathrm{m}}$ of the biscarbamates studied here are over 100 ${ }^{\circ} \mathrm{C}$. That the network of fibers corresponds to the biscarbamates was confirmed by partially melting the PCL component at $60{ }^{\circ} \mathrm{C}$. Figure 8.11 shows optical micrographs of both slow-cooled and quenched samples of biscarbamates in PCL from such partial melting experiments. The left column represents micrographs of quenched samples and the right column corresponds to those of the slow-cooled samples. It is seen from both the SEM (Figure 8.10) and OM images (Figure 8.11) that the slow-cooled samples form longer and wider fibers than those of the corresponding quenched samples. This difference could be attributed to the better formation and entanglement of the fibrils in the slow-cooled samples as compared to the quenched samples in which these are hampered due to the arrest of the molecules during rapid cooling. Similar behavior was seen in the spherulitic morphology as well, with the slow-cooled samples forming larger spherulites. $^{15,29}$

To study the effect of concentration on the gel fiber morphology we prepared gels of biscarbamates in PCL at different concentrations. Figure 8.12 shows the micrographs 
of $\mathrm{PCL} / \mathrm{C}_{11}$ and $\mathrm{PCL} / \mathrm{C}_{13}$ gels at $10 \%, 15 \%$ and $20 \%$ compositions. It is seen that there is no significant difference in the fiber morphology except an increase in fiber density with concentration. The dense fibrous matrix implies that PCL also forms fibrous morphology.
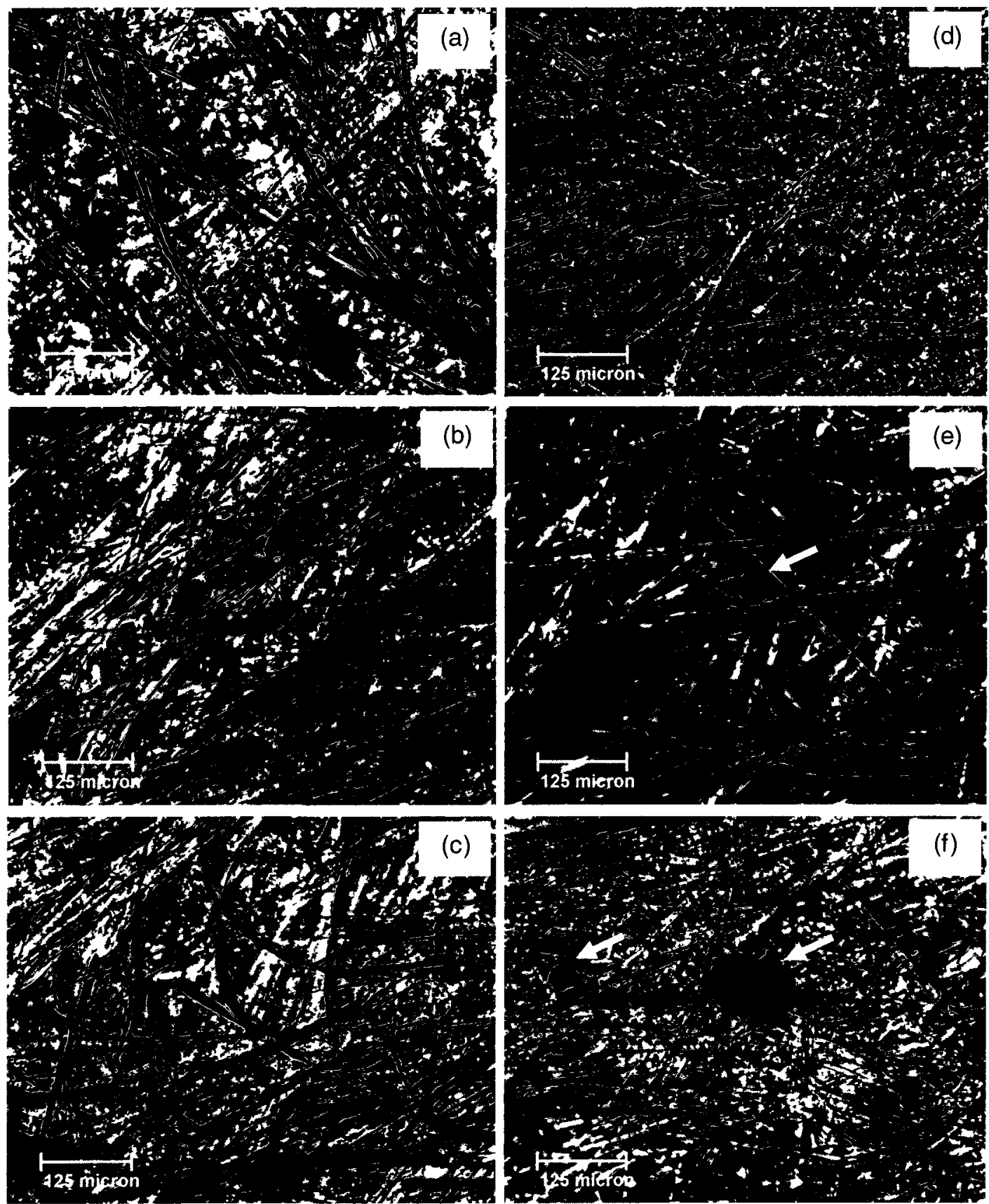

Figure 8.12. Optical micrographs of PCL/C $\mathrm{C}_{11}(\mathrm{a}, \mathrm{b}, \mathrm{c})$ and $\mathrm{PCL} / \mathrm{C}_{13}(\mathrm{~d}, \mathrm{e}, \mathrm{f})$ biscarbamate gels at different compositions of $\mathrm{C}_{11}$ and $\mathrm{C}_{13}$ : (a,d) $10 \%$, (b, e) $15 \%$, and (c, f) $20 \%$. White arrows indicate the globular precipitates of $\mathrm{C}_{13}$. 
With an increase in $\mathrm{C}_{13}$ concentration, precipitation occurs along with gelation leading to less stable and opaque gels. With a relative concentration of $10 \%$ of $\mathrm{C}_{13}$, only fibers are
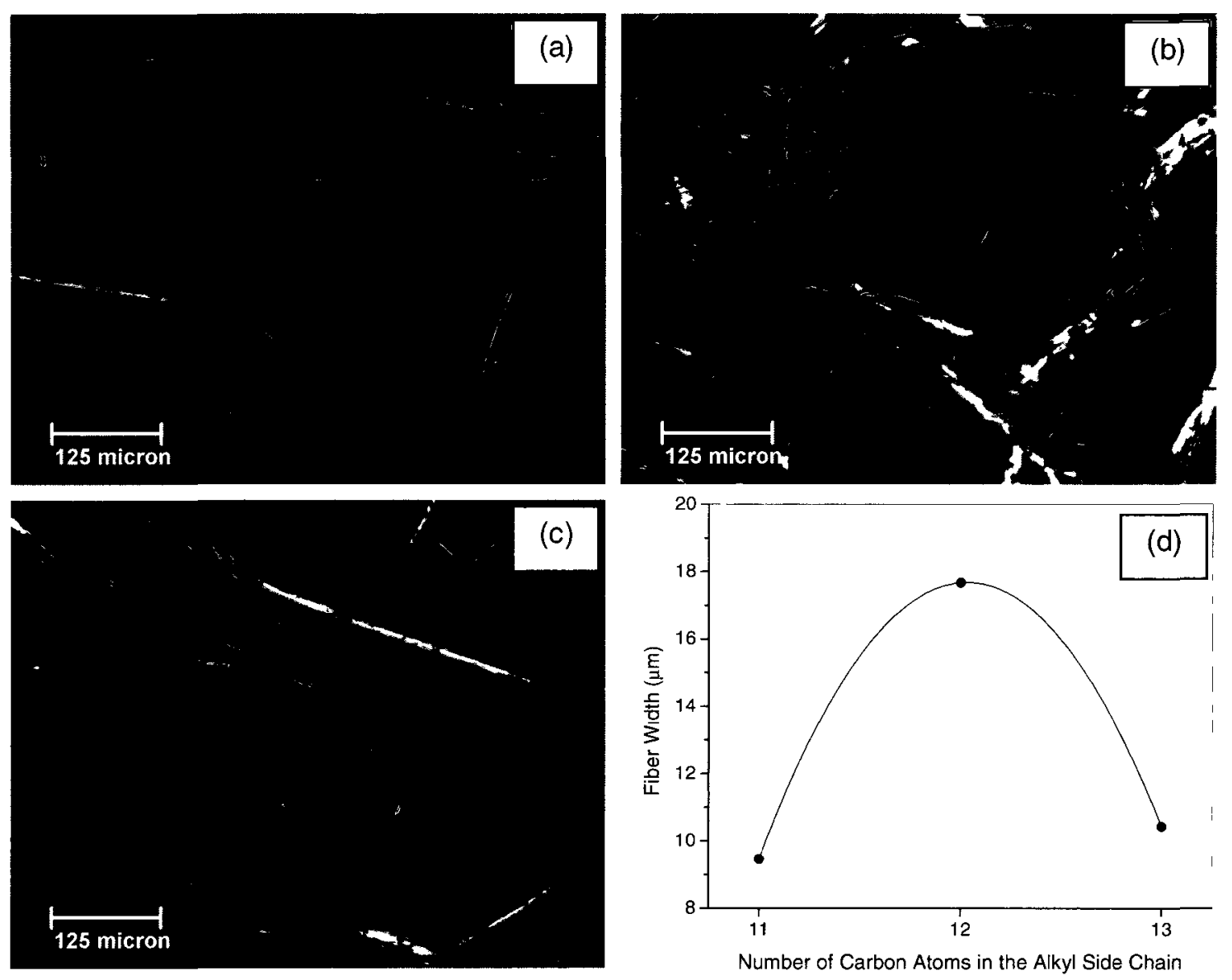

Figure 8.13. Optical micrographs showing the change in the fiber width as a function of alkyl side chain length at a constant (15\%) composition: (a) $\mathrm{C}_{11}$, (b) $\mathrm{C}_{12}$, and (c) $\mathrm{C}_{13}$. $\mathrm{A}$ graph of the variation is shown in (d).

seen (Figure 8.12d). As its concentration is increased to 15 and $20 \%$, precipitation in the form of aggregates occurs (indicated by white arrows in Figures $8.12 \mathrm{e}$ and f). These are crystal mass of the biscarbamate and appear black due to the large thickness.

To further investigate the effect of alkyl chain length, we studied the PCL/biscarbamate gels of $\mathrm{C}_{11}, \mathrm{C}_{12}$ and $\mathrm{C}_{13}$ at a constant composition. Figure 8.13 shows 
the effect of alkyl side chain length on the morphology in the OM of the partially melted xerogels prepared with the same concentration of the biscarbamates. A plot of the gel fiber widths is given in Figure $8.13 \mathrm{~d}$. It is seen that among the three biscarbamates, $\mathrm{C}_{11}$ and $\mathrm{C}_{13}$ form longer and thinner fibers than those of $\mathrm{C}_{12}$. We attribute this to the distinct difference in the (hydrogen bond mediated) self-assembling behaviour between the odd and even number of carbon atoms in the side chain. Results of the studies, discussed in Chapter 3, show that the odd and even number of carbon atoms in the alkyl side chain exhibit different thermal and crystallization behavior.

\subsubsection{Bulk Morphology of the Composite Xerogels}

The morphology in the bulk of the xerogels was investigated by cutting them with a razor blade and recording SEM images of the cross sections. Figure 8.14 shows such cross sections for the PCL/ biscarbamate xerogels with $\mathrm{C}_{11}, \mathrm{C}_{12}$, and $\mathrm{C}_{13}$ at $15 \% \mathrm{w} / \mathrm{w}$ concentration. The SEM image of $\mathrm{PCL} / \mathrm{C}_{11}$ gel (Figure 8.14a) shows pores with the size of a few microns which are homogeneously distributed over the scanned area of the sample. However, a more porous morphology is observed with larger and irregular pores with inhomogeneous distribution in the case of PCL/ $\mathrm{C}_{12}$ gel (Figure 8.14b). We attribute the porosity to the formation of hollow biscarbamate fibers which are impregnated in the PCL matrix upon gelation. The difference in the pore size is consistent with the difference in the fiber width of biscarbamates with odd versus even number of carbon atoms in the alkyl side chains (Figure 8.13). Contrary to the gels containing $C_{11}$ and $C_{12}$, SEM image of the $\mathrm{PCL} / \mathrm{C}_{13}$ gel shows macro voids along with some small pores (Figure 8.14c). An enlarged view of the macro voids reveals a network of $C_{13}$ fibers impregnated 
in the polymer matrix. Gelation of $\mathrm{C}_{13}$ accompanied by precipitation could be responsible for the macro voids in the bulk of the composite gel.
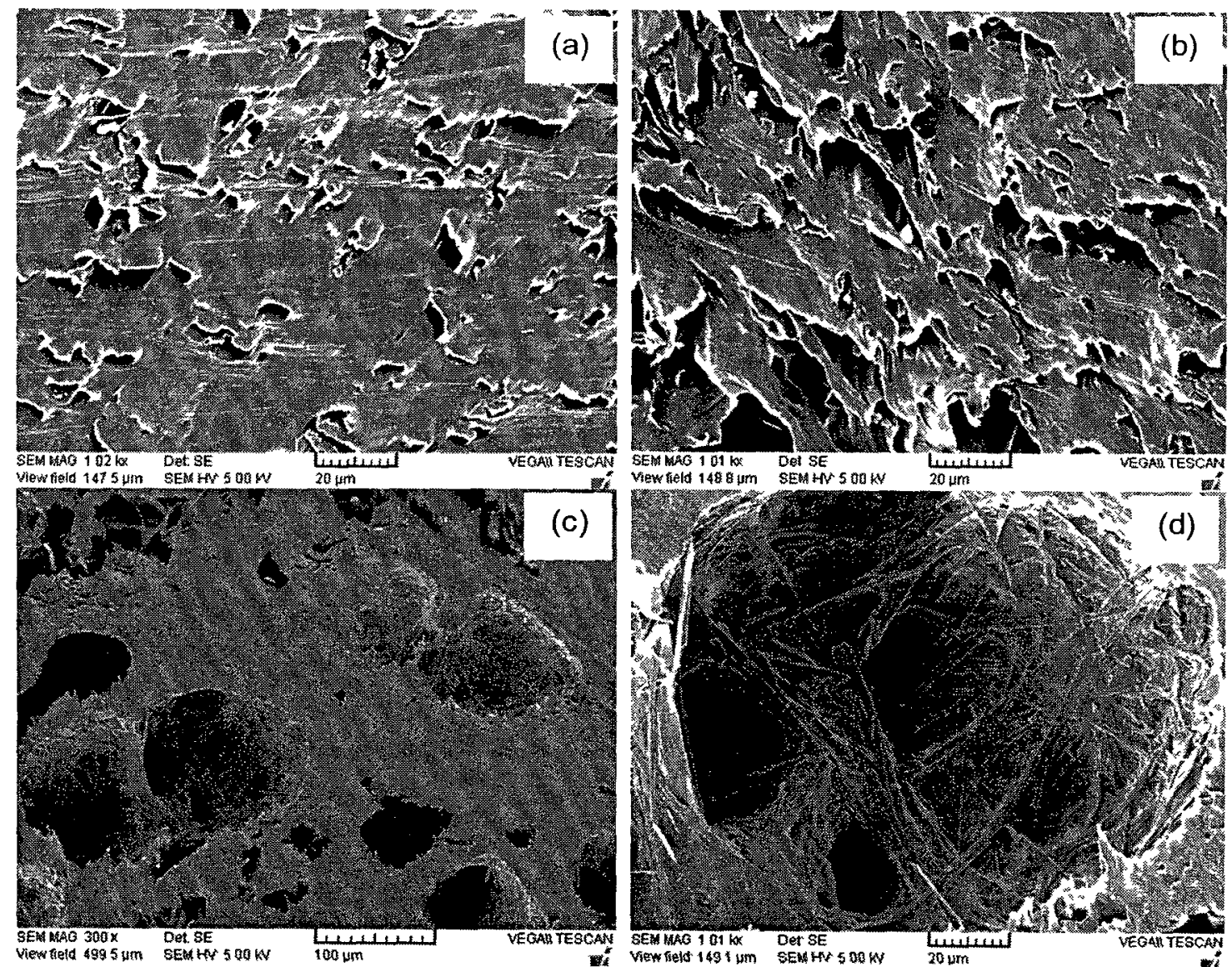

Figure 8.14. SEM images of cross sections of PCL/15\% biscarbamate gels with different number of carbon atoms in the alkyl side chains of the biscarbamate molecules: (a) $\mathrm{C}_{11}$, (b) $\mathrm{C}_{12}$, (c) $\mathrm{C}_{13}$. (d) is the magnified view of (c).

To examine the effect of concentration on the extent of porosity, SEM micrographs of the gels were recorded with different concentrations of biscarbamates. Figure 8.15 shows the cross-sectional view of $\mathrm{PCL} / \mathrm{C}_{12}$ with $90 / 10,85 / 15$, and $80 / 20$ (relative wt \%) compositions. A low biscarbamate concentration results in gels with less porosity while an increase in concentration leads to higher porosity with less control on the pore size distribution. These observations thus indicate that the morphology of these composite 
gels can be tailored by controlling two competing phenomena - gelation versus precipitation - by right choice of the biscarbamate with appropriate side chain length. On the other hand, the extent of porosity and pore size distribution of the composite gels prepared with the same biscarbamate can be controlled by changing the composition of the gel components.

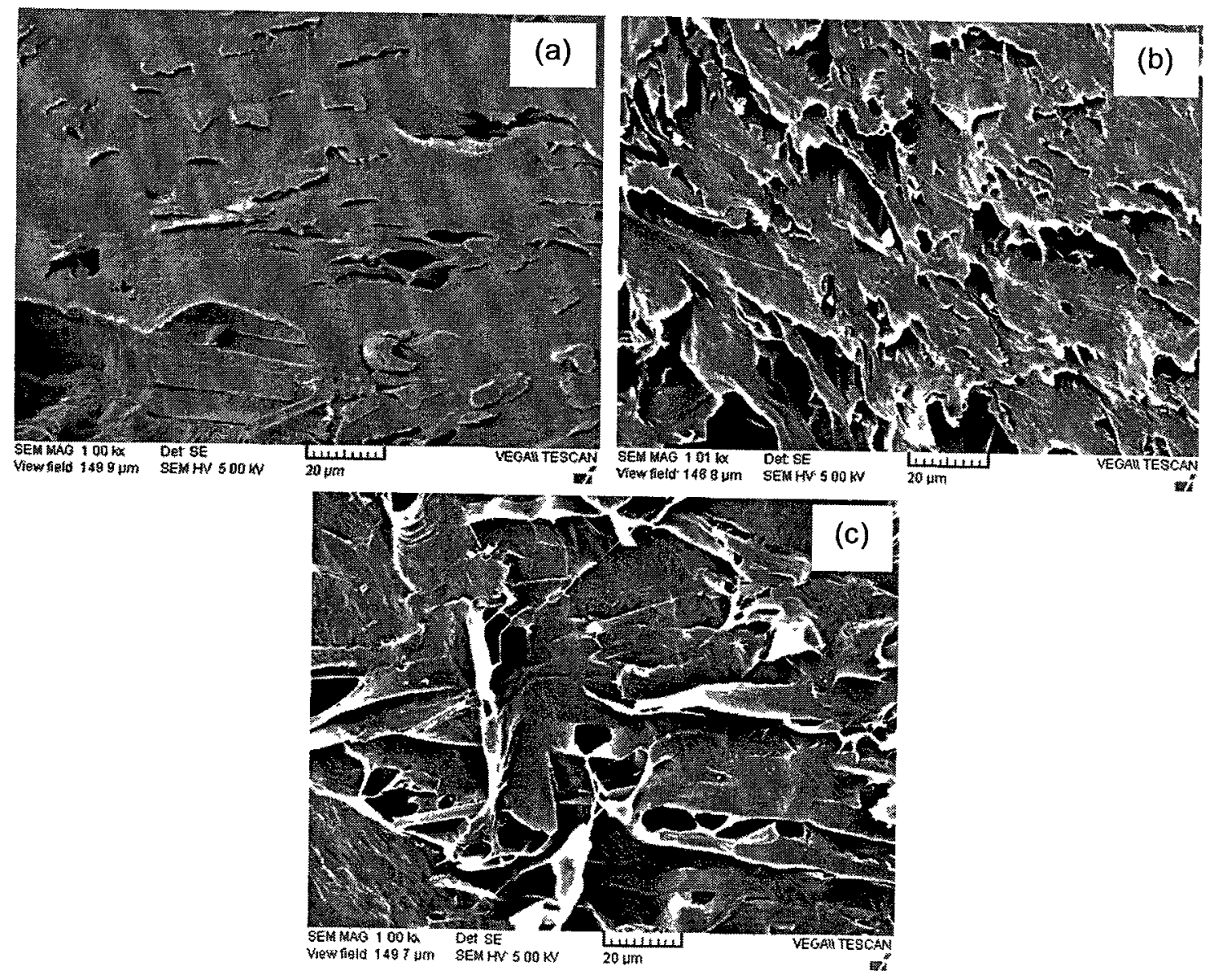

Figure 8.15. SEM images of cross sections of $\mathrm{PCL} / \mathrm{C}_{12}$ biscarbamate gels with different concentrations of $\mathrm{C}_{12}$. (a) $10 \%$, (b) $15 \%$, and (c) $20 \%$.

The benzonitrile/ biscarbamates gels that we reported before ${ }^{16}$ were very fragile. As mentioned in the Introduction, it was expected that impregnating the gel fibers in a polymer matrix would improve their handling. While we were able to cut the gels in the present study with a razor blade to look at the cross section, it was not possible to do so 
with the benzonitrile/biscarbamate gels. Although we did not perform extensive mechanical property measurements, the elongation of the present gels was measured using a manual stretching devise (shown under Table 8.2). ${ }^{33}$

Tabel 8.2. Elongation ratios of PCL/biscarbamate xerogels with varying concentrations of biscarbamates with different alkyl side chain lengths.

\begin{tabular}{cccc}
\hline \% composition & \multicolumn{3}{c}{ Biscarbamates } \\
\cline { 2 - 4 } & $\mathrm{C}_{11}$ & $\mathrm{C}_{12}$ & $\mathrm{C}_{13}$ \\
\hline 10 & $6.39 \pm 1.43$ & $5.98 \pm 1.49$ & $5.11 \pm 1.39$ \\
15 & $6.34 \pm 1.37$ & $5.19 \pm 1.33$ & $4.31 \pm 1.42$ \\
20 & $6.04 \pm 1.41$ & $4.14 \pm 1.51$ & $3.13 \pm 1.59$ \\
\hline
\end{tabular}

Sample dimension: Initial Length $=\sim 2 \mathrm{~cm}$; Width $=\sim 3 \mathrm{~mm}$; Thickness $=\sim 0.5 \mathrm{~mm}$

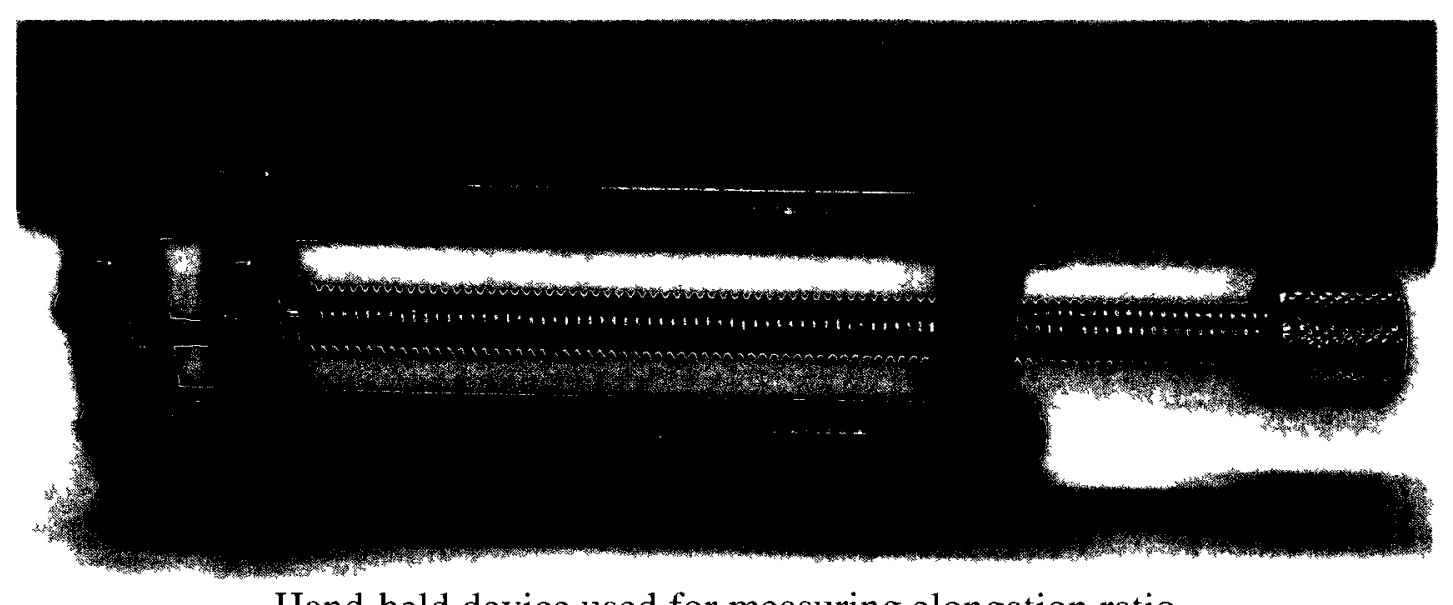

Hand-held device used for measuring elongation ratio

Table 8.2 lists the elongation ratios calculated using Eq. 8.4 for the PCL/ $\mathrm{C}_{11}, \mathrm{PCL} / \mathrm{C}_{12}$, and $\mathrm{PCL} / \mathrm{C}_{13}$ gels for different relative concentrations. The large error in these measurements is due to the inhomogeneity of the porous structure of the gels as discussed above. The intent here is to note the trend.

$$
\lambda=\left(\mathrm{L}-\mathrm{L}_{0}\right) / \mathrm{L}_{0}
$$


Compared to the fragile gels without the polymer, preparing them with a polymer matrix enhances the elongation, as seen from Table 8.2. It is seen that $\lambda$ decreases with an increase in the alkyl side chain length, as well as the relative concentration of the biscarbamates. The significant reduction in $\lambda$ upon increasing the relative concentration from 10 to $20 \%$ for the $\mathrm{PCL} / \mathrm{C}_{13}$ gel could be attributed to the precipitated crystalline aggregates serving as reinforcing filler in the polymer matrix.

\subsubsection{X-ray Diffraction of the Composite Gel}

To investigate the structural features of the components upon gelation, we recorded the XRD traces of the neat components and the composite xerogels at ambient temperature. Figure 8.16 shows the $\mathrm{XRD}$ traces of neat $\mathrm{PCL}$, neat $\mathrm{C}_{12}$ and a representative $\mathrm{PCL} / \mathrm{C}_{12}: 85 / 15$ (relative wt \%) composite xerogel. Neat PCL shows two intense reflections at $d=4.2$ and 3.7 , with a shoulder at $d=4.0 \AA$. XRD trace of neat $\mathrm{C}_{12}$ shows a number of reflections at $d=3.5,3.8,4.1,4.6,5.6$, and $8.4 \AA$. X-ray diffraction studies on a series of biscarbamate molecules homologous to $\mathrm{C}_{12}$ showed two common reflections at $d=4.6$ and $3.8 \AA$ and were assigned to the distance between the molecules in the hydrogen bonding plane and the distance between such two planes respectively. ${ }^{29}$ The low intensity reflection at $d=4.6 \AA$ is smeared out due to the low concentration of $\mathrm{C}_{12}$ in the composite gel. Appearance of those two peaks in the XRD trace of the composite xerogel confirms hydrogen bond mediated self-assembly of the biscarbamate molecules in the composite gels. The XRD trace of the composite xerogel simply consists of the peaks corresponding to PCL and $\mathrm{C}_{12}$, which indicates the immiscibility at the molecular level. 


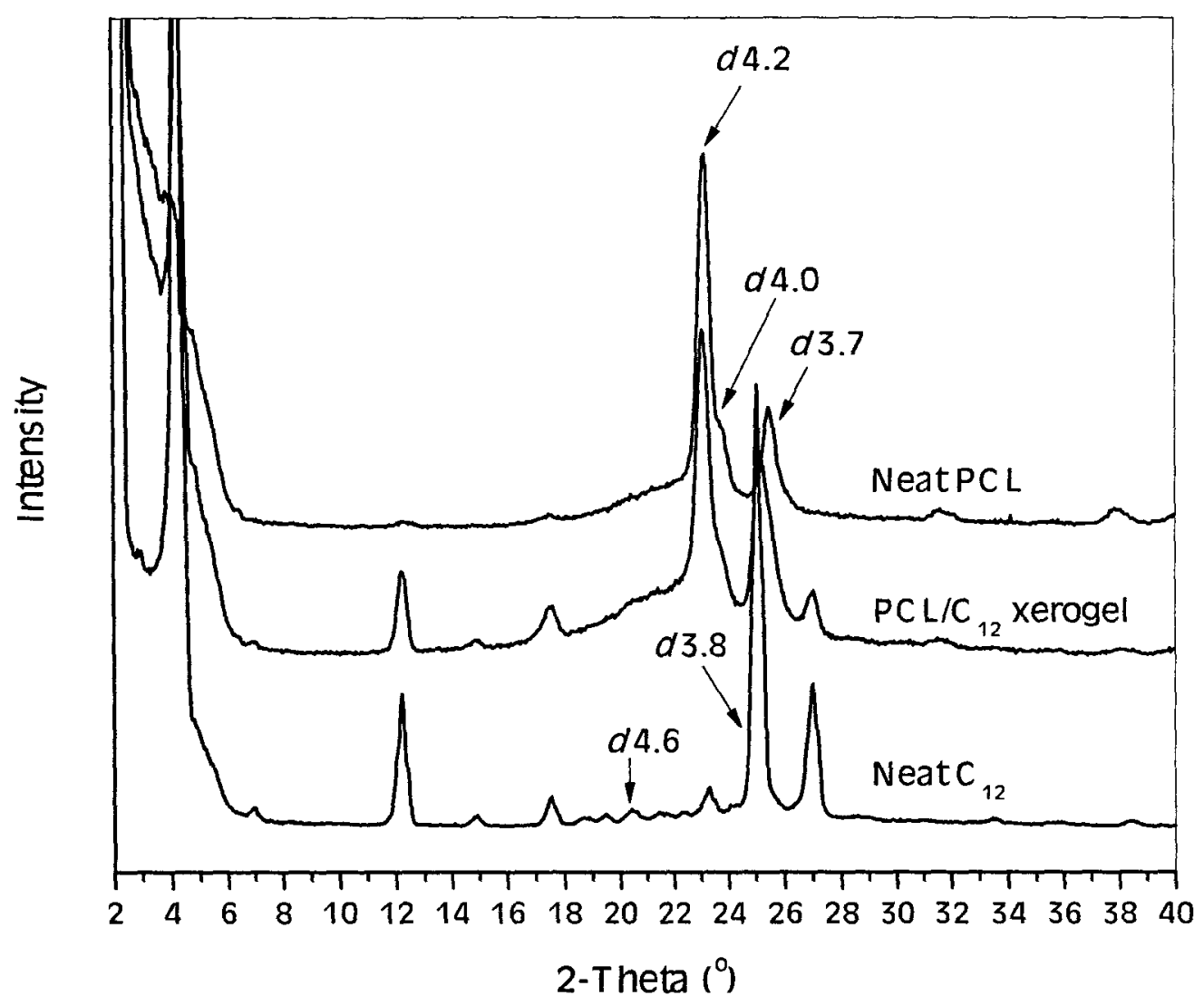

Figure 8.16. XRD traces of neat $\mathrm{C}_{12}$, neat $\mathrm{PCL}$, and $\mathrm{PCL} / 15 \% \mathrm{C}_{12}$ xerogel recorded at ambient temperature. The values of $d$-spacings are in $\AA$.

\subsubsection{Infrared Spectroscopy of the Composite Gel}

The interaction between the components of the composite gel via possible hydrogen bond exchange and/or change in its strength was investigated with IR spectroscopy. Figure 8.17 shows the IR traces of neat PCL, neat $\mathrm{C}_{12}$ and PCL/ $\mathrm{C}_{12}$ xerogel at ambient temperature. IR spectrum of neat PCL shows a strong absorption band at $1721 \mathrm{~cm}^{-1}$ corresponding to the stretching vibration of $\mathrm{C}=\mathrm{O}$ group typical of an aliphatic ester. Absorption band corresponding to $\mathrm{C}-\mathrm{O}$ and $\mathrm{C}-\mathrm{C}$ stretching in the amorphous phase appears as a broader band centered at $1165 \mathrm{~cm}^{-1}$. The symmetric and asymmetric $\mathrm{CH}_{2}$ stretching bands appear at 2865 and $2945 \mathrm{~cm}^{-1}$ respectively. ${ }^{34}$ Infrared spectra of neat $C_{12}$ 


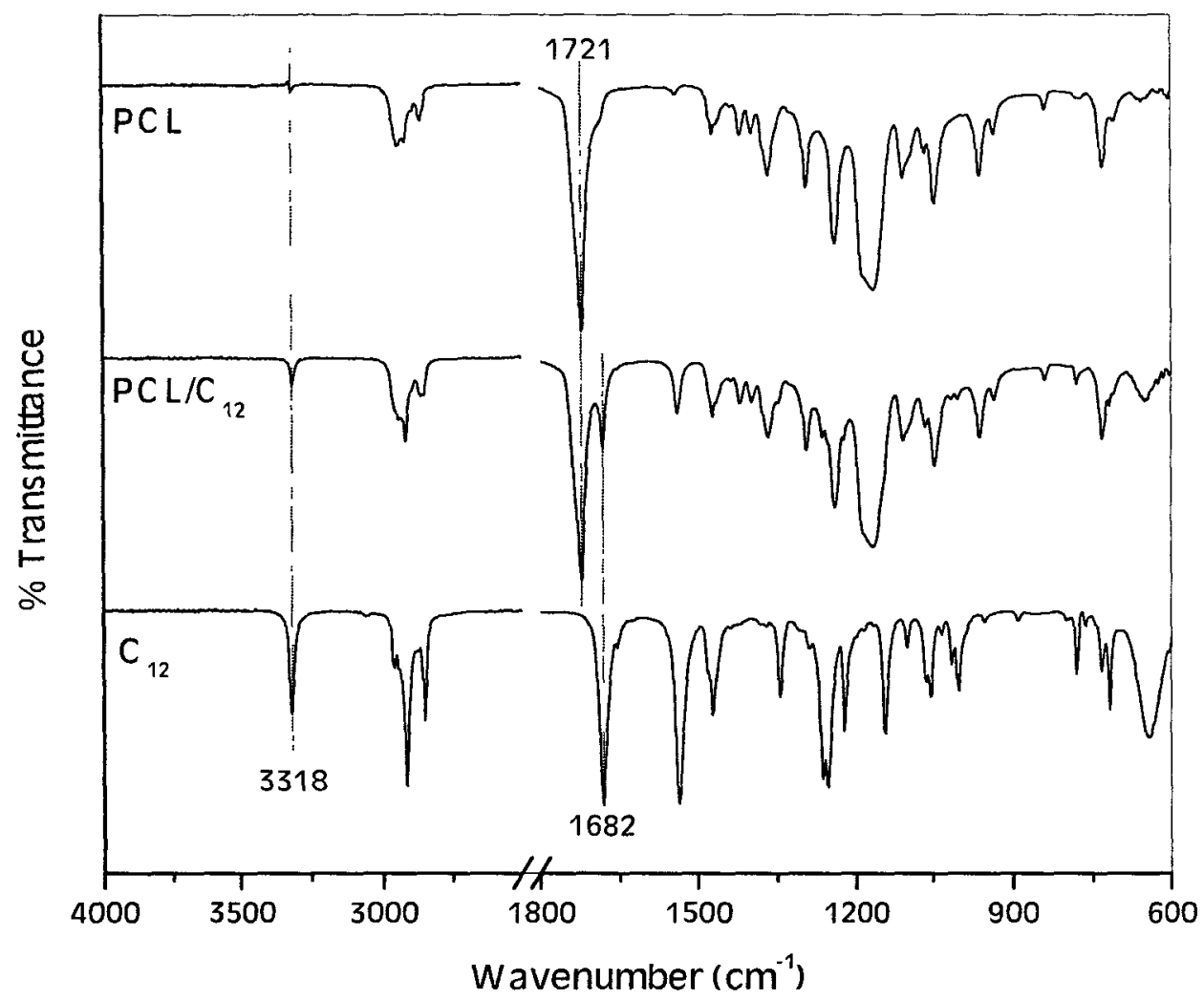

Figure 8.17. ATR - FTIR spectra of neat $\mathrm{C}_{12}$, PCL/15\% $\mathrm{C}_{12}$ xerogel, and neat PCL.

shows absorption bands at 3319 and $1682 \mathrm{~cm}^{-1}$ corresponding to the H-bonded N-H and $\mathrm{C}=\mathrm{O}$ groups respectively. Strong absorption bands appeared at 2850 and $2916 \mathrm{~cm}^{-1}$ correspond to the symmetric and asymmetric $\mathrm{CH}_{2}$ vibrations of $\mathrm{C}_{12}$ molecules respectively. The absorption bands belonging to the individual components appear essentially at the same position without any shift in their absorption frequency which could otherwise mean an interaction between the components. Appearance of the absorption bands at the same frequencies and absence of free $\mathrm{N}-\mathrm{H}$ and $\mathrm{C}=\mathrm{O}$ bands in the IR spectra of the $\mathrm{PCL} / \mathrm{C}_{12}$ gel confirms the presence of intermolecular $\mathrm{H}$-bonding during the aggregation of the $\mathrm{C}_{12}$ molecules into a fibrillar structure in the gel. $\mathrm{C}_{12}$ and PCL in 
the two-component gels do not affect each other's absorption frequencies in the IR spectra indicating self-sorting aggregation of the biscarbamates in the gels and rules out the possibility of the H-bond exchange between the components.

\subsection{Conclusions}

We conclude that biscarbamates remained immiscible in blends with PCL though both of the components possess hydrogen bonding donor-acceptor moieties. The immiscibility and self-sorting characteristics at the molecular level were confirmed by DSC, X-ray diffraction, FTIR and microscopy studies. DSC measurements showed that there is no significant change in the melting temperatures of the components upon blending. However, blending does result in significant reduction in their heats of fusion and hence the crystallinity. There was a distinct difference between the crystallization in solvent cast films and the bulk of the blend. In the former, PCL formed spherulites and the biscarbamates formed crystalline aggregates in the polymer matrix. However, in the bulk, the latter formed spherulites, and PCL formed droplets. We exploited this immiscibility to fabricate two-component organogels in $\mathrm{CHCl}_{3}$. Neither of the neat components gel $\mathrm{CHCl}_{3}$. However, when they are dissolved together, within a narrow range of alkyl side chain lengths, they form gel upon cooling the solution. Biscarbamate below $\mathrm{C}_{11}$ remain soluble and those beyond $\mathrm{C}_{13}$ precipitate. Microscopic studies showed that biscarbamates form the hollow gel fibers which are impregnated in the PCL matrix and immobilizes the solvent. Hollow nature of the gel fibers results in microchannels and macrovoids depending on the alkyl side chain length of the biscarbamate. The extent of porosity and the pore dimensions can be tailored by the right choice of biscarbamate 
molecules with odd versus even number of carbon atoms in the alkyl side chains as well as varying the composition with the same biscarbamate molecule. Impregnation of the gel fibers in the polymer matrix enhances the mechanical robustness of the gel fibers. Thus these are examples of two-component physical gels comprised of an immiscible pair of a low molecular weight organogelator and a biocompatible polymer. 


\subsection{References}

1. Special Issue on Supramolecular Chemistry and Self-Assembly, Service, R. F.; Szuromi, P.; Uppenbrink, J. Eds. Science 2002, 295, 2395.

2. (a) Palermo, V.; Samori, P. Angew. Chem. Int. Ed. 2007, 46, 4428. (b) Philp, D.; Stoddart, J. F. Angew. Chem. Int. Ed. 1996, 35, 1154; (c) Lawrence, D. S.; Jiang, T.; Levett, M. Chem. Rev. 1995, 95, 2229; (d) Rosen, B. M.; Wilson, C. J.; Wilson, D. A.; Peterca, M.; Imam, M. R.; Percec, V. Chem. Rev. 2009, 109, 6275; (e) Szaciłowski, K. Chem. Rev. 2008, 108, 3481.

3. (a) Piepenbrock, M-O. M.; Lloyd, G. O.; Clarke, N.; Steed. J. W. Chem. Rev. 2010, 110, 1960; (b) Terech, P.; Weiss, R.G. Chem. Rev. 1997, 97, 3133.

4. (a) Zhang, P.; Wang, H.; Liu, H.; Li, M. Langmuir 2010, 26, 10183; (b) Yan, N.; He, G.; Zhang, H.; Ding, L.; Fang, Y. Langmuir 2010, 26, 5909; (c) Zhang, Y-M.; Lin, Q.; Wei, T-B.; Qin, X-P.; Li, Y. Chem. Commun. 2009, 6074; (d) Chung, J. W.; Yoon, S-J.; Lim, S-J.; An, B-K.; Park, S. Y. Angew. Chem. Int. Ed. 2009, 48, 7030.

5. (a) Lee, H. Y.; Nam, S. R.; Hong, J-I. J. Am. Chem. Soc. 2007, 129, 1040; (b) Hirst, A. R.; Smith, D. K.; Harrington, J. P. Chem. Eur. J. 2005, 11, 6552; (c) Hirst, A. R.; Smith, D. K.; Feiters, M. C.; Geurts, H. P. M.; Wright, A. C.; J. Am. Chem. Soc. 2003, 125,9010 .

6. (a) Suzuki, M.; Hanabusa, K. Chem. Soc. Rev., 2010, 39, 455; (b) Suzuki, M.; Yanagida, R.; Setoguchi, C.; Shirai, H.; Hanabusa, K. J. Polym. Sci. Polym. Chem. 2008, 46, 353; 
(c) Suzuki, M.; Setoguchi, C.; Shirai, H.; Kenji Hanabusa, K. Chem. Eur. J. 2007, 13, 8193; (d) Suzuki, M.; Owa, S.; Shirai, H.; Hanabusa, K. J. Polym. Sci. Polym. Chem. 2006, 44, 3817.

7. (a) Sun, S.; Chen, X.; Liu, J.; Yan, J.; Fang, Y. Polym. Eng. Sci. 2009, 99; (b) Wilder, E. A.; Hall, C. K.; Khan, S. A.; Spontak, R. J. Langmuir 2003, 19, 6004; (c) Mercurio, D. J.; Spontak, R. J. J. Phys. Chem. Part B 2001, 105, 2091.

8. (a) Kelly, T. L.; Yano, K.; Wolf, M. O. Langmuir 2010, 26, 421; (b) Liu, X.; Ma, P. X. Biomaterials 2009, 30, 4094; (c) Rathod, S. B.; Ward, T. L. J. Mater. Chem. 2007, 17, 2329.

9. Kim, H-C.; Park, S-M.; Hinsberg, W. D. Chem. Rev. 2010, 110, 146.

10. (a) Krafft, M. P.; Giulieri, F.; Fontaine, P.; Goldmann, M. Langmuir 2001, 17, 6577; (b) Cornils, B. Angew. Chem. Int. Ed. Engl 1997, 36, 2057.

11. Kato, T. Science 2002, 295, 2414.

12. Heeres, A.; van der Pol, C.; Stuart, M.; Friggeri, A.; Feringa, B. L.; van Esch, J. J. Am. Chem. Soc. 2003, 125, 14252.

13. (a) Botterhuis, N. E.; Karthikeyan, S.; Spiering, A. J. H.; Sijbesma, R. P. Macromolecules 2010, 43, 745; (b) Hwang, I.W.; Kamada, T.; Ahn, T. K.; Ko, D. M.; Nakamura, T.; Tsuda, A.; Osuka, A.; Kim, D. J. Am. Chem. Soc. 2004, 126, 16187; (c) Bilgicer, B. Xing, X.; Kumar, K. J. Am. Chem. Soc. 2001, 123, 11815; (d) Rowan, S. J.; Hamilton, D. G.; Brady, P. A.; Sanders, J. K. M. J. Am. Chem. Soc. 1997, 119, 2578.

14. Hirst, A. R.; Miravet, J. F.; Escuder, B.; Noirez, L.; Castelletto, V.; Hamley, I. W.; Smith, D. K. Chem. Eur. J. 2009, 15, 372. 
15. Khan, M. K.; Sundararaian, P. R. J. Phys. Chem. B 2008, 112, 4223.

16. Khanna, S.; Khan, M. K.; Sundararajan, P. Langmuir 2009, 25, 13183.

17. Moniruzzaman, M.; Sundararajan, P. R. Langmuir 2005, 21, 3802.

18. (a) Nam, S. R.; Lee, H. Y.; Hong, J-I. Chem. Eur. J. 2008, 14, 6040; (b) Lohr, A.; Wurthner, F. Chem. Commun. 2008, 2227; (c) Smulders, M. M. J.; Schenning, A. P. H. J.; Meijer, E. W. J. Am. Chem. Soc. 2008, 130, 606.

19. (a) Llusar, M.; Sanchez, C. Chem. Mater. 2008, 20, 782; (b) Shimizu, T.; Masuda, M.; Minamikawa, H. Chem. Rev. 2005, 105, 1401.

20. (a) Singh, N. K.; Purkayastha, B. D.; Roy, J. K.; Banik, R. M.; Yashpal, M.; Singh, G.; Malik, S.; Maiti, P. ACS Appl. Mater. Interfaces 2010, 2, 69; (b) Luo, H.; Meng, X.; Cheng, C.; Dong, Z.; Zhang, S.; Li, B. J. Phys. Chem. B 2010, 114, 4739.

21. (a) Seyednejad, H.; Vermonden, T.; Fedorovich, N. E.; van Eijk, R.; van Steenbergen, M. J.; Dhert, W. J. A.; van Nostrum, C. F.; Hennink, W. E. Biomacromolecules 2009, 10, 3048; (b) Mattanavee, W.; Suwantong, O.; Puthong, S.; Bunaprasert, T.; Hoven,V. P.; Supaphol, P. ACS Appl. Mater. Interfaces 2009, 5, 1076; (c) Zapata, P.; Su, J.; Garcia, A. J.; Meredith, J. C. Biomacromolecules 2007, $8,1907$.

22. (a) Chen, A-L.; Ni, H-C.; Wang, L-F.; Chen, J-S. Biomacromolecules 2008, 9, 2447;

(b) Kim, B-S.; Park, S. W.; Hammond, P. T. ACS Nano 2008, 2, 386.

23. (a) Wang, W.; Jin, Y.; Ping, P.; Chen, X.; Jing, X.; Su, Z. Macromolecules 2010, 43, 2942; (b) Luo, X.; Mather, P. T. Macromolecules 2009, 42, 7251; (c) Lee, K. M.; Knight, P. T.; Chung, T.; Mather, P. T. Macromolecules 2008, 41, 4730; (d) Luo, H. Y.; Liu, Y.; Yu, Z. J.; Zhang, S.; Li, B. J. Biomacromolecules 2008, 9, 2573. 
24. Feng, J.; Gao, C.; Shen, J. Chem. Mater. 2004, 16, 1319.

25. Costantino, U.; Bugatti, V.; Gorrasi, G.; Montanari, F.; Nocchetti, M.; Tammaro, L.; Vittoria, V. ACS Appl. Mater. Interfaces 2009, 1, 668.

26. O’Bryan, G.; Wong, B. M.; McElhanon, J. R. ACS Appl. Mater. Interfaces 2010, 2, 1594.

27. (a) Ajili, S. H.; Ebrahimi, N. G.; Ansari, M. Rheol Acta 2008, 47, 81; (b) Sonnenschein, M. F.; Lysenko, Z.; Brune, D. A.; Wendt, B. L.; Schrock, A. K. Polymer, 2005, 46, 10158; (c) Wang, S. H.; Silva, L. F.; Kloss, J.; Munaro, M.; de Souza, G. P.; Wada, M. A.; Gomez, J. G. C.; Zawadzki, S.; Akcelrud, L. Macromol. Symp. 2003, 197, 255; (d) van Bogart, J. W. C.; Gibson, P. E.; Cooper, S. L. J. Polym. Sci. Polym. Phys. Ed. 1983, 21, 65; (e) Ann, T. O.; Han, K. T.; Jeong, H. M.; Lee, S. W. Polymer International 1992, 29, 115.

28. Goodbrand, B.; Boils, D.; Sundararajan, P. R.; Wong, R. U.S. Patent 6,414,051, 2002.

29. Khanna, S.; Moniruzzaman, M.; Sundararajan, P. R. J. Phys. Chem. B 2006, 110, 15251.

30. (a) Jenkins, M. J.; Harrison, K. L. Polym. Adv. Tech. 2006, 17, 474; (b) Koenig, M. F.; Huang, S. J. Polymer, 1995, 36, 1877; (c) Crescenzi, V.; Manzini, G.; Calzolari, G.; Borri, C. Eur. Polymer J., 1972, 8, 449.

31. Jabarin, S. A.; Stein, R. S. J. Phys. Chem. 1973, 77, 399.

32. Goulet, L.; and Prud'homme, R. E. J. Polym. Sci. Polym. Phys. Ed., 1990, 28, 2329.

33. Vaysse, M.; Khan, M. K.; Sundararajan, P. Langmuir 2009, 25, 7042. 
34. (a) Tadokoro, H.; Kobayashi, M.; Yoshidome, H; Tai, K.; Makino, D. J. Chem. Phys. 1968, 49, 3359; (b) Hubble, D.; Cooper, S. J. Polym. Sci., Polym. Phys. Ed. 1977, 15, 1143; (c) Coleman, M. M.; Zarian, J. J. Polym. Sci., Polym. Phys. Ed. 1979, 17, 837; (d) Yan, C.; Li, H.; Zhang, J.; Ozaki, Y.; Shen, D.; Yan, D.; Shi, AC.; Yan, S. Macromolecules 2006, 39, 8041. 
Chapter 9

Conclusions and Recommendations for Future Work 


\subsection{Conclusions}

The purpose of this thesis was to systematically study the effects of varying the structural features of a series of hydrogen bond-mediated self-assembling biscarbamates on their crystallization behaviour and morphology in solid state as well as the gelation behaviour from the solution phase.

Thermal analysis showed that the biscarbamate molecules studied in this work do not show any polymorphism and are highly crystalline in nature. The outward spherulitic morphology of these biscarbamates was found to be dependent on the sample preparation protocol, i.e., quenching or slow cooling of the samples although the extent of intermolecular interactions and hence the molecular packing was independent of these processes.

We studied the crystallization behaviour and morphology of a series of homologous biscarbamate molecules with alkyl side chains of different carbon atom parity as the first instance of structural features that affected the functional properties of these biscarbamates. Biscarbamate molecules with $\left(\mathrm{CH}_{2}\right)_{6}$ spacer between the hydrogen bonding motifs with odd versus even number of carbon atoms in the alkyl side chains showed an odd-even alternation in melting temperatures and heats of fusion although the odd-even effect was less pronounced in the latter case. Biscarbamates with odd number of carbon atoms showed higher melting temperatures than the even numbered biscarbamates, which is in contrast to the thermal properties of $n$-alkanes. We found that carbon atom parity in alkyl side chains influences the extent of packing of these molecules leading to different thermal behaviour and spherulitic morphology upon crystallization from the melt. Biscarbamates with odd number of carbon atoms in the 
alkyl side chains show higher spherulite size and spherulite growth rate compared to the consecutive even numbered biscarbamates resulting in the odd-even effect in the spherulitic morphology similar to that in the thermal properties. It was seen that the spherulite size, spherulite growth rate and the bulk crystallization rate increases with the increase in alkyl side chain length, reaching to a maximum at a certain length and then decreases with further increase. Hence the length and carbon atom parity of the alkyl side chains as well as the sample preparation protocol (i.e., quenching versus slow-cooling) play an important role in the morphology of these molecules. We rationalize this behaviour with relative contributions of hydrogen bonding and van der Waals forces as discerned from IR spectroscopy. Hence, we conclude that the thermal properties and the morphology of these molecules can be tailored to the desired functional level by changing the alkyl side chain length with right carbon atom parity.

As the second instance of our pursuit to investigate the structure-property relationship of biscarbamates, we studied the thermal properties and morphology of a series of homologous biscarbamate molecules with a longer spacer group than those discussed in Chapter 3. While it was expected that a longer spacer would lead to more conformational flexibility, we found that it was not the case with these molecules. With both $\left(\mathrm{CH}_{2}\right)_{6}$ and $\left(\mathrm{CH}_{2}\right)_{12}$ spacers, we found that the maximum in the spherulite size as well as the rate of spherulite growth occur with an alkyl side chain length of $C_{8}$. The Avrami analysis of crystallization shows that the highly symmetric molecule with the $\mathrm{C}_{12}$ spacer and $\mathrm{C}_{12}$ side chain follows two-stage crystallization. Along this series of molecules, a minimum spherulite size, spherulite growth rate and rate of crystallization were observed for this symmetric $\mathrm{C}_{12}-\mathrm{C}_{12}$ biscarbamate. We rationalized this behaviour 
with relative contribution of hydrogen bonding and van der Waals forces as deduced from IR spectroscopy. When the terminal methyl group is replaced with a bulky phenyl group the melting temperature, heat of fusion and the spherulite size of the molecule decreased significantly. Contrary to the expectation that it would add another self assembly code (interaction) and provide increased stability (in terms of melting temperatures etc.), the phenyl terminal groups act as defects. It was thus proved that the properties of these molecules can be tailored to the optimum functional level by varying one of these structural features.

The miscibility behaviour of the biscarbamates was studied by blending two molecules with similar spacer but different alkyl side chain length. It was found that these molecules are capable of hydrogen-bond mediated self-assembly leading to specific association between the same types and does not involve mutual intercalation at the molecular level which implied their immiscibility during blending. The components of the blend exercise a mutual diluent effect, thereby reducing the melting temperatures spherulite size, crystallinity, and the heat of fusion. Isothermal crystallization studies showed that the growth rates of the spherulites are also reduced upon blending, with respect to those of the individual components. In situ observations during the melting of the blends revealed that the spherulites of each constituent do not form separately, but by mixing with and providing nucleating sites for each other. The extent of hydrogen bonding and the packing of alkyl side chains were not affected by blending. The variation in the length of the alkyl side chains plays a role in such immiscibility and selectivity of these molecules during crystallization that paralleled those of monocarbamates and hydrogen bond-mediated self-assembling polymers. 
In another aspect, we were interested in studying the self-assembling behaviour of the biscarbamates in solution phase. Of the polyurethane model compounds studied by our group, the gelation behaviour of biscarbamates with two hydrogen-bonding motifs and symmetrically disposed alkyl chains was found to be very different from that of mono carbamates with a single hydrogen bond group flanked by alkyl chains of unequal lengths. Biscarbamates with long alkyl chains such as $\mathrm{C}_{16}$ and $\mathrm{C}_{18}$ gel various solvents used here (benzonitrile, toluene, xylene, dodecane and 1-octanol), whereas such long side chains promoted only crystallization in the case of mono carbamates.

Hollow fibers were seen in the gelation of biscarbamates, although the system is neither chiral nor amphiphilic. We proposed that due to the predominant van der Waals interaction between the long alkyl chains, in addition to the double hydrogen bonding in biscarbamates, the morphology consists of sheets and tubules, in contrast to long fibers seen in the case of monocarbamates and other organogelators. Because of the bending forces in effect, the sheets and tapes wrap into tubes. Incomplete wrapping shows the eaves trough morphology. While the tubules seen in the case of chiral molecules were attributed to the twisting caused by chirality, the bending of the sheets in the present case was rationalized on the basis of the asymmetry of the strength of the interactions along the three dimensions of fiber growth. Well-oriented fibers were formed in the gels made by simply using a magnetic stirrer on a hot plate, at 100 and $110 \mathrm{rpm}$. A preliminary study on the gelation of mixtures of biscarbamates with odd and even number of $\mathrm{CH}_{2}$ groups in the side chains, e.g., $\mathrm{C}_{9}$ and $\mathrm{C}_{8}$ showed that the presence of the odd member promotes long fiber formation for $\mathrm{C}_{8}$. This is perhaps the first example of the sergeantsoldier principle in a non-chiral system. 
We exploited the above mentioned mechanism of hollow gel fiber formation of biscarbamates to fabricate a novel biscarbamate-based organogelator for benzonitrile doped with metal nanoparticles and organic dye molecules. These are examples of lumen-loaded organogel fibers. Addition of PVP-coated silver nanoparticles during the gelation of $\mathrm{C}_{12}$ led to the deposition of nanoparticles on the sheets. Complete wrapping of these sheets eventually led to SNP-loaded fibers. Likewise, lumen-loaded organogel fibers were prepared with phthalocyanine $(\mathrm{Pc})$ dye molecules with needle-like crystal growth inside the hollow fibers. However, it was found that perylene (Pe) molecules were more prone to form crystals on the outer surface of the $\mathrm{C}_{12}$ fibers. This different behaviour of Pc and Pe molecules was accounted for by their crystal geometry and significantly different crystal-growth kinetics compared with that of $\mathrm{C}_{12}$ fiber formation in the gels. Optimum crystal geometry and comparable crystal growth kinetics with respect to that of $\mathrm{C}_{12}$ gel fibers favors the occlusion of Pc crystals. Thermal analysis showed that $\mathrm{C}_{12}$ forms quite a stable thermo-reversible gel with benzonitrile, and addition of Pc contributes more to the thermal stability of these gels than Pe, although the packing behaviour of the Pc and Pe molecules were not affected during the two-component gel formation. We find that for the dye molecule crystals to be occluded in the hollow gels, the growth rate of the crystals and the size and shape should be similar to those of the gel fibers. We have thus shown that lumen-loaded gel fibers with nanoparticles and dye molecules can be prepared by the two-component gel route, without any inter-molecular interaction in effect, provided that the above-mentioned growth rate, shape, and size conditions are satisfied. 
To further investigate into the miscibility behaviour in polymer matrix, we studied the heterologous blends of biscarbamates with biocompatible polycaprolactone (PCL) as an example. We found that biscarbamates remained immiscible in blends and showed self-sorting characteristics at the molecular level with PCL though both of the components possess hydrogen bonding donor-acceptor moieties. Thermal analysis confirmed that there is no significant change in the melting temperatures of the components upon blending. However, blending does result in significant reduction in their heats of fusion and hence the crystallinity. There was a distinct difference between the crystallization in solvent cast films and the bulk of the blend. In the former, PCL formed spherulites and the biscarbamates formed crystalline aggregates in the polymer matrix. However, in the bulk, the latter formed spherulites, and PCL formed droplets. We exploited this immiscibility to fabricate two-component organogels in chloroform. Neither of the neat components gels chloroform. However, when they are dissolved together, within a narrow range of alkyl side chain lengths, they form gel upon cooling the solution. Biscarbamate below $C_{11}$ remained soluble and those beyond $C_{13}$ precipitated. Biscarbamates formed the hollow gel fibers which are impregnated in the PCL matrix and immobilized the solvent. Hollow nature of the gel fibers resulted in microchannels and macrovoids depending on the alkyl side chain length of the biscarbamate. It was found that the extent of porosity and the pore dimensions could be tailored by the right choice of biscarbamate molecules with odd versus even number of carbon atoms in the alkyl side chains as well as varying the composition with the same biscarbamate molecule. Impregnation of the gel fibers in the polymer matrix enhanced the mechanical robustness of the gels. Thus we conclude that we were able to fabricate 
two-component physical gels comprised of an immiscible pair of a low molecular weight organogelator and a biocompatible polymer.

\subsection{Recommendations for Future Work}

In this present work, we have shown that the length of the alkyl side chains and spacer, carbon atom parity (odd versus even) and the type of terminal groups (methyl versus phenyl) of the alkyl side chains have profound effect on the morphology and crystallization behaviour of biscarbamates in solid state as well as on the gelation in solution phase. It would be of immense interest to similarly study the effect of these structural features on the morphology and crystallization behaviour of another class of self-assembling molecules to validate the generalization derived from this work. Bisurea could be that another class of molecules which self-assemble via bifurcated hydrogen bonding between the donor-acceptor moieties.

We have seen that carbon atom parity of the alkyl side chains show an odd-even alternation in thermal properties and crystallization behaviour of these biscarbamates. It would be of further scientific importance to study the odd-even effect of the carbon atom parity of the spacer group between the hydrogen bonding motifs. Moreover, it would be worthy to investigate the effect of the presence of aromatic group in the spacer instead of the alkyl side chains on their morphology and crystallization.

We revealed the immiscibility, molecular selectivity and self-sorting behaviour of the biscarbamates with even-even carbon atom parity in the alkyl side chains in their homologous blending. These observations could be further generalized by similar studies 
with homologous blends of biscarbamates with odd-odd and odd-even carbon atom parity of the blend components. Heterologous blending of biscarbamates with polymer also showed same self-sorting behaviour with PCL as an example leading to immiscibility driven gelation of the composite system. Other polymers with similar self-assembling traits can also be explored to validate the effectiveness and generalize this approach. 
Appendix A

FTIR Spectra of the Biscarbamates 


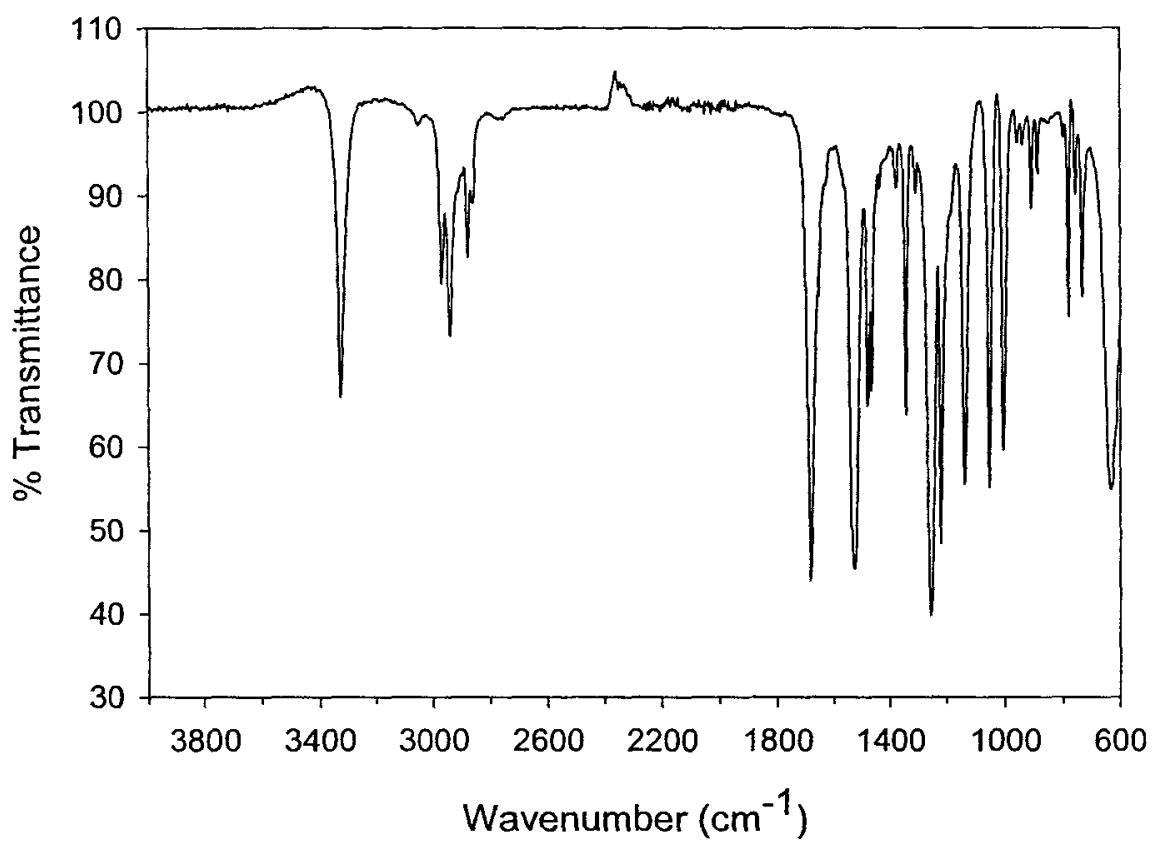

Figure A.1. FTIR spectrum of $\mathrm{C}_{3} \mathrm{C}_{6}$ biscarbamate.

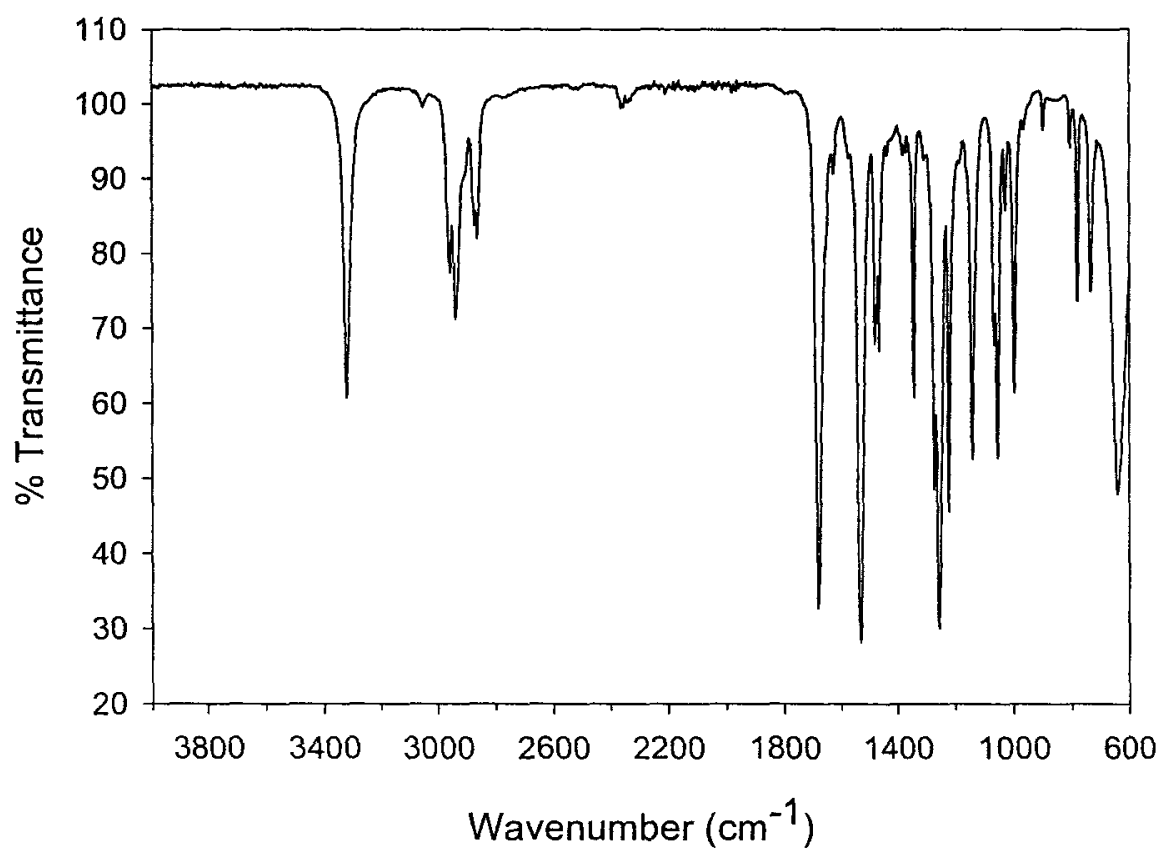

Figure A.2. FTIR spectrum of $\mathrm{C}_{4} \mathrm{C}_{6}$ biscarbamate. 


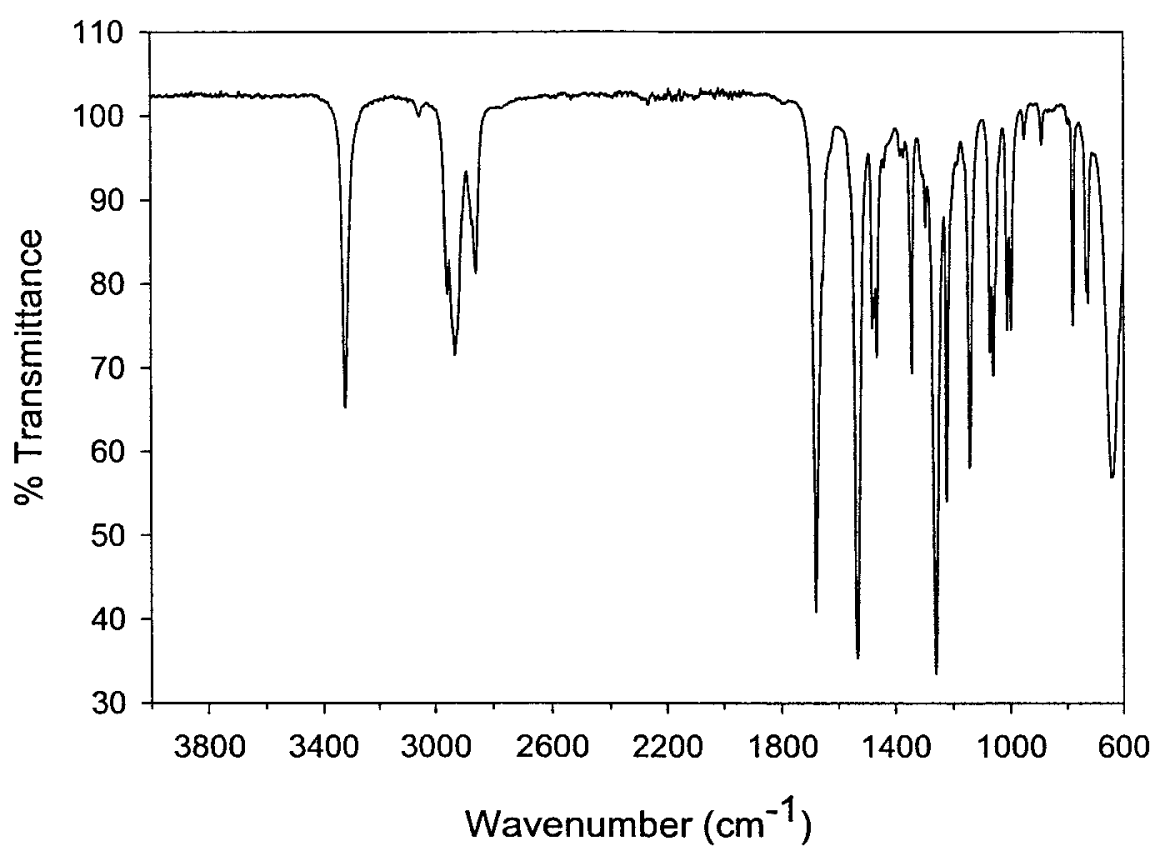

Figure A.3. FTIR spectrum of $\mathrm{C}_{6} \mathrm{C}_{6}$ biscarbamate.

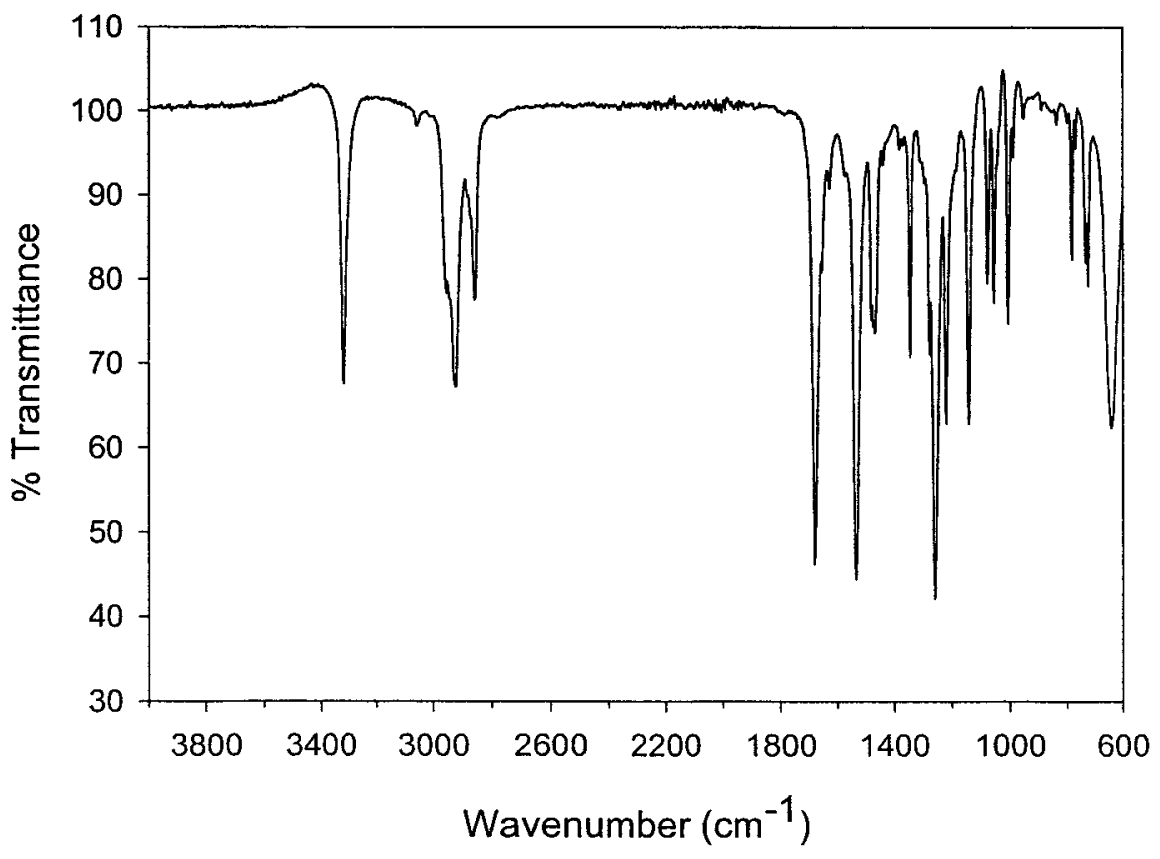

Figure A.4. FTIR spectrum of $\mathrm{C}_{7} \mathrm{C}_{6}$ biscarbamate. 


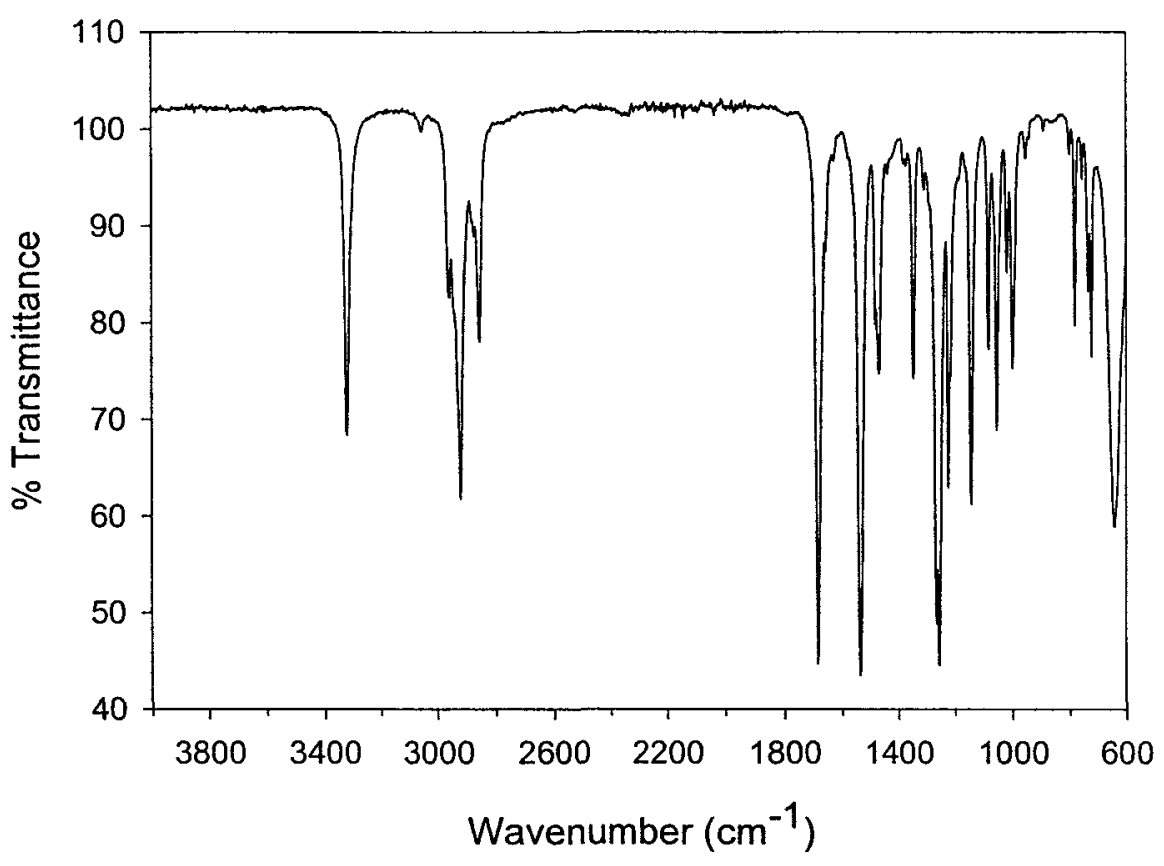

Figure A.5. FTIR spectrum of $\mathrm{C}_{8} \mathrm{C}_{6}$ biscarbamate.

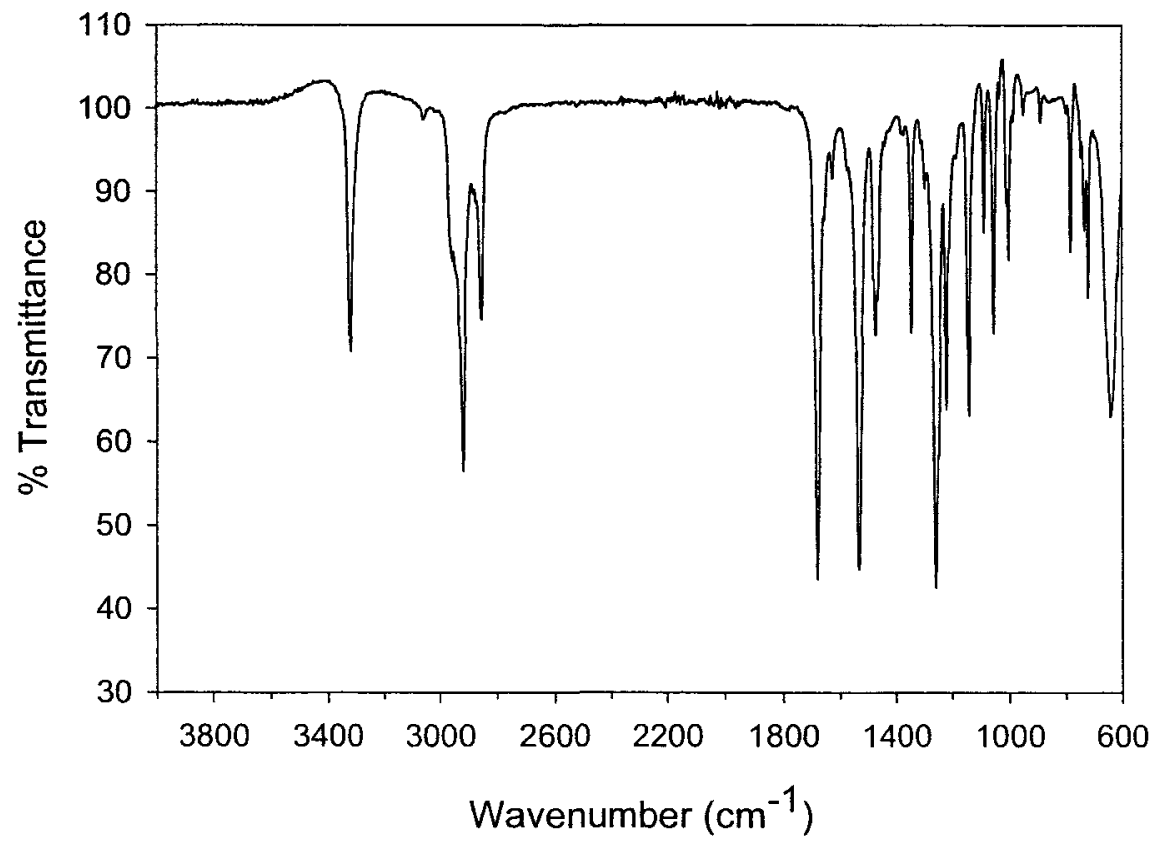

Figure A.6. FTIR spectrum of $\mathrm{C}_{9} \mathrm{C}_{6}$ biscarbamate. 


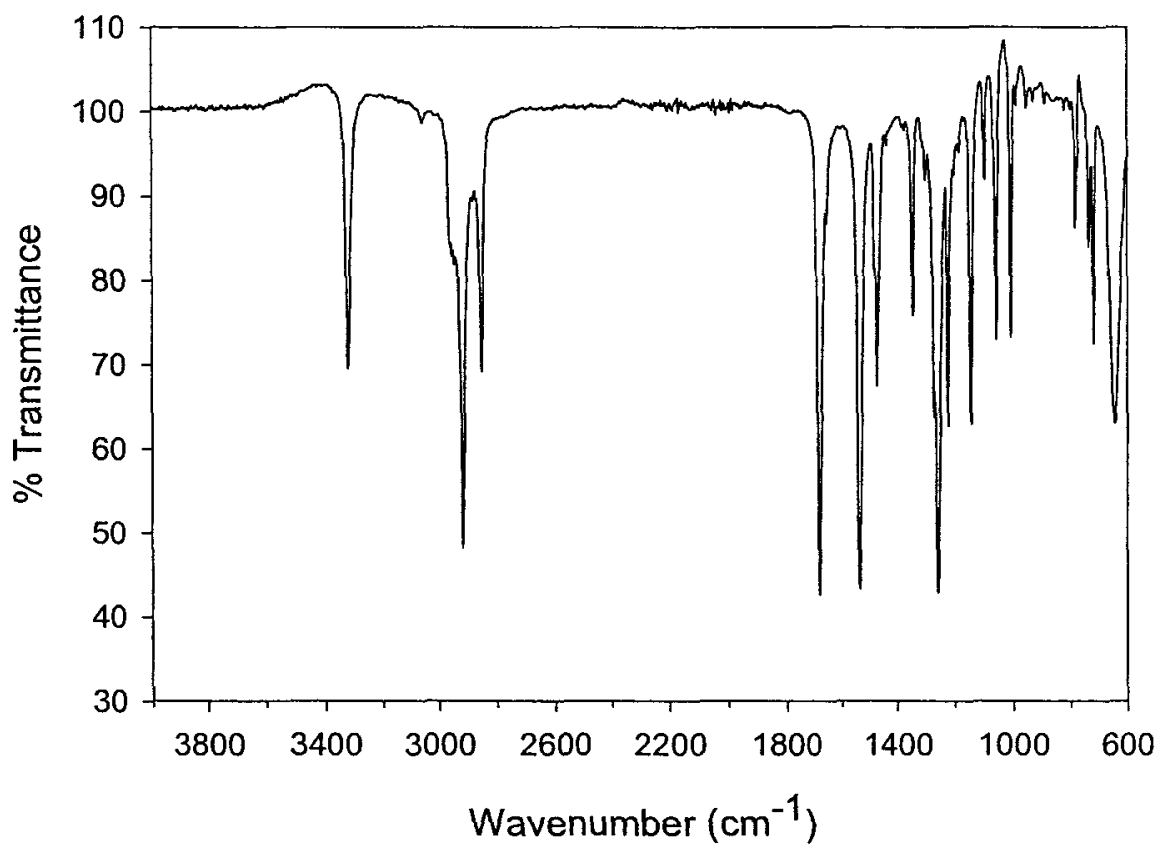

Figure A.7. FTIR spectrum of $\mathrm{C}_{11} \mathrm{C}_{6}$ biscarbamate.

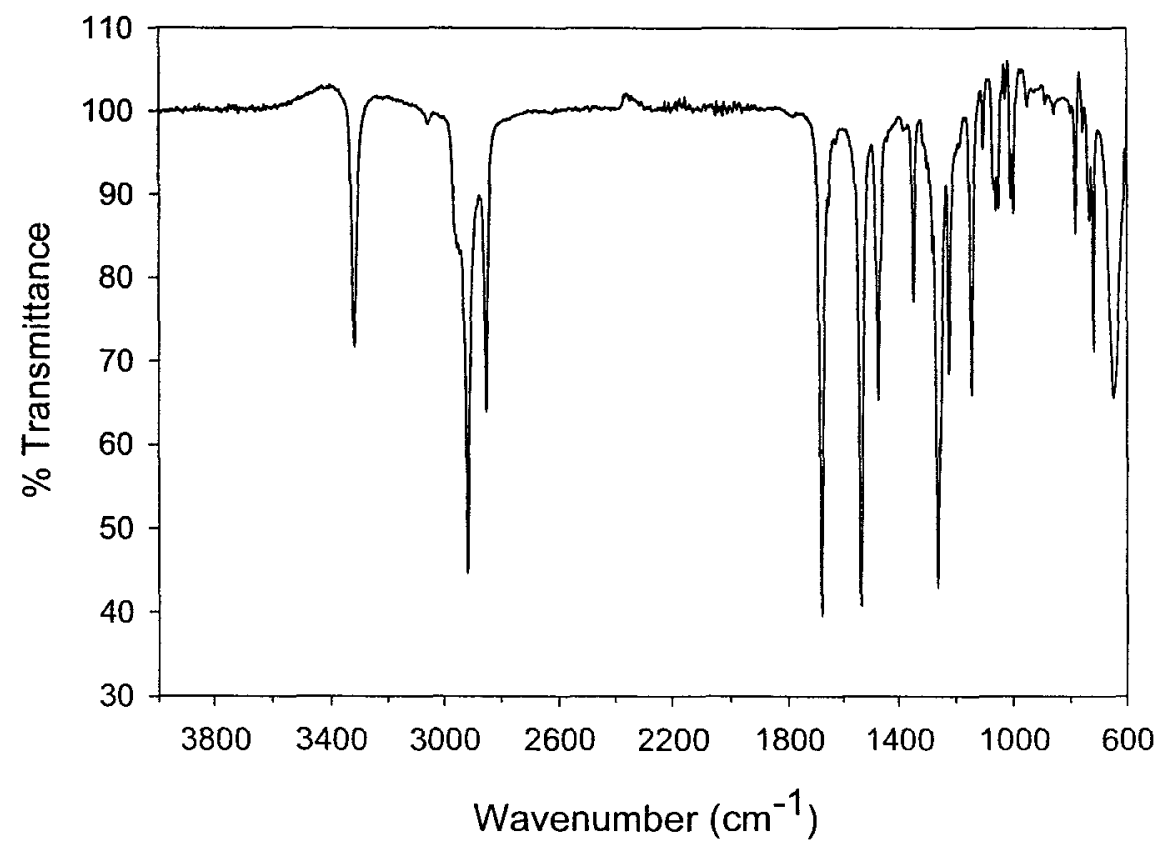

Figure A.8. FTIR spectrum of $\mathrm{C}_{13} \mathrm{C}_{6}$ biscarbamate. 


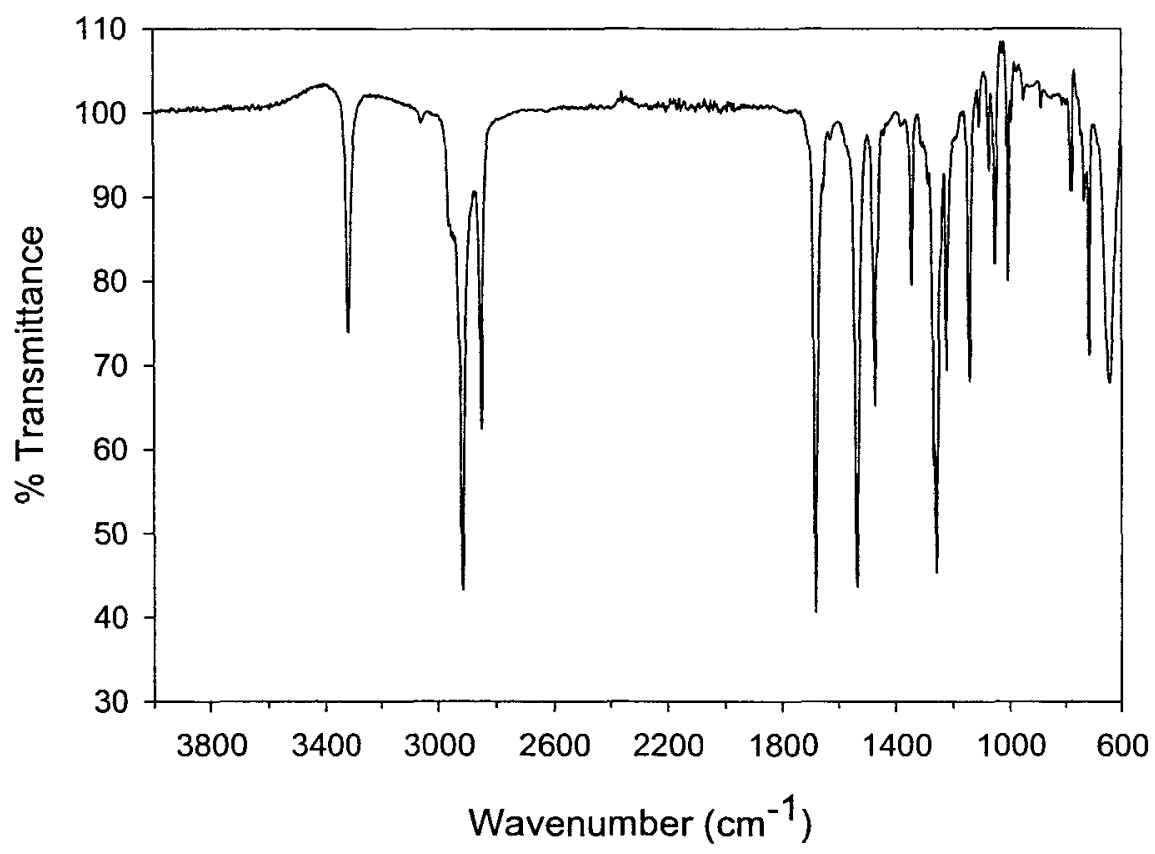

Figure A.9. FTIR spectrum of $\mathrm{C}_{15} \mathrm{C}_{6}$ biscarbamate.

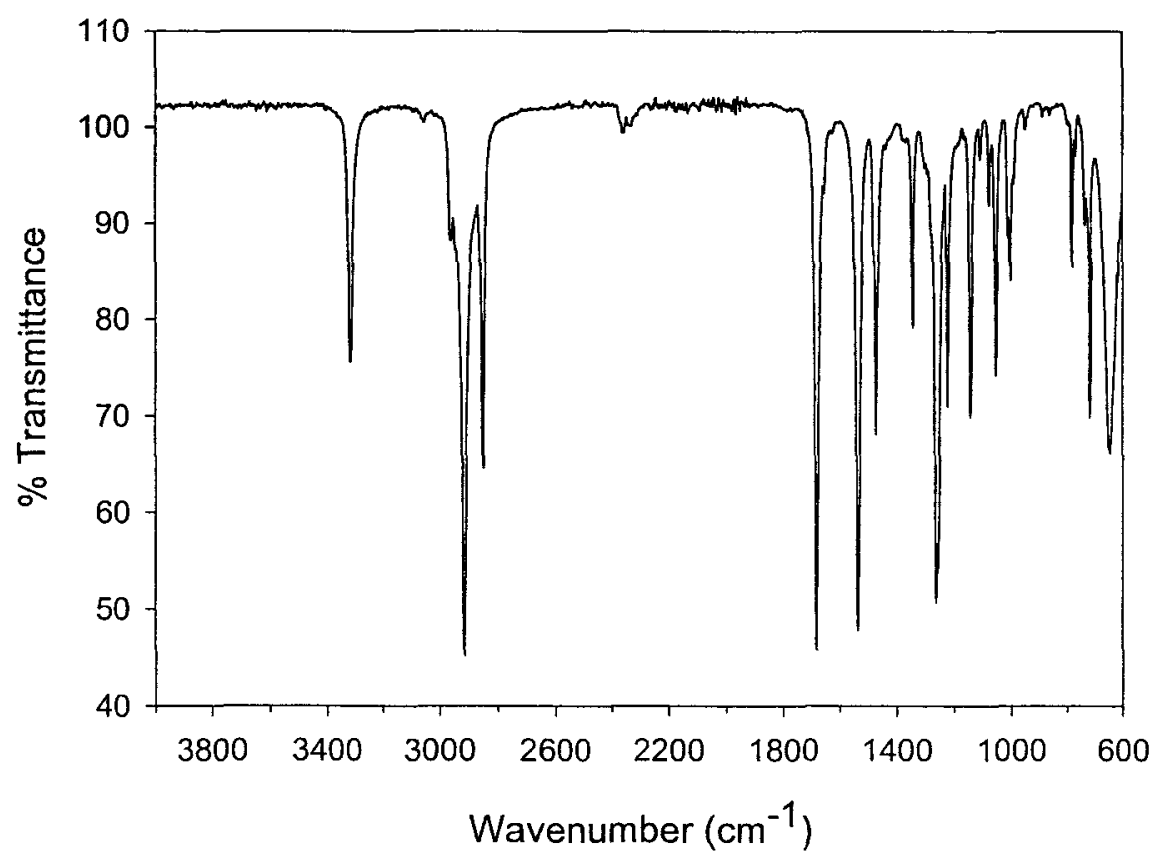

Figure A.10. FTIR spectrum of $\mathrm{C}_{16} \mathrm{C}_{6}$ biscarbamate. 


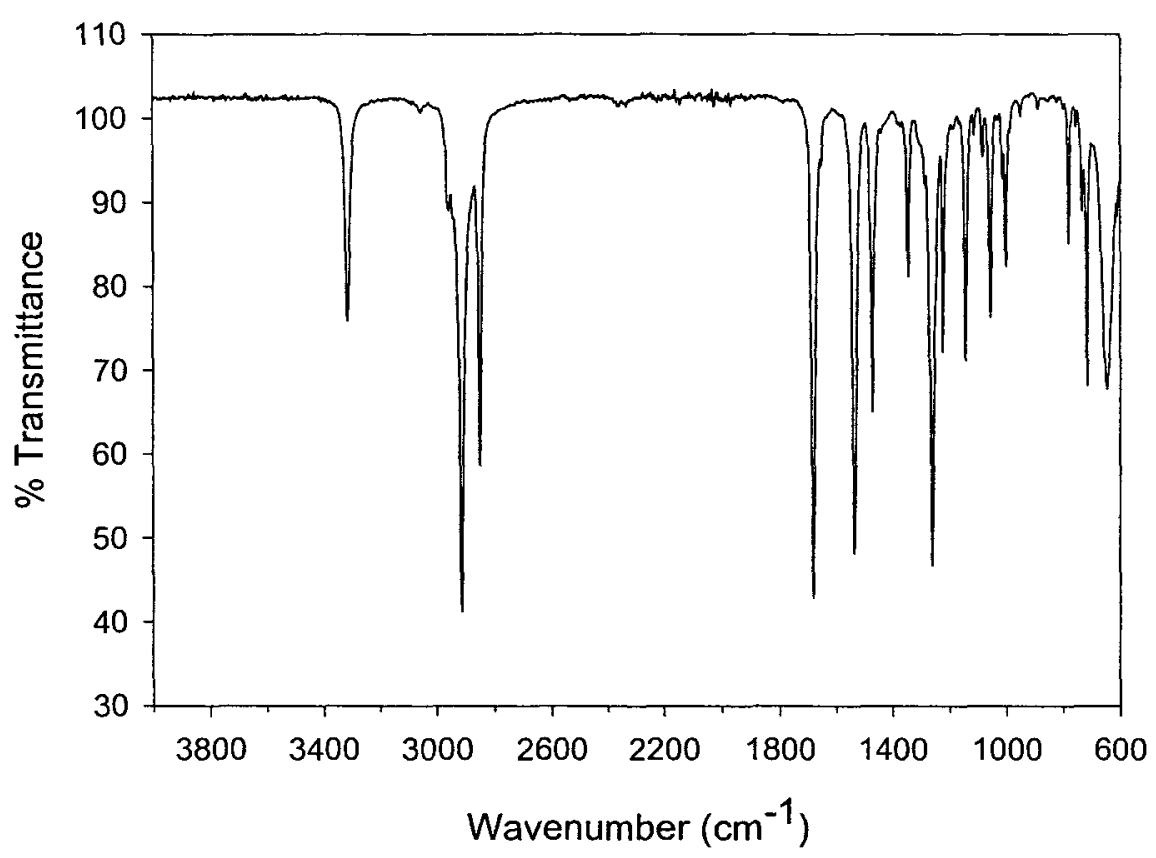

Figure A.11. FTIR spectrum of $\mathrm{C}_{18} \mathrm{C}_{6}$ biscarbamate.

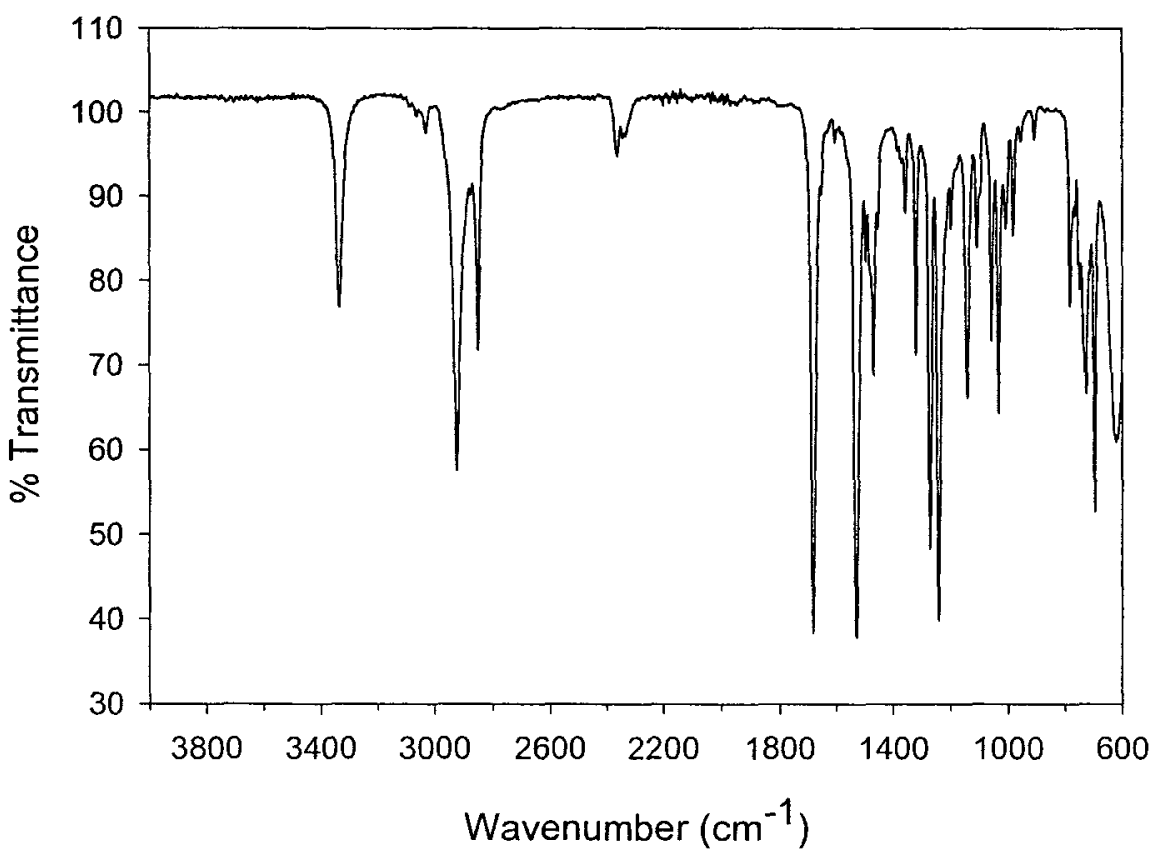

Figure A.12. FTIR spectrum of $\mathrm{PhC}_{6} \mathrm{C}_{12}$ biscarbamate. 


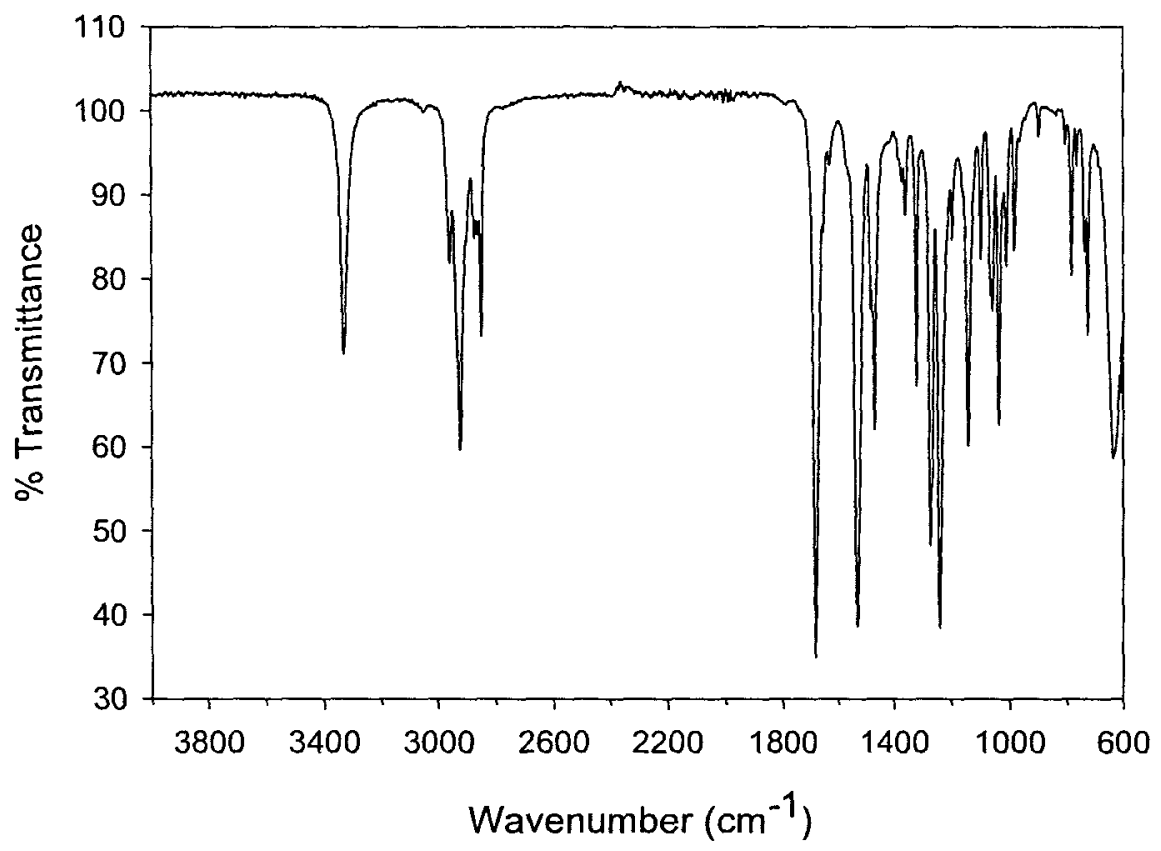

Figure A.13. FTIR spectrum of $\mathrm{C}_{4} \mathrm{C}_{12}$ biscarbamate.

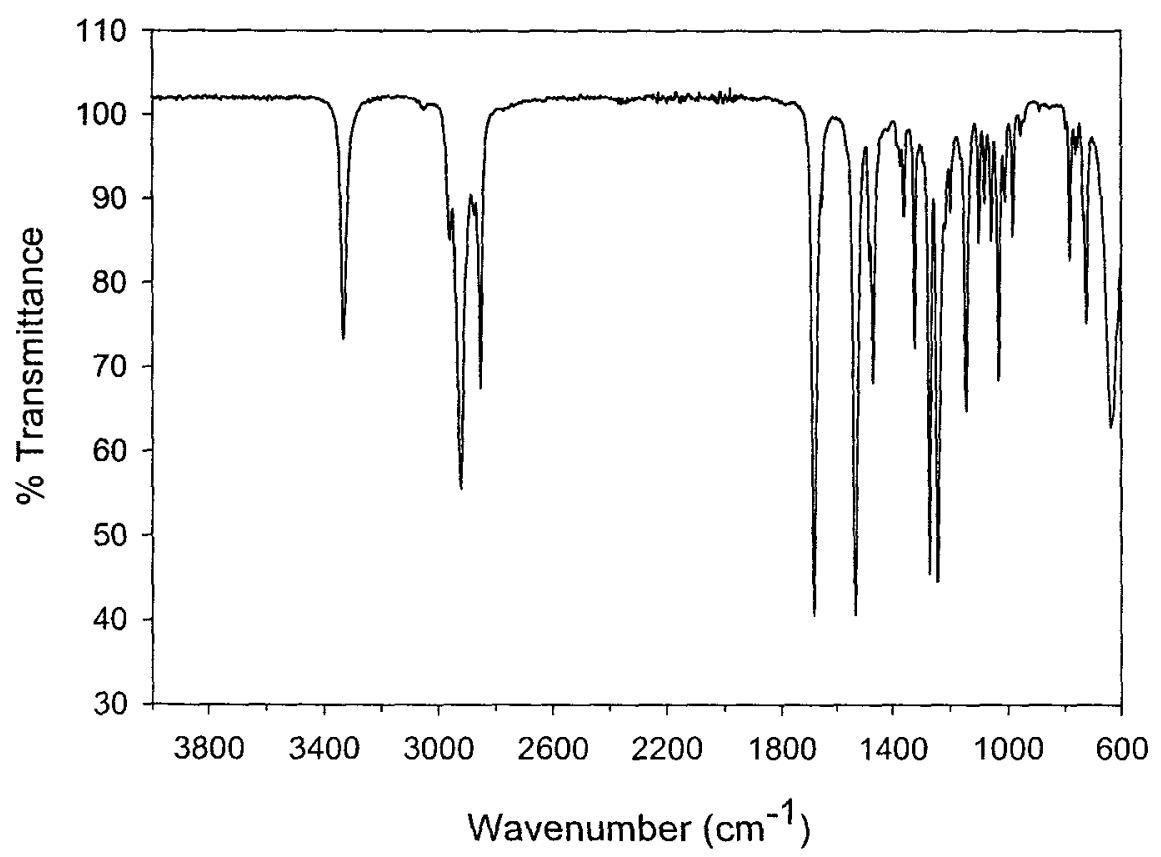

Figure A.14. FTIR spectrum of $\mathrm{C}_{8} \mathrm{C}_{12}$ biscarbamate. 


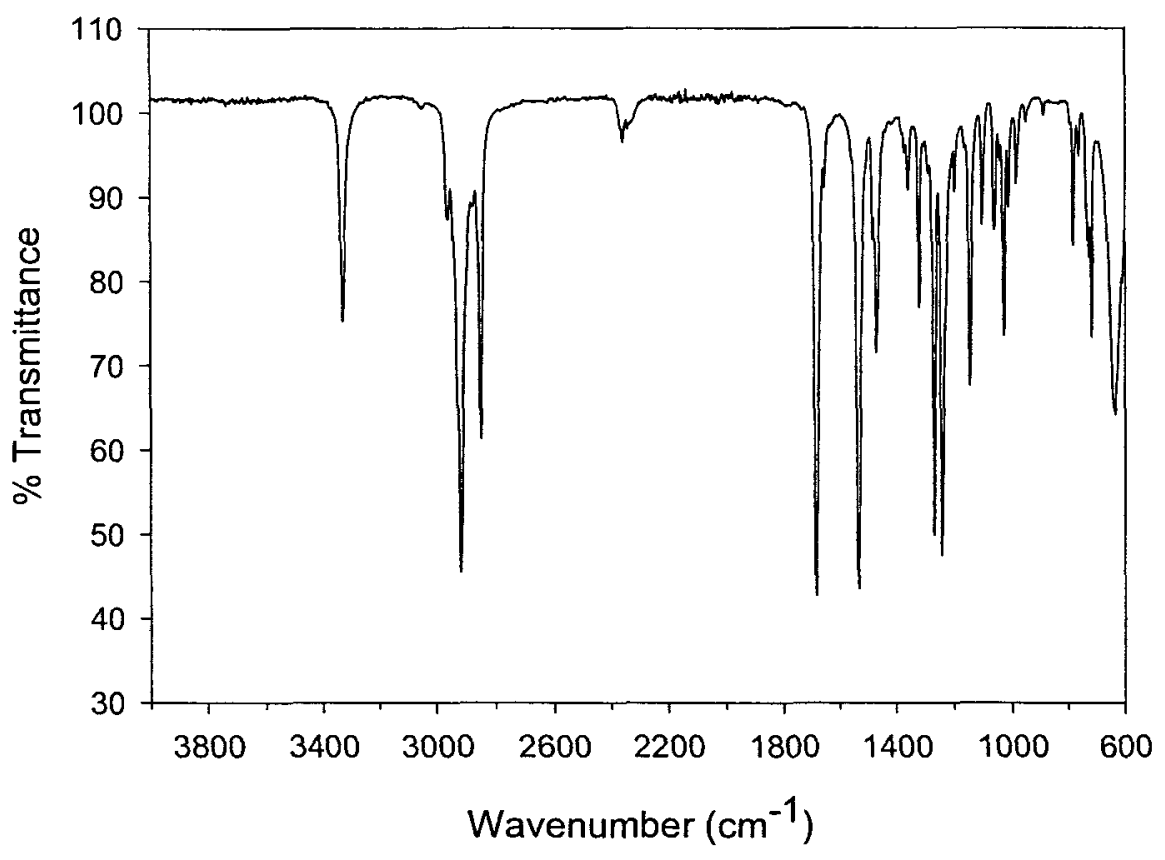

Figure A.15. FTIR spectrum of $\mathrm{C}_{12} \mathrm{C}_{12}$ biscarbamate.

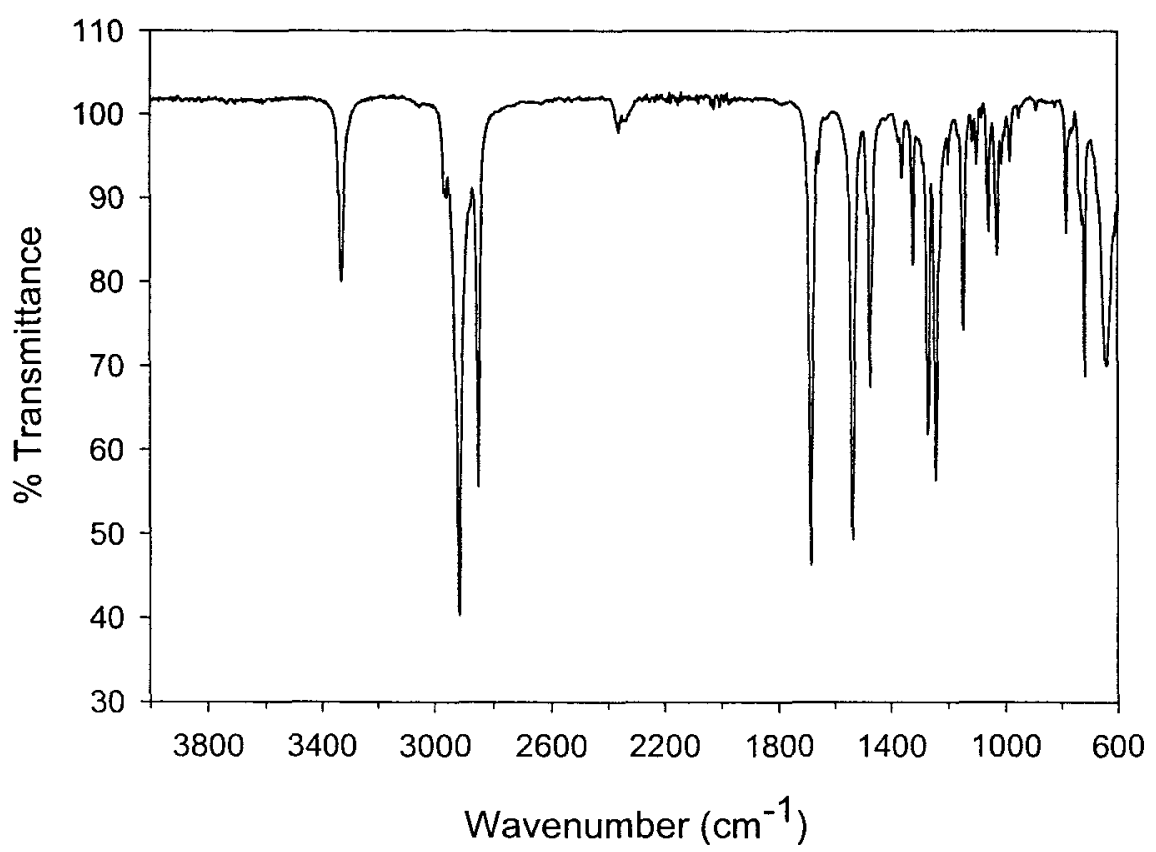

Figure A.16. FTIR spectrum of $\mathrm{C}_{18} \mathrm{C}_{12}$ biscarbamate. 
Appendix B

\section{${ }^{1}$ H NMR Spectra of the Biscarbamates}




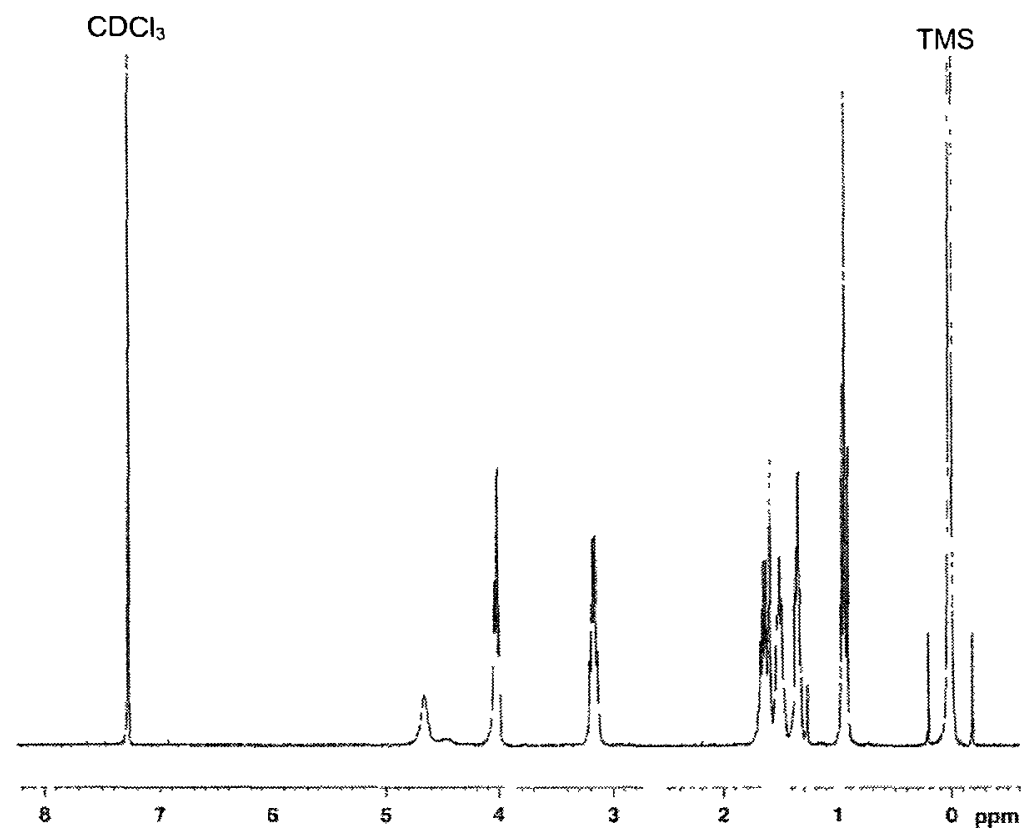

Figure B.1. ${ }^{1} \mathrm{H}$ NMR spectrum of $\mathrm{C}_{3} \mathrm{C}_{6}$ biscarbamate.

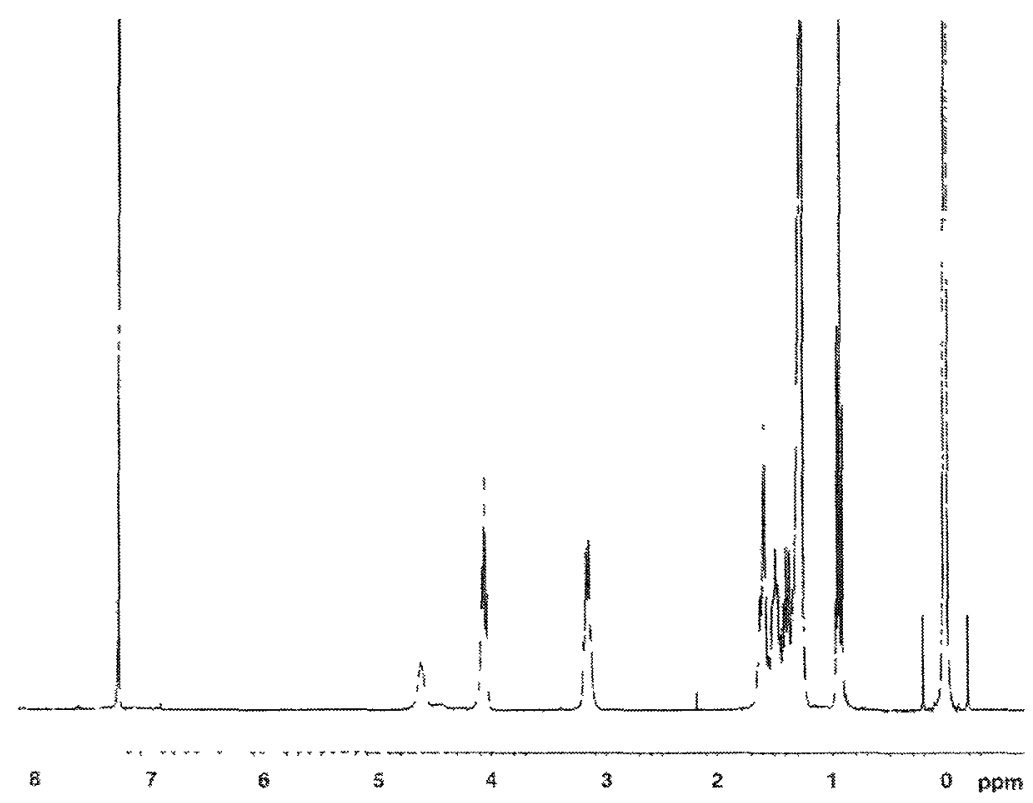

Figure B.2. ${ }^{1} \mathrm{H}$ NMR spectrum of $\mathrm{C}_{4} \mathrm{C}_{6}$ biscarbamate. 


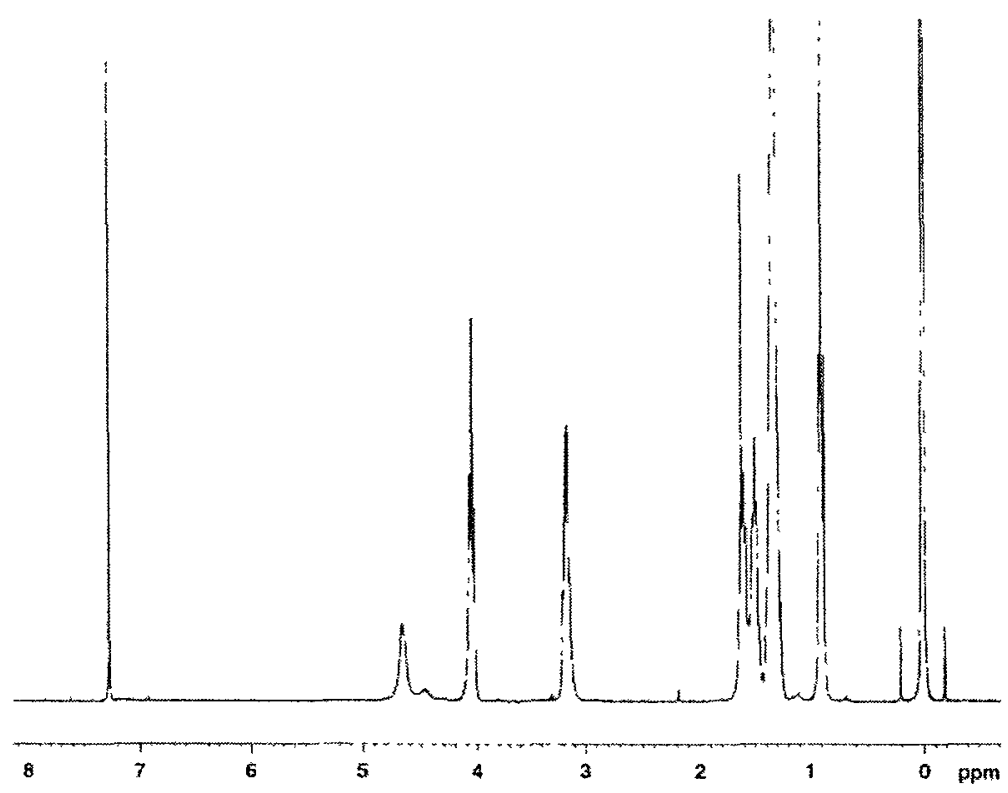

Figure B.3. ${ }^{1} \mathrm{H}$ NMR spectrum of $\mathrm{C}_{6} \mathrm{C}_{6}$ biscarbamate.

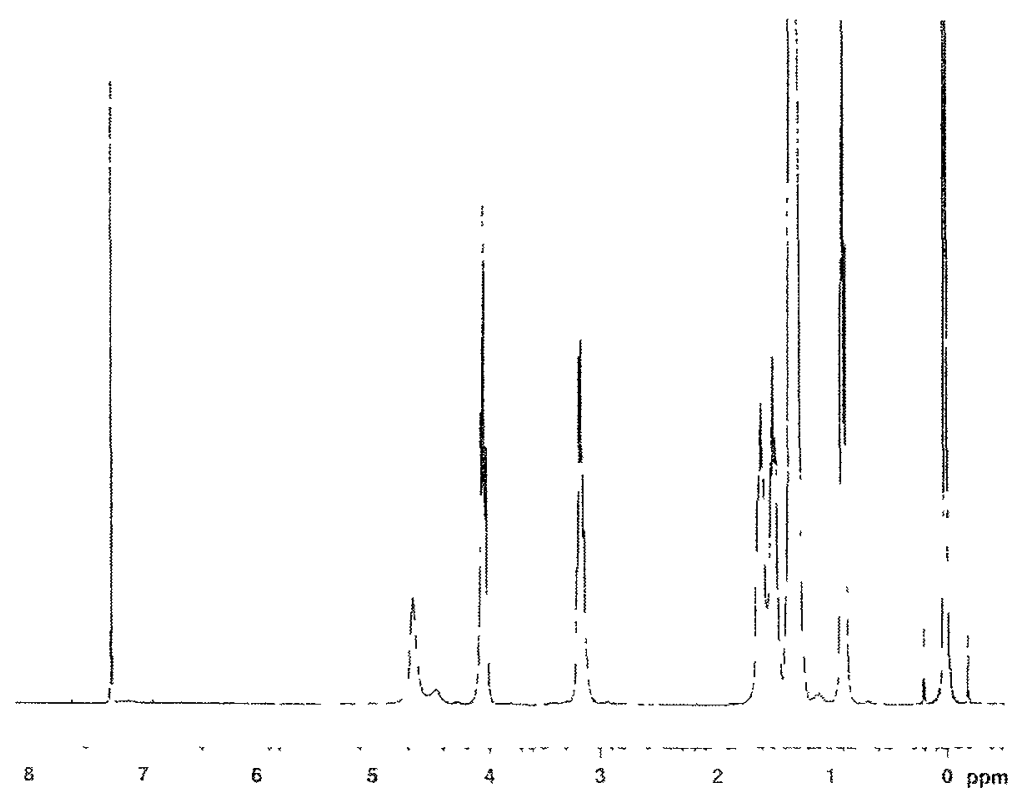

Figure B.4. ${ }^{1} \mathrm{H}$ NMR spectrum of $\mathrm{C}_{7} \mathrm{C}_{6}$ biscarbamate. 


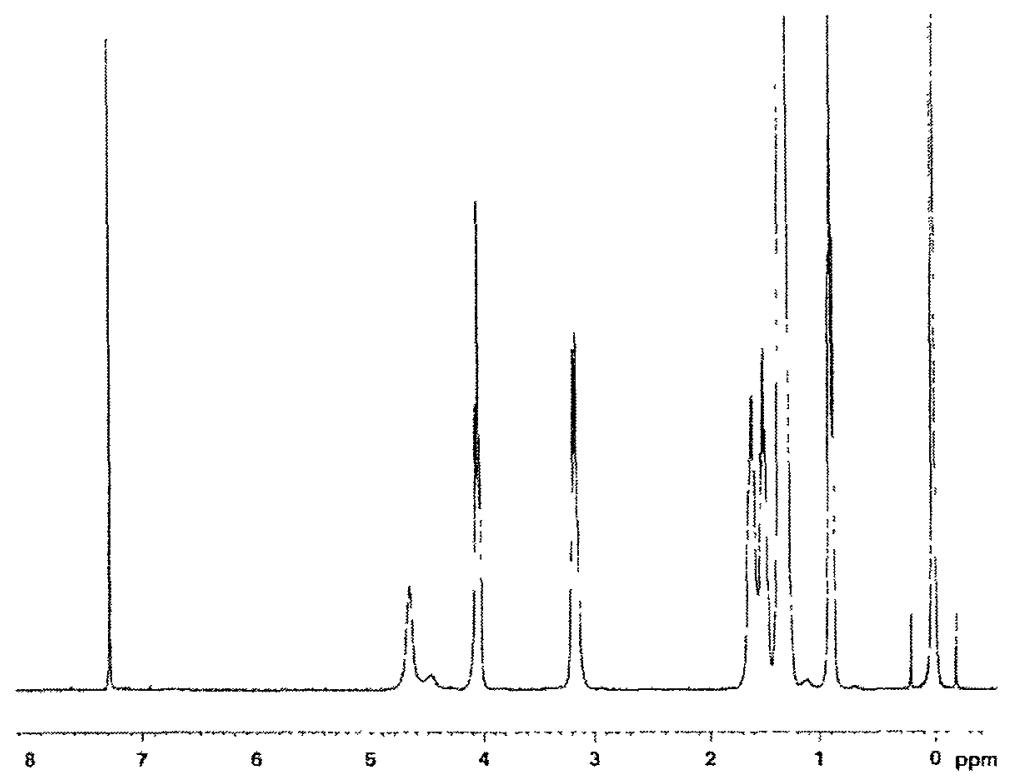

Figure B.5. ${ }^{1} \mathrm{H}$ NMR spectrum of $\mathrm{C}_{8} \mathrm{C}_{6}$ biscarbamate.

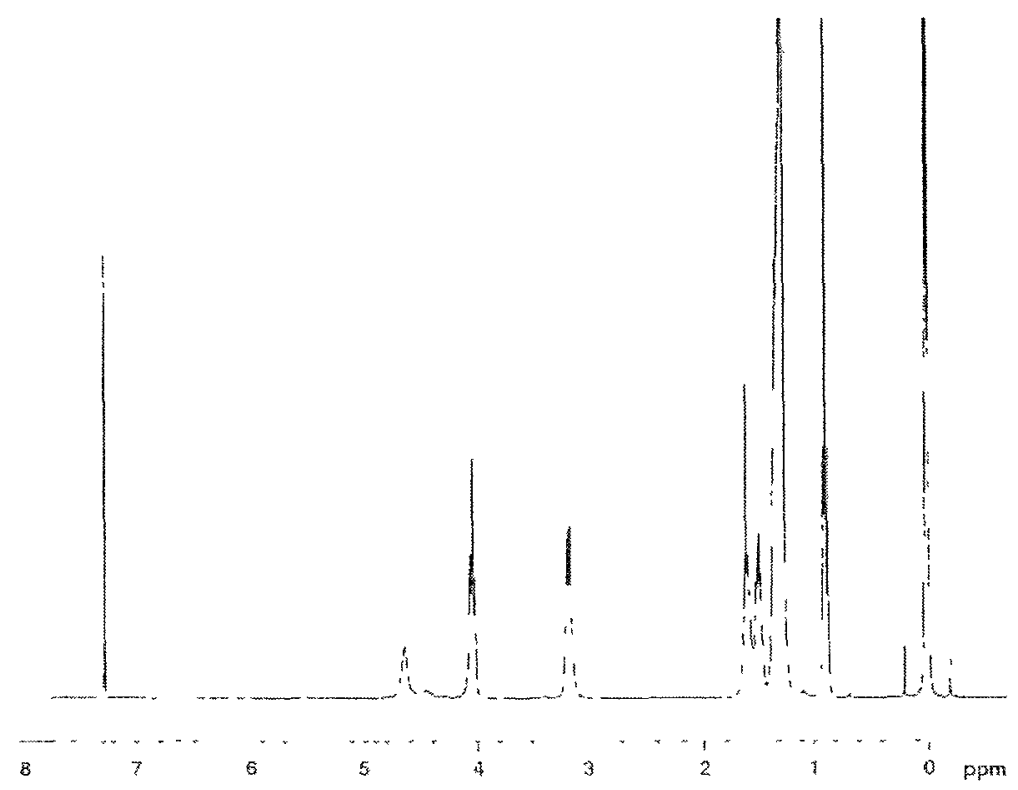

Figure B.6. ${ }^{1} \mathrm{H}$ NMR spectrum of $\mathrm{C}_{9} \mathrm{C}_{6}$ biscarbamate. 


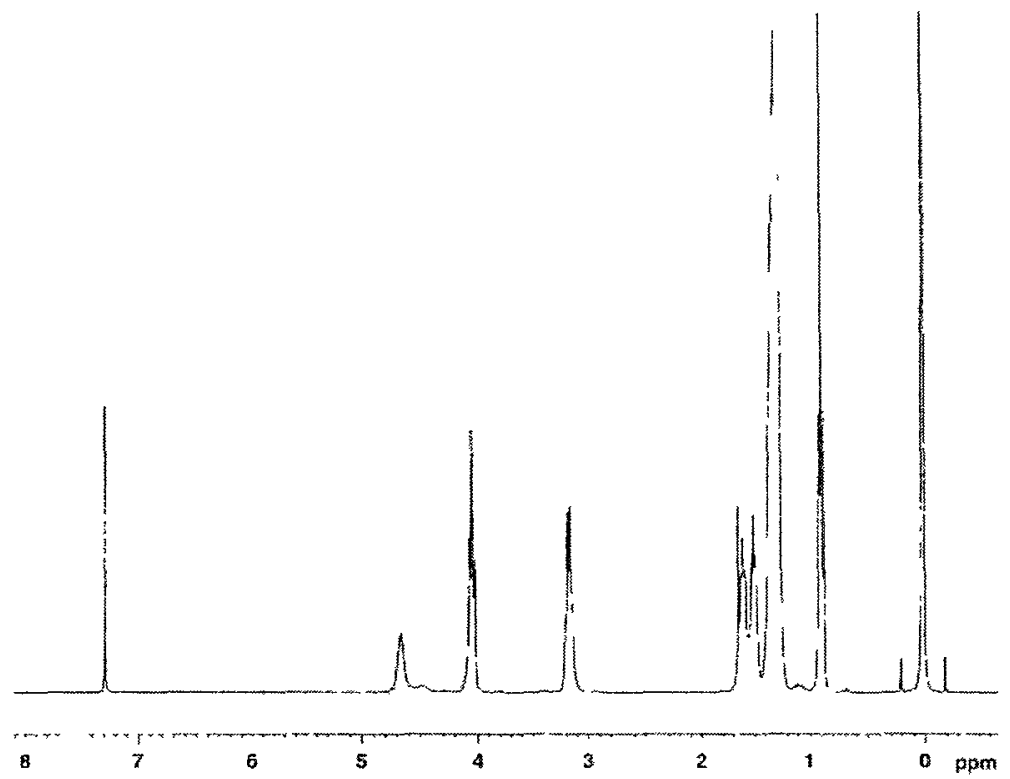

Figure B.7. ${ }^{1} \mathrm{H}$ NMR spectrum of $\mathrm{C}_{11} \mathrm{C}_{6}$ biscarbamate.

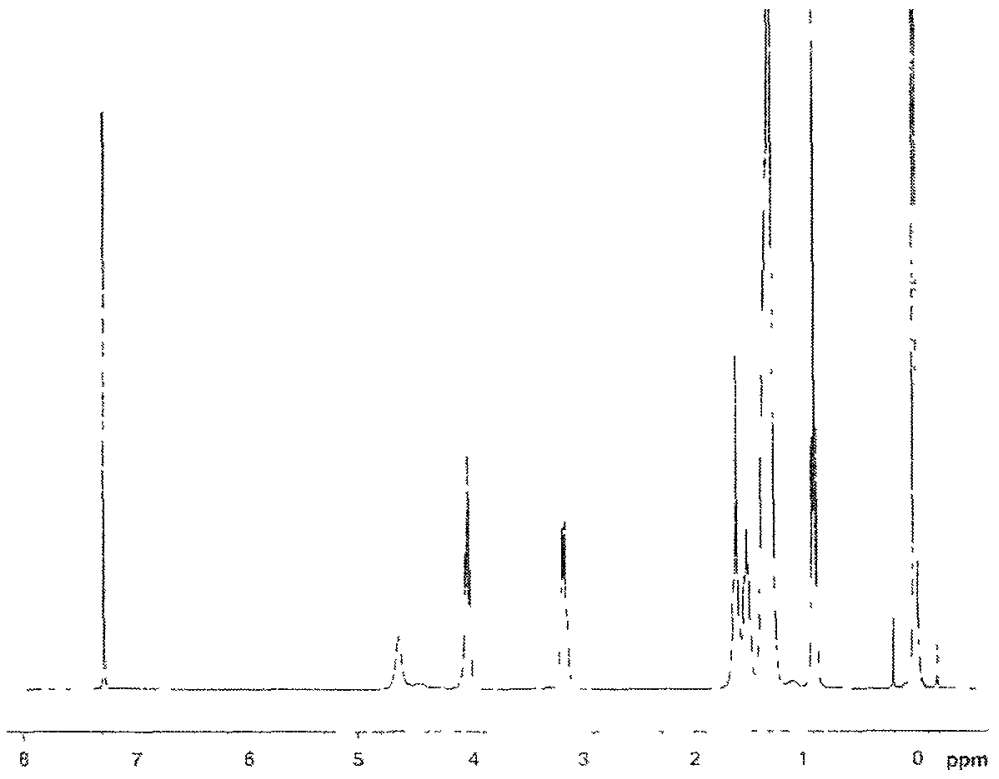

Figure B.8. ${ }^{1} \mathrm{H}$ NMR spectrum of $\mathrm{C}_{12} \mathrm{C}_{6}$ biscarbamate. 


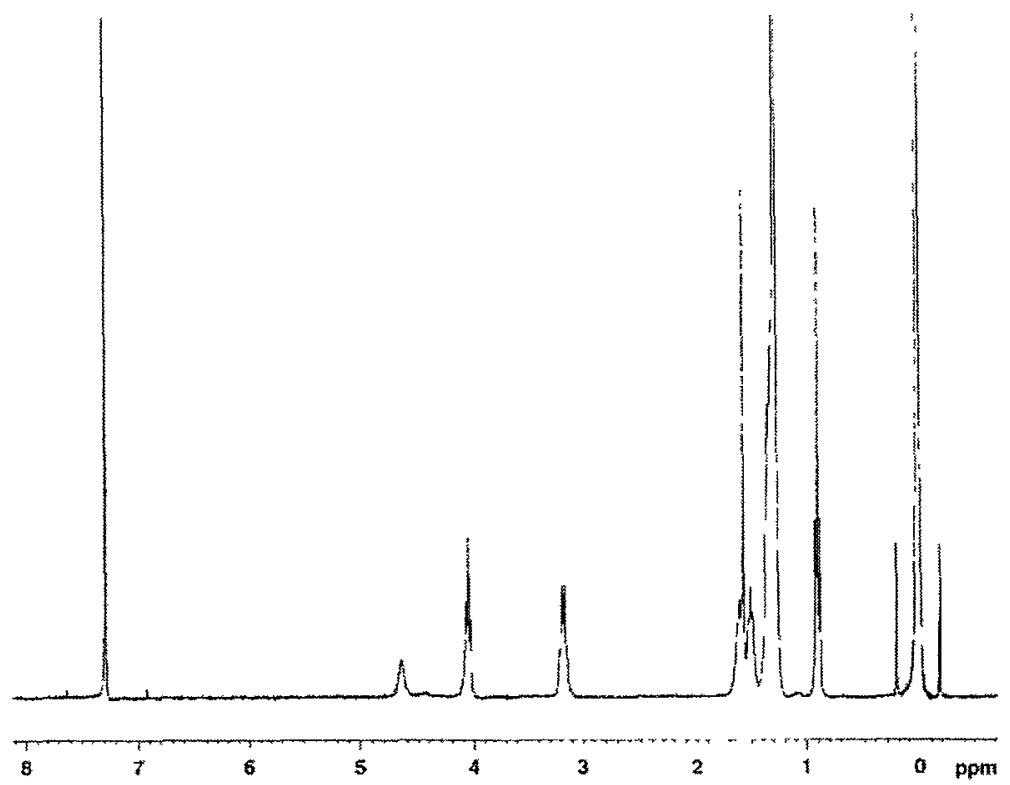

Figure B.9. ${ }^{1} \mathrm{H}$ NMR spectrum of $\mathrm{C}_{13} \mathrm{C}_{6}$ biscarbamate.

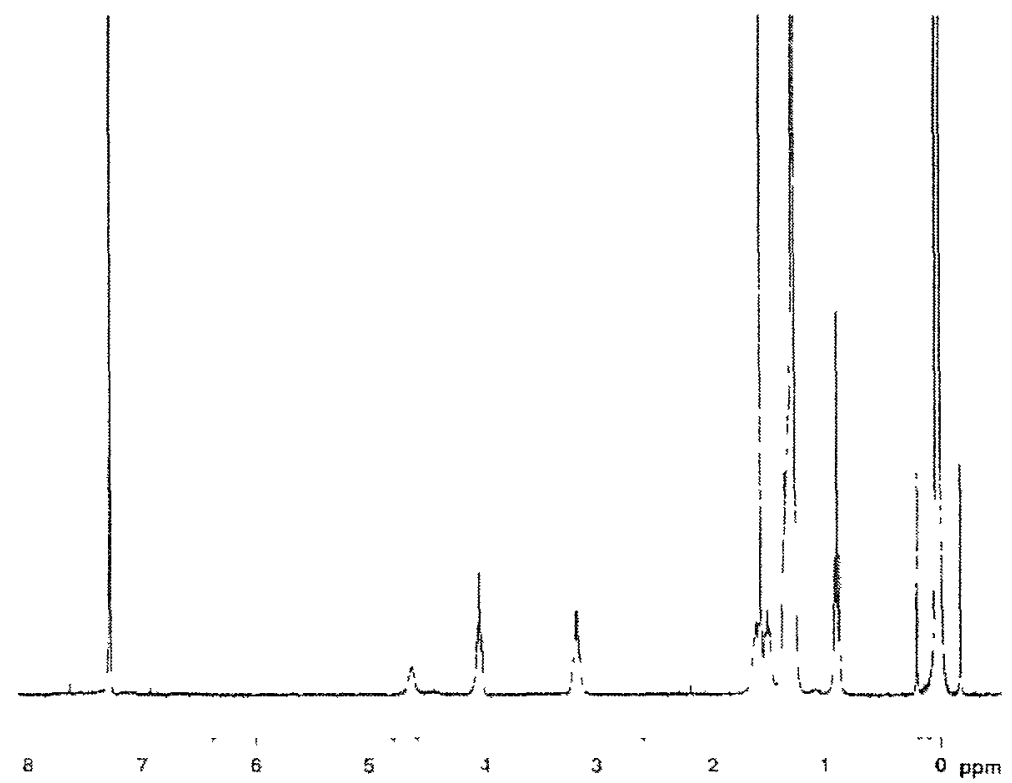

Figure B.10. ' $\mathrm{H}$ NMR spectrum of $\mathrm{C}_{15} \mathrm{C}_{6}$ biscarbamate. 


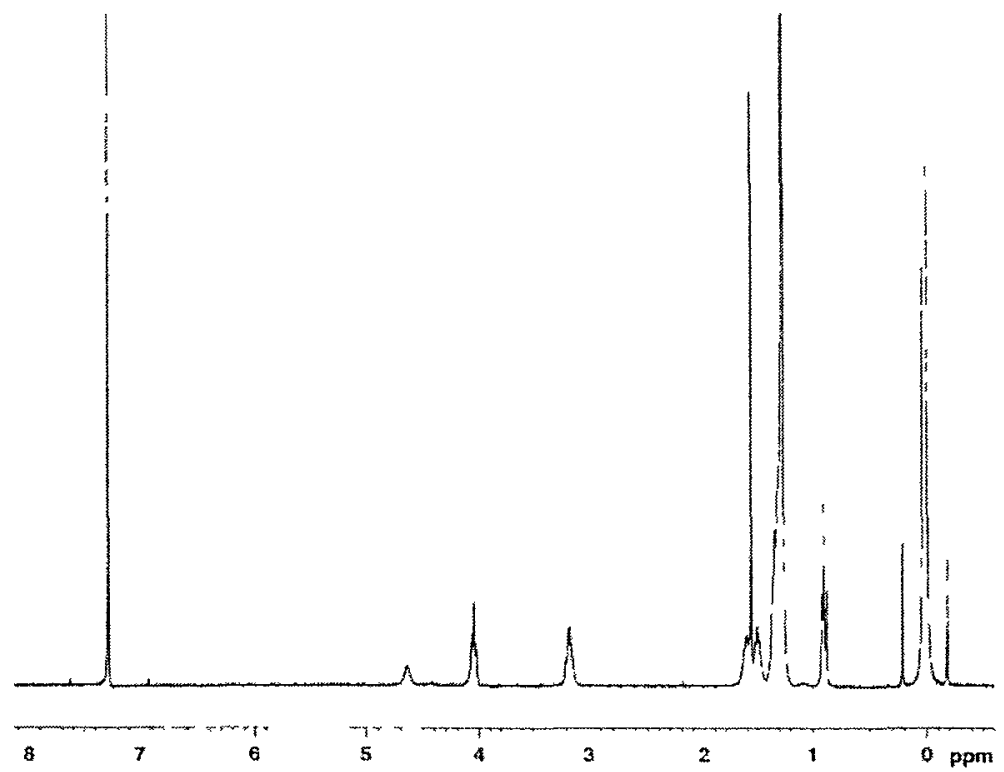

Figure B.11. ${ }^{1} \mathrm{H}$ NMR spectrum of $\mathrm{C}_{16} \mathrm{C}_{6}$ biscarbamate.

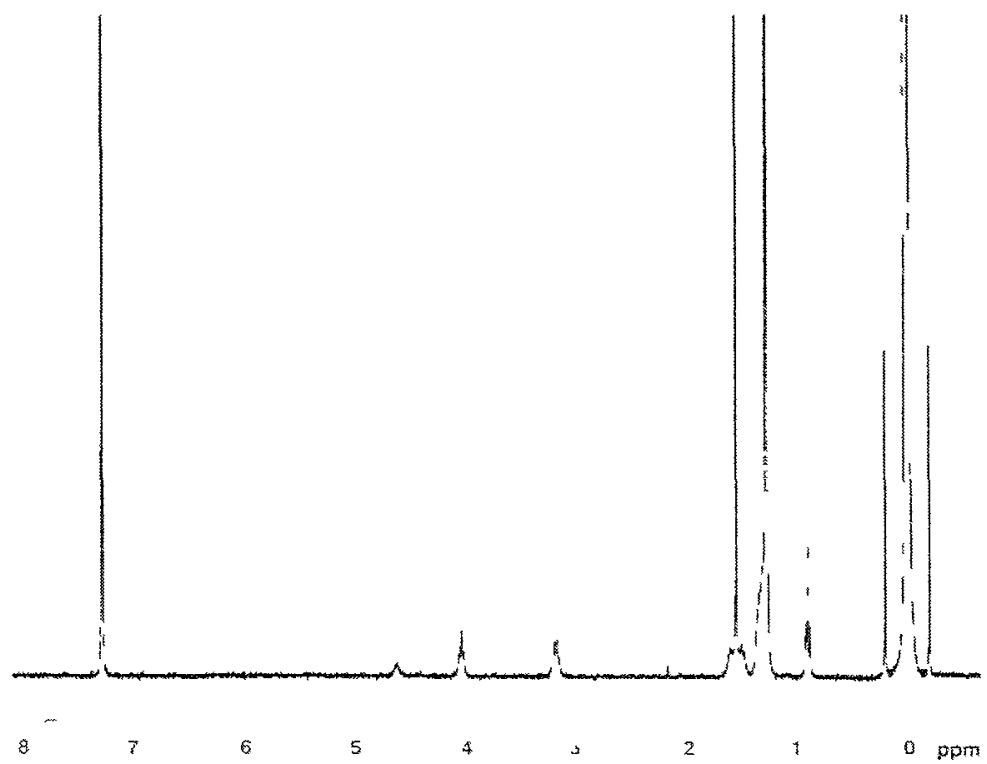

Figure B.12. ${ }^{\mathrm{I}} \mathrm{H}$ NMR spectrum of $\mathrm{C}_{18} \mathrm{C}_{6}$ biscarbamate. 


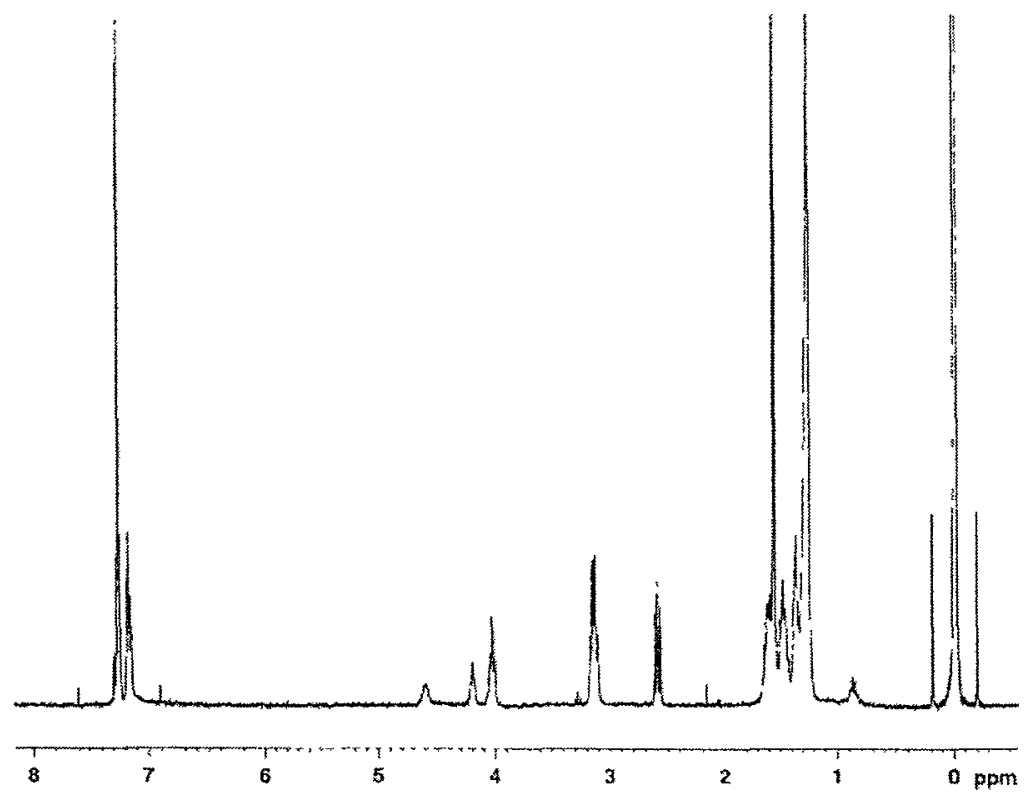

Figure B.13. ${ }^{1} \mathrm{H}$ NMR spectrum of $\mathrm{PhC}_{6} \mathrm{C}_{12}$ biscarbamate.

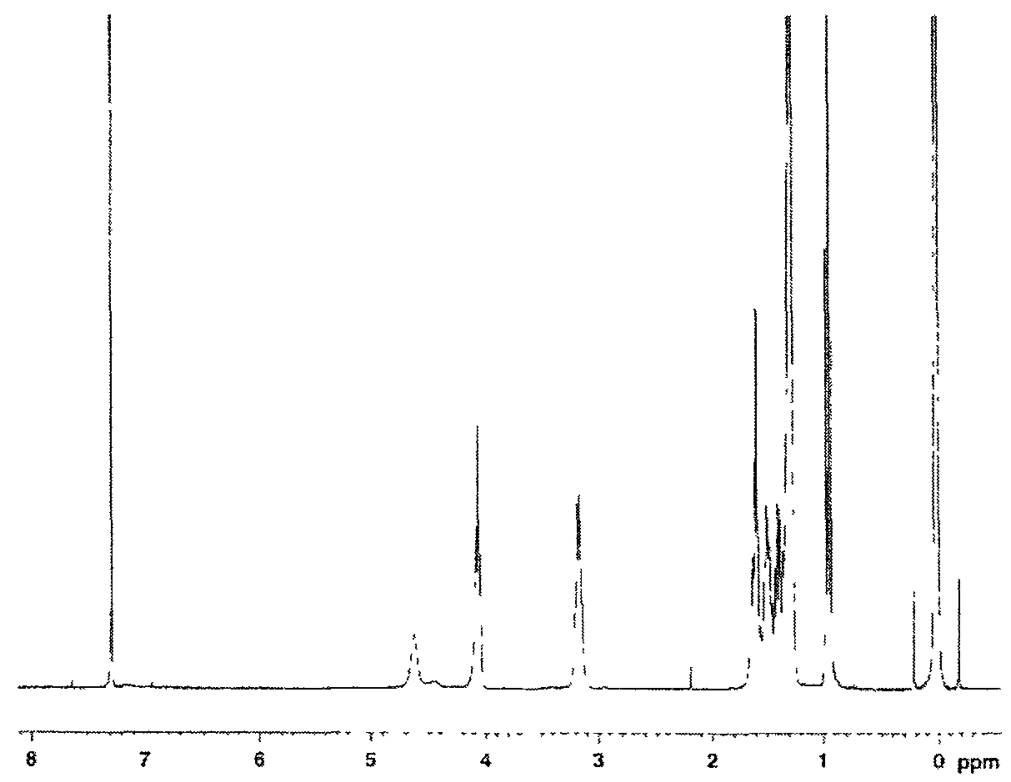

Figure B.14. ${ }^{1} \mathrm{H}$ NMR spectrum of $\mathrm{C}_{4} \mathrm{C}_{12}$ biscarbamate. 


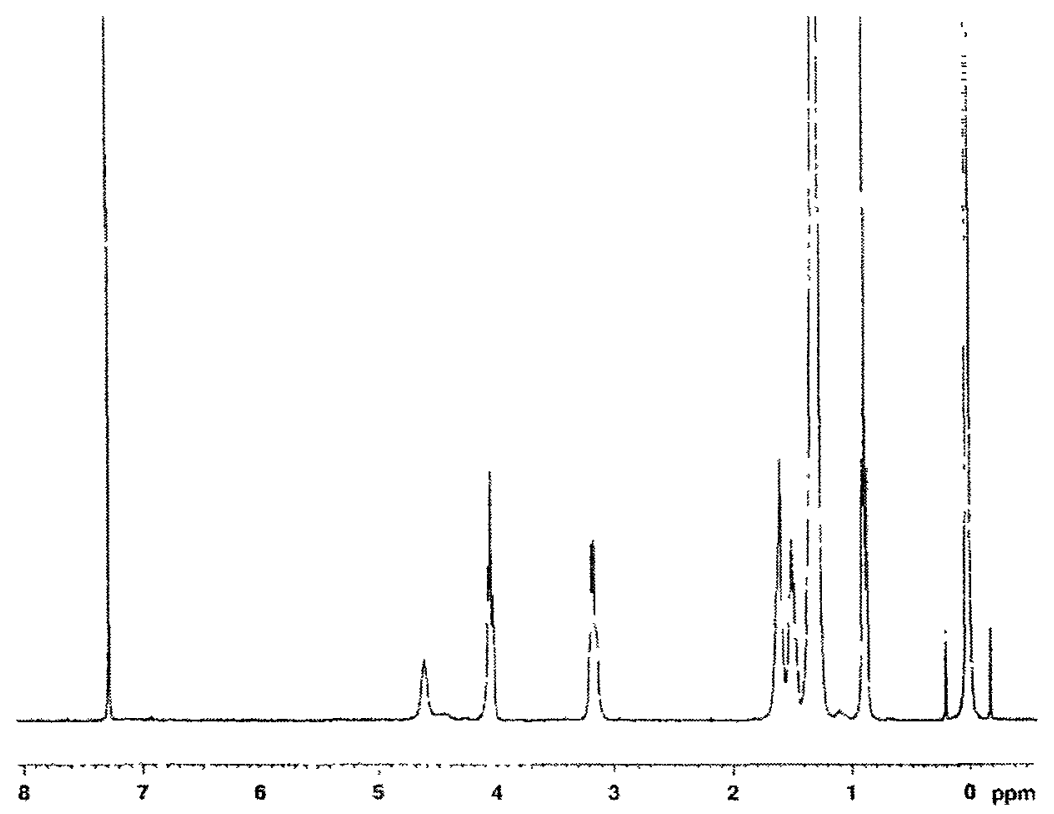

Figure B.15. ${ }^{1} \mathrm{H}$ NMR spectrum of $\mathrm{C}_{8} \mathrm{C}_{12}$ biscarbamate.

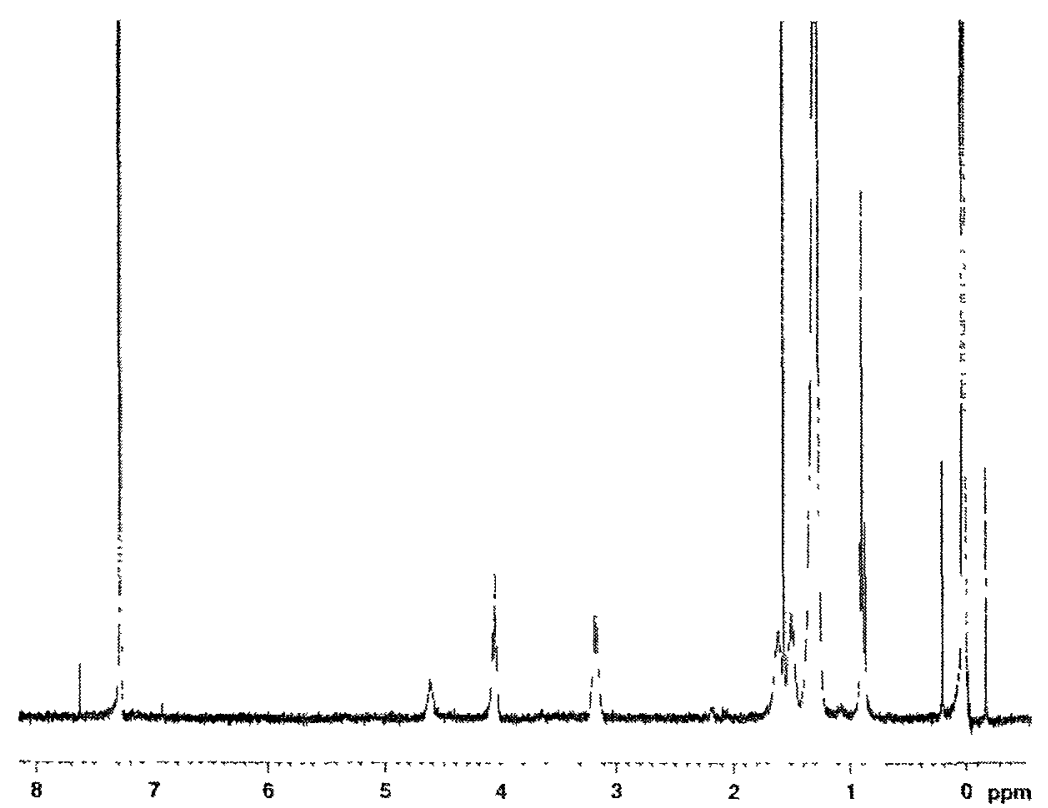

Figure B.16. ${ }^{1} \mathrm{H}$ NMR spectrum of $\mathrm{C}_{18} \mathrm{C}_{12}$ biscarbamate. 